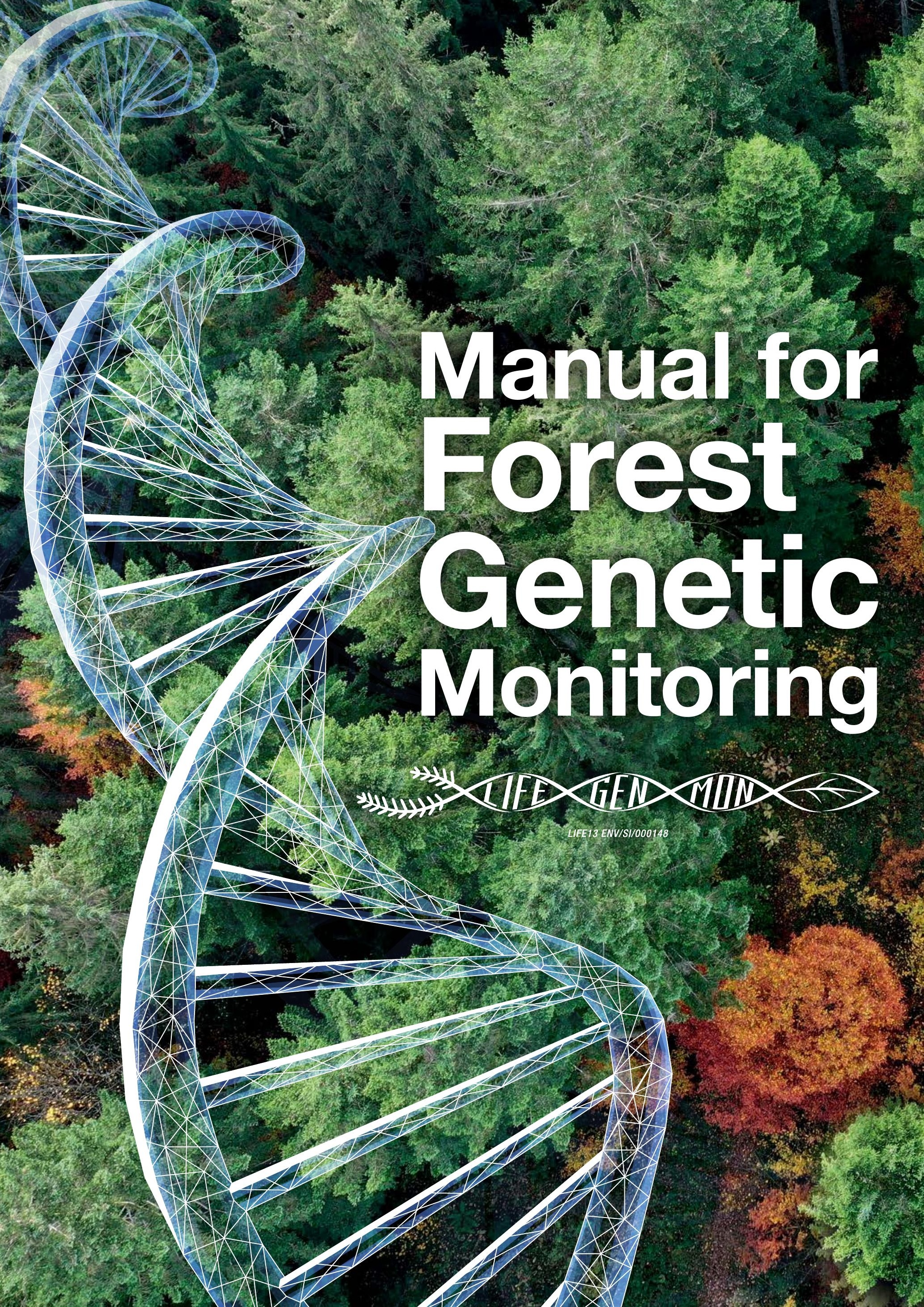





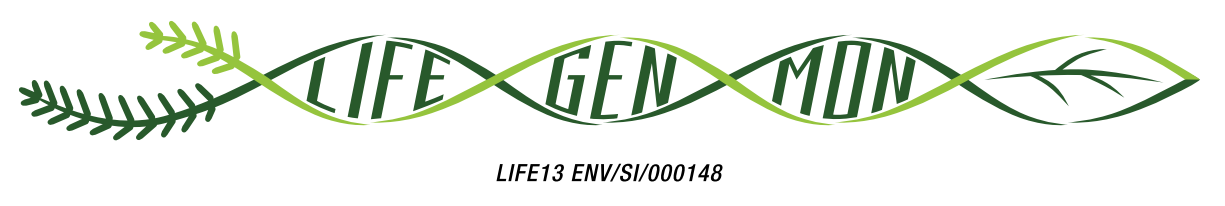

\section{Manual for Forest Genetic Monitoring}

\section{Editors}

Marko Bajc

Filippos A. Aravanopoulos

Marjana Westergren

Barbara Fussi

Darius Kavaliauskas

Paraskevi Alizoti

Fotios Kiourtsis

Hojka Kraigher 


\section{Silva
Slovenica}

Studia Forestalia Slovenica, 167

ISSN 0353-6025

ISBN 978-961-6993-56-2

Publisher: Slovenian Forestry Institute, Silva Slovenica publishing centre, Ljubljana 2020

Title: Manual for forest genetic monitoring

Editors: Marko Bajc, Filippos A. Aravanopoulos, Marjana Westergren, Barbara Fussi, Darius Kavaliauskas, Paraskevi Alizoti, Fotios Kiourtsis, Hojka Kraigher

Technical editor: Peter Železnik, Katja Kavčič Sonnenschein

Language editor: Paul Steed, Amidas

Design: Boris Jurca, NEBIA

Print: Mediaplan 8

Edition: $1^{\text {st }}$ edition

Price: Free

Circulation: 500

Electronic issue: http://dx.doi.org/10.20315/SFS.167

CIP - Kataložni zapis o publikaciji

Narodna in univerzitetna knjižnica, Ljubljana

$630 * 58: 630 * 16(082)$

$630 * 1: 575.22(082)$

MANUAL for forest genetic monitoring / authors Marko Bajc (ed.) ... [et al.] ; illustrations Klara Jager ... [et al.]. - 1st ed. - Ljubljana :

Slovenian Forestry Institute, Silva Slovenica Publishing Centre, 2020. (Studia Forestalia Slovenica, ISSN 0353-6025; 167)

ISBN 978-961-6993-56-2

1. Bajc, Marko, 1979-

COBISS.SI-ID 42816515 


\section{Contents}

INTRODUCTION

Plot SELECTION

3 PLOT ESTABLISHMENT

3 AND MAINTENANCE

$\triangle$ INDICATORS, VERIFIERS AND

BACKGROUND INFORMATION

\section{BACKGROUND INFORMATION}

5

FIELDWORK

LABORATORY AND DATA ANALYSES

COST ASSESSMENT

8 DECISION SUPPORT FOR SELECTING THE INTENSITY OF FGM

GUIDELINES FOR FOREST

GENETIC MONITORING 


\section{List of Contributors}

\section{EDITORS}

Marko BAJC1, Filippos A. ARAVANOPOULOS², Marjana WESTERGREN', Barbara FUSSI ${ }^{3}$, Darius KAVALIAUSKAS ${ }^{3}$, Paraskevi ALIZOTI², Fotios KIOURTSIS ${ }^{4}$, Hojka KRAIGHER ${ }^{1}$

\section{AUTHORS}

Filippos A. ARAVANOPOULOS ${ }^{2}$, Marjana WESTERGREN ${ }^{1}$, Barbara FUSSI ${ }^{3}$, Darius KAVALIAUSKAS ${ }^{3}$, Paraskevi ALIZOTI², Marko BAJC ${ }^{1}$, Fotios KIOURTSIS ${ }^{4}$, Monika KONNERT ${ }^{3}$, Evangelia V. AVRAMIDOU ${ }^{2,5}$, Dalibor BALLIAN ${ }^{1,6}$, Evangelos BARBAS², Pavlos BEKIAROGLOU ${ }^{4}$, Sándor BORDÁCS ${ }^{7}$, Gregor BOŽIČ ${ }^{1}$, Philip BRAILEY-JONES ${ }^{1}$, Andrej BREZNIKAR ${ }^{8}$, Pavlos CHASILIDIS ${ }^{4}$, Rok DAMJANIĆ ${ }^{1}$, Natalija DOVČ ${ }^{1}$, Anna-Maria FARSAKOGLOU²,9, Domen FINŽGAR ${ }^{1,10}$, Nikitas FRAGKISKAKIS ${ }^{4}$, loannis GANOPOULOS ${ }^{2,11}$, Berthold HEINZE'2, Ermioni MALLIAROU², Georgios ROUSAKIS ${ }^{4}$, Chryse SARVANI ${ }^{4}$, Kristina SEVER ${ }^{8}$, Nataša ŠIBANC ${ }^{1}$, Nikolaos TOURVAS ${ }^{2}$, Živan VESELIČ8 ${ }^{8}$, Zvonimir VUJNOVIĆ13 ${ }^{13}$, Peter ŽELEZNIK' ${ }^{1}$, Hojka KRAIGHER ${ }^{1}$

\section{ADDITIONAL DATA CONTRIBUTORS}

Vlatko ANDONOVSKII ${ }^{14}$, Roland BAIER ${ }^{15}$, Mladen IVANKOVIĆ ${ }^{13}$, Davorin KAJBA ${ }^{16}$, Heino KONRAD ${ }^{12}$, Saša ORLOVIĆ ${ }^{17}$, Srđan STOJNIĆ'17,

\section{BOTANICAL ILLUSTRATIONS EDITORS}

Rok DAMJANIĆ ${ }^{1}$, Katja KAVČIČ SONNENSCHEIN ${ }^{1}$

\section{ACKNOWLEDGEMENTS}

Ricardo ALIA ${ }^{18}$, Tjaša BALOH ${ }^{1}$, Franc BATIČ ${ }^{19}$, Maria BELOVARSKA ${ }^{20}$, Michele BOZZANO ${ }^{9}$, Robert BRUS ${ }^{21}$, Bruno FADY22, Santiago C. GONZÁLES-MARTÍNEZ ${ }^{22}$, Tine GREBENC ${ }^{1}$, Melita HRENKO', Jason HUBERT ${ }^{23}$, Katja KAVČIČ-SONNENSCHEIN ${ }^{1}$, Alenka KORENJAK ${ }^{24}$, Ino-Basilia KOROMPOKI², Vasiliki-Maria KOTINA², Tijana MARTINOVIĆ1,25, Milan MATARUGA ${ }^{26}$, Tanja MRAK', László NAGY27, Despoina PAITARIDOU ${ }^{28}$, Marita PAPAGIANNI ${ }^{2}$, Andrea R. PLUESS ${ }^{29}$, Boris RANTAŠA ${ }^{8}$, Mari RUSANEN ${ }^{30}$, Barbara ŠTUPAR ${ }^{1}$, Urša VILHAR ${ }^{1}$, Ralph JENNER ${ }^{3}$, Susanne NOWAK ${ }^{3}$, Alwin JANSSEN ${ }^{3}$, Barbara BUCHWINKLER ${ }^{3}$, Mark WALTER ${ }^{3}$,

Gerti HAUNEDINGER ${ }^{3}$, Karin GRUBER ${ }^{3}$ 
Affiliations:

1. Slovenian Forestry Institute (GIS), Slovenia

2. Aristotle University of Thessaloniki (AUTh), Greece

3. Bavarian Office for Forest Genetics (AWG), Germany

4. Decentralized Administration of Macedonia \& Thrace, General Directorate of Forests \& Rural Affairs, Greece

5. Institute of Mediterranean Forest Ecosystems, DEMETER, Greece

6. Forestry Faculty, University of Sarajevo, Bosnia and Herzegovina

7. Szent István University, Budapest, Hungary

8. Slovenia Forest Service (ZGS), Slovenia

9. European Forest Genetic Resources Programme (EUFORGEN), European Forest Institute (EFI), Spain

10. Institute of Evolutionary Biology, University of Edinburgh, UK

11. Institute of Plant Breeding and Genetic Resources, HAO ELGO DEMETER, Greece

12. Federal Research and Training Centre for Forests, Natural Hazards and Landscape (BFW), Austria

13. Croatian Forest Research Institute, Jastrebarsko, Croatia

14. Faculty of Forestry, Ss. Cyril and Methodius University in Skopje, North Macedonia

15. Berchtesgaden National Park, Doktorberg 6, Berchtesgaden, 83471, Germany

16. Faculty of Forestry, University of Zagreb, Croatia

17. Institute of Lowland Forestry and Environment (ILFE), Novi Sad, Serbia

18. Forest Research Center, INIA, Spain

19. Department of Agronomy, Biotechnical Faculty, University of Ljubljana, Slovenia

20. Executive Forests Agency, Ministry of Agriculture and Foods, Sofia, Bulgaria

21. Department of Forestry and Renewable Forest Resources, Biotechnical Faculty, University of Ljubljana, Slovenia

22. French National Research Institute for Agriculture, Food and the Environment (INRAe), France

23. Forestry Commission Scotland, UK

24. Ministry of Agriculture, Forestry and Food of the Republic of Slovenia, Slovenia

25. Institute for environmental microbiology, Czech Academy of Sciences, Czech Republic

26. Faculty of Forestry, University of Banja Luka, Rep. Srpska, BiH

27. Hungarian Forest Research Institute (ERTI), Hungary

28. Hellenic Ministry of Environment and Energy

29. Swiss Federal Institute for Forest, Snow and Landscape Research (WSL), Switzerland

30. Natural Resources Institute Finland (Luke), Finland 


\section{PLOT SELECTION}

2.1 Number of plots per species . . . . . . . . . . . . . . . . . . . . . . . . . . . . . 18

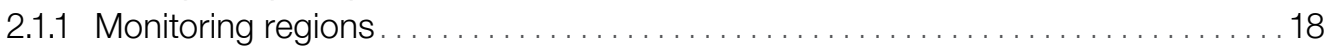

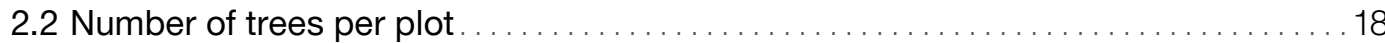

2.3 Criteria for Plot selection . . . . . . . . . . . . . . . . . . . . . . . . . . . . . . . . . . . . . 18

\section{PLOT ESTABLISHMENT AND MAINTENANCE}

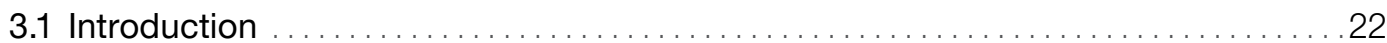

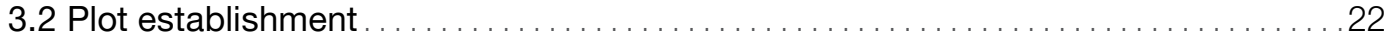

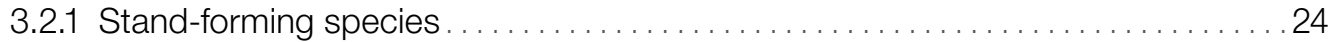

3.2.2 Scattered species ................................................ 26

3.2.3 Natural regeneration subplots . . . . . . . . . . . . . . . . . . . . . . . . . 28

3.3 Labelling, georeferencing, field measurements and observations . ............29

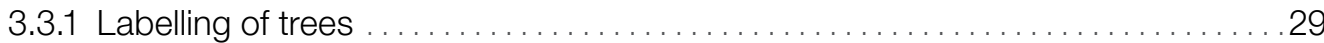

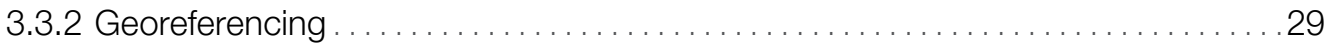

3.4 Plot description (standardised forms developed) . . . . . . . . . . . . . . . . . . . . . 30

3.5 Plot Maintenance ..................................................... 30

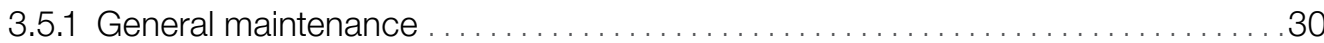

3.5.2 Replacement of trees ........................................ 30

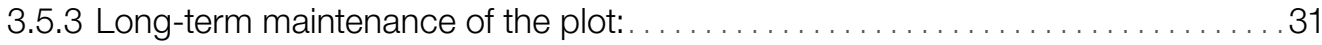

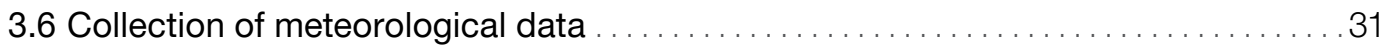

\section{INDICATORS, VERIFIERS AND} BACKGROUND INFORMATION

4.1 Definition of indicators and verifiers / background information ............... 34

4.2 Selection of indicators and verifiers / background information . . . . . . . . . . . . 35

4.3 Description of indicators and verifiers/background information . . . . . . . . . . . . . 36 


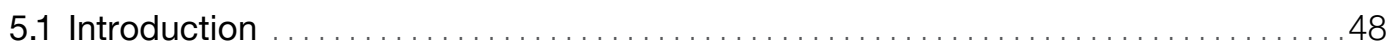

5.2 Verifiers and background information observed/measured in the field . . . . . . . 48

5.2 .1 Verifier: Mortality / Survival ...................................... 49

5.2 .2 Verifier: Natural regeneration abundance ......................... 49

5.2 .3 Background information: $\mathrm{DBH}$ class distribution ..................... 50

5.2 .4 Background information: Height class distribution ..................... 50

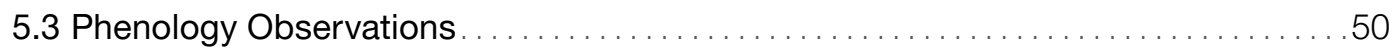

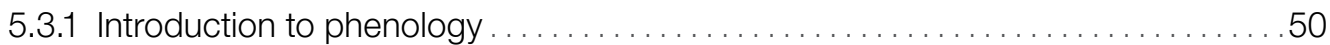

5.3.2 Phenological verifiers and background information ................... 51

5.4 Collecting samples .......................................... 57

5.4 .1 Sampling procedure for DNA analysis . . . . . . . . . . . . . . . . . . 57

5.4 .2 Seed sampling for seed testing ................................ 61

LABORATORY AND DATA ANALYSES

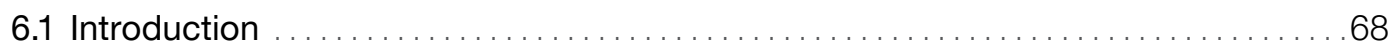

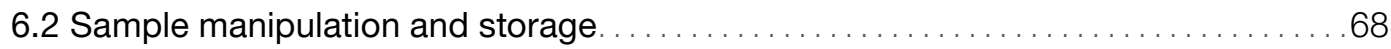

6.2 .1 Sample manipulation . . . . . . . . . . . . . . . . . . . . . . . . . . . 68

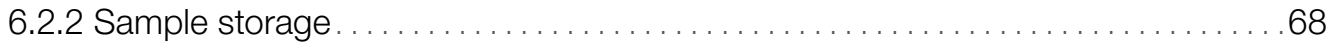

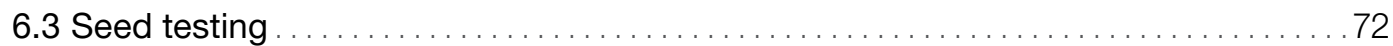

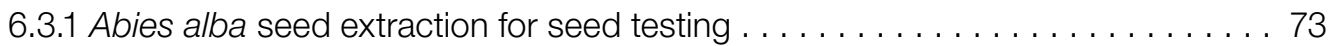

6.3.2 Fagus sylvatica and Abies alba/A. borisii-regis seed preparation

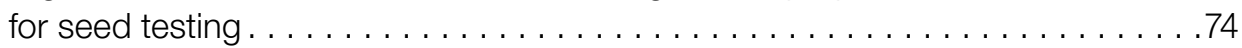

6.3.3 Biochemical Test for Viability, the Topographical Tetrazolium Test . . . . . . . . 78

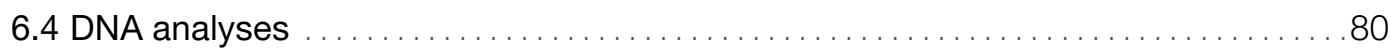

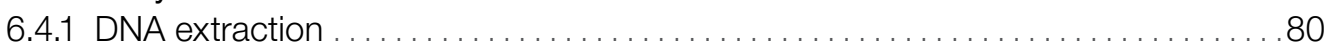

6.4 .2 Genetic markers .............................................. 83

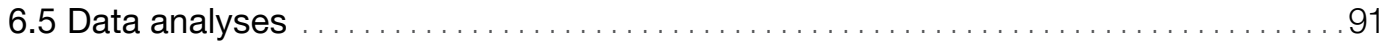

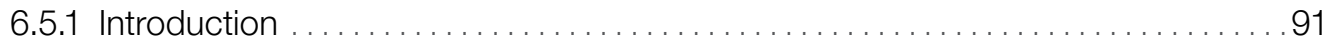

6.5 .2 Database ................................................ 91

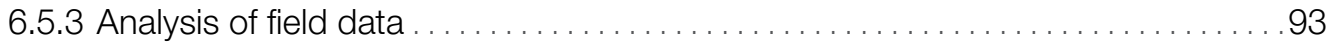

6.5.4 Analysis of Molecular Data ..................................... 99

6.5.5 Analysis of seed testing data ................................. 117

6.5.6 The Key Verifiers............................................. 118

6.5.7 Interpretation of values: stepwise response based on change in 10 years . ... 118

COST ASSESSMENT

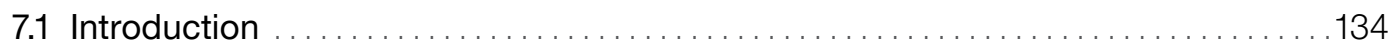

7.2 Cost assessment ............................................... 134

7.2 .1 Cost assessment assumptions ................................ 134

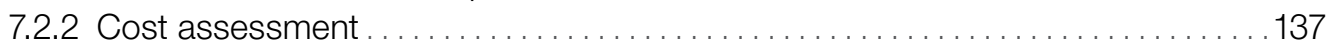

7.3 Conclusions and recommendations. . . . . . . . . . . . . . . . . . . . . . . . . . . . 147

7.3.1 Recommendations for cost-saving measures . . . . . . . . . . . . . . . . . . . . 147 


\section{DECISION SUPPORT FOR SELECTING} THE INTENSITY OF FGM

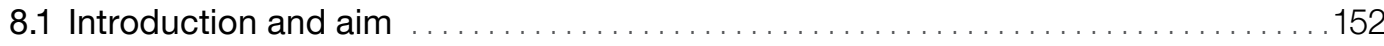

8.2 Questions, which FGM answers . . . . . . . . . . . . . . . . . . . . . . . . . . . . 152

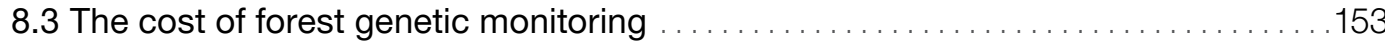

8.4 Information value of FGM verifiers . . . . . . . . . . . . . . . . . . . . . . . . . 155

8.5 Management actions following FGM . . . . . . . . . . . . . . . . . . . . . . . . 155

8.6 Messages to policymakers ................................... 156

GUIDELINES FOR FOREST GENETIC MONITORING

9.1 Introduction .

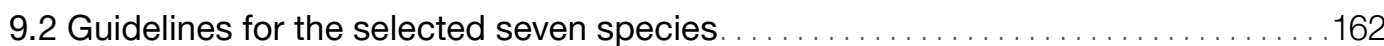

9.2.1 Silver fir (Abies alba Mill.) and King Boris fir (Abies borisii-regis Mattf.). . . . . . . . 163

9.2.2 European beech (Fagus sylvatica L.) . . . . . . . . . . . . . . . . . . . . . . . . . 179

9.2.3 Common ash (Fraxinus excelsior L.) . . . . . . . . . . . . . . . . . . . . . . . . . . . 195

9.2.4 European black pine (Pinus nigra J. F. Arnold) . . . . . . . . . . . . . . . . . . . . 215

9.2.5 European black poplar (Populus nigra L.) . . . . . . . . . . . . . . . . . . . . . . . 235

9.2.6 Wild cherry (Prunus avium (L.) L.) . . . . . . . . . . . . . . . . . . . . . . . . . . . 255

9.2.7 Pedunculate oak (Quercus robur L.) and

Sessile oak (Quercus petraea (Matt.) Liebl.) . . . . . . . . . . . . . . . . . . . . . . . . . . . 271

ANNEX

10.1 Description of designation and maps of monitoring regions . .............. 294

Monitoring regions for firs (Abies alba Mill./ Abies borisii-regis Mafft.) . . . . . . . . 295

Monitoring regions for European beech (Fagus sylvatica) . . . . . . . . . . . . . . 296

Monitoring regions for common ash (Fraxinus excelsior) . . . . . . . . . . . . . . . . 297

Monitoring regions for black pine (Pinus nigra) ........................ 298

Monitoring regions for black poplar (Populus nigra) . . . . . . . . . . . . . . . . . . 299

Monitoring regions for wild cherry (Prunus avium) . . . . . . . . . . . . . . . . . . . . . 300

Monitoring regions for oaks (Quercus robur, Quercus petraea) . ...............301

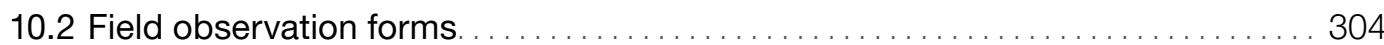

10.2.1 Plot description form ...................................... 305

10.2.2 Form for recording field verifiers . . . . . . . . . . . . . . . . . . . . . . . . . . . . . . 309

10.2.3 Form for recording field background information .................... 316

10.3 Supplementary tables for Chapter 7: Cost assessment ..................321 


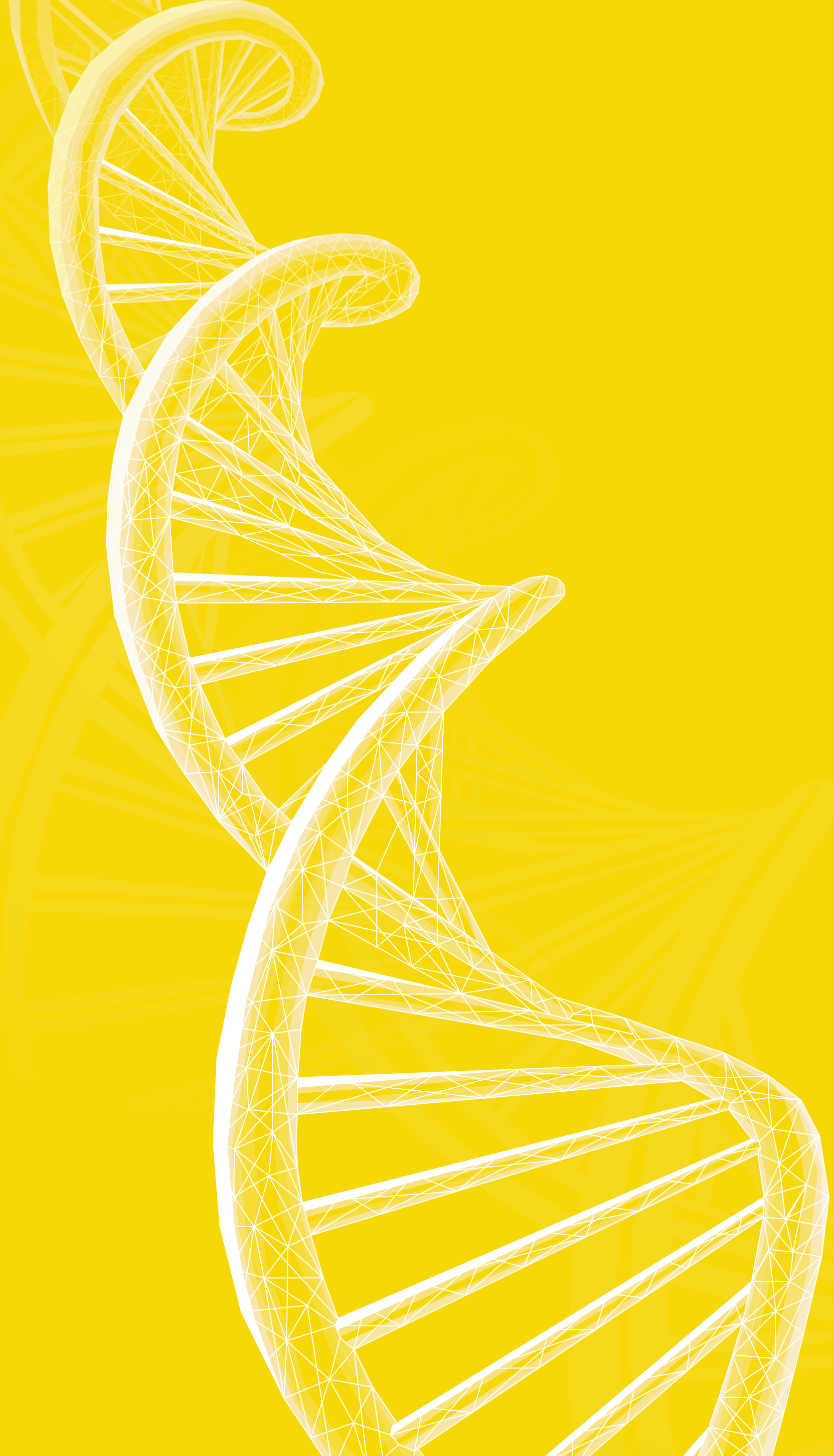




\section{2y \\ LIFE13 ENV/S//000148}

\section{Manual for forest genetic monitoring}
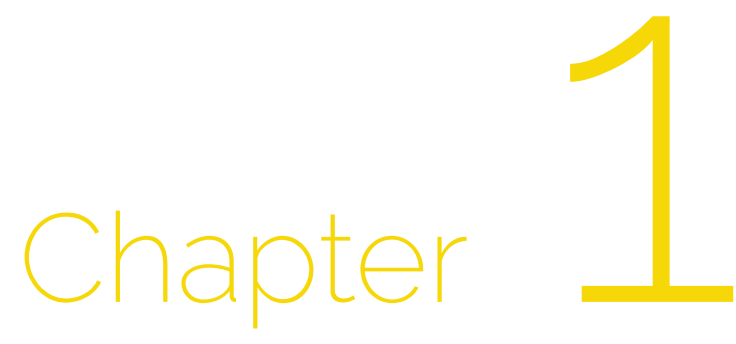

\section{Introduction}

Filippos A. ARAVANOPOULOS ${ }^{1}$, Marko BAJC², Barbara FUSSI ${ }^{3}$, Hojka KRAIGHER²

Citation: Aaravanopoulos et al. (2020) Introduction. In: Bajc et al. (eds) Manual for Forest Genetic Monitoring. Slovenian Forestry Institute: Silva Slovenica Publishing Centre, Ljubljana, pp 11-14. http://dx.doi.org/10.20315/SFS.167

\section{Affiliations:}

1. Aristotle University of Thessaloniki (AUTh), Greece

2. Slovenian Forestry Institute (GIS), Slovenia

3. Bavarian Office for Forest Genetics (AWG), Germany 
Rapid climate change has been recognised as an increasing threat to long-living forest trees, to forest ecosystems and all levels of biodiversity that they harbour, shelter or provide. Genetic diversity is the ultimate source of biological diversity, and is crucial for the vitality of forests and their adaptation to climate change. Moreover, genetic diversity provides resilience in relation to other stress factors, such as pests and diseases.

The Convention on Biological Diversity has since 1992 presented the most comprehensive international agreement and effort to globally conserve biodiversity, including genetic diversity. Article 7 calls for action to "monitor through sampling and other techniques the components of biological diversity" (CBD 1993). The need to monitor biological diversity led to the development of global biodiversity indicators (Graudal et al. 2014), as also reflected in the ensuing Aichi Biodiversity Target Indicators (Convention on Biological Diversity 2010). Other international and regional processes have called for the establishment of criteria and indicators for assessment of genetic diversity, or with regard to Forest Genetic Resources (FGR) ${ }^{1}$ (such as the Forest Europe process, EU Forest Strategy, EU Rural Development Programme, EU Directive on Plant Reproductive Material, EU Regulation on Invasive Alien Species) (see Bouillon et al. 2014).

Genetic aspects should thus be taken into account when monitoring the effects of climate change on forest ecosystems, as they also should be in relation to managing existing forests and establishing new ones, in particular in the selection and production of seed and other reproductive material for reforestation and restoration (ibid).

The objective of Forest Genetic Monitoring (FGM) is to assess the current status of genetic resources and quantify relevant changes at a temporal scale, in order to preserve long-term adaptive evolutionary potential. By observing temporal changes in populations, causal components can be inferred, and their relative importance evaluated. FGM is therefore a prognostic tool and forms a method to secure the conservation of processes that maintain genetic variation in natural populations (Aravanopoulos 2011). FGM may enhance the potential for early detection of potentially harmful changes of forest adaptability before these appear at higher biodiversity levels (e.g. species or ecosystem diversity) and can improve the sustainability of applied forest management practices and direct further research.

The basic principles to be addressed in FGM were established by the European Forest Genetic Resources Programme (EUFORGEN) (Aravanopoulos et al. 2015), that has been continuously contributing to the panEuropean strategy for conservation of FGR (De Vries et al. 2014), and lists supporting the implementation of a pan-European FGM scheme as one of the operational objectives within its Phase VI Action plan (2020-2024) (EUFORGEN 2019).

A primary requirement for the implementation of $F G M$ is the delineation of monitoring regions, i.e. regions where genetic monitoring should be conducted to have a maximum effect. This has also been advanced by a combined data-driven and expert-based approach and applied in the LIFEGENMON project (LIFE ENV/ SI/000148; 2014 - 2020; http://www.lifegenmon.si/) along a broad transect, ranging from the Bavarian Alps in Germany to Mt. Olympus in Greece, covering nine countries and seven tree species or species complexes that differ in their biology and distribution.

Genetic monitoring as proposed in the LIFEGENMON project operates on a scientifically based system that includes a minimum set of conceptual approaches and parameters that would extract the maximum amount of genetic information (Aravanopoulos 2016, Fussi 2016). These are exemplified by the use of indicators and verifiers. An indicator applies to any ecosystem component or process used to infer the sustainability of the related resource (Aravanopoulos et al. 2015).

\footnotetext{
The Food and Agriculture Organisation of the United Nations (FAO) states that "Forest Genetic Resources (FGR) are the heritable materials maintained within and among tree and other woody plant species ... that are of actual or potential economic, environmental, scientific or societal value. They are crucial to the adaptation and protection of our ecosystems, landscapes and production systems, yet are subject to increasing pressures and unsustainable use" (http://www.fao.org/forest-genetic-resources/ background/en/).
} 
An indicator is usually measured on a temporal basis to reflect an achievement or change related to the associated criterion. It must be directly measurable, and the metric used to measure an indicator is referred to as a verifier. Therefore, a verifier involves the estimation of data that improves the specificity or the facilitation of the assessment of an indicator. In practical terms it is the measure of the indicator (Aravanopoulos et al. 2015). This Manual proposes that FGM be assessed using three indicators, namely selection, genetic variation and gene flow/mating system, and a total of 15 verifiers. Indicator selection is assessed by demographic verifiers which pertain to the collection of field data. Genetic variation is assessed using genetic markers by sampling the mature stands and regeneration. Finally, gene flow is also assessed using genetic markers, while open pollinated families are assessed by sampling seeds.

Three options or levels for genetic monitoring are proposed: Basic, Standard and Advanced. The first option (Basic) uses demographic data to assess indicator selection. The second (Standard) uses demographic (as above) and genetic data, to assess genetic variation in addition to selection. Finally, the third option (Advanced) uses, besides the above, open pollinated family (seed) data to further assess selection and genetic variation, gene flow and mating systems (Aravanopoulos et al. 2015).

There is a growing international effort for securing long-term political commitments for implementation of FGM for the following four reasons: (a) FGM can be successfully applied, as proof-of-principle exercises have shown; (b) FGM can provide invaluable insights into the future state of genetic diversity and population survival, especially as a number of genetically important forest tree populations (e.g. marginal, rare, or vulnerable) fall below the genetically effective population size; (c) FGM is a long process and requires regular periodicity of assessments in order to reliably detect and interpret the FGM signal; and (d) the costs of FGM range from low for the basic level to considerable for the advanced level.

Within the LIFEGENMON project, the Manual and Guidelines for FGM have been developed encompassing different monitoring intensities and cost levels. The Decision Support System (DSS) has been developed to aid policymakers in choosing the optimal level of FGM considering the costs and benefits of different levels of such monitoring. Additionally, DSS provides recommendations for implementation of measures for conservation and sustainable use of FGR in the changing climates.

The FGM system as implemented in the LIFEGENMON project is based on sound theoretical genetic monitoring principles, but the authors of this document objectively acknowledge that not all aspects of FGM could be fully tested in the duration of the project. Being a long-term effort, FGM can only reach its full potential after a sufficient number of temporal assessments will have been performed. Like any analytical system, the proposed FGM system will need to be continuously assessed and evaluated to see if it is meeting the expected monitoring objectives, and if needed improved or redesigned (Fussi et al. 2016).

Regarding the future development of FGM, it will likely move its future trajectory from genetic to genomic monitoring. This is expected to increase precision in estimates of population genetic diversity and adaptive genetic potential. As epigenetic variation appears to influence many phenotypic traits involved in local adaptation, epigenomic monitoring may also become an option in the future. At a more comprehensive level, the future of FGM will undoubtedly involve and benefit from integration of data acquired from the monitoring of, not only genetic parameters, but also of climatic, edaphic, physiological, community level parameters, and so on. Emerging GIS, remote sensing and data-mining technologies, will be paramount in this respect for FGM as well.

This manual presents in detail the basis and application of FGM across all of the above levels. It aspires to become a primary guiding document for the application of genetic monitoring in European forests and beyond, and to set the stage for the full implementation of FGM for genetic conservation and sustainable forest management. 


\section{References}

Aravanopoulos FA (2011) Genetic monitoring in natural perennial plant populations. Botany 89:75-81. https://doi. org/10.1139/b10-087

Aravanopoulos FA (2016) Conservation and monitoring of tree genetic resources in temperate forests. Current Forestry Reports 2:119-129. https://doi.org/10.1007/s40725-016-0038-8

Aravanopoulos FA, Tollefsrud MM, Graudal L, Koskela J, Katzel R, Soto A, Nagy L, Pilipovic A, Zhelev P, Bozic G \& Bozzano M (2015) Development of genetic monitoring methods for genetic conservation units of forest trees in Europe. European Forest Genetic Resources Programme (EUFORGEN), Bioversity International, Rome, Italy, 62 pp.

Bouillon P, Hubert J, Bakkebo Fjellstad K, Rusanen M, Zavrl Bogataj A, Olrik DC, Bordács S, Longauer R, Paitaridou D, Koiv K, Koskela J, Orlovic S, Black-Samuelsson S, Wolter F (2015) The implications of global, European and national policies for the conservation and use of forest genetic resources in Europe. European Forest Genetic Resources Programme (EUFORGEN), Bioversity International, Rome, Italy, 42 pp.

Convention on Biological Diversity (2010) Strategic Plan for Biodiversity 2011-2020, including Aichi Biodiversity Targets. https://www.cbd.int/sp/ Accessed 03 December 2020

de Vries SMG, Alan M, Bozzano M, Buriánek V, Collin E, Cottrell J, Ivankovic M, Kelleher C, Koskela J, Rotach P, Vietto L, Yrjänä L (2015) Pan-European strategy for genetic conservation of forest trees and establishment of a core network of dynamic conservation units. European Forest Genetic Resources Programme (EUFORGEN), Bioversity International, Rome, Italy, 40 pp.

EUFORGEN (2019) Strategic objectives and implementation plan for Phase VI (2020-2024). http://www.euforgen.org/ fileadmin/templates/euforgen.org/upload/Documents/EUFORGEN_PhaseVI_Objectives_and_Plan.pdf Accessed 08 December 2020

Food and Agriculture Organisation of the United Nations. Forest Genetic Resources. http://www.fao.org/forest-geneticresources/background/en/ Accessed 03 December 2020

Fussi B, Westergren M, Aravanopoulos F, Baier R, Kavaliauskas D, Finzgar D, Alizoti P, Bozic, G, Avramidoul E, Konnert M, Kraigher H (2016) Forest genetic monitoring: an overview of concepts and definitions. Environmental Monitoring and Assessment 188(8):493. https://doi.org/10.1007/s10661-016-5489-7

Graudal L, Aravanopoulos FA, Bennadji Z, Changtragoon S, Fady B, Kjaer ED, Loo J, Ramamonjisoa L, Vendramin GG (2014) Global to local genetic diversity indicators of evolutionary potential in tree species within and outside forests. For Ecol Manag 333:35-51. https://doi.org/10.1016/j.foreco.2014.05.002 



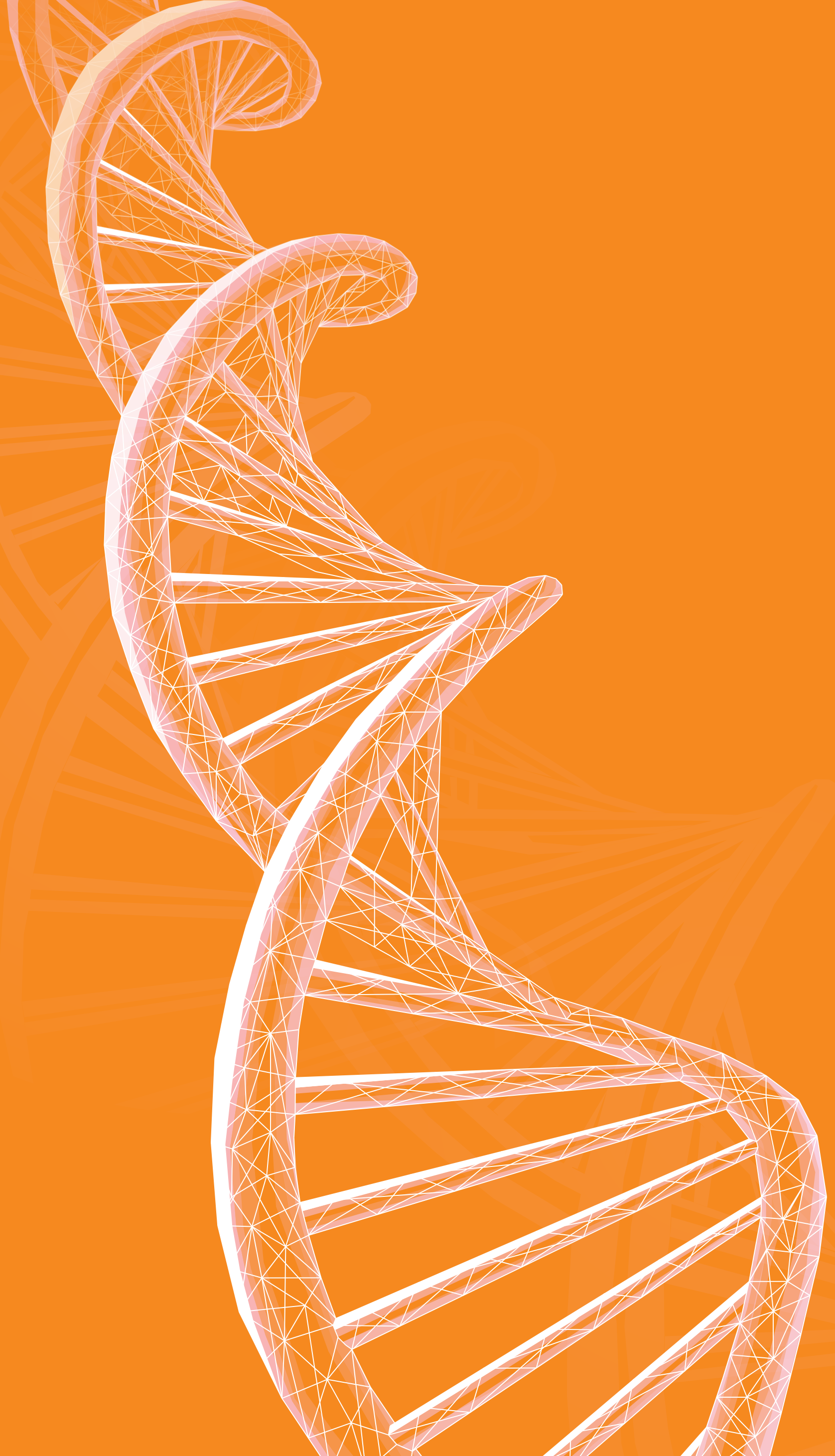




\section{\#\#) \\ LIFE13 ENV/SI/000148}

\section{Manual for forest genetic monitoring}
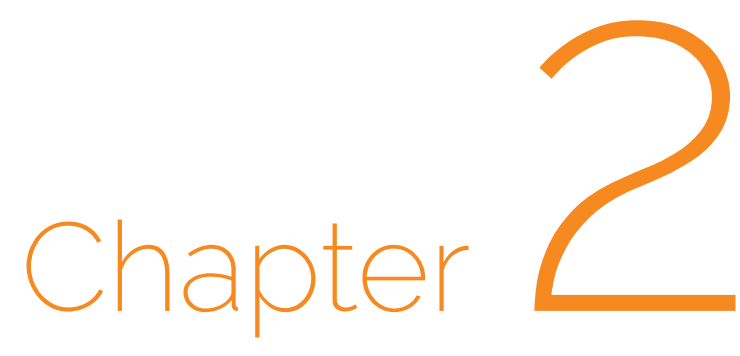

\section{Plot selection}

Hojka KRAIGHER ${ }^{1}$, Marjana WESTERGREN ${ }^{1}$, Filippos A. ARAVANOPOULOS², Barbara FUSSI ${ }^{3}$, Marko BAJC', Dalibor BALLIAN ${ }^{114}$, Gregor BOŽIČ ${ }^{1}$, Domen FINŽGAR ${ }^{1,5}$, Darius KAVALIAUSKAS ${ }^{3}$, Fotios KIOURTSIS ${ }^{6}$, Monika KONNERT ${ }^{3}$, Živan VESELIČ7

Citation: Kraigher et al. (2020) Plot selection. In: Bajc et al. (eds) Manual for Forest Genetic Monitoring. Slovenian Forestry Institute: Silva Slovenica Publishing Centre, Ljubljana, pp 17-19. http://dx.doi.org/10.20315/SFS.167

\section{Affiliations:}

1. Slovenian Forestry Institute (SFI), Slovenia

2. Aristotle University of Thessaloniki (AUTH), Greece

3. Bavarian Office for Forest Genetics (AWG), Germany

4. Forestry Faculty, University of Sarajevo, Bosnia and Herzegovina

5. Institute of Evolutionary Biology, University of Edinburgh, UK

6. Decentralized Administration of Macedonia \& Thrace, General Directorate of Forests \& Rural Affairs, Greece

7. Slovenia Forest Service (SFS), Slovenia 


\subsection{Number of plots per species}

It is recommended that at least one (1) forest genetic monitoring (FGM) plot be established per monitoring region; monitoring regions are delineated per species or species complex (see Annex 10.1: Description of designation and maps of monitoring regions). If neighbouring countries share monitoring regions, international cooperation can reduce the total number of FGM plots across countries so that each monitoring region is represented by one FGM plot.

\subsubsection{Monitoring regions}

Monitoring regions should be delineated based on the following criteria:

1. Representative coverage of environmental zones (see Annex 10.1);

2. Coverage of characterised races or ecotypes, inclusion of marginal and peripheral populations considering latitudinal, altitudinal and ecological margins, as well as leading and rear edge populations of the species distribution range,

3. Consideration of the distribution of EUFORGEN gene conservation units (EUFORGEN, http://portal.eufgis. org/), so that each genetic monitoring region preferably includes at least one gene conservation unit as a genetic monitoring unit, if the relevant requirements are met (see 2.3 Plot selection criteria);

4. Known levels of existing genetic structure and standing genetic variation based on the results of genetic marker research,

5. Relevant results of provenance trials (where available), and

6. Expert knowledge on a country basis should be used to fine tune the locations of the delineated monitoring regions regarding the forest types, vitality, biodiversity and economic value of populations.

7. In the case of unclear or only partial results being available, expert opinion was deemed to be the final stage decisive factor. See Annex 10.1 for monitoring regions over the transect from Bavaria to Greece for Fagus sylvatica, Abies alba/ A. borisii regis, Fraxinus excelsior, Populus nigra, Pinus nigra, Prunus avium and Quercus robur/Q. petraea

\subsection{Number of trees per plot}

A minimum of fifty (50) reproducing trees must be selected for genetic monitoring per plot. In rare cases, for scattered tree species only, the number may be reduced to 30 adult trees (see Chapter 3: Plot establishment and maintenance).

\subsection{Criteria for Plot selection}

Criteria 1 through 4 are based on the EUFGIS minimum requirements for dynamic conservation units of forest trees (see http://portal.eufgis.org/fileadmin/templates/eufgis.org/documents/EUFGIS_Minimum_requirements.pdf)

1. The units should have a designated status (e.g. gene conservation area, approved seed object / basic material, protected area, etc).

2. The designated management for the area can be 'nature protection', 'multipurpose forestry' or other types of management supporting genetic processes that maintain the long-term viability of target tree populations. Exclusion of any clear-cutting under current and future management is paramount so as not to blur the environmental change signal in micro evolutionary genetic processes. 
3. The minimum size and shape of the FGM plot depends on the biology of the target tree species (see Chapter 3: Plot establishment and maintenance), but must be established within a viable population (i.e. a minimum of 50 reproducing trees; in special cases, such as monitoring of the recovery of an endangered population, a lower number of reproducing trees is acceptable).

4. At least one tree species in the stand should be designated as the target species for FGM. If the goal of FGM is to monitor hybridisation, the area where the plot is located must include a sufficient number of putative hybrids. It is recommended that "sister" plots are also established for pure species in the same monitoring region.

5. Presence of stand-level attributes paramount for genetic monitoring, representing the ecological adaptation of the population to the site: reproducing adult trees, presence and survival of natural regeneration (if expected based on the forest stand age), sexual and / or vegetative reproduction.

6. Availability of genetic data in the same or a nearby stand. A stand can be accepted or rejected for genetic monitoring based on the amount of standing genetic variation available.

7. Avoidance of steep slopes or other topographical characteristics which might influence gene flow within the plot. This criterion is not applicable for populations at the upper timberline or other special cases where steep inclination of terrain is unavoidable.

8. All legal, administrative and silvicultural changes need to be documented.

\section{Additional considerations and recommendations (not eliminating criteria)}

9. Priority should be given to plots for which stand history (e.g.: origin of genetic resources, year since last clearcutting, timing of thinning operations, etc.) and high data density, especially in time series and precise plot documentation, is already available. For example, from the Gene Conservation Units (GCUs), experimental plots, yield and growth permanent observation plots, approved seed objects, national forest inventory plots, ICP Forest plots, etc. Background data is important to take into account during selection of monitoring plots and interpretation of monitoring results. Such background data includes:

- Climatic / environmental data

- Soil data

- Vegetation data

- Data on past fructification and presence of natural regeneration

10. Distance of the institution to the monitoring plot. When several potential plots that meet all other requirements are under consideration the priority should be given to the plot the closest to the institution, as the cost of travelling to the more remote plots can increase the total cost of monitoring substantially (see Chapter 7: Cost assessment).

11. Easy accessibility of the plot (e.g.: road, footpath, rock obstacles, etc.). Whenever possible, select FGM plots that can be reasonably easily accessed, as this will reduce the workload in the field and the overall cost of FGM.

12. FGM plots can be promoted as 'research focal points' and included in other monitoring programmes and research projects: national inventories, ICP Forest, greenhouse gas emission/sink monitoring plots, forest soil biodiversity research and monitoring, etc. Such an approach would facilitate long-term continuation of monitoring activities at FGM plots, contribute to securing the long-term budgetary support and increase the amount of different types of data available for FGM plots. 


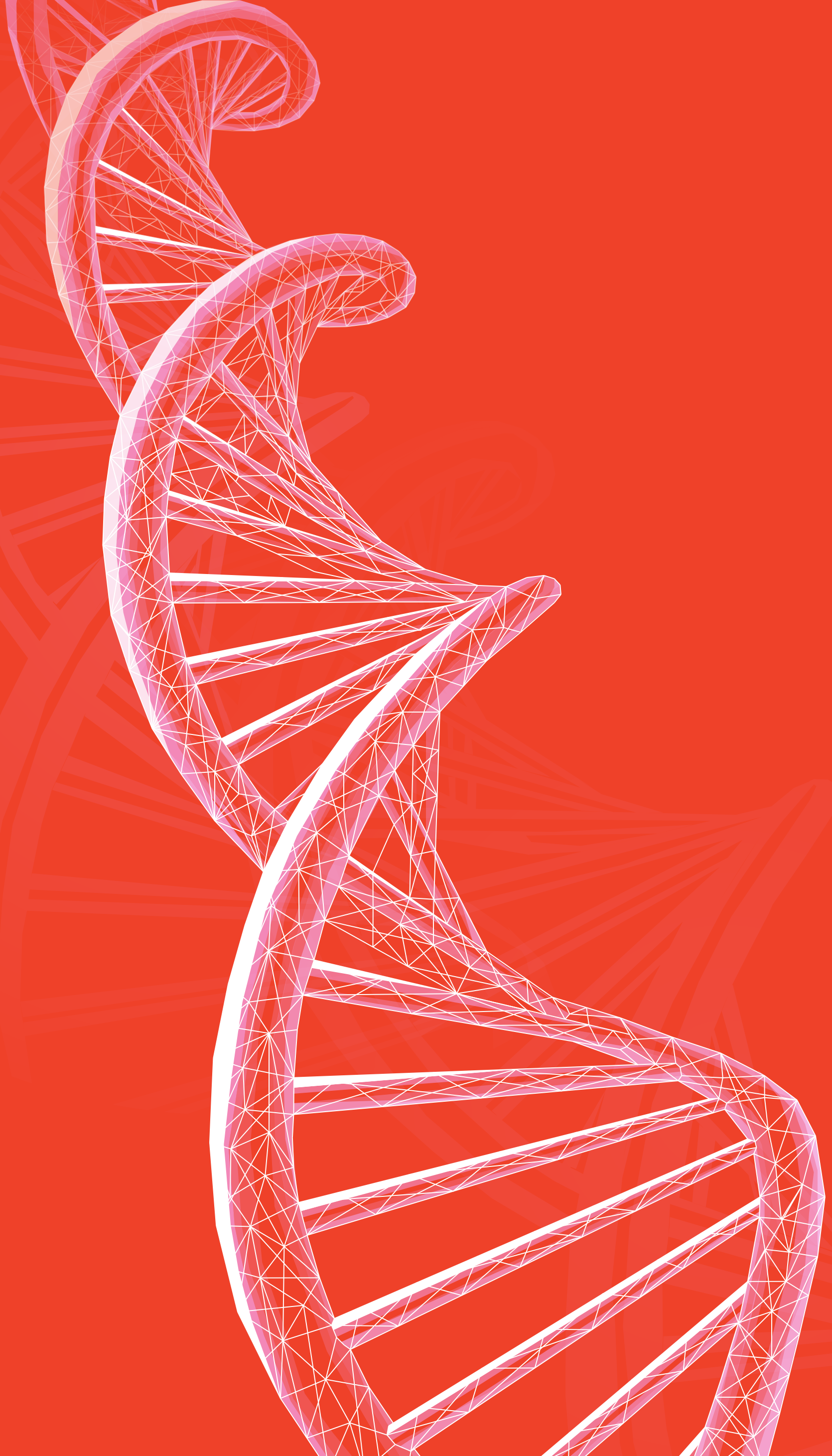




\section{\#\#地 \\ LIFE13 ENV/SI/000148}

\section{Manual for forest genetic monitoring}

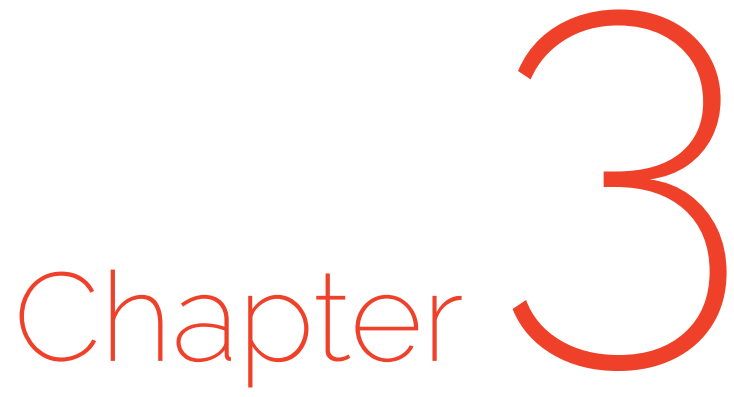

\section{Plot establishment and maintenance}

Natalija DOVČ ${ }^{1}$, Darius KAVALIAUSKAS², Rok DAMJANIĆ ${ }^{1}$,

Filippos A. ARAVANOPOULOS ${ }^{3}$, Barbara FUSSI'2, Marko BAJC1,

Paraskevi ALIZOTI ${ }^{3}$, Domen FINŽGAR ${ }^{1,11}$, Evangelia V. AVRAMIDOU ${ }^{3,7}$,

Dalibor BALLIAN'1,5, Evangelos BARBAS ${ }^{3}$, Pavlos BEKIAROGLOU,

Sándor BORDÁCS ${ }^{8}$, Gregor BOŽIČ ${ }^{1}$, Andrej BREZNIKAR ${ }^{4}$,

Pavlos CHASILIDIS ${ }^{6}$, Anna-Maria FARSAKOGLOU ${ }^{3,10}$, Nikitas FRAGKISKAKIS ${ }^{6}$, Ioannis GANOPOULOS ${ }^{3,9}$, Fotios KIOURTSIS ${ }^{6}$, Monika KONNERT²,

Ermioni MALLIAROU ${ }^{3}$, Georgios ROUSAKIS ${ }^{6}$, Chryse SARVANI ${ }^{6}$, Kristina SEVER ${ }^{4}$, Nikolaos TOURVAS ${ }^{3}$, Marjana WESTERGREN ${ }^{1}$, Hojka KRAIGHER ${ }^{1}$

Citation: Dovč et al. (2020) Plot establishment and maintenance. In: Bajc et al. (eds) Manual for Forest Genetic Monitoring. Slovenian Forestry Institute: Silva Slovenica Publishing Centre, Ljubljana, pp 21-31. http://dx.doi.org/10.20315/SFS.167

\section{Affiliations:}

1. Slovenian Forestry Institute (GIS), Slovenia

2. Bavarian Office for Forest Genetics (AWG), Germany

3. Aristotle University of Thessaloniki (AUTh), Greece

4. Slovenia Forest Service (ZGS), Slovenia

5. Forestry Faculty, University of Sarajevo, Bosnia and Herzegovina

6. Decentralized Administration of Macedonia \& Thrace,

General Directorate of Forests \& Rural Affairs, Greece

7. Institute of Mediterranean Forest Ecosystems, ELGO DEMETER, Greece

8. Szent István University, Budapest, Hungary

9. Institute of Plant Breeding and Genetic Resources, HAO ELGO DEMETER, Greece

10. European Forest Genetic Resources Programme (EUFORGEN),

European Forest Institute (EFI), Spain

11. Institute of evolutionary biology, University of Edinburgh, UK 


\subsection{Introduction}

A forest genetic monitoring (FGM) plot is the basic unit where genetic monitoring is conducted, and is the basis for all the following work. Therefore, it is paramount to follow the instructions for plot establishment and regularly maintain it.

\subsection{Plot establishment}

When a site for FGM (i.e. a forest stand) is confirmed, a smaller area for FGM plot installation is to be selected within it (Figure 3.1). For stand-forming species the location for the FGM plot installation is chosen at random, while for scattered species a preliminary field survey of the selected stand for FGM is required.

Ideally a plot should facilitate the subsequent operations without compromising the FGM values, keeping the plot establishment costs low while avoiding the mistakes that could compromise FGM. Areas with limited range of visibility (i.e. dense understory, or tall regeneration) or harsh working conditions (i.e. long travel distance to the plot or rocky terrain) should be avoided if possible.

Equipment needed for plot establishment:

- a device for distance measurement (a pair of range-finding binoculars is recommended)

- a compass

- a paint with a brush or spray for marking trees

- a GPS receiver that is precise enough and allows saving trees' coordinates.

Measurements of $\mathrm{DBH}$ and tree height which are used for calculating background information $\mathrm{DBH}$ class distribution and height class distribution can also be performed during the plot installation (see Chapters 4 and 5 for details). Therefore, additional equipment is needed:

- a tree calliper or a diameter tape

- a clinometer (preferably a laser clinometer).

An FGM plot for monoecious species consists of 50 unrelated reproducing trees and a minimum distance of $30 \mathrm{~m}$ between any two trees. For dioecious or functionally dioecious species 25 female and 25 male adult reproducing trees need to be selected with the same minimum distance requirement as for the monoecious species. If a tree is flowering, it is regarded as a reproducing tree. Therefore, the best time for FGM plot establishment and tree selection is spring, when potential trees are flowering; e.g. flowering cherry trees can be seen from far away. In case the plot cannot be established in the spring, $\mathrm{DBH}$ and social class can be used as a proxy to identify a reproducing tree for monoecious species. The $\mathrm{DBH}$ to be used as a proxy to recognise a flowering tree should be based on the local conditions and local forester's expertise. For dioecious or functionally dioecious species trees must be selected during the flowering period to be able to positively identify the sex of trees.

For species where clones or hybrids between target autochthonous species and other species occur, the selected trees first need to be genotyped for clonality or hybridisation. If the number of unrelated reproducing trees turns out to be less than 50 due to clones or hybrids being selected during plot installation, another 50 unrelated reproducing trees must be selected and genotyped. Fifty individuals that are confirmed by genotyping not to be hybrids or clones are then randomly selected for FGM. If initial DNA analysis shows a very high percentage of hybridisation, then another stand should be considered for FGM (unless the particular aim is to monitor a hybrid stand).

Since tree species vary in their distribution in the stand, the instructions for plot establishment are separated for stand-forming species and scattered species, which are further divided into two procedures: (i) selection of the centre of the plot for stand-forming species or definition of the sampling frame for scattered species, and (ii) the 
plot installation in the field. The instructions for scattered species cover two different approaches according to population density. Besides the instructions for two types of species, the instructions for natural regeneration (NR) subplot establishment are also described in this chapter.

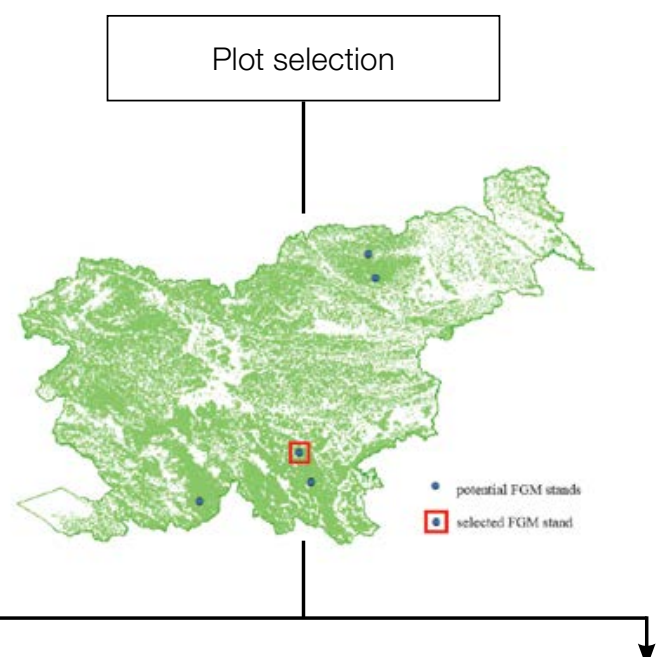

STAND FORMING SPECIES

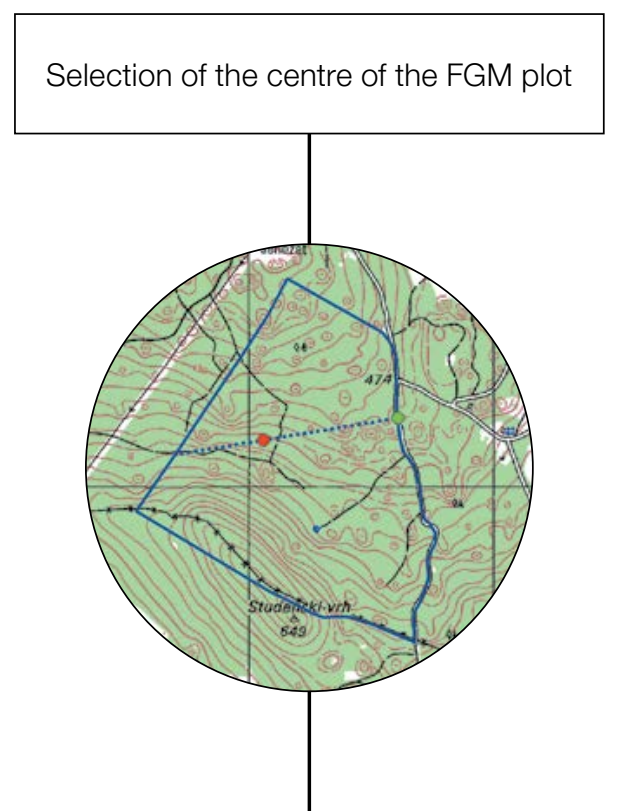

SCATTERED SPECIES

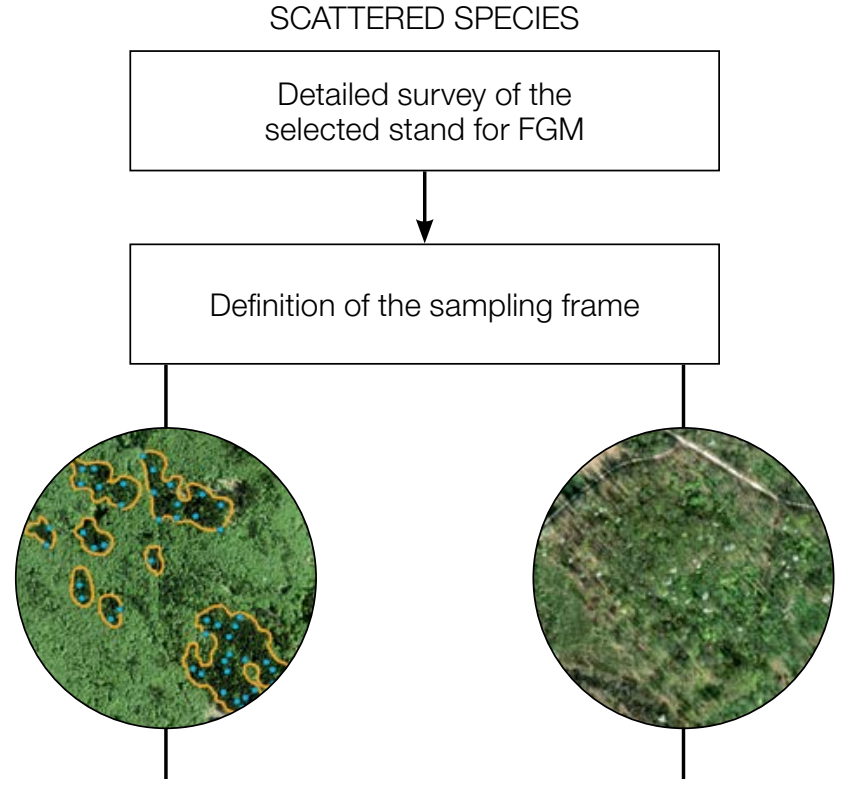

Individuals in clusters
Sporadically occurring trees

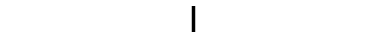

FGM plot installation in the field:

labeling of trees, georeferencing, DBH and height measurements, DNA sampling
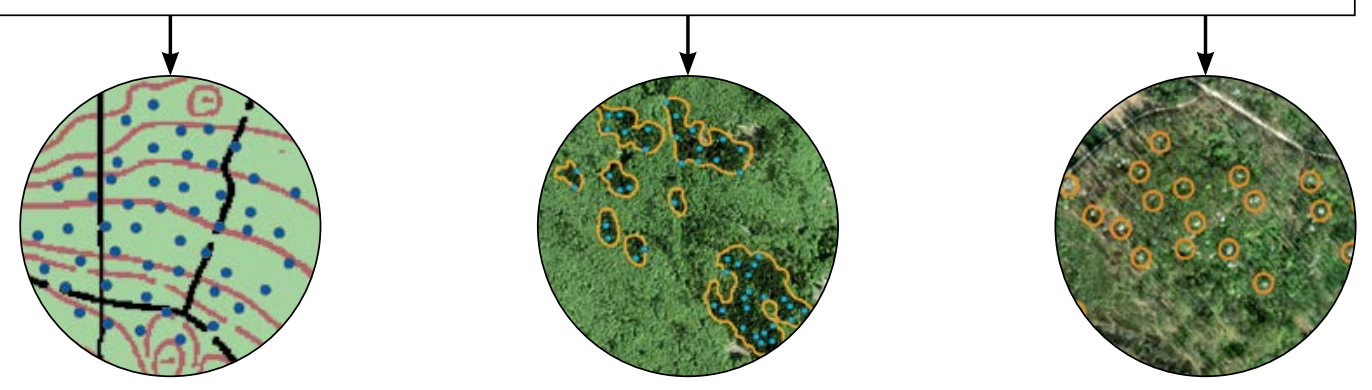

Figure 3.1: Flowchart of the FGM plot establishment, separated for stand-forming and scattered species. For scattered tree species, the design needs to adapt to the species biology and distribution. Examples for ash, cherry and poplar are presented in Chapter 9: Guidelines for forest genetic monitoring. 


\subsubsection{Stand-forming species}

\subsubsection{Selection of the centre of the FGM plot}

When a site (e.g. a forest stand) is confirmed for FGM implementation, a centre of the FGM plot is to be randomly selected. Random sampling, as a way of sampling design, should be used as it is the only statistically safe option. It should be done by preparing a map of the stand using any of the GIS software available (e.g. ArcGis Map, Qgis).

The general procedure for random selection of the centre of the plot (Figure 3.2), consists of the following steps:

- Random selection of a point (green dot) along the forest road or path, which runs along the stand,

- Drawing a line that is approximately perpendicular to the road from the randomly selected point on a road,

- Random selection of one point per line (red dot) - this point represents the centre of the FGM plot.

The minimum distance between a point and the stand border is approximately $150 \mathrm{~m}$. If the selected central point does not meet this criterion, a new point has to be found following the same protocol.

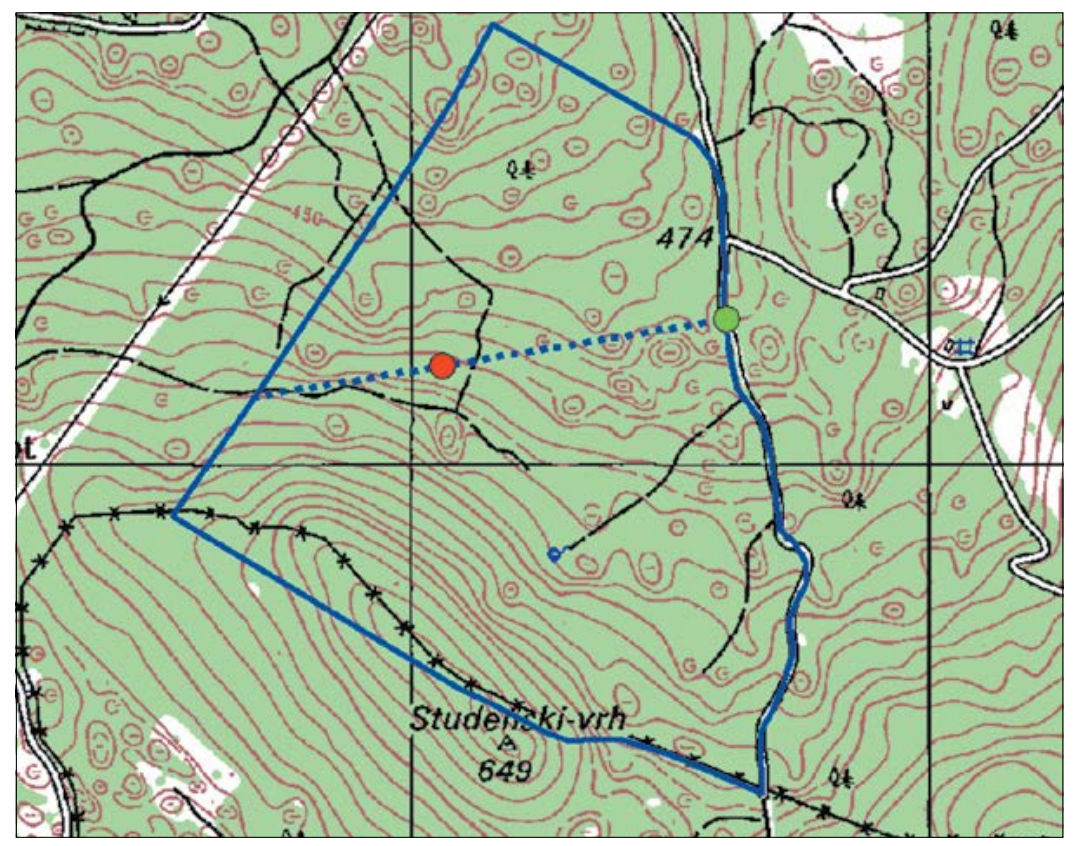

Figure 3.2: Random selection of the centre of the FGM plot

There is a possibility that the selected random point, representing the centre of an FGM plot, falls into an area where the installation of an FGM plot as well as further monitoring would be difficult to implement (due to poor visibility). It is therefore recommended to randomly select one or two spare points following the same procedure, which can be used in case of rejection of the first selected point.

Besides the approach described above, tools for creating random points in GIS software can also be used.

The selected point's coordinates are to be saved into a GPS device that will be used in the field. 


\subsubsection{Plot installation in the field}

In the field, the closest reproducing tree to the saved GPS coordinates becomes the centre of the monitoring plot and is marked with number 1. Other trees are selected in concentric circles around the previously selected central tree with an increasing radius of $30 \mathrm{~m}$ (Figure 3.3). The first tree in each circle should be selected randomly (marked red in Figure 3.3), which can be done in different ways: by using a random azimuth (Table 3.1) observed from the central tree, by following a direction of the second hand on an analogue watch or any other approach that allows for objective selection. Other trees in each circle are selected by appropriately enlarged azimuth and distances to ensure a minimum distance above but as close to $30 \mathrm{~m}$ between any two trees as possible:

- $+60^{\circ}$ for the first circle (a maximum of six trees)

- $+30^{\circ}$ for the second circle (a maximum of 12 trees)

- $+20^{\circ}$ for the third circle (a maximum of 18 trees)

- $+15^{\circ}$ for the fourth circle (a maximum of 24 trees)

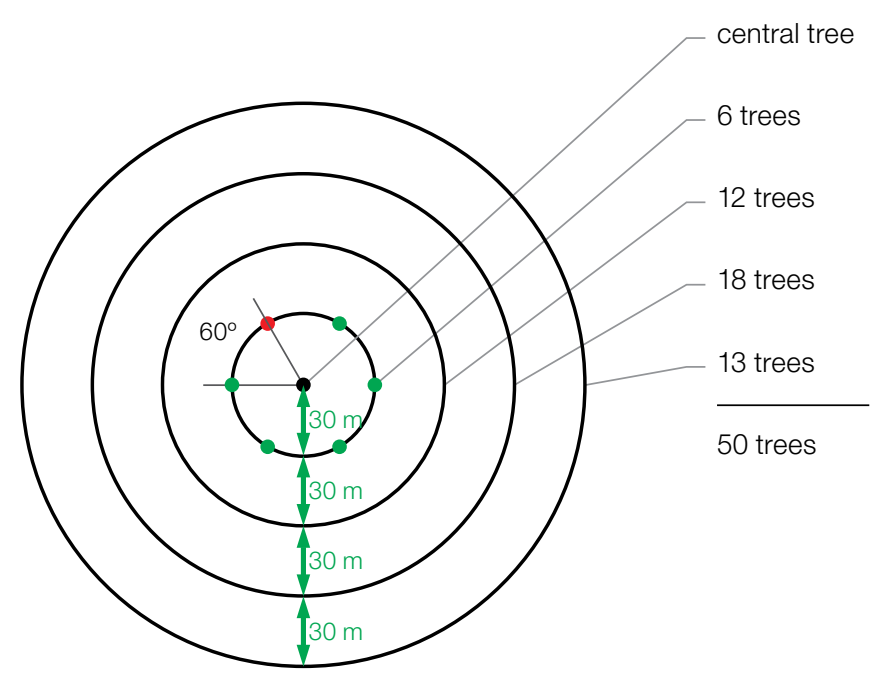

Figure 3.3: Schematics of an FGM plot for stand-forming species; trees are selected in concentric circles around the previously selected central tree with an increasing radius of $30 \mathrm{~m}$. The first tree in each circle (shaded red in the inner circle) is selected randomly.

If it is not possible to find the expected number of trees in each of the inner three circles, additional trees are selected in the outermost circle to reach the number of 50 trees.

Table 3.1: Random azimuths (degrees), which can be used for selection of the first tree in each circle.

\begin{tabular}{rrrrrrrrrrr}
\hline 108 & 15 & 186 & 35 & 178 & 29 & 305 & 351 & 44 & 150 \\
\hline 232 & 23 & 160 & 141 & 112 & 292 & 216 & 83 & 245 & 214 \\
\hline 63 & 65 & 345 & 234 & 95 & 78 & 279 & 323 & 40 & 236 \\
\hline 201 & 313 & 275 & 144 & 182 & 68 & 268 & 289 & 185 & 92 \\
\hline 356 & 177 & 93 & 1 & 145 & 198 & 287 & 251 & 224 & 142 \\
\hline
\end{tabular}

When selecting other trees in each circle, an appropriately enlarged azimuth should primarily be used to search for an approximate location and to follow the number of trees in a particular circle. Sometimes finding a tree with an exact azimuth would result in a significantly longer distance from the central tree, which would mean even larger or skewed circles. There are also cases where the central tree is not visible for various reasons, such as 
large distances, other trees covering the central tree, and topography. In such cases, the tree selection is based exclusively on a minimum distance from three previously selected trees, one tree from the same circle and two trees from the previous (on the inner side) one. The minimum distance should be above but as close to $30 \mathrm{~m}$ as possible.

\subsubsection{Scattered species}

Due to large differences in spatial distribution and density among scattered species' populations, there is no universal approach for FGM plot establishment. Since some species are present individually in the forest, while others occur in groups of different sizes in mixed forest stands or in specific patterns, the procedure for plot establishment is to be devised on a case-by-case basis, with the common requirements of 50 unrelated reproducing trees and a minimum distance of $30 \mathrm{~m}$ between selected trees. In special cases of very low population density (e.g. endangered populations, edge populations), the number of trees can be reduced to 30.

When a site for FGM implementation is confirmed (Chapter 2), the locations where the species appears in sufficient density to set up a monitoring plot must be additionally surveyed in more detail in the field. It is recommended to record a track or save the locations of all suitable trees and NR sites using a smartphone app (e.g. Locus map) or a GPS receiver during this initial surveying, which greatly facilitates further planning, as distribution of trees in the stand can then be viewed in GIS software and trees to be monitored can also be selected in the office. If the target species population is clearly visible and distinguished from other species in an orthophoto of the area, visual inspection of these photos may be used instead of the additional surveying in the field (Figure 3.4).
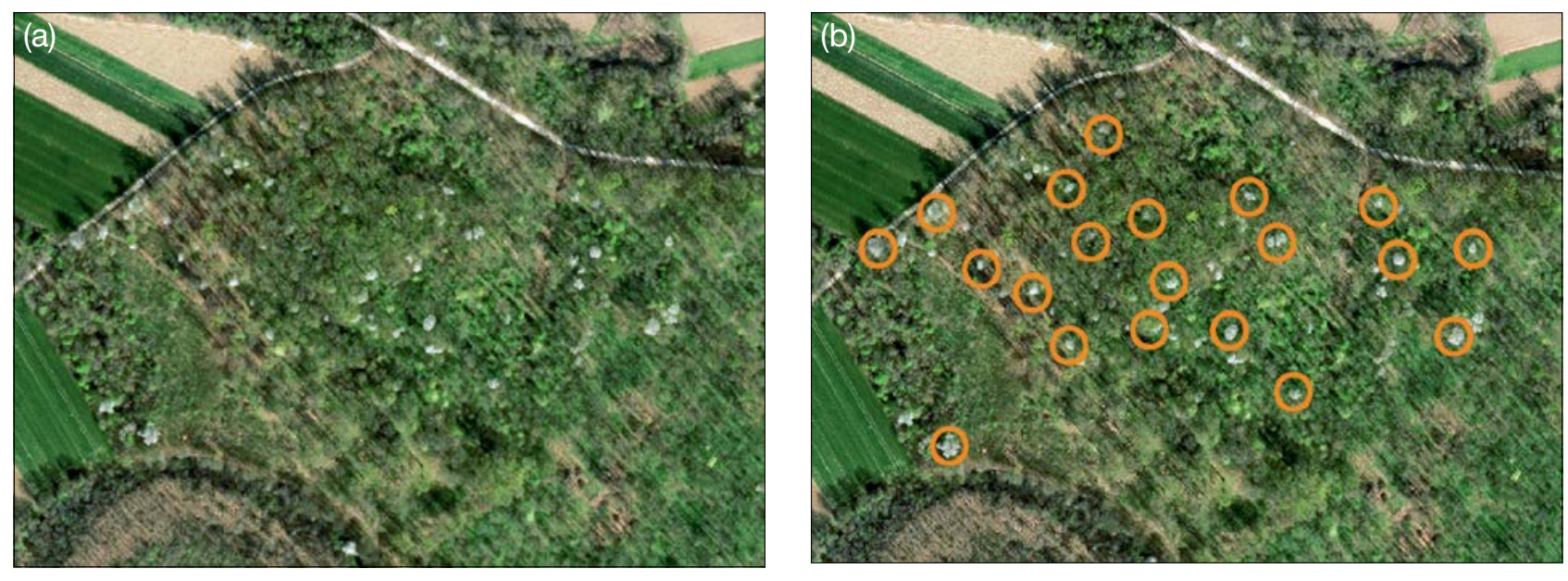

Figure 3.4: (a) Visual inspection of an orthophoto of the area and (b) selection of trees.

In the case of saving trees' locations while carrying out initial surveying in the field, the procedure for plot establishment is as follows:

- saved locations of all trees are plotted as a point feature layer in GIS software,

- 50 (minimum 30) points, representing trees with the minimum distance of $30 \mathrm{~m}$ from each other, are randomly selected,

- during plot installation, pre-selected trees are located in the field and marked.

Procedures for plot establishment without knowing exact tree locations are described below: one for species whose populations appear in the form of clusters of trees, and one for species with low-density populations, where trees occur sporadically across a larger area. 


\subsubsection{Individuals in clusters}

Several plots, which together form one FGM plot, should be installed in the field, one per cluster, where the number of trees in each plot is proportional to the cluster size with the total sum of 50 trees. Clusters of trees must be located within the same stand, where the environmental conditions and the species composition are similar.

\section{A. Definition of the sampling frame}

The locations of tree clusters are plotted on the map in the form of polygons, which all together represent a sampling frame. Trees within a cluster should be selected randomly. The approach that enables random selection is creating an appropriate number of random points with the minimum distance of $35 \mathrm{~m}$ inside each polygon in GIS software (Figure 3.5). The rationale behind using a longer distance between random points is to provide a safety margin for the reduced accuracy of GPS devices in forests and the distance of the nearest tree from the random GPS point. The random points' coordinates are saved into a GPS device which is to be used in the field.

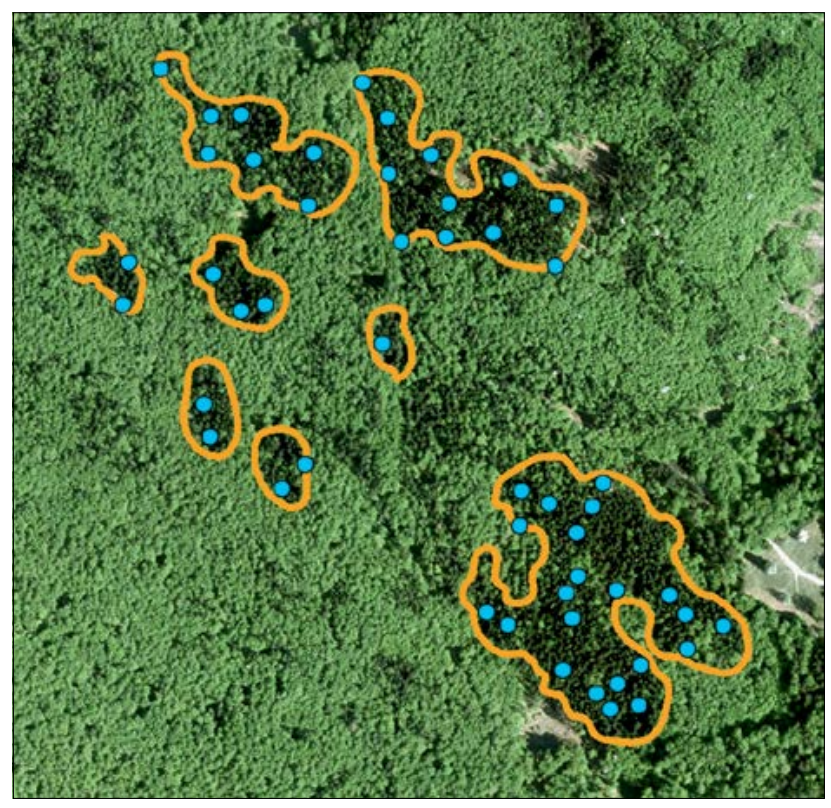

Figure 3.5: Plotted multiple clusters of trees with random points, representing approximate tree locations

\section{B. FGM plot installation in the field}

Once the coordinates of approximate tree locations are known, the procedure for plot installation in the field is as follows:

- find saved GPS coordinates in the forest stand,

- the closest reproducing tree to the saved GPS coordinate is selected and marked.

If the population density is not sufficient to carry out the process described above, the "seek and find approach" (see 3.2.2.2) within all groups can be used.

\subsubsection{Sporadically occurring trees ("seek and find approach")}

In cases where the population occurs in small groups of only a few trees each or trees are present individually, random sampling with the requirements of a minimum number of reproducing trees and a minimum distance of 30 $m$ may become increasingly difficult. The area for tree selection could become too large and thus unmanageable. Furthermore, an initial surveying and saving tree locations may be too time consuming and labour intensive, 
especially where the terrain is difficult. Therefore, it is advisable to get assistance from local foresters who are aware of the area and know where the target species is more likely to occur.

\section{A. Definition of the sampling frame}

With the help of a local forester, a map of the forest stand should be prepared and areas where the target species occurs in higher density marked. Along the nearest existing forest road or path in the area, one or several points are selected that are, based on the local forester's knowledge, the most appropriate starting points for searching for trees in the stand. The GPS coordinates of these points should be saved in a GPS device, which is to be used in the field.

\section{B. FGM plot installation in the field}

A starting point for searching the area should be found on the forest road, from which field personnel conducting the plot installation should start walking toward the area with higher density of the target species. It will be easier to find appropriate trees if a local forester is also present. It is best to comb the area in a systematic pattern using a GPS device or smartphone app with track recording, which ensures that the same area is not inspected repeatedly, or any part of the area is not overlooked. All reproducing trees that meet the minimum distance requirement must be selected. If it is impossible to find 50 reproducing trees, all suitable trees should be selected, but not fewer than 30 trees (exceptionally in the case of endangered or edge populations!) with a minimum distance of $30 \mathrm{~m}$ from each other.

\subsubsection{Natural regeneration subplots}

Inside an established FGM plot a greater number of NR subplots, if possible 20, should be established. NR subplots are to be used for several purposes: DNA sampling and NR abundance / mortality assessment. The establishment of NR subplots should be carried out after germination following each strong or massive fructification event, when fructification occurs every three to 12 years (Table 3.2). If fructification occurs every year or every second year, NR plots are to be established after a strong/massive fructification with approximately five years in between the previous and next round of NR abundance plots. Seed dormancy must be taken into consideration when planning the NR subplot establishment. For example, seed of Common ash (Fraxinus excelsior) usually remains dormant for two winters, meaning that germination and establishment of NR subplots will take place two years after the fructification event.

Table 3.2: Timeline of NR subplot establishment. Twenty new NR plots are established after each assessed fructification event. Preferably two fructification events are assessed per decade.

\begin{tabular}{|c|c|c|c|c|c|c|c|c|c|c|c|c|c|c|c|c|c|c|c|c|c|}
\hline Year of monitoring & 1 & 2 & 3 & 4 & 5 & 6 & 7 & 8 & 9 & 10 & 11 & 12 & 13 & 14 & 15 & 16 & 17 & 18 & 192 & 2021 & 2223 \\
\hline Fructification event & & - & & & & & - & & & & & & & - & & & & & - & & \\
\hline NR subplot establishment & & & - & & & & & - & & & & & & & - & & & & & - & \\
\hline
\end{tabular}

\subsubsection{Definition of the sampling frame}

Natural regeneration centres from the fructification in the previous calendar year (take into account seed dormancy) should be surveyed in the field and their locations logged (GPS coordinates, the number of the tree which is the closest to the NR centre). From all regeneration centres, 20 of them should be chosen randomly for NR plot installation. If 20 or fewer NR centres are present, all should be used. Logging additional information about the location of NR plots, such as the distance (number of steps) and azimuth from the nearest labelled adult tree, is recommended to aid in finding these NR plots in the future. 


\subsubsection{Plot installation in the field}

Inside each selected natural regeneration centre a $1 \mathrm{~m}^{2}$ plot is to be installed and marked with metal rods. The metal rods should be driven into the ground at each corner of the NR plot as deep as possible to prevent them from being removed by animals. The tips of the metal rods should be painted to aid their visibility.

\subsection{Labelling, georeferencing, field measurements and observations}

\subsubsection{Labelling of trees}

Each selected tree must be marked with a corresponding number and a band painted around the trunk to aid the visibility of the trees from all directions. Mark the central tree (number 1) with two or more bands to differentiate it from other trees (Figure 3.6a). It is recommended to paint the number on the side of the tree that is pointing away from the central tree, as this helps locating the central tree, particularly from the outer rings of the plot (Figure 3.6b). In some cases, it helps to label the trees on the side pointing away from paths or roads to avoid confusion with people seeking recreation in the forest.
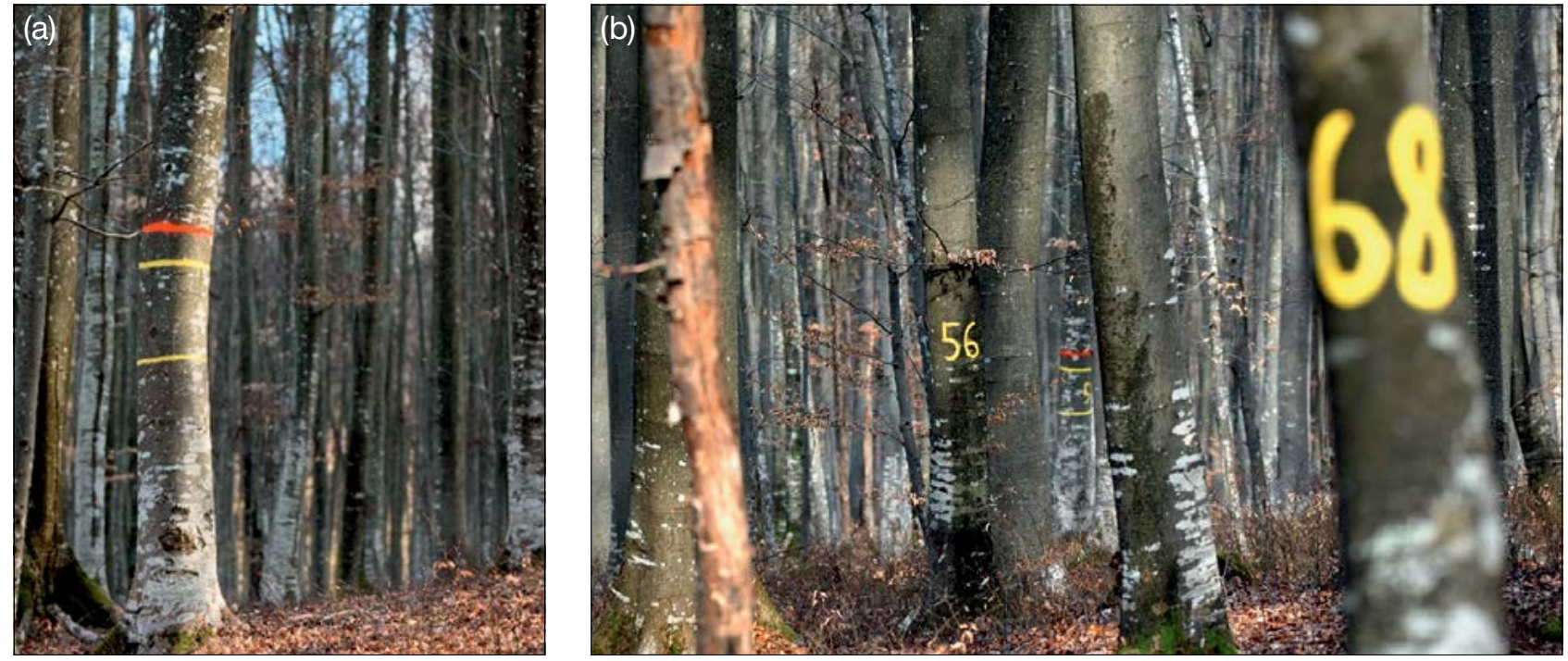

Figure 3.6: (a) The central tree on the genetic monitoring plot is marked with multiple bands to differentiate it from other trees; (b) numbers are painted on selected trees so that they point away from the central tree.

\subsubsection{Georeferencing}

Selected trees within the FGM plot need to be georeferenced, which can be done at the same time as plot establishment. Two georeferencing approaches are described below.

The simplest way to georeference trees is to record the GPS locations of the selected trees using a GPS receiver. However, this method is not suitable in the case of insufficient accuracy and/or precision of the GPS receiver. The accuracy of non-differential GPS receivers that are generally used by foresters can be as low as $15 \mathrm{~m}$ or more in mature forests (Simwanda et al. 2011). Differential GPS devices offer significantly better accuracy and precision (Zhang et al. 2014).

Another way of georeferencing trees is with the measured distance and azimuth from the reference point. The georeferencing calculator tool http://georeferencing.org/georefcalculator/gci3/source/gci3.html can be used to calculate tree locations, where the Locality type must be set to 'Distance at a heading'. The tool allows you to select different coordinate systems.. The disadvantage of a georeferencing calculator is that the input data must be entered for each tree separately, such as the coordinates of the reference point, distance and azimuth. 
A more convenient and faster alternative to the georeferencing calculator presented above is to use the tree georeferencing script which was developed jointly within the LIFEGENMON and LIFE SySTEMiC projects (https://github.com/roks531/Tree-georeferencing). This script calculates the coordinates of individual trees with a single data entry in the form of a table (txt. or csv. can be used). The script operates with data from the projected coordinate systems, e.g. UTM. In cases when the coordinates of the starting reference point are written in the form of latitude, longitude (WGS84), they must be converted into a metric projected coordinate system. The script requires the entry of two separate tables: the first contains data on the tree ID, the measured distance (in metres) from the reference point, the azimuth (degrees from north) and the ID of the reference point according to which the tree is georeferenced. The second table contains the ID of the starting reference points (at least one, there can be several) and its $x$ and $y$ coordinates. It is important that the labelling of reference points in both tables is the same.

It is recommended to select as few reference points as possible with the most accurately measured location. If each tree were used as a reference point for georeferencing the following tree (e.g. tree number 1 is the reference point for georeferencing tree number 2, tree number 2 is the reference point for georeferencing tree number 3 , etc.), observer errors would accumulate and the accuracy of tree locations decrease with the increasing sequential number of georeferenced trees (Abdi et al. 2012).

\subsection{Plot description (standardised forms developed)}

After establishment, the FGM plot should be described in detail in the "FGM Plot description" form, which is part of this Manual. All collected data is then deposited in a database (see Chapter 6.5.2.1). The form consists of two main parts: (i) plot description data and (ii) stand quality and description.

Plot description data contains sections about the exact location, ownership, species composition of the forest stand, characteristics of the region, soil and climate. The silvicultural system, forest management objectives and designated status are also defined.

The stand quality and description part is organised in such a way that one of the possible answers is selected for each descriptor. This part of the form describes the following: forest health condition, whether the forest is managed or not, forest reproductive material, natural regeneration, vertical and horizontal structure of the stand, slope, quality of tree stems and some other items.

The form can be found in Annex 10.2: Field observation forms.

\subsection{Plot Maintenance}

\subsubsection{General maintenance}

Tree markings and NR plot markings must be checked periodically (every two years) and renovated if needed. Metal rods, used for NR plots marking, must be removed when monitoring of NR abundance is finished.

\subsubsection{Replacement of trees}

If a monitored tree dies or is cut due to management, it must be replaced. The nearest suitable tree to the dead one should be chosen considering that the distance requirement of $30 \mathrm{~m}$ to the nearest monitored tree is fulfilled. Otherwise a tree from the periphery (preferably in the outer circle in the case of stand-forming species) of the FGM plot is to be selected. 
If the crown is damaged due to, for example, wind break, ice or snow break, but continues to fructify, the tree is kept for the monitoring. If the damage is too severe and fructification is not expected anymore, the monitored tree must be replaced.

In species where more than 50 individuals are selected initially due to determination of clonality or hybridisation (by genotyping), any suitable individuals from these surplus trees can be used as replacements for lost trees. If clones were detected in the initial larger number of trees, the same genotype can be used as a replacement for the lost individual.

The cause of the loss of a tree on the FGM plot must be determined and logged in the forms and in the database.

Replacement trees have to be marked the same way as the original trees, but with consecutive numbers (51, $52, \ldots)$ to differentiate them from the replaced original trees (numbered 1 to 50 ).

\subsubsection{Long-term maintenance of the plot:}

Gaps in forest cover may occur even in close-to-nature forest management systems. In the case of the removal of a larger number of reproducing trees on the FGM plot due to forest management (e.g. irregular shelter wood), the plot should still be maintained and observations carried out with regard to NR abundance, flowering, and fructification. In such cases, the number of the remaining trees must be recorded at each observation.

Such a situation, when genetic monitoring is severely limited due to a reduced number of reproducing trees may last for several decades, until enough younger trees reach reproductive age and meet the minimum requirements to be included in the FGM. The selection and replacement process should be undertaken over a longer period, so that the selected replacement trees are not biased towards the fastest growing individuals.

\subsection{Collection of meteorological data}

Today climate change is probably the main direct threat to genetic diversity and forest ecosystems. Indirectly it also enhances threats from diseases, pathogens, insects, fire and extreme weather events. Environmental factors play an important role in the reproductive success, growth and survivability of trees. In FGM many verifiers can be partially explained with changing environmental parameters, e.g. temperature and precipitation. To explain changes in various verifiers, it is therefore recommended to install meteorological loggers directly on the FGM plot. The Internet of Things (IOT) is developing fast, and so are data loggers and different environmental sensors. Meteorological loggers are now cheaper, easier to install and enable easy remote data collection. Data is transferred via $2 \mathrm{G} / 3 \mathrm{G} / 4 \mathrm{G}$ connection or a local Wi-Fi network to a Cloud database or FTP server, for example, from where it can be exported for the analysis.

Meteorological data can also be obtained and extrapolated from nearby weather stations. This approach is however not recommended in locations with very heterogeneous conditions or microclimates.

\section{References}

Abdi E, Sisakht S R, Goushbor L, Soufi H (2012) Accuracy assessment of GPS and surveying technique in forest road mapping. Ann For Res 55:309-317

Simwanda M, Wing MG, Sessions J (2011) Evaluating global positioning system accuracy for forest biomass transportation tracking within varying forest canopy. West J Appl For 26:165-173. https://doi.org/10.1093/wjaf/26.4.165

Zhang H, Zheng J, Dorr G, Zhou H, Ge Y (2014) Testing of GPS accuracy for precision forestry applications. Arab J Sci Eng 39: 237 - 245. https://doi.org/10.1007/s13369-013-0861-1 


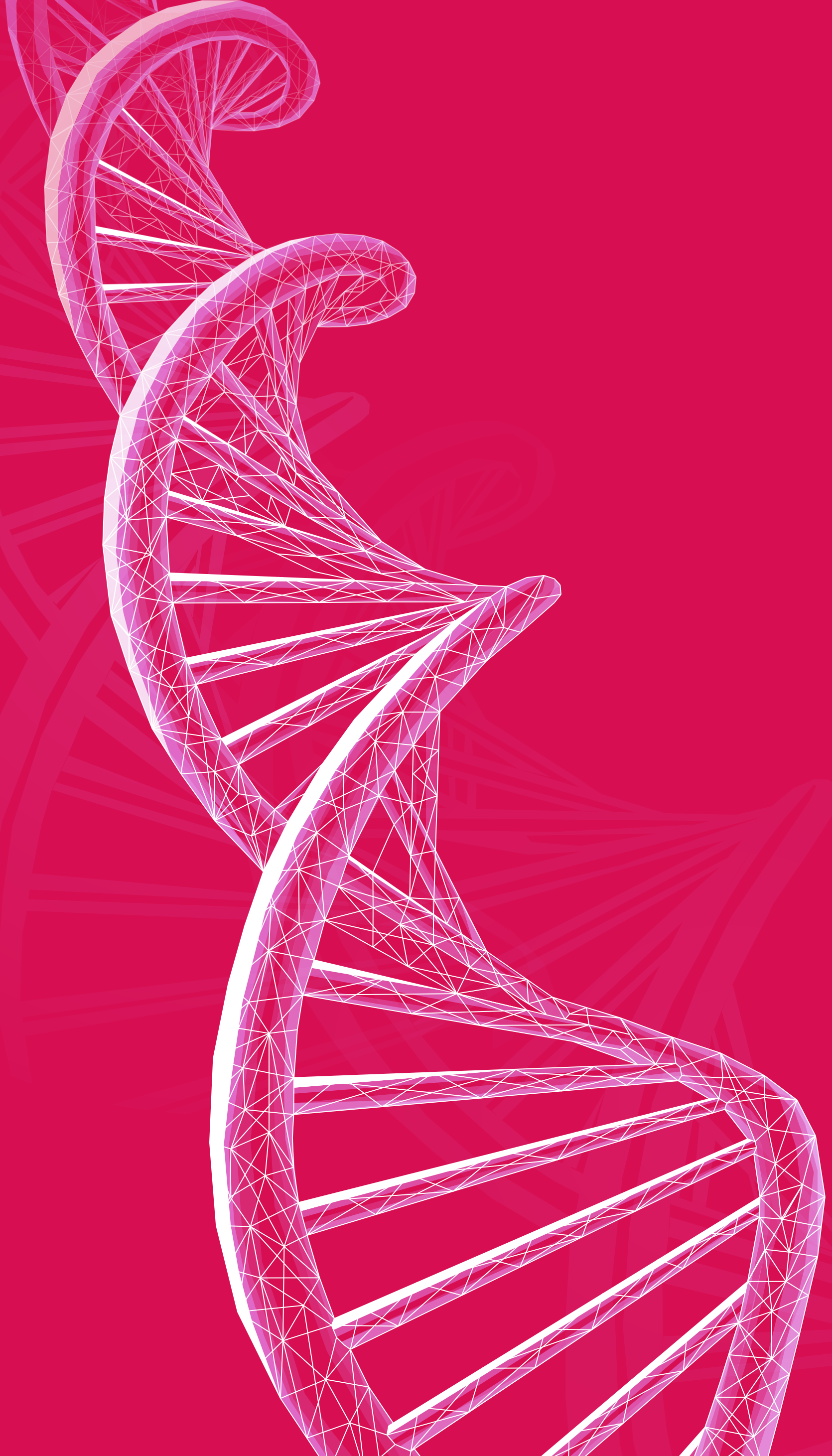




\section{\#\#) \\ LIFE13 ENV/SI/000148}

\section{Manual for forest genetic monitoring}

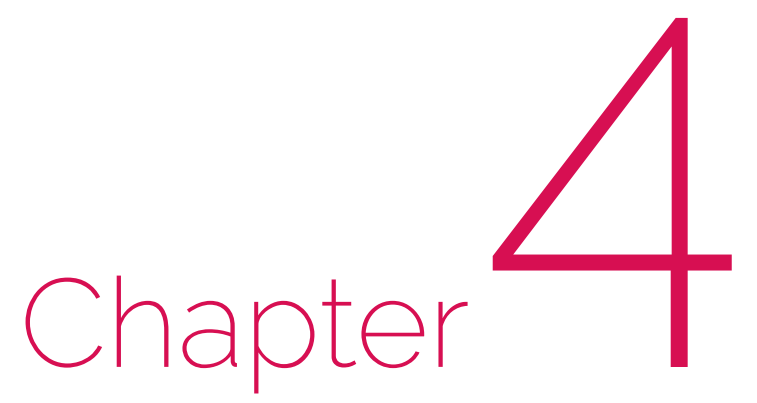

\section{Indicators, verifiers and background information}

Filippos A. ARAVANOPOULOS ${ }^{1}$, Darius KAVALIAUSKAS ${ }^{2}$, Barbara FUSSI',

Marjana WESTERGREN ${ }^{3}$, Paraskevi ALIZOTI', Marko BAJC ${ }^{3}$, Nikolaos TOURVAS', Andrej BREZNIKAR ${ }^{4}$, Pavlos CHASILIDIS ${ }^{5}$, Rok DAMJANIĆ ${ }^{3}$, Natalija DOVČ${ }^{3}$,

Fotios KIOURTSIS 5 , Ermioni MALLIAROU'1, Hojka KRAIGHER ${ }^{3}$

Citation: Aravanopoulos et al. (2020) Indicators, verifiers and background information. In: Bajc et al. (eds) Manual for Forest Genetic Monitoring. Slovenian Forestry Institute: Silva Slovenica Publishing Centre, Ljubljana, pp 33-44. http://dx.doi.org/10.20315/SFS.167

\section{Affiliations:}

1. Aristotle University of Thessaloniki (AUTh), Greece

2. Bavarian Office for Forest Genetics (AWG), Germany

3. Slovenian Forestry Institute (GIS), Slovenia

4. Slovenia Forest Service (ZGS), Slovenia

5. Decentralized Administration of Macedonia \& Thrace,

General Directorate of Forests \& Rural Affairs, Greece 


\subsection{Definition of indicators and verifiers / background information}

Genetic monitoring should operate on a solid scientifically based system that includes a minimum set of conceptual approaches and parameters that would extract the maximum amount of genetic information (Aravanopoulos 2011, 2016, Konnert et al. 2011). These are exemplified by the use of criteria, indicators and verifiers. A criterion is a standard that an entity is assessed by without being a direct measure of performance (Boyle 2000, Aravanopoulos et al. 2015). A criterion will thus normally reflect a goal, target or a comprehensive objective that is often rather complex and challenging to assess (Graudal et al. 2014, Aravanopoulos 2016). An indicator applies to any component or process of the ecosystem used to infer attributes of the sustainability of the resource (Boyle 2000, Aravanopoulos et al. 2015). Indicators are, by definition, used to track progress and should always be defined in relation to a given target (Feld et al. 2009). An indicator is usually measured on a temporal basis to reflect an achievement or change related to the associated criterion. Indicators in biodiversity assessment fall within one of four categories: state, pressure, response, and benefit (Graudal et al. 2014, Sparks et al. 2011, UNEP/WCMC 2011). Clearly, Forest Genetic Monitoring (FGM) indicators at the population level are state indicators, i.e. indicators that refer to the condition and status of aspects of biodiversity (Graudal et al. 2014, Aravanopoulos 2016).

As such an indicator must be directly measurable, and the metric used to measure an indicator is referred to as a verifier. Therefore, a verifier involves the estimation of parametric data that improves the specificity or the facilitation of the assessment of an indicator (Boyle 2000, Aravanopoulos et al. 2015). In practical terms, the verifier is the measure of the indicator (Aravanopoulos et al. 2015).

Herein FGM uses a single criterion: the conservation of genetic diversity and adaptive evolutionary potential in natural populations that emphasises the maintenance of evolutionary processes within forest tree populations to safeguard their potential for continuous adaptation (Aravanopoulos 2011, Namkoong et al. 1996). The scientific basis for genetic monitoring lies in the genecological approach, and three factors are the major forces of evolution at the microscale: natural selection, genetic drift, and gene flow. The effects of natural selection can lead to differentiation associated with local adaptation, while genetic drift can lead to differentiation associated with stochastic changes and genetic erosion. These changes are mediated by the action of gene flow that can lead to genetic homogenisation. The action of mutation is considered as negligible for relatively short-term processes (Aravanopoulos 2011, 2016). Therefore, genetic monitoring focuses on the temporal evaluation of three indicators: (1) natural selection, (2) genetic variation per se where the evaluation of genetic drift is incorporated as well, and (3) gene flow / mating system. The assessment of each indicator is based on a number of verifiers that are introduced below. The number of verifiers per indicator ranges from what is considered as the absolute minimum needed (key verifiers) for the assessment of an indicator, to the most comprehensive (optimal) evaluation where all verifiers listed below are included.

Further to the verifiers, there is additional information that can be important, if not to assess the status of an indicator (as a verifier is), then to provide information that would assist in inferring the status of the genetic monitoring unit and interpreting the value of the verifier parameter and its potential relative change. Such more general information is presented under the term "background information". 


\subsection{Selection of indicators and verifiers / background information}

The indicators and verifiers for the FGM scheme in this Manual are presented in Table 4.1 below. Corresponding to the indicators that have been selected are the relevant selected verifiers and background information.

Table. 4.1: List of indicators and verifiers/background information for forest genetic monitoring at the basic, standard, and advanced levels. X: level at which a certain verifier is recorded. V: verifier, BI: background information.

\begin{tabular}{|c|c|c|c|c|c|}
\hline Indicator & Verifier name & Type & Basic & Standard & Advanced \\
\hline \multirow{13}{*}{ Selection } & Mortality / Survival & $\mathrm{V}$ & $x$ & $x$ & $x$ \\
\hline & NR abundance & v & $x$ & $x$ & $x$ \\
\hline & Flowering & V & $x$ & $x$ & $x$ \\
\hline & Fructification & V & $x$ & $x$ & $x$ \\
\hline & $\%$ filled seeds & V & & & $x$ \\
\hline & $\%$ germination & V & & & $x$ \\
\hline & Crown dieback (ash) & $\mathrm{Bl}$ & $x$ & $x$ & $x$ \\
\hline & Sex ratio (dioecious species) & $\mathrm{Bl}$ & & $x$ & $x$ \\
\hline & DBH class distribution & $\mathrm{Bl}$ & & $x$ & $x$ \\
\hline & Height class distribution & $\mathrm{Bl}$ & & $x$ & $x$ \\
\hline & Flowering synchronisation & $\mathrm{Bl}$ & & & $x$ \\
\hline & Budburst & $\mathrm{Bl}$ & & $x$ & $x$ \\
\hline & Senescence & $\mathrm{Bl}$ & & $x$ & $x$ \\
\hline \multirow{9}{*}{$\begin{array}{l}\text { Genetic } \\
\text { variation }\end{array}$} & Allele frequencies & $\mathrm{V}$ & & $x$ & $x$ \\
\hline & Latent genetic potential & V & & $x$ & $x$ \\
\hline & Inbreeding coefficient & V & & $x$ & $x$ \\
\hline & Effective population size & V & & $x$ & $x$ \\
\hline & Allelic richness & V & & $x$ & $x$ \\
\hline & Linkage disequilibrium & V & & $x$ & $x$ \\
\hline & Interspecific hybridisation * & $\mathrm{Bl}$ & & $x$ & $x$ \\
\hline & Multiplicity & $\mathrm{BI}$ & & $x$ & $x$ \\
\hline & F-analysis outlier test & $\mathrm{BI}$ & & $x$ & $x$ \\
\hline \multirow{5}{*}{$\begin{array}{l}\text { Gene flow } \\
\text { / mating } \\
\text { system }\end{array}$} & Gene flow & V & & & $x$ \\
\hline & Multi-locus population outcrossing rate & V & & & $x$ \\
\hline & Actual inbreeding rate & V & & & $x$ \\
\hline & Effective number of pollen donors & $\mathrm{Bl}$ & & & $x$ \\
\hline & Biparental inbreeding & $\mathrm{BI}$ & & & $x$ \\
\hline
\end{tabular}

* Hybridising species only

The selection of indicators and verifiers follows the three levels of genetic monitoring, basic standard and advanced. The selection is based on: (1) the premise of the comprehensive assessment of the indicator, by using the least number of verifiers (Aravanopoulos 2011, Aravanopoulos et al. 2015), (2) the amenability of each verifier for temporal evaluation, and (3) the time and cost required for the assessment of each verifier (see Chapter 7 below). In total there are 15 verifiers, six verifiers for selection, six for genetic variation and three for the indicator of gene flow/mating system. There are also eight parameters needed as background information, four related to selection, three related to mating system/ gene flow and one to genetic variation. From the 15 verifiers, four are related to quantitative field observations, nine are derived from molecular genetic markers and two from seed testing. The actual number of assessed background information parameters depends on the specificities of the monitored species in question, as not all are relevant to all species. Background information "sex ratio" is, for example, only assessed for dioecious species. 


\subsection{Description of indicators and verifiers/background information}

\section{Indicator I: SELECTION}

Selection is a key indicator as it constitutes an evolutionary force that can alter allele frequencies even at a few generations. The operation of selection will increase the adaptation of the population to the current environmental conditions, although at a possible loss of genetic diversity. Therefore, its assessment is a complex integral part of FGM that is carried out in light of the performance of the other FGM indicators.

\section{Verifier: Mortality / Survival}

A change in the trend beyond typical expectations in Mortality or Survival (Mortality $=1$ - Survival) indicates an underlying selection pressure, i.e. dieback when the value of mortality is increased. Mortality / Survival refers to the number of trees that have died relative to the baseline (and to the previous assessment).

\section{Verifier: Natural regeneration abundance (NR)}

A change in the regeneration abundance in the plot may indicate an underlying selection pressure that has resulted in the reduction or absence or dieback of seedlings and saplings. Regeneration abundance is defined as the number of seedlings per unit area.

\section{Verifier: Flowering}

Flowering - the production of flowers is an interesting verifier for genetic monitoring. Absence of flowering may negatively affect the panmictic equilibrium (El-Kassaby et al. 1984, 1988), which may result in non-random crossfertilisation and increased selfing (Bhumibhamon 1978). The presence, abundance and timing of flowering, are highly sensitive to climate, making flowering phenology one of the most variable plant traits (Chuine 2010). Flowering phenology is the study of the timing of the male and female flower development by recording the different phenophases (Ducci et al. 2012). Flowering phenology is a crucial factor affecting tree reproduction fitness, which occurs via gene exchange among genotypes that determines the genetic variation of the produced seed crop and the survival success of the produced seedlings (Alizoti et al. 2010).

\section{Verifier: Fructification}

Fructification is the production of the reproductive organs and fruits of a plant (Merriam-Webster 2003). Fructification is the major determinant in the transmission of parental genetic information to the offspring. It is a main factor of the reproductive success of genotypes and of populations (Müller-Starck et al. 2005, Seifert and Müller-Starck 2009). The intensity and periodicity between consecutive fructification years is species-specific and varies depending on weather conditions, resource availability and genetic control (Mund et al. 2010 and references therein). Therefore, in some forest tree species fructification occurs at different intensities and there are some years with many fruits or cones and others with less or even none. It is important to note that trees of one species often synchronise their reproduction over larger areas, as a consequence of genetic and environmental interaction (Selås et al. 2002, Seifert and Müller-Starck 2009). Fructification is an important parameter in the interpretation of values of the effective population size.

\section{Verifier: Percentage of filled seeds}

A change in the percentage of filled seeds indicates a selection pressure (in the case of a reduction), or an indication of recovery (in the case of an increase). It is also an important parameter in the interpretation of values of effective population size. The estimation of the percentage of filled seeds is carried out for a tree in which 
fruits / seeds have been sampled. This estimation takes into account the post-pollination aborted seeds and is related to inbreeding. The estimate is based on the number of filled seeds out of a random sample of 1,000 seeds converted to a percentage.

\section{Verifier: Percentage germination}

Seed germination capacity under changing environmental conditions affects the distribution and abundance of species. Even when seeds are available, climate change related stress may adversely affect germination and result in the absence of natural regeneration (de Melo et al. 2015, Wang et al. 2016). Within forest genetic monitoring, the assessment of reproductive fitness, which indicates the ability of an individual to survive and reproduce, can be estimated as the combined percentage of filled seeds and germination (estimated based on the total number of seeds sampled and the total number of germinated filled seeds) (Aravanopoulos 2011, Aravanopoulos et al. 2015, Aravanopoulos 2016). The object of the germination test according to the ISTA (2020) rules is to determine the maximum germination potential of a seed lot, which can then in turn be used to compare the quality of different lots and also estimate the field planting value. Various different methods are available to test seed viability. However, the most precise and reliable method is the germination test (Rao et al. 2006). Germination of a seed in a laboratory test is based on the emergence and development of the seedling to a stage where an analysis of its essential structures indicates whether or not it is able to develop further into a satisfactory plant under favourable conditions in soil. The percentage germination indicates the proportion by number of seeds which have produced seedlings classified as normal under the species-specific conditions and within the period specified (ISTA 2020).

\section{Background information: Crown dieback (only ash)}

Crown dieback is a background information used only in the FGM of Fraxinus sp. and is used to assess the severity of damage by the fungus Hymenoscyphus fraxineus, a chronic fungal disease of ash trees in Europe.

\section{Background information: Sex ratio (only dioecious species)}

Sex ratio refers to the recording of individual tree sex in dioecious species. Sex ratio is important as the more the equal distribution of the different sexes, the higher the effective population size is expected to be.

\section{Background information: DBH class distribution}

A change in the distribution curve of the tree diameters in the plot may indicate an underlying selection pressure, i.e. dieback of mature trees, or dieback of young trees.

\section{Background information: Height class distribution}

A change in the distribution curve of the tree heights in a plot may indicate an underlying selection pressure, i.e. cessation of growth or dieback of mature trees, or cessation of growth or dieback of young trees.

\section{Background information: Flowering synchronisation}

Flowering synchronisation, the maturation of female and male flowers at the same time, ensures the overlap of female flower receptivity and pollen shedding and thus affects the panmictic equilibrium (El-Kassaby et al. 1984, 1988). Under panmixia, all male and female parents should have equal probability to participate in equal mating events and be crossed with all individuals of the other sex. Absence of flowering synchronisation can result in non-random cross-fertilisation, a higher percentage of empty seeds and increased selfing (Bhumibhamon 1978). 


\section{Background information: Budburst}

Budburst (also termed bud break, leaf unfolding or bud flush) is the period spanning from the cessation of bud dormancy to shoot elongation (end of leaf unfolding). It is determined by several environmental factors (chilling requirements and forcing temperatures) necessary for initiation of the process, but it is also under strong genetic control (Geburek 2004, Ducci et al. 2012). Data on the timing and duration of budburst provides important information on tree and population response to changing environmental conditions. Data on phenological phases (i.e. phenophases) of budburst is required for integrated evaluation of different aspects within FGM. The ability of a species to adjust to the abiotic environmental conditions in the long term, via shifts in phenology, can be considered as an indicator of its vulnerability to future climatic changes. The main objective of budburst observations on FGM plots is to provide supplementary and complementary information on the phenotypic plasticity of the forest tree population during the year.

\section{Background information: Senescence}

Leaf senescence is a collective series of degenerative events that decrease metabolic activity and cause the death of cells, tissues and leaf organs. Senescence is conditioned by numerous environmental, physiological as well as genetic factors. Information about the timing and duration of leaf senescence provides important information with regard to understanding the actual state of the trees and forest tree populations in a changing environment.

\section{Indicator II: GENETIC VARIATION}

Genetic variation is the prerequisite for future adaptation and evolution. It is proposed to be evaluated by the parameters listed below. A difference in parameters that reflect genetic variation, e.g. a reduction in such variation, would reflect a decline in genetic diversity and potentially correspond to a decrease in the adaptive capacity of the population.

\section{Verifier: Allele frequencies}

A change in allele frequencies may indicate a change in the amount of genetic variation. A detection of frequency shifts and moreover loss of alleles is an indication of a change in genetic diversity that can be attributed to one or a combination of different evolutionary forces that operate in the genecological model. Allele frequencies, as well as changes in clinal variation, can be assessed by studying populations across the distribution range, and the results may provide evidence for adaptive responses to environmental change. This verifier may be inconclusive by itself; therefore it should always be taken into account in conjunction with other verifiers of the genetic variation indicator.

\section{Verifier: Allelic richness}

Allelic richness ( $\mathrm{Ar}$ ) is the total number of alleles in a population for a single locus averaged over all loci. Allelic richness is an estimate corrected by sample size (e.g. by rarefaction). It is used less commonly than heterozygosity as a genetic diversity measure, as it is harder to take into account the stochastic process of genetic drift for allelic richness. Nevertheless, allelic richness is considered to be a parameter that is more useful for gene conservation than allelic evenness (i.e. heterozygosity) (Brown and Schoen 1992, Rajora and Mosseler 2001, Aravanopoulos 2011). This verifier is associated with the use of microsatellite (SSR) genetic markers.

\section{Verifier: Latent genetic potential}

Latent genetic potential (LGP) is an important genetic parameter that reflects the aptitude of a population to preserve adaptability under the multiplicity of changing environmental conditions (Stebbins and Hartl 1988, Bergmann et al. 1990). A population genetic analysis reveals its "operating genetic potential" (i.e. the part of its 
genetic composition which guarantees the survival of the population under present realised conditions, which is analogous to the effective number of alleles), while the remaining part in this context is currently "latent". This portion of genetic diversity is related to low frequency alleles in the population, which can nevertheless play a significant role for future adaptation under drastically changing environmental conditions, which can be of great importance for conservation practices (Aravanopoulos 2011, 2016). Therefore a change, and especially a reduction, of latent genetic potential may indicate a reduction of the overall adaptive capacity of the population. Latent genetic potential is computed as the difference between the total and effective number of alleles summed over all loci.

\section{Verifier: Inbreeding coefficient}

The inbreeding coefficient $\left(F_{I S}\right)$ is the correlation of uniting gametes relative to gametes drawn at random from a subpopulation. It describes the variance within individuals, relative to their subpopulations. $F_{\text {Is }}$ depends on the ratio of observed heterozygotes to the one expected under Hardy-Weinberg equilibrium, so it can also be seen as the reduction of heterozygosity of an individual compared to the subpopulation in the context of several (sub) populations that form the total (meta)population. An increase in inbreeding is evidently associated with a potential reduction of genetic diversity.

\section{Verifier: Effective population size}

Effective population size $\left(\mathrm{N}_{\mathrm{e}}\right)$ is one of the most (if not the most) important genetic parameters for genetic monitoring, as when it is small genetic drift becomes much more important than selection, and plays a paramount role in the evolutionary process. Therefore, a change, especially a reduction, in effective population size below acceptable threshold levels indicates the onset of genetic drift (as well as that of inbreeding). Hence it indicates both the onset of random and stochastic processes in the population and that of inbreeding and a potential reduction of genetic variation, which overall raise questions as to the future adaptive capacity of the population. Effective population size is defined as the number of individuals that will contribute genes to the next generation by means of cross-breeding, or, more formally, the effective population size of an actual population is the number of individuals in a theoretical ideal population having the same magnitude of random genetic drift as the actual population. It is notoriously difficult to estimate effective population size in natural populations based on demographic models, and currently the most widely used approaches employ genetic markers. In addition, genetic estimators appear more conservative than demographic models. In this protocol effective population size estimation is based on genetic markers.

\section{Verifier: Linkage disequilibrium}

Linkage disequilibrium (LD) is the non-random association of alleles at different loci in each population, and is seen when the frequency of association of the different alleles at a locus is higher or lower than what would be expected if the loci were associated randomly (i.e. were independent) (Weir 1979). Linkage disequilibrium can be affected both by evolutionary forces (see the Hardy-Weinberg equilibrium above) and demographic properties (population structure, asexual reproduction). For instance, linkage disequilibrium will manifest itself or become more prominent in small populations, in populations under strong evolutionary forces or under admixture. Therefore, linkage disequilibrium can be a powerful signal to denote underlying genetic and demographic processes in a population.

\section{Background information: Interspecific hybridisation}

The estimation of interspecific hybridisation is a parameter of importance when the plot or the greater area contain sympatric populations of potentially cross-fertilising taxa. This is a situation not uncommon in forest trees, e.g. in fir, oak, ash, poplar, etc. Its estimation is vital to assess the objective of conservation in terms of the taxon involved. It is a very dynamic phenomenon in terms of the evolution of genetic diversity and heterozygosity over time, and it is important when detecting a change in genetic diversity values to know if interspecific hybridisation 
has played a role in this. Interspecific hybridisation has often been considered as a source for genetic and phenotypic novelties and as force for evolution (e.g. Leroy et al. 2017); however, hybridisation can also cause genetic erosion and interrupt species integrity and lead to species extinction (Soltis and Soltis 2009, Vit et al. 2014, Neale and Wheeler 2019). It calls for the genotyping of the presumed hybrid swarm with species-specific genetic markers while including reference samples of the parental species in the analysis. Ideally a speciesspecific genetic marker should be the same genetic locus present in the parental species in which different alleles are fixed within it, but are variable in the interspecific hybrid population. Hybridisation is computed on a percentage basis as the number of individuals over the total that bear species-specific alleles of both species. Based on the number of loci and alleles amenable to interspecific estimation assessment, more information can be deduced such as the percentage of backcrosses or higher filial generations.

\section{Background information: Genetic multiplicity}

Genetic multiplicity (hypothetical gametic multilocus diversity; Vgam), defines the actual or potential capacity of a population to provide allelic solutions to environmental perturbations. Genetic multiplicity measures the potential of a population for producing genetically diverse gametes. Genetic multiplicity reflects a genetic variation parameter important under environmental change. It shows the potential of a population to produce genetically different gametes that can form the next generation (Müller-Starck 1995), and quantifies the ability of forest tree populations to create genetic variation and thus facilitate adaptation to changing environmental conditions (Gregorius et al. 1986, Müller-Starck 1995). Therefore, a change and especially a reduction of genetic multiplicity may indicate a reduction of the overall adaptive capacity of the population. It is measured as the highest possible number of different alleles, the highest number of possible genotypes (as individual counts or on a per locus basis), the percentage of polymorphic loci $(P)$ and the average number of alleles per locus. It is assessed as a collection of the above parameters.

\section{Background information: F-analysis outlier test}

Outlier locus detection is a population-level analysis that employs estimates of population genetic differentiation to detect loci with significantly higher or lower genetic differentiation than expected under the expectations of neutrality. Such loci that present a peculiar variation pattern are likely to be under selection.

\section{Indicator III: GENE FLOW / MATING SYSTEM}

Gene flow and mating system is the indicator enabling us to follow the level to which genes are exchanged among individuals and populations, which is vital for future adaptation and evolution. It is proposed to be evaluated by the parameters listed below.

\section{Verifier: Gene flow (Nm)}

Gene flow is the exchange of genes through seed and pollen among populations that differ in genotypic frequencies. Gene flow is interceded by the mating system that mediates the recombination and assortment of genes between generations and determines the extent to which genes are exchanged among individuals, as well as immigration and emigration. It can be considered either beneficial or harmful from the point of view of a conservation genetics, forest genetic monitoring or tree breeding (Burczyk et al. 2004). Gene flow causes changes in the composition of the gene pool (allele frequencies) of the recipient population by incorporating alleles into its gene pool. The introduction of new alleles through gene flow increases genetic variability within the population and enables evolution and the combinations of traits (Encyclopaedia Britannica 2019, Mallet 2001, Burczyk et al. 2004, Aravanopoulos 2011). Gene flow is determined by the mating system that mediates the recombination and variety of genes between generations and determines the level to which genes are exchanged between individuals and populations (Aravanopoulos 2011). Gene flow measurements provide indirect information on the level of migration among subpopulations. 


\section{Verifier: Multi-locus population outcrossing rate (tm)}

The mating system is one of the key factors shaping population genetic structure (Hartl and Clark, 1989, Del Castillo and Trujillo 2008, Whitehead et al. 2018). Different mating systems influence the levels and dynamics of genetic diversity, effective population size and population differentiation, and overall it can affect population resilience and adaptation (Del Castillo and Trujillo 2008). Plant mating systems are usually defined by the mixed mating model, where one portion of seeds and ensuing plants are derived from various levels of inbreeding and the rest are derived from outcrossing at random (Ritland 2002). In particular, outcrossing promotes gene flow, homogenises populations, increases heterozygosity, and favours gametic linkage equilibrium (Del Castillo and Trujillo 2008). Outcrossing refers to the mating of genetically unrelated individuals and is the opposite of inbreeding (Aravanopoulos 2011). Multilocus outcrossing rate (tm) is an estimate of the proportion of outcrossed progeny produced by the population as a whole, in which pollination events include mating between relatives and unrelated individuals. A difference, e.g. an increase in the multilocus population outcrossing rate (tm), is an indication of maintenance if not of an increase of multilocus genetic variation, a result that will likely result in the maintenance of population adaptive capacity.

\section{Verifier: Actual inbreeding rate}

The estimation of actual inbreeding rate (single locus and multilocus) is based on seed and genetic data (Rajora et al. 2000, 2002; O'Connell et al. 2006). This is an important parameter as well, since, for example, an increase in the inbreeding rate may lead to allelic fixation and the reduction of population genetic diversity. The estimation of inbreeding rates can be marker-based, however as potential inbreeding depression may adversely affect seed development and germination, actual inbreeding rates are more reliable. Actual inbreeding rate is calculated by combining selfing estimates $(1-\mathrm{tm})$ from the mating systems analysis and seed-trait-based inbreeding estimates. It is the ratio of: [number of empty seeds per fruit + (number of filled seeds per fruit $\times$ selfing rate)] / [number of inbred seeds per fruit + number of filled seeds per fruit].

\section{Background information: Effective number of pollen donors (Nep)}

The effective number of pollen donors is the number of pollen donors contributing to each seed family. The effective number of pollen donors is often much lower than the absolute number of contributing pollen donors (Ritland 1989, Smouse and Sork 2004, Sork and Smouse 2006). If the number of pollen donors is small, the progeny may be less genetically diverse (Apsit et al. 2002). Information about the probability that progenies share the same father can reveal the extent of diversity in the pollen donor pool and provide an indicator of the effective number of pollen donors (Nep) for a given maternal plant (Ritland 1989). For outcrossing species, the effective number of pollen donors may be a more sensitive indicator of mating than the outcrossing rate per se. For example only a single unrelated tree can ensure outcrossing, but it is very important to know whether that outcrossing represents few or many other trees.

\section{Background information: Biparental inbreeding}

Inbreeding influences the evolution of many plant and animal populations (Porcher and Lande 2016). Inbreeding has several negative consequences; for example it can decrease effective population size (Paland and Schmid 2003, Tallmon et al. 2004) and a population's speed of adaptation (Glémin and Ronfort 2013). Inbreeding in monoecious plants can arise through two different mechanisms: (a) biparental inbreeding, when a plant mates with a related individual, or (b) self-fertilisation, when a plant mates with itself (Furstenau and Cartwright 2017). Biparental inbreeding or mating between relatives occurs at various frequencies in many natural plant populations, which also often present substantial rates of self-fertilisation (Ritland 2002, Porcher and Lande 2016). Biparental inbreeding causes apparent selfing or increased homozygosity, in contrast to random mating (Ritland 2002). 


\section{References}

Alizoti PG, Kilimis K, Gallios P (2010) Temporal and spatial variation of flowering among Pinus nigra Arn. clones under changing climatic conditions. For Ecol Manag 259:786-797. https://doi.org/10.1016/j.foreco.2009.06.029

Apsit VJ, Dyer RJ, Sork VL (2002) Patterns of mating in an insect-pollinated tree species in the Missouri Ozark Forest Ecosystem Project. In: Shifley SR; Kabrick JM (eds) Proceedings of the Second Missouri Ozark Forest Ecosystem Project Symposium: Post-treatment results of the landscape experiment. General Technical Report NC-227. US Dept of Agriculture, Forest Service, North Central Forest Experiment Station, St. Paul, MN, pp 212-226. https://doi. org/10.2737/NC-GTR-227

Aravanopoulos FA (2011) Genetic monitoring in natural perennial plant populations. Botany 89:75-81. https://doi. org/10.1139/B10-087

Aravanopoulos FA (2016) Conservation and monitoring of tree genetic resources in temperate forests. Curr For Rep 2(2):29119. https://doi.org/10.1007/s40725-016-0038-8

Aravanopoulos FA, Tollefsrud MM, Kätzel R, Soto A, Graudal L, Nagy L, Koskela J, Bozzano M, Pilipovic A, Zhelev P, Božič G (2015) Development of genetic monitoring methods for genetic conservation units of forest trees in Europe. European Forest Genetic Resources Programme (EUFORGEN), Bioversity International, Rome, Italy

Bergmann F, Gregorius HR, Larsen JB (1990) Levels of genetic variation in European Silver fir (Abies alba) - Are They Related to the Species Decline? Genetica 82(1):1-10. https://doi.org/10.1007/BF00057667

Bhumibhamon S (1978) Studies on Scots pine seed orchards in Finland with special emphasis on the genetic composition of the seed. Commun Inst For Fenn 94:1-118

Boyle TJ (2000) Criteria and indicators for the conservation of genetic diversity. In: Young A, Boshier T, Boyle T (eds) Forest conservation genetics. CSIRO Publ., Collingwood, pp 239-251

Brown AHD, Schoen DJ (1992) Plant population genetic structure and biological conservation. In: Sandlund OT, Hindar K, Brown AHD (eds) Conservation of Biodiversity for Sustainable Development Scandinavian University Press, Oslo, pp 88-104.

Burczyk J, DiFazio SP, Adams WT (2004) Gene flow in forest trees: How far do genes really travel? For Genet 11:179-192

Chuine I (2010) Why does phenology drive species distribution? Philos Trans R Soc Lond B Biol Sci 365:3149-3160. https://doi.org/10.1098/rstb.2010.0142

de Melo RB, Franco AC, Silva CO, Piedade MTF, Ferreira CS (2015) Seed germination and seedling development in response to submergence in tree species of the Central Amazonian floodplains. AoB Plants 7:plv041. https://doi. org/10.1093/aobpla/plv041

Del Castillo RF, Trujillo S (2008) Effect of inbreeding depression on outcrossing rates among populations of a tropical pine. New Phytol 177:517-524. https://doi.org/10.1111/j.1469-8137.2007.02260.x

Ducci F, De Cuyper B, Pâques LE, Proietti R, Wolf H (2012) Reference protocols for assessment of trait and reference genotypes to be used as standards in international research projects. CRA SEL, Arezzo, Italy

El-Kassaby YA, Fashler AMK, Sziklai O (1984) Reproductive phenology and its impact on genetically improved seed production in a Douglas-fir seed orchard. Silvae Genet 33:120-125.

El-Kassaby YA, Ritland L, Fashler AMK, Devitt D (1988) The role of reproductive phenology upon the mating system of a Douglas-fir seed orchard. Silvae Genet 37: 76-82

Feld CK, da Silva PM, Sousa JP, De Bello F, Bugter R, Grandin U, Hering D, Lavorel S, Mountford O, Pardo I, Pärtel M, Römbke J, Sandin L, Jones KB, Harrison P (2009) Indicators of biodiversity and ecosystem services: a synthesis across ecosystems and spatial scales. OIKOS 118:1862-1871. https://doi.org/10.1111/j.1600-0706.2009.17860.x

Furstenau TN, Cartwright RA (2017) The impact of self-incompatibility systems on the prevention of biparental inbreeding. PeerJ 5:e4085. https://doi.org/10.7717/peerj.4085/supp-1

Geburek T (2004) Die Weitergabe genetischer Information - eine wichtige Komponente bei der Waldverjüngung. BFWPraxisinformation 4:18-20.

Glémin S, Ronfort J (2013) Adaptation and maladaptation in selfing and outcrossing species: new mutations versus standing variation. Evolution 67:225-240. https://doi.org/10.1111/j.1558-5646.2012.01778.x

Graudal L, Aravanopoulos F, Bennadji Z, Changtragoon S, Fady B, Kjær ED, Loo J, Ramamonjisoa L, Vendramin GG (2014) Global to local genetic diversity indicators of evolutionary potential in tree species within and outside forests. For Ecol Manag 333:35-51. https://doi.org/10.1016/j.foreco.2014.05.002

Gregorius HR, Krauhausen J, Müller-Starck G (1986) Spatial and temporal genetic differentiation among the seed in a stand of Fagus sylvatica L. Heredity 57:255-262. https://doi.org/10.1038/hdy.1986.116

Hartl DL, Clark AG (1989) Principles of population genetics, 2nd edn. Sinauer Associates, Sunderland, Massachusetts, USA 
Konnert M, Maurer W, Degen B, Kätzel R (2011) Genetic monitoring in forests - early warning and controlling system for ecosystemic changes. Iforest 4:77-81. https://doi.org/10.3832/ifor0571-004

Leroy T, Roux C, Villate L, Bodénès C, Romiguier J, Paiva JAP, Dossat C, Aury JM, Plomion C, Kremer A, (2017) Extensive recent secondary contacts between four European white oak species. New Phytol 214:865-878. https://doi. org/10.1111/nph.14413

Mallet J (2001) Gene flow. In: Woiwod IP, Reynolds DR, Thomas CD (eds) Insect movement: Mechanisms and consequences: Proceedings of the Royal Entomological Society's 20th Symposium. CABI Publishing, Wallingford, UK, pp 337-360

Merriam-Webster (n.d.) "Outcrossing". Merriam-Webster.com Dictionary. https://www.merriam-webster.com/dictionary/ outcrossing. Accessed 16 December 2019

Merriam-Webster Inc. (2003) Merriam-Webster's collegiate dictionary, 11th edn. Merriam-Webster Incorporated, Springfield, Massachusetts, USA

Müller-Starck G (1995) Genetic variation in high elevated populations of Norway spruce (Picea abies (L.) Karst.) in Switzerland. Silvae Genet 44:356-361

Müller-Starck G., Ziehe M., Schubert R. (2005) Genetic diversity parameters associated with viability selection, reproductive efficiency, and growth in forest tree species. In: Scherer-Lorenzen M, Körner C, Schulze ED (eds) Forest diversity and function. Ecological studies (Analysis and synthesis), vol 176. Springer, Berlin, Heidelberg, pp 87-108. https://doi.org/10.1007/3-540-26599-6_5

Mund M, Kutsch WL, Wirth C, Kahl T, Knohl A, Skomarkova MV, Schulze ED (2010) The influence of climate and fructification on the inter-annual variability of stem growth and net primary productivity in an old-growth, mixed beech forest. Tree Physiol 30:689-704. https://doi.org/10.1093/treephys/tpq027

Namkoong G, Boyle T, Gregorious HR, Joly H, Savolainen O, Ratman W, Young A (1996) Testing criteria and indicators for assessing the sustainability of forest management: genetic criteria and indicators. Working paper No. 10. Centre for International Forestry Research, Bogor, Indonesia. https://doi.org/10.17528/cifor/000070

Neale DB, Wheeler NC (2019) Hybridization and Introgression. In: The Conifers: Genomes, Variation and Evolution. Springer, Cham, pp 387-429. https://doi.org/10.1007/978-3-319-46807-5_15

O'Connell LM, Mosseler A, Rajora OP (2006) Impacts of forest fragmentation on the mating system and genetic diversity of white spruce (Picea glauca) at the landscape level. Heredity 97 (6): 418-426. https://doi.org/10.1038/sj.hdy.6800886.

Paland S, Schmid B (2003) Population size and the nature of genetic load in Gentianella germanica. Evolution 57:22422251. https://doi.org/10.1111/j.0014-3820.2003.tb00236.x

Porcher E, Lande R (2016) Inbreeding depression under mixed outcrossing, self-fertilization and sib-mating. BMC Evol Biol 16:105. https://doi.org/10.1186/s12862-016-0668-2

Rajora OP, Mosseler A, Major JE (2000) Indicators of population viability in red spruce, Picea rubens. II. Genetic diversity, population structure, and mating behavior. Can J Bot 78:941-956. https://doi.org/10.1139/b00-066

Rajora OP, Mosseler A (2001) Challenges and opportunities for conservation of forest genetic resources. Euphytica 118:197-212. https://doi.org/10.1023/A:1004150525384

Rajora OP, Mosseler A, Major JE (2002) Mating system and reproductive fitness traits of eastern white pine (Pinus strobus) in large, central versus small, isolated, populations. Can J Bot 80(11): 1173-1184. doi:10.1139/B02-105.

Rao NK, Hanson J, Dulloo ME, Ghosh K, Nowell D, Larinde M (2006) Manual of seed handling in genebanks. Handbooks for Genebanks No. 8. Bioversity International, Rome, Italy

Ritland K (1989) Correlated matings in the partial selfer Mimulus guttatus. Evolution 43:848-859. https://doi. org/10.1111/j.1558-5646.1989.tb05182.x

Ritland K (2002) Extensions of models for the estimation of mating systems using $n$ independent loci. Heredity 88:221-228. https://doi.org/10.1038/sj.hdy.6800029

Seifert T, Müller-Starck G (2009) Impacts of fructification on biomass production and correlated genetic effects in Norway spruce (Picea abies [L.] Karst.). Eur J For Res 128:155. https://doi.org/10.1007/s10342-008-0219-5

Selås V, Piovesan G, Adams JM, Bernabei M (2002) Climatic factors controlling reproduction and growth of Norway spruce in southern Norway. Can J For Res 32:217-225. https://doi.org/10.1139/x01-192

Smouse PE, Sork VL (2004) Measuring pollen flow in forest trees: An exposition of alternative approaches. For Ecol Manag 197:21-38. https://doi.org/10.1016/j.foreco.2004.05.049

Soltis P S, Soltis DE (2009) The role of hybridization in plant speciation. Annu Rev Plant Biol 60:561-588. https://doi. org/10.1146/annurev.arplant.043008.092039

Sork VL, Smouse PE (2006) Genetic analysis of landscape connectivity in tree populations. Landsc Ecol 21:821-836. https://doi.org/10.1007/s10980-005-5415-9 
Sparks TH, Butchart SHM, Balmford A, et al. (2011) Linked indicator sets for addressing biodiversity loss. Oryx 45:411-419. https://doi.org/10.1017/S003060531100024X

Stebbins GL, Hartl DL (1988) Comparative evolution: Latent potentials for anagenetic advance. Proc Natl Acad Sci USA 85(14):5141-5145

Tallmon DA, Luikart G, Beaumont MA (2004) Comparative evaluation of a new effective population size estimator based on approximate Bayesian computation. Genetics 167:977-988. https://doi.org/10.1534/genetics.103.026146

Encyclopaedia Britannica (2019) »Gene flow«. Encyclopædia Britannica. https://www.britannica.com/science/gene-flow. Accessed 16 December 2019

The International Seed Testing Association (ISTA) (2020) International Rules for Seed Testing. Bassersdorf, Switzerland. https://doi.org/10.15258/istarules.2020.F

UNEP/WCMC (2011) National Indicators, Monitoring and Reporting for the Strategic Plan for Biodiversity 2011-2020

Vit P, Wolfova K, Urfus T, Tajek P, Suda J (2014) Interspecific hybridization between rare and common plant congeners inferred from genome size data: assessing the threat to the Czech serpentine endemic Cerastium alsinifolium. Preslia 86:95-117

Wang Z, Wang L, Liu Z, Li Y, Liu Q, Liu B (2016) Phylogeny, seed trait, and ecological correlates of seed germination at the community level in a degraded sandy grassland. Front Plant Sci 17. https://doi.org/10.3389/fpls.2016.01532

Weir BS (1979) Inferences about linkage disequilibrium. Biometric 35(1):235-254. https://doi.org/10.2307/2529947

Whitehead MR, Lanfear R, Mitchell RJ, Karron JD (2018). Plant mating systems often vary widely among populations. Front Ecol Evol 6. https://doi.org/10.3389/fevo.2018.00038 



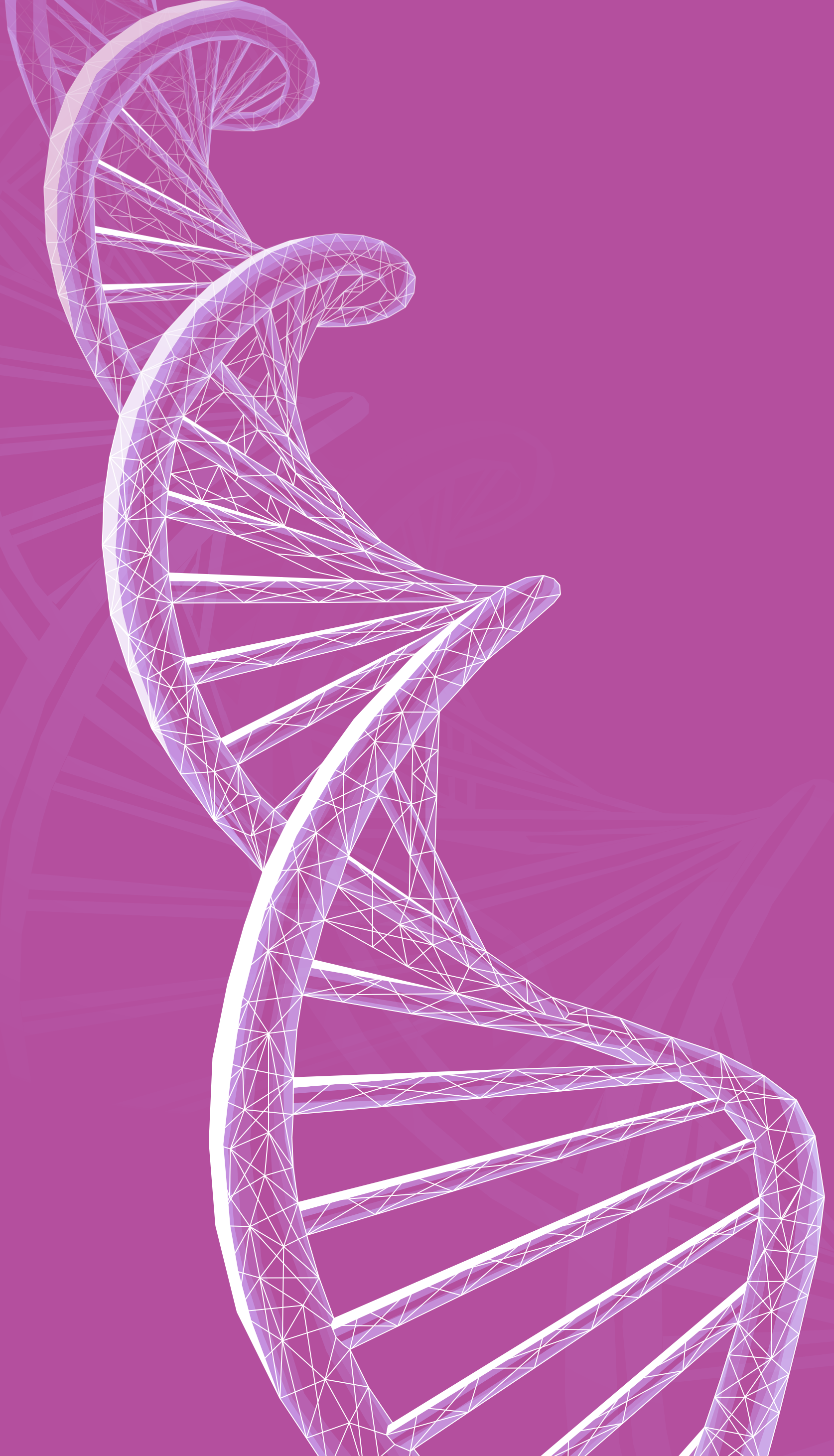




\section{\# \\ LIFE13 ENV/SI/000148}

\section{Manual for forest genetic monitoring}

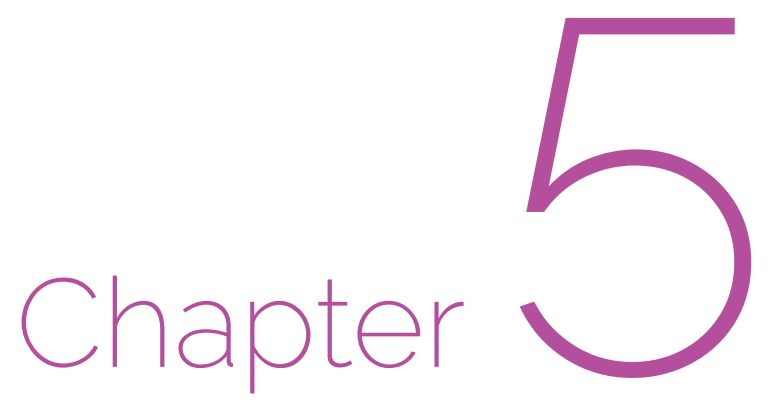

\section{Fieldwork}

Darius KAVALIAUSKAS ${ }^{1}$, Barbara FUSSI', Filippos A. ARAVANOPOULOS²,

Paraskevi ALIZOTI2, Marjana WESTERGREN ${ }^{3}$, Marko BAJC ${ }^{3}$, Rok DAMJANIĆ ${ }^{3}$,

Natalija DOVČ${ }^{3}$, Ermioni MALLIAROU², Evangelia AVRAMIDOU ${ }^{2,4}$,

Dalibor BALLIAN ${ }^{3,5}$, Pavlos BEKIAROGLOU ${ }^{6}$, Gregor BOŽIČ3, Andrej BREZNIKAR?,

Pavlos CHASILIDIS ${ }^{6}$, Anna-Maria FARSAKOGLOU ${ }^{2,8}$, Domen FINŽGAR ${ }^{3,9}$,

Ioannis GANOPOULOS ${ }^{2,10}$, Fotios KIOURTSIS ${ }^{6}$, Monika KONNERT'1,

Nataša ŠIBANC ${ }^{3}$, Nikolaos TOURVAS², Hojka KRAIGHER ${ }^{3}$

Citation: Kavaliauskas et al. (2020) Fieldwork. In: Bajc et al. (eds) Manual for Forest Genetic Monitoring. Slovenian Forestry Institute: Silva Slovenica Publishing Centre, Ljubljana, pp 47-64. http://dx.doi.org/10.20315/SFS.167

Affiliations:

1. Bavarian Office for Forest Genetics (AWG), Germany

2. Aristotle University of Thessaloniki (AUTh), Greece

3. Slovenian Forestry Institute (GIS), Slovenia

4. Institute of Mediterranean Forest Ecosystems, DEMETER, Greece

5. Forestry Faculty, University of Sarajevo, Bosnia and Herzegovina

6. Decentralized Administration of Macedonia \& Thrace,

General Directorate of Forests \& Rural Affairs, Greece

7. Slovenia Forest Service (ZGS), Slovenia

8. European Forest Genetic Resources Programme (EUFORGEN), European Forest Institute (EFI), Spain

9. Institute of Evolutionary Biology, University of Edinburgh, UK

10. Institute of Plant Breeding and Genetic Resources, HAO ELGO DEMETER, Greece 


\subsection{Introduction}

This chapter includes detailed recommendations on how to prepare and carry out regular fieldwork activities in the frame of the forest genetic monitoring (FGM) system, after the FGM plot is selected and installed. The regular work on the established FGM plot depends on the FGM level (basic, standard or advanced) that has to be performed on a regular basis (e.g. phenology observations, mortality evaluation, assessment of natural regeneration abundance, sampling, etc.). To guarantee comparable results, fieldwork and data collection techniques must be optimised and standardised to supplement and confirm the information obtained from the laboratory work. Therefore, detailed fieldwork procedures are of paramount importance for FGM. Overall regular FGM fieldwork after certain preparation and training can be performed by field technicians, foresters or scientists.

\subsection{Verifiers and background information observed/measured in the field}

A list of verifiers and background information which should be recorded during fieldwork at different FGM levels (basic, standard and advanced) is presented in Table 5.1 (example from FGM guidelines for European beech).

Table 5.1: List of verifiers and background information with a short description and observation frequency to be recorded during fieldwork at the beech monitoring plots.

\begin{tabular}{|c|c|c|c|c|}
\hline & Name & Basic level & Standard level & Advanced level \\
\hline \multirow{5}{*}{$\frac{\infty}{\frac{\infty}{\frac{D}{L}}}$} & \multirow{2}{*}{$\begin{array}{l}\text { Mortality / } \\
\text { survival }\end{array}$} & $\begin{array}{l}\text { Adult trees: Counting of the } \\
\text { remaining marked trees every } \\
10 \text { years and after every extreme } \\
\text { weather event/disturbance }\end{array}$ & Same as basic level & Same as basic level \\
\hline & & Natural regeneration: / & $\begin{array}{l}\text { Counting of remaining seedlings } \\
\text { on the natural regeneration } \\
\text { subplots, twice per decade }\end{array}$ & Same as standard level \\
\hline & \multirow[b]{2}{*}{ Fructification } & Stand-level estimate, every year & $\begin{array}{c}\text { Individual tree level observation, } \\
\text { during two major flowering } \\
\text { events per decade, ideally } \\
\text { equally spaced* }\end{array}$ & $\begin{array}{c}\text { Individual tree level observation, } \\
\text { during two major flowering } \\
\text { events per decade, ideally } \\
\text { equally spaced* }\end{array}$ \\
\hline & & Stand-level estimate, every year & $\begin{array}{l}\text { Individual tree level observation, } \\
\text { the same year as the } \\
\text { assessment of the flowering at } \\
\text { the standard level (regardless of } \\
\text { the fructification intensity) }\end{array}$ & $\begin{array}{l}\text { Counting of fruit, the same years } \\
\text { as the assessment of flowering } \\
\text { at the advanced level, regardless } \\
\text { of the fructification intensity } \\
{ }^{*} \text { Seeds are also collected } \\
\text { for laboratory analyses every } \\
\text { assessed fructification event }\end{array}$ \\
\hline & $\begin{array}{l}\text { Natural } \\
\text { regeneration } \\
\text { abundance }\end{array}$ & Stand-level estimate, every year & $\begin{array}{l}\text { Counting of seedlings in the } \\
1^{\text {st }} \text { and } 6^{\text {th }} \text { years after every } \\
\text { assessed fructification event }\end{array}$ & $\begin{array}{l}\text { Counting of seedlings in the } 1^{\text {st }} \text {, } \\
6^{\text {th }}, 11^{\text {th }} \text {, and } 16^{\text {th }} \text { years after every } \\
\text { assessed fructification event }\end{array}$ \\
\hline \multirow{5}{*}{ 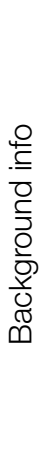 } & $\begin{array}{l}\mathrm{DBH} \text { class } \\
\text { distribution }\end{array}$ & / & Measurement every 10 years & Same as standard level \\
\hline & $\begin{array}{l}\text { Height class } \\
\text { distribution }\end{array}$ & / & Measurement every 10 years & Same as standard level \\
\hline & Budburst & / & $\begin{array}{c}\text { Individual tree level observation, } \\
\text { every } 5 \text { years }\end{array}$ & $\begin{array}{c}\text { Individual tree level observation, } \\
\text { every year }\end{array}$ \\
\hline & Senescence & / & $\begin{array}{c}\text { Individual tree level observation, } \\
\text { every } 5 \text { years }\end{array}$ & $\begin{array}{l}\text { Individual tree level observation, } \\
\text { every year }\end{array}$ \\
\hline & $\begin{array}{l}\text { Flowering } \\
\text { synchronisation }\end{array}$ & / & / & $\begin{array}{l}\text { Individual tree level observation, } \\
\text { during each assessed major } \\
\text { flowering event }\end{array}$ \\
\hline
\end{tabular}

* Ideally at least one major fructification event should be assessed per decade. However, a major flowering event does not necessarily lead to a major fructification event. If no major fructification event follows the assessed flowering event, assessment of both flowering and fructification needs to be repeated during the next major flowering event, regardless of the time passed between successive major flowering events. Basic level observations are used to identify major flowering and fructification events. 


\subsubsection{Verifier: Mortality / Survival}

A change in Mortality or Survival (Mortality = 1 - Survival) indicates an underlying selection pressure, i.e. dieback when the value of mortality is increased. Mortality/Survival refer to the number of trees that have died relative to the baseline (and to the previous assessment). The reason for dieback should be investigated and logged when possible (extreme weather events, disease, age, etc.). Foresters should be approached for determining the cause of dieback and its scale with regard to the wider area (and thus whether the increased mortality is local or widespread).

\subsubsection{Adult trees}

The verifier for the mortality adult trees is estimated by counting the marked trees remaining alive every 10 years and after every extreme weather event/disturbance. Mortality is the difference between the initial number of marked trees and the trees remaining alive of the original 50 .

\subsubsection{Natural regeneration}

Mortality/survival of natural regeneration is only assessed at standard and advanced levels and calculated from the verifier Natural regeneration abundance. Mortality is the difference between the initial number of NR plants and the plants remaining alive at the time of the next counting. For each round of assessment, the NR is counted first in the year of germination and then again after 5 years at the standard level, while at the advanced level the counting is also performed after 10 and 15 years. Assessment of NR abundance is carried out twic per decade, ideally approximately every 5 years.

\subsubsection{Verifier: Natural regeneration abundance}

This verifier describes the presence and abundance of natural regeneration at the monitoring plot. At the basic level this verifier is recorded at the stand level every year in the autumn. Expert opinion is used for estimation considering the situation over the whole monitoring plot. Two values should be recorded, one for new natural regeneration (current-year seedlings) and one for established regeneration (saplings older than one year).

At the standard and advanced levels this verifier is recorded by counting seedlings in each of the 20 NR subplots. The counting starts the first autumn after the germination event following an assessed fructification event and

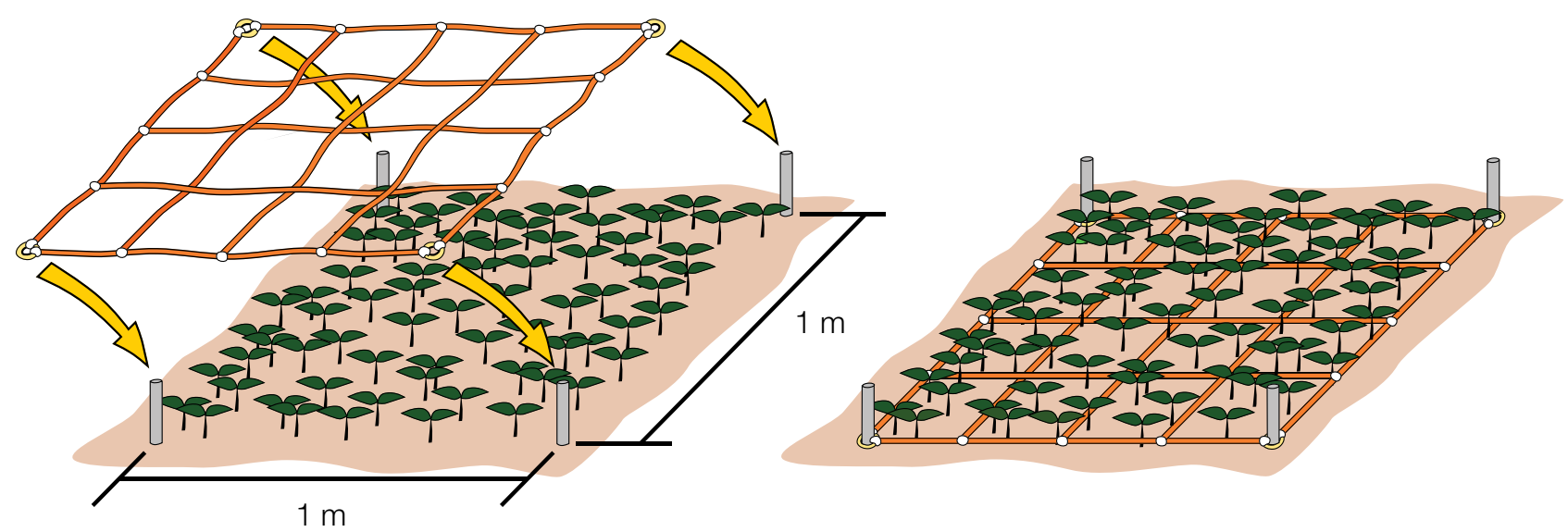

Figure 5.1: Counting of seedlings/saplings for assessment of natural regeneration abundance is best done by using a grid system. A net assembled from string or rope is attached to the marking rods at the corners of each NR subplot. Plants are then counted in each cell of the grid separately and the numbers combined to get the total for the entire NR subplot. Such an approach facilitates the counting as it is much easier to keep track of which plants have already been counted and which not, as compared to counting across the entire NR subplot. 
is repeated the $5^{\text {th }}$ autumn at the standard level and the $5^{\text {th }}, 10^{\text {th }}$ and $15^{\text {th }}$ autumns at the advanced level. The time between fructification events and germination events will depend on the seed dormancy of the species in question. All seedlings present at each of the 20 NR sublots must be counted. Any older saplings that are present on the NR subplot must not be included. During the next counting round, only saplings of the appropriate age must be counted - in the 5th year, 5-year old saplings.

Since many seedlings/saplings can be present at each $1 \mathrm{~m}^{2} \mathrm{NR}$ subplot, using a "grid approach" during counting i.e. dividing the NR subplot into smaller squares - is recommended to facilitate the counting. A simple and efficient way of doing that is by assembling a net made out of string or rope, the corners of which can be attached to the metal rods used for marking NR subplots (Figure 5.1; subchapter 3.2.3.2).

\subsubsection{Background information: DBH class distribution}

$\mathrm{DBH}$ (in cm), is taken at $1.3 \mathrm{~m}$ from the ground, i.e. approximately at an adult's breast height, always perpendicular to the tree trunk axis, using a calliper, or alternatively a measuring tape to measure tree circumference and then compute the diameter. If using callipers, two measurements must be taken perpendicular to one another and an average calculated to account for trees with asymmetric trunk cross section. If a tree is a multitrunk one, then all individual trunk (stem) diameters are measured and the average is calculated and recorded. A note should be taken that tree is multitrunk. On inclined terrain the $\mathrm{DBH}$ must be measured from the higher side of the slope. The DBH class distribution is estimated as part of the descriptive statistics of the stand data.

Equipment needed for DBH measurements:

- a calliper, or alternatively a measuring tape to measure tree circumference and then compute the diameter.

\subsubsection{Background information: Height class distribution}

Height (in metres with one decimal) is measured from the ground to the tallest part of the crown, using a clinometer (preferably a laser clinometer) or a telescopic measuring pole (for small trees).

Equipment needed for height measurements:

- hypsometer/tape for height measurements,

- a telescopic measuring pole (for small trees).

\subsection{Phenology Observations}

\subsubsection{Introduction to phenology}

Phenology is the study of the timing of the biological events in plants, such as flowering and leafing. Phenological traits (e.g. bud break, flowering, etc.) are conditioned by numerous environmental (e.g. chilling requirements, temperature sum, etc.) and physiological factors required for initiation of the processes, but they are also under strong genetic control (Ducci et al. 2012). Data about the timing and the duration of certain phenology events (budburst, flowering, leaf senescence, etc.) provides important information in understanding the actual state of the trees and forest tree populations in the changing environment. Changes in the timing of phenology events may be caused by various factors e.g. fluctuations and changes in climate or other environmental impacts, which affects not only the state of the single trees, but also ecological processes (e.g. mating system) at the stand and population level (Beuker et al. 2010). Data on phenological phases (i.e. phenophases) of budburst, flowering, leaf senescence, etc. is required for integrated evaluations of different aspects within FGM. The ability of a species to adjust, via shifts in phenology, to the abiotic environmental conditions in the long term can be considered as an indicator of its vulnerability to future climatic changes. The main objective of phenological observations on FGM plots is to provide supplementary and complementary information on the status and development of phenological traits related to growth of the forest tree population during the year. The data gained during phenological observations 
will contribute to FGM and enable us to determine the state and tendencies of the annual development stages of the forest tree population and their dependence on various conditions. It is important to detect trends and possible factors (natural and/or anthropogenic) causing changes in the timing and duration of phenological stages (starting time, duration of period and magnitude) (Beuker et al. 2010). Shifts in species' phenologies can thus result in disruptions to the ecosystem processes and services upon which human livelihood depends.

\subsubsection{Phenological verifiers and background information}

\subsubsection{Verifier: Flowering}

Flowering phenology is the study of the timing of the development of male and female flowers by recording the different phenophases (Ducci et al. 2012). Flowering phenology is a crucial factor affecting tree reproduction fitness, via gene exchange among genotypes that determines the genetic variation of the produced seed crop and the survival success of the produced seedlings (Alizoti et al. 2010).

Procedures for phenology observations describe the scoring system that can be followed for the assessment of developmental phases (phenophases) of male and female flowers from dormant flowering buds to fully developed flowers/conelets/strobili. Phenological observations take into account the phenological stage (phenophase), the part of the tree crown recorded (top, middle, low) and the direction of observations (N-north; NE-north-east; E-east; SE-south-east; S-south; SW-south-west; W-west; NW-north-west; ALL - all around crown). The data is used for the construction of phenograms indicating the initiation, duration and ending of the phenomenon. This verifier describes the presence of (proportion of trees) flowering and flowering intensity.

\section{Fieldwork procedures for flowering assessment at different FGM levels:}

\subsection{Basic level}

This verifier is recorded every year at the stand level based on expert opinion. Recording is carried out when flowering is in full progress. The estimate of average condition is provided after a walk throughout the monitoring plot. Two scores are given, one for flowering intensity and one for proportion of flowering trees in the stand (see the tables below).

\begin{tabular}{llr} 
Code & Flowering intensity at the stand level & Average proportion of the crown flowering (\%) \\
\hline 1 & No flowering: No or only occasional flowers appearing on trees & $0-10$ \\
\hline 2 & Weak flowering: Some flowers appearing on trees. & $>10-30$ \\
\hline 3 & Moderate flowering: Moderate number of flowers appearing on trees. & $>30-60$ \\
\hline 4 & Strong flowering: Abundant number of flowers on trees. & $>60-90$ \\
\hline 5 & Massive: Huge number of flowers on trees. & $>90$ \\
\hline
\end{tabular}

\begin{tabular}{lr}
\hline Code Proportion of trees in the stand with the given flowering intensity stage (\%) & $0-10$ \\
\hline 1 & $>10-30$ \\
\hline 2 & $>30-60$ \\
\hline 3 & $>60-90$ \\
\hline 4 & $>90$ \\
\hline 5 &
\end{tabular}

\subsection{Standard level}

This verifier is recorded during two major flowering events per decade, ideally equally spaced in time from one another. It is recorded based on expert opinion at an individual tree level on all 50 monitored trees. A major flowering event is when at the basic level flowering intensity is strong or massive (code 4 or 5 ) and the proportion 
of trees with the given flowering intensity is above $60 \%$ (code 4 or 5). Recording is carried out when flowering is in full progress. One score is provided for each tree (see table below).

Detail fieldwork procedure:

1. Flowering phenological observations will be carried out on selected and marked FGM trees (50 tress per FGM plot).

2. Observations must be made separately for each individual tree by using binoculars or digital photographs.

3. The observed part of the crown should be reported in the datasheet (1. top/2. middle/3. top and middle of the crown). The whole crown or the highest part (top) of the crown should be evaluated, if possible.

4. The crown direction on which the observations were made needs to be reported in the datasheet (N-north; NEnorth-east; E-east; SE-south-east; S-south; SW-south-west; W-west; NW-north-west; ALL - all around crown).

5. If only one part of the crown from one direction is visible, then the same part of the crown and the same observation direction should be considered for subsequent phenological observations through the whole year, as well as for following years.

6. The observation of flowering must be carried out at regular intervals once per week. In some tree species observations might overlap with budburst phenology.

7. Flowering of different tree species can be initiated at different times depending on species biology and environmental conditions.

\begin{tabular}{llr} 
Code Description & Proportion of the crown flowering (\%) \\
\hline 1 & No flowering: No or only occasional flowering appearing on a tree. & $0-10$ \\
\hline 2 & Weak flowering: Some flowers appearing on a tree. & $>10-30$ \\
\hline 3 & Moderate flowering: Moderate number of flowers on a tree. & $>30-60$ \\
\hline 4 & Strong flowering: Abundant number of flowers on a tree. & $>60-90$ \\
\hline 5 & Massive: Huge number of flowers on a tree. & $>90$ \\
\hline
\end{tabular}

\subsection{Advanced level}

This verifier is recorded during two major flowering events per decade, ideally equally spaced in time from one another. It is recorded based on expert opinion at an individual tree level on all 50 monitored trees. A major flowering event is when at the basic level flowering intensity is strong or massive (code 4 or 5 ) and the proportion of trees with the given flowering intensity is above $60 \%$ (code 4 or 5 ). On average, two visits to the plot are needed; the first one early enough to observe the early stages of flowering and the second one when flowering is in full progress. Besides the flowering intensity, female and male flower development stages are recorded as well.

\section{Female and male flowering development stages for seven different species and species complexes} are described and illustrated in the individual species-specific guidelines for FGM (Chapter 9).

\begin{tabular}{lr}
\hline Code Proportion of the crown flowering (\%; male and female flowering together) & $0-10$ \\
\hline 1 & $>10-30$ \\
\hline 2 & $>30-60$ \\
\hline 3 & $>60-90$ \\
\hline 4 & $>90$ \\
\hline 5 & \\
\hline
\end{tabular}




\subsubsection{Verifier: Fructification}

The intensity and periodicity of fructification between consecutive mast years is species specific and varies depending on weather conditions, resources availability, abundance of pollinators in the case of anemophilous species and genetic control (Mund et al. 2010 and references therein). The initiation of fructification for a tree is an important sign, indicating its reproductive maturation, and suggesting that part of the resources allocated up to that point totally to vegetative growth and defence, will from that point onwards be allocated to reproduction (Seifert and Müller-Starck 2009).

Procedures for phenology observations describe the scoring system that can be used for the assessment of fructification. Phenology observations take into account the periodicity and intensity of fructification. The data are collected at the stand level and on a per tree basis depending on the monitoring level (basic/standard/advanced). This verifier describes the presence of fructification and its abundance.

\section{Fieldwork procedures for fructification assessment at different FGM levels:}

\subsection{Basic level}

This verifier is recorded every year at the stand level. The estimate of average condition is provided after a walk throughout the monitoring plot. Two scores are given, one for fructification intensity and one for proportion of fructifying trees in the stand.

\begin{tabular}{clc} 
Code & Fructification intensity at the stand level & Average proportion of the crown bearing fruit (\%) \\
\hline 1 & No fructification: No or only occasional fruit appearing on trees & $0-10$ \\
\hline 2 & Weak fructification: Some fruit appearing on trees & $>10-30$ \\
\hline 3 & Moderate fructification: Moderate amount of fruit appearing on trees & $>30-60$ \\
\hline 4 & Strong fructification: Abundant amount of fruit appearing on trees & $>60-90$ \\
\hline 5 & Massive: Huge amount of fruit appearing on trees & $>90$ \\
\hline
\end{tabular}

\begin{tabular}{lr}
\hline Code Proportion of trees in the stand with the given stage of fructification intensity (\%) & $0-10$ \\
\hline 1 & $>10-30$ \\
\hline 2 & $>30-60$ \\
\hline 3 & $>60-90$ \\
\hline 4 & $>90$ \\
\hline 5 &
\end{tabular}

\subsection{Standard level}

This verifier is recorded during the same years as the assessment of the flowering at the standard level (regardless of the fructification intensity) for most of the species (i.e. for pine species maturation of cones and release of seeds occurs the second year after flowering), ideally capturing two fructification events per decade. It is recorded at an individual tree level on all 50 monitored trees.

Detailed fieldwork procedure:

1. Fructification phenological observations will be carried out on the selected and marked FGM trees (50 trees per FGM plot).

2. Observations must be made separately for each individual tree by using binoculars, and the percentage of the crown bearing fruits/mature cones is assessed (see table below). 
3. The observed part of the crown should be reported in the datasheet (Excel file) (1. top/2. middle/3. top and middle of the crown). The whole crown or the highest part (top) of the crown should be evaluated, if possible.

4. The crown direction on which the observations were made needs to be reported in the datasheet (N-north; NEnorth-east; E-east; SE-south-east; S-south; SW-south-west; W-west; NW-north-west; ALL - all around crown).

5. If only one part of the crown from one direction is visible, then the same part of the crown and the same observation direction should be considered for subsequent phenological observations for following years.

6. Evaluation of fructification must be done once during the fructification season and before seed/fruits shedding or dispersing.

\begin{tabular}{clc} 
Code & Fructification intensity & Proportion of the crown fructifying (\%) \\
\hline 1 & No fructification: No or only occasional fruit appearing on a tree. & $0-10$ \\
\hline 2 & Weak fructification: Some fruit appearing on a tree. & $>10-30$ \\
\hline 3 & Moderate fructification: Moderate amount of fruit appearing on a tree. & $>30-60$ \\
\hline 4 & Strong fructification: Abundant amount of fruit appearing on a tree. & $>60-90$ \\
\hline 5 & Massive: Huge amount of fruit appearing on a tree. & $>90$ \\
\hline
\end{tabular}

\subsection{Advanced level}

This verifier is recorded at an individual tree level on all 50 monitored trees during the same years as the assessment of flowering at the advanced level, regardless of the fructification intensity. The verifier is recorded by counting fruit using binoculars and must be carried out before the fruit starts falling. The average of three rounds of counting is reported. Each round of counting consists of the number of fruits that the observer is able to count in 30 seconds. For all trees, the same part of the crown should be investigated. Once the observation part of the crown part is selected, the same one should be selected for every subsequent monitoring of this verifier. The upper third of the crown is preferred to the bottom and middle part for counting.

Two values are recorded; the number of fruits and the part of the crown monitored.

Ideally, one major fructification event should be captured following observations of major flowering events per decade. However, a major flowering event does not necessarily lead to a major fructification event. If no major fructification event follows the assessed flowering event, assessment of both flowering and fructification needs to be repeated during the next major flowering event, regardless of the time passed between successive major flowering events. Basic level observations are used to identify major fructification events. A major fructification event is when at the basic level fructification intensity is strong or massive (code 4 or 5 ) and the proportion of trees with the given fructification intensity is above $60 \%$ (code 4 or 5 ).

\section{Number of fruits counted in 30 seconds (average of 3 rounds)}

$\mathrm{X}$

\section{Code Part of the crown monitored}

\begin{tabular}{ll}
\hline 1 & Bottom \\
\hline 2 & Middle \\
\hline 3 & Top \\
\hline
\end{tabular}

\subsubsection{Background information: Budburst}

Budburst (also termed bud break, leaf unfolding or bud flush) is the period spanning from dormant bud up to shoot elongation. Information about the timing and duration of budburst provides important information for understanding the actual state of the trees and forest tree populations in the changing environment. 
Procedures for budburst phenology observations describe the scoring system that can be followed for the assessment of developmental/phenological stages from dormant bud to shoot elongation. Phenology observations take into account the stage of the phase and proportion of crown which is affected. Budburst describes the process of flushing. Recording of this background information is only carried out at the standard and advanced levels.

\section{Fieldwork procedures for budburst assessment at different FGM levels:}

\subsection{Standard level}

At standard level, budburst is recorded on an individual tree level on all 50 monitored trees every 5 years. For each tree, two estimates are given: budbursting stage and proportion of the crown budbursting. For a graphical representation and scoring system of budbursting stages see the species' FGM guidelines.

Detailed fieldwork procedure:

1. Observations of budburst should be carried out on selected and marked FGM trees (50 trees per FGM plot).

2. Observations must be made separately for each individual tree by using binoculars or digital photographs.

3. The observed part of the crown should be reported in the datasheet (1. top/2. middle/3. top and middle of the crown). The whole crown or the highest part (top) of the crown should be evaluated, if possible.

4. The crown direction on which the observations were made needs to be reported in the datasheet (N-north; NEnorth-east; E-east; SE-south-east; S-south; SW-south-west; W-west; NW-north-west; ALL - all around crown).

5. If only one part of the crown from one direction is visible, then the same part of the crown and the same observation direction should be considered for subsequent phenological observations through the whole year, as well as for following years.

6. Observations of budburst progress must be carried out at regular intervals (once per week) during the whole flushing period (duration of flushing season depends on the target tree species biology and environmental conditions).

7. Observations of budburst must start early enough to capture the very early stages, when significant differentiation can be recorded on an individual tree basis.

8. Observations will be finalised when all selected trees have reached the final stage (species specific phenology procedure). The most advanced stage (phenophase) has to be recorded.

\begin{tabular}{rr}
\hline Code Proportion of the crown with a given stage of budbursting (\%) & \\
\hline 1 & $>0-33$ \\
\hline 2 & $>33-66$ \\
\hline 3 & $>66-99$ \\
\hline 4 & 100 \\
\hline
\end{tabular}

\subsection{Advanced level}

At advanced level, budburst is recorded on an individual tree level on all 50 monitored trees every year. For the values (stage of budbursting and the proportion of crown affected) see 5.3.2.3.1 Standard level.

\subsubsection{Background information: Senescence}

Leaf senescence is an important trait that may influence the length of the growth period for species that shed their leaves in autumn and is highly influenced by environmental as well as genetic factors. Information about the timing and the duration of leaf senescence phenology provides important information in understanding the actual state of the trees and forest tree populations in the changing environment. 
The procedures for leaf senescence phenology observations describe a scoring system that can be followed for the assessment of leaf senescence. The data are collected at the stand level and on a per tree basis. Recording of this background information is only carried out at the standard and advanced levels. Phenology observations take into account the stage of the phase and the proportion of crown which is affected.

\section{Fieldwork procedures for phenology of leaf senescence assessment:}

\subsection{Standard level}

At standard level, senescence is recorded on an individual tree level on all 50 monitored trees every 5 years. For each tree, two estimates are given: stage of senescence and proportion of the crown senescing. For a graphical representation of stages of senescence see the species' FGM guidelines.

Detailed fieldwork procedure:

1. Leaf senescence observations will be carried out on selected and marked FGM trees ( 50 trees per FGM plot).

2. Observations must be made separately for each individual tree by using binoculars, if necessary, or digital photographs.

3. The observed part of the crown should be reported in the datasheet (1. top/2. middle/3. top and middle of the crown). The whole crown or the highest part (top) of the crown should be evaluated, if it is possible.

4. The crown direction on which the observations were made needs to be reported in the datasheet (N-north; NEnorth-east; E-east; SE-south-east; S-south; SW-south-west; W-west; NW-north-west; ALL - all around crown).

5. If only one part of the crown from one direction is visible, then the same part of the crown and the same observation direction should be considered for subsequent phenological observations through the whole year, as well as for following years.

7. Leaf senescence should be evaluated two to three times per season (time and duration of leaf senescence observations depends on species biology and environmental conditions).

8. The final stage (stage number 4) is considered as being reached when one or more leaves (including those that have recently fallen from the plant) have turned to their late-season colour. Fully dried or dead leaves that remain on the plant should not be considered. Observations stop when all leaves reach stage number 3 - leaves turn yellow and do not photosynthesize anymore.

9. The proportion of leaves of the visible part of the crown that are in the described stage or have already passed this stage have to be recorded using the leaf senescence classification.

\section{Code Stage of senescence}

\begin{tabular}{ll}
\hline 1 & Leaves/needles are green \\
\hline 2 & Leaves/needles are green changing to yellow (greenish yellow) \\
\hline 3 & Leaves/needles are yellow changing to brown (brownish) \\
\hline 4 & Leaves/needles are brown/shed \\
\hline
\end{tabular}

\section{Code Proportion of the crown with a given score Stage of senescence (\%)}

\begin{tabular}{rr}
\hline 1 & $>0-33$ \\
\hline 2 & $>33-66$ \\
\hline 3 & $>66-99$ \\
\hline 4 & 100 \\
\hline
\end{tabular}




\subsection{Advanced level}

Senescence is recorded on an individual tree level on all 50 monitored trees every year. For the values (stage of senescence and the proportion of crown affected) see 5.3.2.4.1 Standard level.

\subsubsection{Background information: Flowering synchronisation}

Flowering synchronisation is a part of flowering phenology, which focuses on the timing of the development of male and female flowers by recording the different phenophases (Ducci et al. 2012). Flowering synchronisation is only monitored at the advanced level, and it is based on the data collected for verifier Flowering (see 5.3.2.1). It is used to determine whether male and female flowering occur simultaneously within the monitored stand.

\subsection{Advanced level}

Flowering synchronisation is recorded on an individual tree level on all 50 monitored trees, during each assessed major flowering event, in the same years as when seed is collected for most of the species (the same as Flowering at the advanced level).

\subsection{Collecting samples}

\subsubsection{Sampling procedure for DNA analysis}

Sampling is an integral part of FGM. Therefore, standardised sampling procedures are needed to ensure the best results obtained from DNA analysis. The sampling procedures, equipment and materials needed for sampling are described within this chapter. Species-specific examples and advice for sampling (e.g. possible options for material to be sampled, peculiarities of seed collection for seed testing, etc.) are given.

\section{Equipment needed for sampling:}

- Plastic/paper bags for sampling material (100 bags for 50 adults and 50 natural regeneration samples);

- Branch scissors/cutters or knife;

- Plastic/aluminium labels;

- Rechargeable electric drill, extra batteries;

- 6-10 mm diameter drill, extra drills;

- 0.5-litre washing bottle with distilled water, extra 5 litres of distilled water;

- Distilled water to clean the drill;

- Cotton bags or boxes for seed/cones;

- Plastic bags with silica gel to keep samples dry during sampling and transportation;

- Waterproof pens;

- Styrofoam or other heat insulating boxes with cooling packs for protecting the samples from excessive temperature fluctuations.

\subsubsection{Adult trees sampling}

All labelled trees within an FGM plot must be sampled (50 adult reproducing trees for monoecious species; 25 female and 25 male adult reproducing trees for dioecious and functionally dioecious species). Material from each tree must be stored in a separate plastic/paper/cotton bag. For hybridising species and species with vegetative 
reproduction (clones), the initial number of adult trees to be sampled and genotyped can be higher (e.g. 100, see Table 5.2), as only pure-species individuals and only a single individual of the same genotype can be included in the monitoring. If initial DNA analysis shows a very high percentage of hybridisation, then another stand should be considered for FGM (unless the particular aim is to monitor a hybrid stand).

\section{A note on sample size for dioecious species:}

It should be noted that 25 male and 25 female reproducing trees in the case of dioecious or functionally dioecious species represent half the number of possible parental contributions to the next generation in comparison to 50 monoecious reproducing individuals. The decision to operate with the same total number of adult reproducing trees for dioecious and monoecious species was based primarily on practical considerations, namely to avoid the increase of workload and cost if a total of 100 reproducing trees were monitored (especially regarding phenological and other field observations) and potentially an excessive increase of the monitoring plot area. The users should be aware of this sample size issue in dioecious species.

Sampling material for genetic analysis can be (Figure 5.2: a, b, c, d):

- Branches with buds (2 - 3 branches per tree, 5 - $10 \mathrm{~cm}$ long with 1 or 2 buds), cut with branch scissors/ cutters or knife;

- Fresh leaves/needles (collect 5 - 10 fresh leaves/needles from every tree);

- Wood with part of the cambium taken by drilling $4 \mathrm{~cm}$ into each tree (obtained with a rechargeable electric drill and filling up $2 \mathrm{ml}$ of an Eppendorf tube, or with an increment borer, taking two $3 \mathrm{~cm}$ deep wood cores).
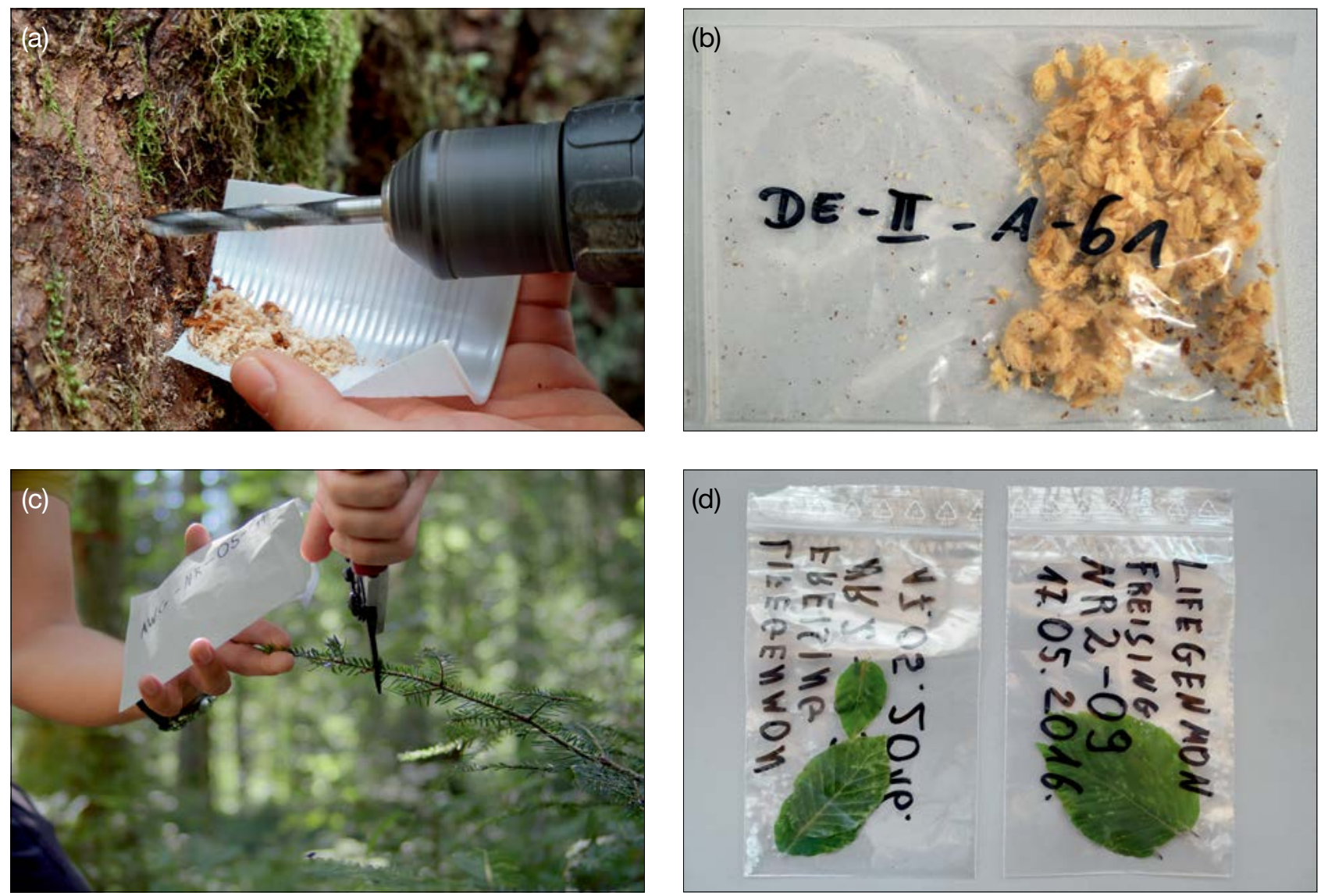

Figure 5.2: Sampling material for genetic analysis ( $a$ and $b$ - wood with part of cambium; $c$ and $d$ - fresh leaves or needles). 
From the above options, choose the type of material which is easier to collect. The sampled material for genetic analysis can be a combination of different types, e.g. buds, fresh leaves, or wood with part of the cambium. Before sampling is initiated, it is necessary to obtain the owner's permission for the type of material that is going to be sampled (e.g. in case of drilling). Broadleaves are more sensitive to sampling by drilling, so less invasive approaches might be preferred (leaves, twigs with buds). However, if the drilling of broadleaves is performed between January and March (outside the vegetation period) then the wounds will heal faster. To avoid negative impacts on stem (log) quality it is better to drill in the stump, the lowest possible part of the stem, close to the ground. In case of drilling conifers, any wound resulting from drilling is filled with resin in a very short time.

Bags with material for DNA analysis must be labelled in a systematic and consistent way. The following sample labelling convention was used in the LIFEGENMON project: DE-I-FSY-A-01

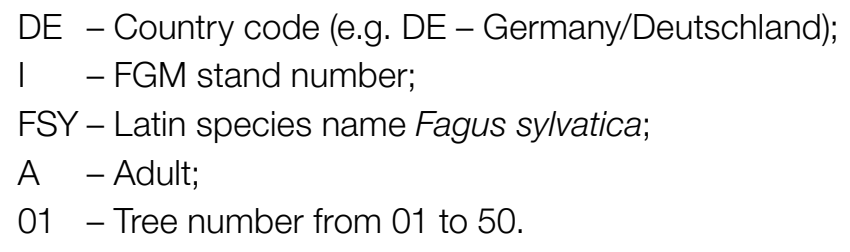

It is advisable that all sample types are put in insulating boxes (such as Styrofoam boxes used for shipping temperature sensitive materials) with some cooling packs to prevent excessive temperature fluctuations in the field and during transportation.

\subsubsection{Natural regeneration (NR) sampling}

Sampling of natural regeneration should be done at the 20 NR subplots (next to the abundance/survival $1 \mathrm{~m}^{2}$ plot) the third year after germination (3-year old plants). Fifty NR samples are collected: 3 plants from 10 randomly chosen NR subplots, 2 from the other 10 subplots. For hybridising species and species with vegetative reproduction (clones), 100 saplings should be sampled and genotyped. Hybridisation percentage is calculated from the results for all 100 samples, 50 non-hybridised individuals of unique genotypes are then randomly selected for calculation of other molecular genetic verifiers and background information.

Natural regeneration material suitable for DNA extraction:

- branches with buds (2 or 3 branches per individual, 3 to $5 \mathrm{~cm}$ long with 1 or 2 buds), cut with branch scissors/cutters or knife;

- fresh leaves/needles (pick off 2 to 5 fresh leaves from every individual).

Recommendation: the quantity of plant material for DNA extraction can be reduced; usually it is enough to collect 2 or -3 buds/leaves for DNA extraction. However, it is always better to have a few buds more for repetitions in the lab. Material from each tree must be stored in a separate plastic/paper/cotton bag.

Bags must be labelled in a systematic and consistent way. The following NR sample labelling convention was used in the LIFEGENMON project: DE-I-FSY-NR-01

DE - Country code (e.g. DE - Germany/Deutschland);

I - Stand number;

FSY - Latin species name Fagus sylvatica;

NR - Natural regeneration;

01 - Tree number from 01 to 50. 


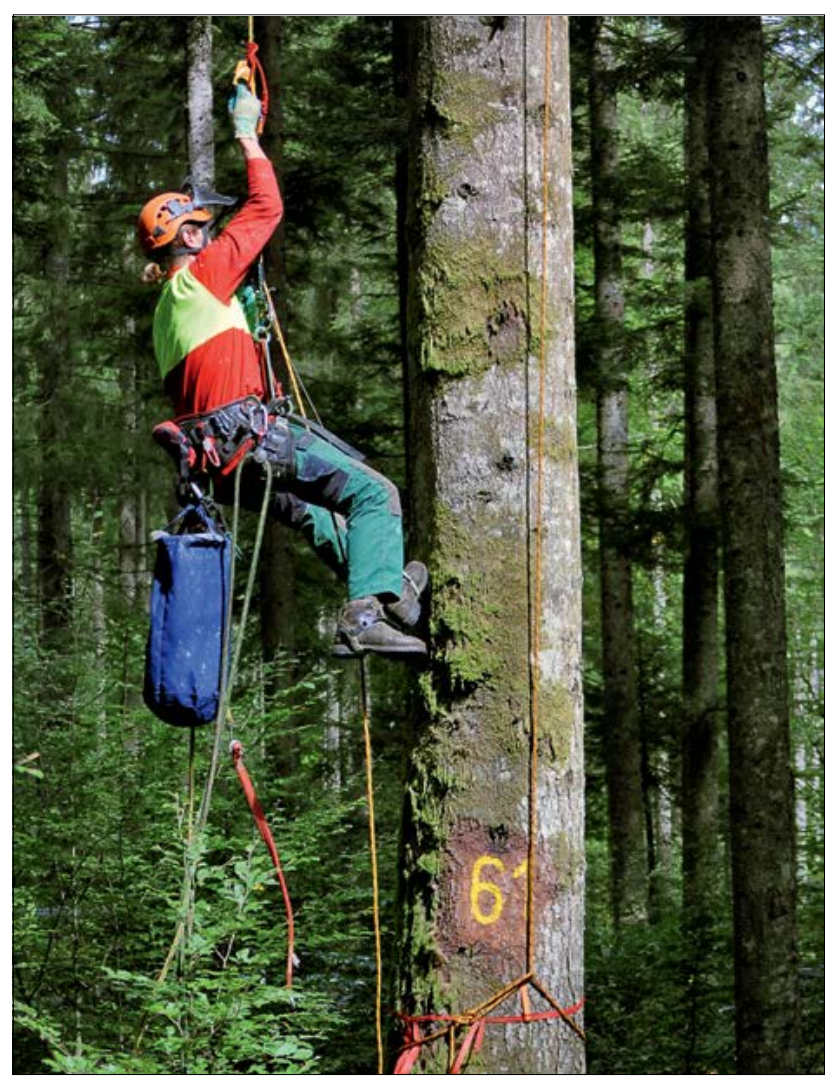

Figure 5.3: Cones collection in Abies alba FGM plot (Germany)
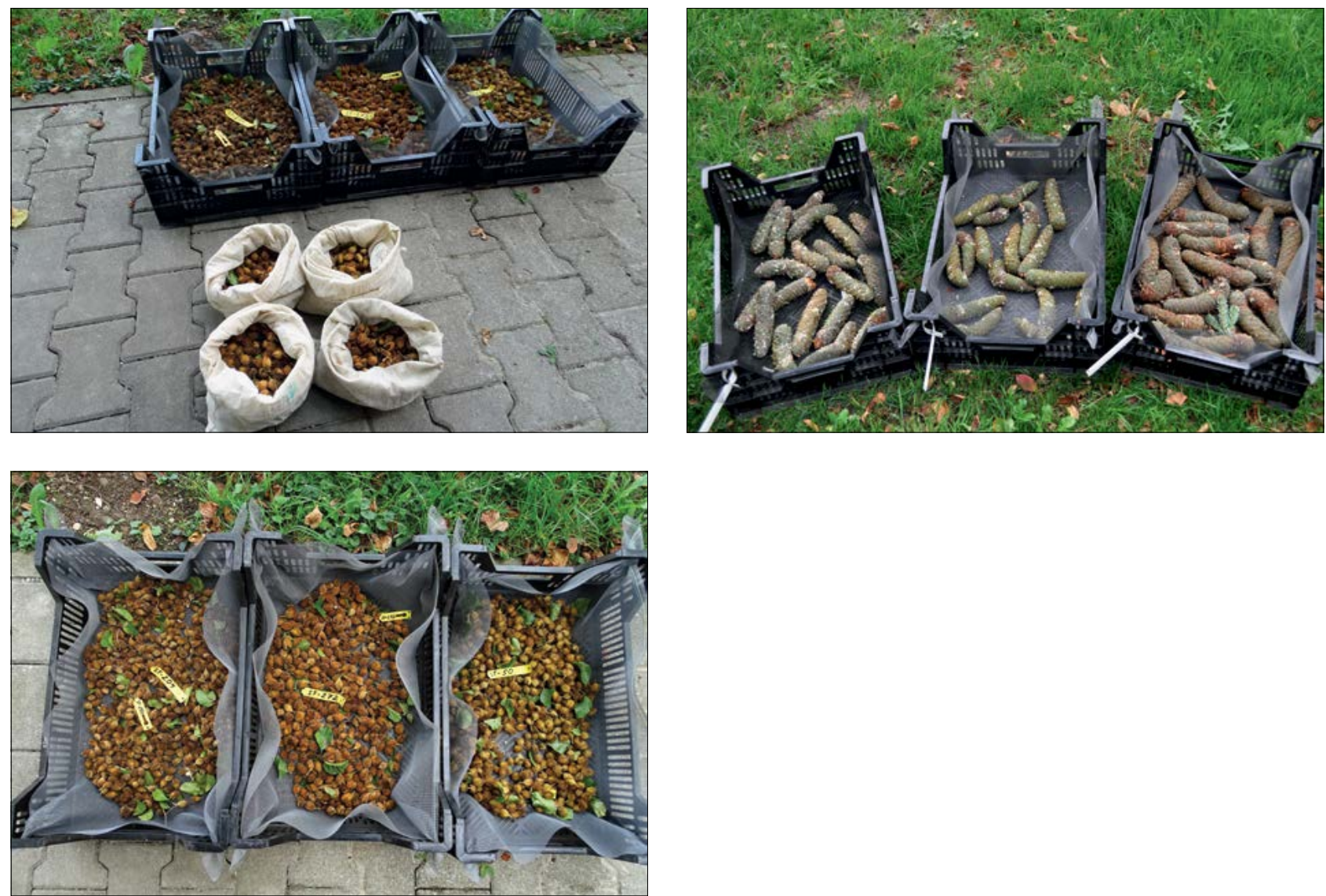

Figure 5.4: Collected seed/cones (Fagus sylvatica and Abies alba) 


\subsubsection{Seed sampling}

Seeds are needed for DNA analysis and for seed testing at the advanced level of monitoring.

The time of seed collection differs from country to country and depends on the biology of the target tree species and the environmental/climatic conditions of a certain area. For example, in the case of Abies alba seed collection usually starts at the end of August in central Europe, but during September to October in southern Europe; Fagus sylvatica seed collection usually starts in September and can last until November.

- Seeds must be collected from the 20 selected seed trees and at least 200-300 seeds per mother tree must be sampled from several different branches (higher number of seeds are needed to be sure to have sufficient number of full seed), 20 full seeds per tree will be used for DNA analysis, for a total of 400 seeds for all tested seed trees per assessment. For hybridising species 30 full seeds per tree are used for DNA analysis; hybridisation percentage is calculated from the results for all 600 seeds, 400 non-hybrid seeds are then randomly selected for calculation of other molecular genetic verifiers and background information.

- Seeds of Fagus sylvatica must be collected by climbing onto the trees, cutting several branches (if necessary) and collecting the fruits with seeds inside directly from the branches.

- Seeds of Abies alba must be collected by climbing onto the trees and collecting the cones prior to the opening of their scales phase (when cone scales are closed the seeds still remain within the cone) (Figure 5.3).

- Seeds from different mother trees must be stored in separate cotton bags or boxes that should be tagged (Figure 5.4).

- Bags must be labelled in a systematic and consistent way. The following seed sample labelling convention was used in the LIFEGENMON project: DE-I-FSY-ST-X

$$
\begin{aligned}
& \text { DE - (e.g. DE - Germany/Deutschland); } \\
& \text { I - FGM stand number; } \\
& \text { FSY - Latin species name Fagus sylvatica } \\
& \text { ST - Seed tree; }
\end{aligned}
$$

$\mathrm{X} \quad$ - Tree number as marked on the seed tree (numbering must be kept as it was given during adult trees selection).

All plant material collected for DNA analysis must be kept at a temperature of around $2-3^{\circ} \mathrm{C}$ (not frozen/not below $0^{\circ} \mathrm{C}$ ), no longer than 3 days, until sent to the DNA lab as fast as possible. Time for seed and cones transportation to the DNA lab can take more time, since there is no risk of DNA degradation.

\subsubsection{Seed sampling for seed testing}

According to the ISTA (2020) rules the goal of seed sampling is to obtain a sample size suitable for seed testing. A sample for seed testing, in the frame of FGM, is obtained from the genetic monitoring plot by collecting small portions of seed at random from different positions and mixing them to produce a bulk sample. Each stage in sampling must be performed using appropriate methods and equipment. In this chapter we describe the seed sampling procedure for heavy and light (wind dispersed) seed collection for seed testing of target trees species within FGM.

\subsubsection{Seed sampling for seed testing of species with heavy seed (e.g. Fagus spp., Quercus spp.)}

Heavy seeds of certain species, such as Fagus spp. and Quercus spp., have to be collected during mast years and from the ground after the seed fall, so that they can be tested. The time of seed collection from the ground differs from country to country and depends on the biology of the target tree species and the environmental/ climatic conditions of a certain area. For example, in central Europe seed of Fagus sylvatica must be collected in 
October-November after seed fall. Seed of Quercus spp. for seed testing must be collected in autumn after seed fall. The seed sample has to be representative, and thus seed has to be collected across the whole FGM area. Therefore, collection of seed must be carried out systematically, by moving from one edge of the FGM plot to the other and collecting some available/visible seed from the ground every 10 meters (see Figure 5.5).

Seed of Prunus avium must be collected by climbing onto the trees and before the fruit ripens and gets eaten by birds. The time for fruit collection may also differ from country to country depending upon environmental/climatic conditions of the certain area. Usually seeds of wild cherry have to be collected from late spring till mid-summer in Europe.

For seed testing and according to ISTA (2020), different amounts of seed are required for different species (Table 5.2). Seed from different FGM plots must be stored in separate cotton bags or perforated boxes that should be tagged. All seed must be sent to the seed testing lab as fast as possible after seed collection.

\subsubsection{Seed sampling for seed testing of species with lightweight seed (wind dispersed) (e.g. Abies spp., Populus spp., Pinus spp., Fraxinus spp.)}

For lightweight (wind dispersed) seed of species like Abies spp., Populus spp., and Pinus spp., seed for seed testing cannot be collected from the ground and after the seed dispersal in a mast year. In case this option was selected then excessive effort and time would be needed. For conifers, mature cones should be collected prior to cone scale opening and seed shedding; timing of seed shedding/collection is different for different species (e.g. for Abies spp. the seed of a mast year is dispersed in the same year after flowering and in contrast for Pinus spp. the seed of a mast year is dispersed two years after flowering). Therefore, seed/cones for those species have to be collected by climbing onto the trees. For example, for seed testing of Abies spp. the seed mixture can be used from cones collected for DNA analysis (the same applies to the species with heavy seeds):

- At least 10 cones must be collected from each of the 20 selected seed trees (approximately the same number of cones has to be collected from all the trees (10 cones per tree/200 cones per 20 seed trees) (Figure 5.6);

- Cones must be collected by climbing onto the tree and collecting seed-filled cones (with closed cone scales) directly from the branches;

- Cones from different mother trees must be stored in separate cotton bags or boxes until their scales open (procedures can be used to open the cone scales, e.g., by first soaking them and then putting them in chambers with a controlled temperature below $50^{\circ} \mathrm{C}$ for a few days);

- Collected cones must be kept 2-3 months in a dry place with a good ventilation system until the cone scales open and seeds become available;

- Seed from all 10 cones per single tree should be mixed;

- Approximately 200 seeds ( $20 \mathrm{~g}$ of seeds, depending upon the species) have to be obtained for the genetic analysis (20 seeds per tree will be analysed, however, more seeds are needed for DNA analysis, as some can be empty) and the rest of seed will be used for seed testing;

- All remaining seed from 20 seed trees has to be mixed and $120 \mathrm{~g}$ ( 3000 seeds) of clean seed mixture must be taken for seed testing of Abies spp. (Table 5.2 and Table 5.3).

Seed of Fraxinus spp. must be collected before seeds start to fall down (the time for seed collection can differ from country to country and depends on the biology of the species and environmental/climatic conditions of certain areas). Therefore, seed must be collected by climbing onto the trees.

The seed lifetime of Populus spp. is very limited (2-4 days), therefore, it has to be collected as soon as possible after the appearance of the white cotton-like fibres (usually in May, but this can differ from country to country and depends on biology of the species and environmental/climatic conditions of certain area). Therefore, seed must be collected by climbing onto the trees. 
(a)
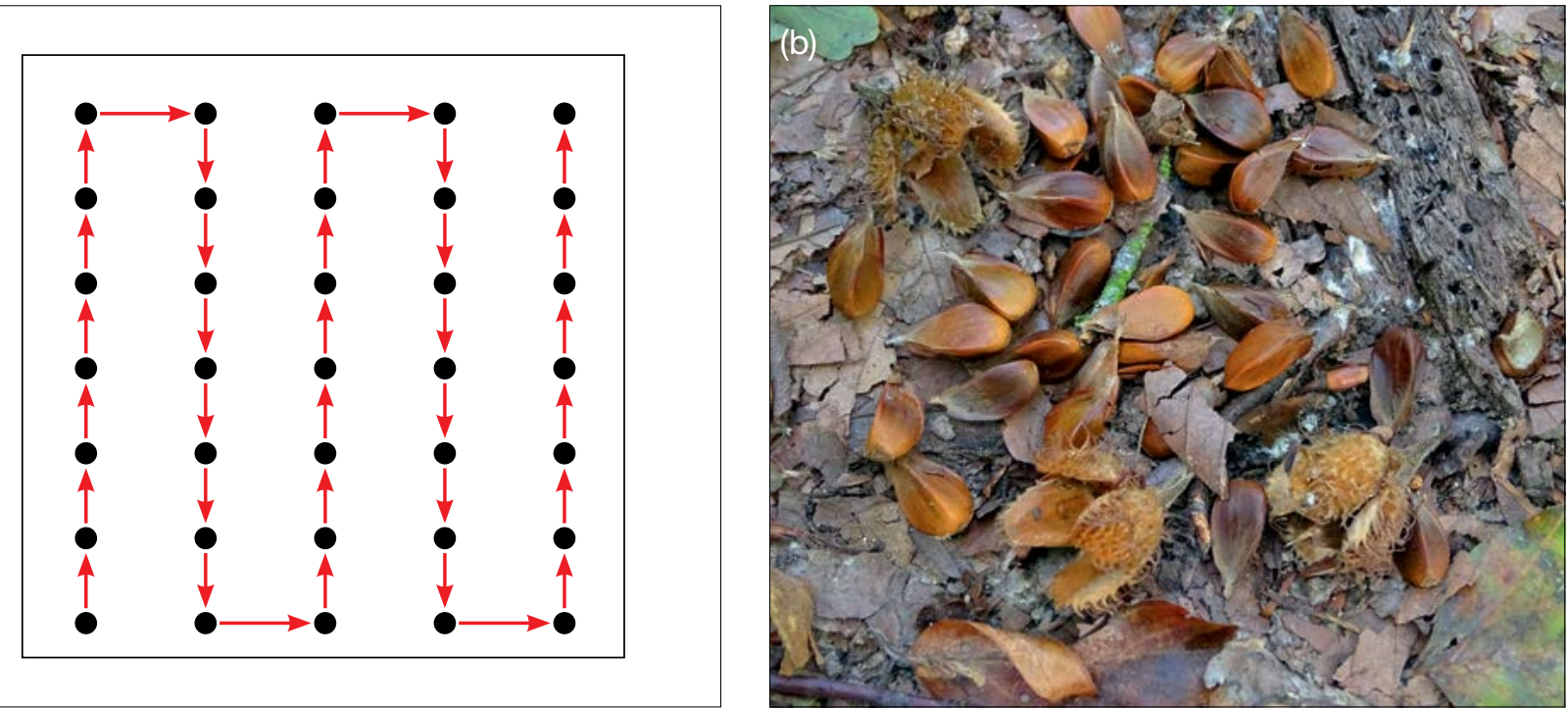

Figure 5.5. Systematic seed sampling from ground (a); Fagus sylvatica seed on the ground (b).

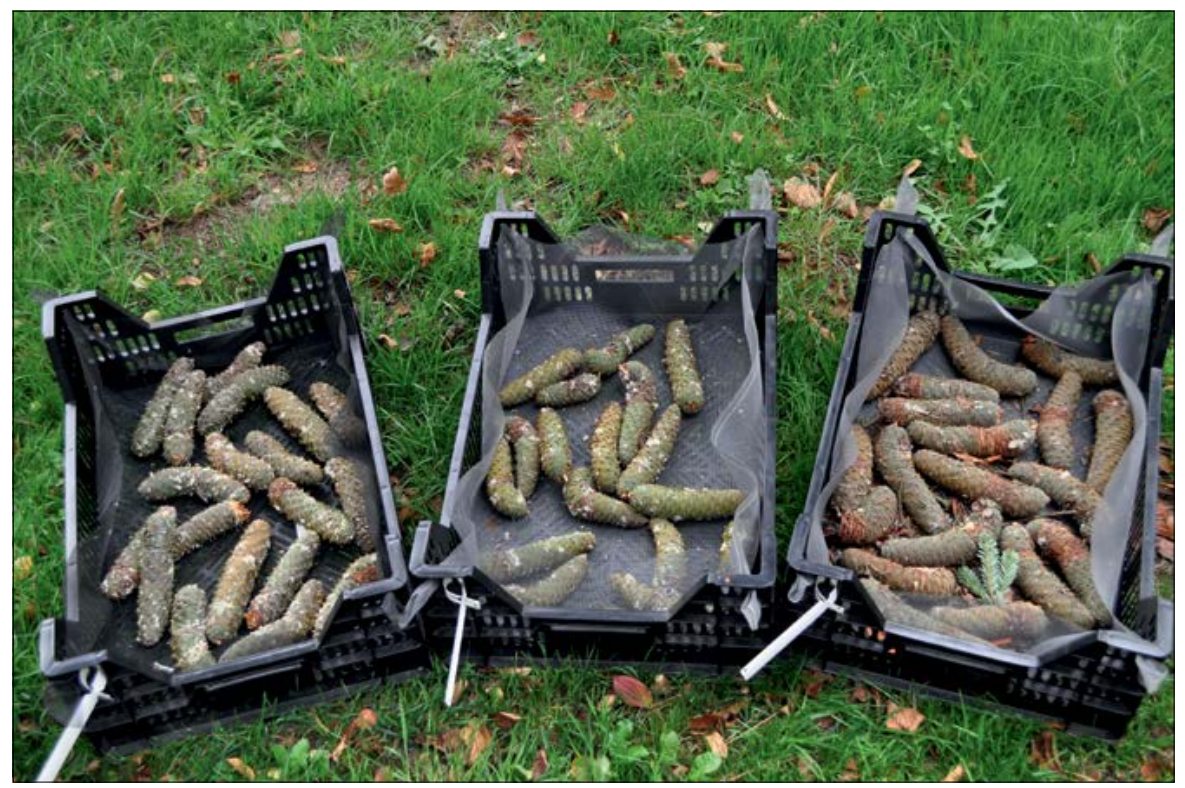

Figure 5.6: Abies alba cones collected from individual trees.

Table 5.2. Seed testing sample sizes. Each sample size is derived from a nominal 1,000-seed weight for each species which, on the available evidence, is expected to be adequate for the majority of samples tested.

\begin{tabular}{lccc} 
& & \multicolumn{2}{c}{ Minimum sample weight } \\
\cline { 3 - 4 } Species & Maximum weight of lot [g] & Submitted sample [g] & $\begin{array}{c}\text { Working sample for purity } \\
\text { analysis [g] }\end{array}$ \\
\hline Abies alba Mill. & 1,000 & 240 & 120 \\
\hline Fagus sylvatica L. & 5,000 & 1,000 & 600 \\
\hline Fraxinus spp. & 1,000 & 400 & 200 \\
\hline Pinus nigra J. F. Arnold & 1,000 & 100 & 50 \\
\hline Populus spp & 50 & 5 & 2 \\
\hline Prunus avium (L.) L. & 1,000 & 900 & 450 \\
\hline Quercus spp. & 5,000 & 500 seeds & 500 seeds \\
\hline
\end{tabular}


Table 5.3. Overview of material needed for genetic analysis and seed testing within FGM.

\begin{tabular}{|c|c|c|}
\hline \multicolumn{3}{|c|}{ Genetic analysis (DNA extraction) } \\
\hline & Regular species & Species with hybridisation / clones \\
\hline \multirow{4}{*}{ Adult trees } & Monoecious species: & Monoecious species: \\
\hline & 50 reproducing individuals & $\begin{array}{c}50 \text { reproducing individuals (genotyped as part } \\
\text { of the tree selection process; if hybrids/clones } \\
\text { are detected, sample and genotype another 50; } \\
50 \text { non-hybrid individuals with unique genotypes } \\
\text { are then randomly selected for FGM and further } \\
\text { analyses) }\end{array}$ \\
\hline & $\begin{array}{l}\text { Dioecious or functionally dioecious species } \\
\text { (such as Common ash): }\end{array}$ & $\begin{array}{l}\text { Dioecious or functionally dioecious species } \\
\text { (such as Common ash): }\end{array}$ \\
\hline & 25 female and 25 male reproducing trees & 25 female and 25 male reproducing trees \\
\hline $\begin{array}{l}\text { Natural } \\
\text { regeneration }\end{array}$ & 50 saplings per assessment & $\begin{array}{c}100 \text { saplings per assessment (all } 100 \text { are } \\
\text { genotyped, } 50 \text { non-hybrid individuals with unique } \\
\text { genotypes are then randomly selected for further } \\
\text { analyses; if necessary, sample and genotype } \\
\text { another } 50 \text { ) }\end{array}$ \\
\hline Seed & $\begin{array}{c}\text { Single tree harvests from } 20 \text { selected seed } \\
\text { trees; at least } 200 \text { - } 300 \text { seeds per tree must be } \\
\text { collected from several different branches and } \\
\text { mixed; } 20 \text { seeds per tree will be analysed, } 400 \\
\text { seed in total }\end{array}$ & $\begin{array}{l}\text { Single tree harvests from } 20 \text { selected seed trees; } \\
\text { at least } 200 \text { - } 300 \text { seeds per tree must be collected } \\
\text { from several different branches and mixed; } 30 \\
\text { seeds per tree will be analysed, } 600 \text { seed in total }\end{array}$ \\
\hline \multicolumn{3}{|l|}{ Seed testing } \\
\hline Seed & \multicolumn{2}{|c|}{$\begin{array}{l}\text { Mixed seed collected from the ground or seed mixture from cones/seed collected from } 20 \text { single trees } \\
\text { (Table 5.2) }\end{array}$} \\
\hline
\end{tabular}

\section{References}

Alizoti PG, Kilimis K, Gallios P (2010) Temporal and spatial variation of flowering among Pinus nigra Arn. clones under changing climatic conditions. For Ecol Manag 259:786-797. https://doi.org/10.1016/j.foreco.2009.06.029

Beuker E, Raspe S, Bastrup-Birk A, Preuhsler T (2010) Phenological Observations. Manual Part VI. In: Manual on methods and criteria for harmonized sampling, assessment, monitoring and analysis of the effects of air pollution on forests. UNECE, ICP Forests, Hamburg

Ducci F, De Cuyper B, Pâques LE, Proietti R, Wolf H (2012) Reference protocols for assessment of trait and reference genotypes to be used as standards in international research projects. CRA SEL, Arezzo, Italy

Mund M, Kutsch WL, Wirth C, Kahl T, Knohl A, Skomarkova MV, Schulze ED (2010) The influence of climate and fructification on the inter-annual variability of stem growth and net primary productivity in an old-growth, mixed beech forest. Tree Physiol 30:689-704. https://doi.org/10.1093/treephys/tpq027

Seifert T, Müller-Starck G (2009) Impacts of fructification on biomass production and correlated genetic effects in Norway spruce (Picea abies [L.] Karst.). Eur J For Res 128:155. https://doi.org/10.1007/s10342-008-0219-5

The International Seed Testing Association (ISTA) (2020) International Rules for Seed Testing. Bassersdorf, Switzerland. https://doi.org/10.15258/istarules.2020.F 



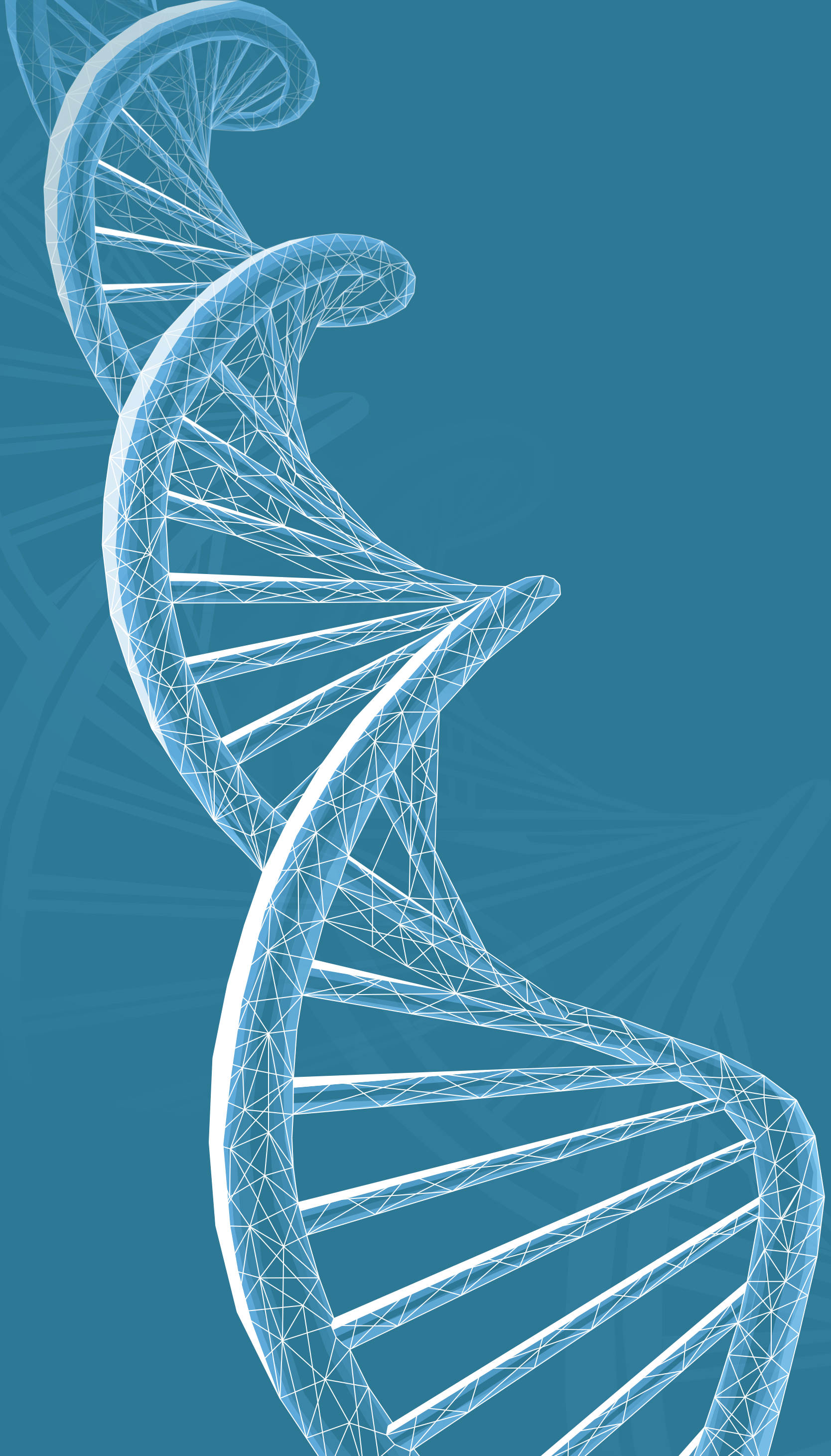




\section{\#) TIFE KIEN ATIM $\Leftrightarrow$ \\ LIFE13 ENV/S/ $/ 000148$}

\section{Manual for forest genetic monitoring}
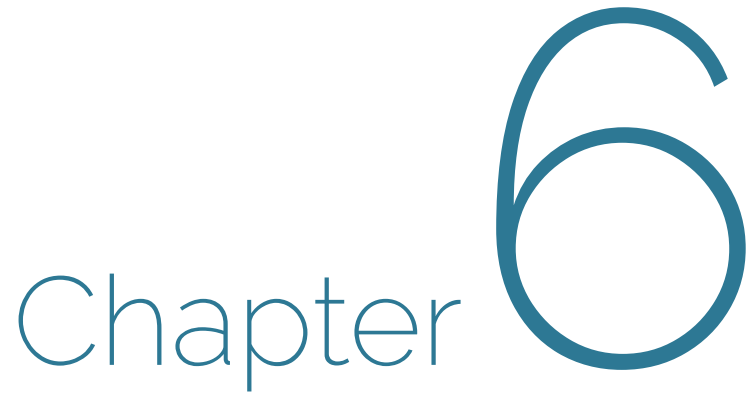

\section{Laboratory and data analyses}

Filippos A. ARAVANOPOULOS ${ }^{1}$, Barbara FUSSI², Marjana WESTERGREN ${ }^{3}$, Marko BAJC ${ }^{3}$, Darius KAVALIAUSKAS², Nikolaos TOURVAS ${ }^{1}$, Rok DAMJANIĆ3 Natalija DOVČํ, Nataša ŠIBANC ${ }^{3}$, Paraskevi ALIZOTI', Ermioni MALLIAROU', Evangelia AVRAMIDOU'1,4, Evangelos BARBAS', Gregor BOŽIČ3, Philip BRAILEY-JONES ${ }^{3}$, Anna-Maria FARSAKOGLOU ${ }^{1,5}$, Domen FINŽGAR ${ }^{3,6}$, Ioannis GANOPOULOS ${ }^{1,7}$, Monika KONNERT ${ }^{2}$, Hojka KRAIGHER1 ${ }^{3}$

Citation: Aaravanopoulos et al. (2020) Laboratory and data analyses. In: Bajc et al. (eds) Manual for Forest Genetic Monitoring. Slovenian Forestry Institute: Silva Slovenica Publishing Centre, Ljubljana, pp 67-130. http://dx.doi.org/10.20315/SFS.167

Affiliations:

1. Aristotle University of Thessaloniki (AUTh), Greece

2. Bavarian Office for Forest Genetics (AWG), Germany

3. Slovenian Forestry Institute (GIS), Slovenia

4. Institute of Mediterranean Forest Ecosystems, DEMETER, Greece

5. European Forest Genetic Resources Programme (EUFORGEN), European Forest Institute (EFI), Spain

6. Institute of Evolutionary Biology, University of Edinburgh, UK

7. Institute of Plant Breeding and Genetic Resources, HAO ELGO DEMETER, Greece 


\subsection{Introduction}

Laboratory analyses constitute a major part of forest genetic monitoring (FGM), and all three indicators (selection, genetic variation, and gene flow/mating systems), examined as part of this project are based on data and results produced by such analyses. Laboratory analyses can be divided into three major parts: (1) sample manipulation and storage, (2) seed testing and (3) DNA analysis. The first is of paramount importance, as plant tissue and DNA storage are essential for eventually revisiting old samples in order to use an improved protocol or a new type of analysis. In a temporal evaluation exercise, as genetic monitoring is, this ability is clearly very important for proper sample comparison. Seed testing is essential as a parameter related to fitness, needed for the advanced level of FGM application. DNA analysis constitutes the sole basis for the evaluation of two indicators (genetic variation and gene flow/mating systems), while it also contributes to indicator "selection" through the analysis of $\mathrm{F}_{\text {ST }}$ outlier tests. This chapter includes information on databases, data integrity checks and data filtering, and concludes by providing important insights into the interpretation of genetic monitoring values which are linked to the required actions in the genetic monitoring plot and potentially beyond.

\subsection{Sample manipulation and storage}

\subsubsection{Sample manipulation}

The same general rules apply to handling and manipulation of all sample types, and following the ISO/IEC 17025:2017 laboratory standard is recommended.

a. Maintain traceability of samples and analyses. Make sure to label all samples correctly and consistently across all phases of analysis, starting with labelling in the field. Keeping good records of your samples and analyses is of utmost importance.

b. Prevent cross-contamination of samples. All surfaces and tools used in the manipulation of samples must be decontaminated to prevent transfer of DNA between different samples. There are a number of commercial products (liquids, foams) available that destroy DNA on surfaces, but $5 \%$ sodium hypochlorite $(\mathrm{NaClO})$ can be used to the same effect. Tools used for manipulation of samples (tweezers, scissors, knives, hole punches, etc.) must be decontaminated between sample manipulations. An easy and fast way of achieving this is by burning. The working ends of tools can be directly burned in the flame of a Bunsen burner or a hand propane/ butane torch, or immersed in ethanol and ignited. Allow 15-20 seconds for the tools to cool down before using them on the next sample.

c. Vials for storage of plant tissue samples and DNA must be sterile, DNA/RNA-free, nuclease- and pyrophosphatefree. For storage of samples at ultra-low temperatures (below $-70^{\circ} \mathrm{C}$ ), suitable cryovials, containers and labels/ labelling markers must be used that maintain their integrity and function at such low temperatures. Many suitable products exist on the market, so consult your local suppliers.

d. All consumables (such as pipette tips for aliquoting extracted DNA) and media (such as DNA storage buffers) must be sterile, DNA/RNA-free, nuclease- and pyrophosphate-free.

\subsubsection{Sample storage}

The strategy for storing fresh plant tissue for DNA analysis will depend on the type of tissue and time in which samples can be processed in the laboratory. As a general rule, samples should be processed as fast as possible and stored in a way that minimises degradation of DNA. For storage of seeds for testing of germination see subchapter 6.2.2.4. 


\subsubsection{Storage of plant tissue samples for DNA extraction in the field}

\subsection{A "wet" approach}

Many plant tissues can be kept stable in the field by placing them in a plastic zip-lock bag and storing them away from direct sunlight and fluctuating temperatures. Styrofoam boxes, such as those used for shipping temperature-sensitive materials, are a convenient solution for providing temperature buffering and protection from direct sunlight for the samples. A small quantity of wet ice or a cooling pack should be put inside the box, but make sure that samples do not come in direct contact with ice or cooling packs. Samples collected and stored in such a way should be placed in a continuous source of controlled refrigeration within the same day (Prendini et al. 2002).

\subsection{A "dry" approach}

The rapid desiccation of plant tissue samples by silica gel is another popular approach to preventing excessive degradation of DNA until samples are delivered to the laboratory. Samples should be placed in labelled paper bags and then placed into plastic zip-lock bags with silica gel. Use a minimum of 10-fold the amount of indicating silica gel compared to plant tissue (10:1 silica gel to sample ratio by weight). Bags with samples and silica gel should be kept inside tightly closed plastic boxes or sealable plastic bags and away from direct sunlight. Desiccation of samples in the field is only effective for samples with a high surface to volume ratio, such as leaves or needles. Larger twigs, fruit or similar thicker sample types may take too long to dry, potentially resulting in degradation of DNA, and therefore it is recommended that such samples are kept at lower temperatures (see 6.2.2.1.1) and placed in a continuous source of controlled refrigeration within the same day. (Prendini et al. 2002, Chase and Hills 1991)

\subsubsection{Storage of plant tissue samples for DNA extraction in the laboratory}

\subsection{Short-term storage}

Samples of most fresh plant tissues (twigs with leaves/needles/buds, bark with cambium), can be safely stored at $+2^{\circ} \mathrm{C}$ to $+4^{\circ} \mathrm{C}$ for $2-3$ days without significant effects on the quantity or quality of the DNA (Sytsma and Schaal 1985, Prendini et al. 2002). Non-recalcitrant seeds are generally far less susceptible to degradation of DNA and can be safely stored at $+2^{\circ} \mathrm{C}$ to $+4^{\circ} \mathrm{C}$ for weeks or even months, depending on the species, but it is recommended that the moisture level is controlled in order to prevent fungal and/or bacterial growth.

\subsection{Medium-term storage}

Fresh plant tissue samples can be stored in a freezer $\left(-20 /-80^{\circ} \mathrm{C}\right)$ for up to several years. Although biological degradation (enzymatic) of DNA is largely inhibited in a frozen state, chemical degradation of DNA can still occur. If sufficient resources are available, it is recommended that long-term storage strategies are used whenever possible (Prendini et al. 2002, Campbell et al. 2018).

\subsection{Long-term storage}

For long-term storage, the DNA is best preserved through cryopreservation, that is by keeping the samples in a vitreous state (below the glass transition point for water-based materials) In a vitreous state, both biological and chemical degradation of DNA is inhibited to the maximum extent possible (Campbell et al. 2018, Center for Plant Conservation 2020). For long-term cryopreservation, samples are usually stored in liquid nitrogen vapour-phase cryopreservation systems or specialised mechanical ultra-low temperature freezers, both capable of maintaining the temperature below the glass transition point for biological samples (reported as between -132 below and $-136^{\circ} \mathrm{C}$ ) (Prendini et al. 2002, Campbell et al. 2018, Center for Plant Conservation 2020). As cryopreservation systems require special infrastructure and/or are associated with considerable initial investment 
and running costs, they are often not feasible for many research institutions (Campbell et al. 2018, Center for Plant Conservation 2020).

Many plant tissues can be kept stable in long-term storage at less stringent conditions $\left(-80^{\circ} \mathrm{C}\right.$ to $\left.-20^{\circ} \mathrm{C}\right)$ for the extraction of high quality DNA. Neubig et al. (2014) showed that plant material frozen for 24 years maintained high quality of DNA regardless of whether tissue was stored at $-20^{\circ} \mathrm{C}$ or $-80^{\circ} \mathrm{C}$. Seed in particular retains high quality DNA even without cryopreservation, and DNA of high quality can be extracted even from old non-viable seed if kept at stable conditions at or below $-20^{\circ} \mathrm{C}$ (Walters et al. 2006). Although cryopreservation is undoubtedly the most reliable and safest approach for long-term storage of plant tissue with little risk of degradation of DNA, good preservation of DNA in plant tissues can be achieved even at higher sub-zero temperatures (Walters et al. 2006, Neubig et al. 2014). In order to minimise the risk of degradation of DNA, the following recommendations for long-term storage of plant tissue samples should be followed:

a. Stable storage conditions must be assured, and temperature fluctuations avoided. Generally, the lower the storage temperature, the better. Long-term storage below the glass transition point, that is cryopreservation, is the most recommended, followed by storage at $-80^{\circ} \mathrm{C}$ and finally $-20^{\circ} \mathrm{C}$. Storage at temperatures above $-20^{\circ} \mathrm{C}$ is to be avoided.

b. Freezing and thawing cycles cause damage to the tissue and DNA (see Boxes 6.1 and 6.2), therefore it is advisable to store plant tissue samples in several replicates, so that only one replicate is removed from storage and thawed for DNA extraction instead of thawing the entire lot. If possible, divide the replicates between at least two storage systems, minimising the risk of losing all replicates in the event of a catastrophic equipment failure.

c. Since most processes of degradation of DNA depend on the presence of water, desiccation of samples (by freeze-drying or by silica gel) before freezing can provide an additional level of protection against the degradation of the DNA, particularly in the event of thawing due to equipment malfunctioning. Non-recalcitrant seed in particular should be dry, and it is recommended to air-dry the seed for up to a week before freezing (Walters et al. 2006).

d. If sufficient resources are available it is advisable that DNA extracts are stored in addition to plant tissue specimens, as extracted DNA samples are more stable than tissue (Prendini et al. 2002). For more information on DNA sample storage see Chapter 6.2.2.3.

\section{Box 6.1: The freeze-thaw cycles, Part I}

With any storage approaches involving freezing of plant tissue samples, repeated freeze-thaw cycles should be avoided! Besides possible direct contribution to DNA degradation (see Box 6.2: The freeze-thaw cycles, Part II in 6.2.4.1), freeze-thaw cycles cause rupture of cell and organelle membranes, therefore exposing DNA to DNA-degrading enzymes and increasing the risk of enzymatic digestion of DNA when samples are thawed. (Campbell et al. 2018)

\subsubsection{Storage of extracted DNA}

Proper storage conditions ensure that the quantity and integrity of extracted DNA is preserved at the levels suitable for downstream analysis. Although DNA is considered a fairly stable biological macromolecule, it is nevertheless susceptible to degradation by various mechanisms. Assuming all nuclease activity has been removed during the DNA isolation procedure from plant tissues, chemical degradation represents the major threat to DNA preservation (Adams et al. 1999, Briggs 1999, Bada et al. 1999, Soltis and Soltis 1993, Thomas and Paabo 1994, Yagi et al. 1996). Additionally, DNA is sensitive to high temperatures and ionising radiation, including parts of the ultraviolet spectrum, so every precaution should be taken to avoid exposing DNA to such conditions. (Prendini et al. 2002, Campbell et al. 2018) 
In aqueous solutions, which are the preferred medium for storing DNA, hydrolytic cleavage, deamination, depurination, depyrimidination and oxidative damage are the major causes of DNA degradation (Briggs 1999, Bada et al. 1999, Thomas and Paabo 1994). Hydrolysis, deamination, depurination and depyrimidination can be inhibited by storing DNA in buffered alkaline solutions ( $\mathrm{pH} 8.0-9.0)$, as these degradation processes are catalysed in acidic conditions. Oxidative damage is enhanced in the presence of metal cations (Fe3+, Cu2+, etc.) through a Fenton reaction, with concentrations above $5 \mathrm{ppb}$ already having a detrimental effect. Therefore, addition of chelating agents such as EDTA to DNA storage solution is recommended (Prendini et al. 2002).

\subsection{DNA storage strategies}

Regardless of the storage strategy, it is always recommended that several aliquots are made of the same DNA sample, so that one can be used immediately for downstream applications, while others are placed in long-term storage. The period for which DNA can be preserved depends both on storage conditions, as well as the quantity, integrity and purity of the extracted DNA (Table 6.1).

Similar rules apply to storage of extracted DNA samples as for storage of fresh plant tissue samples - the safest strategy is storing DNA in a vitreous state, i.e. below the glass transition temperature for water-biological polymer solutions, which is particularly important when considering very long-term storage (Campbell et al. 2018).

Although certain advances have been made in the storage of desiccated DNA samples at room temperature, both in the form of commercial systems as well as "in-house" developed protocols, it is premature to advocate transition to dry DNA storage at room temperature, particularly for samples with higher inhibitor loads (such as plant tissues) and longer time periods (Ivanova and Kuzmina 2013).

Table 6.1: Commonly used strategies for storing DNA samples. RT - room temperature.

\begin{tabular}{|c|c|c|c|}
\hline Storage strategy & Conditions & Medium & Period $^{1}$ \\
\hline Short-term & $+2^{\circ} \mathrm{C}$ to $+8^{\circ} \mathrm{C}$ & 10mM Tris- $\mathrm{HCl}, 0.5 \mathrm{mM}$ EDTA, pH 8.5 - 9.0 & weeks to months \\
\hline Medium-term & $-20 /-80^{\circ} \mathrm{C}$ & 10mM Tris- $\mathrm{HCl}, 0.5 \mathrm{mM}$ EDTA, pH 8.5 - 9.0 & several years \\
\hline Long-term & $-80^{\circ} \mathrm{C}$, precipitate & Ethanol & years to decades \\
\hline Very long-term & $-196^{\circ} \mathrm{C}$ (liquid nitrogen) & 10mM Tris- $\mathrm{HCl}, 0.5 \mathrm{mM}$ EDTA, pH 8.5 - 9.0 & decades \\
\hline Very long-term & -136 to $-150^{\circ} \mathrm{C}$ (ultra-freezer) & 10mM Tris- $\mathrm{HCl}, 0.5 \mathrm{mM}$ EDTA, $\mathrm{pH} 8.5$ - 9.0 & decades \\
\hline Very long-term & RT, desiccated (waterless) & Various $^{2}$ & decades $^{3}$ \\
\hline
\end{tabular}

1 The listed periods should be considered as estimates based on the values reported in the literature and experience of the laboratories involved in the LIFEGENMON project.

2 Most approaches for storing DNA samples in a desiccated form involve the use of a protective matrix, such as trehalose or polyvinyl alcohol (PVA). Protecting the desiccated DNA samples from rehydration and temperature fluctuations must be assured in order to prevent degradation of DNA.

${ }^{3}$ Removal of water in theory assures similar levels of protection against degradation of DNA as cryopreservation, but depends heavily on complete prevention of rehydration of desiccated DNA samples, which is often difficult to achieve in the long term.

Internal ongoing tests conducted by Qiagen $\mathrm{GmbH}$, an established manufacturer of DNA/RNA isolation kits, suggest that high molecular weight DNA can safely be stored in Tris-EDTA based solution at pH 8.5 for at least 16 years at $-20^{\circ} \mathrm{C}$ and at least 8 years at $+2^{\circ} \mathrm{C}$ to $+8^{\circ} \mathrm{C}$, provided the DNA is of high purity (absence of nuclease activity) (Hartmann et al. 2016). It should be noted that DNA used in the Qiagen trials was isolated from blood samples and that plant material is generally much more problematic in terms of removal of impurities during the DNA extraction process, urging caution when deciding upon the most suitable storage strategy for plant DNA samples. 


\section{Box 6.2: Freeze-thaw cycles, Part II}

Although considered common knowledge in molecular genetics laboratories, the actual effects of repeated freeze-thaw cycles on DNA quality remain a matter of some controversy. A study by Schuster and Appleby (1983) reported no evidence of repeated freeze-thaw cycles causing degradation of DNA, questioning the use of radio-labelled DNA in previous studies as the radioactive label itself could be the cause of degradation of DNA rather than the number of freeze-thaw cycles. In line with the principle 'better safe than sorry', it is still recommended that DNA samples are stored in aliquots in order to minimise degradation, not just due to repeated freeze-thaw cycles, but also chemical degradation, and also reduce the possibility of contamination of the whole DNA sample. (Prendini et al. 2002, Campbell et al. 2018)

\subsubsection{Storage of seed for seed testing}

Seed for seed testing within FGM should be collected at maturity, during or just before natural dispersal (Hay and Smith 2003), if seed is collected too early (undeveloped seed) it might lose viability and can fail to germinate during seed testing (Pedrini et al. 2020, De Vitis et al. 2020). An exception is the collection of 'green seed' of Fraxinus spp. before dormancy is established, if this is to be used for immediate germination testing. A sample for seed testing, in the frame of FGM, is obtained from the genetic monitoring plot by collecting small portions of seed at random from different positions across the plot to get a representative sample or from different parts of the crown (if seed/cones are collected directly from trees by climbing) and mixing them to produce a bulk sample. Alternatively, portions of seed collected from 20 trees for DNA analyses can be mixed and used for seed testing. Each stage of seed testing must be performed using appropriate methods and equipment according to ISTA rules (2020, available at https://www.seedtest.org/en/ista-rules-2019-_content---1--3410.html). Since the results of seed testing are vital for FGM, e.g. for estimation of actual inbreeding rate, it must be performed in the same year/season as the seed is collected. Longer storage of seed can drastically decrease the germinability and affect the results of Germination Test (GT) and Topographical Tetrazolium test (TT) (Biochemical test for Viability), particularly in recalcitrant species. Therefore, seed testing has to be performed as soon as seed is delivered to the seed testing laboratory.

\subsection{Seed testing}

The seed testing (seed weight, seed germination (GT) and biochemical test for viability (TT) tests) is to be done according to the protocols of the International Rules for Seed Testing (ISTA, 2020, available at https://www. seedtest.org/en/ista-rules-2019-_content---1--3410.html). Each sample size is derived from a nominal 1,000-seed weight for each species which, on the available evidence, is expected to be adequate for the majority of samples tested, except for Quercus and Prunus spp., where the submitted sample size should be 500 seeds.

Seed testing methods for the seven target tree species of the LIFEGENMON project are presented in Table 6.2. For example, for Abies alba only a GT test and for Fagus sylvatica only a TT test were performed in the LIFEGENMON project. It is possible to do both test types (TT and GT) for both species, but a TT test is preferred as it is considerably faster. 
Table 6.2: Type of test recommended by ISTA (2020) for the species selected within the LIFEGENMON project

\begin{tabular}{ccc} 
& Type of test recommended by ISTA: \\
GT - Germination Test & \\
Species & $T$ - Topographical Tetrazolium Test & Remarks \\
\hline
\end{tabular}

Abies alba Mill. GT Prechill 21 days and up to 28 days for germination

\begin{tabular}{lcc}
\hline Fagus sylvatica L. & TT & $\begin{array}{c}\text { If GT applied: } 24 \text { weeks } \\
\text { for germination/breaking dormancy }\end{array}$ \\
\hline $\begin{array}{l}\text { Fraxinus spp. } \\
\text { Pinus nigra J. F. Arnold }\end{array}$ & GT & $\begin{array}{r}\text { If GT applied: } 9 \text { months } \\
\text { of stratification and up to } 56 \text { days for germination * }\end{array}$ \\
\hline Populus spp. & GT & $\begin{array}{l}\text { Up to } 21 \text { day for germination } \\
\text { Up to } 10 \text { days for germination }\end{array}$ \\
\hline Prunus avium (L.) L. & TT & $\begin{array}{c}\text { If GT applied: prechill 3-4 months } \\
\text { and up to } 28 \text { days for germination }\end{array}$ \\
\hline Quercus spp. & GT & $\begin{array}{l}\text { Up to } 28 \text { days for germination } \\
\text { (pre-preparation is advisable; consult specific protocols) }\end{array}$ \\
\hline
\end{tabular}

if Fraxinus excelsior and F. angustifolia seed is collected green before multiple dormancy develops, it will germinate readily

\subsubsection{Abies alba seed extraction for seed testing}

After the cones are harvested:

- Cones from single trees must be kept in labelled separate plastic boxes;

- The bottom of the box must be covered by a net to save the seeds from falling down through the holes in the bottom (see Figure 6.1a);
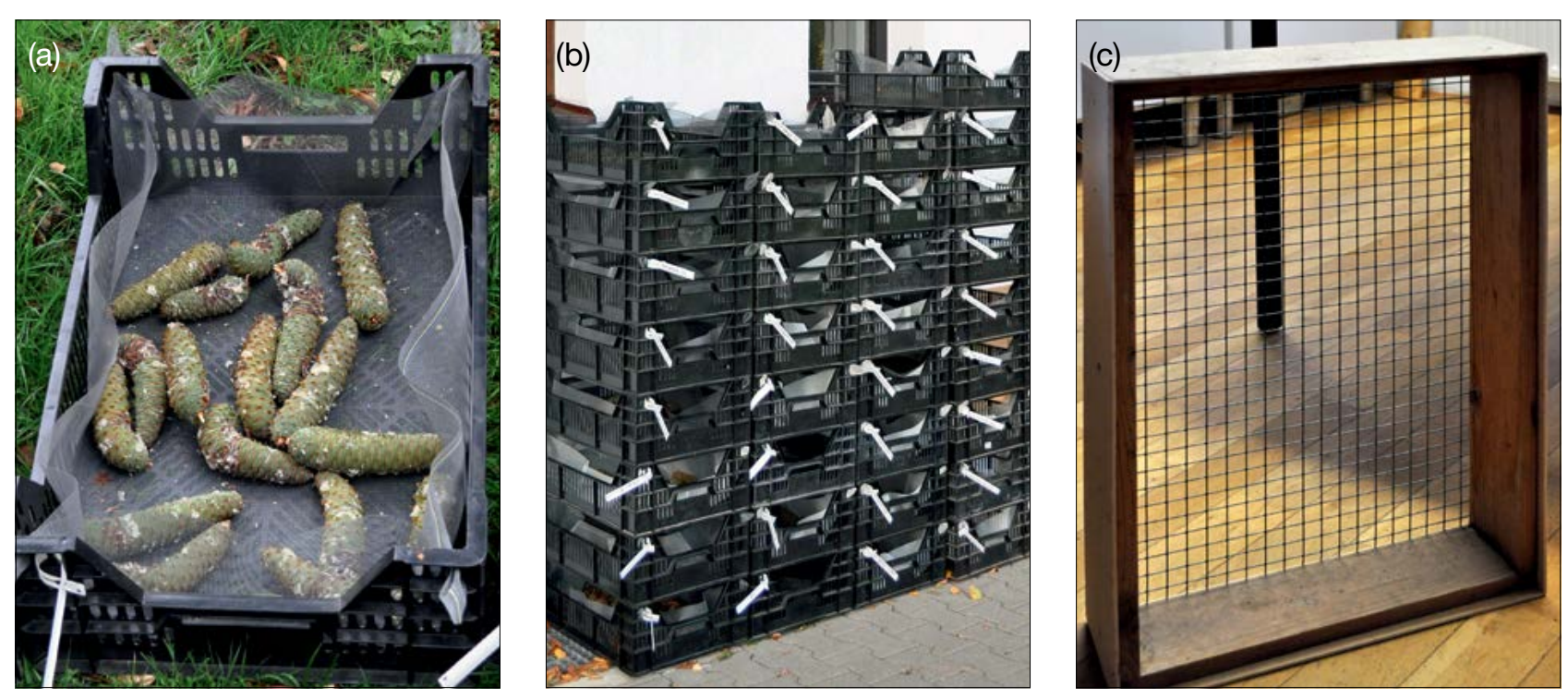

Figure 6.1: Boxes used for keeping of Abies alba cones until their scales are shed, and the seed is released (a and b); a sieve used for separation of seed from other parts of the Abies alba cones after they fall apart (c) (Photos: Darius Kavaliauskas).

- All boxes with the cones must be kept in a good ventilated place for a few months, until cone scales start to tumble off (Figure 6.1b).

- After Abies alba cones shed their scales, the seeds of each tree should be cleaned separately (Figure 6.1c sieve for cleaning Abies spp. seed from cone parts, wings etc.). 


\subsubsection{Fagus sylvatica and Abies alba/A. borisii-regis seed preparation for seed testing}

- After cleaning the seeds of debris, $120 \mathrm{~g}$ of seed mixture prepared from equal quantities of seed collected from all sampled trees for Abies spp. and $600 \mathrm{~g}$ for Fagus sy/vatica is used for further analysis; be aware that empty seeds should not be removed during the cleaning. A representative sample of the submitted sample should be taken as the working sample.

- All analyses are to be done according to ISTA protocols (2020). Each sample size is derived from a nominal 1,000-seed weight for each species which, based on the available evidence, is expected to be adequate for the majority of samples tested.

Note: For FGM only pure seed is used, so no purity determination is necessary since all seed collection is done with the purpose to analyse the weight of 1,000 seeds, and do the germination (GT)/viability (TT) testing only, unless there are also any pests and diseases to be identified.

Table 6.3: Submitted and working sample sizes for seeds of selected tree species, modified after ISTA (2020).

\begin{tabular}{lcc} 
Species & Submitted sample & Working sample \\
\hline Abies alba & $240 \mathrm{~g}$ & $120 \mathrm{~g}$ \\
\hline Fagus sylvatica & $1000 \mathrm{~g}$ & $600 \mathrm{~g}$ \\
\hline Fraxinus spp. & $400 \mathrm{~g}$ & $200 \mathrm{~g}$ \\
\hline Pinus nigra & $100 \mathrm{~g}$ & $50 \mathrm{~g}$ \\
\hline Populus spp. & $5 \mathrm{~g}$ & $2 \mathrm{~g}$ \\
\hline Prunus avium & $500 \mathrm{seeds}$ & 500 seeds \\
\hline Quercus spp. & 500 seeds & 500 seeds \\
\hline
\end{tabular}

\section{Weight determination}

Weight determination must follow ISTA protocols (2020).

The working sample should be the entire pure seed fraction. A change of the moisture content of the working sample should be avoided as far as possible by storing the working samples before testing only for short periods and in moisture-proof containers.

Counting replicates: From the working sample count out at random, by hand or with a germination counter, 8 replicates, each of 100 seeds. Weigh each replicate in grams to three decimal places.

\section{Calculation and expression of results}

- If counting is carried out by a machine, calculate the weight of 1,000 seeds from the weight of the whole working sample.

- If counting is performed by replicates, then from eight or more weights of 100-seed replicates calculate the average weight of 1,000 seeds.

- The result shall be expressed to the number of decimal places used in the determination according to formula:

$$
\text { Weight of } 1,000 \text { seeds }(g)=\frac{(\text { Sum of } 8 \text { replicates }(g) \times 10)}{8}
$$

\section{Germination test}

Germination tests (GT) must follow the ISTA (2020) protocols, considering the simplification as presented below. 


\section{Percentage germination}

The germination percentage indicates the proportion of seeds which have produced seedlings classified as normal under the conditions and within the period specified in Table 6.4.

\section{The essential seedling structures}

The following structures are essential to a seedling's continued development into a satisfactory plant: root radicle; shoot axis; cotyledons; terminal buds.

\section{Normal seedlings}

Normal seedlings show the potential for continued development into satisfactory plants when grown in good quality soil and under favourable conditions of moisture, temperature and light. To be classified as normal a seedling must conform to one of the following categories:

1. Intact seedlings: seedlings with all their essential structures well developed, complete in proportion and healthy.

2. Seedlings with slight defects: seedlings showing certain slight defects of their essential structures provided they show an otherwise satisfactory and balanced development comparable to that of intact seedlings of the same test.

3. Seedlings with secondary infection: seedlings which would have conformed with the Categories 1 or 2 above, but which have been affected by fungi or bacteria from sources other than the parent seed.

\section{Abnormal seedlings}

Abnormal seedlings do not show the potential to develop into normal plants when grown in good quality soil and under favourable conditions of moisture, temperature and light.

The following seedlings are classified as abnormal:

1. Damaged seedlings: seedlings with any of the essential structures missing or so badly and irreparably damaged that balanced development cannot be expected.

2. Deformed and unbalanced seedlings: seedlings with weak development or physiological disturbances or in which essential structures are deformed or out of proportion.

3. Decayed seedlings: seedlings with any of their essential structures so diseased or decayed, as a result of primary infection, that normal development is prevented.

\section{Multigerm seed units}

Seed units which are capable of producing more than one seedling.

\section{Ungerminated seeds}

Seeds which have not germinated by the end of the test period when tested under the conditions given in Table 6.4, are classified as follows:

1. Hard seeds: seeds which remain hard at the end of the test period, because they have not absorbed water.

2. Fresh seeds: seeds, other than hard seeds, which have failed to germinate under the conditions of the germination test, but which remain clean and firm and have the potential to develop into a normal seedling.

3. Dead seeds: seeds which at the end of the test period are neither hard nor fresh nor have produced any part of a seedling.

4. Other categories: in some circumstances empty and ungerminated seeds may be further categorised according to classes described in ISTA rules 5.2.7.A.

Ungerminated seeds have to be examined and the percentage of empty seeds determined as this value is used for calculation of the percentage of filled seeds which is an advanced level verifier for the indicator Selection. Consequently, 
removal of empty seeds prior to the germination test (or the biochemical test of viability, if used instead) must not be performed, unless a separate determination of the percentage of empty seeds is made, but this will increase the workload and the number of seeds necessary for the tests. The percentage of empty seeds is calculated in the same way as the germination percentage (see "Calculation and expression of results" below and section 6.5.5.1.2).

\section{Materials}

Paper or sand are commonly used substrates according to Table 6.4. Soil or artificial compost are not recommended primary testing substrates. They are, however, permitted in special cases only.

\section{Working sample}

Four hundred seeds in replicates of 100 are taken at random from the pure seed and spaced uniformly and adequately apart on the moist substrate. Replicates may be divided into sub-replicates of 50 or 25 seeds depending on the size of seeds and the amount of space needed between them.

Multigerm seed units are not broken up for the germination test, but are tested as though they were single seeds.

\section{Duration of the test}

Duration of the test for individual species is given in Table 6.4. The period of treatment required to break dormancy before or during the ISTA test is not included in the test period.

\section{Evaluation}

For evaluation, the essential structures must be sufficiently developed to permit detection of any abnormality.

When samples tested on paper produce seedlings which cannot readily be evaluated, a retest should be made in sand or soil of good quality at the temperature indicated in Table 6.4 and under favourable conditions of moisture and light.

Table 6.4: Germination methods (For certain species indicated in column 6, duplicate test (with or without prechilling) is necessary.

\begin{tabular}{|c|c|c|c|c|c|}
\hline \multirow[b]{2}{*}{ Species } & \multicolumn{4}{|c|}{ Prescriptions for: } & \multirow{2}{*}{$\begin{array}{l}\text { Additional directions including } \\
\text { recommendations for breaking } \\
\text { dormancy }\end{array}$} \\
\hline & Substrate & $\begin{array}{l}\text { Temperature } \\
{ }^{\circ} \mathrm{C}\end{array}$ & $\begin{array}{l}\text { First count } \\
\text { (days) }\end{array}$ & $\begin{array}{l}\text { Final count } \\
\text { (days) }\end{array}$ & \\
\hline Abies alba & TP / BP & $\begin{array}{l}20^{\circ} \mathrm{C} / 16 \mathrm{~h}+ \\
30^{\circ} \mathrm{C} / 8 \mathrm{~h}\end{array}$ & 7 & 28 & Prechill 21 days at $3-5^{\circ} \mathrm{C}$ \\
\hline Fagus sylvatica & TP & $\begin{array}{l}3^{\circ} \mathrm{C} / 16 \mathrm{~h}+ \\
5^{\circ} \mathrm{C} / 8 \mathrm{~h}\end{array}$ & - & - & $\begin{array}{l}\text { 1. Duration of the test depends on } \\
\text { dormancy and in an extreme case } \\
\text { could require about } 24 \text { weeks. } \\
\text { 2. Use TT (tetrazolium test). }\end{array}$ \\
\hline Pinus nigra & TP & $\begin{array}{l}20^{\circ} \mathrm{C} / 16 \mathrm{~h}+ \\
30^{\circ} \mathrm{C} / 8 \mathrm{~h}\end{array}$ & 7 & $21 ;(14)$ & \\
\hline Fraxinus spp. & TP & $\begin{array}{l}20^{\circ} \mathrm{C} / 16 \mathrm{~h}+ \\
30^{\circ} \mathrm{C} / 8 \mathrm{~h}\end{array}$ & 14 & 56 & $\begin{array}{l}\text { 1. Pretreat seed for } 2 \text { months at } 20^{\circ} \mathrm{C} \\
\text { followed by } 7 \text { months at } 3-5^{\circ} \mathrm{C} \text {. } \\
\text { 2. Use TT (tetrazolium test). }\end{array}$ \\
\hline Prunus avium & $S$ & $\begin{array}{l}20^{\circ} \mathrm{C} / 16 \mathrm{~h}+ \\
30^{\circ} \mathrm{C} / 8 \mathrm{~h}\end{array}$ & 7 & 28 & $\begin{array}{l}\text { 1. Prechill } 3-4 \text { months at } 3-5^{\circ} \mathrm{C} \text {; } \\
\text { 2. Use TT (tetrazolium test). }\end{array}$ \\
\hline Populus spp. & TP & $\begin{array}{l}20^{\circ} \mathrm{C} / 16 \mathrm{~h}+ \\
30^{\circ} \mathrm{C}-8 \mathrm{~h}\end{array}$ & 3 & 10 & \\
\hline Quercus spp. & TS; (S) & $20^{\circ} \mathrm{C} / 24 \mathrm{~h}$ & 7 & 28 & $\begin{array}{l}\text { Soak seed for up to } 48 \text { hours and cut } \\
\text { off at scar end of seed and remove } \\
\text { pericarp. }\end{array}$ \\
\hline
\end{tabular}

The abbreviations have the following meanings:
TP - top of paper;
$S$ - sand;
BP - between papers;
TS - top of sand;

TT - topographical Tetrazolium Test; 

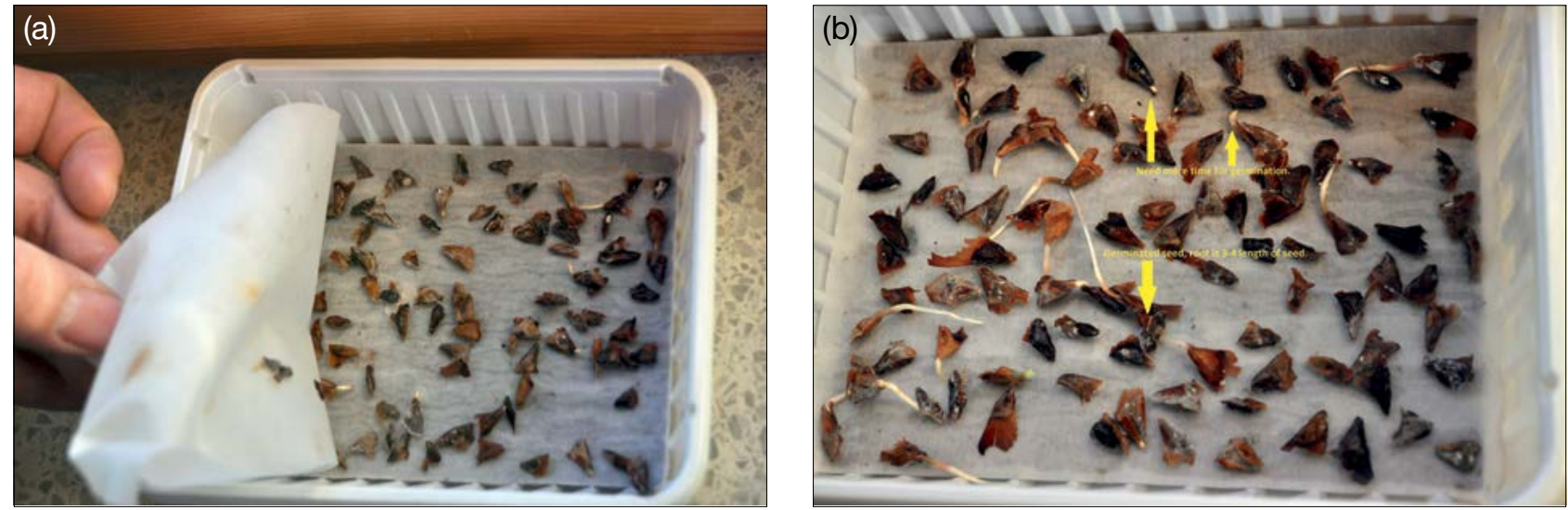

Figure 6.2: (a) Boxes with seeds (BP - seeds between the papers); (b) Examples of germinating Abies alba seeds. (Photos: Darius Kavaliauskas)

At the end of the germination test, the classification of ungerminated seeds as fresh must be determined. The evaluation of empty and insect damaged seeds may be made prior to the germination test.

Multigerm seed units are counted as single units and the result of the test indicates the percentage of units which have produced at least one normal seedling. The number of normal seedlings produced by 100 seed units or the number of seed units which have produced one, two or more than two normal seedlings, may also be determined.

\section{Calculation and expression of results}

Results are expressed as a percentage by number. When four 100 -seed replicates of a test are within the maximum tolerated range the average represents the percentage germination to be reported on the modified certificate, based on the ISTA International Seed Analysis Certificate. The average percentage is calculated to the nearest whole number.

Table 6.4 "Germination methods" indicates the permissible substrates, the duration of the test and recommended additional treatments for dormant samples:

- Substrates - The sequence of alternative substrates is the same and does not indicate any preference: TP; BP; S. BP as well as TP may be substituted by PP (pleated paper).

- Temperature - The sequence of alternative temperatures is the same throughout and does not indicate any preference: alternating temperatures, highest first; constant temperatures, highest first.

- First count - The time for the first count is approximate and refers to the highest temperature alternative in paper substrates. If a lower temperature alternative is chosen or when the test is made in sand, the first count may have to be delayed. For a test in sand with a final count after 7-10 (14) days the first count may be omitted altogether.

- Light - Illumination of the test is generally recommended for the sake of better developed seedlings. If in certain cases light is needed to promote germination of dormant samples or if, on the other hand, light may be inhibitory to germination and the substrates should be kept in darkness, this is indicated in the last column.

Specifically for Abies spp.: Four replicates of 100 seeds per replicate are used for the germination test of Abies alba (in total 400 seeds). Prechill for Abies alba seed is 21 day at $3-5^{\circ} \mathrm{C}$ in the fridge. Substrate according to ISTA (2020) is TP - top of the paper, however, the germination test substrate for Abies alba can be BP - between paper (optional) (Figure 6.2a). Some additional cellulose paper can be used below to keep the water/moisture for seeds. All replicates must be kept in the germination chambers for 28 days (duration can be prolonged two weeks more). Two temperature regimes are 
used: 16 hours at $20^{\circ} \mathrm{C}$ and 8 hours at $30^{\circ} \mathrm{C}$ (repeat every day during all germination test). First count of germinated seed on the 7th day (count the seeds per replicate which have a root with a length 3-4 times that of the seed length (Figure 6.2b)). Germinated seed are counted every 7 days until the end of the germination test.

Results are given as percentages (average of 4 replicates): percentage of normal seedlings, abnormal seedlings, hard seeds, fresh seeds and dead seeds. The rest of the seeds which do not germinate during the test have to be opened (cut with a scalpel) and evaluated why they were not germinating (the possible reasons are: empty seeds; fresh seeds; hard seeds; dead seeds).

\subsubsection{Biochemical Test for Viability, the Topographical Tetrazolium Test}

Preparation and treatment of the seed

The seed should be prepared in order to facilitate penetration of the tetrazolium solution. The prepared seeds or embryos are then completely immersed in the tetrazolium solution at the temperature and for the period described in the ISTA rules. At the end of this period the solution is decanted and the seed rinsed with water and examined.

At the examination each seed is evaluated as viable or non-viable on the basis of the staining patterns and tissue soundness.

Specific directions for preparation, treatment and evaluation of each approved species are given in the ISTA protocols (2020) and Table 6.5.

Specifically for Fagus sylvatica: Four replicates of 100 seeds per replicate are used for the tetrazolium test of Fagus sylvatica (in total $\mathbf{4 0 0}$ seeds). The pericarp needs to be removed from all seeds, and seeds then soaked in water for 18 hours at $20^{\circ} \mathrm{C}$. After that the seed coat is removed and the seeds soaked in $1 \%$ of $\mathrm{TZ}$ solution for $\approx 10-18$ hours at $30^{\circ} \mathrm{C}$. After staining the cotyledons are opened and the seeds evaluated. The maximum area of unstained, flaccid or necrotic tissue permitted is: radicle tip, $1 / 3$ distal area of cotyledons if superficial.

Results are given in the percentage of viable seeds, non-viable (e.g. insect damage or not stained during TT test) seeds and empty seeds.

Table 6.5. prescribes the procedures for pre-moistening (type and time), preparation of pre-moistened seeds before staining, staining (concentration of the solution and time), and preparation of evaluation according to

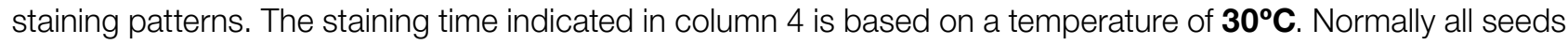
with a completely stained embryo and those with unstained or necrotic parts as noted in column 6 are viable. For some species, the endosperm (true endosperm, perisperm, gametophyte tissue) must also be completely stained. For evaluation note that the whole structure in question has to be taken into account, so if a portion is removed during preparation before staining it is considered as fully stained or as a part of the maximum area that can be unstained. 
Table 6.5: Procedures for tetrazolium tests

\begin{tabular}{|c|c|c|c|c|c|c|c|c|}
\hline \multirow[b]{2}{*}{ Species } & \multicolumn{2}{|c|}{$\begin{array}{c}\text { Premoistening at } \\
20^{\circ} \mathrm{C} \\
\end{array}$} & \multirow[b]{2}{*}{$\begin{array}{c}\text { Preparation before } \\
\text { staining }\end{array}$} & \multicolumn{2}{|c|}{ Staining } & \multirow[b]{2}{*}{$\begin{array}{c}\text { Preparation for } \\
\text { evaluation and } \\
\text { tissue to be } \\
\text { observed }\end{array}$} & \multirow{2}{*}{$\begin{array}{c}\text { Evaluation } \\
\text { Maximum area of } \\
\text { unstained, flaccid } \\
\text { or necrotic tissue } \\
\text { permitted }\end{array}$} & \multirow[b]{2}{*}{ Remarks } \\
\hline & Type & $\begin{array}{l}\text { Min. } \\
\text { time } \\
\text { (hours) }\end{array}$ & & $\begin{array}{l}\text { Solution } \\
\text { percentage }\end{array}$ & $\begin{array}{l}\text { Optimum } \\
\text { time (hours) } \\
\text { in } 30^{\circ} \mathrm{C}\end{array}$ & & & \\
\hline \multirow{4}{*}{$\begin{array}{l}\text { Abies } \\
\text { spp. }\end{array}$} & \multirow[t]{2}{*}{ W } & \multirow[t]{2}{*}{18} & $\begin{array}{c}\text { 1. Cut } \\
\text { transversely at } \\
\text { both ends to } \\
\text { open embryo } \\
\text { cavity. }\end{array}$ & 1 & $18-24$ & $\begin{array}{l}\text { 1. Cut } \\
\text { longitudinally } \\
\text { through } \\
\text { endosperm and } \\
\text { expose embryo; } \\
\text { remove seed } \\
\text { coat. }\end{array}$ & $\begin{array}{l}\text { Small superficial } \\
\text { necrosis on } \\
\text { endosperm at } \\
\text { distal end. }\end{array}$ & $\begin{array}{l}\text { Old and dry } \\
\text { seeds may } \\
\text { give more } \\
\text { consistent } \\
\text { results if } \\
\text { soaked for } \\
48 \text { hours. } \\
\text { Addition of } \\
\text { fungicide } \\
\text { may help } \\
\text { evaluation. }\end{array}$ \\
\hline & & & $\begin{array}{l}\text { 2. Cut } \\
\text { longitudinally } \\
\text { beside embryo. }\end{array}$ & 1 & $12-18$ & $\begin{array}{l}\text { 2. Expose } \\
\text { embryo; remove } \\
\text { seed coat. }\end{array}$ & $\begin{array}{l}\text { None. Including } \\
\text { endosperm. }\end{array}$ & \\
\hline & \multirow[t]{2}{*}{$\begin{array}{l}\text { Prepare } \\
\text { the dry } \\
\text { seeds }\end{array}$} & & $\begin{array}{l}\text { 1. Cut } \\
\text { transversely at } \\
\text { both ends, to } \\
\text { open embryo } \\
\text { cavity. }{ }^{*} \text { Treat TZ } \\
\text { imbibed seeds } 3 x \\
\text { with low pressure }\end{array}$ & 1 & 18 & $\begin{array}{l}\text { 1. Cut } \\
\text { longitudinally } \\
\text { through } \\
\text { endosperm and } \\
\text { expose embryo; } \\
\text { remove seed } \\
\text { coat. }\end{array}$ & $\begin{array}{l}\text { None, except } \\
\text { small superficial } \\
\text { necrosis on the } \\
\text { outer part of the } \\
\text { endosperm, not } \\
\text { in connection with } \\
\text { embryo cavity. }\end{array}$ & $\begin{array}{l}\text { Old and dry } \\
\text { seeds may } \\
\text { give more } \\
\text { consistent } \\
\text { results if } \\
\text { soaked for } \\
48 \text { hours. } \\
{ }^{\star} \text { Optional }\end{array}$ \\
\hline & & & $\begin{array}{l}\text { 2. Cut } \\
\text { longitudinally } \\
\text { beside embryo. }\end{array}$ & 1 & 12 & $\begin{array}{l}\text { 2. Expose } \\
\text { embryo; remove } \\
\text { seed coat. }\end{array}$ & & \\
\hline \multirow{4}{*}{$\begin{array}{l}\text { Fagus } \\
\text { spp. }\end{array}$} & \multicolumn{2}{|c|}{$\begin{array}{l}\text { Remove } \\
\text { pericarp.* }\end{array}$} & \multirow{2}{*}{$\begin{array}{l}\text { 1. Remove seed } \\
\text { coat }\end{array}$} & \multirow[b]{2}{*}{$1 ; 0,5$} & \multirow{2}{*}{$\begin{array}{l}10-12 \\
15-18\end{array}$} & \multirow{2}{*}{$\begin{array}{l}\text { 1. Open } \\
\text { cotyledons. }\end{array}$} & \multirow{2}{*}{$\begin{array}{l}\text { Radicle tip, 1/3 } \\
\text { distal area of } \\
\text { cotyledons if } \\
\text { superficial. }\end{array}$} & \multirow{2}{*}{$\begin{array}{l}{ }^{*} \text { Pericarp of } \\
\text { very dry seeds } \\
\text { is easier to } \\
\text { remove after } \\
\text { soaking for a } \\
\text { few hours. }\end{array}$} \\
\hline & \multirow[b]{2}{*}{ W } & \multirow[b]{2}{*}{18} & & & & & & \\
\hline & & & $\begin{array}{c}\text { 2. Cut } \\
\text { longitudinally } \\
\text { through } \\
\text { cotyledons, } \\
\text { avoiding embryo } \\
\text { axis. } \\
\end{array}$ & 1 & $16-24$ & $\begin{array}{l}\text { 2. Remove seed } \\
\text { coat and expose } \\
\text { inner side of } \\
\text { cotyledons. }\end{array}$ & & \\
\hline & $\begin{array}{r}\text { Rem } \\
\text { pericarp } \\
\text { seec }\end{array}$ & $\begin{array}{l}\text { ove } \\
\text { of dry } \\
\text { ds. * }\end{array}$ & $\begin{array}{l}\text { Remove seed } \\
\text { coat. }\end{array}$ & 1 & 18 & - & $\begin{array}{l}\text { Radicle tip, } 1 / 3 \\
\text { distal area of } \\
\text { cotyledons if } \\
\text { superficial. }\end{array}$ & $\begin{array}{l}{ }^{*} \text { Pericarp of } \\
\text { very dry seeds } \\
\text { is easier to } \\
\text { remove after } \\
\text { soaking for a } \\
\text { few hours. }\end{array}$ \\
\hline \multirow{4}{*}{$\begin{array}{l}\text { Fraxinus } \\
\text { spp. }\end{array}$} & \multicolumn{2}{|c|}{$\begin{array}{l}\text { Remove } \\
\text { pericarp.* }^{*}\end{array}$} & \multirow{2}{*}{$\begin{array}{l}\text { Cut seed coat } \\
\text { from both edges, } \\
\text { so two halves of } \\
\text { the endosperm } \\
\text { are visible. }\end{array}$} & \multirow{2}{*}{1} & \multirow{2}{*}{$18-24^{*}$} & \multirow{2}{*}{$\begin{array}{l}\text { Expose embryo } \\
\text { by splitting } \\
\text { endosperm into } \\
\text { two halves. }\end{array}$} & \multirow{2}{*}{$\begin{array}{l}\text { None, except } \\
\text { small necrosis on } \\
\text { endosperm away } \\
\text { from the embryo. }\end{array}$} & \multirow{2}{*}{$\begin{array}{l}{ }^{*} \text { Freshly } \\
\text { harvested } \\
\text { seeds } \\
\text { need only } \\
\text { 8-10 hours. }\end{array}$} \\
\hline & W & 18 & & & & & & \\
\hline & \multicolumn{2}{|c|}{$\begin{array}{l}\text { Remove } \\
\text { pericarp of dry } \\
\text { seeds.* }\end{array}$} & \multirow{2}{*}{$\begin{array}{l}\text { Cut longitudinally } \\
\text { on both sides a } \\
\text { small piece off, } \\
\text { to open embryo } \\
\text { cavity. }\end{array}$} & \multirow[t]{2}{*}{1} & \multirow[t]{2}{*}{$18^{\star}$} & \multirow{2}{*}{$\begin{array}{l}\text { Expose embryo } \\
\text { by splitting } \\
\text { endosperm into } \\
\text { two halves. }\end{array}$} & \multirow{2}{*}{$\begin{array}{l}\text { None, except } \\
\text { small necrosis on } \\
\text { endosperm away } \\
\text { from the embryo. }\end{array}$} & \multirow{2}{*}{$\begin{array}{c}{ }^{\star} \text { Freshly } \\
\text { harvested } \\
\text { seeds need } \\
\text { only } 8 \text { hours. }\end{array}$} \\
\hline & W & 18 & & & & & & \\
\hline
\end{tabular}




\begin{tabular}{|c|c|c|c|c|c|c|c|c|}
\hline \multirow[b]{2}{*}{ Species } & \multicolumn{2}{|c|}{$\begin{array}{c}\text { Premoistening at } \\
20^{\circ} \mathrm{C}\end{array}$} & \multirow[b]{2}{*}{$\begin{array}{c}\text { Preparation before } \\
\text { staining }\end{array}$} & \multicolumn{2}{|c|}{ Staining } & \multirow[b]{2}{*}{$\begin{array}{c}\text { Preparation for } \\
\text { evaluation and } \\
\text { tissue to be } \\
\text { observed }\end{array}$} & \multirow{2}{*}{$\begin{array}{c}\text { Evaluation } \\
\text { Maximum area of } \\
\text { unstained, flaccid } \\
\text { or necrotic tissue } \\
\text { permitted }\end{array}$} & \multirow[b]{2}{*}{ Remarks } \\
\hline & Type & $\begin{array}{l}\text { Min. } \\
\text { time } \\
\text { (hours) }\end{array}$ & & $\begin{array}{l}\text { Solution } \\
\text { percentage }\end{array}$ & $\begin{array}{l}\text { Optimum } \\
\text { time (hours) } \\
\text { in } 30^{\circ} \mathrm{C} \\
\end{array}$ & & & \\
\hline $\begin{array}{l}\text { Pinus } \\
\text { nigra }\end{array}$ & \multicolumn{2}{|c|}{$\begin{array}{l}\text { Prepare the dry } \\
\text { seeds. }\end{array}$} & $\begin{array}{c}\text { Cut transversely } \\
1 / 3 \text { from } \\
\text { distal end } 1 \text { of } \\
\text { endosperm to } \\
\text { open embryo } \\
\text { cavity. }\end{array}$ & 1 & 18 & $\begin{array}{l}\text { Extract embryo } \\
\text { and endosperm } \\
\text { from seed coat. }\end{array}$ & $\begin{array}{l}\text { None, including } \\
\text { endosperm, except } \\
\text { small superficial } \\
\text { necrosis on the } \\
\text { outer part of the } \\
\text { endosperm, not } \\
\text { in connection with } \\
\text { embryo cavity. }\end{array}$ & $\begin{array}{c}\text { Embryos } \\
\text { shorter than } \\
\text { 1/3 embryo } \\
\text { cavity are } \\
\text { non-viable. }\end{array}$ \\
\hline \multirow{5}{*}{$\begin{array}{l}\text { Prunus } \\
\text { spp. }\end{array}$} & \multicolumn{2}{|c|}{$\begin{array}{l}\text { Crack the } \\
\text { stones and cut } \\
\text { a small piece } \\
\text { of cotyledon } \\
\text { at distal end or } \\
\text { incise seed. }\end{array}$} & \multirow[t]{2}{*}{$\begin{array}{l}\text { Remove seed } \\
\text { coat, soak and } \\
\text { change water } \\
\text { every hour for at } \\
\text { least } 5 \text { hours. }\end{array}$} & \multirow[t]{2}{*}{$1 ; 0,5$} & \multirow[t]{2}{*}{$\begin{array}{l}8-12 \\
12-18\end{array}$} & \multirow[t]{2}{*}{$\begin{array}{l}\text { Spread } \\
\text { cotyledons } \\
\text { apart. }\end{array}$} & \multirow[t]{2}{*}{$\begin{array}{l}\text { Radicle tip, } 1 / 3 \\
\text { distal area of } \\
\text { cotyledons if } \\
\text { superficial. }\end{array}$} & \multirow[t]{2}{*}{$\begin{array}{l}\text { *Large seeded } \\
\text { species need } \\
\text { longer staining } \\
\text { time ( } 24 \\
\text { hours). }\end{array}$} \\
\hline & W & 18 & & & & & & \\
\hline & \multicolumn{2}{|c|}{$\begin{array}{l}\text { Crack the } \\
\text { stones, }\end{array}$} & \multirow[b]{3}{*}{$\begin{array}{l}\text { Remove seed } \\
\text { coat. }{ }^{\star \star}\end{array}$} & \multirow[b]{3}{*}{1} & \multirow[b]{3}{*}{18} & \multirow[b]{3}{*}{$\begin{array}{l}\text { Spread } \\
\text { cotyledons } \\
\text { apart. }\end{array}$} & \multirow[b]{3}{*}{$\begin{array}{l}\text { Radicle tip, } 1 / 3 \\
\text { distal area of } \\
\text { cotyledons if } \\
\text { superficial. }\end{array}$} & \multirow{3}{*}{$\begin{array}{c}\text { *Large seeded } \\
\text { species need } \\
\text { longer staining } \\
\text { time (24 hours). } \\
\text { ** Open } \\
\text { cotyledons } \\
\text { carefully } \\
\text { in: Prunus } \\
\text { persica, } \\
\text { Prunus } \\
\text { domestica. }\end{array}$} \\
\hline & W & 18 & & & & & & \\
\hline & \multicolumn{2}{|c|}{$\begin{array}{l}\text { Change water if } \\
\text { necessary (if it } \\
\text { smells of bitter } \\
\text { almond). }\end{array}$} & & & & & & \\
\hline
\end{tabular}

The abbreviations have the following meanings:

W - in water;

$\mathrm{BP}+\mathrm{W}$ - slow moistening followed by at least 2-3 hours in water to achieve full-imbibition of all seeds.

\subsection{DNA analyses}

\subsubsection{DNA extraction}

The success of all molecular genetic analyses is directly dependent on the quality and quantity of its target, the DNA. Therefore, great attention should be given to the process of isolation of DNA to ensure that the quality and quantity of the isolated DNA is at the level required for successful completion of downstream analyses.

The focus of this chapter is not to review many of the existing protocols for isolation of DNA from plant tissues there are far too many - but to present the approaches used or successfully tested by the laboratories involved in the LIFEGENMON project.

DNA of sufficient quality and quantity can be successfully isolated by both commercial column-based DNA extraction kits and traditional laboratory protocols based on in-house prepared reagent solutions.

\subsubsection{The amount of plant tissue to use for DNA extraction}

The optimal amount of plant tissue to use for DNA extraction depends on the DNA extraction procedure used. It is advisable to use the amounts recommended by the manufacturer of commercial DNA isolation kits or the authors of traditional DNA isolation protocols. Although counterintuitive at the first glance, using larger amounts 
of plant tissue than recommended can have negative effects on the yield and particularly the quality (purity) of the isolated DNA. In certain cases, using more material can give better results, but this should be first verified on a smaller number of samples, as the results depend on the plant species and type of tissue used.

Weighing the tissue of each sample can be very time consuming, particularly if working with many samples at a time. Simplified approaches can be used to reduce the workload and time necessary for completion of this task (see Box 6.3: "Alternative units" for measuring the mass of plant tissue for DNA extraction).

\section{Box 6.3: "Alternative units" for measuring the mass of plant tissue for DNA extraction}

1. On a random subset of samples (10-15) count the number of "alternative units" that correspond to the recommended amount (mass) of plant tissue to be used for each of the test samples; examples of "alternative units": a) conifers: needles; b) broadleaves: disks of equal diameter cut from leaves using a hole punching tool (see image 6.3); c) buds: buds.

(a)
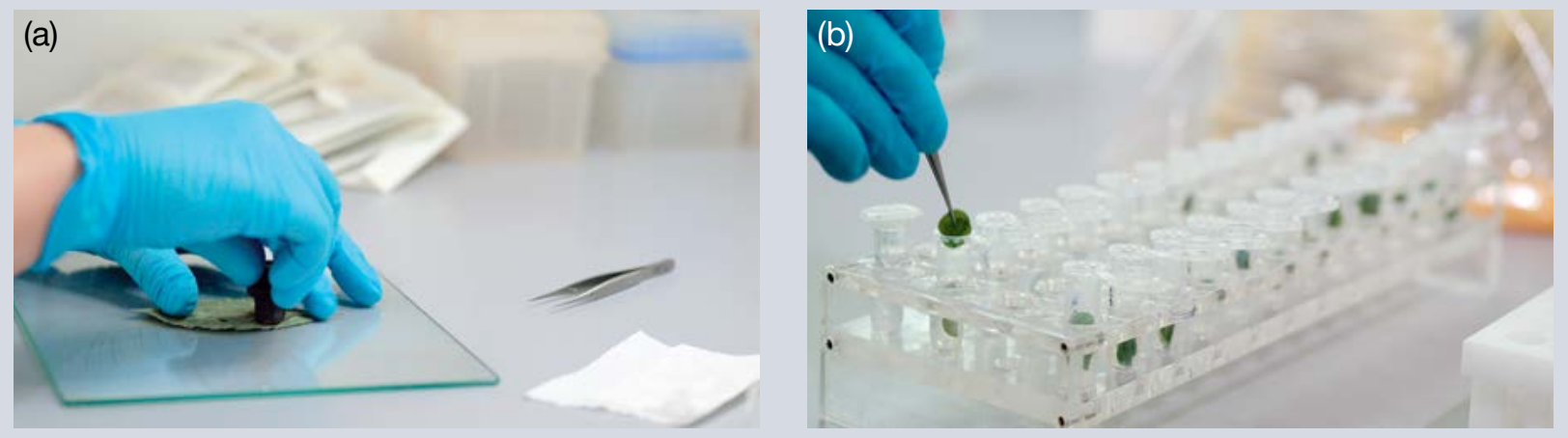

Figure 6.3: (a) Discs are cut from desiccated European beech leaves using a punching tool; (b) A number of discs corresponding to the required mass of plant material is added to tubes for DNA extraction instead of weighing each sample. (Photos: Mark Walter)

2. Calculate the average number of "alternative units" that correspond to the recommended mass of plant tissue.

3. Use the average number of "units" instead of weighing for all the samples to be analysed. Make sure that you always select comparable units - needles and leaves of approximately the same size; take into account the age of plants analysed and the maturity level of the tissue used - leaves of young plants or not fully mature leaves are thinner than leaves of mature trees, so more "units" are needed to match the required mass. Determine this value for each species, age group and tissue type individually.

Using a standardised amount of tissue minimises the variability in the quantity and purity of the isolated DNA across the samples.

\subsubsection{Disruption of plant tissue}

Good disruption of tissue is crucial for successful isolation of DNA from plant tissues. The finer the tissue particles, the better the diffusion of reagents into the tissue is. Different approaches to the disruption of plant tissue are summarised in Table 6.6.

In general, use of bead mills or similar powered disruption equipment is recommended over manual disruption for the following reasons: a) it is much more time efficient as it enables simultaneous processing of many samples up to 192 samples when using 96-well plates; b) it enables more uniform disruption conditions, less variation between samples and disruption runs.

Disruption of desiccated tissue or tissue frozen in liquid nitrogen is recommended over fresh tissue. When using tissue frozen in liquid nitrogen, make sure to avoid excessive increases in temperature during the disruption process, and to use only equipment/consumables designed to withstand such low temperatures. 
Table 6.6: Plant tissue disruption approaches. Manual - this involves the use of a mortar and a pestle or 1.5/2.0-ml tubes and micro-pestles; Beads / Mill - disruption with a bead mill and grinding beads; Buffer - refers to the first buffer used in the DNA isolation protocol which stabilises DNA and inhibits enzymatic (nucleolytic) activity.

\begin{tabular}{lcccc} 
State of tissue & Buffer & Manual & Beads / Mill & Notes \\
\hline Fresh & + & + & - & - \\
\hline Fresh & - & + & + & 2 \\
\hline Fresh & + & - & - & + \\
\hline Frozen (liq. $\mathrm{N}_{2}$ ) & - & + & + & + \\
\hline Frozen (liq. $\mathrm{N}_{2}$ ) & - & - & - & 3 \\
\hline Desiccated & - & - & + & + \\
\hline Desiccated & - & + & & \\
\hline
\end{tabular}

1 Not recommended, as during disruption, cell and organelle membranes are ruptured, exposing nucleic acids to nucleases.

2 Movement of grinding beads through the buffer causes an increase in temperature due to friction and severe shear forces that can fragment DNA.

${ }_{3}$ With manual disruption of dried plant tissue special care should be taken to prevent cross-contamination between samples as dispersal of powdered desiccated tissue particles can be difficult to control in open systems.

\subsubsection{DNA extraction protocols}

DNA extraction protocols used in the LIFEGENMON project or successfully tested by laboratories involved in the project are presented in Table 6.7. It should be noted that many different protocols for extraction of DNA from plant tissues that yield good quantity and quality of DNA exist, both in the form of commercially available kits and traditional laboratory protocols.

Most traditional plant tissue DNA extraction protocols are based on either the CTAB-based protocol first described by Doyle and Doyle (1987) or SDS-based protocol described by Dellaporta et al. (1983). Different modifications and applications of the aforementioned protocols were reviewed and summarised by Demeke and Jenkins (2010) and Nishiguchi et al. (2002).

Many suitable commercially available column-based plant tissue DNA extraction kits are available on the market. Forest genetics laboratories of AUTH and SFI both rely on such kits with good results.

Both the traditional laboratory protocols and commercial kits have their pros and cons. The choice of a DNA extraction protocol will ultimately depend on the preferences of an individual laboratory. It is recommended that molecular genetics laboratories that wish to get involved in the FGM continue using the DNA extraction protocols that they are familiar with and consistently give good results.

Table 6.7: DNA extraction protocols used by laboratories involved in the LIFEGENMON project for extracting DNA from plant tissues. AWG - Bavarian Office for Forest Genetics, Germany; AUTh - Aristotle University of Thessaloniki, Greece; $\mathrm{SFI}$ - Slovenian Forestry Institute. $\mathrm{LN}_{2}$ - liquid nitrogen.

\begin{tabular}{lccc} 
Laboratory & Sample preparation & Tissue disruption & DNA extraction \\
\hline AWG & Desiccation, Silica Gel & Bead Mill, desiccated & Modified CTAB protocol \\
\hline AUTh & Freezing & Manual, frozen $\mathrm{LN}_{2}$ & $\begin{array}{c}\text { Macherey-Nagel, NucleoSpin } \\
\text { Plant II Kit }\end{array}$ \\
\hline SFI & Desiccation, freeze-drying & Bead Mill, desiccated & Qiagen, DNeasy Plant 96 Kit \\
\hline
\end{tabular}

\subsubsection{DNA quantity, purity and integrity}

Regardless of the DNA extraction protocol used, it is important to assess the quantity and quality of the extracted DNA. This is particularly important when testing a new protocol, but should be done regularly on at least a subset 
of samples for each DNA extraction performed, preferably on all the samples. In this way DNA concentrations can be standardised, which greatly facilitates downstream analyses (Guichoux et al. 2011). A generally applied approach of addressing the question of DNA quantity and purity is by spectrophotometric analysis of DNA samples. Absorbance at $230 \mathrm{~nm}, 260 \mathrm{~nm}$ and $280 \mathrm{~nm}$ is measured. DNA has an absorption maximum at 260 $\mathrm{nm}$, while wavelengths of 230 and $280 \mathrm{~nm}$ are used to assess the presence of residual impurities by calculating $260 \mathrm{~nm} / 230 \mathrm{~nm}$ and $260 \mathrm{~nm} / 280 \mathrm{~nm}$ absorbance ratios (see Table 6.8 for details). As a rule of thumb, DNA concentrations of around $100 \mathrm{ng} / \mathrm{\mu l}$ are aimed for but will depend on the type of tissue being used. The accuracy of the measurement of DNA purity by absorbance depends on the DNA concentration itself, and both A260/280 and A260/230 ratios exhibit considerable variability at DNA concentrations below $50 \mathrm{ng} / \mathrm{\mu l}$, therefore taking at least 3 replicate measurements is recommended (Koetsier and Cantor 2019). Likewise, absorbance measurements are sensitive to $\mathrm{pH}$ of the solution, with acidic DNA solutions generally giving lower A260/280 ratio values, while basic DNA solutions tend to overestimate the A260/280 ratio (Wilfinger et al. 1997).

In addition to DNA quantity and purity, it is also recommended to assess the integrity of the extracted DNA. This can be assessed by $1 \%$ agarose gel electrophoresis. A good DNA extraction, yielding DNA of high quality, is indicated by an intense band of DNA over $10 \mathrm{kBp}$ in size with very little smearing.

Table: 6.8: Explanation of values for $260 / 280 \mathrm{~nm}$ and $260 / 230 \mathrm{~nm}$ absorbance ratios for extracted DNA samples.

\begin{tabular}{|c|c|c|c|}
\hline Absorbance ratio & $\begin{array}{l}\text { Absorbance ratio } \\
\text { for pure DNA }\end{array}$ & Low absorbance ratio value & High absorbance ratio value \\
\hline \multirow{3}{*}{$260 / 280 \mathrm{~nm}$} & \multirow{3}{*}{$\sim 1,8$} & Protein contaminants & \multirow{3}{*}{$\begin{array}{l}\text { High concentration of RNA } \\
\text { (>15\% of total nucleic acids) }\end{array}$} \\
\hline & & $\begin{array}{c}\text { Phenol (carry over from DNA extraction } \\
\text { or residual contaminant from plant } \\
\text { tissues - polyphenolics) }\end{array}$ & \\
\hline & & Very low DNA concentration & \\
\hline \multirow{3}{*}{ 260/230 nm } & \multirow{3}{*}{$2,0-2,2$} & $\begin{array}{l}\text { Polysaccharides (common problem } \\
\text { with plant tissues) }\end{array}$ & \multirow{3}{*}{$\begin{array}{c}\text { Different concentration of free } \\
\text { EDTA in blank and extracted DNA } \\
\text { sample can result in A260/230 } \\
\text { ratios }>3.0\end{array}$} \\
\hline & & $\begin{array}{c}\text { Phenolics (carry over from DNA } \\
\text { extraction or residual contaminant from } \\
\text { plant tissues - polyphenolics) }\end{array}$ & \\
\hline & & $\begin{array}{l}\text { Residual chaotropic salts (such as } \\
\text { guanidine, commonly used in column- } \\
\text { based DNA extraction kits) }\end{array}$ & \\
\hline
\end{tabular}

\subsubsection{Genetic markers}

\subsubsection{Selection of genetic markers}

While new technologies have emerged, microsatellites are still the most frequently used marker in the population genetics of wild populations. Because of their high mutation rates (Whittaker et al. 2003), microsatellites are excellent markers for the study of the following genetic monitoring indicators: (i) genetic drift and (ii) gene flow (Selkoe and Toonen 2006). Nevertheless microsatellites are known to be riddled with biases, such as allelic dropouts and null alleles (Flores-Rentería and Krohn 2013, Oddou-Muratorio et al. 2009). Despite the fact that specific software is available in order to estimate the presence of biases, those inferences are rarely fully concordant with each other, and thus raise the issue of loss of accuracy. One way to ameliorate the unfavourable effects of such biases before the start of a genetic monitoring project is to pre-screen the proposed markers in small scale experiments. Even though this significantly increases the cost of the baseline genetic assessment, the benefits in reliability of estimates might be worth it.

Another type of a genetic marker system proposed for genetic monitoring is single nucleotide polymorphisms (SNPs). Putatively neutral SNPs provide more robust estimates of demographic statistics compared to microsatellites, as SNPs are scattered into multiple chromosomes and contigs, enabling researchers to get a more representative sampling of the genome. Aside from assessments of demography, SNPs located in gene 
regions allow the study of indicator selection with molecular data (Brousseau et al. 2016, Csilléry et al. 2014, Roschanski et al. 2016). While SSR markers linked to coding regions (EST-SSRs) exist for some species, the low number of loci (usually 10-20) employed in most population genetics studies do not provide enough power to detect outliers. Large sets of SNPs obtained from more advanced techniques such as RAD sequencing, genotyping by sequencing, and even exome sequencing have started to become commonplace for a plethora of population studies in recent years (Benestan et al. 2015, Tyrmi et al. 2020). However, for the foreseeable future, small SNP sets such as the ones obtained by KASP assays (Csilléry et al. 2014, Roschanski et al. 2016) will probably be more economically viable for the genetic monitoring of forest populations. The downside of such small scale assays is that they are notorious for being prone to ascertainment bias. This is the type of bias expected to occur due to high genetic distance (Nei 1973) between the individuals used for locus discovery and the samples genotyped (Albrechtsen et al. 2010). For the purposes of genetic monitoring at the stand level this is not necessarily damaging, provided that the unbiased proportion of SNPs left in a dataset (i.e. polymorphic sites) is large enough for accurate calculations of demographic parameters. Nevertheless, caution must be applied to any comparisons between populations from different regions and/or evolutionary lineages as part of a comprehensive genetic monitoring activity, especially if the aim is to decide their conservation status. In that case, diversity statistics may be biased, leading forest managers to incorrect decisions.

Ultimately, these issues will become of less importance, as genetic monitoring transitions to the more robust genome sampling methods referenced above, even though these are not bias free either (Lowry et al. 2017). Long term storage of DNA from early sampling events might be the best bet for informed comparisons with future samples.

\subsubsection{Microsatellite markers (SSRs)}

\subsection{Selection of suitable Microsatellite markers (SSRs)}

Search the available scientific literature for the available SSRs and consult colleagues from other laboratories who have experience in working with SSRs for the species in question. When selecting suitable SSR markers from literature or developing new ones, it is recommended to consider the following criteria:

- SSRs with perfect repeat motifs are preferred over those with imperfect repeats as there is no equivalency between detected allele length and sequence for the latter - several alleles of the same size can have a different nucleotide sequence (Estoup et al. 1995). Such differences go undetected by fragment analysis and result in reduced observed polymorphism of SSRs with imperfect repeats (Urquhart et al. 1994, Estoup et al. 2001, Gusmão et al. 2006, Guichoux et al. 2011).

- SSR repeat units typically range from 1 to 6 nucleotides. Dinucleotide repeat SSRs are the most commonly used, and since they generally have narrower allelic ranges it is easier to combine more in a single multiplex PCR. However, dinucleotide repeat SSRs are often more prone to producing PCR artefacts such as stutter bands (Chambers and MacAvoy 2000), making allele scoring more difficult (Levinson and Gutman 1987, Meldgaard and Morling 1997). SSRs with longer repeat units are reportedly significantly less prone to "stuttering" (Edwards et al. 1991, Flores-Rentería and Krohn 2013) and are sometimes preferred for applications such as forensics and parentage determination (Kirov et al. 2000, Cipriani et al. 2008).

- Selecting SSR loci with a sufficient number of repeats is necessary to ensure polymorphism. However, SSRs with numerous repeats can also have some undesirable characteristics, such as increased allele dropout (Kirov at al. 2000, Buchan et al. 2005) and stuttering (Hoffman and Amos 2005). An intermediate number of repeats should be ideal, as it represents a good compromise between preserving the sufficient level of polymorphism, while avoiding some of the drawbacks related to very high mutation rates. Van Asch et al. (2010) recommend using SSR loci with 12 to 16 repeats for the best results.

- When selecting SSR markers from published studies, choose the ones with reported null allele frequency no higher than 10\%, preferably lower (Oddou-Muratorio et al. 2009).

- If linkage maps are available, select SSRs from as many different chromosomes as possible. 
- Focus on the SSRs that have been successfully used on as large a number of samples as possible and on samples from different parts of the species distribution range, as this will minimise the chance of ascertainment bias.

- If monitoring a species in a region where it is expected that hybridisation takes place, make sure to select markers that have been tested successfully for transferability between the hybridising species. It is recommended that tests are performed on samples of both species to check the performance of the SSRS used. Lack of detectable alleles or high null allele rates indicate problems with primer annealing (mutations in the primer annealing region flanking the SSR in one of the species) - such SSRs should be avoided, or primers redesigned.

- Since it is desirable that as many SSRs markers as possible are combined in a single multiplexed PCR reaction, annealing temperatures of the primers and allelic ranges of markers must be considered. Markers with overlapping allelic ranges must be labelled with different fluorophores or be PCR amplified and analysed in separate reactions. Likewise, it is recommended that ideally annealing temperatures $\left(T_{m}\right)$ of primers in the same multiplexed PCR differ by no more than $2-3^{\circ} \mathrm{C}$, but certainly not more than $5^{\circ} \mathrm{C}$. (Butler et al. 2005a, Guichoux et al. 2011, Hill et al. 2009).

- The total number of SSRs used will depend on the specific question to be answered, resources available and the characteristics of individual SSRs themselves (polymorphism). Ten to 25 SSRs are generally used in population genetics studies.

- Always start with a larger number of potential SSRs, in case some fail to perform as desired.

\subsection{PCR}

Amplification of SSR markers is preferentially done in multiplexed PCR (Chamberlain et al. 1988, Edwards and Gibbs 1994), as such an approach greatly increases the throughput and at the same time reduces the cost and the amount of labour per sample (Elnifro et al. 2000, Lederer et al. 2000, Galan et al. 2003, Renshaw et al. 2006).

The goal of multiplexing is to combine the desired number of SSR markers (usually 10 to 25) in as few PCR reactions as possible, with each marker assigned a given fluorophore dye. Multiplex PCR is a sensitive technique, and many variables need to be considered in order to develop efficient and robust multiplexes (Guichoux et al. 2011), starting with the selection or development of primers. Specialised commercially available PCR multiplexing kits (such as Qiagen Multiplex PCR Kit, KAPA Biosystems KAPA2G Fast Multiplex mix and others) greatly facilitate optimisation of PCR multiplexes.

Allelic ranges of markers labelled with the same fluorophore must not overlap. Markers with overlapping allelic ranges can only be combined in the same multiplex if they are labelled with different fluorophores. The number and type of different fluorophores (different colours of emitted fluorescence) that can be used will depend on the capillary electrophoresis detection platform. These usually range from 4 to 6 , of which one colour channel is always assigned to the internal size standard.

The annealing temperatures of the primers used should be high, ideally $58^{\circ} \mathrm{C}$ or higher and not excessively different between primer pairs (Butler et al. 2005a, Hill et al. 2009, Qiagen 2010).

To ensure successful co-amplification of different SSR markers, it is essential that primers are checked for potential secondary structure formation, primer dimerisation and interactions with other primers in the multiplex (Vallone and Butler 2004, van Asch et al. 2010). Freely available computer programs, such as Multiplex Manager v1.2 (Holleley and Geerts 2009) have been developed to aid in designing an optimal multiplexing solution considering prior marker information.

The amount of template DNA added to each PCR reaction is of crucial importance and should be standardised. Although too little DNA can result in poor signal intensity, marker-to-marker imbalance and allele dropout, too much template DNA is usually more problematic (Livingstone et al. 2009, Guichoux et al. 2011). Excessive 
amounts of template DNA can lead to off-scale fluorescence signal with associated pull-up effects, marker-tomarker imbalance, split peaks and enhanced stuttering (Kline et al. 2005). The recommended concentration of template DNA in multiplex PCR is between 0.5 to $4 \mathrm{ng} / \mathrm{\mu l}$.

The optimal annealing temperature for the multiplex PCR should be established empirically. Use the $T_{m}$ of the primer pair with the lowest $T_{m}$ as the starting point. PCR cyclers with temperature gradient function greatly speed up the temperature optimisation stage as up to 6 different temperatures can be tested simultaneously.

It is advisable that primers for each SSR marker are first tested individually (and validated) in simplex PCR on a set of representative samples, particularly if primers were newly designed. The samples used should ideally be representative of the genetic diversity (encompassing different populations) of the studied species (or populations) in order to avoid later problems with ascertainment bias and to cover as many different alleles as possible. SSR markers exhibiting high level of null alleles, excessive stuttering, split peaks and/or other artefacts should be discarded or primers for their amplification redesigned already at the simplex stage (Guichoux et al. 2011). Markers that perform successfully individually are then tested in multiplex PCR on the same set of samples. The results - genotype data - from simplex and multiplex amplification then need to be compared and multiplexes further optimised (problematic markers may need to be discarded) until multiplexes perform efficiently.

Even if markers perform well in simplex PCR, it is often the case that amplification in multiplex form will not be optimal. Below are listed the most common problems and recommendations on how to approach fixing them.

a. Marker-to-marker imbalance is the result of heterogeneous amplification efficiency of different markers in the same multiplex PCR, resulting in different signal intensities between markers. Modern detection platforms have broad dynamic ranges of their detectors enabling reliable detection of signals of significantly different intensities. Nevertheless, the more uniform the signal is, the more reliable and simple automatic reading of electropherograms is. A common reason for marker-to-marker imbalance is differences in $T_{m}$ of the primers in the multiplex. Touch-down PCR protocols can be used to alleviate this problem (Rithidech and Dunn 2003, Renshaw et al. 2006). If $\mathrm{T}_{\mathrm{m}}$ is not the reason behind the observed amplification imbalance, this problem can be addressed by adjusting the primer concentrations - increase for the weakest markers and/or decrease for the strongest ones.

b. Stuttering is a common phenomenon that corresponds to the amplification of PCR products that differ from the actual allele by one or few repeats and is caused by DNA polymerase slippage (Levinson and Gutman 1987, Meldgaard and Morling 1997). Stutter peaks are usually shorter than the actual allele. Several approaches have been suggested to reduce stuttering: i) decrease the denaturation temperature to $83^{\circ} \mathrm{C}$ (Olejniczak and Krzyzosiak 2006); ii) PCR additives such as bovine serum albumin, formamide or dimethyl sulfoxide; iii) use of specialised multiplex PCR kits and/or modified new-generation polymerases, such as fusion types (Fazekas et al. 2010); iv) modification of primers with inclusion of part of the microsatellite region (Flores-Rentería and Whipple 2011); v) use of SSRs with the length of the repeat unit longer than 2 nucleotides. In general, low or moderate stuttering is not a particular problem in terms of accurate designation of alleles and their sizes, but may require more work in the form of manual checking of automated size calling results.

C. Split peaks (N-1 peaks). Split peaks are caused by incomplete non-template addition of adenine to PCR fragments by Taq polymerase, resulting in double peaks - the "true-to-template DNA fragment" and an additional peak $1 \mathrm{bp}$ longer corresponding to the adenylated fragment. Split peaks can compromise automatic peak recognition, particularly for heterozygotes with nearby alleles. Complete adenylation and thus reduction in the intensity of split peak formation can be achieved by i) reducing the amount of template DNA, down to $10 \mathrm{ng}$ (Lederer et al. 2000, Butler 2005b); ii) decreasing the concentration of primers; iii) reducing the number of PCR cycles or iv) using other types of DNA polymerases (Hu 1993, Vallone et al. 2008).

d. Primer-dimers and other artefactual bands. Various artefacts can be produced in multiplex PCR, including those resulting from complementarity of parts of sequences between primers of the same primer pair, as well as between primers of different markers (Brownie et al. 1997, Hill et al. 2009). Artefacts in the form of additional bands can be formed due to nonspecific primer annealing or pseudogene amplification. 
Increasing the stringency of PCR conditions (increasing temperature of annealing, shortening annealing times) can sometimes reduce artefact formation, but careful primer and multiplex PCR design in the first place is the best guarantee against the formation of such artefacts. If artefacts do not interfere with allele calling, they can simply be omitted during scoring, but sometimes such markers are best excluded from the multiplex or primers for their amplification redesigned (Guichoux et al. 2011).

Although SSR multiplexes reported in the literature are a good starting point, the PCR conditions and cycling protocols listed rarely produce optimal results from the start. It is to be expected that at least some level of optimisation will have to be performed before being able to apply multiplexed SSRs analysis on a routine and high throughput basis.

\subsection{Fragment analysis}

Fragment analysis of SSR markers entails the preparation of PCR amplified samples, subsequent separation and detection of the PCR amplicons on an automated high-resolution capillary electrophoresis detection platform (i.e., a sequencer or genetic analyser) and raw data analysis - allele size calling and binning. Unless otherwise noted, the information listed below is based on user manuals and analysis protocols developed by manufacturers (Applied Biosystems/Thermo Fisher Scientific 2010, 2014) of the capillary electrophoresis systems as well as protocols and first-hand experience of the laboratories involved in the LIFEGENMON project.

\section{a. Dilution of PCR samples}

Modern genetic analysers have highly sensitive fluorescence detection sensors, often necessitating the concentration of fluorophore-labelled PCR amplicons to be reduced for the emitted fluorescence to fall within the recommended detection range. Sample overloading can also affect the signal intensity and resolution, and result in clogging of capillaries, so should be avoided. The level of dilution will depend on the sensitivity and detection range of the genetic analyser, the efficiency and number of cycles of PCR amplification of SSR markers and fluorophores used, and has to be determined empirically for each multiplex. Generally, up to 100-fold dilutions are required. Dilutions should be optimised so that average sample to size standard peak intensity ratio is between 3:1 to 1:1. PCR samples can be diluted in formamide or molecular biology-grade water (nucleic acid- and DNase/ RNase-free). Diluted samples should be processed as soon as possible and exposed to ambient light as little as possible in order to prevent "bleaching" of fluorophores.

\section{b. Denaturation of diluted PCR samples}

Denaturation of PCR amplicons is necessary as only single-stranded DNA (ssDNA) will migrate in correlation to the fragment size during electrophoresis. Diluted PCR samples are combined with an internal size standard in formamide and incubated at $95^{\circ} \mathrm{C}$ for 3-5 minutes to achieve complete denaturation of dsDNA fragments. Different size standards are available, covering different DNA fragment size ranges. Care should be taken to select a size standard that extends over the entire allelic range of the analysed SSR markers. Follow the manufacturer's instructions for recommended ratios of denaturation mix components, e.g. formamide, sample and size standard. In contact with water formamide will hydrolyse into formic acid and formate, reducing its denaturing efficiency. In addition, the formate ions migrate preferentially into the capillaries during electrokinetic injection, causing a loss of signal intensity. Formamide should be stored at $-20^{\circ} \mathrm{C}$, and freezing/thawing more than two times avoided. It is recommended that aliquots of formamide are prepared to avoid its degradation. Denatured PCR products are best analysed immediately, as signal intensity will decrease with storage. Denatured samples should not be stored for longer than $24 \mathrm{~h}$ at room temperature, 5 days at $2-8^{\circ} \mathrm{C}$ or 1 week at $-20^{\circ} \mathrm{C}$.

\section{c. Capillary electrophoresis}

On most modern detection platforms electrophoretic separation of DNA fragments is highly automated and very little human input is required, apart from loading the plates with denatured samples, uploading or creating the sample list and selecting the appropriate run protocol. Likewise, operating software supplied with the genetic analysers comes with run protocols optimised for different types of analyses. Depending on the genetic analyser 
used, some optimisation of sample injection and run conditions (injection and run time, injection and run voltage) is usually possible and can improve data quality, run-to-run precision and/or throughput. Laboratories should approach such exercises with caution and consult the applicable technical documents and/or authorised technical support before introducing any changes to the electrophoresis conditions, and thoroughly validate the changed run protocols to ensure optimal results.

Injection time affects signal intensity and resolution. Increasing injection time can improve signal intensity for samples with low PCR product concentration, but longer injection times also decrease resolution, leading to a decreased peak height to width ratio. Increasing injection voltage affects signal intensity but does not significantly affect resolution. Still, lower voltages are preferred to ensure better accuracy of injection timing, and thus reproducibility in sample loading across samples and runs.

Any changes to electrophoresis conditions must take into consideration the range of DNA fragment lengths (allelic ranges of analysed SSR markers and internal size standard) and required resolution. Most often, optimisation of run times is performed to increase throughput. The optimal run time for a given run voltage should be determined through trial runs. The electrophoresis run time should be approximately $10 \%$ longer than the migration time of the largest DNA fragment of interest. In general, two size standard fragments immediately shorter than the smallest analysed fragment and the two size standard fragments immediately longer than the longest analysed fragment should be included to assure accurate generation of sizing curves. Increasing electrophoresis run voltage will shorten run times but is not recommended as higher migration speeds can lead to suboptimal separation of fragments and reduction in resolution.

\section{d. Allele calling and binning}

After raw data is generated by genetic analysers, the corresponding genotypes need to be read. Reading of genotypes is composed of two successive steps: true allele size calling (allele size expressed as actual (raw) detected fragment size in decimal numbers) and binning (assigning true allele sizes to discrete integer units, differing from one another by the size of the repeat unit) (Idury and Cardon 1997).

Allele calling encompasses identification of peaks in the electropherogram corresponding to alleles and determination of their actual size (length). Software provided with the capillary electrophoresis systems, e.g. Peak Scanner, MSA and GeneMapper by Applied biosystems/Thermo Fisher Scientific, GenomeLab (Beckman Coulter/Sciex), as well as third-party software, e.g. Geneious (Biomatters Ltd.), enable high level of automation of allele calling and can usually deal with many common genotyping problems, including stutter peaks, excessive baseline noise, "signal spikes" caused by debris or micro bubbles and off-scale peaks (Guichoux et al. 2011). Nevertheless, depending on the quality of the markers, allele calling may require some level of manual editing. As manual editing can be labour intensive and, by definition, introduces some level of subjectivity and error, it is important to select well-performing markers and optimise multiplexes and PCR to the highest degree possible (Scandura et al. 2006, Guichoux et al. 2011) and apply consistent rules for manual editing across all markers, samples and projects.

Binning, as the next step in genotyping, is critical and inconsistencies and arbitrary decisions regarding binning have been reported as a significant cause of SSR-based genotyping error (Ewen et al. 2000, Weeks et al. 2002, Morin et al. 2010). Many software packages developed by the capillary electrophoresis systems manufacturers or third-party software enable automatic binning. However, it is recommended that bins are checked, i.e. verified, manually, and adjusted if necessary, during the initial bin set-up phase and the consequent analysis. Raw data with actual detected allele size values is advisable to be stored for later reference, as well as comparisons. A simple, fast and efficient way to determine bin thresholds is to produce raw allele size distribution plots (Figure 6.4). This can be done by exporting actual DNA fragment size data to a spreadsheet, sorting the values by their size and producing scatter plots of the cumulative allele size dataset for each marker (Jayashree et al. 2006, Guichoux et al. 2011). Bins can then be set up around these size distributions at points where discrete breaks in periodic size classes are observed. Allele size distribution plots can serve several additional purposes: 
a. They provide a useful visual aid for quick identification of alleles that deviate from the expected periodicity of repeats, i.e. "mutant alleles" or "off-ladder variants". When such off-ladder alleles are detected, a manual check should be performed to determine whether off-ladder size is true or perhaps the result of inconsistent allele calling in the case of stutters, split peaks or other artefactual peaks. In such cases it is recommended to also perform simplex PCR under optimal conditions to check if off-ladder fragments are also produced under optimal conditions. If they are, and if such an allele variant is confirmed in several different individuals, it is likely that such an off-ladder allele is indeed true and should be considered as a unique, mutant allele with its own bin.

b. They enable identification of "allelic drift", i.e. a phenomenon of detected spacing between adjacent alleles differing slightly from the expected repeat length - for dinucleotide SSRs this spacing can vary between 1.8 to 2.2 bp (Amos et al. 2007); additionally, the spacing between adjacent alleles can change across the allelic range.

c. They can be used to detect shifts in detected allele sizes due to hardware malfunctioning or wear and degraded consumables. In this function, raw allele size distribution plots in combination with analysis of standard samples should always be considered when any changes to the analysis is introduced (change of fluorophore, change of polymerase, changes to the PCR cycling protocols or PCR mix composition, changes of the electrophoresis reagents (polymer and capillary type) or electrophoresis conditions, as these factors can all affect the detected size of DNA fragments (Hartzell et al. 2003, Sgueglia et al. 2003, Hahn et al. 2001, Ghosh et al. 1997). If shifts in detected allele sizes are detected due to any changes introduced, bins should be adjusted accordingly.

d. They can be used as part of the data integrity check to identify allele size values outside of the expected thresholds (see subchapter 6.5.4.1).

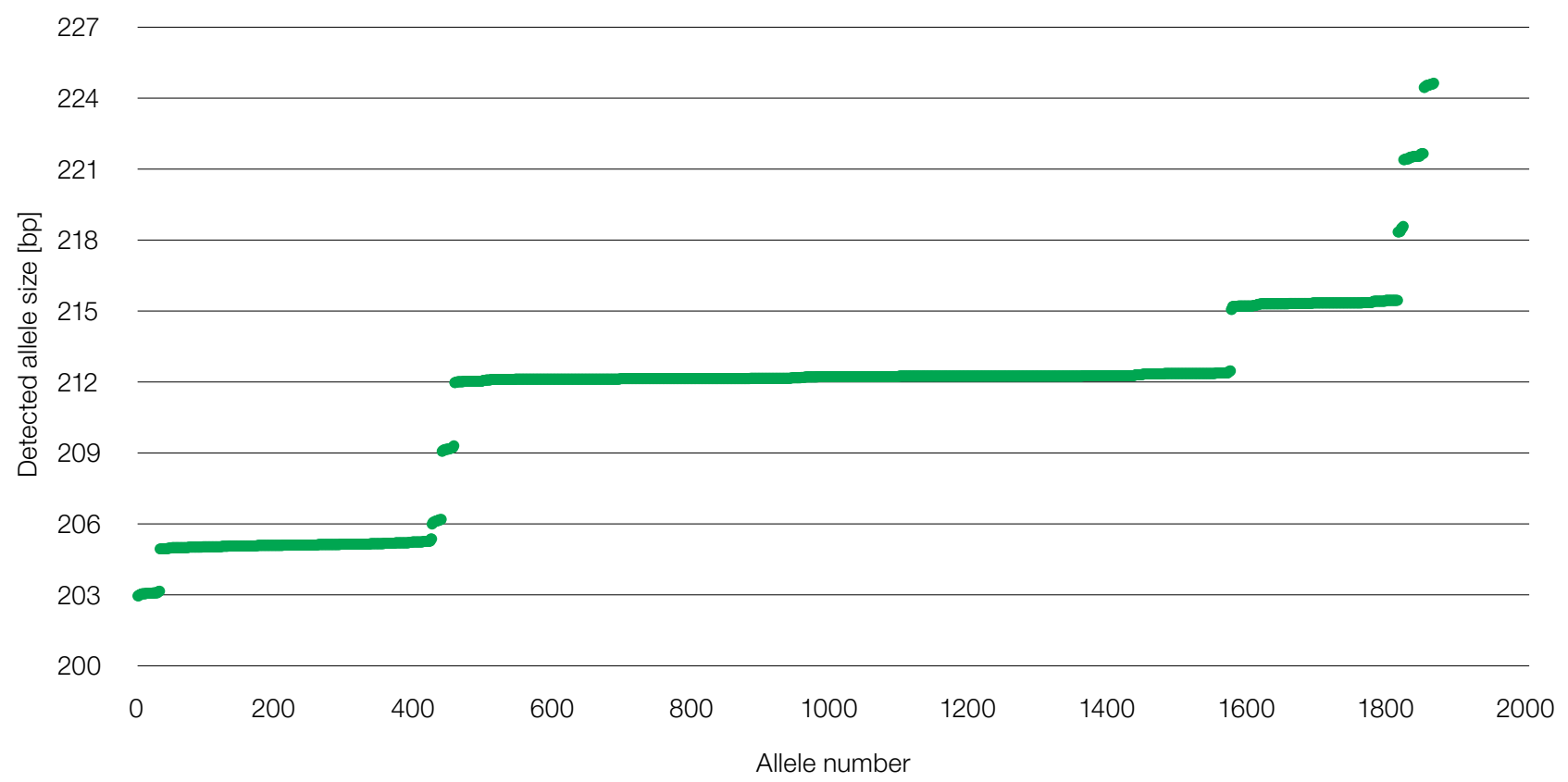

Figure 6.4: The detected amplicon size distribution of 1,864 alleles for a trinucleotide repeat marker Aag01 for Abies alba Mill. Most alleles follow the expected periodicity of 3 bp, except for an allele at the expected size of 206 bp, where two variants were detected - the expected 206-bp variant and an off-ladder 205-bp variant, which in this particular population represents one of the more frequent alleles. A manual check revealed that the presence of both expected and off-ladder variants was not the result of inconsistent allele calling as Aag01 is a "well-behaved" marker without split peaks and only minor stuttering. Additionally, several individuals were identified carrying both, the 205- and 206-bp variant, and the presence of both variants was also detected in adult reproducing trees, seeds and natural regeneration of different age. In this case, the 205-bp variant was considered a unique "mutant" allele, different from the expected 206-bp allele. 


\subsubsection{Single Nucleotide Polymorphism markers (SNPs)}

\subsection{Selection of suitable SNP markers}

Search the available scientific literature for the available SNPs and consult colleagues from other laboratories who have experience in working with the associated genotyping platform and the species in question. When selecting suitable SNP loci from literature or developing new ones, it is recommended to consider the following criteria:

- If linkage maps are available, select SNPs from as many different chromosomes as possible.

- Focus on the SNPs that have been successfully used on as large a number of samples as possible and on samples from different parts of the species distribution range, as this will minimise the chance of ascertainment bias. The same advice holds true regarding the reference samples utilised in order to develop a new SNP panel.

- If monitoring a species in a region where it is expected that hybridisation takes place, make sure to select SNPS that have been tested successfully for transferability between the hybridising species. It is recommended that tests are performed on samples of both species to check the performance of the SNPs used.

- Depending on the research question, gene-linked or neutral SNPs might be best suited.

- Always start with a larger number of potential SNP loci than you think is needed, as a lot of them might be dropped due to missing values, lack of variation (low minor allele frequency), or presence of bias.

- The total number of SNPs used will depend on the specific question to be answered and resources available. For example, around 180 unlinked SNPs are expected to be sufficient for accurate estimations of effective population size (Waples and Do 2010).

- If the number of SNPs available is not enough for your research question, and there are no funds to develop a larger panel, consider using SNPs detected in phylogenetically related species. However, expect high failure rates.

-While transferability of SNPs between genotyping platforms is generally high, expect some loss of variants (Semagn et al. 2014).

- If employing a multiplex high-throughput genotyping (e.g. genotyping by sequencing, RAD-seq), make sure you have the computational resources in order to analyse your dataset.

\subsection{DNA requirements for analysis of SNP markers}

DNA requirements for analysis of SNP markers will depend on the genotyping approach and/or service provider used. In terms of quality, genomic DNA extracts of high purity and integrity are required. To assure best results DNA extracts should have UV absorbance ratios A260/A280 > 1.8 and A260/A230 1.8 to 2.0. Refer to subchapter 6.4.1.4 for a more detailed explanation of assessment of DNA quality.

Analysis of SNP markers can be carried out in house or rely on outsourcing and the DNA quantity values presented below should serve as general guidelines, as the required quantities will vary depending on the type of analysis and the service provider.

For SNP analysis by high throughput sequencing (HTS), such as RAD-sequencing, a total amount of approximately $3 \mu \mathrm{g}$ of DNA is required at concentrations $50-100 \mathrm{ng} / \mathrm{\mu l}$.

For SNP analysis by KASP (Kompetitive Allele Specific PCR) the required quantity of DNA depends both on the size of the genome of the organism in question and the number of SNP markers analysed. Approximately $10 \mathrm{ng}$ of DNA per SNP marker are required for genomes in the $2-3.5$ Gbp range. For analysis of 200 SNP markers of Abies alba, which has an approximately 30-Gbp genome, this would translate into $20 \mu \mathrm{g}$ of DNA. Since such quantities of DNA are sometimes difficult to obtain, Whole Genome Amplification (WGA) can be performed prior 
to KASP itself in order to assure sufficient quantity of template DNA, although this pre-amplification step can increase the base-call error rate. For $2-3.5 \mathrm{Gbp}$ genomes approximately $50 \mathrm{ng}$ of genomic DNA are sufficient for KASP analysis of $500-1,000$ SNPs with prior WGA step by primer extension pre-amplification (PEP) technique.

\subsection{Data analyses}

\subsubsection{Introduction}

Forest genetic monitoring aims to assess a forest population's capacity to survive, reproduce, and persist under rapid environmental changes on a long-term scale (Fussi et al. 2016). Three indicators, (1) selection, (2) genetic variation and (3) gene flow/mating system, are monitored with a set of verifiers. To do so, field, laboratory and molecular marker data needs to be collected/produced and analysed to regularly assess verifiers for the above three indicators. The data collection/production and analysis must be standardised and data available for long term comparisons.

In order to compare the results across time, the same set of genetic markers (e.g. microsatellites - nSSRs, single nucleotide polymorphisms - SNPs) should be used and analysed for the assessment of verifiers. With rapid changes in technology and increases in the available markers, it is wise to store tissue samples for genetic analysis at a later point in time to maintain comparability. As an added value, standardised data from numerous FGM plots for the same tree species may be compared to elucidate whether a particular population is performing better or worse than the others.

This chapter describes the acquisition and assessment of data, including: (a) data types (field, molecular), (b) data filtering, (c) data analysis (R-script tool, genetic software, etc.) and interpretation of values, and (d) data storage. To guarantee long-term comparable results of genetic monitoring, it is important to follow the described procedures, which have been standardised within the LIFEGENMON project.

\subsubsection{Database}

Databases are sets of data that are arranged in tables and rows, as in Microsoft Excel or similar programs, but interconnected in relationships. Tables have their own predefined structure that ensures that the data is in the right format and in the right place. The user enters data into the database in a systematic and orderly manner via forms. The database then enables the user to retrieve the correct data quickly and easily. Compared to Microsoft Excel, database tables normally have very strict rules regarding what data can be inserted and how, which is very important to exclude user input errors. These are not the only errors which we can avoid using a database, for example Ziemann et al. (2016) showed with a programmatic scan of leading genomics journals that approximately one-fifth of papers with supplementary Excel gene lists contained erroneous gene name conversions.

\subsubsection{LIFEGENMON Database}

In FGM we are dealing with many different data types, e.g. genetic, phenological, meteorological data and other field data. A database which contains all these data types enables us to more easily and quickly detect temporal changes and interpret the results. There are many possibilities regarding database selection. In LIFEGENMON two database management systems have been tested: Open Foris and a standalone PostgreSQL database. The underlying database schema for both is the same (Figure 6.5). The database schema is based on the guidelines which are part of this manual, and can be used as a template to recreate the database.

\section{Open Foris}

Open Foris is a set of free and open-source software tools that facilitates flexible and efficient data collection, analysis and reporting. Open Foris Collect is the main entry point for data collected in field-based inventories. 
It provides a fast, easy, flexible way to set up a survey with a user-friendly interface. Collect handles multiple data types and complex validation rules, all in a multilanguage environment. Due to its user-friendly interface it offers an effective open-source solution for research projects that are financially limited regarding professional database management. Open Foris also has a tool called Calc, where R scripts can be created and automated calculations can be made. Open Foris is by default based on a SQLite database or PostgreSQL. However, the data is saved in a binary form, which means it is not directly accessible with SQL queries (it first needs to be converted to other formats). It is also slow in some cases, especially when we are inserting larger amounts of data into tables, which is very often the case with genetic data.

\section{PostgreSQL}

PostgreSQL is a free and open-source relational database management system. PostgreSQL has a long history of development behind it and has gained a strong reputation for reliability, feature robustness, and performance. Compared to Open Foris, the main benefits are better performance, stability and unlimited possibilities for user

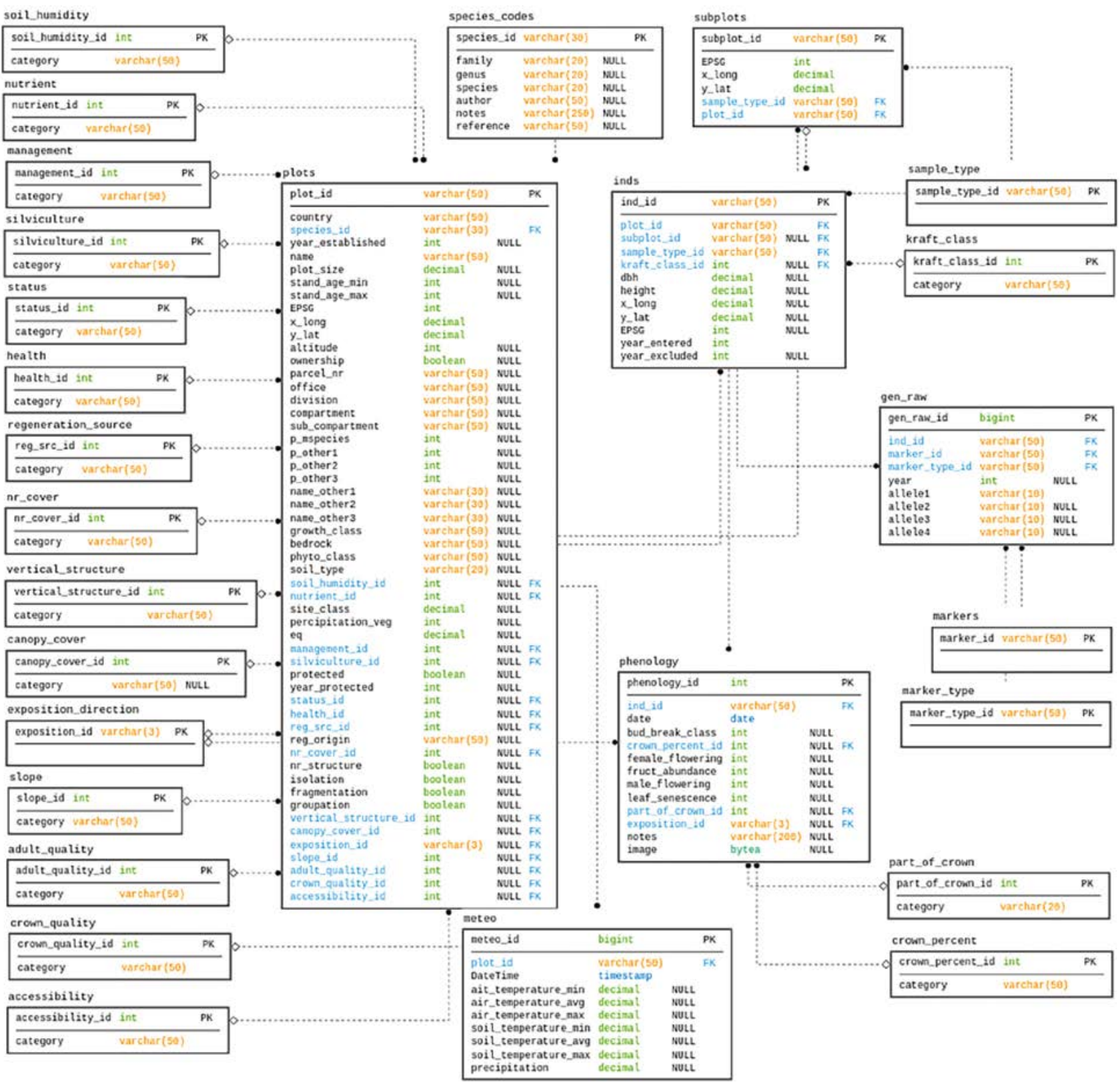

Figure 6.5: A schematic diagram of the database design. In the tables the first column represents column names, second column is the allowed data type, e.g. int, NULL - this field can be skipped when inserting data, PK - primary key, FK - foreign key. 
control, modifications and interactions with various programming languages, e.g. with popular languages for data analysis like $R$ and Python. In LIFEGENMON an application was created in R (easyRpopgen) for displaying and analysing the results from FGM data (see subchapter 6.5.4.4 on R-script tool). We found that currently the only minor benefit of Open Foris compared to standalone PostgreSQL is the included user interface.

In the future Open Foris could change the way data is stored and a PostgreSQL database connected with Open Foris user interface could be a very attractive option, but as for now we recommend using just PostgreSQL and if needed to develop a user interface which best suits the needs of FGM.

\subsubsection{Analysis of field data}

Potential verifiers of selection in the population can be assessed through changes in population demographics such as mortality rates, the abundance of trees established through natural regeneration, sex ratios and age class distributions. These demographic factors are affected by the reproductive success and ability of a cohort to adapt to stressors such as environmental stressors, disease and herbivory, thus reflecting the natural selection pressures acting on the population. It can also be assessed through flowering phenology, which has been shown to be an important component mediating the reproductive fitness of individuals (Munguía-Rosas et al. 2011), and thus adaptive strategies influenced by evolutionary drivers (Kudo 2006).

\subsubsection{Field data integrity check}

Trees are assessed in-field for verifiers and background information, such as mortality, natural regeneration abundance, diameter at breast height (DBH), height class distribution, and phenological patterns (including budburst, flowering, and senescence). The in-field assessment of these properties presents challenges from a data-collection standpoint. Principally, observational and protocol errors add to the natural variability observed in phenotypic data through intra-species variability and microclimate effects, and can add 1-2 weeks uncertainty to the measured values (Schaber and Badeck 2002, and references therein). They can also result in spurious observations that are unexpected for a given method, such as unusually high records of tree diameter or height. It is therefore necessary that in the first instance researchers proceed with caution and attentiveness when carrying out the analysis and collating data, but also that the data is rigorously checked once collected for any potential errors that could compromise its integrity. One way to ensure data integrity with so many data types as in FGM and different protocols is to use a database system (see subchapter LIFEGENMON database).

Data outliers are observations that lie far outside the expected range or distribution of the collected data. Outliers can be possible indicators of incorrectly gathered or mislabelled data and so need to be considered before data analysis. Cautiously removing outliers has been shown to be an effective method in improving the reliability of time-series phenological data (Linkosalo et al. 1996). In general, a simple way to remove outliers from the data is through graphical diagnosis with boxplot visualisations of the data. In a classic boxplot any value smaller or greater than 1.5 times the interquartile range of the sampled values will be considered as an outlier, signified graphically with a point outside the boxplot's whiskers. With normally distributed data, a z-score approach can also be followed. In this approach, raw values are transformed to z-scores:

$$
z_{i}=\frac{x_{i}-\bar{x}}{s}
$$

where $z_{i}=$ normalised $z$-score, $x_{i}=$ raw value, $\bar{x}=$ sample mean, $s=$ standard deviation of the sample. Data points are considered outliers if the $z$-score is greater than a given threshold e.g. more than 3 standard deviations from the mean, as was implemented by Gerard et al. (2020). A discordancy test with a similar approach is presented by King (1953) which can also be used on normal data, wherein a test statistic Ti is calculated by comparing the excess of an extreme observation from the closest observation in the total range, and the value this value if Ti exceeds a critical value (detailed in Barnett and Lewis 1978). This test was implemented in Linkosalo et al. 
(1996). Month-mistakes (a protocol error where the month of observation has been incorrectly assigned) can also be reliably detected though the distribution-free 30-day residual rule due to the large deviation of such values (Schaber and Badeck 2002). Using one or a combination of these approaches should allow for the detection and correction or removal of outlier values.

Finally, the expertise of the researcher is also an important factor in filtering outlier values that are unrealistic (but may still sit within a given distribution model and thereby not be removed through outlier detection), such as abnormally high tree diameters for a given species. Given that phenology describes phenomena with a natural and sequential progression (e.g. budburst occurs before flowering, which occurs before leaf senescence), data must also be sense-checked to ensure that the measurement of these variables is in fact proceeding in a logical order.

\subsubsection{Field data analysis}

\subsection{Verifiers}

In FGM, selection indicator verifiers are measured at various temporal points throughout the year over a period of many years. For most of the verifiers population level averages can be calculated in different time periods. In general, the verifiers can be compared across years and populations through different parametric and nonparametric statistical approaches, depending on the type of response variable. For verifiers which are numerical variables, the population level average is compared over the years using linear regression models or linear mixed effect models (where a random effect can be defined, which is important when observations/measurements are performed on the same objects). For verifiers where evaluation is done using a code table, ordinal regression (e.g. the clmm model in R, where random effects can be defined) or the Kruskal Wallis test can be used. Count data usually follows the Poisson distribution. Therefore, for count data verifiers, Poisson regression (generalised linear models or generalised mixed effect models with Poisson family) may be used for the analysis.

\subsection{Mortality / Survival}

\section{Background}

Mortality / survival refers simply to the number of trees that have died relative to the baseline (and to the previous assessment). A change in Mortality or Survival (Mortality = 1-Survival) indicates an underlying selection pressure, i.e. dieback when the value of mortality is increased. It is therefore an important indicator of potential selection pressures put on a population resulting in death, as the surviving trees likely had some adaptive response to such a pressure.

\section{Calculation}

Mortality is expressed as the mortality rate calculated by the following equation

$$
m=1-\left(\frac{N_{1}}{N_{0}}\right)^{1 / t}
$$

where $N_{0}$ and $N_{1}$ are the tree counts at the beginning and at the end of the census interval and $t$ is the length of the census interval in years. The mortality rate calculated according to this equation is the annual mortality rate and is constant, which means that it is interpreted as the average annual mortality rate for that decade. If we omit the exponent, we get a 10-year mortality rate.

If original trees had to be replaced due to management, the mortality can also be expressed as the absolute number of dead trees per 50 trees over a 10-year period, calculated by subtracting the remaining alive trees from the initial marked trees:

$$
\text { Mortality }=N_{0}-N_{1}
$$


where $N_{0}$ is the initial number of trees and $N_{1}$ is the number of trees remaining alive. If any of the original 50 trees is cut down due to the management, the replacement tree should be included within both the initial number of trees and the remaining trees. Trees that have been cut down due to the management are not considered as dead trees. The initial number of trees at each ten-year interval is 50 (see section 3.4.2 Replacement of trees).

The difference in mortality between censuses is described using a chain index and the growth rate, where the value of mortality in census $\mathrm{c}$ is always compared with the mortality in census $\mathrm{c}-1$.

\subsection{Natural Regeneration Abundance (NR)}

\section{Background}

In the maintenance of forest tree stocks, many natural factors contribute to mortality including aging, herbivory and disease, along with any potential thinning due to human activity such as harvesting resources. It is therefore imperative that for a forest stand to remain sustainable it must be continuously restocked through the establishment of new tree seedlings. This can be achieved through artificial regeneration, natural regeneration of the tree stock or a combination of both. In artificial regeneration trees are grown separate from the forest i.e. in nurseries and transplanted into the forest at the appropriate age. Through natural regeneration, forests are instead restocked with trees that can develop from seeds that fall and germinate in situ. The abundance of trees established through natural regeneration is therefore indicative of underlying selection pressures affecting reproductive success, seedling and sapling survival rates and adult tree mortality rates (affecting the stock from which forests can be regenerated). Regeneration abundance is defined as the number of seedlings per unit area.

\section{Calculation}

At the basic level NR abundance is assessed using expert opinion, whether there is a sufficient amount of NR present on the FGM plot. At standard and advanced levels it is determined by counting all plants in twenty 1 $\mathrm{m}^{2}$ plots after different fructification events, as stated in the species specific guidelines. Like mortality, this is a population-level assessment that can be qualitatively compared between time periods/age class cohorts.

At the basic level change in NR abundance over the years is described based on expert opinion. At the standard level NR abundance in year $t$ on the first set of NR subplots is compared to NR abundance in year $t+6$ on the second set of NR subplots, if the next fructification event is assessed after 6 years. On both sets of NR subplots, seedlings are counted again after 5 years (in year $t+5$ for the first set of NR subplots and in year $t+11$ for the second set of NR subplots). In the same way, the abundance of 5-year-old seedlings on both sets of NR subplots is compared. A model that takes the discrete nature of the count variable into account is suitable for analysis, such as the Poisson regression model. At the advanced level, seedlings from each set of NR subplots are counted in the year of germination and 5, 10 and 15 years after germination. The analysis is carried out in the same way as at the standard level by comparing the NR abundance of the same age.

\subsection{Flowering}

\section{Background}

Flowering phenology is the study of timing of the male and female flowers development by recording the different phenophases (Ducci et al. 2012). Flowering phenology is a crucial factor affecting tree reproduction fitness, via gene exchange among genotypes that determines the genetic variation of the produced seed crop and the survival success of the produced seedlings (Alizoti et al. 2010).

\section{Calculation}

Phenology observations take into account the assessment of flowering abundance/proportion of flowering trees at the stand level (basic FGM level) and at individual tree level (standard FGM level), and developmental phases (phenophases) of male and female flowers from dormant flowering buds to fully developed flowers/ 
conelets/strobili (advanced FGM level). The data are used for the assessment of the abundance of flowering and proportion of flowering trees (basic, standard and advanced FGM). Additional data (advanced FGM) are used for the construction of phenograms indicating the initiation, duration, ending and synchronisation of the phenomenon and the different phenophases. These data is analysed by using parametric and non-parametric statistical methods to assess the significance of phenological differences among individual trees within population or populations. All relevant software performing parametric and non-parametric statistical analysis (i.e. SPSS, R) can be used to assess flowering phenology data.

\subsection{Fructification}

\section{Background}

The intensity and periodicity of fructification between consecutive mast years is species specific and varies depending on weather conditions, resource availability and genetic control (Mund et al. 2010 and references therein). The beginning of fructification is an important sign which indicates the maturation of trees and shows that all resources previously dedicated for vegetative growth and defence becomes also allocated for reproduction (Seifert and Müller-Starck 2009).

\section{Calculation}

Phenology observations take into account the periodicity and intensity of fructification. The data is collected at the stand level (basic FGM level) and on a per tree basis (standard and advanced FGM level) and is analysed by using parametric and non-parametric statistical methods to assess the significance of phenological differences among individual trees within population or populations. All relevant software performing parametric and nonparametric statistical analysis (i.e. SPSS, R) can be used to assess fructification data.

\subsection{Background information}

\subsection{Crown dieback (Fraxinus excelsior only)}

\section{Background}

Crown dieback is a background information used only in the FGM of European ash (Fraxinus exce/sior). The causal agent of crown dieback in $F$. excelsior is the fungal pathogen Hymenoscyphus fraxineus. Symptoms of the disease first appeared in European F. excelsior populations in the early 1990s, leading to a widespread epidemic which is still ongoing. The disease is characterised by necrotic lesions on the leaves, twigs and stems of infected hosts, leading to wilting and crown dieback (recent research has been summarised by Gross et al. 2013). The severity of crown dieback is closely linked to the genetic potential of an individual or population to confer resistance to the fungal pathogen which causes it. Genetic markers have been identified which suggest that resistance to ash dieback is a polygenic trait which may respond well to both natural selection and breeding programs (Harper et al. 2016, Stocks et al. 2019). This is therefore likely a very strong selection pressure on populations of $F$. excelsior. Ash dieback can be effectively monitored through both visual in-field inspection of diseased and healthy trees, and through molecular testing for the genetic markers which may confer increased resistance (Menkis et al. 2019).

\section{Calculation}

Evidence of selection for ash dieback resistance could be compared between cohorts of the same age between different assessments and between populations through monitoring mortality rates due to dieback and the rate of crown loss and infection spread in non-healthy trees from each cohort and population over time.

For the analysis the percentages of ash trees in the different defoliation classes can be calculated. ANOVA with the least significant difference post hoc test can be used to analyse significant differences in defoliation between different time periods for means of each defoliation class.

For the analysis software like SPSS or programming languages like R or Python can be used. 


\subsection{Sex ratio (dioecious species only)}

\section{Background}

The sex ratio refers to the recording of individual tree sex in dioecious species. Sex ratios are generally in equilibrium, as expected by Fisher's Law (Fisher 1930), or tend to be slightly biased towards males (Lloyd 1974, Barrett et al. (2010). The ecological genetics of sex ratios was reviewed by Barret et al. (2010). They posit that sex ratios are thought to be biased towards males primarily due to an uneven expenditure on reproduction between the sexes including earlier onset of male flowering, increased frequency of flowering in males, and greater mortality in females. This effect may however become mitigated as a cohort ages and female trees become more reproductively active. The monitoring of sex ratios in dioecious tree species populations is important due to its impact on effective population sizes, as populations with skewed sex ratios tend to have lower effective population sizes (Wright 1938). Having a reduced effective population size can in turn lead to the reduced effectiveness of natural selection on a population through a decreased effective size of the genetic stock available, leading to increased rates of genetic drift and inbreeding, and subsequently loss of genetic variability (Charlesworth 2009). Sex ratio changes between cohorts such as adult and natural regeneration trees can therefore be indicative of the genetic capability of the cohort to respond to natural selection and their long-term viability and sustainability.

\section{Calculation}

As we are comparing the observed counts of observations for each sex with the expected counts, the theoretical expectation of sex ratio so to speak or the ratios in different time periods, we can use a chi-square test or G-test.

Loglinear analysis can be used for more advanced analysis if we want to incorporate more data to look at possible correlations between the sex ratio of a population and other life history characteristics.

If data from other spatial locations (plots) is available, a Gaussian generalised linear mixed model (GLMM) can be used to quantify temporal and spatial variation in sex ratios, where sex ratio is modelled as a function of year, $x$ and $y$ coordinates of a geographic coordinate system and their interaction. The location and year should be included as random effects to account for non-dependence of counts from the same site and year.

For the analysis software like SPSS or programming languages like R or Python can be used.

\subsection{DBH and height class distribution}

\section{Background}

The height of trees and diameter at breast height $(\mathrm{DBH})$ are measures of tree size that can be representative of the age of a tree. Beyond this the size of plants has been shown to influence flowering phenology, though this effect may most strongly be observed in annually flowering trees (Otárola et al. 2013). Tree size can potentially moderate flowering phenology through affecting light availability and resource acquisition (Muller-Landau et al. 2006), thus contributing to their ability to reproduce and pass on their genetics to the next generation. The distribution curves of tree diameters and tree heights in a plot indicate current and historic selection pressures affecting the successional trends of tree canopies (Buchholz and Pickering 1978).

\section{Calculation}

To gain insight into the variation of $\mathrm{DBH}$ and height classes distributions between different time periods, data can first be plotted and for visualisation a non-linear least squares exponential function can be fitted to the distributions (using the nls function in the R package "stats" (R Core Team 2020)). To quantitatively compare these distributions the Anderson-Darling k-sample test can be used (as an alternative to the Kolmogorov-Smirnov test). For this we can use the function adKSampleTest, or the function adAllPairsTest in the R package "PMCMRplus" to make all-pair comparisons (Pohlert 2020). 
As tree size is correlated with different verifiers and environmental parameters, other analyses considering these correlations can be performed. Linear regression can be performed to see whether residuals of DBH and height are correlated with temperature or precipitation, for example. Such analysis can provide insight into whether the increased temperature has a negative effect on $\mathrm{DBH}$ and height.

\subsection{Budburst}

\section{Background}

Budburst (also termed bud break, leaf unfolding or bud flush) is the period spanning from dormant buds up to shoot elongation. Information about the timing and the duration of budburst provides important information in understanding the actual state of the trees and forest tree populations in the changing environment. It is important to detect trends and possible factors (natural and/or anthropogenic) causing changes in the timing and duration of phenological stages (starting time, duration of period and magnitude) (Beuker et al. 2010).

\section{Calculation}

Phenology observations take into account the stage of the phase and the proportion of crown which is affected. Observations are conducted on 50 trees once per week during the flushing period. The data is used for the construction of phenograms indicating the initiation, duration and ending of the phenomena on a per tree basis and is analysed by using parametric and non-parametric statistical methods to assess the significance of phenological differences among individual trees within population or populations. Any relevant software performing parametric and non-parametric statistical analyses (i.e. SPSS, R) can be used to assess budburst phenology data.

\subsection{Flowering synchronisation}

\section{Background}

Flowering synchronisation is a part of flowering phenology, which focuses on the timing of the male and female flowers development by recording the different phenophases (Ducci et al. 2012). Flowering synchronisation is monitored only at the advanced level, and is based on the data collected for the verifier "Flowering". It is used to determine whether male and female flowering times occur simultaneously within the monitored stand.

\section{Calculation}

Phenology observations take into account the developmental phases (phenophases) of male and female flowers from dormant flowering buds to fully developed flowers/conelets/strobili. The data is used for the construction of phenograms indicating the initiation, duration, ending and synchronisation of the phenomenon and the different phenophases on a per tree basis, and is analysed by using parametric and non-parametric statistical methods to assess the significance of phenological differences among individual trees within population or populations. Any relevant software performing parametric and non-parametric statistical analyses (i.e. SPSS, R) can be used to assess flowering synchronisation.

The flowering synchronisation is evaluated by using the Askew $\left(\mathrm{PO}_{\mathrm{o}}\right)$ - Phenological Overlap index (Askew and Blush 1990) below:

$$
\begin{aligned}
P O_{o} & =\sum_{j=1}^{t} \sum_{k=1}^{t} \frac{P O_{j k}}{(t(t-1))} \\
P O_{j k} & =\frac{\sum_{i=1}^{n}\left(s_{i j k}-\Delta_{i j k}\right)}{\sum_{i=1}^{n} s_{i j k}}
\end{aligned}
$$

Overall Phenological Overlap index for all outcross mating combinations between all monitored trees; $j \neq k$

Phenological Overlap index for a tree $j$ and a tree $k$ over $n$ observations $i ; j \neq k$ 


$$
\Delta_{i j k}=\left|m_{i k}-p_{i j}\right|
$$

The absolute value of the difference between $m_{i k}$ and $p_{i j} ; j \neq k$

Where:

$p_{i j}=$ proportion of monitored male flowers from the individual $j$ that are shedding pollen on day $i ; m_{i k}=$ proportion of monitored female flowers from the individual $k$ that are receptive on day $i ; s_{i j k}=$ the larger of the $p_{i j}$ and $m_{j k}$;

\subsection{Senescence}

\section{Background}

Leaf senescence is the collective series of degenerative events that decrease metabolic activities and cause the death of cells, tissues and leaf organ (Lim et al. 2007). Information about the timing and duration of leaf senescence therefore provides important data for understanding the actual state of the trees and forest tree populations in the changing environment.

\section{Calculation}

Phenology observations take into account the scoring system which can be used for assessment of leaf senescence; the stage of the phase and the proportion of crown which is affected. The data is used for the construction of phenograms indicating the initiation, duration and ending of the phenomena on a per tree basis and is analysed by using parametric and non-parametric statistical methods to assess the significance of phenological differences among individual trees within population or populations. Any relevant software performing parametric and non-parametric statistical analyses (i.e. SPSS, R) can be used to assess senescence data.

\subsubsection{Analysis of Molecular Data}

\subsubsection{Molecular data integrity check}

Traditionally researchers genotype samples using a set of hyper-variable microsatellite loci in an effort to gain sufficient statistical power for downstream analyses. However, these loci are expected to have higher error rates (Flores-Rentería and Krohn 2013), which in turn may lead to lower power and biased inferences (Dąbrowski et al. 2015).

One of the most common issues in microsatellite genotyping is the presence of stutter bands. These occur as a result of polymerase slippage and may cause high error rates, particularly in the case of heterozygotes with adjacent alleles (Clarke et al. 2001). In the planning stages of a project, trinucleotide repeat markers should be preferred over dinucleotide microsatellites as they generally display lower incidence of this phenomenon (FloresRentería and Krohn 2013). Furthermore, primers that include the part of the microsatellite region have been proposed to mitigate slippage (Flores-Rentería and Whipple 2011). A reduction in stutter could be achieved by optimising the PCR reaction conditions and program (for details see 6.4.2.2.2). Ultimately, even after optimisation in the lab stutter bands may be present and re-screening of problematic samples might be necessary (Dewoody et al. 2006). The software 'Micro-Checker' (Van Oosterhout et al. 2004) can be employed to detect loci that may be mis-scored due to stuttering by identifying deficiencies of heterozygotes with adjacent alleles.

Allelic dropout or short allele dominance describe the stochastic failure of the largest allele in a heterozygous sample to amplify in PCR. This is known to be caused by: (i) low quality and low quantity of DNA template (Taberlet et al. 1996), and (ii) the competitive nature of PCR (i.e. alleles of shorter length amplify more effectively than larger ones) (Gagneux et al. 1997). Since this problem is not systematic, a DNA purification step and/or a second PCR amplification should increase the chances of detecting dropped alleles (Flores-Rentería and Krohn 2013). A sign of allelic dropout in a locus is the presence of a large amount of homozygotes at the extremes of the allelic range, which can be identified with the software 'Micro-Checker' (Van Oosterhout et al. 2004). 
If alleles systematically fail to amplify due to mutations in the primer binding regions, then they are referred as null alleles (Oddou-Muratorio et al. 2009). Apart from the usual issues associated with genotyping errors, such as bias in genetic diversity/differentiation statistics, a major impact of null alleles is the exclusion of correct parents in parentage analyses (Dakin and Avise 2004). Several computer programs are available, so researchers may calculate the presence and frequency of null alleles, for example 'genepop' (Rousset 2008), 'ML-NullFreq' (Kalinowski and Taper 2006), 'Micro-Checker' (Van Oosterhout et al. 2004), and 'Cervus' (Summers and Amos 1997). Nevertheless, discrepancies in the estimations of the number and/or frequency of null alleles exist between software packages, making inference difficult. For this reason, it is suggested to employ multiple methods and use the median values (Dąbrowski et al. 2015). Nunziata et al. (2015) excluded loci showing null alleles when $\mathrm{F}_{\text {ST }}$ values between different sampling points were lower than when loci with null alleles were included.

Stochastic genotyping errors may also arise from human mistypes during the scoring process. A list of private alleles like the one provided by 'GenAlEx' (Peakall and Smouse 2006) or 'poppr' (Kamvar et al. 2014) should provide indications for spurious alleles to be investigated further. Special attention should be devoted to alleles not respecting the marker repeat motif. However, this characteristic alone is not necessarily a reason for their removal, as scoring outside of the repeat motif can be a deliberate choice in order to accurately record diversity, particularly in the case of compound microsatellites (e.g. (GT)6(ACA)9) (Flores-Rentería and Krohn 2013). The detection of alleles that have not previously been reported in the literature and/or are situated outside of the reported range must also be dealt with caution. If such an allele presents itself multiple times in the dataset, then there is no reason to dispute its existence. Conversely, if this allele is only found in a single sample, a repeat of the PCR reaction is recommended (Flores-Rentería and Krohn 2013).

A Principal Components Analysis (PCA) could also prove useful in uncovering scoring errors. Samples that appear to be located far from their respective populations require manual review. Furthermore, with a PCA it is possible to identify possible artefact alleles that manifest themselves as highly influential for sample differentiation. This can easily be inspected by plotting the loadings of alleles which form a principal component in the R package "adegenet" (Jombart 2008) with the function "loadingplot".

Finally, in a multiplex PCR scenario, if the concentration of PCR products is several times above the recommended range, then spectral overlap between dyes might be present (Flores-Rentería and Krohn 2013). In that case, artefact peaks originating from real alleles of another channel would be present in the electropherogram, a phenomenon known in the literature as "bleedthrough" or "pull-up". Scoring these artefact peaks as real alleles means that the same allele would be scored twice, creating a link between two alleles from different loci. In turn, this is expected to create a signal detectable as a spurious linkage disequilibrium (LD) between the loci. Therefore, significant LD should be investigated further between markers with overlapping PCR products.

In general, researchers should try to extract as much information as possible from the published literature regarding marker reproducibility among laboratories and the presence of unwanted interactions between loci (i.e. true linkage disequilibrium) at the planning stages of a project. Moreover, it is recommended that a representative sample of the dataset (e.g. 10\%) is re-analysed for quality control (Dewoody et al. 2006). After data comparison, the error rate has to be expressed for each locus and over all loci as:

- error rate per reaction: the proportion of PCR reactions yielding at least one incorrect allele over the total number of reactions, as well as

- error rate per allele: the proportion of alleles that are incorrect over the total number of alleles (Hoffman and Amos 2005).

\subsubsection{Molecular data filtering}

Data filtering is an important step for the extraction of robust results from raw data. Filters are essential for the amelioration of the effects of missing values, as well as for disentangling the effects of different evolutionary processes. 
In data filtering, the first step is the elimination of loci with large sets of missing values (cut-off value to be defined before the start of the analysis). The second involves individual samples that exceed a predefined level of missing values, which should also be removed from all further analyses.

Setting an overall cut-off for missing values for loci (e.g. 10\%) entails an expectation that missing data is relatively evenly distributed among cohorts and samples. This premise however cannot be guaranteed when geographically isolated samples, or samples from different phylogenetic lineages are jointly analysed (e.g. A. alba and A. borisiiregis). In such cases there is a high chance that ascertainment bias might be encountered. This is the type of bias expected to occur due to high genetic distance between the individuals used for locus discovery on the one hand, and the samples genotyped on the other. SNP arrays are known to be particularly prone to this type of bias (Albrechtsen et al. 2010). For instance, in the LIFEGENMON dataset the Greek populations (A. borisii-regis and Fagus sylvatica) exhibited lower values of gene diversity compared to their Central European counterparts according to the SNP data, but displayed similar values in the SSR dataset. These discrepancies might be the result of ascertainment bias, and therefore, for such experimental designs, it might be advantageous to perform the filtering on a cohort basis.

As a third step, a filter based on Minor Allele Frequency (MAF) may also be employed. The rationale for this filter is the elimination of uninformative markers and potential genotyping errors obscuring inferences (Roesti et al. 2012). For SSRs, a usual MAF filter employed is $5 \%$ or $1 \%$, as these markers provide relatively little information. However, it might be useful to monitor the temporal progression of allelic frequencies of these loci, especially if they are linked to expressed sequences (EST-SSRS), as such loci can potentially give an insight into adaptive genetic diversity. For SNP genotyping via the KASP platform, the low error rate of the technique compared to genotyping by next-generation sequencing technologies (Semagn et al. 2014), means that discarding loci with low frequency polymorphisms from all further analyses is probably excessive. This is especially true for smaller datasets, where it can lead to loss of private alleles and weaken the signal of gene flow. Therefore it is suggested to remove only markers with the minor allele occurring up to twice in the dataset (Pluess et al. 2016), or a MAF filter to be applied specifically to analyses that require it (e.g. estimation of effective population size, $F_{S T}$ outlier tests, etc.), according to the respective software's manual.

Linkage disequilibrium (LD) consists of an additional consideration when analysing molecular marker datasets. The presence of LD between pairs of loci could signify the physical proximity of these loci in the genome, but it could also occur between unlinked loci as a result of drift. Failure to discard linked markers results in wrong estimates of variables that depend on this signal, such as the estimation of effective population size $(\mathrm{Ne})$ via the LD-method (Hill 1981). Multiple software packages are available for LD calculation, such as "Arlequin" (Excoffier and Lischer 2010) and the R package "poppr" (Kamvar et al. 2014). Because this is a procedure where multiple hypotheses are tested, the chance of incorrectly detecting LD between a pair of loci is high. Therefore, it is critical to perform multiple test corrections. For SSR data, this is usually achieved by employing the sequential Bonferroni correction (Rice 1989). For SNP datasets, this correction might be too conservative and thus the false discovery rate (FDR) (Benjamini and Hochberg 1995) is used instead. The package "multcomp" (Hothorn et al. 2008) is available in $R$ for those calculations.

Calculation of summary statistics from a dataset that potentially contains loci under selection could obscure the signal of demographic processes. For this reason, it is advised to remove loci for which there is strong evidence that they display adaptive polymorphisms, when investigating demography. These loci exhibit outlier $F_{S T}$ values and are expected to be detected by one or preferably more $F_{S T}$ outlier detection methods (see "F-analysis outlier test" for more details).

The presence of null alleles can have an impact on the calculation of summary statistics from a dataset that potentially contains a higher percentage of them. The presence of null alleles can be checked using various software (e.g. Micro-checker (Van Oosterhout et al. 2004), CERVUS (Kalinowski et al. 2007), and the R package "PopGeneReport" (Adamack and Gruber 2014)). If the presence of null alleles is very high it is advised to remove loci from further analysis (Chapuis et al. 2008, Belletti et al. 2012). 


\subsection{SNP data filtering}

For the LIFEGENMON datasets, the treatment of missing data followed that of similar works described in the literature (Csilléry et al. 2020; Heer et al. 2018).

\subsubsection{Data analysis}

\subsection{Verifiers}

\subsection{Allele Frequency}

\section{Background}

Loci and alleles are the basic units measured in population genetics. A locus is a distinct genetic unit under consideration, such as an entire gene, a single nucleotide base pair (A-T and C-G), or a string of nucleotides. For each genetic locus there can be several variants, known as alleles. Single nucleotide polymorphisms (SNPs) are substitutions of a single nucleotide at a specific position in the genome. In a diploid organism, an SNP locus can therefore either contain two copies of the same allele making that locus monomorphic, or two different alleles making the locus polymorphic. Simple sequence repeats (SSRs, also known as microsatellites) are sets of repeated DNA sequences at a locus on a chromosome. They can therefore contain multiple substitutions and more than two alleles.

The variation of alleles across loci segregate individuals and populations from one another genetically, and underpin all subsequent measures used in population genetics. The allele frequency is simply the relative frequency of chromosomes across all individuals within a population that carry a specific allele. This is calculated from the frequency of observed genotypes within a population.

\section{Calculation}

Considering an SNP within a diploid population with the alleles B and b, the genotype frequencies are represented as BB (homozygous B), bb (homozygous b) and $\mathrm{Bb}$ (heterozygous). The allele frequency is calculated as follows:

$$
\begin{gathered}
p=f(B B)+\frac{1}{2} f(B b) \\
q=f(b b)+\frac{1}{2} f(B b) \\
p+q=1
\end{gathered}
$$

Where:

$f(B B), f(B b), f(b b)=$ Genotype frequencies; $p=$ The frequency of allele $B ; q=$ The frequency of allele $b$.

\subsection{Allelic Richness}

\section{Background}

The number of alleles $(A)$ and allelic richness $(A r)$ are representative of the amount of variation within a population. This is important in the context of long-term conservation, as populations containing higher levels of genetic variability are expected to be more able to respond to selection pressures and maintain the health of individuals (Petit et al. 2008). Ar may also be a useful indicator of past population bottlenecks or decreases in population size (Nei et al. 1975).

The $A$ found in a studied population depends on sample size, as increased sampling increases the chance of finding new alleles. $A r$ is therefore used as a special case of $A$ corrected for sample size differences between populations using rarefaction (Kalinowski 2004). 
The effective number of alleles $(A e)$ represents the actual genetic diversity present across numerous individuals within a population. Ae is the number of alleles that would be expected at each locus in a population under the Hardy-Weinberg $(H-W)$ equilibrium. It is therefore closely related to the expected heterozygosity of a population (He). This is also referred to as Nei's Genetic Diversity, $D$ / gene diversity, $v$. It is itself a special case of $A r$ as defined by Kalinowski (2004). Like Ae, He is the proportion of heterozygotes expected under $H$-W equilibrium and can be calculated based on these principles. Ae is often far lower than $A$, when allele frequencies are unequal. Alleles with low frequencies contribute little to $A e$. This is often due to several characteristics of the population, such as fluctuating population sizes across generations, overlapping generations, non-random mating (sexual selection, etc.), number of offspring produced by individuals varying more than by chance, and unequal sex ratios.

Calculations

\section{Number of alleles (A)}

$$
\begin{array}{cc}
A=\left(\frac{1}{I}\right) A_{i}=\frac{\sum_{i=1}^{I} A_{i}}{I} & \text { Number of alleles (A) } \\
A p=\sum_{i=1}^{I} A p_{i} & \text { Number of private alleles (Ap) }
\end{array}
$$

Where

$A=$ the mean number of alleles per locus; $A_{i}=$ the number of alleles at a specific locus; $A p=$ the number of private alleles in a population; $A p_{i}=$ the number of private alleles found within a population for a specific locus; $I=$ the total number of loci considered; $i=$ a specific locus.

\section{Allelic richness (Ar and pAr)}

$$
\begin{gathered}
N_{j}=\sum N_{g j} \\
Q_{g j G}=\frac{\left(\begin{array}{c}
\left.N_{j}-N_{g j}\right) \\
G
\end{array}\right)}{\left(\begin{array}{c}
N_{j} \\
G
\end{array}\right)} \\
P_{g j G}=1-Q_{g j G} \\
A_{r i}=\sum_{g=1}^{G} P_{g j G} \\
A_{r}=\frac{\sum_{i=1}^{I} A_{r i}}{I} \\
p A_{r i}=\sum_{g=1}^{G}\left[P_{g j G\left(\prod_{j^{\prime}=1, j^{\prime} \neq j}^{I} Q_{g j^{\prime} G}\right)}\right] \\
p A_{r}=\frac{\sum_{i=1}^{I} p A_{r i}}{I}
\end{gathered}
$$

Sample size of population $j$ at locus $i$

Probability of finding no alleles of type $g$ in sample size $G$ from population $j$

Probability of finding at least one allele of type $g$ in sample size $G$ from population $j$

Estimated allelic richness of locus i in sample size $G$ from population $j$

Mean allelic richness across all loci

Estimated private allelic richness of locus $i$ in sample size $G$ from population j

Mean private allelic richness across all loci

Where

$N_{j}=$ the sample size of population $j$ at a given locus $i ; N_{g j}=$ the number of copies of an allele $g$ at locus $i$ in a single individual (sample) from population $j ; g=$ a specific allele within locus $i ; G=$ a subsample of considered alleles at locus $i$ in population $j$; $I=$ the total number of loci considered; $i=$ a specific locus; $Q_{g j a}=$ the probability of finding no alleles of type $g$ in sample size $G$ from population $j ; P_{g j G}=$ the chance of finding at least one allele 
of type $g$ in sample size $G$ from population $j . A_{r i}=$ the estimated allelic richness of locus $i$ in sample size $G$ from population $j ; A_{r}=$ the mean allelic richness across all loci in population $j ; p A_{r i}=$ the estimated private allelic richness of locus $i$ in sample size $G$ from population $J ; p A_{r}=$ the mean private allelic richness across all loci in population $j$.

\section{Effective Number of Alleles (Ae)}

$A e$ across all loci in a population is calculated as the arithmetic mean of individual locus values. Because Ae is a nonlinear function of expected heterozygosity, it should be computed from per locus estimates and not from overall heterozygosity.

$$
H o=\frac{\sum f(B b)}{I}
$$

$$
\text { Observed heterozygosity (Ho) }
$$

For loci with 2 alleles

$$
H e_{i}=1-p^{2}-q^{2}=2 p q
$$

Expected heterozygosity per locus ( $\mathrm{He})$

For loci with 2 or $>2$ alleles

$$
\begin{array}{cc}
H e_{i}=1-\sum p_{i}^{2} & \text { Expected heterozygosity per locus (He) } \\
H e=\frac{\sum_{i}^{I} H e_{i}}{I} & \text { Expected heterozygosity }(\mathrm{He}) \\
A e_{i}=\frac{1}{\left(1 / H e_{i}\right)}=\frac{1}{\sum p_{i}^{2}} & \text { Effective number of alleles per loci (Ae) }
\end{array}
$$

Where

$\mathrm{Ho}=$ mean observed heterozygosity; $\mathrm{He}_{i}=$ expected heterozygosity for a specific locus; $\mathrm{He}=$ mean expected heterozygosity; $A e_{i}=$ the effective number of alleles for a specific locus; $A e=$ the harmonic mean of the effective number of alleles across all loci in a population; $I=$ the total number of loci considered; $i=$ a specific locus.

\subsection{Effective Population Size (Ne)}

\section{Background}

The effective population size $(\mathrm{Ne})$ is a concept aimed at measuring the amount of genetic drift occurring in a population at a given time. It is the size of an idealised population (under $\mathrm{H}-\mathrm{W}$ equilibrium) that would lose heterozygosity from one generation to the next at the same rate as the observed population. Populations often experience dramatic fluctuations in size from one generation to the next (e.g. bottlenecks). This results in rates of genetic drift that are higher than may be expected from the census population size. Ne is also affected by overlapping generations, the spatial distribution of individuals, and by highly variable offspring numbers per 'family' (resulting in a non-Poisson distribution), and variable proportions of males and females.

\section{Calculation}

A relatively simple way of viewing the $\mathrm{Ne}$ is through calculating the harmonic mean of the census size across the number of generations considered. This is used as this is especially sensitive to the smallest values in a dataset, and therefore reflects smaller past populations more so than the arithmetic mean. This calculation only accounts for fluctuating population sizes, though will give an indication of $\mathrm{Ne}$ for use in long-term genetic monitoring that is easily calculated from demographic data. 


$$
N e=\frac{1}{\frac{1}{T} \sum_{t=1}^{T} \frac{1}{N_{t}}}
$$

Effective population size (Ne)

OR

$$
N e=\frac{1}{\left(\sum_{t=1}^{T} \frac{1}{N_{t}}\right) / T}
$$

Effective population size (Ne)

Where

$\mathrm{Ne}=$ Effective population size; $T=$ The total number of generations considered; $t=\mathrm{A}$ specific generation; $N_{t}=$ The census population size at generation $t$.

\subsection{Latent Genetic Potential (LGP)}

\section{Background}

Latent Genetic Potential (LGP) was first defined by Bergmann et al. (1990) to distinguish between the physiological and evolutionary adaptive potential of a population. They describe the 'operating genetic potential' as being the section of genetic composition which guarantees the survival of the population under currently realised conditions, being akin to the effective number of alleles $(A e / v)$. The remaining genetic composition in this context is currently 'latent'. This portion of genetic diversity is related to low frequency alleles in the population, which can play a large role in adaptation and evolution under changing environmental conditions. This in turn could be of great importance to forest conservation practices (Aravanopoulos 2016). LGP therefore represents the adaptive ability of a population, as it reflects the difference between the observed and expected number of alleles in a population across all (observed) loci.

LGP has been used to infer both the potential of populations to adapt to changing conditions, and the negative impacts of stressors on this. For example, thinning of standing populations through logging has been shown to reduce both LGP and the hypothetical gametic multilocus diversity ( $\left.v_{\text {gam }}\right)$ of populations (Rajora et al. 2000b), as has habitat fragmentation (O'Connell et al. 2006). LGP has also been shown to be sensitive to other stressors such as forest fires (Rajora and Pluhar 2003).

Calculation

$$
\begin{gathered}
H e_{i}=1-\sum p_{i}^{2} \\
A e_{i}=\frac{1}{\left(1 / H e_{i}\right)}=\frac{1}{\sum p_{i}^{2}} \\
L G P=\sum_{i}^{I} A_{i}-A e_{i}
\end{gathered}
$$

Expected heterozygosity per locus (He)

Effective number of alleles per locus (Ae))

Latent genetic potential (LGP)

Where

$H e_{i}=$ the expected heterozygosity for a specific locus; $A e_{i}=$ the effective number of alleles for a specific locus; $A_{i}=$ the observed number of alleles for a specific locus; $L P G=$ latent genetic potential for a population; $p_{i}=$ the allele frequency of an allele at a specific locus; $I=$ the total number of loci in a population; $i=$ a specific allele. 


\subsection{Inbreeding Coefficient (FIS)}

\section{Background}

The inbreeding coefficient is an F-statistic, derived from local $F$. This is a measure of heterozygote deficiency in a population, i.e. the amount of heterozygosity observed in the population against the amount expected under the Hardy-Weinberg principle. $F$ can be calculated and partitioned to take into account the heterozygosity found at various levels of population structure and through different driving pressures. The two most commonly used statistics are the inbreeding coefficient $\left(F_{I S}\right)$ and fixation coefficient $\left(F_{S T}\right)$, representing the heterozygote deficiency observed from a subpopulation that can be partitioned due to inbreeding, and the heterozygote deficiency of an individual within the total population that can be partitioned due to the Wahlund effect, respectively. $F_{/ S}$ specifically can be thought of as the correlation of uniting gametes relative to gametes drawn at random from a subpopulation.

\section{Calculation}

To calculate F statistics, you must first assess the observed and expected heterozygosity of a population. This is presented as the mean across all loci within a population.

$$
\begin{array}{cc}
H o_{i}=f(B b) & \text { Observed heterozygosity per locus (Ho) } \\
H e_{i}=1-\sum p_{i}^{2} & \text { Expected heterozygosity per locus (He) } \\
F=\sum_{i=1}^{I} \frac{H o_{i}}{H e_{i}} / I & \text { Local F } \\
F_{I S}=\sum_{i=1}^{I} \frac{H e_{i}-H o_{i}}{H e_{i}} / I & \text { Inbreeding coefficient }\left(F_{I S}\right)
\end{array}
$$

Where

$\mathrm{Ho}_{\mathrm{i}}=$ the observed heterozygosity of a specific locus; $\mathrm{He}_{\mathrm{i}}=$ the expected heterozygosity of a specific locus; $\mathrm{F}=$ local $\mathrm{F}$ for a population; $F_{I S}=$ the inbreeding coefficient for a population; $\mathrm{I}=$ the total number of loci considered; $\mathrm{i}=$ a specific locus; $p_{i}=$ the allele frequency of an allele at a specific locus.

\subsection{Linkage Disequilibrium}

\section{Background}

Linkage disequilibrium $(L D)$ is the non-random association of alleles at different loci in each population (Weir 1979). Under linkage equilibrium ( $L E$ ) alleles would be associated randomly. $L D$ can be calculated both overall for all loci within a population and globally, and pairwise for each locus. $L D$ between loci can be affected by many driving forces of interest in population genetics, including selection, gene flow, genetic drift and mutation, along with demographic properties such as population sub-structure, asexual reproduction, bottlenecks and inbreeding. While under completely null conditions loci would eventually become in $L E$, these processes allow $L D$ to persist in a population, as detailed in a review by Slatkin (2008). Global pairwise $L D$ between loci can be used in the filtering of markers prior to the generation of other genetic statistics.

\section{Calculation}

When considering multiple loci, this measure can be summarised with a single measure called the index of association $\left(I_{A}\right)$. Due to the way $V_{o}$ and $V_{e}$ are determined, $I_{A}$ is sensitive to the observed number of loci, and will invariably increase as this does. Agapow and Burt (2001) improved this method to account for this, and yield an unbiased statistic of association $(d)$. 


$$
\begin{gathered}
V_{o}=\sum \operatorname{var}_{i^{1}}+2 \sum \sum \operatorname{cov}_{i^{1}, i^{2}} \\
V_{e}=\sum \operatorname{var}_{i} \\
I_{A}=\frac{V_{o}}{V_{e}}-1 \\
\bar{r}_{d}=\frac{\sum \sum \operatorname{cov}_{i^{1}, i^{2}}}{\sum \sum \sqrt{\operatorname{var}_{i^{1}} \cdot \operatorname{var}_{i^{2}}}}
\end{gathered}
$$

Observed variance of pairwise distances between loci $\left(V_{0}\right)$

Expected variance of pairwise distances $\operatorname{loci}\left(V_{e}\right)$

Index of association $\left(I_{A}\right)$

Unbiased index of association $\left(r_{d}\right)$

\section{Where}

$I_{A}=$ index of association between multiple loci in a population; $V_{e}=$ the expected variance of pairwise distances between loci in linkage equilibrium; $V_{0}=$ the observed variation of pairwise distances between loci; $i=$ a specific locus; $i^{1} / i^{2}=$ two contrasting loci; $\operatorname{var}_{i}=$ the variance of pairwise distances between a given loci and other loci; $\mathrm{Cov}_{i, i_{2}}=$ the covariance of distances summed across each pair of loci in a dataset; $r_{d}=$ the unbiased index of association.

\subsection{Gene Flow (Nm)}

\section{Background}

Gene flow (gene migration) is the movement or introduction of genetic material (DNA) (by interbreeding) from one population of a species to another (immigration and emigration), thus causing a change in the composition of the gene pool (allele frequencies) of the receiving population. Gene flow measurement provides indirect information on the level of migration among subpopulations ( Burczyk et al. 2004). Gene flow (Nm) can be interpreted as the effective number of migrants exchanged between demes per generation (Wright 1969). Both Nm estimation methods (based on $F_{\mathrm{ST}}$ and private alleles) assume neutrality, therefore any kind of selection will lead to bias (Yamamichi and Innan 2012). However, $\mathrm{F}_{\mathrm{ST}}$ and private allele frequencies based $\mathrm{Nm}$ estimation provide some understanding of migration and are useful in FGM, e.g. high $\mathrm{Nm}$ indicates high gene flow and more stable and intact genetic processes.

\section{Calculation}

The Wright island model (Wright 1931) and degree of genetic differentiation $\left(F_{S T}\right)$ estimated among populations of a species is used to infer $\mathrm{Nm}$ - the number of migrant individuals entering a population each generation (Wright 1969).

$$
N m=\left(\frac{1-F_{S T}}{4 F_{S T}}\right)
$$

Another way to estimate gene flow is the private alleles method (Slatkin 1985). This requires a larger sample size to obtain a sufficient number of private alleles (alleles that occur in only one population). The idea behind this method is that under high gene flow private alleles that occur in only one population will be at very low frequency because they are possibly caused by new mutations that have not yet had time to spread (Slatkin 1985, 1987). Slatkin (1985) showed that the logarithm of $\mathrm{Nm}$ is linearly related to the algorithm of the average frequency of private alleles. Within the project LIFEGENMON we used the Slatkin (1985) private alleles method implemented in the GenePop software (see below). This calculates a multilocus estimate of the effective number of migrants (Nm) based on the private allele method. This option provides a multilocus estimate of the effective number of migrants (Nm) according to Slatkin (1985) and Slatkin and Barton (1989). Four estimates of Nm are provided, three using the regression lines published in Barton and Slatkin (1986), and a corrected estimate using the values from the closest regression line as described by Barton and Slatkin (1986). 
Genepop reference page: https://kimura.univ-montp2.fr/ rousset/Genepop.htm

Genepop is also available as an R package on CRAN, and as a stand-alone executable. Both are based on the latest version of the Genepop C++ sources, version 4.7.3 (06 December 2019; Rousset 2008, Rousset 2017).

\subsection{Multilocus Population Outcrossing Rate}

\section{Background}

Outcrossing promotes gene flow, homogenizes populations, increases heterozygosity, and favours gametic linkage equilibrium (Del Castillo and Trujillo 2008). Overall multilocus $\left(t_{m}\right)$ and single-locus $\left(t_{s}\right)$ population outcrossing rates can be considered as the same parameter. However, more accurate estimates of natural outcrossing rates should be assessed using multilocus models, such as a mixed-mating model (Ritland and Jain 1981, Ritland 2002). The multilocus outcrossing rate $\left(t_{m}\right)$ is an estimate of the proportion of outcrossed progeny produced by a single maternal parent, or by the population as a whole, in which outcrossing events include mating between relatives and unrelated individuals (Ritland 2002).

\section{Calculation}

Based on the mixed mating model, the estimation procedure of the outcrossing rates $\left(t_{s}-\right.$ single locus and $t_{m}-$ multilocus outcrossing rates) based on single- and multilocus genotypes was applied according to Ritland (2002). The multilocus estimates of outcrossing rate $\left(\mathrm{t}_{\mathrm{m}}\right)$ are thought to give more accurate results in comparison to single locus estimates (Ritland and Jain 1981, Ritland 2002). Multilocus $\left(t_{m}\right)$ and single-locus $\left(t_{s}\right)$ outcrossing rates can be estimated using MLTR (Ritland, 2002). Variance estimates within the LIFEGENMON project were calculated based on 10,000 bootstraps. Bootstrapping is a non-parametric way to find the standard error (or variance) of estimates. Bootstrapping assumes that observations are independent, and you need a reasonable number of observations. The standard error is estimated based on a selected number of bootstraps during computation on MLTR (Ritland 2002). Resampling for bootstrapping can be conducted within families or individuals within families (Ritland 2002). For the LIFEGENMON project resampling was conducted at the family level, because actual mating system parameters varied between families.

$$
\begin{array}{rlr}
\hat{t}_{m} & =1-\hat{s}_{m} & \begin{array}{l}
\text { Multilocus estimation for individual } \\
\text { outcrossing rate }
\end{array} \\
\hat{s}_{m}=\frac{I_{m}-P_{m}^{s}}{P_{m}^{s}-P_{m}^{t}} & \text { Multilocus estimation for individual selfing rate } \\
\operatorname{Var}\left(\hat{s}_{m}\right)=\frac{P_{m}^{t}\left(1-P_{m}^{t}\right)}{\left(P_{m}^{s}-P_{m}^{t}\right)^{2}} & \begin{array}{l}
\text { Variance of the multilocus individual selfing } \\
\text { rate }
\end{array}
\end{array}
$$

Where

$P_{m}$ is the probability of observing an m-th possible multilocus progeny genotype for the given parent genotype; $s$ in the equations above indicates selfing, $t$ indicates outcrossing. $I_{m}=1$ if genotype $m$ is the observed progeny genotype and 0 if it is not;

$$
P_{m}^{s}=\prod_{l o c i} P_{k l(m)}^{i j, s}
$$

$$
P_{m}^{t}=\prod_{l o c i} P_{k l(m)}^{i j, t}
$$

Where

$P_{k l}^{i j}$ is the probability of observing progeny genotype $A_{k} A_{l}$, given parent genotype $A_{i} A_{j} ; s$ in the equations above indicates selfing, $t$ indicates outcrossing. 


$$
P_{k l}^{i j, s}=\left(2-\delta_{k l}\right) D_{k}^{i j} D_{l}^{i j} \quad P_{k l}^{i j, t}=\frac{1}{2}\left(2-\delta_{k l}\right)\left(D_{k}^{i j} p_{l}+D_{l}^{i j} p_{k}\right)
$$

Where

$D_{k}^{i j}$ and $D_{l}^{i j}$ are the probabilities that allele $k$ or allele / is transmitted to the progeny, given parent genotype $A_{i} A_{j} ; p_{k}$ and $p_{l}$ are the frequencies of alleles / and $k$ in the population; $\delta_{k l}$ is a Kronecker operator which equals 1 if alleles $l$ and $k$ are the same or 0 if they are different.

$$
D_{k}^{i j}=\left(\frac{\delta_{i k}+\delta_{j k}}{2}\right) \quad D_{l}^{i j}=\left(\frac{\delta_{i l}+\delta_{j l}}{2}\right)
$$

Multilocus population outcrossing rate $\left(t_{m}\right)$ and single-locus outcrossing rate $\left(t_{s}\right)$ varies from 0 to 1 (in some cases $t_{m}=1.2$ (LIFEGENMON results, unpublished)). When the multilocus population outcrossing rate $\left(t_{m}\right)$ is close or equal to $1\left(t_{m} \geq 1\right)$ then this means that offspring are outcrossed (no self-fertilisation). When the multilocus population outcrossing rate $\left(t_{m}\right)$ is lower than $1\left(t_{m}<1\right)$, then part of the offspring is derived by self-fertilisation.

MLTR reference page: http://kermitzii.com/softwares/

\subsection{Actual Inbreeding Rate}

\section{Background}

Inbreeding is the mating of individuals that are related to each other by ancestry. Inbreeding (mating between close relatives) increases offspring homozygosity and usually results in reduced fitness. In homozygous genotypes, recessive deleterious alleles are unmasked and the benefits of heterozygosity in over-dominant loci are lost (Aravanopoulos and Zsuffa 1998). The inbreeding rate indicates the increase in average inbreeding level in a population from one generation to the next.

\section{Calculation}

The estimation of actual inbreeding rate (single locus and multilocus) is based on seed and genetic data. Estimation of inbreeding rates can be marker-based only, however, as potential inbreeding depression may adversely affect seed development and germination, actual inbreeding rates are more reliable. The actual inbreeding rate is calculated by combining selfing estimates (from the mating systems analysis) and seed-trait-based inbreeding estimates (Rajora et al. 2000a).

$$
\text { Actual Inbreeding Rate }=\frac{B+C \cdot \hat{s}_{m}}{B+C}
$$

Where

$B$ is the estimated proportion of inbred seeds and is calculated as $(1-C) \cdot F$, where $F$ is the estimated proportion of empty seeds attributed to selfing and is based on prior knowledge (e.g. from published literature on the respective species). In the absence of prior information, the attribution of $80 \%$ (i.e. $F=0.8$ ) of the empty seeds as a result of selfing is a reasonable choice (Rajora et al. 2000a, based on Picea glauca (Moench) Voss data); $C$ is the percentage of filled seeds (see sections 6.3 and 6.5.5.1.1 for determination of percentage of filled seeds); $\hat{s}_{m}$ is the multilocus estimate of the selfing rate (Ritland 2002), see 6.5.4.3.1.8 for equation. 


\subsection{Background information}

\subsection{Interspecific hybridisation}

\section{Background}

Interspecific hybridisation is the hybridisation observed between organisms that are treated as distinct species. To discriminate between pure species and interspecific hybrids, there needs to be a set of verified reference samples of both (or more) hybridising species. Genotype data of pure species can then be used to simulate hybrid genotypes through programs such as HybridLab (Nielsen et al. 2006) or in R using the "adegenet" package (Jombart 2008, Jombart and Ahmed 2011). "Pure" and "hybrid" reference groups can then be included in STRUCTURE analysis (Pritchard et al. 2000) or another clustering program to determine the levels of hybridisation between individual species in natural communities.

STRUCTURE is a stand-alone program and not easily implementable within $\mathrm{R}$, along with being relatively slow to carry out analyses. An R-based alternative can be found through "snapclust" and Discriminate Analysis of Principal Components (DAPC) analyses, which are complementary methods carried out using the "adegenet" package in $\mathrm{R}$ to cluster species/populations and visualise these clusters. All three implementations described here attempt to cluster individuals into groupings based on genetic similarity, and can be used to both assess hybridisation between species and the underlying population structure and divergence (or lack thereof, referred to as admixture) between hypothesised populations within species.

It should be noted that if analysis of hybridisation reveals a high level of hybridisation ( $>50 \%)$ during the first assessment in any cohort (adult trees, natural regeneration, seed), such a stand should not be used for FGM, unless monitoring of hybridisation is the main purpose of the monitoring.

\section{STRUCTURE Algorithm Summary}

To assign individuals to a species or population grouping, STRUCTURE utilises a model-based clustering method to infer population structure using genotype data consisting of unlinked markers. STRUCTURE assumes a model wherein there are $\mathrm{K}$ populations or species, each of which is characterised by a set of allele frequencies at each locus. Individuals are assigned probabilistically to a population/species, or jointly two or more populations/species based on their genotypes. STRUCTURE estimates the allele frequencies in each cluster, and population/species membership for each individual sample. Markov-chain Monte Carlo permutations are used to integrate over the parameter space and make cluster assignments. The optimum value of $\mathrm{K}$ for a set of individuals is determined post hoc through the Evanno-Structure method (Evanno et al. 2005). STRUCTURE analysis must therefore be run for many values of $\mathrm{K}$, increasing the amount of time it takes to carry out. STRUCTURE assumes $H-W$ and linkage equilibrium, making it important to filter individuals and loci which deviate from these assumptions prior to analysis.

\section{Snapclust Algorithm Summary}

Snapclust (implemented in the package "adegenet", (Jombart 2008, Jombart and Ahmed 2011) is a genetic clustering approach combining 'model-based' and 'geometry-based' methods to effectively assign individuals to clusters while performing faster than entirely 'model-based' approaches, including STRUCTURE. Snapclust relies on the $\mathrm{H}-\mathrm{W}$ equilibrium to compute the likelihood of a given clustering solution.

Snapclust assigns groups to individuals (based on the user given number of groups, $K$ ), and then runs many iterations of the Snapclust model, reassigning individuals each time, until two successive models converge (i.e. log-likelihoods in two successive iterations become negligible $\left(10^{-10}\right)$.

Snapclust also requires the total number of clusters present to be defined a priori. This is in opposition to STRUCTURE analysis, where this is done post hoc. Several information criteria can be used to assess the optimum number of clusters. Two popular statistics are the Akaike Information Criterion (AIC) (Akaike et al. 1998) and the Bayesian Information Criterion (BIC) (Schwarz 1978). The three statistics measure the deviance 
of the model (lack of fit), but give differing penalties for dataset complexity. When using these statistics to find the optimum number of clusters for a dataset, the Snapclust model is iterated over several potential values of $K$ (e.g. 1-20), and the chosen statistic(s) calculated for each resulting model. This can then be plotted to compare statistical values between models. Generally lower values of each statistic indicate a better fit of the model, but in practice a sharp decrease in the statistics value with increasing $\mathrm{K}$ is most likely to reveal the optimum number of clusters (Jombart et al. 2010).

\section{Discriminant Analysis of Principal Components (DAPC)}

DAPC utilises Principal Component Analysis (PCA) paired with Discriminant Analysis (DA) to identify genetic structures. It is distinct from other approaches including Snapclust and STRUCTURE in that it is an entirely 'geometric' approach, where individuals are clustered based on their distances in genetic space without assuming specific population genetics models (Jombart et al. 2010).

As detailed in the paper of introducing this approach (Jombart et al. 2010), DAPC attempts to reduce the limitations of both constituent techniques. PCA can summarise the overall variability among individuals but cannot discriminate between divergence between groups and within groups. DA alternatively partitions genetic variation into a between-group and within-group component and attempts to maximise the first while minimising the second, allowing discrimination of individuals into pre-defined groups. DA is limited by the need for the number of variables (alleles) to be less than the number of observations (individuals), which is often not the case in SNP datasets, and is also hampered by correlations between variables, which is common in compositional datasets. In DAPC, data is first transformed by using PCA, from which the variable values (using each PCA axis) are subjected to DA. This ensures variables submitted to DA are not correlated, and that their number is less than the number of analysed individuals. DAPC can be used to complement Snapclust analysis rather than to assign individuals to clusters as a method to visualise a priori (Snapclust-derived) cluster diversity in reduced space.

\subsection{Multiplicity - Hypothetical Gametic Multilocus Diversity $\left(V_{\text {gam }}\right)$}

\section{Background}

Hypothetical Gametic Multilocus Diversity $\left(v_{\text {gam }}\right)$ is a special case of gene diversity which characterises the potential diversity of a population's gametic output. This signifies the adaptive/evolutionary potential of a sexually reproducing population, being the effective number of multilocus gametes that can be produced (Gregorius 1978). When calculating $v_{\text {gam }}$ it is assumed that the loci assessed are in linkage equilibrium, and that there is no fecundity selection in the population (i.e. individuals do not have a fitness advantage through traits that increase the number of offspring) (Hattemer 1991). It is therefore only a hypothetical estimation of this capacity.

Genetic variation within a population is necessary for adaptation and survival in heterogeneous environments (Müller-Starck 1995). As a measure of the ability of a population to create genetic variation and facilitate adaptation to changing environmental conditions (Gregorius et al. 1986), $v_{\text {gam }}$ can be indicative of a population's response to and ability to withstand long-term environmental stress. This was shown in European beech (Fagus sylvatica), where more 'air pollution tolerant' sub-populations had $90 \%$ higher $v_{\text {gam }}$ than more 'sensitive' sub-populations (Müller-Starck 1989). $V_{\text {gam }}$ has also been used to demonstrate a potential reduction in a gene pool's ability to adapt to changing conditions following anthropogenic disturbances such as logging (Wickneswari et al. 2004).

\section{Calculation}

$V_{\text {gam }}$ is calculated as the product of all single locus diversities $(A e)$ across all loci. It therefore requires $\mathrm{He}$ and $\mathrm{Ae}$ to be first calculated for each locus.

$$
H e_{i}=1-\sum p_{i}^{2}
$$




$$
\begin{gathered}
A e_{i}=\frac{1}{\left(1 / H e_{i}\right)}=\frac{1}{\sum p_{i}^{2}} \\
v_{g a m}=\prod_{i}^{I} A_{e i}
\end{gathered}
$$

Hypothetical gametic multilocus diversity $\left(v_{\text {gam }}\right)$

Where:

$p_{i}=$ the allele frequency of the major allele at a given locus; $H e_{i}=$ the expected heterozygosity at a specific locus; $A e_{i}=$ the expected number of alleles at a specific locus; $v_{\text {gam }}=$ hypothetical gametic multilocus diversity; $I=$ the total number of unlinked loci; $i=$ a specific locus.

\subsection{F-statistics outlier detection}

\section{Background}

Genetic markers can be split into two categories based on whether they are thought to be affected by selection pressures or not. Neutral markers are those which have no (or very little) effect on fitness, and are therefore driven by stochastic neutral processes over natural (or artificial) selection pressures (Kimura 1983). Alternatively, markers which are under a selection pressure are referred to as non-neutral, adaptive or outlier loci. There is growing interest in utilising non-neutral markers along with neutral markers to assess the adaptive potential of a population to changing environmental conditions (Eizaguirre and Baltazar-Soares 2014) and in genetic monitoring (Funk et al. 2012). However, traditional population genetics analyses tend to be performed only on neutral markers, which reflect the geographic structure of subpopulations and genetic connectivity, driven by genetic drift, mutation and dispersal limitation. This makes neutral markers useful to assess past demographic processes.

The main approach used to detect signals of natural selection in a population is through looking for loci with unexpectedly large differences in allele frequencies between populations (Lewontin and Krakauer 1973). Outlier testing is usually performed using the $\mathrm{F}_{\mathrm{ST}}$ (fixation index) outlier method in standalone applications such as Lositan (Antao et al. 2011) and Bayescan (Fischer et al. 2011). In $\mathrm{R}$ the $\mathrm{F}_{\mathrm{ST}}$ outlier detection can be easily and rapidly implemented using the OutFLANK method (Whitlock and Lotterhos 2015).

\section{Algorithm Summary}

The following is a simplified description of the OutFLANK algorithm, for a more in-depth description consult the original paper (Whitlock and Lotterhos 2015). In the OutFLANK algorithm, low heterozygosity loci are first removed (i.e. He $<0.1$ in the whole population and minor allele frequency $<5 \%$ ). F' ST $_{\text {T }}$ is calculated as the chosen measure of genetic differentiation for each locus and averaged over all loci considered. This is a variation of the fixation index $\left(\mathrm{F}_{\mathrm{ST}}\right)$ as defined by Weir and Cockerham (1984) which is not corrected for sample size in its calculation of variance component.

$$
F_{s t}=\frac{v a r_{a}}{v a r_{a}+v a r_{b}+v a r_{c}}
$$

$F_{S T}($ Weir and Cockerham 1984)

Where:

$v r_{a}=$ 'between populations' variance component of an allele; $v r_{b}=$ 'between individuals within sub-populations' variance components; $v r_{c}=$ 'between gametes within individuals' variance components.

Loci within the top and bottom 5\% of $F_{S T}^{\prime}$ values are temporarily trimmed. From the trimmed $F_{S T}^{\prime}$ values a $X^{2}$ distribution model is constructed. A likelihood model based on the distribution of $F_{S T}^{\prime}$ values is subsequently used to find the degrees of freedom ( $d f$ ) of the model. Once both the null $X^{2}$ distribution of $F_{\text {ST }}$ values and the $d f$ are known, this distribution can be used to test the diversifying selection, where $F_{S T}^{\prime}$ values fall on the right-hand 
tail of the distribution. This is iterated numerous times with outlier loci removed as they are found, until no new outlier loci are found.

\subsection{Effective Number of Pollen Donors $\left(\mathrm{N}_{\mathrm{ep}}\right)$}

\section{Background}

The effective number of pollen donors is the number of pollen donors contributing to each seed family. Because pollen sources are not represented equally among progeny, this number is often much smaller than the absolute number of contributing pollen donors (Smouse and Sork 2004, Sork and Smouse 2006, Sork et al. 1999). The effective number of pollen donors is an excellent indicator of the genetic diversity of a seed crop. If the number of pollen donors is small, the progeny may be less genetically diverse (Apsit et al. 2002).

\section{Calculation}

The number of effective pollen donors Nep (Ritland 2002) can be estimated based on multilocus correlation of paternity (rp) (Ritland 2002), which is estimated using MLTR (Ritland, 2002) and the following formula:

$$
N e p=\frac{1}{r p}
$$

Where rp is the correlation of paternity in MLTR (Ritland 2002).

MLTR reference page: http://kermitzii.com/softwares/

\subsection{Biparental Inbreeding}

\section{Background}

Biparental inbreeding or mating between relatives occurs at various frequencies in many natural plant populations, which also often have substantial rates of self-fertilisation (Ritland 2002, Porcher and Lande 2016). Biparental inbreeding causes apparent selfing or increased homozygosity in contrast to random mating (Ritland 2002). Therefore, the level of biparental inbreeding is an important parameter for conservation genetics and genetic monitoring.

\section{Calculation}

Single (ts) and multilocus (tm) outcrossing rates are used to calculate biparental inbreeding (BI) (mating among relatives) (biparental inbreeding $=\mathrm{tm}$-ts).

$$
B I=(t m-t s)
$$

Where tm is the multilocus outcrossing rate and ts is the single locus outcrossing rate in MLTR (Ritland 2002).

According to Ritland (2002), when true selfing is also present the difference between multilocus (tm) and single-locus (ts) estimates of outcrossing can be used to estimate the level of biparental inbreeding. However, Ritland (2002) states that this difference is always an underestimate, as it depends upon the number of loci used. A higher number of loci thus provides estimates of biparental inbreeding closer to the true value (Ritland 2002).

Biparental inbreeding can be estimated using MLTR based on the number of bootstraps (Ritland 2002). Bootstrapping is a non-parametric way to find the standard error (or variance) of estimates. Bootstrapping assumes that observations are independent, and you also need a reasonable number of observations. The standard error is estimated based on the selected number of bootstraps during computation with MLTR (Ritland 2002). Resampling for bootstrapping can be conducted within families or individuals within families (Ritland 2002). In the LIFEGENMON project resampling was conducted at the family level, because actual mating 
system parameters varied between families. The difference between the two estimates ( $\mathrm{tm}-\mathrm{ts}$ ) thus provides a measure of the frequency of mating events between close relatives (Ritland 2002).

MLTR reference page: http://kermitzii.com/softwares/

If mating occurs between relatives, the single-locus selfing rate should be higher than the multilocus selfing rate, and the difference is a minimum estimate of the apparent selfing due to biparental inbreeding (Ritland 2002). When biparental inbreeding is close to zero, this indicates no mating among relatives. Therefore, when the single locus (ts) outcrossing rate is slightly smaller than the multilocus outcrossing rate ( $\mathrm{ts}<\mathrm{tm}$ ), this indicates low probability of biparental inbreeding.

\subsection{Software and packages used}

Table 6.9: Software and packages required to calculate the verifiers. Where $R$ packages are dependent on other packages to run, those packages have also been included. Where R packages import features from other packages, they have not been included as these are usable within the package that imports them. Packages are also cited only on their first mention in the table to conserve space and preserve readability.

\section{Verifier}

1. Allele Frequency

2. Allelic Richness

\section{Required software / packages}

R software: adegenet (Jombart 2008, Jombart and Ahmed 2011), ade4 (Dray and Dufour 2007)

R software: custom functions (Dupuis et al. 2018); matrixStats (Bengtsson 2014), dplyr (Wickham et al. 2020), pegas (Paradis 2010), adegenet, ape, ggplot2 (Wickham 2016), DescTools (Signorell 2020), PopGenReport (Adamack and Gruber 2014), knitr (Xie 2020), poppr (Kamvar et al. 2014), mmod (Winter 2012)

3. Effective Population Size R software: Custom function, adegenet, ade4

4. Latent Genetic Potential R software: poppr, adegenet, ade4, custom function

5. Inbreeding Coefficient R software: hierfstat (Goudet 2005), matrixStats

6. Linkage Disequilibrium R software: poppr, adegenet, ade4

7. Multilocus Population Outcrossing Rate MLTR software (Ritland 2002)

GenePop software is available as a stand-alone executable (Rousset 2008, Rousset 2017)

8. Gene Flow (Nm) based on the latest version of the Genepop $\mathrm{C}++$ sources, version 4.7.3 (06 December 2019; Rousset 2008, Rousset 2017).

\section{Background Information}

9. Interspecific Hybridisation

STRUCTURE software (Pritchardet al. 2000, Hubisz et al. 2009). R software: pophelper (Francis 2017), dplyr, tidyr (Wickham and Henry 2020), gridExtra (Baptiste 2020), plyr, adegenet, ade4, ggplot2, cairo (Urbanek and Horner 2020)

10. Hypothetical Gametic Multilocus Diversity R software: poppr, adegenet, ade4, custom function

11. F-stats outlier detection $\quad$ R software: dartR (Gruber et al. 2018), adegenet, ade4

12. Biparental Inbreeding MLTR software (Ritland, 2002)

13. Effective Number of Pollen Donors (Nep) MLTR software (Ritland 2002) and following the formula by Ritland (1989)

Note: "poppr", "dartR" and "pegas" are dependent on adegenet. adegenet is dependent on ade4. Pophe/per is dependent on cairo and ggplot2. PopGenReport is dependent on adegenet and knitr.

\subsubsection{4 easyRpopgen: An R-script for calculating genetic parameters from SSR and SNP data}

\subsection{Purpose}

easyRpogen is an open-source, web-based Shiny application designed to facilitate the analysis and interpretation of results from population genetics studies principally within the R environment. It is able to efficiently process common genetic markers such as single nucleotide polymorphisms (SNPs) and simple sequence repeats (SSRs, commonly 
referred to as microsatellites). There are both many stand-alone programs (e.g. GenAlEx) and R packages available in CRAN and other repositories which can be used for this purpose, but a comprehensive analysis pipeline often requires switching between programs, or finding the correct $R$ package to perform the required function. This is complicated by the number of $R$ packages available which contain a number of overlapping and distinct functions and purposes. Aggregating these packages and functions can be time-consuming, labour intensive and difficult to comprehend for researchers, especially those not already familiar with the R coding platform.

easyRpopgen simplifies and streamlines this process by combining the functions of a number of these packages and other functions to create a novel pipeline which is robust and accessible to a general user. easyRpopgen is built on the backbone of genetic analysis $\mathrm{R}$ packages including poppr, ade4, adegenet, pegas, hierfstat and PopGenReport, bringing together their discrete functions to a fully usable analysis platform.

From conception the application has been created to be used as an integral part of data analysis and result dissemination within the LIFEGENMON project, and as a stand-alone application that can be used by any interested researchers working in this field. It is therefore tailored to the research questions and methodologies used within this project, but general enough that many other researchers will be able to benefit from the analyses conducted within the package.

\subsection{Overview of the application}

\section{Data import and filtering}

Genetic marker data can be imported from csv files in the style of GenAlEx, Genemapper, or STRUCTURE formatted data. Imported data files are converted to a 'genind' object, which is the primary data storage file type common to many of the packages aggregated in the pipeline. This data storage file can handle both SNP and SSR data and incorporates the associated metadata, so it is carried with the data through all the analyses. Further to importing data from these common formats, for the purposes of the LIFEGENMON project data can also be directly imported to the application from the LIFEGENMON server. Phenology data can be imported to the application directly from the LIFEGENMON server.

When importing data, the user will define a project ID (e.g. LGM_Abies) which will be associated with all files and reports subsequently downloaded from the application. This allows easy tracking of which stages of analysis have been carried out for each project.

Population strata can also be defined for imported data. This is useful for both the LIFEGENMON project and general use. The populations defined across the project are stratified by both location (Slovenia, Germany and Greece) and age class cohort (adults, natural regeneration and seeds). Defining strata independently means that analyses can be carried out taking into account interactive and nested effects.

Data filtering can be carried out on the data prior to any analysis of the data. Filtering parameters include missing data (missing loci and missing individuals), minor allele frequency, global linkage disequilibrium and HardyWeinberg equilibrium (HW). The purpose of these filtering steps is both to remove patchy data which can have a disproportionate effect on analysis outcomes, and to remove potentially incorrectly sequenced data by removing that with a pattern of high deviation from HW across a majority of samples. Removing loci in linkage disequilibrium also removes their effect on outcomes as many analyses require loci to be in equilibrium, as those in disequilibrium effectively act as double counts. Users can choose whether to perform some or all of these filtering steps, along with choosing the stringency to which they filter missingness and minor allele frequencies. This accounts both for the user's preference for filtering, and the fact that some data will be imported to the application pre-filtered.

At the filtering stage outlier detection can also be performed using the R package "pcadapt". This generates two datasets for export - a 'neutral' dataset composed of markers which are not determined to be actively affected by selection processes, and an 'outlier' dataset of those which are. This allows the demarcation between demographic and selective process effects on population divergence. If outlier selection is not performed or the filtering section is skipped entirely, then all further sections will use the unfiltered, whole dataset imported. 


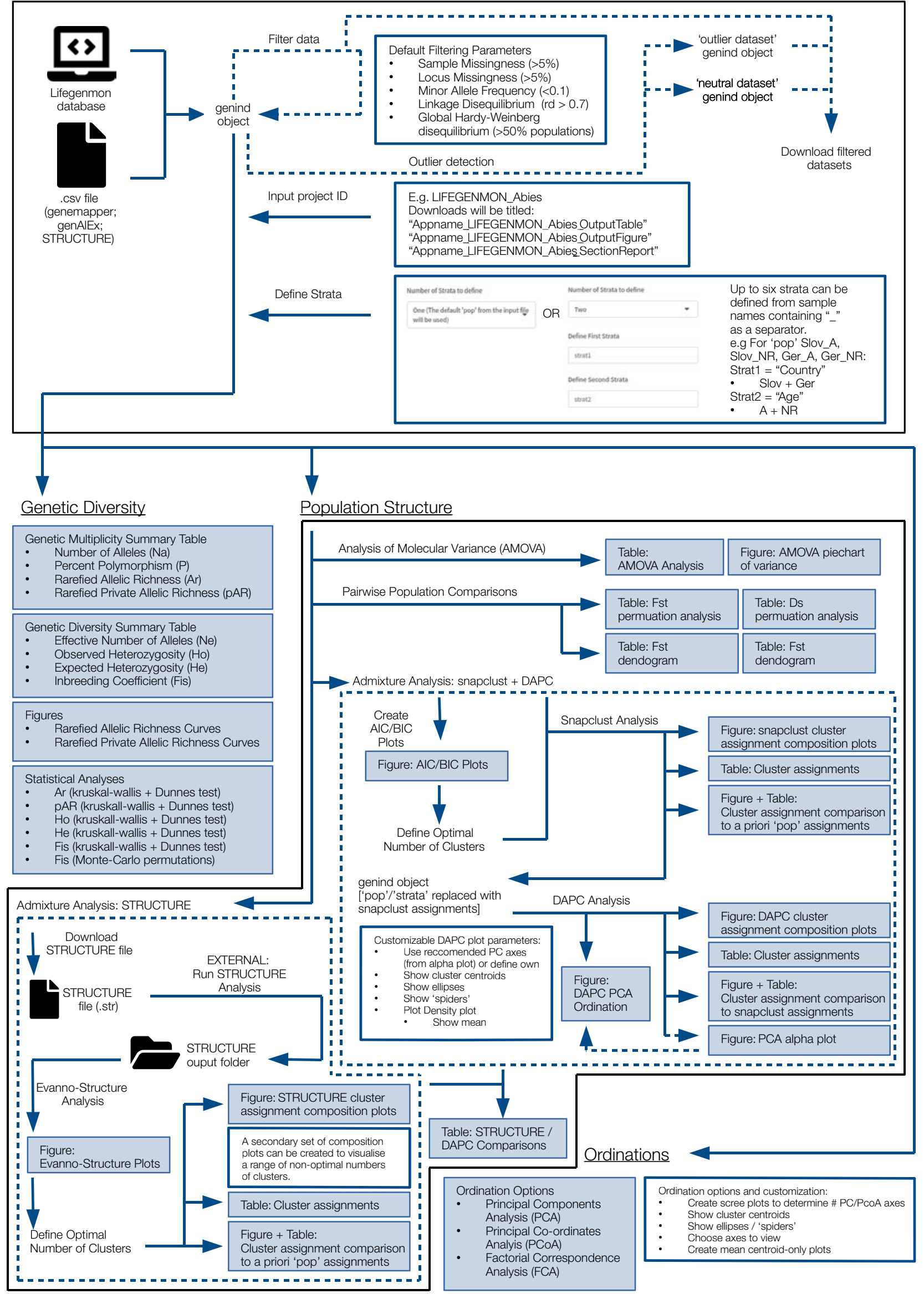

Figure 6.6: Schematics of the genetic analyses performed by the easyRpopgen application. 


\section{Data Analysis and Report Generation}

Genetic analysis is split into three discrete sections within the application:

- Genetic Diversity

- Population Structure

- Ordinations

The metrics generated at this stage are described in a previous section of the manual (Verifiers), so will not be discussed in detail here. Metrics calculated and statistical analyses conducted by the application are summarised in the 'Genetic Analysis Schematic' (Figure 6.6). The three sections of genetic analyses - and many of the calculations within - can be conducted separately to one another as suits the needs of the application user. Each figure and table generated can also be separately downloaded, or a section report can be created containing all of the outputs generated.

Phenological data is dealt with in a part of the application dedicated to the activities concerning the LIFEGENMON project, and will require sign-in to access. Within this section phenological data can be downloaded from the database and compared between locations and year. Similar to the analysis of genetics data a report on these analyses can also be generated.

All analyses within the application are conducted at the push of a button, requiring no expertise in $\mathrm{R}$ to be carried out. The R code is run in the background, with only the resulting graphs and tables shown on the front-end of the application. For transparency and reproducibility, the user can access the underlying R scripts used as well.

\subsubsection{Analysis of seed testing data}

\subsubsection{Verifiers}

\subsection{Percentage of filled seeds}

\section{Background}

The estimation of the percentage of filled seeds is carried out per tree in which fruits/seeds have been sampled. A change in the percentage of filled seeds between cohorts indicates a potential selection pressure (in the case of reduction), or an indication of recovery (in the case of increase). The percentage of filled seeds is also an important parameter in the interpretation of values of effective population size of the subsequent cohort.

\section{Calculation}

The estimate is based on the number of filled seeds out of a random sample of seeds (usually 400) used for the germination (GT) or the biochemical viability test (TT) converted to a percentage. The percentage of filled seeds can also be calculated as 1 - percentage of empty seeds, which is also determined at the end of the GT or TT.

\subsection{Percentage of germination}

\section{Background}

The percentage germination indicates the proportion by number of seeds which have produced seedlings classified as normal under the species-specific conditions and within the period specified (ISTA 2020). A germination test is generally used to assess what proportion of seeds will germinate under favourable conditions and produce normal seedlings, which have the vital structures (roots, shoots and sufficient food reserves) and are capable of developing into reproductively mature plants. According to ISTA (2020) 400 seeds in replicates of 100 are taken at random from the pure seed. The duration of the test for individual species is different and if necessary, it may be extended as indicated in the ISTA rules. Every seedling must be evaluated in accordance with the general principles (ISTA 2020). When four 100-seed replicates of a test are within the maximum tolerated 
range the average represents the percentage germination to be reported. Seeds which have not germinated by the end of the test period when tested under the specific conditions are classified as follows: hard seeds, fresh seeds, dead seeds, other categories (in some circumstances empty and ungerminated seeds may be further categorised according to classes described in the ISTA rules (2020)).

\section{Calculation}

The result of the germination test is calculated as the average of four 100-seed replicates. It is expressed as a percentage by number of normal seedlings. The percentage is calculated to the nearest whole number $(0.5$ is taken to the higher figure). The percentage of abnormal seedlings, hard, fresh, dead and empty seeds is calculated in the same way. The sum of the percentage of normal and abnormal seedlings and ungerminated seeds must be 100 (ISTA 2020).

Alternative to the germination test a tetrazolium test (TT) (Biochemical test for Viability) for species with long lasting seed dormancy can be applied. Again, four replicates of 100 seeds each are used and processed as described in detail in the ISTA rules (2020). The number of seeds considered viable is determined in each replicate and the percentage of viable seeds calculated as mentioned above. The percentages of non-viable seeds and empty seeds are calculated in the same way.

\subsubsection{The Key Verifiers}

In the process of FGM by assessing the three indicators a number of verifiers are proposed as typical verifiers or background information. They are also proposed in terms of the monitoring scheme - basic, standard or advanced. Among all the verifiers, three verifiers are considered to be "key verifiers", i.e. they exert a level of priority importance over the others. The designation of key verifiers has a particular significance in the frame of the interpretation of values for genetic monitoring (see Chapter 6.5.6. below).

For the indicator "selection" the most important verifiers in providing an evaluation of the indicator are those suggested for the basic level. Among them it is deemed that natural regeneration abundance has a priority of importance. Natural regeneration abundance reflects the realised fitness at the stand level. It is the realised outcome of flowering, fructification, evaluation of seeds and regeneration, while in its presence mortality at the mature tree level can be overcome. Therefore this verifier has been considered as the key verifier for the indicator "selection".

For the indicator "genetic variation" the most important verifiers are those proposed at the standard level. Among them, we consider that effective population size has a priority of importance. A reduction in effective population size below acceptable levels will trigger stochastic population processes, as well as inbreeding, and will evidently make genetic drift more important than selection. In this respect its importance for the evaluation of genetic monitoring becomes paramount. Therefore this verifier has been considered as the key verifier for the indicator "genetic variation".

For the indicator "gene flow-mating systems" all verifiers are considered at the advanced level. Among them, we consider that actual inbreeding rate has a priority of importance. This parameter takes into account both the marker-based inbreeding rate and the percentage of filled seeds, which is a realisation of the potential inbreeding depression. The actual inbreeding rate has been considered as the key verifier for the indicator "gene flow mating systems".

\subsubsection{Interpretation of values: stepwise response based on change in 10 years}

Genetic monitoring faces three major constraints and challenges: (a) the lack of historical or baseline data, (b) the use of proxies for genetic diversity, and (c) the absence of established protocols in comparing genetic monitoring indicators in temporal scale. Here we focus on the third constraint, given that the first two are dealt with by definition: genetic monitoring per se accumulates historical data and in addition it uses actual genetic diversity and differentiation values rather than proxies. In this respect, genetic monitoring operates on reference points and 
their comparison, rather than threshold values. Reference points are specific values of measurable properties of biological systems used as benchmarks for FGR management and scientific advice, while absolute threshold values (or trigger points), are precise reference points that trigger a conservation concern of unacceptable risk or irreversible harm (Grant 2007). Identifying threshold values can be tricky, as threshold values are case-dependent and likely differ among species (Flanagan et al. 2018, Atkinson et al. 2004). Therefore, preference is given to the statistically significant and/or critical difference of temporal reference points, taking into account though that such a critical difference constitutes a threshold point by itself.

Several authors have stressed the importance of defining thresholds, or critical difference values, in genetic monitoring (Aravanopoulos 2011, Bruford et al. 2017, Namkoong et al. 2002, Leroy et al. 2018, Hoban et al. 2014). It is not uncommon to detect statistically significant differences among different populations or in the same populations across time scales. For genetic monitoring as an early warning system of genetic change, besides establishing statistically significant differences in temporal comparisons, their magnitude should in addition be considerable in order to raise concern. This magnitude (critical difference or threshold between different temporal evaluations) is set for each verifier based on earlier recommendations, mostly deriving from the existing limited literature, expert opinion and ad hoc evaluations. Bootstrapping across markers for a generation of 1,000 replicates from which $\mathrm{Cl}$ is calculated is for now the most appropriate way of testing for statistical significance to compare most of the verifiers based on molecular data (implemented in GenAlEx (Peakall and Smouse 2006)).

The literature in general identifies three levels of critical difference for comparative purposes: (a) statistically significant differences (ssd), (b) differences that in addition to the above exceed by $\geq 25 \%$ the baseline value, and (c) differences that besides being statistically significant exceed by $\geq 50 \%$ the baseline value (Aravanopoulos 2011, 2016, Boyle 2000, Namkoong et al. 1996, Namkoong et al. 2002).

For most of the verifiers an ANOVA approach (such as a t-test) can be used to test for statistically significant differences among the values obtained over temporal assessments. The treatment of some specific verifiers that deviate from the above approach is discussed below.

Potentially significant differences in the verifier "allele frequencies" can be tested by constructing contingency tables and conducting the associated analysis using a Fisher's exact test, or alternatively a $x^{2}$ (or a G) test. Fisher's test is preferred as an exact statistic that can be performed directionally, while the $x^{2}$ test is an approximate statistic and is limited by the need of the expected frequency in each cell of the contingency table to be $\geq 5.0$.

The verifier "effective population size ( $\mathrm{Ne}$ )" is an exception to the rule of using comparative reference points. In this case, a minimum threshold (or trigger) value of $\mathrm{Ne} \geq 500$ is suggested. This value is based on a re-appraisal of case studies and simulation efforts, which indicate that it requires an $\mathrm{Ne} \geq 100$ to limit the loss in total fitness to $<10 \%$ after five generations, or better an $\mathrm{Ne} \geq 500$ that will prevent genetic erosion and maintain adaptive genetic diversity (Frankham et al. 2014, Hoban et al. 2014, Hoban et al. 2020, Leroy et al. 2018, Willoughby et al. 2017).

The verifier "linkage disequilibrium (LD) is potentially the hardest to assess properly. LD varies across populations, individuals, chromosomes within an individual, even at different regions within a chromosome (Aravanopoulos 2014, Evans and Cardon 2005, Weiss and Clark 2002). Therefore, it is important that the temporal comparison should involve the same genes. Two measures of LD are employed, the Pearson's squared correlation coefficient $r^{2}$ (Hill and Robertson 1968) and the standardised linkage disequilibrium coefficient D' (Lewontin 1964). Their significance is tested with the Spearman rank correlation test (Evans and Cardon 2005).

Results from genetic monitoring should be evaluated in the context of the pre-specified criteria for significant change (Aravanopoulos 2011, Flanagan et al. 2018). Overall, small differences in parameter (verifier) values are to be expected, and given the recommended sample sizes it is very likely to find notable and perhaps statistically significant differences at least in demographic parameters. The biological interpretation and significance of such differences will need to be established on non-statistical foundations taking into account that their biological significance calls for an assessment of the underlying biological (genecological) processes that are used for genetic monitoring assessment. A scheme of how to assess differences in temporal evaluations at different levels is given below. 
Table 6.10. Levels of critical difference among temporal evaluations, levels of response and advised action (ssd: statistically significant differences).

\begin{tabular}{cccc} 
No. & Level of difference & Level of response & Action \\
\hline 1 & ssd; outside the $95 \% \mathrm{Cl}$ & $1^{\text {st }}$ level & consult foresters on field situation \\
\hline 2 & $\begin{array}{c}\text { ssd; } 25 \% \text { difference } \\
\text { from baseline assessment }\end{array}$ & $2^{\text {nd }}$ level & $\begin{array}{r}\text { revision of silvicultural / } \\
\text { management plans, facilitation of NR }\end{array}$ \\
\hline 3 & $\begin{array}{c}\text { ssd; } 50 \% \text { difference } \\
\text { from baseline assessment }\end{array}$ & $3^{\text {rd level }}$ & $\begin{array}{c}\text { intensive site monitoring, } \\
\text { consider ex situ conservation }\end{array}$ \\
\hline
\end{tabular}

Independence among parameters cannot be fully achieved and interdependence among indicators and parameters cannot be completely avoided. Evidently, there could be situations where 'conflicting' results with respect to critical level differences may be observed (Namkoong et al. 2002, Aravanopoulos 2011). In this respect, the minimum number of verifiers that show a negative trend (in the $2^{\text {nd }}$ or $3^{\text {rd }}$ level of difference) under which a corrective action must be taken is presented below for each level:

Basic level: Mortality, NR abundance, Fructification, Flowering: three out of four have to show a negative trend, under the condition that NR abundance is one of them.

Standard level: the four verifiers from the basic level, plus: Allele frequencies, Allelic richness (SSR), Linkage disequilibrium (SNP), Latent genetic potential, $F_{I S}$ inbreeding coefficient, Effective population size, six out of 10 verifiers need to show negative trend, out of which NR abundance and Ne have to show a negative trend.

Advanced level. The 10 verifiers from the standard level, plus: gene flow, multilocus population outcrossing rate, actual inbreeding rate: eight out of 13 need to show a negative trend, out of which NR abundance, Ne and actual inbreeding rate have to show a negative trend.

\section{References}

Adamack AT, Gruber B (2014) PopGenReport: simplifying basic population genetic analyses in R. Methods Ecol Evol 5(4):384-387. https://doi.org/10.1111/2041-210X.12158

Adams RP, Zhong M, Fei Y (1999) Preservation of DNA in plant specimens-inactivation and reactivation of DNAses in field specimens. Mol Ecol 8:681-683. https://doi.org/10.1046/j.1365-294X.1999.84600.x

Agapow PM, Burt A (2001) Indices of multilocus linkage disequilibrium. Mol Ecol Notes 1:101-102. https://doi. org/10.1046/j.1471-8278.2000.00014.x

Akaike H, Pazen E, K Tanabe, Kitagawa G (1998) Selected papers of Hirotugo Akaike. Springer Science \& Business Media. https://doi.org/10.1007/978-1-4612-1694-0

Albrechtsen A, Nielsen FC, Nielsen R (2010) Ascertainment biases in SNP chips affect measures of population divergence. Mol Biol Evol 27(11):2534-2547. https://doi.org/10.1093/molbev/msq148

Alizoti PG, Kilimis K, Gallios P (2010) Temporal and spatial variation of flowering among Pinus nigra Arn. clones under changing climatic conditions. For Ecol Manag 259:786-797. https://doi.org/10.1016/j.foreco.2009.06.029

Amos W, Hoffman Jl, Frodsham A et al (2007) Automated binning of microsatellite alleles: problems and solutions. Mol Ecol Notes 7:10-14. https://doi.org/10.1111/j.1471-8286.2006.01560.x

Antao T, Pérez-Figueroa A, Luikart, G (2011) Early detection of population declines: high power of genetic monitoring using effective population size estimators. Evol Appl 4(1):144-154. https://doi.org/10.1111/j.1752-4571.2010.00150.x

Applied biosystems/Thermo Fisher Scientific (2014) User guide: DNA fragment analysis by capillary electrophoresis, Revision B. Thermo Fisher Scientific Inc., Carlsbad

Applied biosystems/Thermo Fisher Scientific/Hitachi (2010) Applied Biosystems 3500/3500xL Genetic Analyzer User Guide. Thermo Fisher Scientific Inc., Carlsbad

Apsit VJ, Dyer RJ, Sork VL (2002) Patterns of mating in an insect-pollinated tree species in the Missouri Ozark Forest Ecosystem Project. In: Shifley SR Kabrick, JM, (eds) Proceedings of the Second Missouri Ozark Forest Ecosystem Project Symposium: Post-treatment Results of the Landscape Experiment. Gen. Tech. Rep. NC-227. St. Paul, MN: U.S. Dept. of Agriculture, Forest Service, North Central Forest Experiment Station, pp 212-226 
Aravanopoulos FA (2011) Genetic monitoring in natural perennial plant populations. Botany 89(2):75-81. https://doi. org/10.1139/b10-087

Aravanopoulos FA (2014) Genomics of Trees. In: Ramawat KG, Merillon JM, Ahuja MR (eds) Tree Biotechnology. CRC Press, Boca Raton, pp 514-557

Aravanopoulos FA (2016) Conservation and monitoring of tree genetic resources in temperate forests. Curr For Rep 2(2):29119. https://doi.org/10.1007/s40725-016-0038-8

Aravanopoulos FA, Zsuffa L (1998) Heterozygosity and biomass production in Salix eriocephala. Heredity 81:396-403. https://doi.org/10.1046/j.1365-2540.1998.00409.x

Askew GR, Blush ThD (1990) Short note: An index of phenological overlap in flowering for clonal conifer seed orchards. Silvae Genet 39(3-4): 168-171.

Atkinson AJ, Trenham PC, Fisher RN, Hathaway SA, Johnson BS, Torres SG, Moore YC (2004) Designing monitoring programs in an adaptive management context for regional multiple species conservation plans. U.S. Geological Survey Technical Report, USGS Western Ecological Research Center, Sacramento

Bada JL, Wang XYS, Hamilton H (1999) Preservation of key biomolecules in the fossil record - current knowledge and future challenges. Philos Trans R Soc Lond, B, Biol Sci 354(1379):77-86. https://doi.org/10.1098/rstb.1999.0361

Baptiste A (2020) GridExtra: Miscellaneous functions for 'grid' graphics. R Package Version 2.3. http://cran.r-project.org/ package=gridExtra. Accessed 28 October 2020

Barnett B, Lewis T (1978) Outliers in statistical data. Wiley, New York

Barrett SCH, Yakimowski SB, Field DL, Pickup M (2010) Ecological genetics of sex ratios in plant populations. Philos Trans R Soc Lond, B, Biol Sci 365(1552):2549-2557. https://doi.org/10.1098/rstb.2010.0002

Barton NH, Slatkin M (1986) A quasi-equilibrium theory of the distribution of rare alleles in a subdivided population. Heredity, 56(3):409. https://doi.org/10.1038/hdy.1986.63

Belletti P, Ferrazzini D, Piotti A, Monteleone I, Ducci F (2012) Genetic variation and divergence in Scots pine (Pinus sylvestris L.) within its natural range in Italy. Eur J Forest Res 131:1127-1138. https://doi.org/10.1007/s10342-011-0584-3

Benestan L, Gosselin T, Perrier C, Sainte-Marie B, Rochette R, Bernatchez L (2015) RAD genotyping reveals fine-scale genetic structuring and provides powerful population assignment in a widely distributed marine species, the American lobster (Homarus americanus). Mol Ecol 24 (13):3299-3315. https://doi.org/10.1111/mec.13245

Bengtsson H (2014) MatrixStats: Methods That Apply to Rows and Columns of a Matrix. R Package Version 0.10.1. rdrr.io. https://rdrr.io/rforge/matrixStats/man/matrixStats-package.html. Accessed 17 November 2020

Benjamini Y, Hochberg Y (1995) Controlling the false discovery rate: a practical and powerful approach to multiple testing. J R Stat Soc Series B Stat Methodol 57(1):289-300

Bergmann F, Gregorius HR, Larsen JB (1990) Levels of genetic variation in European Silver fir (Abies alba) - Are They Related to the Species Decline? Genetica 82(1):1-10. https://doi.org/10.1007/BF00057667.

Beuker E, Raspe S, Bastrup-Birk A, Preuhsler T (2010) Phenological Observations. Manual Part VI. In: Manual on methods and criteria for harmonized sampling, assessment, monitoring and analysis of the effects of air pollution on forests. UNECE, ICP Forests, Hamburg

Boyle TJ (2000) Criteria and indicators for the conservation of genetic diversity. In: Young A, Boshier T, Boyle T (eds) Forest conservation genetics. CSIRO Publ., Collingwood, pp 239-251

Briggs DEG (1999) Molecular taxonomy of animal and plant cuticles - selective preservation and diagenesis. Philos Trans $R$ Soc Lond, B, Biol Sci 354:7-16. https://doi.org/10.1098/rstb.1999.0356

Brousseau L, Postolache D, Lascoux M, Drouzas A D, Källman T, Leonarduzzi C, Liepelt S, et al (2016) Local adaptation in European Firs assessed through extensive sampling across altitudinal gradients in Southern Europe. PLoS ONE 11(7):1-16. https://doi.org/10.1371/journal.pone.0158216

Brownie J, Shawcross S, Theaker J, Whitcombe D, Ferrie R, Newton C, Little S (1997) The elimination of primer-dimer accumulation in PCR. Nucleic Acids Res 25:3235-3241.https://dx.doi.org/10.1093/nar/25.16.3235

Bruford MW, Davies N, Dulloo ME, Faith DP and M Walters (2017) Monitoring changes in genetic diversity. In: Walters M, Scholes RJ (eds) The GEO handbook on biodiversity observation networks, Springer Nature, Switzerland, pp 107-128

Buchan JC, Archie EA, Van Horn RC, Moss CJ, Alberts SC (2005) Locus effects and sources of error in noninvasive genotyping. Mol Ecol Notes 5:680-683.https://doi.org/10.1111/j.1471-8286.2005.01002.x

Buchholz K, Pickering, JL (1978) DBH-distribution analysis: an alternative to stand-age analysis. Bull Torrey Bot Club 105(4):1-282.https://doi.org/10.2307/2484921

Burczyk J, DiFazio, SP, Adams WT (2004). Gene flow in forest trees: how far do genes really travel? Forest Genetics 11(3-4):179. 
Butler JM (2005a) Constructing STR multiplex assays. In: Carracedo A (ed) Forensic DNA typing protocols. Methods in Molecular Biology, Humana Press, pp 53-65.

Butler JM (2005b) Forensic DNA typing: biology, technology, and genetics of STR Markers. Elsevier Academic Press, London

Campbell LD, Astrin JJ, DeSouza Y, Giri J, Patel AA, Rawley-Payne M, Rush A and Sieffert N (2018) The 2018 Revision of the ISBER Best Practices: Summary of Changes and the Editorial Team's Development Process. Biopreservation and Biobanking 16(1): 3-6. https://doi.org/10.1089/bio.2018.0001

Center for Plant Conservation (2020) Guidelines for Tissue Collection and Storage Related to Genetic Studies of Rare Plants. CPC Best Plant Conservation Practices to Support Species Survival in the Wild. https://plantnucleus.com/ best-practices/guidelines-tissue-collection-and-storage-related-genetic-studies-rare-plants. Accessed 25 November 2020

Chamberlain JS, Gibbs RA, Rainer JE, Nguyen PN, Thomas C (1988) Deletion screening of the Duchenne muscular dystrophy locus via multiplex DNA amplification. Nucleic Acids Res 16:11141-11156. https://dx.doi.org/10.1093/ nar/16.23.11141

Chambers GK, MacAvoy ES (2000) Microsatellites: consensus and controversy. Comp Biochem Physiol B Biochem Mol Biol 126:455-476. https://doi.org/10.1016/s0305-0491(00)00233-9

Chapuis M, Lecoq M, Michalakis Y, Loiseau A, Sword GA, Piry S, Estoup A (2008) Do outbreaks affect genetic population structure? A worldwide survey in Locusta migratoria a pest plagued by microsatellite null alleles. Mol Ecol 17:6403653. https://doi.org/10.1111/j.1365-294X.2008.03869.x

Charlesworth B (2009) Effective population size and patterns of molecular evolution and variation. Nat Rev Genet 10(3):195205. https://doi.org/10.1038/nrg2526

Chase M, Hills J (1991) Silica gel: an ideal material for field preservation of leaf samples for DNA studies. Taxon 40:215-220. https://doi.org/10.2307/1222975

Cipriani G, Marrazzo MT, Di Gaspero G et al (2008) A set of microsatellite markers with long core repeat optimized for grape (Vitis spp.) genotyping. BMC Plant Biol 8:1-127. https://doi.org/10.1186/1471-2229-8-127

Clarke LA, Rebelo CS, Gonçalves J, Boavida MG, Jordan P (2001) PCR amplification introduces errors into mononucleotide and dinucleotide repeat sequences. Mol Pathol 54 (5):351-353. https://doi.org/10.1136/mp.54.5.351

Csilléry K, Lalagüe H, Vendramin GG, González-Martínez SC, Fady B, Oddou-Muratorio S (2014) Detecting short spatial scale local adaptation and epistatic selection in climate-related candidate genes in European beech (Fagus sylvatica) populations. Mol Ecol 23(19):4696-4708. https://doi.org/10.1111/mec.12902

Csilléry K, Ovaskainen O, Sperisen C, Buchmann N, Widmer A, Gugerli F (2020) Adaptation to local climate in multi-trait space: evidence from Silver fir (Abies alba Mill.) populations across heterogeneous environment. Heredity 124(1):77.92. https://doi.org/10.1038/s41437-019-0240-0

Dąbrowski MJ, Bornelöv S, Kruczyk M, Baltzer N, Komorowski J (2015) True null allele detection in microsatellite loci: a comparison of methods, assessment of difficulties and survey of possible improvements. Mol Ecol Res 15(3):477-488. https://doi.org/10.1111/1755-0998.12326

Dakin EE, Avise JJ (2004) Microsatellite null alleles in parentage analysis. Heredity 93(5):504-509. https://doi.org/10.1038/ sj.hdy. 6800545

De Vitis M, Hay FR, Dickie, JB, Trivedi C, Choi J, Fiegener R. (2020). Seed storage: maintaining seed viability and vigor for restoration use. Restor Ecol 28(S3):S249-S255 https://doi.org/10.1111/rec.13174

Del Castillo RF, Trujillo S (2008) Effect of inbreeding depression on outcrossing rates among populations of a tropical pine. New Phytol 177(2):517-524. https://doi.org/10.1111/j.1469-8137.2007.02260.x

Dellaporta SL, Wood J, Hicks JB (1983) A plant DNA minipreparation: version II. Plant Mol Biol Rep 1:19-21. https://doi. org/10.1007/BF02712670

Demeke T, Jenkins GR (2010) Influence of DNA extraction methods, PCR inhibitors and quantification methods on real-time PCR assay of biotechnology-derived traits. Anal Bioanal Chem Res 396(6):1977-1990. https://doi.org/10.1007/ s00216-009-3150-9

Dewoody J, Nason JD, Hipkins VD (2006) Mitigating scoring errors in microsatellite data from wild populations: Review. Mol Ecol Notes 6(4):951-957.https://doi.org/10.1111/j.1471-8286.2006.01449.x

Doyle JJ, Doyle JL (1987) A rapid DNA isolation procedure from small quantities of fresh leaf tissue. Phyto Bull 19:11-15.

Dray S, Dufour AB (2007) The Ade4 package: implementing the duality diagram for ecologists. J Stat Soft 22(4):1-20. https://doi.org/10.18637/jss.v022.i04

Ducci F, De Cuyper B, Pâques LE, Proietti R, Wolf H (2012) Reference protocols for assessment of trait and reference genotypes to be used as standards in international research projects. CRA SEL-Arezzo, Italy 
Dupuis JR, Jeffrey CO, Brunet BMT, Longcore T, Johnson JJ, Sperling FAH (2018) Genomic data indicate ubiquitous evolutionary distinctiveness among populations of California metalmark butterflies. Conserv Genet 19 (5):1097-1108. https://doi.org/10.1007/s10592-018-1081-8

Edwards A, Civitello A, Hammond HA, Caskey CT (1991) DNA typing and genetic mapping with trimeric and tetrameric tandem repeats. Am J Hum Genet 49:746-756.

Edwards MC, Gibbs RA. 1994. Multiplex PCR: advantages, development, and applications. PCR Meth Appl 3:65-75. https://doi.org/10.1101/gr.3.4.s65

Eizaguirre C, Baltazar-Soares M (2014) Evolutionary conservation-evaluating the adaptive potential of species. Evol Appl 7(9):963-967. https://doi.org/10.1111/eva.12227

Elnifro EM, Ashshi AM, Cooper RJ, Klapper PE (2000) Multiplex PCR: optimization and application in diagnostic virology. Clin Microbiol Rev 13:559-570. https://doi.org/10.1128/cmr.13.4.559-570.2000

Estoup A, Garnery L, Solignac M, Cornuet JM (1995) Microsatellite variation in honeybee (Apis mellifera L.) populations: hierarchical genetic structure and test of the infinite allele and stepwise mutation models. Genetics, 140:679-695.

Estoup A, Wilson IJ, Sullivan C, Cornuet JM, Moritz C (2001) Inferring population history from microsatellite and enzyme data in serially introduced cane toads, Bufo marinus. Genetics 159(4):1671-1687.

Evanno G, Regnaut S, Goudet J (2005) Detecting the number of clusters of individuals using the software STRUCTURE: a simulation study. Mol Ecol 14: 2611-2620. doi: 10.1111/j.1365-294X.2005.02553.x

Evans DM, LR Cardon (2005) A comparison of linkage disequilibrium patterns and estimated population recombination rates across multiple populations. Am J Hum Genet 76:681-687. https://doi.org/10.1086/429274

Ewen KR, Bahlo M, Treloar SA et al (2000) Identification and analysis of error types in high-throughput genotyping. Am J Hum Genet 67:727-736. https://doi.org/10.1086/303048

Excoffier L, Lischer HEL (2010) Arlequin suite ver. 3.5: A new series of programs to perform population genetics analyses under Linux and Windows. Mol Ecol Res 10 (3):564-567. https://doi.org/10.1111/j.1755-0998.2010.02847.x

Fazekas AJ, Steeves R, Newmaster SG (2010) Improving sequencing quality from PCR products containing long mononucleotide repeats. BioTechniques 48:277-281. https://doi.org/10.2144/000113369

Fischer MC, Foll M, Excoffier L, Heckel G (2011) Enhanced AFLP genome scans detect local adaptation in high-altitude populations of a Small rodent (Microtus arvalis). Mol Ecol 20(7):1450-1462. https://doi. org/10.1111/j.1365-294X.2011.05015.x

Fisher RA (1930) The genetical theory of natural selection, Oxford University Press, London

Flanagan SP, Forester BR, Latch EK, Aitken SN, Hoban S (2018) Guidelines for planning genomic assessment and monitoring of locally adaptive variation to inform species conservation. Evol Appl 11:1035-1052. https://doi.org/10.1111/ eva.12569

Flores-Rentería L, Krohn A (2013) Scoring microsatellite loci. Microsatellites. In: Kantartzi SK (ed) Methods in Molecular Biology. Humana Press, Totowa, pp 319-336

Flores-Rentería L, Whipple AV (2011) A new approach to improve the scoring of mononucleotide microsatellite loci. Am $J$ Bot 98 (3):e51-e53. https://doi.org/10.3732/ajb.1000428

Francis RM (2017) Pophelper: An R package and web app to analyse and visualize population structure. Mol Ecol Res 17(1):27-32. https://doi.org/10.1111/1755-0998.12509

Frankham R, Bradshaw CJ, Brook BW (2014) Genetics in conservation management: Revised recommendations for the 50/500 rules, Red List criteria and population viability analyses. Biol Conserv 170:56-63. https://doi.org/10.1016/j. biocon.2013.12.036

Funk WC, McKay JK, Hohenlohe PA, Allendorf FW (2012) Harnessing genomics for delineating conservation units. Trends Ecol Evol 27(9):489-496. https://doi.org/10.1016/j.tree.2012.05.012

Fussi B, Westergren M, Aravanopoulos F, Baier R, Kavaliauskas D, Finžgar D, Alizoti P, Božič G, Avramidou E, Konnert M, Kraigher H (2016) Forest genetic monitoring: an overview of concepts and definitions. Environ Monit Assess 188(8):112. https://doi.org/10.1007/s10661-016-5489-7

Gagneux, P, Boesch C, Woodruff DC (1997) Microsatellite scoring errors associated with non-invasive genotyping based on nuclear DNA amplified from shed hair. Mol Ecol 6(9):861-68. https://doi.org/10.1111/j.1365-294X.1997.tb00140.x

Galan M, Cosson JF, Aulagnier S, Maillard JC, Thévenon S, Hewison AJM (2003) Cross-amplification tests of ungulate primers in roe deer (Capreolus capreolus) to develop a multiplex panel of 12 microsatellite loci. Mol Ecol Notes 3:142-146. https://doi.org/10.1046/j.1471-8286.2003.00384.x

Gerard FF, George CT, Hayman G, Chavana-Bryant C, Weedon GP (2020) Leaf phenology amplitude derived from MODIS NDVI and EVI: maps of leaf phenology synchrony for Meso- and South America. Geosci Data J 7(1):13-26. https://doi. org/10.1002/gdj3.87 
Ghosh S, Karanjawala ZE, Hauser ER et al (1997) Methods for precise sizing, automated binning of alleles, and reduction of error rates in largescale genotyping using fluorescently labelled dinucleotide markers.

Goudet J (2005) Hierfstat, a package or R to compute and test hierarchical F-statistics. Mol Ecol Notes 2:184-186. https:// doi.org/10.1111/j.1471-8286.2004.00828.x

Grant WS (2007) Status and trends in genetic resources of captured fisheries. In: Bartley DM, Harvey BJ, Pullin RSV (eds) Workshop on status and trends in aquatic genetic resources. FAO Publ., Rome, pp 29-81

Gregorius H (1978) The concept of genetic diversity and its formal relationship to heterozygosity and genetic distance. Math Biosci 41(3-4):253-71. https://doi.org/10.1016/0025-5564(78)90040-8

Gregorius HR, Krauhausen J, Müller-Starck G (1986) Spatial and temporal genetic differentiation among the seed in a stand of Fagus sylvatica I. Heredity 57:255-262. https://doi.org/10.1038/hdy.1986.116

Gross A, Holdenrieder O, Pautasso M, Queloz V, Sieber TN (2013) Hymenoscyphus pseudoalbidus, the causal agent of European ash dieback. Mol Plant Pathol 15(1):5-21. https://doi.org/10.1111/mpp.12073

Gruber B, Unmack PJ, Berry OF, Georges A (2018) Dartr: An R package to facilitate analysis of SNP data generated from reduced representation genome sequencing. Mol Ecol Res 18(3):691-699. https://doi.org/10.1111/1755-0998.12745

Guichoux E, Lagache L, Wagner S, Chaumeil P, LéGer P, Lepais O, Lepoittevin C, Malausa T, Revardel E, Salin F et al (2011) Current trends in microsatellite genotyping. Mol Ecol Res 11:591-611. https://doi. org/10.1111/j.1755-0998.2011.03014.x

Gusmão L, Butler JM, Carracedo A et al (2006) DNA commission of the international society of forensic genetics (ISFG):an update of the recommendations on the use of Y-STRs in forensic analysis. Int J Legal Med 20:191-200. https://doi. org/10.1007/s00414-005-0026-1

Hahn M, Wilhelm J, Pingoud A (2001) Influence of fluorophore dye labels on the migration behaviour of polymerase chain reaction-amplified short tandem repeats during denaturing capillary electrophoresis. Electrophoresis 22:2691-2700. https://doi.org/10.1002/1522-2683(200108)22:13

Harper AL, Mckinney LV, Nielsen LR, Havlickova L, Li Y, Trick M, Bancroft I (2016) Molecular markers for tolerance of European ash (Fraxinus excelsior) to dieback disease identified using Associative Transcriptomics. Sci Rep 6(1):1-7. https://doi.org/10.1038/srep19335

Hartmann C, Lennartz K, Ibrahim H, Coz A, Kasper Y, Lenz C, Mathur D, Polidori M (2016) Application note: stable 16-year storage of DNA purified with the QIAamp® DNA Blood Mini Kit. Qiagen GmbH. https://www.qiagen.com/us/ resources/download.aspx?id=705c6944-4633-4101-8500-a6642d253a0e\&lang=en Accessed 1 October 2020

Hartzell B, Graham K, McCord B (2003) Response of short tandem repeat systems to temperature and sizing methods. Forensic Sci Int 133:228-234. https://doi.org/10.1016/s0379-0738(03)00074-4

Hattemer HH (1991) Genetic variation in European populations of forest trees. In: Müller-Starck G, Ziehe M (eds) J.D. Sauerlander's Verlag, Frankfurt am Main, pp 271

Hay FR, Smith RD (2003) Seed maturity: when to collect seeds from wild plants. In: Smith RD, Dickie JB, Linington SH, Pritchard HW, Pro-bert RJ (eds) Seed conservation: turning science into practice. The Royal Botanic Gardens Kew, Richmond, pp 97-133

Heer K, Behringer D, Piermattei A, Bässler C, Brandl R, Fady B, Jehl H, et al (2018) Linking dendroecology and association genetics in natural populations: stress responses archived in tree rings associate with SNP genotypes in Silver fir (Abies alba Mill.). Mol Ecol 27(6):1428-1438. https://doi.org/10.1111/mec.14538

Hill CR, Butler JM, Vallone PM (2009) A 26plex autosomal STR assay to aid human identity testing. J Forensic Sci 54:10081015. https://doi.org/10.1111/j.1556-4029.2009.01110.x

Hill WG (1981) Estimation of effective population size from data on linkage disequilibrium. Genet Res 38(3):209-216. https:// doi.org/10.1017/S0016672300020553

Hill WG, Robertson A (1968) Linkage disequilibrium in finite populations. Theor Appl Genet 38:226-231. https://doi. org/10.1007/BF01245622

Hoban S, Arntzen J A, Bruford MW, Godoy JA, Rus Hoelzel A, Segelbacher G, Bertorelle G et al (2014) Comparative evaluation of potential indicators and temporal sampling protocols for monitoring genetic erosion. Evol Appl 7:984-998. https://doi.org/10.1111/eva.12197

Hoban S, Bruford M, D'Urban JJ et al (2020): Genetic diversity targets and indicators in the CBD post-2020 Global Biodiversity Framework must be improved. Biol Conserv 248:108654. https://doi.org/10.1016/j.biocon.2020.108654

Hoffman Jl, Amos W (2005) Microsatellite genotyping errors: detection approaches, common sources and consequences for paternal exclusion. Mol Ecol 14(2):599-612. https://doi.org/10.1111/j.1365-294X.2004.02419.x

Holleley CE, Geerts PG (2009) Multiplex manager 1.0: a cross-platform computer program that plans and optimizes multiplex PCR. BioTechniques 46:511-517. https://doi.org/10.2144/000113156 
Hothorn T, Frank Bretz, Westfall P (2008) Simultaneous inference in general parametric models. Biom J 50(3):346-363. https://doi.org/10.1002/bimj.200810425

Hu G (1993) DNA Polymerase-catalyzed addition of nontemplated extra nucleotides to the 3' of a DNA fragment. DNA Cell Biol 12:763-770. https://doi.org/10.1089/dna.1993.12.763

Hubisz MJ, Falush D, Stephens M, Pritchard JK (2009) Inferring weak population structure with the assistance of sample group information. Mol Ecol Res 9(5):1322-1332. https://doi.org/10.1111/j.1755-0998.2009.02591.x

Idury RM, Cardon LR (1997) A simple method for automated allele binning in microsatellite markers. Genome Res 7:11041109. https://doi.org/10.1101/gr.7.11.1104

ISTA (2020) International Rules for Seed Testing. International Seed Testing Assoc., Zurich

Ivanova N, Kuzmina K (2013) Protocols for dry DNA storage and shipment at room temperature. Mol Ecol Resour 13(5):890-898. https://doi.org/10.1111/1755-0998.12134

Jayashree B, Reddy PT, Leeladevi Y, Crouch JH, Mahalakshmi V et al (2006) Laboratory information management software for genotyping workflows: applications in high throughput crop genotyping. BMC Bioinform 7:383. https://doi. org/10.1186/1471-2105-7-383

Jombart T (2008) Adegenet: an R package for the multivariate analysis of genetic markers. Bioinformatics 24(11):14031405. https://doi.org/10.1093/bioinformatics/btn129

Jombart T, Ahmed I (2011) Adegenet 1.3-1: new tools for the analysis of genome-wide SNP Data. Bioinformatics 27(21):3070-3071. https://doi.org/10.1093/bioinformatics/btr521

Jombart T, Devillard S, Balloux F (2010) Discriminant analysis of principal components: a new method for the analysis of genetically structured populations. BMC Genet 11(94):1-15. https://doi.org/10.1371/journal.pcbi.1000455

Kalinowski ST (2004) Counting alleles with rarefaction: private alleles and hierarchical sampling designs. Conserv Genet 5(4):539-43. https://doi.org/10.1023/B:COGE.0000041021.91777.1a

Kalinowski ST, Taper ML (2006) Maximum likelihood estimation of the frequency of null alleles at microsatellite loci. Conserv Genet 7(6):991-995. https://doi.org/10.1007/s10592-006-9134-9

Kalinowski ST, Taper ML, Marshall TC (2007) Revising how the computer program CERVUS accommodates genotyping error increases success in paternity assignment. Mol Ecol 16: 1099-1106. http://dx.doi. org/10.1111/j.1365-294X.2007.03089.x

Kamvar ZN, Tabima JF, Grünwald NJ (2014) Poppr: an R package for genetic analysis of populations with clonal, partially clonal, and/or sexual reproduction. PeerJ 2:e281. https://doi.org/10.7717/peerj.281

Kimura M (1983) The neutral theory of molecular evolution. Cambridge University Press, Cambridge. https://doi. org/10.1017/CBO9780511623486

King EP (1953) On some procedures for the rejection of suspected data. J Am Stat Assoc 48(263):531-533. https://doi.org/ 10.1080/01621459.1953.10483490

Kirov G, Williams N, Sham P, Craddock N, Owen MJ (2000) Pooled genotyping of microsatellite markers in parent-offspring trios. Genome Res 10:105-115. https://doi.org/10.1101/gr.10.1.105

Kline MC, Duewer DL, Redman JW, Butler JM (2005) Results from the NIST 2004 DNA quantitation study. J Forensic Sci 50:571-578.

Koetsier G, Cantor E (2019) Technical note: A practical guide to analysing nucleic acid concentration and purity with microvolume spectrophotometers. New England Biolabs Inc. https://www.neb.com/-/media/catalog/application-notes/ mvs_analysis_of_na_concentration_and_purity.pdf?rev=be7c8e19f4d34e558527496ea51623dc. Accessed 19th October 2020

Kudo G (2006) Flowering phenologies of animal-pollinated plants: reproductive strategies and agents of selection. In: Harder LD, Barrett SCH (eds) Ecology and evolution of flowers. Oxford Univ. Press, New York, pp 139-158

Lederer T, Seidl S, Graham B, Betz P (2000) A new pentaplex PCR system for forensic casework analysis. Int J Legal Med 114:87-92. https://doi.org/10.1007/s004140000161

Leroy G, Carroll EL, Bruford MW, DeWoody A, Strand A, Waits L, Wang J (2018) Next-generation metrics for monitoring genetic erosion within populations of conservation concern. Evol Appl 11:1066-1083. https://doi.org/10.1111/eva.12564

Levinson G, Gutman GA (1987) Slipped-strand mispairing: a major mechanism for DNA sequence evolution. Mol Biol Evol 4:203-221. https://doi.org/10.1093/oxfordjournals.molbev.a040442

Lewontin RC (1964) The interaction of selection and linkage. I. General considerations; heterotic models. Genetics 49:49-67.

Lewontin RC, Krakauer J (1973) Distribution of gene frequency as a test of the theory of the selective neutrality of polymorphisms. Genetics 74(1):175-195. 
Lim PO, Kim HJ, Nam HG (2007) Leaf senescence. Annu Rev Plant Biol 58(1):115-136. https://doi.org/10.1146/annurev. arplant.57.032905.105316

Linkosalo T, Hakkinen R, Hari P (1996) Improving the reliability of a combined phenological time series by analyzing observation quality. Tree Physiol 16(7):661-664. https://doi.org/10.1093/treephys/16.7.661

Livingstone D, Freeman B, Tondo CL, Cariaga KA, Oleas NH, Meerow AW, Schnell RJ, Kuhn DN (2009) Improvement of high-throughput genotype analysis after implementation of a dual-curve Sybr Green I-based quantification and normalization procedure. HortScience 44:1228-1232. https://doi.org/10.21273/HORTSCI.44.5.1228

Lloyd DG (1974) Theoretical sex ratios of dioecious and gynodioecious angiosperms. Heredity 32(1):11-34. https://doi. org/10.1038/hdy.1974.2.

Lowry DB, Hoban S, Kelley JL, Lotterhos KE, Reed LK, Antolin MF, Storfer A (2017) Breaking RAD: An evaluation of the utility of restriction site-associated DNA sequencing for genome scans of adaptation. Mol Ecol Res 17(2):142-52. https://doi.org/10.1111/1755-0998.12635

Meldgaard M, Morling N (1997) Detection and quantitative characterization of artificial extra peaks following polymerase chain reaction amplification of 14 short tandem repeat systems used in forensic investigations. Electrophoresis 18:1928-1935. https://doi.org/10.1002/elps.1150181107

Menkis A, Bakys R, Åslund MS, Davydenko K, Elfstrand M, Stenlid J, Vasaitis R (2019) Identifying Fraxinus excelsior tolerant to ash dieback: Visual field monitoring versus a molecular marker. For Pathol 50(1), e12572. https://doi. org/10.1111/efp.12572

Morin PA, Martien KK, Archer Fl et al (2010) Applied conservation genetics and the need for quality control and reporting of genetic data used in fisheries and wildlife management. Heredity 101:1-10. https://doi.org/10.1093/jhered/esp107

Muller-Landau HC, Condit RS, Chave J, Thomas SC, Bohlman SA, Bunyavejchewin S, Ashton, P et al (2006) Testing metabolic ecology theory for allometric scaling of tree size, growth, and mortality in tropical forests. Ecol Lett 9(5):575588. https://doi.org/10.1111/j.1461-0248.2006.00904.x

Müller-Starck G (1989). Genetic Implications of Environmental Stress in Adult Forest Stands of Fagus Sylvatica L. In Genetic Effects of Air Pollutants. In: Scholz G, Gregorius HR, Rudin D (eds) Forest Tree Populations. Springer, Berlin, pp 128-142

Mund M, Kutsch WL, Wirth C, Kahl T, Knohl A, Skomarkova MV, Schulze ED (2010) The influence of climate and fructification on the inter-annual variability of stem growth and net primary productivity in an old-growth, mixed beech forest. Tree Physiol 30:689-704. https://doi.org/10.1093/treephys/tpq027

Müller-Starck G (1995) Genetic variation in high elevated populations of Norway spruce (Picea abies L. Karst.) in Switzerland. Silvae Genet 44:5-6.

Munguía-Rosas MA, Ollerton J, Parra-Tabla V, De-Nova JA (2011) Meta-analysis of phenotypic selection on flowering phenology suggests that early flowering plants are favoured. Ecol Lett 14(5):511-521. https://doi. org/10.1111/j.1461-0248.2011.01601.x

Namkoong G, Boyle T, El-Kassaby YA, Palmberg-Lerche C, Eriksson G, Gregorius HR, Joly H, Kremer A, Savolainen O, Wickneswari R, Young A, Zeh-Nlo M, Prabhu R (2002) Criteria and indicators for sustainable forest management: assessment and monitoring of genetic variation. Forest Resources Div. FAO, Rome

Namkoong G, Boyle T, Gregorious HR, Joly H, Savolainen O, Ratman W, Young A (1996) Testing criteria and indicators for assessing the sustainability of forest management: genetic criteria and indicators. Centre for International Forestry Research (CIFOR), Bogor

Nei M (1973) Analysis of gene diversity in subdivided populations. Proc Natl Acad Sci USA 70:3321-3323. https://doi. org/10.1073/pnas.70.12.3321

Nei M, Maruyama T, Chakraborty R (1975) The bottleneck effect and genetic variability in populations. Evolution 29(1): 1-10. https://doi.org/10.2307/2407137

Neubig KM, Whitten WM, Abbott JR, Elliott S, Soltis DE, Soltis PS (2014) Variables affecting DNA preservation in archival plant specimens. In: Applequist WL, Campbell LM (eds) DNA banking for the 21st century: proceedings of the US workshop on DNA banking. William L. Brown Center at the Missouri Botanical garden, St. Louis, Missouri, pp 81-112

Nielsen EE, Bach LA, Kotlicki P (2006) Hybridlab (Version 1.0): A program for generating simulated hybrids from population samples. Mol Ecol Notes 6(4):971-973. https://doi.org/10.1111/j.1471-8286.2006.01433.x

Nishiguchi MK, Doukakis P, Egan M, Kizirian D, Phillips A, Prendini L, Rosenbaum HC, Torrres E, Wyner Y, DeSalle R, Giribet G (2002) DNA isolation procedures. In: DeSalle R, Giribet G, Wheeler W (eds) Methods and tools in biosciences and medicine - Techniques in molecular systematics and evolution. Birkhäuser Verlag / Springer Basel AG, Basel, pp 249-287

Nunziata SO, Scott DE, Lance SL (2015) Temporal genetic and demographic monitoring of pond-breeding amphibians in three contrasting population systems. Conserv Genet 16:1335-1344. https://doi.org/10.1007/s10592-015-0743-z 
O'Connell LM, Mosseler A, Rajora OP (2006) Impacts of forest fragmentation on the mating system and genetic diversity of white spruce (Picea glauca) at the landscape level. Heredity 97 (6): 418-426. https://doi.org/10.1038/sj.hdy.6800886.

Oddou-Muratorio S, Vendramin GG, Buiteveld J, Fady B (2009) Population estimators or progeny Tests: what Is the best method to assess null allele frequencies at SSR loci? Conserv Genet 10(5):1343-1347. https://doi.org/10.1007/ s10592-008-9648-4

Olejniczak M, Krzyzosiak WJ (2006) Genotyping of simple sequence repeats factors implicated in shadow band generation revisited. Electrophoresis 27:3724-3734. https://doi.org/10.1002/elps.200600136

Otárola MF, Sazima M, Solferini VN (2013) Tree size and its relationship with flowering phenology and reproductive output in Wild Nutmeg trees. Ecol Evol 3(10):3536-3550 https://doi.org/10.1002/ece3.742

Paradis E (2010) Pegas: an R package for population genetics with an integrated-modular approach. Bioinformatics 26(3):419-420. https://doi.org/10.1093/bioinformatics/btp696.

Peakall R, Smouse PE (2006) Genalex 6: Genetic analysis in Excel. Population genetic software for teaching and research. Mol Ecol Notes 6(1):288-295 https://doi.org/10.1111/j.1471-8286.2005.01155.x.

Pedrini S, Gibson-Roy P, Trivedi C, Gálvez-Ramírez C, Hardwick K, Shaw N, Frischie S, Laverack G, Dixon K (2020) Collection and production of native seeds for ecological restoration. Restor Ecol 28:S227-S237. https://doi.org/10.1111/ rec.13190

Petit RJ, El Mousadik A, Pons O (2008) Identifying populations for conservation on the basis of genetic markers. Conserv Biol 12(4):844-855. https://doi.org/10.1111/j.1523-1739.1998.96489.x

Pluess AR, Frank A, Heiri C, Lalagüe H, Vendramin GG, Oddou-Muratorio S (2016) Genome-environment association study suggests local adaptation to climate at the regional scale in Fagus sylvatica. New Phytol 210 (2):589-601. https:// doi.org/10.1111/nph.13809

Pohlert T (2020) Calculate pairwise multiple comparisons of mean rank sums extended. R package version 1.7.0. PMCMRplus. https://CRAN.R-project.org/package=PMCMRplus. Accessed 30 October 2020

Porcher E, Lande R (2016) Inbreeding depression under mixed outcrossing, self-fertilization and sib-mating. BMC Evol Biol 16(1):105. https://doi.org/10.1186/s12862-016-0668-2

Prendini L, Hanner R, DeSalle R (2002) Obtaining, storing, and archiving specimens and tissue samples for use in molecular studies. In: DeSalle R, Giribet G, Wheeler W (eds) Methods and tools in biosciences and medicine Techniques in molecular systematics and evolution. Birkhäuser Verlag / Springer Basel AG, Basel, pp 176-248.

Pritchard, JK, Stephens M, Donnelly P (2000) Inference of population structure using multilocus genotype data. Genetics 155: 945-959. https://doi.org/10.1007/s10681-008-9788-0

Qiagen (2010) Multiplex PCR Kit Handbook. https://www.qiagen.com/si/resources/download.aspx?id=a541a49c-cd0640ca-b1d2-563d0324ad6c\&lang=en. Accessed 10 October 2020

R Core Team (2020) R: A language and environment for statistical computing. R Foundation for Statistical Computing. https://www.R-project.org/. Accessed 28 October 2020

Rajora OP, Mosseler A, Major JE (2000a) Indicators of population viability in red spruce, Picea rubens. II. Genetic diversity, population structure, and mating behavior. Can J Bot 78:941-956. https://doi.org/10.1139/b00-066

Rajora OP, Rahman MH, Buchert GP, Dancik BP (2000b) Microsatellite DNA analysis of genetic effects of harvesting in old-growth eastern white pine (Pinus strobus) in Ontario, Canada. Mol Ecol 9(3):339-348. https://doi. org/10.1046/j.1365-294X.2000.00886.X

Rajora OP, Pluhar SA (2003) Genetic diversity impacts of forest fires, forest harvesting, and alternative reforestation practices in black spruce (Picea mariana). Theor Appl Genet 106(7):1203-1212. https://doi.org/10.1007/ s00122-002-1169-9

Renshaw MA, Saillant E, Bradfield SC, Gold JR (2006) Microsatellite multiplex panels for genetic studies of three species of marine fishes: red drum (Sciaenops ocellatus), red snapper (Lutjanus campechanus), and cobia (Rachycentron canadum). Aquaculture 253:731-735. https://doi.org/10.1016/j.aquaculture.2005.09.012

Rice WR (1989) Analyzing table of statistical tests. Evolution 43(1):223-225. https://doi.org/10.1111/j.1558-5646.1989. tb04220.x

Rithidech K, Dunn JJ (2003) Combining multiplex and touchdown PCR for microsatellite analysis. Methods Mol Biol 226:295-300. https://doi.org/10.1385/1-59259-384-4:295

Ritland K (1989) Correlated matings in the partial selfer Mimulus guttatus. Evolution 43(4):848-859. https://doi. org/10.1111/j.1558-5646.1989.tb05182.x

Ritland K (2002) Extensions of models for the estimation of mating systems using an independent loci. Heredity 88:221-228. https://doi.org/10.1038/sj.hdy.6800029

Ritland K, Jain S (1981) A model for the estimation of outcrossing rate and gene frequencies using an independent loci. Heredity 47(1):35-52. https://doi.org/10.1038/hdy.1981.57 
Roesti M, Salzburger W, and Berner D (2012) Uninformative polymorphisms bias genome scans for signatures of selection. BMC Evol Biol 12(1):94. https://doi.org/10.1186/1471-2148-12-94

Roschanski AM, Csilléry K, Liepelt S, Oddou-Muratorio S, Ziegenhagen B, Huard F, Ullrich KK, Postolache D, Vendramin GG, Fady B (2016) Evidence of divergent selection for drought and cold tolerance at landscape and local scales in Abies alba Mill. In the French Mediterranean Alps. Mol Ecol 25(3):776-794. https://doi.org/10.1111/mec.13516

Rousset F (2008) Genepop'007: A complete re-implementation of the Genepop Software for Windows and Linux. Mol Ecol Res 8(1):103-106.https://doi.org/10.1111/j.1471-8286.2007.01931.x

Rousset F (2017) Genepop version 4.6. 9. Semantic Scholar. https://www.semanticscholar.org/paper/Genepop-version4.6.9-Rousset/88ae28e934a876a0fd981468cfe8d0517b40714b. Accessed 30 October 2020

Scandura M, Capitani C, lacolina L, Marco A (2006) An empirical approach for reliable microsatellite genotyping of wolf DNA from multiple non-invasive sources. Conserv Genet 7:813-823. https://doi.org/10.1007/s10592-005-9106-5

Schaber J, Badeck, FW (2002) Evaluation of methods for the combination of phenological time series and outlier detection. Tree Physiol 22(14):973-982. https://doi.org/10.1093/treephys/22.14.973

Schuster D, Appleby D (1983) Does freezing and thawing of DNA solutions insert nicks in the double helix. Focus 5(2):1. https://doi.org/10.1.1.713.3395

Schwarz G (1978) Estimating the dimension of a model. Ann Stat 6(2):462-464.

Seifert T, Müller-Starck G (2009) Impacts of fructification on biomass production and correlated genetic effects in Norway spruce (Picea abies [L.] Karst.). Eur J For Res 128:155. https://doi.org/10.1007/s10342-008-0219-5

Selkoe KA, Toonen RJ (2006) Microsatellites for ecologists: a practical guide to using and evaluating microsatellite markers. Ecol Lett 9(5):615.629. https://doi.org/10.1111/j.1461-0248.2006.00889.x

Semagn K, Babu R, Hearne S, Olsen M (2014) Single nucleotide polymorphism genotyping using kompetitive allele specific PCR (KASP): overview of the technology and its application in crop improvement. Mol Breed 33(1):1-14. https://doi. org/10.1007/s11032-013-9917-x

Sgueglia J, Geiger S, Davis J (2003) Precision studies using the ABI Prism 3100 Genetic Analyzer for forensic DNA analysis. Anal Bioanal Chem 376:1247-1254. https://doi.org/10.1007/s00216-003-1998-7

Signorell A (2020) Tools for Descriptive Statistics. DescTools. https://cran.r-project.org/package=DescTools. Accessed 30 October 2020

Slatkin M (1985) Rare alleles as indicators of gene flow. Evolution 39(1):53-65. https://doi.org/10.1111/j.1558-5646.1985. tb04079.x

Slatkin M (1987) Gene flow and the geographic structure of natural populations. Science 236(4803):787-792. https://doi. org/10.1126/science.3576198

Slatkin M, Barton $\mathrm{NH}$ (1989) A comparison of three indirect methods for estimating average levels of gene flow. Evolution 43(7):1349-1368. https://doi.org/10.1111/j.1558-5646.1989.tb02587.x

Slatkin, M (2008) Linkage disequilibrium: understanding the genetic past and mapping the medical future. Nat Rev Genet 9(6):477-485. https://doi.org/10.1038/nrg2361.Linkage

Smouse PE, Sork VL (2004) Measuring pollen flow in forest trees: a comparison of alternative approaches. Forest Ecol Manage 197:21-38. https://doi.org/10.1016/j.foreco.2004.05.049

Soltis PS, Soltis DE (1993) Ancient DNA. Prospects and limitations. N Z J Bot 31:203-209. https://doi.org/10.1080/002882 5X.1993.10419497

Sork VL, Nason J,Campbell DR, Fernández, J F (1999) Landscape approaches to the study of gene flow in plants. Trends in Ecol Evol 14(6):219-224. https://doi.org/10.1016/s0169-5347(98)01585-7

Sork VL, Smouse PE (2006) Genetic analysis of landscape connectivity in tree populations. Landscape Ecol 21(6):821-836. https://doi.org/10.1007/s10980-005-5415-9

Stocks JJ, Metheringham CL, Plumb WJ, Lee SJ, Kelly LJ, Nichols RA, Buggs, RJA (2019) Genomic basis of European ash tree resistance to ash dieback fungus. Nat Ecol Evol 3(12):1686-1696. https://doi.org/10.1038/s41559-019-1036-6

Summers K, Amos W (1997) Behavioral, ecological, and molecular genetic analyses of reproductive strategies in the Amazonian Dart-Poison Frog, Dendrobates ventrimaculatus. Behav Ecol 8(3):260-267. https://doi.org/10.1093/ beheco/8.3.260

Sytsma KJ, Schaal BA (1985) Genetic variation, differentiation, and evolution in a species complex of tropical shrubs based on isozymic data. Evolution 39:582-593. https://doi.org/10.1111/j.1558-5646.1985.tb00396.x

Taberlet P, Griffin S, Goossens B, Questiau S, Manceau V, Escaravage N, Waits LP, Bouvet J (1996) Reliable genotyping of samples with very low DNA quantities using PCR. Nucleic Acids Res 24(16):3189-3194. https://doi.org/10.1093/ nar/24.16.3189 
Thomas WK, Paabo S (1994) DNA sequences from old tissue remains. In: Zimmer EA, White TJ, Cann RL, Wilson AC (eds) Methods in Enzymology. Molecular Evolution: Producing the Biochemical Data. Academic Press, San Diego, pp 406-419.

Tyrmi JS, Vuosku J, Acosta JJ, Li Z, Sterck L, Cervera MT, Savolainen O, Pyhäjärvi T (2020) Genomics of clinal local adaptation in Pinus sylvestris under continuous environmental and spatial genetic setting. G3: Genes, Genomes, Genetics 10(8):2683-2696. https://doi.org/10.1534/g3.120.401285

Urbanek S, Horner J (2020) Cairo: R graphics device using cairo graphics library for creating high-quality bitmap (PNG, JPEG, TIFF), vector (PDF, SVG, PostScript) and display (X11 and Win32) output. R Package Version 1.5-12.2. Https:// CRAN.R-Project.Org/Package=Cairo. Accessed 28 October 2020

Urquhart A, Kimpton CP, Downes TJ, Gill P (1994) Variation in Short Tandem Repeat sequences-a survey of twelve microsatellite loci for use as forensic identification markers. International Journal of Legal Medicine 107:13-20. https:// doi.org/10.1007/BF01247268

Vallone PM, Butler JM (2004) AutoDimer: a screening tool for primer dimer and hairpin structures. BioTechniques 37:226-231. https://doi.org/10.2144/04372ST03

Vallone PM, Hill CR, Butler JM (2008) Demonstration of rapid multiplex PCR amplification involving 16 genetic loci. Forensic Sci Int Genet 3:42-45. http://dx.doi.org/10.1016/j.fsigen.2008.09.005

van Asch B, Pinheiro R, Pereira R et al (2010) A framework for the development of STR genotyping in domestic animal species: characterization and population study of 12 canine X-chromosome loci. Electrophoresis 31:303-308. https:// doi.org/10.1002/elps.200900389

Van Oosterhout C, Hutchinson WF, Wills DP, Shipley P (2004) MICRO-CHECKER: software for identifying and correcting genotyping errors in microsatellite data. Mol Ecol Notes 4(3):535-538. https://doi.org/10.1111/j.1471-8286.2004.00684.x

Walters C, Reilley AA, Reeves PA, Baszczak J, Richards CM (2006) The utility of aged seeds in DNA banks. Seed Sci Res 16(3):169. https://doi.org/10.1079/SSR2006246

Waples RS, Do C (2010) Linkage disequilibrium estimates of contemporary Ne using highly variable genetic markers: a largely untapped resource for applied conservation and evolution. Evol Appl 3(3):244-262.

Weeks DE, Conley YP, Ferrell RE, Mah TS, Gorin MB (2002) A tale of two genotypes: consistency between two highthroughput genotyping centers. Genome Res 12:430-435. https://dx.doi.org/10.1101/gr.211502

Weir BS (1979) Inferences about linkage disequilibrium. Biometric 35(1):235-254. https://doi.org/10.2307/2529947

Weir BS, Cockerham CC (1984) Estimating F-statistics for the analysis of population structure. Evolution 38(6):1358-1370. https://doi.org/10.2307/2408641

Weiss KM, Clark AG (2002) Linkage disequilibrium and the mapping of complex human traits. Trends Genet 18:19-24. https://doi.org/10.1016/s0168-9525(01)02550-1

Whitlock MC, Lotterhos KE (2015) Reliable detection of loci responsible for local adaptation: Inference of a null model through trimming the distribution of FST. Am Nat 186:S24-S36. https://doi.org/10.1086/682949

Whittaker, JC, Harbord RM, Boxall N, Mackay I, Dawson G, Sibly RM (2003) Likelihood-based estimation of microsatellite mutation rates. Genetics 164(2):781-787.

Wickham H (2016) Ggplot2: Elegant graphics for data analysis. Springer-Verlag, New York

Wickham H, François R, Henry L, Müller K (2020) Dplyr: A grammar of data manipulation. Cran. https://CRAN.R-project. org/package=dplyr. Accessed 29 October 2020

Wickham H, Henry L (2020) Tidyr: Easily tidy data with 'spread' and 'gather' functions. Cran. https://cran.r-project.org/web/ packages/tidyr/index.html. Accessed 28 October 2020

Wickneswari R, Ho WS, Lee KS, Lee CT (2004) Impact of disturbance on population and genetic structure of tropical forest trees. For Genet 11(3-4):193-201.

Wilfinger WW, Mackey K, Chomczynski P (1997) Effect of pH and ionic strength on the spectrophotometric assessment of nucleic acid purity. BioTechniques 22:474-481. https://doi.org/10.2144/97223st01

Willoughby JR, Ivy, JA, Lacy RC, Doyle JM, DeWoody JA (2017) Inbreeding and selection shape genomic diversity in captive populations: Implications for the conservation of endangered species. PLoS ONE 12(4):e0175996. https://doi. org/10.1371/journal.pone.0175996

Winter DJ (2012) MMOD: an R library for the calculation of population differentiation statistics. Molecular Ecology Resources 12(6):1158-1160. https://doi.org/10.1111/j.1755-0998.2012.03174.x

Wright S (1931) Evolution in Mendelian populations. University of Chicago Press, Chicago

Wright S (1938) Size of population and breeding structure in relation to evolution. Science 87:430-431. https://www.jstor. org/stable/2457575 
Wright S (1969) Evolution and the genetics of populations: The theory of gene frequencies. The University of Chicago Press, Chicago

Xie, Y (2020) Knitr: A General-Purpose Package for Dynamic Report Generation in R. R Package Version 1.28. Cran. https://cran.r-project.org/web/packages/knitr/index.html. Accessed 28 October 2020

Yagi N, Satonaka K, Horio M, Shimogaki H et al (1996) The role of DNAse and EDTA on DNA degradation in formaldehyde fixed tissues. Biotech Histochem 71:123-129. https://doi.org/10.3109/10520299609117148

Yamamichi M, Innan H (2012) Estimating the migration rate from genetic variation data. Heredity 108(4):362-363. https://doi. org/10.1038/hdy.2011.83

Ziemann M, Eren Y, El-Osta A (2016) Gene name errors are widespread in the scientific literature. Genome Biol 17:177. https://doi.org/10.1186/s13059-016-1044-7 



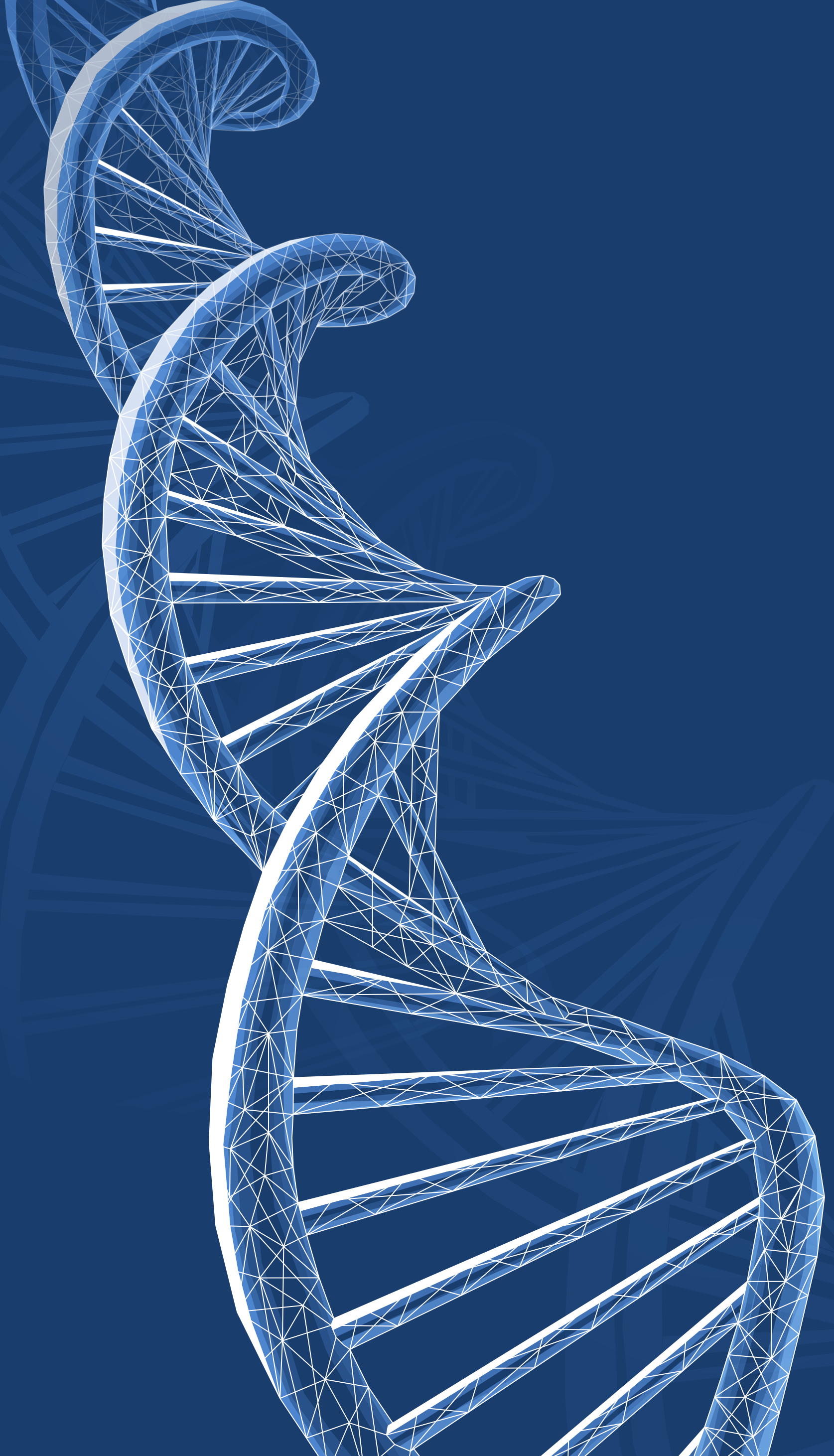




\section{\#\#) \\ LFE13 ENV/S/ $/ 000148$}

\section{Manual for forest genetic monitoring}

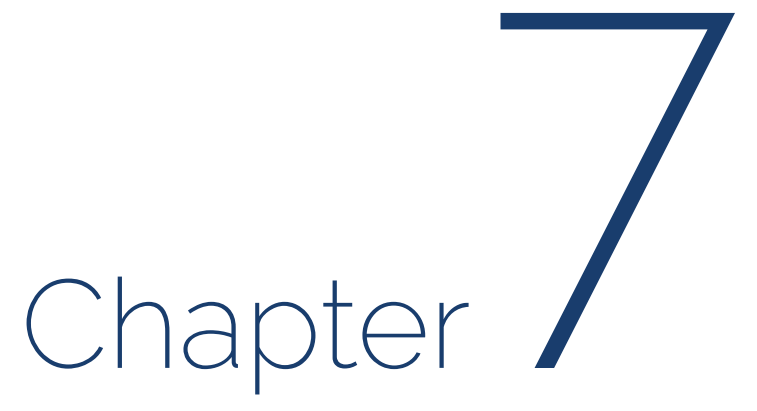

\section{Cost assessment}

Marko BAJC ${ }^{1}$, Filippos A. ARAVANOPOULOS ${ }^{3}$, Darius KAVALIAUSKAS², Marjana WESTERGREN'1, Fotios KIOURTSIS ${ }^{4}$, Evangelia AVRAMIDOU ${ }^{3,6}$, Pavlos BEKIAROGLOU ${ }^{4}$, Pavlos CHASILIDIS ${ }^{4}$, Rok DAMJANIĆ ${ }^{1}$, Natalija DOVČ', Domen FINŽGAR ${ }^{1,5}$, Barbara FUSSI'2, Ermioni MALLIAROU ${ }^{3}$, Georgios ROUSAKIS ${ }^{4}$, Chryse SARVANI ${ }^{4}$, Hojka KRAIGHER ${ }^{1}$

Citation: Bajc et al. (2020) Cost assessment. In: Bajc et al. (eds) Manual for Forest Genetic Monitoring. Slovenian Forestry Institute: Silva Slovenica Publishing Centre, Ljubljana, pp 133-148. http://dx.doi.org/10.20315/SFS.167

\section{Affiliations:}

1. Slovenian Forestry Institute (GIS), Slovenia

2. Bavarian Office for Forest Genetics (AWG), Germany

3. Aristotle University of Thessaloniki (AUTh), Greece

4. Decentralized Administration of Macedonia \& Thrace, General Directorate of Forests \& Rural Affairs, Greece

5. Institute of Evolutionary Biology, University of Edinburgh, UK

6. Institute of Mediterranean Forest Ecosystems, DEMETER, Greece 


\subsection{Introduction}

The purpose of this document is to present the costs associated with implementation of forest genetic monitoring. The cost assessment presented in this document was based on an analysis of the actual costs of activities carried out in the LIFEGENMON project. Each participating partner institution logged their costs, including material cost, outsourcing, travelling costs and cost of labour throughout the duration of the project. Costs were divided in three basic categories: 1) Material costs, 2) Cost of labour (effective work) and 3) Cost of travel. As the cost of person-hour per staff category can vary considerably between countries, cost of labour is presented both as person-hours per staff category and actual costs of labour. Costs were assessed per species/country/monitoring level/indicator/verifier.

\subsection{Cost assessment}

\subsubsection{Cost assessment assumptions}

As costs necessary for carrying out forest genetic monitoring depend on many different factors, including the biology of the monitored tree species and travelling distance to plots, certain assumptions were considered in the presented cost assessment calculations in order to have the results as comparable as possible across countries:

1. Costs were calculated for a 10-year monitoring interval.

2. Both evaluated species, the European beech (Fagus sylvatica L.) and Silver fir/King Boris' fir (Abies alba Mill./ Abies borisii-regis Mattf.) are stand forming species. It is expected that for scattered species, all the work performed in the field would inevitably require more person-hours to complete.

3. Costs are presented with VAT included (Germany 19\%, Greece 24\%, Slovenia 22\%).

4. Costs are presented for optimised activities as when routinely performed by fully trained and experienced personnel; it should be noted that when introducing new methods or approaches it must be taken into consideration that additional lead-in costs may arise during the establishment and optimisation phase of the process.

5. Plot selection: For the plot selection process five (5) visits to plots under evaluation were considered, with an average distance of $100 \mathrm{~km}$ from the institution to the plot.

6. Material cost: The actual cost of materials and outsourcing, as reported by LIFEGENMON project partners, was used in the calculations.

7. Cost of labour: The average total cost of a person-hour per staff category per country was used in the calculations.

8. Cost of travelling: This was calculated for a distance of $100 \mathrm{~km}$ from the institution to the plot for all countries and species. Travelling times were calculated by using average travelling speed to LIFEGENMON FGM plots for each country.

9. Plot establishment: During the LIFEGENMON project several changes were made to the original FGM system: 1) FGM plot design was changed to include the random selection of plot location within the monitored stand and random selection of individual trees within the plot whenever possible; 2) the number of samples was reduced from 250 to 50 for adult trees and from 200 to 50 for natural regeneration (NR) as a result of analysis of the minimum required number of samples for assessment of molecular genetic verifiers based on the data obtained during the first FGM assessment. Additionally, the establishment of NR plots within the FGM plot was changed from four NR plots to 20 NR plots (see Chapter 3 "Plot establishment and 
maintenance" for details). The new plot design was only tested in Slovenia, and all costs affected by the plot design change and the reduced number of samples were calculated by adjusting the costs from all partners by the same conversion factor, which was determined by comparing the costs of the improved plot design with the costs of the original plot design in Slovenia.

\section{Field observations and measurements:}

The number of visits necessary for recording of field observations that were used for calculating the costs was based on the recorded averages across all three countries participating in the LIFEGENMON project. The actual number of visits will depend on the monitored species and local environmental conditions.

a. Mortality / Survival: One (1) assessment of all 50 monitored trees per monitoring interval for all levels.

\section{b. Budburst:}

Basic level: Not assessed.

Standard level: Two (2) assessments per monitoring interval, six (6) observations per assessment.

Advanced level: Ten (10) assessment per monitoring interval, six (6) observations per assessment.

\section{c. Flowering:}

Basic level: Ten (10) stand-level assessments per monitoring interval, one (1) observation per assessment. Standard and advanced levels: Two (2) assessments on the individual tree-level per monitoring period, two (2) observations per assessment.

\section{d. Fructification:}

Basic level: Ten (10) stand-level assessments per monitoring interval, one (1) observation per assessment. Standard and advanced levels: Two (2) individual tree level assessments per monitoring period, one (1) observation per assessment.

\section{e. Natural regeneration (NR) abundance:}

Basic level: Ten (10) stand-level assessments per monitoring interval, one (1) observation per assessment. Standard level: Three (3) assessments of NR subplots per monitoring period, one (1) observation per assessment.

Advanced level: Three (3) assessments of NR subplots in the first monitoring period, six (6) assessments of NR subplots in subsequent monitoring intervals, one (1) observation per assessment.

\section{f. Senescence:}

Basic level: Not assessed.

Standard level: Two (2) assessments per monitoring interval, two (2) observations per assessment. Advanced level: Ten (10) assessments per monitoring interval, two (2) observations per assessment.

\section{g. DBH class distribution:}

Basic level: Not assessed.

Standard and advanced levels: One (1) assessment of all 50 monitored adult trees per monitoring interval, one (1) observation per assessment.

\section{h. Height class distribution:}

Basic level: Not assessed.

Standard and advanced levels: One (1) assessment of all 50 monitored adult trees per monitoring interval, one (1) observation per assessment. 
i. In Greece field observations (phenology assessment) were carried out by high resolution photo documentation and drone imagery, followed by digital image analysis. Although this approach provides full documentation and verification of observations, it proved to be considerably more time consuming and labour intensive compared to visual observation, and is therefore not recommended to be used as standard in FGM.

\section{Sampling for laboratory analyses:}

\section{a. Adult trees:}

Basic level: Not performed.

Standard and advanced levels: One (1) sampling of all 50 monitored adult trees in the first FGM interval only.

\section{b. Natural regeneration:}

Basic level: Not performed.

Standard and advanced levels: One (1) sampling of 50 NR seedlings for each assessed fructification event per monitoring interval, which equals two (2) sampling visits and 100 NR samples per monitoring interval.

\section{Seed:}

Basic and standard levels: Not performed.

Advanced level: Sampling of seed from 20 trees randomly selected from all 50 monitored adult trees for each assessed fructification event per monitoring interval, which equals two (2) samplings per monitoring interval.

12. Laboratory analyses: For genotyping, only the analysis of SSR markers was considered in the overall assessment. SNP markers were also analysed in the LIFEGENMON project, but only for a subset of samples from the first assessment interval, consequently not all comparative analyses could be performed on the SNP data set. Additionally, a different number of SNPs and samples were analysed for each of the monitored species, making comparison of costs less informative.

13. All values were rounded to the closest integer value in the presented tables.

14. All costs were calculated for monitoring of a single plot per species.

15. Costs of an average 10-year monitoring interval were calculated as an average of the first 50 monitoring years (first five monitoring intervals). 


\subsubsection{Cost assessment}

\subsubsection{Cost of an average 10-year forest genetic monitoring interval per species, country and monitoring level}

More detailed information on cost assessment, including information on the number of person-hours per different staff categories needed for completion of different monitoring activities, are listed in Annex 10.3: Supplementary tables for Chapter 7: Cost assessment.

Table 7.1: Cost of an average 10-year monitoring interval per plot, species, country and monitoring level. All presented values are in Euros (€). DE - Germany; GR p - Greece, photographic field observations; GR v - Greece, visual field observations; SI - Slovenia.

\begin{tabular}{|c|c|c|c|c|c|c|c|}
\hline Level & Country & $\begin{array}{c}\text { Plot } \\
\text { selection }\end{array}$ & $\begin{array}{c}\text { Plot } \\
\text { establishment }\end{array}$ & $\begin{array}{c}\text { Field } \\
\text { observations }\end{array}$ & Sampling & $\begin{array}{c}\text { Lab } \\
\text { analyses }\end{array}$ & Total \\
\hline \multirow{3}{*}{ Basic } & $\mathrm{DE}$ & 832 & 426 & 9,472 & 0 & 0 & 10,730 \\
\hline & GR & 388 & 307 & 4,422 & 0 & 0 & 5,117 \\
\hline & $\mathrm{SI}$ & 415 & 186 & 4,883 & 0 & 0 & 5,484 \\
\hline \multirow{4}{*}{ Standard } & DE & 832 & 2,184 & 25,530 & 460 & 5,198 & 34,203 \\
\hline & GR p * & 388 & 1,455 & 25,328 & 377 & 3,182 & 30,729 \\
\hline & $\mathrm{GR} v$ * & 388 & 1,455 & 12,329 & 377 & 3,182 & 17,730 \\
\hline & $\mathrm{SI}$ & 415 & 1,235 & 14,286 & 346 & 3,522 & 19,805 \\
\hline \multirow{4}{*}{ Advanced } & DE & 832 & 2,184 & 53,872 & 6,434 & 21,088 & 84,409 \\
\hline & $G R p$ * & 388 & 1,455 & 79,735 & 12,036 & 18,605 & 112,219 \\
\hline & $\mathrm{GR} v$ * & 388 & 1,455 & 26,697 & 12,036 & 18,605 & 59,181 \\
\hline & SI & 415 & 1,235 & 31,880 & 5,748 & 18,394 & 57,674 \\
\hline \multicolumn{8}{|c|}{ Abies alba Mill./ Abies borisii-regis Mafft. } \\
\hline Level & Country & $\begin{array}{c}\text { Plot } \\
\text { selection }\end{array}$ & $\begin{array}{c}\text { Plot } \\
\text { establishment }\end{array}$ & $\begin{array}{c}\text { Field } \\
\text { observations }\end{array}$ & Sampling & $\begin{array}{l}\text { Lab } \\
\text { analyses }\end{array}$ & Total \\
\hline \multirow{3}{*}{ Basic } & DE & 832 & 426 & 9,472 & 0 & 0 & 10,730 \\
\hline & GR & 388 & 307 & 4,422 & 0 & 0 & 5,117 \\
\hline & SI & 415 & 186 & 4,883 & 0 & 0 & 5,484 \\
\hline \multirow{4}{*}{ Standard } & $\mathrm{DE}$ & 832 & 2,184 & 23,272 & 415 & 5,198 & 31,900 \\
\hline & GR p * & 388 & 1,455 & 22,156 & 377 & 2,856 & 27,232 \\
\hline & $\mathrm{GR} v$ * & 388 & 1,455 & 11,642 & 377 & 2,856 & 16,718 \\
\hline & SI & 415 & 1,235 & 13,420 & 346 & 3,309 & 18,726 \\
\hline \multirow{4}{*}{ Advanced } & $\mathrm{DE}$ & 832 & 2,184 & 47,367 & 5,670 & 20,892 & 76,945 \\
\hline & GR p * & 388 & 1,455 & 63,843 & 7,044 & 16,007 & 88,737 \\
\hline & $\mathrm{GR} v$ * & 388 & 1,455 & 23,330 & 7,044 & 16,007 & 48,224 \\
\hline & $\mathrm{SI}$ & 415 & 1,235 & 28,147 & 4,184 & 16,577 & 50,559 \\
\hline
\end{tabular}

* Phenological observations (field observations) in Greece were performed by high resolution digital photography and image analysis, which added significantly more to the total cost of FGM compared to the approach used in Germany and Slovenia, which relied on visual observation. In order to have more comparable results, the expected cost of visual observations of phenology in Greece was also assessed based on data from Germany and Slovenia. 


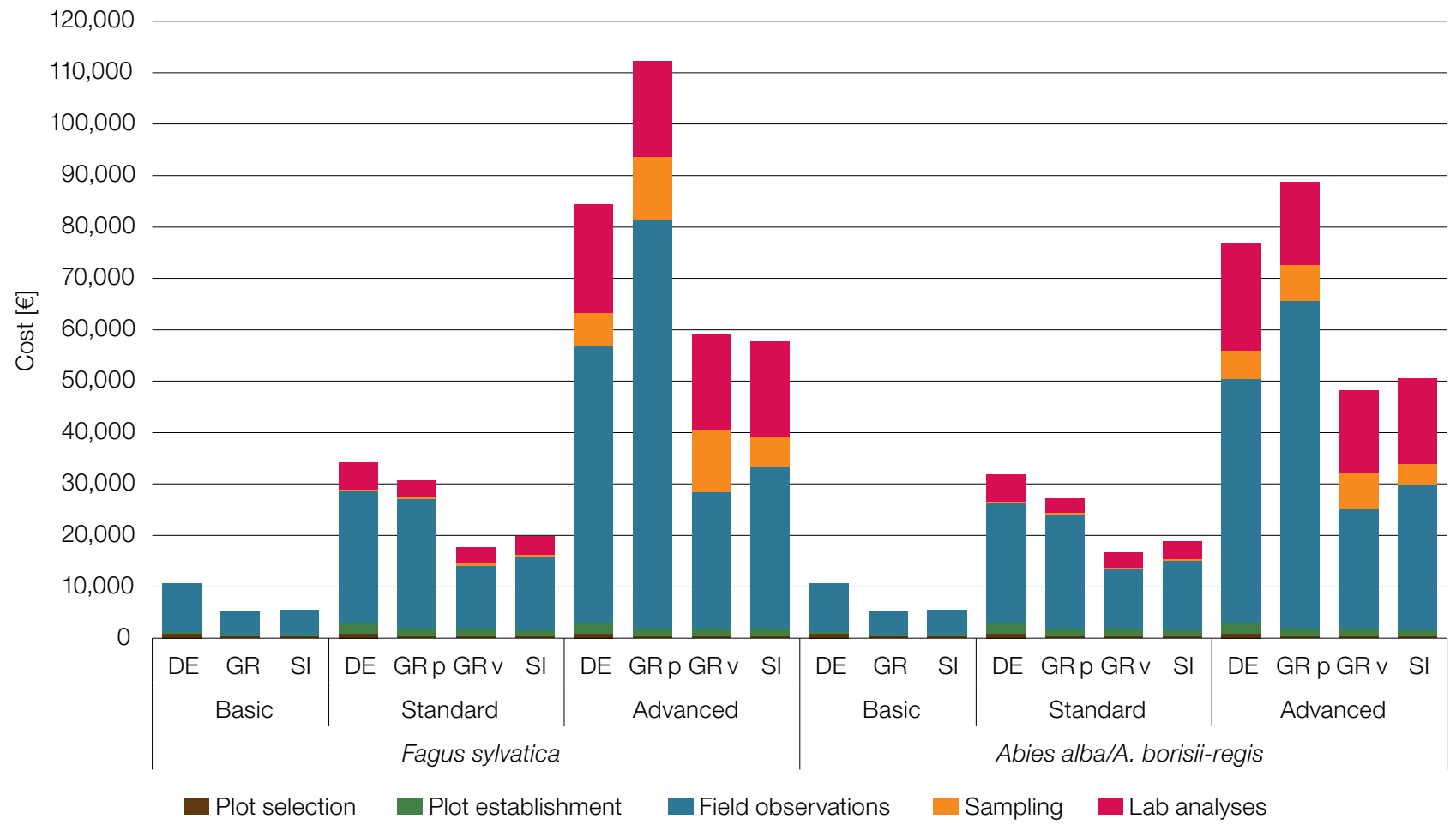

Figure 7.1: Assessed cost of forest genetic monitoring of European beech (Fagus sylvatica) and Silver fir/King Boris' fir (Abies alba/Abies borisii-regis) for an average 10-year monitoring interval. DE - Germany; GR p - Greece, photographic field observations; GR v - Greece, visual field observations; SI - Slovenia.

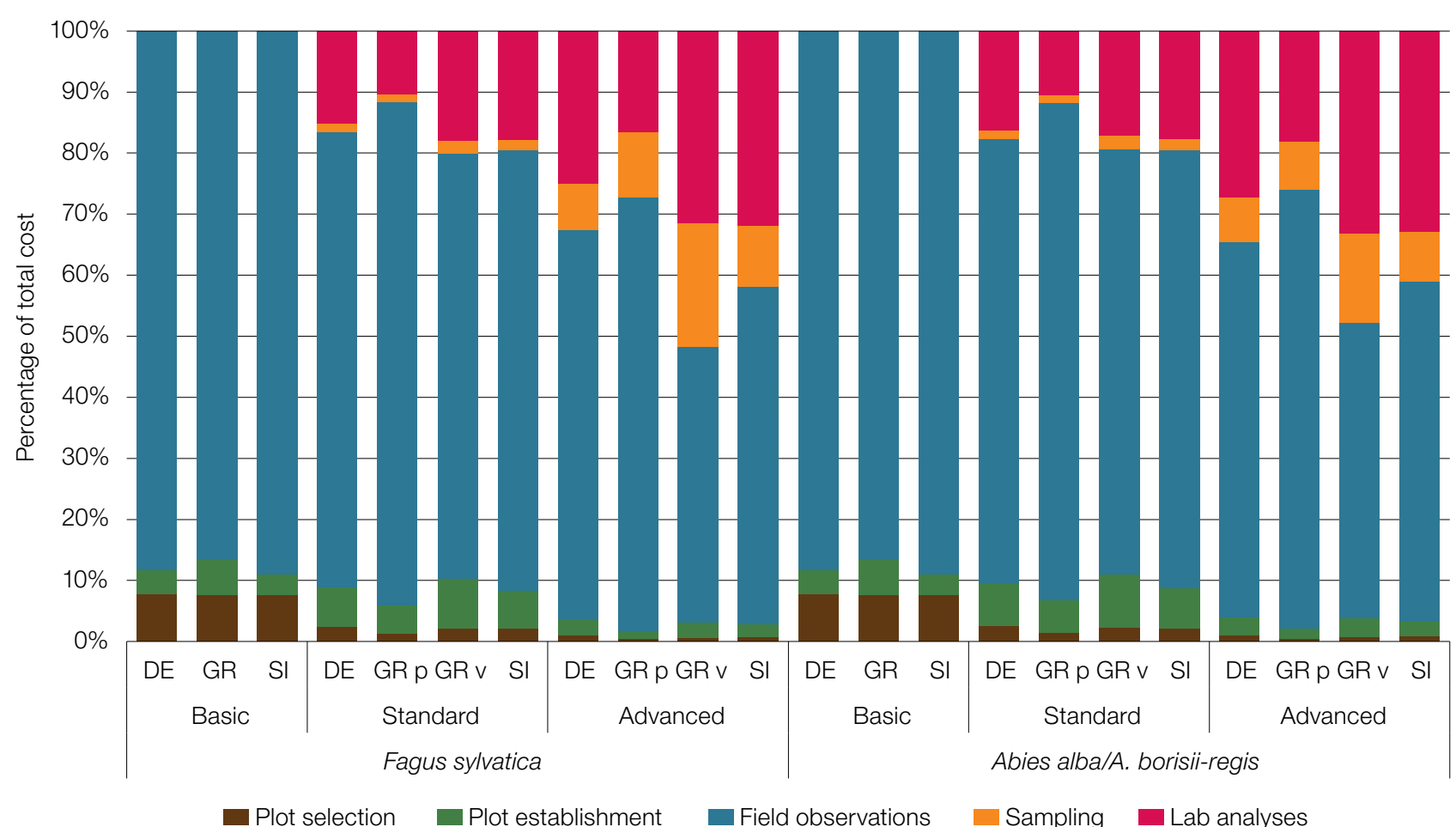

Figure 7.2: Relative contribution of different forest genetic monitoring activities to the total cost of an average 10-year monitoring interval for European beech (Fagus sylvatica) and Silver fir/King Boris' fir (Abies alba/Abies borisii-regis). DE - Germany; GR p - Greece, photographic field observations; GR v - Greece, visual field observations; SI - Slovenia. 
Table 7.2: Contribution of different cost categories to the total cost of an average 10-year forest genetic monitoring interval per plot, species, country and monitoring level. Travelling costs include the cost of mileage, daily subsistence and person-hours spent driving. DE - Germany; GR p - Greece, photographic field observations; GR v - Greece, visual field observations; SI - Slovenia.

\begin{tabular}{|c|c|c|c|c|c|}
\hline Level & Country & Materials [€] & Effective work [€] & Travelling [€] & Total $[€]$ \\
\hline \multirow{3}{*}{ Basic } & DE & 105 & 5,565 & 5,060 & 10,730 \\
\hline & GR & 87 & 2,188 & 2,842 & 5,117 \\
\hline & SI & 13 & 2,596 & 2,875 & 5,484 \\
\hline \multirow{4}{*}{ Standard } & DE & 1,972 & 21,744 & 10,487 & 34,203 \\
\hline & GR p* & 1,957 & 22,240 & 6,532 & 30,729 \\
\hline & $G R v^{*}$ & 1,957 & 9,241 & 6,532 & 17,730 \\
\hline & SI & 1,978 & 10,693 & 7,134 & 19,805 \\
\hline \multirow{4}{*}{ Advanced } & DE & 16,828 & 44,459 & 23,122 & 84,409 \\
\hline & GR $p^{*}$ & 24,601 & 72,227 & 15,391 & 112,219 \\
\hline & $G R v^{\star}$ & 24,601 & 19,188 & 15,391 & 59,181 \\
\hline & SI & 17,735 & 22,434 & 17,505 & 57,674 \\
\hline \multicolumn{6}{|c|}{ Abies alba Mill./ Abies borisii-regis Mafft. } \\
\hline Level & Country & Materials [€] & Effective work [€] & Travelling $[€]$ & Total $[€]$ \\
\hline \multirow{3}{*}{ Basic } & DE & 105 & 5,565 & 5,060 & 10,730 \\
\hline & GR & 87 & 2,188 & 2,842 & 5,117 \\
\hline & SI & 13 & 2,596 & 2,875 & 5,484 \\
\hline \multirow{4}{*}{ Standard } & DE & 1,972 & 20,164 & 9,764 & 31,900 \\
\hline & GR p* & 1,659 & 19,536 & 6,037 & 27,232 \\
\hline & $G R v^{*}$ & 1,659 & 9,022 & 6,037 & 16,718 \\
\hline & SI & 1,737 & 10,474 & 6,515 & 18,726 \\
\hline \multirow{4}{*}{ Advanced } & DE & 16,852 & 40,640 & 19,453 & 76,945 \\
\hline & GR p* & 17,147 & 58,707 & 12,883 & 88,737 \\
\hline & $G R v^{*}$ & 17,147 & 18,194 & 12,883 & 48,224 \\
\hline & $\mathrm{SI}$ & 14,078 & 21,805 & 14,676 & 50,559 \\
\hline
\end{tabular}

* Phenological observations (field observations) in Greece were performed by high resolution digital photography and image analysis, which added significantly more to the total cost of FGM compared to the approach used in Germany and Slovenia, which relied on visual observation. In order to have more comparable results, the expected cost of visual observations of phenology in Greece was also assessed based on data from Germany and Slovenia. 


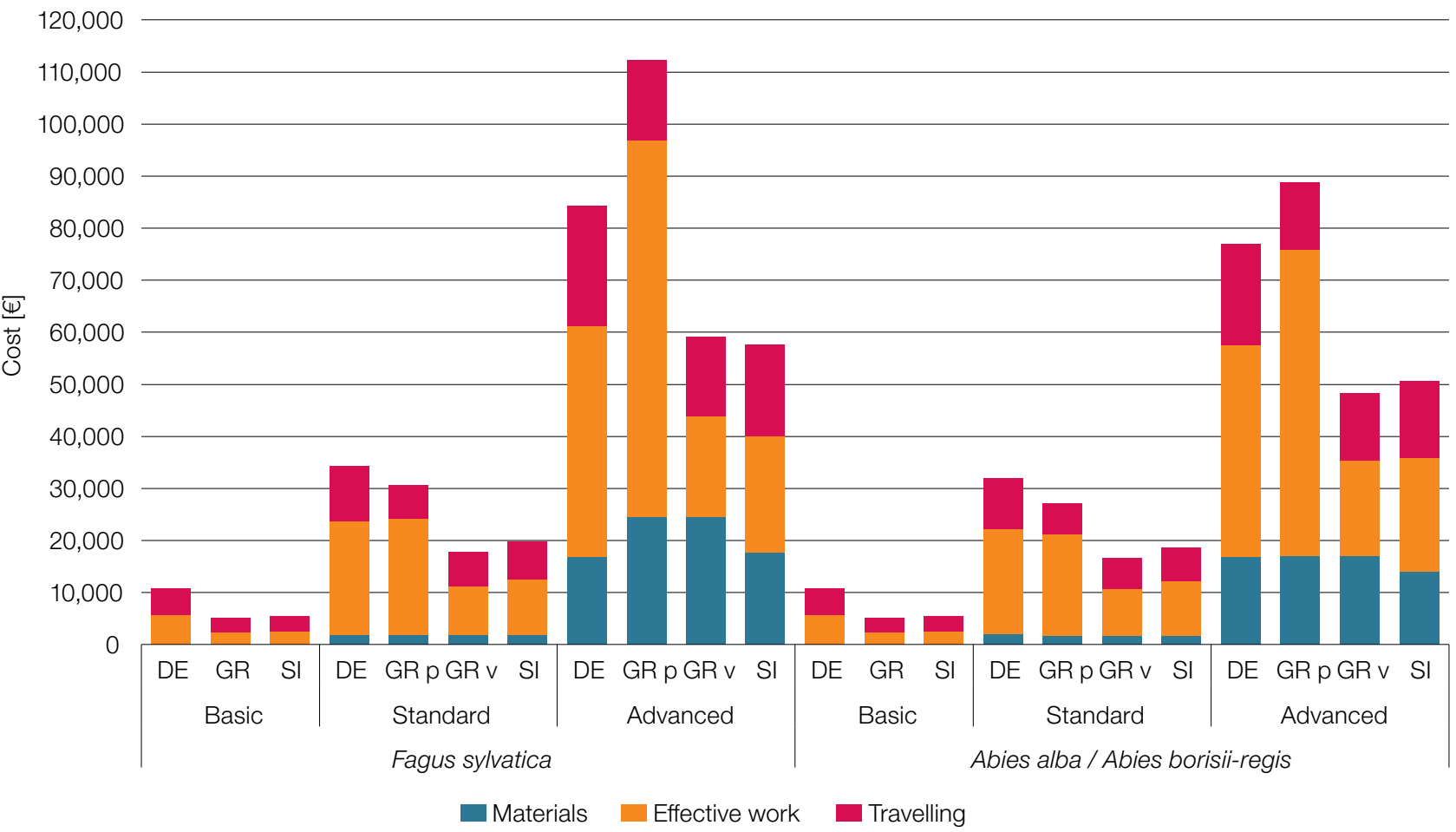

Figure 7.3: Contributions of different cost categories to the total cost of an average 10-year forest genetic monitoring interval per plot for European beech (Fagus sy/vatica) and Silver fir/King Boris' fir (Abies alba/Abies borisii-regis). Travelling costs include the cost of mileage, daily subsistence and person-hours spent driving. DE - Germany; GR p - Greece, photographic field observations; GR v - Greece, visual field observations; SI - Slovenia.

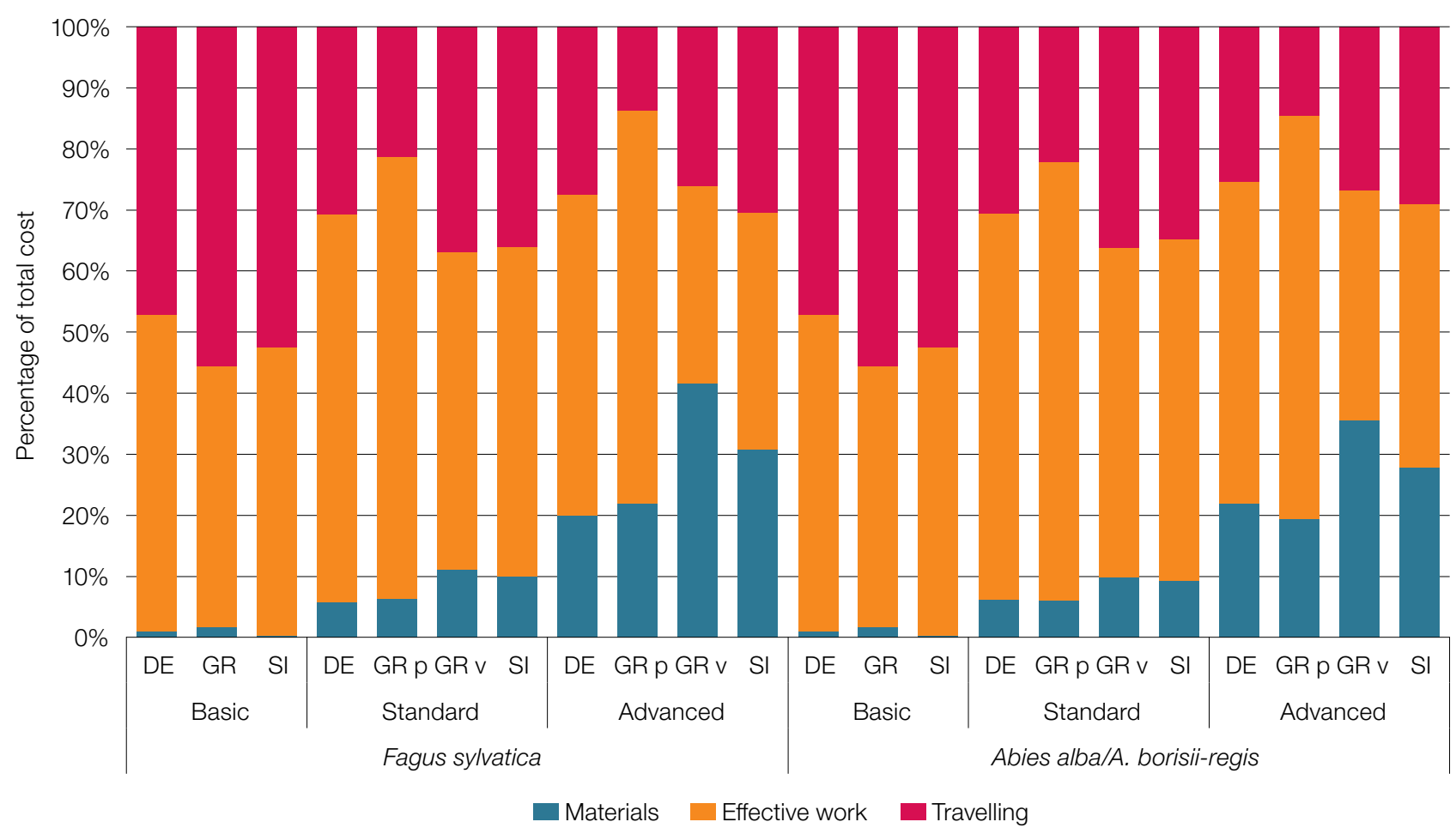

Figure 7.4: Relative contributions of different cost categories to the total cost of an average 10-year forest genetic monitoring interval per plot for European beech (Fagus sylvatica) and Silver fir/King Boris' fir (Abies alba/Abies borisiiregis). Travelling costs include the cost of mileage, daily subsistence and person-hours spent driving. DE - Germany; GR p - Greece, photographic field observations; GR v - Greece, visual field observations; SI - Slovenia. 


\subsubsection{Cost per indicator}

Table 7.3: Contribution of genetic monitoring indicators Selection, Genetic variation and Gene flow/Mating system to the total cost of an average 10-year forest genetic monitoring interval calculated per plot, species, country and monitoring level. DE - Germany; GR p - Greece, photographic field observations; GR v - Greece, visual field observations; SI - Slovenia.

\begin{tabular}{|c|c|c|c|c|c|}
\hline Level & Country & $\begin{array}{l}\text { Selection } \\
{[€]}\end{array}$ & $\begin{array}{c}\text { Genetic } \\
\text { variation }[€]\end{array}$ & $\begin{array}{c}\text { Gene flow / } \\
\text { Mating system [€] }\end{array}$ & Total [€] \\
\hline \multirow{3}{*}{ Basic } & DE & 10,730 & 0 & 0 & 10,730 \\
\hline & GR & 5,117 & 0 & 0 & 5,117 \\
\hline & $\mathrm{SI}$ & 5,484 & 0 & 0 & 5,484 \\
\hline \multirow{4}{*}{ Standard } & $\mathrm{DE}$ & 27,038 & 7,166 & 0 & 34,203 \\
\hline & GR $p^{*}$ & 26,249 & 4,480 & 0 & 30,729 \\
\hline & $G R v^{*}$ & 13,251 & 4,480 & 0 & 17,730 \\
\hline & SI & 15,111 & 4,693 & 0 & 19,805 \\
\hline \multirow{4}{*}{ Advanced } & $\mathrm{DE}$ & 54,877 & 13,766 & 15,766 & 84,409 \\
\hline & GR $p^{*}$ & 80,350 & 11,844 & 20,025 & 112,219 \\
\hline & $G R v^{*}$ & 27,311 & 11,844 & 20,025 & 59,181 \\
\hline & SI & 32,430 & 11,626 & 13,617 & 57,674 \\
\hline
\end{tabular}

Abies alba Mill./ Abies borisii-regis Mafft.

\begin{tabular}{lccccc}
\hline Level & Country & Selection $[€]$ & $\begin{array}{c}\text { Genetic } \\
\text { variation [€] }\end{array}$ & $\begin{array}{c}\text { Gene flow / } \\
\text { Mating system [€] }\end{array}$ & Total [€] \\
\hline \multirow{3}{*}{ Basic } & DE & 10,730 & 0 & 0 & 10,730 \\
& GR & 5,117 & 0 & 0 & 5,117 \\
\hline \multirow{3}{*}{ Standard } & SI & 5,484 & 0 & 0 & 5,484 \\
& DE & 24,780 & 7,121 & 0 & 31,900 \\
& GR p* & 23,078 & 4,154 & 0 & 27,232 \\
\hline \multirow{3}{*}{ Advanced } & GR v & 12,564 & 4,154 & 0 & 16,718 \\
& SI & 14,246 & 4,480 & 0 & 18,726 \\
\hline & DE & 48,372 & 13,607 & 14,966 & 76,945 \\
\hline
\end{tabular}

* Phenological observations (field observations) in Greece were performed by high resolution digital photography and image analysis, which added significantly more to the total cost of FGM compared to the approach used in Germany and Slovenia, which relied on visual observation. In order to have more comparable results, the expected cost of visual observations of phenology in Greece was also assessed based on data from Germany and Slovenia. 


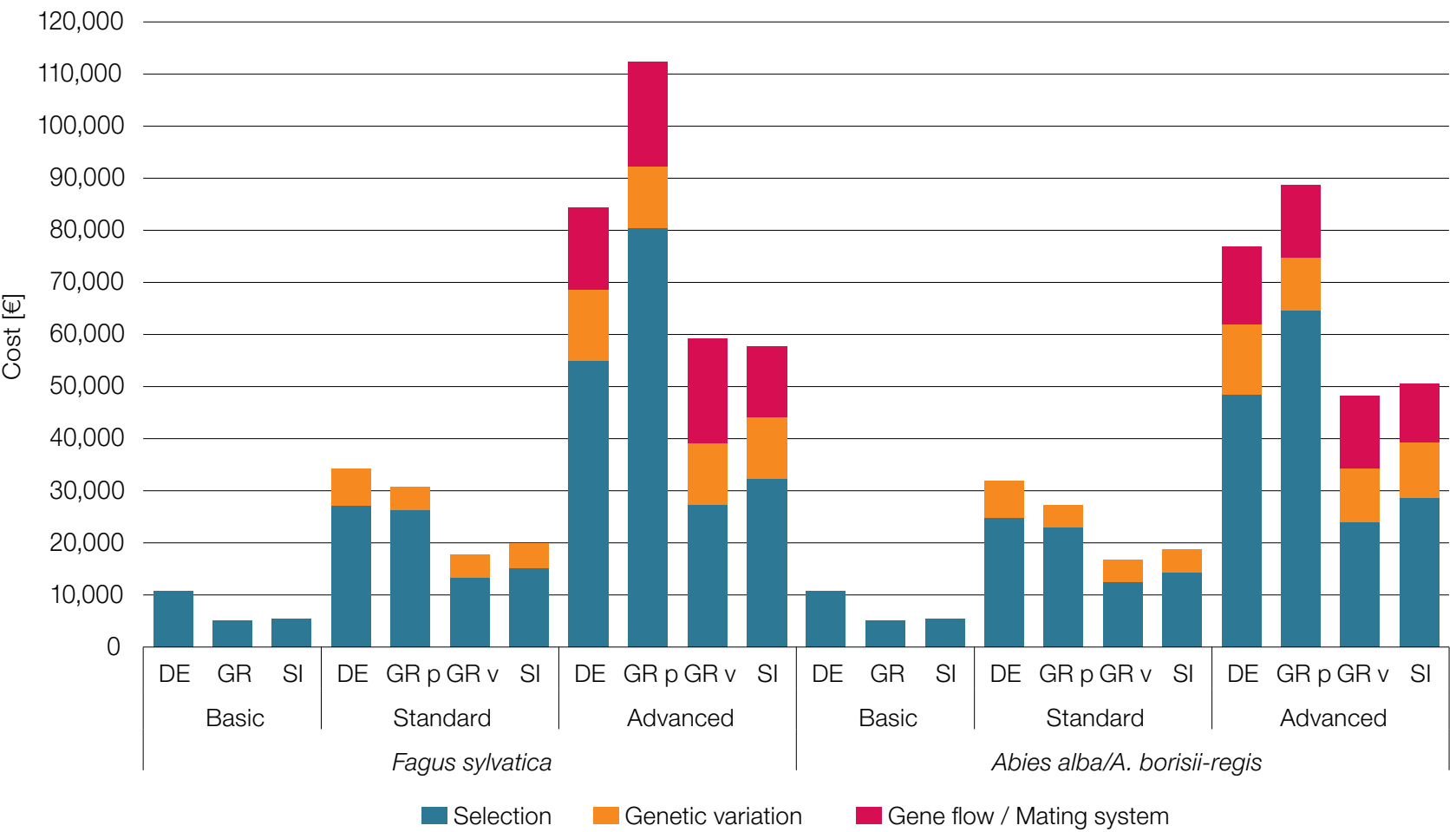

Figure 7.5: Contribution of different indicators - Selection, Genetic variation, Gene flow/Mating system - to the total cost of an average 10-year forest genetic monitoring interval per plot for European beech (Fagus sylvatica L.) and Silver fir/King Boris' fir (Abies alba Mill./Abies borisii-regis Mafft.). DE - Germany; GR p - Greece, photographic field observations; GR v - Greece, visual field observations; SI - Slovenia.

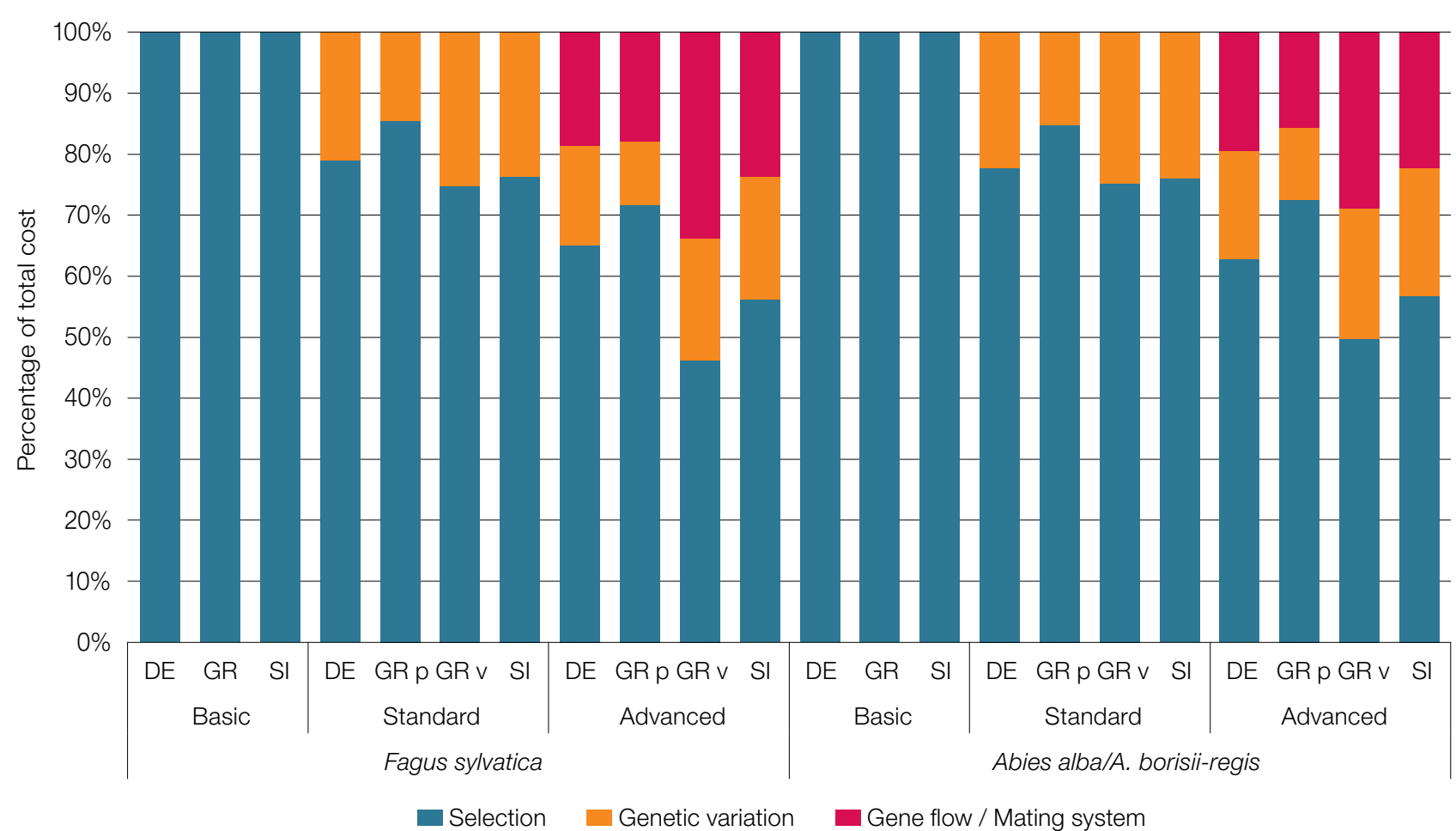

Figure 7.6: Relative contribution of different indicators - Selection, Genetic variation, Gene flow/Mating system - to the total cost of an average 10-year forest genetic monitoring interval per plot for European beech (Fagus sylvatica L.) and Silver fir/King Boris' fir (Abies alba Mill./Abies borisii-regis Mafft.). DE - Germany; GR p - Greece, photographic field observations; GR v - Greece, visual field observations; SI - Slovenia. 


\subsubsection{Cost per verifier}

Table 7.4: Cost of individual verifiers/background information for an average 10-year forest genetic monitoring interval per plot, country and monitoring level based on averages for European beech and Silver fir / King Boris fir. For Greece only the expected cost of monitoring with visual field observations was considered in the calculations. A $100 \mathrm{~km}$ distance to the FGM was considered for all countries. DE - Germany; GR - Greece; SI - Slovenia. Plot select. - Plot selection; Plot establ. - Plot establishment; Field observ. - Field observations/measurements; Lab. analys. - Laboratory analyses; NR abundance - Natural regeneration abundance; DBH class distr. - Diameter at breast height class distribution; Height class distr. - Height class distribution; Flowering synch. - Flowering synchronisation; AF - Allele frequency; LGP Latent genetic potential; $F_{\text {IS }}$ - Inbreeding coefficient; $N_{e}$ - Effective population size; AR - Allelic richness; LD - Linkage disequilibrium; Intersp. Hybr. - Interspecific hybridisation; $\mathrm{t}_{\mathrm{m}}$ - Multi-locus population outcrossing rate; $\mathrm{N}_{\mathrm{m}}$ - Gene flow estimate; $V_{\text {GAM }}$ - Hypothetic gametic multilocus diversity; $\mathrm{N}_{\mathrm{ep}}$ - Effective number of pollen donors; Biparent. inbr. Biparental inbreeding. Type: V - Verifier; BI - Background information. Indicator: I - Selection; II - Genetic variation; III - Gene flow / Mating system; Total 1 - Total cost for an average monoecious, non-hybridising species; Total 2 - Total cost for a dioecious species with all possible verifiers/background information.

\begin{tabular}{|c|c|c|c|c|c|c|c|c|c|c|c|c|}
\hline \multirow[b]{2}{*}{ Activity } & \multirow[b]{2}{*}{ Parameter } & \multirow[b]{2}{*}{ Type } & \multirow[b]{2}{*}{ Indicator } & \multicolumn{3}{|c|}{$\begin{array}{c}\text { Cost, } \\
\text { BASIC Level [€] } \\
\end{array}$} & \multicolumn{3}{|c|}{$\begin{array}{c}\text { Cost, } \\
\text { STANDARD Level [€] }\end{array}$} & \multicolumn{3}{|c|}{$\begin{array}{c}\text { Cost, } \\
\text { ADVANCED Level [€] }\end{array}$} \\
\hline & & & & $\mathrm{DE}$ & GR & $\mathrm{SI}$ & DE & GR & $\mathrm{Sl}$ & $\mathrm{DE}$ & GR & $\mathrm{SI}$ \\
\hline Plot select. & NA & NA & NA & 832 & 388 & 415 & 832 & 388 & 415 & 832 & 388 & 415 \\
\hline Plot establ. & NA & NA & NA & 426 & 307 & 186 & 2,184 & 1,455 & 1,235 & 2,184 & 1,455 & 1,235 \\
\hline Sampling & NA & NA & NA & - & - & - & 460 & 377 & 346 & 6,434 & 9,540 & 4,966 \\
\hline \multirow{11}{*}{$\begin{array}{l}\text { Field } \\
\text { observ. }\end{array}$} & Mortality/Survival & $\mathrm{V}$ & I & 717 & 351 & 364 & 717 & 351 & 364 & 717 & 351 & 364 \\
\hline & NR Abundance & V & । & 2,489 & 1,116 & 1,158 & 5,477 & 2,675 & 2,947 & 7,721 & 3,819 & 4,264 \\
\hline & Flowering & V & I & 3,132 & 1,477 & 1,680 & 5,174 & 2,420 & 2,952 & 7,017 & 3,060 & 3,862 \\
\hline & Fructification & V & I & 3,132 & 1,477 & 1,680 & 4,671 & 2,093 & 2,590 & 6,080 & 2,947 & 3,173 \\
\hline & Crown dieback * & $\mathrm{Bl}$ & I & 3,788 & 1,950 & 2,370 & 3,788 & 1,950 & 2,370 & 3,788 & 1,950 & 2,370 \\
\hline & Sex ratio ** & $\mathrm{Bl}$ & I & - & - & - & 1,030 & 481 & 562 & 1,403 & 633 & 758 \\
\hline & DBH class distr. & $\mathrm{Bl}$ & 1 & - & - & - & 1,207 & 612 & 595 & 1,207 & 612 & 595 \\
\hline & Height class distr. & $\mathrm{Bl}$ & I & - & - & - & 1,207 & 612 & 595 & 1,207 & 612 & 595 \\
\hline & Flowering synch. & $\mathrm{Bl}$ & I & - & - & - & - & - & - & 1,597 & 642 & 832 \\
\hline & Budburst & $\mathrm{BI}$ & 1 & - & - & - & 4,801 & 2,600 & 3,090 & 20,868 & 10,913 & 13,661 \\
\hline & Senescence & $\mathrm{BI}$ & 1 & - & - & - & 2,283 & 1,101 & 1,372 & 8,574 & 4,260 & 5,233 \\
\hline \multirow{16}{*}{ Lab. analys. } & \% filled seeds & V & I & - & - & - & - & - & - & 416 & 808 & 374 \\
\hline & $\%$ germination & $v$ & I & - & - & - & - & & - & 416 & 808 & 374 \\
\hline & $\mathrm{AF}$ & $\mathrm{V}$ & $\|$ & - & - & - & 743 & 431 & 488 & 1,680 & 1,308 & 1,395 \\
\hline & LGP & V & $\|$ & - & - & - & 743 & 431 & 488 & 1,680 & 1,308 & 1,395 \\
\hline & $F_{1 S}$ & V & $\|$ & - & - & - & 743 & 431 & 488 & 1,680 & 1,308 & 1,395 \\
\hline & $\mathrm{N}_{\mathrm{e}}$ & V & $\|$ & - & - & - & 743 & 431 & 488 & 1,680 & 1,308 & 1,395 \\
\hline & $A R^{* * *}$ & V & $\|$ & - & - & - & 743 & 431 & 488 & 1,680 & 1,308 & 1,395 \\
\hline & LD *** & $\mathrm{Bl}$ & $\|$ & - & - & - & 743 & 431 & 488 & 1,680 & 1,308 & 1,395 \\
\hline & Intersp. hybr. ${ }^{\star \star \star \star}$ & $\mathrm{Bl}$ & $\|$ & - & - & - & 743 & 431 & 488 & 1,680 & 1,308 & 1,395 \\
\hline & $V_{\text {GAM }}$ & $\mathrm{Bl}$ & $\|$ & - & - & - & 743 & 431 & 488 & 1,680 & 1,308 & 1,395 \\
\hline & F $_{\text {ST }}$ Outlier test & $\mathrm{BI}$ & ॥ & - & - & - & 743 & 431 & 488 & 1,680 & 1,308 & 1,395 \\
\hline & $\mathrm{N}_{\mathrm{m}}$ & V & III & - & - & & & & - & 1,680 & 1,308 & 1,395 \\
\hline & $t_{m}$ & V & III & - & - & - & - & - & - & 1,680 & 1,308 & 1,395 \\
\hline & Actual inbr. rate & V & III & - & - & - & - & - & - & 1,680 & 1,308 & 1,395 \\
\hline & $N_{e p}$ & $\mathrm{Bl}$ & III & - & - & - & - & - & - & 1,680 & 1,308 & 1,395 \\
\hline & Biparent. inbr. & $\mathrm{Bl}$ & III & - & - & - & - & - & - & 1,680 & 1,308 & 1,395 \\
\hline Total $1[€]$ & & & & 10,728 & 5,117 & 5,484 & 34,210 & 17,701 & 19,919 & 85,428 & 55,905 & 56,683 \\
\hline Total $2[€]$ & & & & 14,516 & 7,067 & 7,855 & 39,770 & 20,564 & 23,339 & 92,300 & 59,795 & 61,206 \\
\hline
\end{tabular}

* Fraxinus excelsior only; ** Dioecious species only; ${ }^{* *}$ AR - SSR markers only, LD - SNP markers only; **** Only for species where interspecific hybridisation is occurring in nature. 


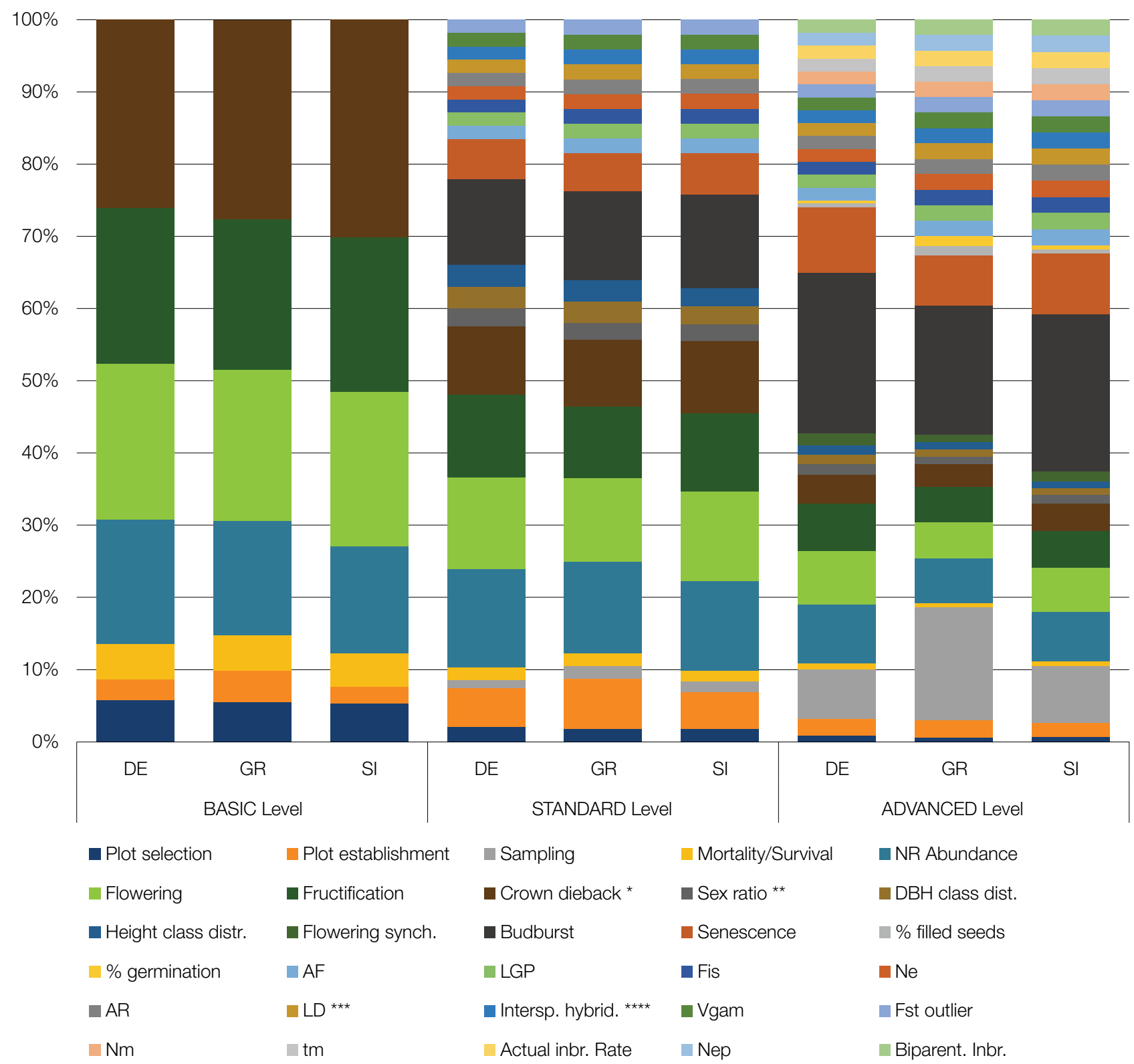

Figure 7.7: Relative contribution of verifiers and background information to the total cost of an average 10-year forest genetic monitoring interval per plot, country and monitoring level based on averages for European beech and Silver fir / King Boris fir. For Greece only the expected cost of monitoring with visual field observations was considered in the calculations. A $100 \mathrm{~km}$ distance to the FGM was considered for all countries. DE - Germany; GR - Greece; SI - Slovenia. Plot select. - Plot selection; Plot establ. - Plot establishment; NR abundance - Natural regeneration abundance; DBH class distr. - Diameter at breast height class distribution; Height class distr. - Height class distribution; Flowering synch. - Flowering synchronisation; AF - Allele frequency; LGP - Latent genetic potential; $F_{1 S}$ - Inbreeding coefficient; $\mathrm{N}_{\mathrm{e}}$ - Effective population size; AR - Allelic richness; LD - Linkage disequilibrium; Intersp. Hybr. - Interspecific hybridisation; $\mathrm{t}_{\mathrm{m}}$ - Multi-locus population outcrossing rate; $\mathrm{N}_{\mathrm{m}}$ - Gene flow estimate; $\mathrm{V}_{\mathrm{GAM}}$ - Hypothetic gametic multilocus diversity; $\mathrm{N}_{\mathrm{ep}}$ - Effective number of pollen donors; Biparent. inbr. - Biparental inbreeding.

* Fraxinus excelsior only; ${ }^{* \star}$ Dioecious species only; ${ }^{* \star}$ AR - SSR markers only, LD - SNP markers only; ${ }^{\star \star \star *}$ Only for species where interspecific hybridisation is occurring in nature. 


\subsubsection{Cost of a cross-country/species average 10-year monitoring interval}

Table 7.5: Cost of an average 10-year forest genetic monitoring interval per plot and monitoring level. Average values were calculated from data for all three countries and both species. For Greece only the expected cost of monitoring with visual field observations was considered in the calculation of the average values. A $100 \mathrm{~km}$ distance to the FGM was considered for all countries and species. SD - standard deviation.

\begin{tabular}{lrrrrrrrrrrrrr} 
& \multicolumn{1}{c}{} & \multicolumn{1}{c}{$\begin{array}{c}\text { Plot } \\
\text { Level }\end{array}$} & Plot selection & \multicolumn{1}{c}{ establishment } & \multicolumn{2}{c}{ observations } & \multicolumn{2}{c}{ Sampling } & \multicolumn{4}{c}{ Lab analyses } & Total \\
\hline & {$[€]$} & SD & {$[€]$} & SD & {$[€]$} & SD & {$[€]$} & SD & {$[€]$} & SD & {$[€]$} & SD \\
\hline Basic & 545 & 203 & 307 & 98 & 6,259 & 2,280 & 0 & 0 & 0 & 0 & 7,110 & 2,564 \\
Standard & 545 & 203 & 1,625 & 406 & 16,747 & 5,514 & 387 & 40 & 3,878 & 954 & 23,180 & 7,074 \\
Advanced & 545 & 203 & 1,625 & 406 & 35,215 & 11,333 & 6,853 & 2,477 & 18,594 & 1,928 & 62,832 & 13,346 \\
\hline
\end{tabular}

Table 7.6: Contribution of different cost categories to the total cost of an average 10-year forest genetic monitoring interval per plot and monitoring level. Average values were calculated from data for all three countries and both species. For Greece only the expected cost of monitoring with visual field observations was considered in the calculation of the average values. A $100 \mathrm{~km}$ distance to the FGM was considered for all countries and species. SD - standard deviation.

\begin{tabular}{lrrrrrrrrrrrrr} 
Level & \multicolumn{3}{c}{ Materials } & \multicolumn{2}{c}{ Effective work } & \multicolumn{2}{c}{ Effective work } & \multicolumn{2}{c}{ Travelling } & \multicolumn{2}{c}{ Travelling } & Total \\
\hline & {$[€]$} & \multicolumn{1}{c}{ SD } & [person-h] & SD & {$[€]$} & SD & [person-h] & SD & {$[€]$} & SD & {$[€]$} & SD \\
\hline Basic & 68 & 40 & 152 & 3 & 3,450 & 1,505 & 93 & 7 & 3,593 & 1,038 & 7,110 & 2,564 \\
Standard & 1,879 & 130 & 614 & 28 & 13,556 & 5,285 & 233 & 42 & 7,745 & 1,726 & 23,180 & 7,074 \\
Advanced & 17,873 & 3,224 & 1,314 & 68 & 27,786 & 10,595 & 551 & 152 & 17,172 & 3,379 & 62,832 & 13,346 \\
\hline
\end{tabular}

\subsubsection{Effects of the travelling distance on the cost of an average 10-year forest genetic monitoring interval}

The travelling cost can contribute significantly to the total cost of forest genetic monitoring, representing on average $52 \%, 34 \%$ and $27 \%$ of the total cost for the basic, standard and advanced levels, respectively, calculated for a $100 \mathrm{~km}$ distance to the FGM plot. The distance to the FGM plot will inevitably vary in real life. In the LIFEGENMON project, for example, the distance to plots ranged from $15 \mathrm{~km}$ to $175 \mathrm{~km}$. Consequently, the effects of travelling distance on the total cost of an average 10-year FGM interval were also assessed using the example of FGM of European beech in Slovenia:

- Costs were calculated for a 10-year FGM interval, based on the average of the first 50 years of monitoring.

- Cost of travelling was calculated for three distances from the institution to the plot: $25 \mathrm{~km}, 100 \mathrm{~km}$ and 175 $\mathrm{km}$. Other cost categories, i.e. cost of materials and cost of effective work, were unchanged.

Table 7.7: Contribution of different cost categories to the total cost of an average 10-year genetic monitoring interval on a European beech (Fagus sylvatica L.) plot in Slovenia in relation to the travelling distance.

\begin{tabular}{lccccc} 
Level & Distance to plot $[\mathrm{km}]$ & Materials $[€]$ & Effective work [€] & Travelling [€] & Total [€] \\
\hline \multirow{3}{*}{ Basic } & 25 & 13 & 2,596 & 719 & 3,328 \\
& 100 & 13 & 2,596 & 2,875 & 5,484 \\
\hline \multirow{3}{*}{ Standard } & 175 & 13 & 2,596 & 5,031 & 7,641 \\
& 25 & 1,978 & 10,693 & 1,784 & 14,454 \\
\hline \multirow{3}{*}{ Advanced } & 100 & 1,978 & 10,693 & 7,134 & 19,805 \\
& 175 & 1,978 & 10,693 & 12,485 & 25,156 \\
\hline
\end{tabular}


80,000

70,000

60,000

50,000

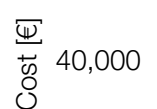

30,000

20,000

10,000

0

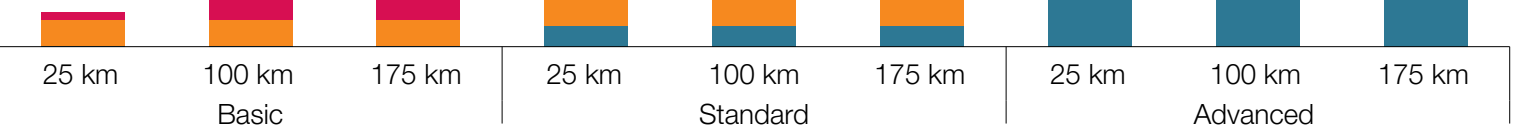

Distance to the plot

Materials Effective work Travelling

Figure 7.8: Contribution of different cost categories to the total cost of an average 10-year genetic monitoring interval on a European beech (Fagus sylvatica L.) plot in Slovenia in relation to the travelling distance. Values for all three levels of FGM, i.e. basic, standard and advanced, are presented.

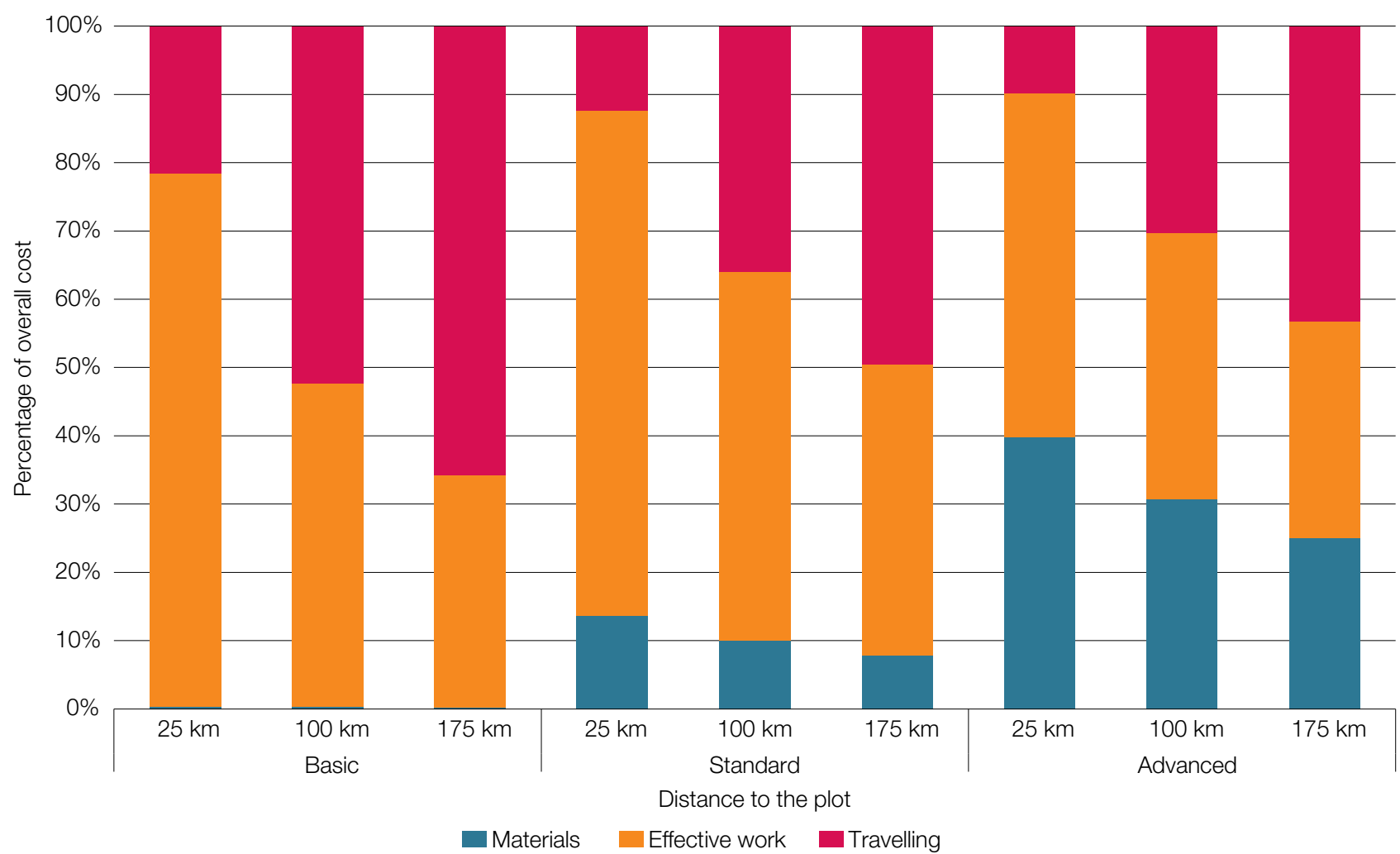

Figure 7.9: Relative contribution of different cost categories to the total cost of an average 10-year genetic monitoring interval on a European beech (Fagus sylvatica L.) plot in Slovenia in relation to the travelling distance. Values for all three levels of FGM, i.e. basic, standard and advanced, are presented. 


\subsection{Conclusions and recommendations}

In terms of activities necessary for carrying out FGM, Field observations and measurements contribute the most to the total cost of FGM (Table 7.1, Figures 7.1 and 7.2). For a $100 \mathrm{~km}$ distance to the plot, Field observations and measurements represent on average $88 \%, 72 \%$ and $55 \%$ of the total cost for basic, standard and advanced monitoring levels, respectively.

Of the three cost categories, Effective work contributes the most to the total cost of FGM. For a $100 \mathrm{~km}$ distance to the plot, Effective work represents on average $47 \%, 57 \%$ and $43 \%$ of the total cost for basic, standard and advanced monitoring levels, respectively.

Cost category Travelling costs (mileage, daily subsistence, work hours spent travelling) can have a significant impact on the overall cost of forest genetic monitoring. For a $100 \mathrm{~km}$ distance to the plot, Travelling costs represent on average $52 \%, 34 \%$ and $27 \%$ of the total cost for basic, standard and advanced monitoring levels, respectively. The contribution of Travelling costs to the total cost of FGM directly depends on the travelling distance and can, for longer travelling distances (see Table 7.7, Figures 7.8 and 7.9), exceed $40 \%$ of total cost for all monitoring levels.

The contribution of the cost category Materials (consumables, materials and outsourcing necessary for carrying out FGM activities) to the total cost of FGM changes significantly across the monitoring levels and accounts on average for $1 \%, 9 \%$ and $30 \%$ of the total cost for basic, standard and advanced monitoring levels, respectively. Besides more consumables required for laboratory analysis, Sampling contributes significantly to the cost of Materials at the advanced level, with a $25 \%$ share on average.

No significant differences in the cost of FGM between the two analysed species were observed at the basic level, but total cost of FGM of Silver/King Boris' fir is on average 6\% and $13 \%$ lower than that of European beech for the standard and advanced levels, respectively. The reason for the observed lower cost of FGM for the fir is that parameter Senescence is not monitored for Abies. Similar results are expected for other comparisons of standforming broadleaves vs. conifers.

Both species analysed in the LIFEGENMON project were stand-forming and monoecious. The cost of FGM for scattered species, dioecious species and species that hybridise or/and form clones will be higher due to more fieldwork, observations (sex ratio, crown dieback (Fraxinus excelsior)) and/or additional laboratory analyses (identification of clones, hybrids) that need to be performed. Based on an estimation of the cost of verifiers and background information (Table 4), the total cost of FGM of scattered dioecious species that require the assessment of all proposed verifiers and background information would be at least 39\% higher at the basic level, $17 \%$ at the standard level and $8 \%$ at the advanced level.

The assessed cost of FGM is the highest in Germany - on average 84\% higher than in Greece and 72\% higher than in Slovenia; the cost of FGM in Slovenia was 7\% higher than Greece. By far the most significant reason for the observed differences in cost of FGM between countries is the cost of person-hour per staff categories.

\subsubsection{Recommendations for cost-saving measures}

1. Use fully trained and experienced personnel to carry out all FGM activities. Experienced personnel will perform their tasks faster and with fewer mistakes that would require repeating the task, thus saving time and money.

2. Organise work well. Certain field observations or measurements can be done within the same visit to the plot. For example, logging GPS coordinates, measuring DBH and height of selected trees can all be done in the same day by two field technicians. Such an approach will reduce the number of trips to the plot and consequently reduce the cost of travelling.

3. It is recommended not to use extensive photographic documentation of phenology as a routine procedure - it increases the total cost of the standard and advanced level FGM by $77 \%$ on average! 
4. The most variable cost category is Travelling costs. As FGM is a long-term process, Travelling costs can contribute significantly to the total cost of FGM. In order to reduce the contribution of Travelling costs to the total cost of FGM, the following measures can be taken:

- During the FGM plot selection process several different plots will usually be inspected, and their suitability assessed. If several different plots meet all the criteria for an FGM plot (Chapter 2), select the one that is the closest to the institution tasked with carrying out the FGM.

- Include the Forest Service (or equivalent) in FGM to perform field observations and measurements. The forest service is usually organised as a network with local offices across the country. Local or regional foresters are very familiar with forests in their area of responsibility (AoR), and will have to travel much shorter distances if the FGM plot is located in their AoR. Proper training of foresters (or other personnel) is paramount to assure consistency and comparability of field measurements and observations - workshops or trainings need to be organised.

- When performing labour intensive fieldwork that cannot be completed in a single day for FGM plots that require longer travelling times to get to, such as plot establishment or sampling seeds, it is advisable to have the field personnel stay overnight locally in contrast to travelling to the plot and back every day. In such a way fewer trips need to be made and more effective work is done per day, ultimately reducing the overall cost of such activities, despite the additional cost of lodging.

- When performing labour intensive fieldwork, allocate more personnel to the task, if possible. More people will be able to do more work in the same amount of time, while also reducing travelling cost per capita and the number of trips necessary to complete the task.

5. Consider international collaboration - countries sharing the same species and environmental classification zones do not always need to conduct FGM separately. 



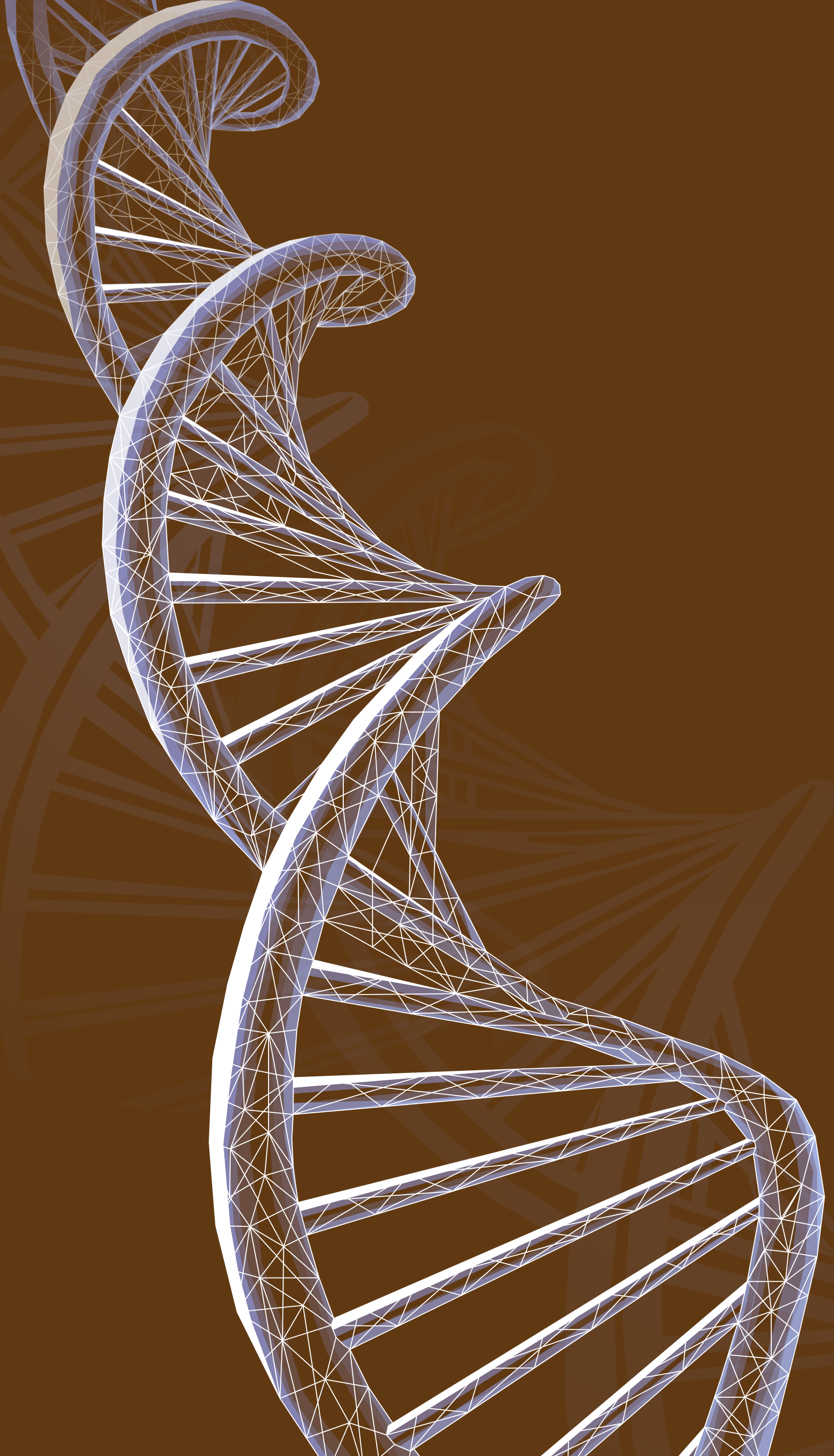




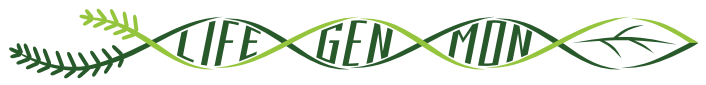 \\ LIFE13 ENV/S/ $/ 000148$}

\section{Manual for forest genetic monitoring}

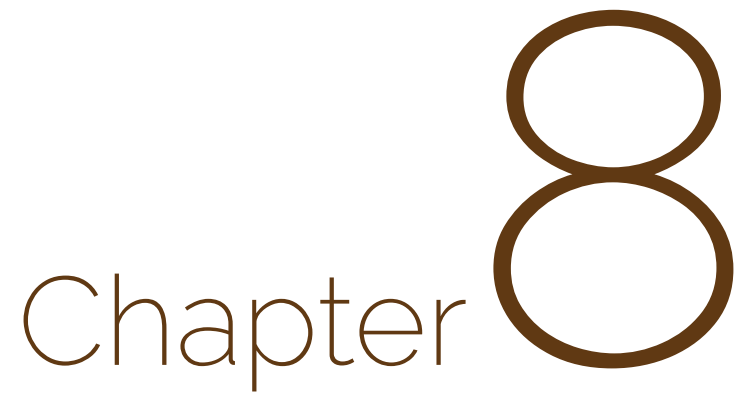

\section{Decision support for selecting the intensity of FGM}

Marjana WESTERGREN ${ }^{1}$, Marko BAJC ${ }^{1}$, Filippos A. ARAVANOPOULOS²,

Rok DAMJANIĆ ${ }^{1}$, Barbara FUSSI ${ }^{3}$, Darius KAVALIAUSKAS ${ }^{3}$, Fotios KIOURTSIS ${ }^{4}$,

Paraskevi ALIZOTI², Andrej BREZNIKAR ${ }^{5}$, Hojka KRAIGHER ${ }^{1}$

Citation: Westergren et al. (2020) Decision support for selecting the intensity of FGM. In: Bajc et al. (eds) Manual for Forest Genetic Monitoring. Slovenian Forestry Institute: Silva Slovenica Publishing Centre, Ljubljana, pp 151-156. http://dx.doi.org/10.20315/SFS.167

\section{Affiliations:}

1. Slovenian Forestry Institute (GIS), Slovenia

2. Aristotle University of Thessaloniki (AUTh), Greece

3. Bavarian Office for Forest Genetics (AWG), Germany

4. Decentralized Administration of Macedonia \& Thrace, General Directorate of Forests \& Rural Affairs, Greece

5. Slovenia Forest Service (ZGS), Slovenia 


\subsection{Introduction and aim}

This chapter is aimed at the policymakers at the local, national, regional and European scales to help them choose the best level of genetic monitoring considering the questions to be answered and human and financial resources, as well as expertise, available. It is advisable that policymakers consult scientists working with forests and genetics to determine the questions that are most relevant at the national level.

The combination of information in the tables below will help to decide on the level of FGM to implement. Table 8.1 lists the questions that can be answered using the data obtained by verifiers and background information assessed within the proposed FGM system. The costs for recording each of the verifiers for a 10-year period are presented in Table 8.2.

\subsection{Questions, which FGM answers}

A non-exhaustive list of questions FGM can answer is listed in Table 8.1.

Table 8.1: A set of questions that can be answered by a given level of forest genetic monitoring.

\begin{tabular}{|c|c|c|c|}
\hline \multirow[b]{2}{*}{ Question } & \multicolumn{3}{|c|}{ Forest genetic monitoring level } \\
\hline & Basic & Standard & Advanced \\
\hline Is fructification frequent enough (as expected for a given tree species)? & $x$ & $x$ & $x$ \\
\hline Is fructification abundant enough (as expected for a given tree species)? & $x$ & $x$ & $x$ \\
\hline Is there unexpected mortality that may cause population decline? & $x$ & $x$ & $x$ \\
\hline Is there enough natural regeneration to maintain evolutionary potential? & $x$ & $x$ & $x$ \\
\hline Is the effective population size large enough to sustain evolutionary potential? & & $x$ & $x$ \\
\hline $\begin{array}{l}\text { Is the population undergoing long-term decline as estimated by the demographic } \\
\text { models? }\end{array}$ & & $x$ & $x$ \\
\hline $\begin{array}{l}\text { Is the variability in the population (genetic - molecular markers, phenotypic - trait } \\
\text { variation) large enough to maintain evolutionary potential? }\end{array}$ & & $\mathrm{x}$ & $\mathrm{x}$ \\
\hline $\begin{array}{l}\text { What is the reason for low regeneration abundance (not enough flowering, lack } \\
\text { of synchronisation between male and female flowering, seed abortion, or lack of } \\
\text { germination)? }\end{array}$ & & & $x$ \\
\hline Is there high inbreeding in a population? Is it increasing? & & & $x$ \\
\hline $\begin{array}{l}\text { Can the gene flow from other populations counteract the decline of the monitored } \\
\text { population? }\end{array}$ & & & $x$ \\
\hline $\begin{array}{l}\text { Does the population have the potential to overcome the challenges imposed by the } \\
\text { environment? }\end{array}$ & & & $x$ \\
\hline
\end{tabular}

At a minimum, the indicator Selection with its basic level verifiers is considered adequate to give an overall insight into whether the forest stand is facing decline. However, monitoring this indicator at the basic level will not explain the underlying causes of a change.

All verifiers within an indicator at a given level should be recorded for a full insight into the indicator in question, consistent with the monitoring level. The four basic level verifiers under the indicator Selection (the minimum number of verifiers to monitor) will raise the alarm when the monitored population is in decline, but will not give insight into what may be causing the decline. For that, the other two indicators and higher-level verifiers must be monitored and analysed. 


\subsection{The cost of forest genetic monitoring}

The costs occurring per verifier for monitoring a single genetic monitoring plot which consists of 50 adult trees for all monitoring levels and an additional 40 natural regeneration centres $\left(1 \mathrm{~m}^{2}\right.$ each) for standard and advanced levels during a 10-year monitoring period were calculated as the average of costs that have occurred across six monitoring plots in three countries (Germany, Slovenia, Greece) for two stand-forming species: the European beech (Fagus sylvatica L.) and Silver fir / King Boris fir (Abies alba Mill. / A. borisii regis Mafft.) complexes. The costs per verifier refer to the assumptions and frequency of verifier observations as described in Chapter 7 (Cost assessment). Costs are divided into:

- material costs: consumables, mileage to travel to / back from the plot, subsistence and outsourcing of sampling / genetic analysis,

- person-hours: work hours needed to carry out field observations, sampling, laboratory work and genotyping.
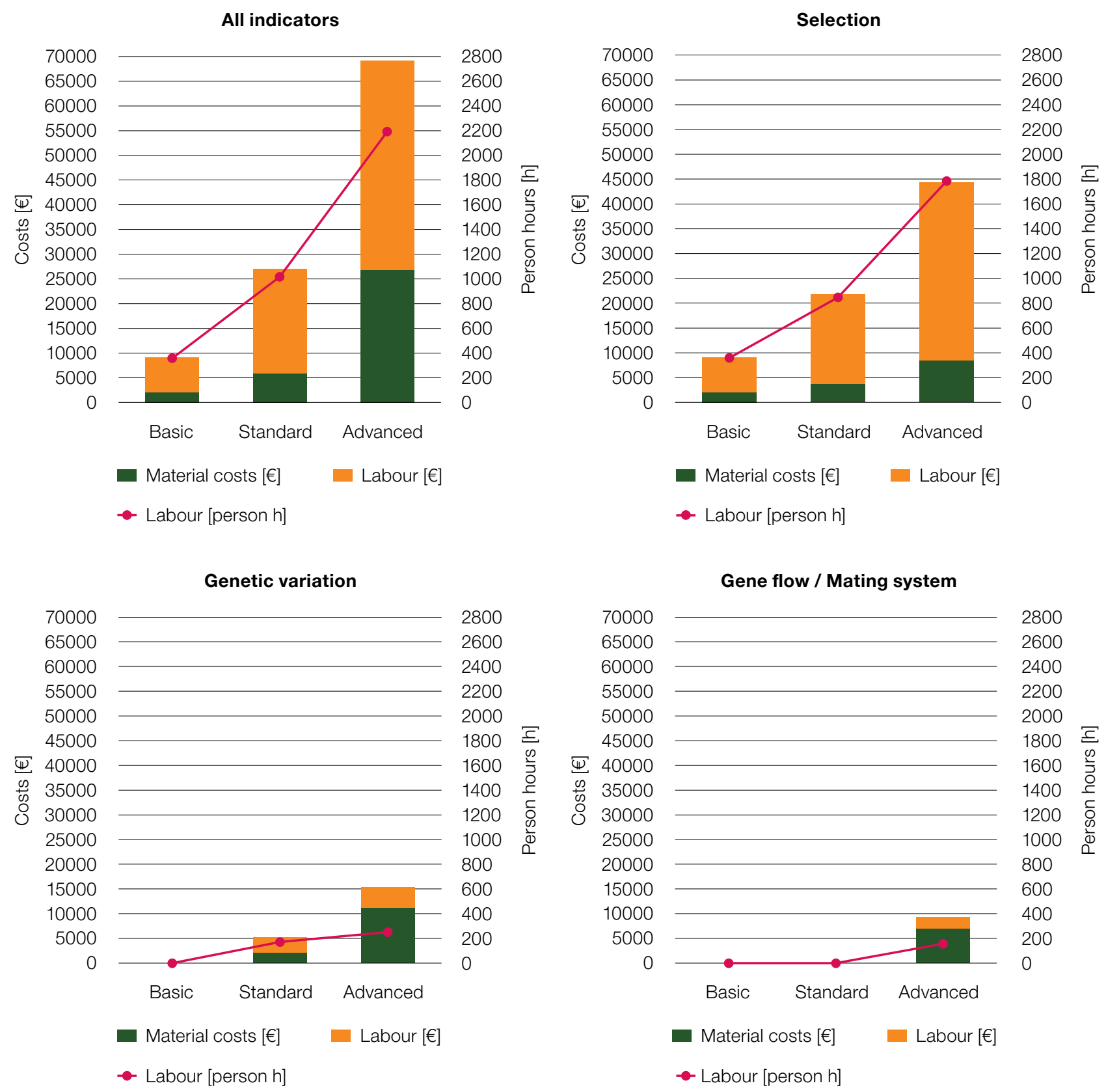

Figure 8.1: Total costs of genetic monitoring per decade, material costs and time requirements per monitoring level. 
The average costs per verifier and background information as well as for plot selection, plot establishment and sampling are presented in Table 8.2. At the basic level, the total average cost of genetic monitoring per decade is approximately $\mathbf{2 , 0 0 0}$ EUR and $\mathbf{3 6 0}$ person-hours. The total cost of the genetic monitoring per decade at the standard level is approximately 5,900 EUR and 1,020 person-hours and the advanced level 26,800 EUR and 2,190 person-hours.

Table 8.2: Cost and information value of verifiers and background information, plot selection, establishment and sampling for monitoring 50 adult trees and 40 natural regeneration centres for a period of 10 years. Costs are divided into material costs which include consumables, mileage to travel to / back from the plot, subsistence and outsourcing of sampling / genetic analysis and person-hours, which include hours needed to carry out field observations, sampling, travelling, laboratory work, genotyping and data analysis. Verifier type: $\mathrm{V}=$ verifier, $\mathrm{BI}=$ background information. Information value: $\mathrm{H}=$ high, $\mathrm{M}=$ medium, $\mathrm{L}=$ low. Type of work: $\mathrm{F}=$ field work, $\mathrm{L}=$ laboratory work. Empty cell: verifier not recorded at a given level. Values were rounded to nearest 10 EUR and 5 person-hours.

\begin{tabular}{|c|c|c|c|c|c|c|c|c|c|c|}
\hline \multirow[b]{2}{*}{ Indicator } & \multirow[b]{2}{*}{ Verifier name } & \multirow[b]{2}{*}{ Type } & \multirow[b]{2}{*}{$\begin{array}{l}\text { Info } \\
\text { value }\end{array}$} & \multirow[b]{2}{*}{$\begin{array}{l}\text { Work } \\
\text { type }\end{array}$} & \multicolumn{2}{|c|}{ Basic level } & \multicolumn{2}{|c|}{ Standard level } & \multicolumn{2}{|c|}{ Advanced level } \\
\hline & & & & & $\begin{array}{c}\text { Material } \\
{[€]}\end{array}$ & $\begin{array}{c}\text { Labour } \\
\text { [person } \mathrm{h} \text { ] }\end{array}$ & $\begin{array}{c}\text { Material } \\
{[€]}\end{array}$ & $\begin{array}{c}\text { Labour } \\
\text { [person } \mathrm{h}]\end{array}$ & $\begin{array}{c}\text { Material } \\
{[€]}\end{array}$ & $\begin{array}{c}\text { Labour } \\
\text { [person } \mathrm{h}]\end{array}$ \\
\hline \multirow{13}{*}{ Selection } & Mortality / survival & V & M & $\mathrm{F}$ & 20 & 20 & 20 & 20 & 20 & 20 \\
\hline & NR abundance & V & $\mathrm{H}$ & $\mathrm{F}$ & 240 & 60 & 450 & 155 & 620 & 230 \\
\hline & Flowering & V & M & $\mathrm{F}$ & 580 & 65 & 750 & 125 & 860 & 175 \\
\hline & Fructification & V & M & $\mathrm{F}$ & 580 & 65 & 690 & 110 & 690 & 160 \\
\hline & $\%$ filled seeds & V & $\mathrm{L}$ & L & & & & & 160 & 20 \\
\hline & $\%$ germination & V & L & L & & & & & 160 & 20 \\
\hline & Crown dieback (ash) & $\mathrm{Bl}$ & L & $\mathrm{F}$ & 430 & 110 & 430 & 110 & 430 & 110 \\
\hline & Sex ratio & $\mathrm{Bl}$ & L & $\mathrm{F}$ & & & 150 & 25 & 170 & 35 \\
\hline & DBH class distribution & $\mathrm{BI}$ & L & $\mathrm{F}$ & & & 40 & 35 & 40 & 35 \\
\hline & Height class distribution & $\mathrm{Bl}$ & L & $\mathrm{F}$ & & & 40 & 35 & 40 & 35 \\
\hline & Flowering synch. & $\mathrm{Bl}$ & L & $\mathrm{F}$ & & & & & 0 & 45 \\
\hline & Budburst & $\mathrm{BI}$ & L & $\mathrm{F}$ & & & 630 & 130 & 3,160 & 605 \\
\hline & Senescence & $\mathrm{Bl}$ & $\mathrm{L}$ & $\mathrm{F}$ & & & 230 & 60 & 1,150 & 240 \\
\hline \multirow{9}{*}{$\begin{array}{l}\text { Genetic } \\
\text { variation }\end{array}$} & Allele frequencies & V & M & L & & & 210 & 15 & 1,040 & 20 \\
\hline & Latent genetic potential & V & M & L & & & 210 & 15 & 1,040 & 20 \\
\hline & Inbreeding coefficient & V & M & L & & & 210 & 15 & 1,040 & 20 \\
\hline & Effective population size & V & $\mathrm{H}$ & L & & & 210 & 15 & 1,040 & 20 \\
\hline & Allelic richness & V & M & L & & & 210 & 15 & 1,040 & 20 \\
\hline & Linkage disequilibrium & V & M & L & & & 210 & 15 & 1,040 & 20 \\
\hline & Interspecific hybrid. & $\mathrm{Bl}$ & L & L & & & 210 & 15 & 1,040 & 20 \\
\hline & Multiplicity & $\mathrm{Bl}$ & L & L & & & 210 & 15 & 1,040 & 20 \\
\hline & F-analysis outlier test & $\mathrm{Bl}$ & L & $\mathrm{L}$ & & & 210 & 15 & 1,040 & 20 \\
\hline \multirow{5}{*}{$\begin{array}{l}\text { Gene flow } \\
\text { / mating } \\
\text { system }\end{array}$} & Gene flow & V & M & L & & & & & 1,040 & 20 \\
\hline & $\begin{array}{l}\text { Multi-locus population } \\
\text { outcrossing rate }\end{array}$ & V & M & L & & & & & 1,040 & 20 \\
\hline & Actual inbreeding rate & V & $\mathrm{H}$ & L & & & & & 1,040 & 20 \\
\hline & Eff. $N$ of pollen donors & $\mathrm{Bl}$ & L & L & & & & & 1,040 & 20 \\
\hline & Biparental inbreeding & $\mathrm{Bl}$ & L & $\mathrm{L}$ & & & & & 1,040 & 20 \\
\hline \multirow{3}{*}{$\begin{array}{l}\text { Common } \\
\text { activities }\end{array}$} & Plot selection & NA & NA & NA & 70 & 20 & 70 & 20 & 70 & 20 \\
\hline & Plot establishment & NA & NA & NA & 120 & 10 & 600 & 50 & 600 & 50 \\
\hline & Sampling & NA & NA & NA & 0 & 0 & 92 & 20 & 5,130 & 100 \\
\hline
\end{tabular}


The total cost of monitoring the indicator Selection per decade at the basic level is approximately $\mathbf{2 , 0 0 0}$ EUR and 360 person-hours, at the standard level 3,800 EUR and 850 person-hours, and at the advanced level 8,500 EUR and 1,790 person-hours. The cost of monitoring the indicator Genetic variation is approximately 2,100 EUR and 170 person-hours at the standard level, and 11,250 EUR and 250 person-hours at the advanced level. The cost for monitoring the indicator Gene flow/mating system, which is carried out only at the advanced level, is approximately 7,000 EUR and 160 personhours per decade.

\subsection{Information value of FGM verifiers}

High information value was assigned to three verifiers: Natural regeneration abundance (basic, standard and advanced levels, indicator selection), Effective population size (standard and advanced levels, indicator genetic variation) and Actual inbreeding rate (advanced level, indicator gene flow / mating system). These are the three verifiers that directly inform us that the monitored population is facing decline and immediate forest management change is needed. If there is no natural regeneration, the stand will not be renewed. If effective population size becomes very low, the number of parents contributing to the next generation may be too low to ensure persistence of genetic variation in the monitored population. If the actual inbreeding rate (a combination of marker and seed traits information) becomes very high, this may lead to allele fixation and the reduction of population genetic diversity.

All other verifiers are considered to have medium information value. Individually, they are difficult to interpret, but considered together they give a more complete picture of the state of the monitored population. They also provide information that helps to interpret the three high information value verifiers.

All background information has been considered to have low information value. However, the background information is crucial to interpret both the verifiers with medium and high information value.

\subsection{Management actions following FGM}

Depending on the trend of the verifier values, one may decide to increase the monitoring level from basic to standard, or advanced, looking for the reasons of the observed trends, or apply different forest management actions. These should include silvicultural measures that promote dynamic genetic processes to favour adaptation and preserve genetic diversity (Koskela et al. 2013), primarily maintenance or increase of the number of reproducing trees and seedling survival via, for example, establishing adequate light conditions, single plant protection, understory and weed removal / control, ground preparation or fire prevention and herbivore control, including fencing. Thinning is beneficial but should not reduce the number of reproducing trees (the effective population size) to a too low number. When conducting thinning, keep a wide variation of flowering and flushing trees (i.e. early and late flushers). In contrast to the commonly accepted value of effective population sizes of 50 or more trees being enough to counteract the decline of population fitness, recent conservation literature has increased this cut-off value to 100 (Frankham et al. 2014). With an effective population size equal to or higher than 100 , the loss in total fitness remains less than $10 \%$ over five generations in the wild, while to retain evolutionary potential for reproductive fitness in perpetuity an effective population size of 1,000 or more is needed (Frankham et al. 2014). Hoban et al. (2020) set the effective population size under which the population has a reduced ability to adapt to environmental change at 500. 


\subsection{Messages to policymakers}

Forest genetic resources do not know borders. To support, conserve, manage and use forest genetic resources, regional collaboration is to be aimed for.

The changing environment and any forest management measures can influence genetic diversity. The current speed of climate change and forestry interventions have the greatest direct impact on the future generations of forest trees.

Genetic monitoring is needed to feed information into sustainable forest management. Genetic monitoring is the only tool to follow the adaptation of trees to changing conditions in different parts of the distribution range, e.g. rear or leading edges, whether established through natural regeneration, assisted gene flow or assisted migration or planting in plantations. It provides invaluable information for sustainable forest management.

Genetic monitoring can be adapted to the questions posed and funds available. Genetic monitoring can be applied in practice on basic, standard, and advanced levels. The level selected depends on the monitored population, the questions posed and the level of detail one wants to achieve, as well as the funds, human resources and expertise available.

Cooperation is vital for genetic monitoring implementation. Implementation of the forest genetic monitoring requires cooperation between foresters and researchers with the needed expertise.

Long-term storage of baseline tissue samples and data is essential for monitoring. Long term storage facilities for tissue samples or DNA and data are necessary for forest genetic monitoring to reach its full potential. Availability of samples or DNA for all the monitored years enables laboratories to re-analyse all the samples - from "time zero" onward - when more advanced and informative DNA analysis approaches become available. These storage facilities can be centralised or organised at the national level.

Transfer of forest reproductive material within the region can support the adaptation of forests to future climates and the changing environment. Forest genetic resources from neighbouring countries, and countries within the range of expected future climates, might help forest resilience when enrichment planting with forest reproductive material from such regions is implemented.

Transfer of forest reproductive material across country borders needs to follow legal requirements. Legal requirements for use of forest reproductive material from other countries within the national territory, and cross-border transfer of forest reproductive material from non-EU and non-OECD countries, are to be met. Professional advisory service / institution is to be established within the national territory to support any decision on the use of forest reproductive material from non-national forest genetic resources.

\section{References}

Frankham R, Bradshaw CJA, Brook BW (2014) Genetics in conservation management: Revised recommendations for the 50/500 rules, Red List criteria and population viability analyses. Biol Conserv 170:56-63. https://doi.org/10.1016/j. biocon.2013.12.036

Hoban S, Bruford M, Jackson DJ et al (2020) Genetic diversity targets and indicators in the CBD post-2020 Global Biodiversity Framework must be improved. Biol Conserv 248:108654. https://doi.org/10.1016/j.biocon.2020.108654

Koskela J, Lefèvre F, Schueler S, Kraigher H, Olrik DC, Hubert J, et al (2013) Translating conservation genetics into management: pan-European minimum requirements for dynamic conservation units of forest tree genetic diversity. Biol Conserv 157:39-49. https://doi.org/10.1016/j.biocon.2012.07.023 



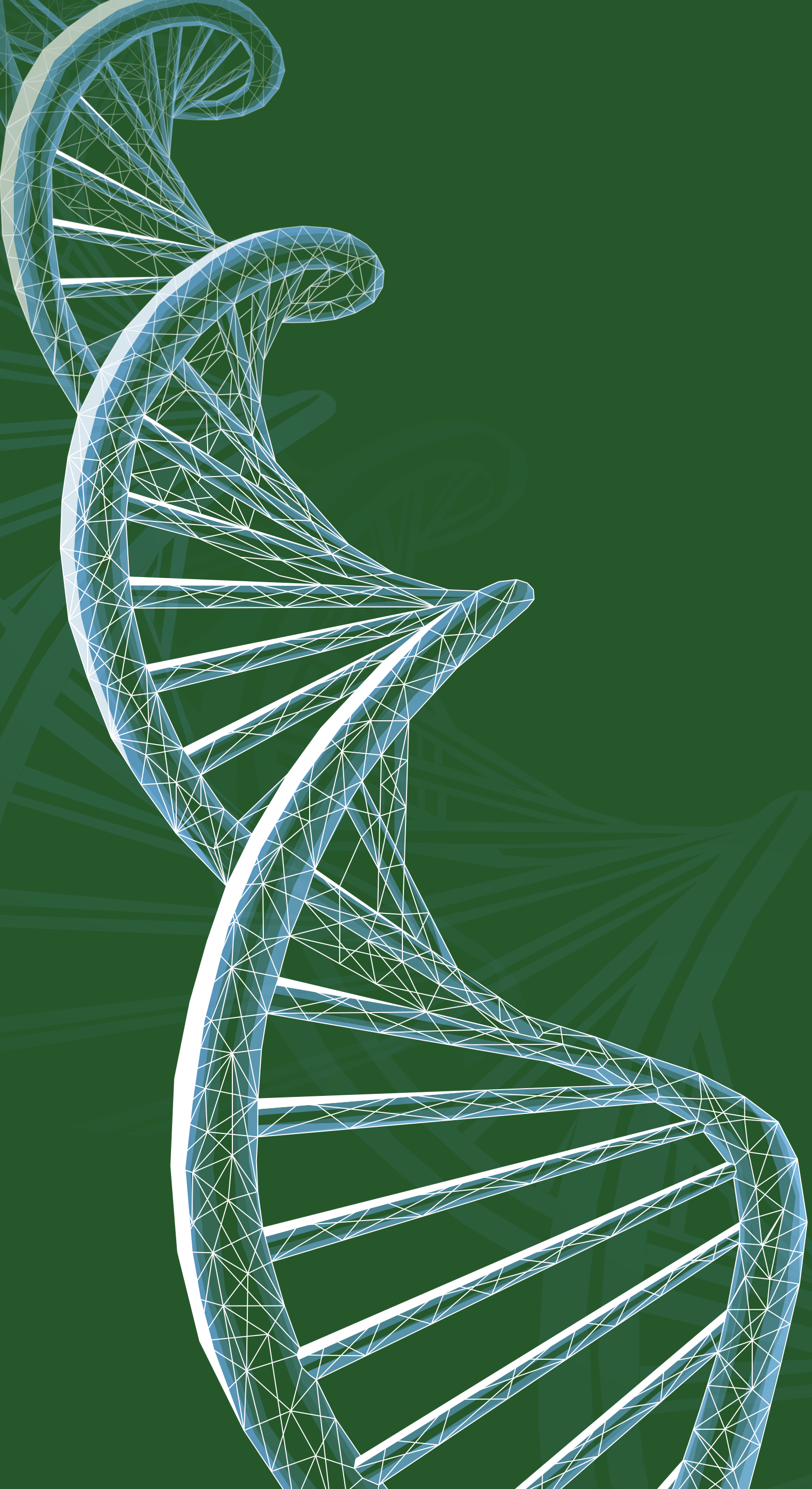




\section{\#\#) \\ LFE13 ENV/S/ 000148 \\ Manual for forest genetic monitoring}

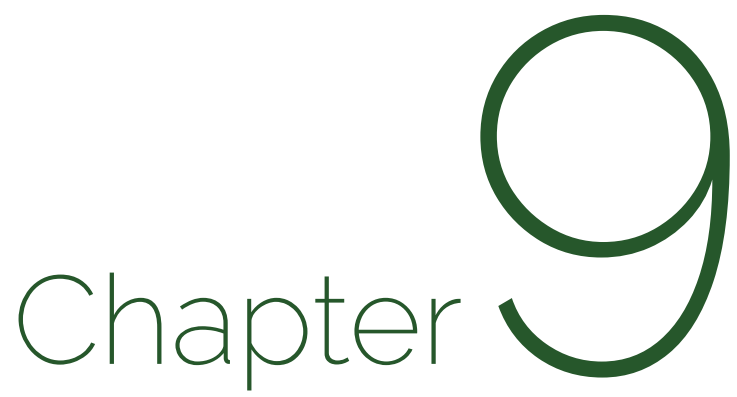

\section{Guidelines for forest genetic monitoring}

Darius KAVALIAUSKAS ${ }^{1}$, Marjana WESTERGREN², Paraskevi ALIZOTI', Gregor BOŽIČㄹ, Barbara FUSSI ${ }^{1}$, Kristina SEVER ${ }^{4}$, Andrej BREZNIKAR ${ }^{4}$, Marko BAJC2 , Filippos A. ARAVANOPOULOS ${ }^{3}$, Dalibor BALLIAN 2,5 , Evangelos BARBAS ${ }^{3}$, Sándor BORDÁCS ${ }^{6}$, Rok DAMJANIĆ2 ${ }^{2}$ Natalija DOVČ², Domen FINŽGAR ${ }^{2,7}$, Berthold HEINZE', Fotios KIOURTSIS ${ }^{9}$, Monika KONNERT'1, Nikolaos TOURVAS ${ }^{3}$, Zvonimir VUJNOVIĆ ${ }^{10}$, Peter ŽELEZNII² ${ }^{2}$, Hojka KRAIGHER²

Citation: Kavaliauskas et al. (2020) Guidelines for forest genetic monitoring. In: Bajc et al. (eds) Manual for Forest Genetic Monitoring. Slovenian Forestry Institute: Silva Slovenica Publishing Centre, Ljubljana, pp 159-290. http://dx.doi.org/10.20315/SFS.167

Affiliations:

1. Bavarian Office for Forest Genetics (AWG), Germany

2. Slovenian Forestry Institute (GIS), Slovenia

3. Aristotle University of Thessaloniki (AUTh), Greece

4. Slovenia Forest Service (ZGS), Slovenia

5. Forestry Faculty, University of Sarajevo, Bosnia and Herzegovina

6. Szent István University, Budapest, Hungary

7. Institute of Evolutionary Biology, University of Edinburgh, UK

8. Austrian Federal Research Centre for Forests (BFW), Austria

9. Decentralized Administration of Macedonia \& Thrace,

General Directorate of Forests \& Rural Affairs, Greece

10. Croatian Forest Research Institute, Jastrebarsko, Croatia 


\subsection{Introduction}

Forest genetic monitoring (FGM) guidelines for seven target tree species and species complexes (Abies alba Mill./ Abies borisii-regis Mattf. complex, Fagus sylvatica L., Fraxinus excelsior L., Pinus nigra J. F. Arnold, Populus nigra L., Prunus avium (L.) L., Quercus petraea (Matt.) Liebl./Quercus robur L. complex) were developed within the LIFEGENMON project in order to facilitate the implementation of their genetic monitoring at the European level. They provide concise guidance on how to select, establish and maintain forest genetic monitoring plots and on recording all field level verifiers (e.g. mortality/survival, flowering, fructification, natural regeneration abundance) and background information (e.g. DBH class distribution, height class distribution, bud break, leaf senescence, etc.) for different 'model' tree species at different monitoring levels (basic, standard and advanced). The emphasis was put on the specificity of genetic monitoring for each tree species or species complex (Table 9.1) taking into account their biology (mating/reproduction system, ecology, etc.), their distribution (scattered or continuous) and their specific economic and ecological value. Therefore, the selected species represent a wide range of situations regarding biological, ecological and conservation aspects, making the ensuing species-specific guidelines amenable to a wider application within European forestry that goes beyond the seven species themselves. The guidelines for forest genetic monitoring of Fagus sylvatica and Abies alba/Abies borisii-regis were prepared based on the results and experience gained from actual genetic monitoring of these species conducted in the frame of the LIFEGENMON project in Germany, Slovenia and Greece. In total six FGM plots - three for Fagus sy/vatica and three for Abies alba/Abies borisii-regis were established. The above test sites will remain available for future genetic monitoring and research.

Overall the FGM guidelines of the seven selected species and species complexes are expected to contribute to the establishment of a network of genetic monitoring plots across Europe for the early assessment of climate change impacts on the genetic variation of forest tree populations, so that their adaptive management can be implemented on time efficiently and effectively.

The guidelines are primarily intended for the personnel conducting fieldwork related to FGM, and include detailed instructions on how to carry out regular field observations and measurements for such monitoring, such as phenology observations, mortality/survival assessment, assessment of natural regeneration abundance, etc. To guarantee comparable results across different years and people conducting the observations, fieldwork and data collection techniques must be standardised. After proper preparation and training, field observations can be performed by field technicians, foresters or scientists. Since many of the observations in the field depend on the visual assessment and are, at least to a certain degree, subject to individual interpretation, it is recommended that training sessions are organised for the personnel on how to conduct the field observations in order to assure the highest possible level of comparability and reliability of the collected data. 
Table 9.1. List of species for which FGM guidelines within the LIFEGENMON project have been prepared. All seven selected species/species complexes are considered ecologically and economically important. Conservation status IUCN (in Europe, according to the IUCN Red list): LC - Least concern, NT - Near threatened, DD - data deficient, NE not evaluated; Population trend (in Europe, according to the IUCN Red list): - - stable, $\downarrow$ - decreasing, ? - unknown, NE - not evaluated; Distribution: SF - stand-forming, SC - scattered; Classification: D - deciduous, C - coniferous; Pollination: W - wind pollinated, I - insect pollinated; Oeciousness: M - monoecious, D - dioecious.

\begin{tabular}{|c|c|c|c|c|c|c|}
\hline Species & $\begin{array}{l}\text { Conservation } \\
\text { status - IUCN }\end{array}$ & $\begin{array}{l}\text { Population } \\
\text { trend }\end{array}$ & Distribution & Classification & Pollination & $\begin{array}{l}\text { Dioecious/ } \\
\text { Monoecious }\end{array}$ \\
\hline Fagus sylvatica & LC $^{1}$ & -1 & SF & $\mathrm{D}$ & W & M \\
\hline $\begin{array}{l}\text { Abies albal } \\
\text { Abies borisii-regis }\end{array}$ & $\begin{array}{l}\mathrm{LC}^{1} \\
\mathrm{NE}\end{array}$ & $\overline{N E}^{1}$ & SF & C & W & M \\
\hline Populus nigra & $\mathrm{DD}^{3}$ & $\downarrow^{3}$ & SC & $\mathrm{D}$ & W & $\mathrm{D}$ \\
\hline Fraxinus excelsior & NT ${ }^{4}$ & $\downarrow^{4}$ & $\mathrm{SF} / \mathrm{SC}$ * & $\mathrm{D}$ & W & M \\
\hline Pinus nigra & $\operatorname{LC}^{5}$ & -5 & SF & C & W & M \\
\hline Prunus avium & $\operatorname{LC}^{6}$ & $-{ }^{6}$ & SC & $\mathrm{D}$ & I & M \\
\hline $\begin{array}{l}\text { Quercus roburl } \\
\text { Quercus petraea }\end{array}$ & $\begin{array}{l}\text { LC }^{7} \\
\text { LC }^{8}\end{array}$ & $\begin{array}{l}\downarrow^{7} \\
?^{8}\end{array}$ & SF & $\mathrm{D}$ & W & M \\
\hline
\end{tabular}

* The Common ash can form pure stands but is more commonly found growing in smaller groups of trees in mixed stands akin to species with scattered distribution.

\section{Table References}

1. Barstow M, Beech E (2018) Fagus sylvatica. The IUCN Red List of Threatened Species 2018: e.T62004722A62004725. https://dx.doi.org/10.2305/IUCN.UK.2018-1.RLTS.T62004722A62004725.en Accessed 04 December 2020

2. Farjon, A (2017) Abies alba. The IUCN Red List of Threatened Species 2017: e.T42270A83978869. https://dx.doi. org/10.2305/IUCN.UK.2017-2.RLTS.T42270A83978869.en Accessed 04 December 2020

3. Harvey-Brown Y, Barstow M, Mark J \& Rivers, MC (2017) Populus nigra. The IUCN Red List of Threatened Species 2017: e.T63530A68106816 https://dx.doi.org/10.2305/IUCN.UK.2017-3.RLTS.T63530A68106816.en Accessed 04 December 2020

4. Khela S \& Oldfield S (2018) Fraxinus excelsior. The IUCN Red List of Threatened Species 2018: e.T203367A67807718. https://dx.doi.org/10.2305/IUCN.UK.2018-1.RLTS.T203367A67807718.en Accessed 04 December 2020

5. Farjon A (2013) Pinus nigra. The IUCN Red List of Threatened Species 2013: e.T42386A2976817. https://dx.doi. org/10.2305/IUCN.UK.2013-1.RLTS.T42386A2976817.en Accessed 04 December 2020

6. Rivers MC (2017) Prunus avium. The IUCN Red List of Threatened Species 2017: e.T172064A50673544. https://dx.doi. org/10.2305/IUCN.UK.2017-3.RLTS.T172064A50673544.en Accessed 04 December 2020

7. Gorener V, Khela S \& Barstow M (2017) Quercus petraea. The IUCN Red List of Threatened Species 2017: e.T62539A3116237. https://dx.doi.org/10.2305/IUCN.UK.2017-3.RLTS.T62539A3116237.en Accessed 04 December 2020

8. Barstow M \& Khela S (2017) Quercus robur. The IUCN Red List of Threatened Species 2017: e.T63532A3126467. https://dx.doi.org/10.2305/IUCN.UK.2017-3.RLTS.T63532A3126467.en Accessed 04 December 2020 
9.2 Guidelines for the selected seven species 


\section{Guidelines for genetic monitoring of}

\subsubsection{Silver fir \\ (Abies alba Mill.) \\ and}

\section{King Boris fir (Abies borisii-regis Mattf.)}

Darius KAVALIAUSKAS', Barbara FUSSI', Dalibor BALLIAN²,3,

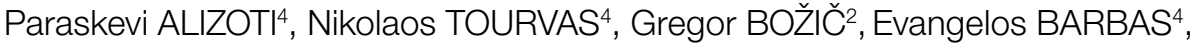
Marjana WESTERGREN², Marko BAJC², Rok DAMJANIĆ², Natalija DOVČ²,

Filippos A. ARAVANOPOULOS ${ }^{4}$, Hojka KRAIGHER ${ }^{2}$

Botanical illustrations by Anja RUPAR

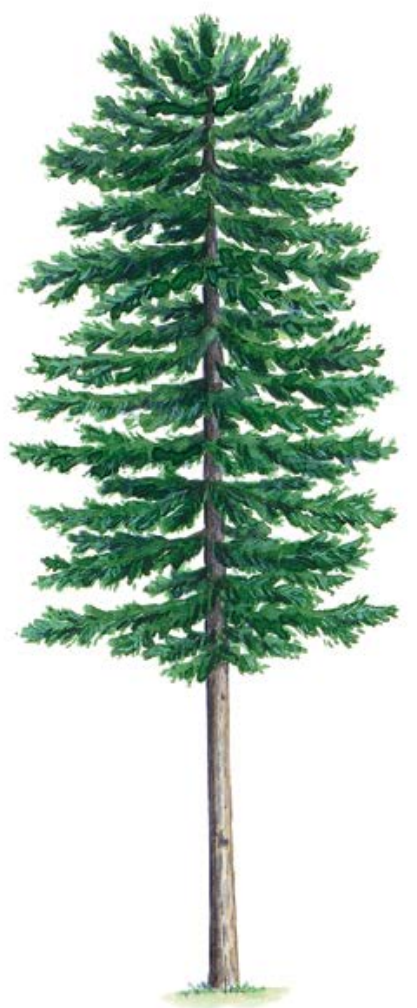

Citation: Kavaliauskas et al. (2020) Guidelines for genetic monitoring of Silver fir (Abies alba Mill.) and King Boris fir (Abies borisii-regis Mattf.). In: Bajc et al. (eds) Manual for Forest Genetic Monitoring. Slovenian Forestry Institute: Silva Slovenica Publishing Centre, Ljubljana, pp 163-178. http://dx.doi.org/10.20315/SFS.167

\footnotetext{
Affiliations:

1. Bavarian Office for Forest Genetics (AWG), Germany

2. Slovenian Forestry Institute (SFI), Slovenia

3. University of Sarajevo, Forestry Faculty, Bosnia and Herzegovina

4. Aristotle University of Thessaloniki (AUTh), Greece
} 


\section{Executive summary}

Silver fir (Abies alba Mill.) and King Boris fir (Abies borisii-regis Mattf.) are wind-pollinated, monoecious, generally outcrossing conifer tree species, which belong to the Abies genus. Silver fir is one of the most important forest tree species from an economic and ecological point of view in several European countries. King Boris fir is an important natural hybrid between Abies alba and Abies cephalonica Loudon, growing mainly in Greece. Both species are facing many threats and challenges due to climate change, and therefore they are both considered for forest genetic monitoring.

The guidelines briefly describe Silver fir and King Boris fir, their reproduction system, environmental requirements and threats. They provide guidance on how to establish and maintain a forest genetic monitoring plot and on recording all field level verifiers and phenotypic data at the basic, standard, and advanced monitoring levels.
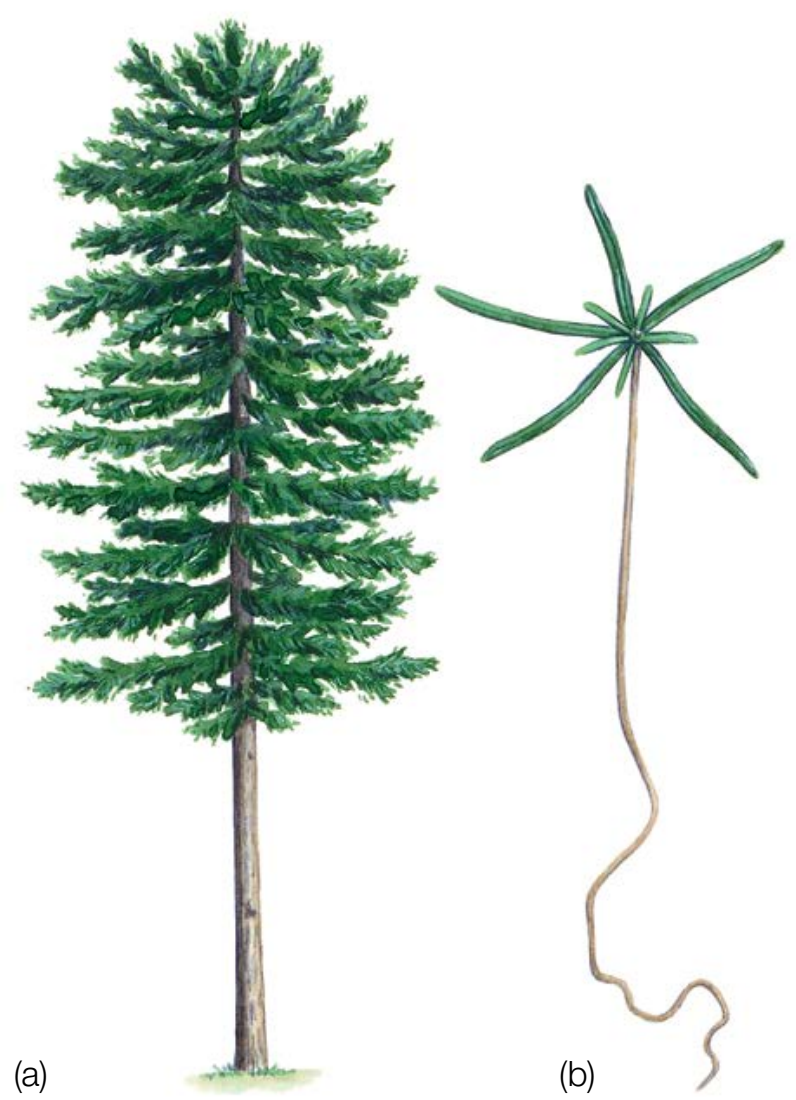

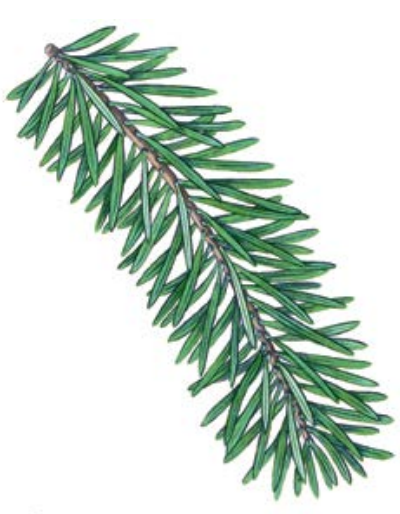

(C)

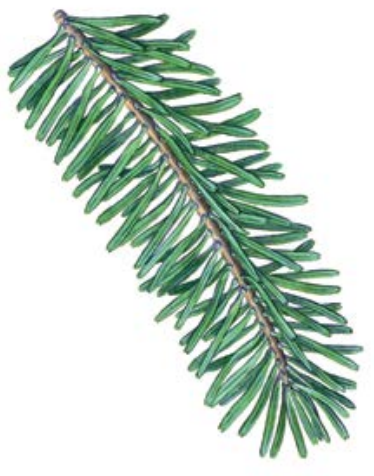

(d)

Figure 1: Silver fir (Abies alba) habitus (a); a seedling of Silver fir/King Boris fir (b); a branch with needles of the King Boris fir (c) and the Silver fir (d).

\section{Species description}

Silver fir and King Boris fir (Figure 1) are monecious conifer tree species, which in optimal conditions can reach more than $50 \mathrm{~m}(60 \mathrm{~m})$ in height and more than $1.5 \mathrm{~m}(2.0 \mathrm{~m})$ in diameter $(\mathrm{DBH})[1,4,16,28]$. Due to the low growth of the peak shoot the older trees lose their conical appearance and become oval at the top. The wood has no resin or coloured core. The branches stand in whorls and not hanging, but mostly horizontally laid, more or less flat. The bark is rough and uncracked, up to the age of 50 years old. In older age the bark gains the form of squared shells of cork, which remain attached to the tree and are hard to separate $[1,4,7,26,27,28]$. The needles of silver fir are dark green and glossy on their upper side, while the lower side has two silver green waxy bands of 6-8 rows of stomata [16, 28]. 


\section{Reproduction}

Abies alba and Abies borisii-regis are wind-pollinated, monoecious, generally outcrossing species with a chromosome number of $2 n=24$. Seeds of both species are wind-dispersed and female flowers are located on the upper top twigs, in the form of small cones. Male flowers usually are located a bit lower in the crown, in the armpit of needles, in the form of catkins. Male flowers are roughly $2 \mathrm{~cm}$ long with two pollen bags. Silver fir flowers in spring, from April to June, depending on altitude and latitude [1, 4, 7, 26, 27, 28].

Firs are long-lived species, attaining reproductive ability the earliest at the age of 20 years and averaging at the age of 60 years [14]. Female flowers are in the form of cones, in young age dark green, egg-shaped, about $2 \mathrm{~cm}$ long and upright. The mature cone is yellowish to dark brown, cylindrical, up to $16 \mathrm{~cm}$ long and up to $5 \mathrm{~cm}$ wide. Cones always stand upright on twigs, decaying in the same year, and in October shells with seeds fall, with a naked axis (spindle of a cone) is left on the branch. Winged seeds disperse by wind. While the tree is young, it fructifies every two years, but old trees and those at higher altitudes fructify less often, every three years or more $[1,4,7,26,27,28]$. However, some trees may fructify every year (LIFEGENMON observations in Abies alba FGM plot in southern Germany).

Despite high amounts of pollen production, silver fir is considered a weak seed producer, because of few buds developing into female flowers. Moreover, insect attacks, late frost, usually in late May and early June, depending on the altitude $[8,10]$, and inadequate pollination decrease seed production drastically $[6,15,17,18,19,20,23$, $24,25]$. The whole cycle from flowering to seed maturation and dispersion takes place in one year. The period from flowering and pollination to the maturation of the seed lasts from 90 to 120 days $[3,9,12,13$, 29]. Silver fir seed mature and disperse between September and November.

\section{Environment}

Silver fir is distributed in Central Europe and in some parts of Eastern and Sothern Europe [4, 26, 27, 28]. Distribution of King Boris fir is limited to the southern part of the Balkan Peninsula. Silver fir is a species of moderate continental climate softened by the ocean, and in contrast to other Mediterranean Abies species it prefers cooler and moister conditions. Silver fir tolerates a wide variety of soil types with different nutrient content and alkalinity conditions, except compact and hydromorphic soils [16]. Deep and moist but not too wet soils are preferred, with a pH from acid to neutral. Silver fir is a highly shade tolerant tree species and can remain in a densely shaded selective forest for a very long time [16, 28]. Silver fir can form pure stands, but can usually be found in the upper tree limit mixed with Norway spruce (Picea abies (L.) H. Karst.) or Scots pine (Pinus sylvestris L.) and at lower altitudes it can grow with European beech (Fagus sylvatica L.) [1, 16, 28, 4 and references therein].

\section{Threats}

Silver firs are very sensitive to temperature requirements, because offspring suffer from late spring frosts [21]. Young silver fir plants, up to three years, are very sensitive to drought, and if drought lasts for a longer time then the young plants cannot survive [1, 4, 22]. In addition, natural regeneration of silver fir is very susceptible to animal browsing. Silver fir is also sensitive to forest fires, air pollution, especially to $\mathrm{SO}_{2}$ exposure during winter [16 and references therein]. Because of the changing climate silver firs are more susceptible to diseases and pests, e.g. mistletoe and bark beetles have already damaged silver fir in the Mediterranean, especially in those areas where droughts occur more frequently [16 and references therein]. Insects like Ips typographus L., Cinaria pectinatae Nördlinger and Epinotia nigricana Herrich-Schäffer affect the bark and buds of silver fir. The fungi Armillaria mellea (Vahl) P. Kumm agg. and Heterobasidion annosum (Fr.) Bref. are responsible for butt rot and windthrow [16 and references therein]. 


\section{Plot establishment and maintenance}

Silver fir is a stand forming tree species which can form pure or mixed forest stands with Norway spruce, Scots pine, European beech and other tree species [1, 28, 4 and references therein]. Therefore, a regular FGM scheme, as for other stand forming tree species e.g. Fagus sylvatica, can be applied for genetic monitoring of Abies alba and Abies borisii-regis. Key steps for successful FGM plot establishment for Abies alba and Abies borisii-regis are: FGM plot selection according to the described criteria (e.g. high priority should be given to forest stands for which high data density and precise plot documentation is already available) [2].

However, FGM of Abies borisii-regis due to geographically disjunct distribution, biology (e.g. hybridisation) and the threats (e.g. climate change, pests and diseases), can be more challenging and develop the need for larger FGM plots. Therefore, the size and design of the FGM plot should be flexible, depending on the local specificities, but it is not recommended to be bigger than 10 ha for practical purposes.

A forest genetic monitoring plot consists of 50 reproducing trees with the minimum distance of $30 \mathrm{~m}$ between any two trees. If a tree is flowering, it is regarded as a reproducing tree. $\mathrm{DBH}$ and social class can be used as proxies to identify a reproducing tree if the plot is being established outside of the flowering season, relying on the expertise of the local forester. During plot installation, trees should be labelled and coordinates of all trees taken. At the same time DBH can be measured and samples for DNA extraction taken.

In addition, the presence of sufficient density of natural regeneration must be found within the FGM area.

Equipment needed:

- a device for distance measurement (a pair of range-finding binoculars is recommended)

- a compass,

- a paint with a brush or spray for marking trees,

- a tree calliper for DBH measurements, and

- a GPS device that is precise enough and allows saving trees' coordinates.

\subsection{Plot establishment}

\subsubsection{Selection of the centre of the plot}

The general procedure for random plot site selection consists of the following steps (Figure 2a):

- Random selection of a point (green dot) on a map along the forest road or path, which runs along the stand,

- Drawing a line that is approximately perpendicular to the road from the randomly selected point on a road,

- Random selection of one point on the perpendicular line (red dot) - this point represents the centre of the forest genetic monitoring plot.

The minimum distance between the selected central point and stand border is approximately $150 \mathrm{~m}$. If the selected central point doesn't meet this demand, a new point must be selected following the protocol described above.

Instead of the procedure described above, tools for creating random points in GIS software can also be used.

The selected point's coordinate is to be saved into a GPS device that will be used in the field. 
(a)

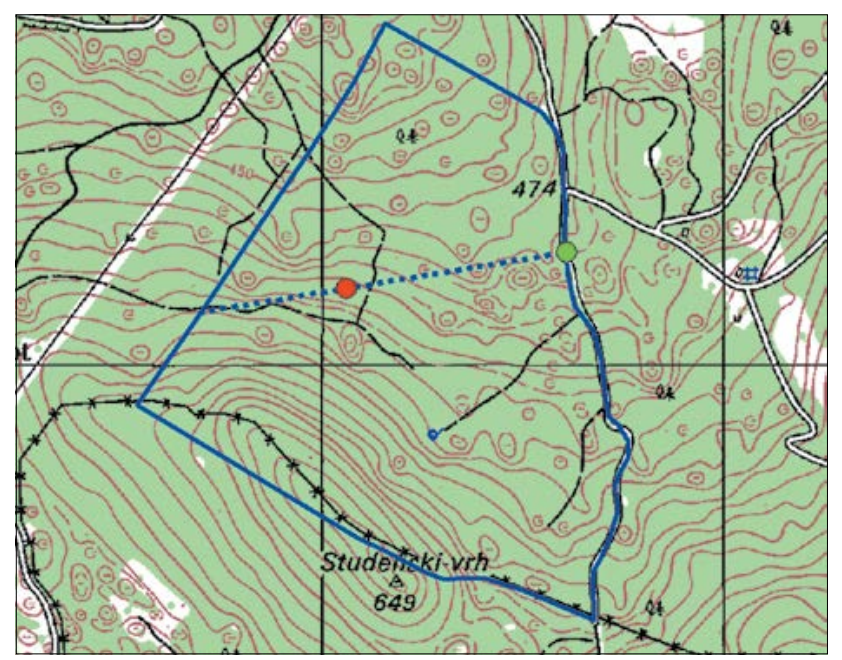

(b)

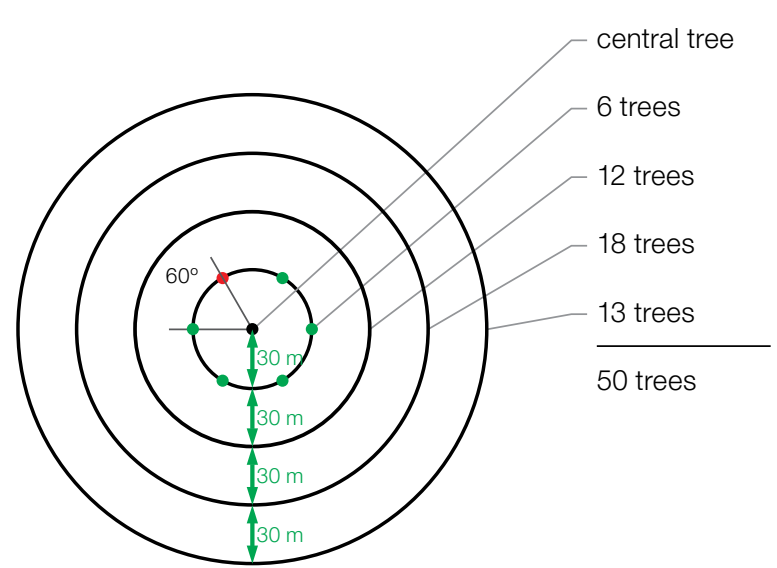

Figure 2: Random selection of the centre of the forest genetic monitoring plot (a); selection of trees in concentric circles around previously selected central tree with an increasing radius of $30 \mathrm{~m}$ (b).

\subsubsection{Plot installation in the field}

In the field, the closest reproducing tree to the saved GPS coordinate becomes the centre of the monitoring plot and is marked with number 1 .

Other trees are selected in concentric circles around the central tree with an increasing radius of $30 \mathrm{~m}$ (Figure 2b). The first tree in each circle should be selected randomly, which can be done in different ways: by using a random azimuth (Table 1) observed from the central tree, by following the direction of the second hand on an analogue watch or any other approach that allows for objective selection. The remaining trees in each circle are selected by appropriately enlarged azimuth to assure a minimum distance of $30 \mathrm{~m}$ between any two trees:

$\cdot+60^{\circ}$ for the first circle

$\cdot+30^{\circ}$ for the second circle

- $+20^{\circ}$ for the third circle

$\cdot+15^{\circ}$ for the fourth circle

If it is not possible to find six (6), 12 and 18 trees in the inner three circles (Figure 2b), additional trees are selected in the outermost circle.

Table 1: Randomly generated azimuths that can be used for selection of the first tree in each circle.

\begin{tabular}{rrrrrrrrrrr}
\hline 108 & 15 & 186 & 35 & 178 & 29 & 305 & 351 & 44 & 150 \\
\hline 232 & 23 & 160 & 141 & 112 & 292 & 216 & 83 & 245 & 214 \\
\hline 63 & 65 & 345 & 234 & 95 & 78 & 279 & 323 & 40 & 236 \\
\hline 201 & 313 & 275 & 144 & 182 & 68 & 268 & 289 & 185 & 92 \\
\hline 356 & 177 & 93 & 1 & 145 & 198 & 287 & 251 & 224 & 142 \\
\hline
\end{tabular}

\subsubsection{Labelling of trees}

All 50 selected trees ( $\mathrm{DBH} \geq 15 \mathrm{~cm}$ ) must be marked with a corresponding number (from 1 to 50 ) and preferably a band painted around the trunk to aid the visibility of the trees from all directions. Coordinates $(X / Y)$ of each tree must be taken (GPS needed). Tree numbers given during adult tree selection must be maintained over the entire monitoring period. The central tree (number 1) can be marked with two or more bands to differentiate it from 
other trees (Figure 3a). It is recommended to paint the number on the side of the tree that is pointing away from the central tree, as this helps locating the central tree, particularly from the outer rings of the plot (Figure 3b). In some cases, it helps to mark the trees on the side pointing away from paths or roads in order to avoid confusing or drawing the attention of the people seeking recreation in the forest.
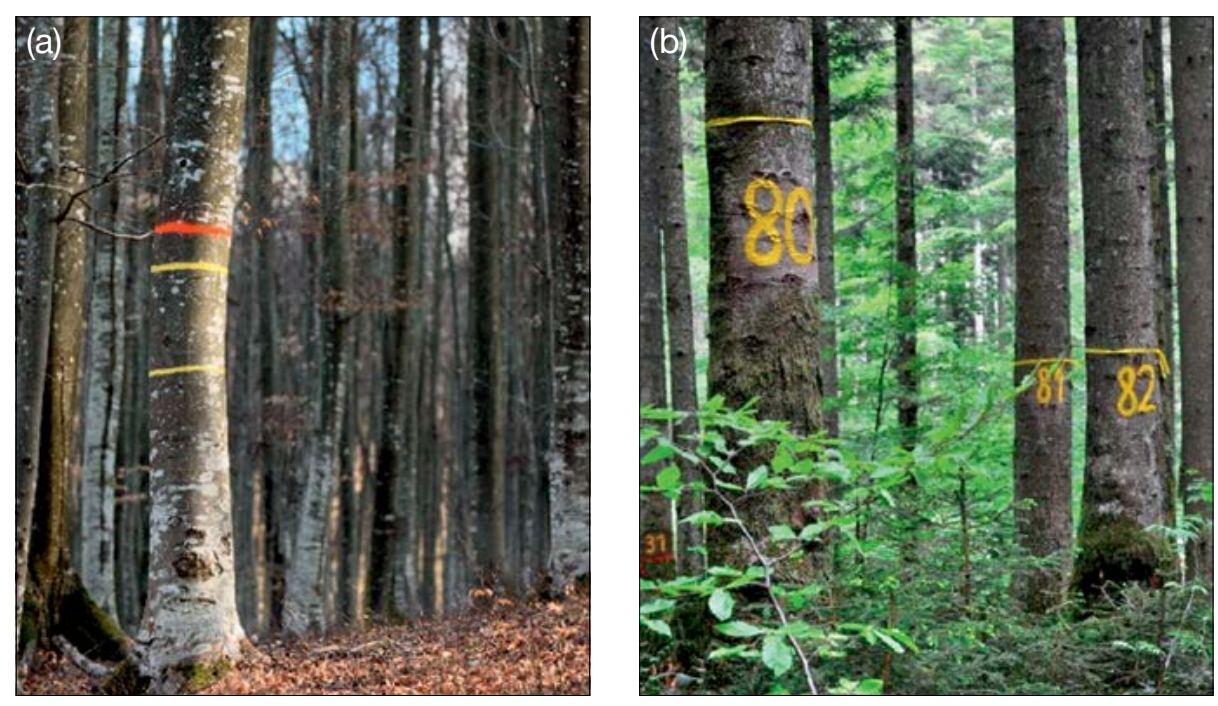

Figure 3. The central tree on the genetic monitoring plot is marked with multiple bands to differentiate it from other trees as done on a European beech FGM plot in Slovenia (a); numbers are painted on selected trees so that they point away from the central tree (b).

\subsection{Establishment of natural regeneration subplots}

The establishment of natural regeneration (NR) subplots should be carried out during germination after a strong or massive fructification event.

Natural regeneration centres from the last mast year should be surveyed in the field and their locations logged (GPS coordinates, number of the tree which is next to a NR centre). From all logged regeneration centres, 20 should be chosen randomly for plot installation. If 20 or fewer natural regeneration centres are present, all should be used.

Inside each selected natural regeneration centre a $1 \mathrm{~m}^{2}$ plot is to be installed and marked with metal rods. Metal rods should be driven into the ground at each corner of the subplot as deep as possible to prevent them from being removed by animals. The tips of the metal rods should be painted to aid their visibility.

\subsection{Plot maintenance}

\subsubsection{General maintenance}

Tree markings and subplot markings must be checked periodically (every two years) and renewed if needed.

\subsubsection{Replacement of trees}

If a monitored tree dies or is cut due to management, it must be replaced. The nearest suitable tree to the dead one should be chosen considering that the distance requirement of $30 \mathrm{~m}$ to the nearest monitored tree is fulfilled. Otherwise a tree from the periphery (preferably in the outer circle) of the FGM plot is to be selected. The replacement tree is marked with the next available number higher than 50, i.e. 51, 52, 53, etc. to positively differentiate it from the original 50 selected trees. 
If the crown is damaged due to, for example, windbreak, ice or snow break, but continues to fructify, the tree is kept for monitoring. If the damage is too severe and fructification is not expected anymore, the monitored tree must be replaced. The cause of damage needs to be recorded, as the damage can affect the values recorded for field verifiers and background information.

\section{Recording of verifiers and background information}

On the monitoring plot, verifiers and background information are periodically recorded. Verifiers are used to monitor the population's genetic properties and its adaptation to environmental changes and/or management, while background information needs to be recorded to assist interpretation of the verifiers.

Higher levels of verifiers (standard, advanced) must also include recording on all the preceding levels (basic, standard). This is not necessary for recording of background information.

Table 2. List of verifiers and background information with short description and observation frequency to be recorded during field work at Abies spp. monitoring plots.

\begin{tabular}{|c|c|c|c|c|}
\hline & Name & Basic level & Standard level & Advanced level \\
\hline \multirow{5}{*}{ 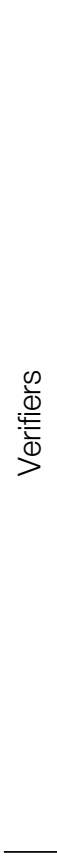 } & \multirow{2}{*}{$\begin{array}{l}\text { Mortality / } \\
\text { survival }\end{array}$} & $\begin{array}{l}\text { Adult trees: Counting of the } \\
\text { remaining marked trees every } \\
10 \text { years and after every extreme } \\
\text { weather event/disturbance }\end{array}$ & Same as basic level & Same as basic level \\
\hline & & Natural regeneration: / & $\begin{array}{l}\text { Counting of remaining seedlings } \\
\text { on the natural regeneration } \\
\text { subplots, twice per decade }\end{array}$ & Same as standard level \\
\hline & \multirow[b]{2}{*}{ Fructification } & Stand-level estimate, every year & $\begin{array}{c}\text { Individual tree level observation, } \\
\text { during two major flowering } \\
\text { events per decade, ideally } \\
\text { equally spaced * }\end{array}$ & $\begin{array}{c}\text { Individual tree level observation, } \\
\text { during two major flowering } \\
\text { events per decade, ideally } \\
\text { equally spaced * }\end{array}$ \\
\hline & & Stand-level estimate, every year & $\begin{array}{l}\text { Individual tree level observation, } \\
\text { the same year as the } \\
\text { assessment of the flowering at } \\
\text { the standard level (regardless of } \\
\text { the fructification intensity) * }\end{array}$ & $\begin{array}{l}\text { Counting of fruit, the same years } \\
\text { as the assessment of flowering } \\
\text { at the advanced level, regardless } \\
\text { of the fructification intensity * } \\
\text { Seeds are also collected for } \\
\text { laboratory analyses for every } \\
\text { assessed fructification event }\end{array}$ \\
\hline & $\begin{array}{l}\text { Natural } \\
\text { regeneration } \\
\text { abundance }\end{array}$ & Stand-level estimate, every year & $\begin{array}{c}\text { Counting of seedlings according } \\
\text { to the protocol in the } 1^{\text {st }} \text { and } \\
6^{\text {th }} \text { years after every assessed } \\
\text { fructification event }\end{array}$ & $\begin{array}{l}\text { Counting of seedlings according } \\
\text { to the protocol in the } 1^{\text {st }}, 6^{\text {th }} \text {, } \\
11^{\text {th }}, 16^{\text {th }} \text { years after every } \\
\text { assessed fructification event }\end{array}$ \\
\hline \multirow{4}{*}{ 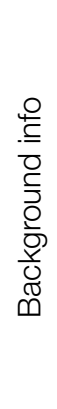 } & $\begin{array}{l}\text { DBH class } \\
\text { distribution }\end{array}$ & / & Measurement every 10 years & Same as standard level \\
\hline & $\begin{array}{l}\text { Height class } \\
\text { distribution }\end{array}$ & / & Measurement every 10 years & Same as standard level \\
\hline & Budburst & / & $\begin{array}{c}\text { Individual tree level observation } \\
\text { according to the protocol, } \\
\text { every } 5 \text { years }\end{array}$ & $\begin{array}{c}\text { Individual tree level observation } \\
\text { according to the protocol, } \\
\text { every year }\end{array}$ \\
\hline & $\begin{array}{c}\text { Flowering } \\
\text { synchronisation }\end{array}$ & / & / & $\begin{array}{l}\text { Individual tree level observation, } \\
\text { during each assessed major } \\
\text { flowering event }\end{array}$ \\
\hline
\end{tabular}

* Ideally at least one major fructification event should be assessed per decade. However, a major flowering event does not necessarily lead to a major fructification event. If no major fructification event follows the assessed flowering event, assessment of both flowering and fructification needs to be repeated during the next major flowering event, regardless of the time passed between successive major flowering events. Basic level observations are used to identify major flowering and fructification events. 


\subsection{Protocols for recording of verifiers}

\subsubsection{Mortality / survival}

Mortality describes the mortality of adult trees and natural regeneration. Its counterpart survival stands for trees that are still alive since the previous assessment. Survival is calculated as $1-$ Mortality.

\subsubsection{Adult trees: Basic, standard and advanced levels}

The verifier mortality of Abies spp. adult trees is estimated by counting the remaining alive marked trees every 10 years and after every extreme weather event/disturbance. Mortality is the difference between initial number of marked trees and the trees remaining alive of the original 50.

\subsubsection{Natural regeneration: Standard and advanced levels}

Mortality of natural regeneration is calculated from the verifier Natural regeneration abundance. Mortality is the difference between the initial number of NR plants and the plants remaining alive at the time of the next counting. For each round of assessment, the NR is counted first in the year of germination and then again after 5 years at the standard level, while at the advanced level the counting is also performed after 10 and 15 years. Assessment of NR abundance is carried out twice per decade, ideally approximately every five years.

\subsubsection{Flowering}

This verifier describes the the flowering intensity and the proportion of trees thus affected. It can usually be recorded in April to May in central Europe.

\subsubsection{Basic level}

This verifier is recorded every year at the stand level. Recording is carried out when flowering is in full progress. The estimate of average condition is provided after a walk throughout the monitoring plot. Two scores are given, one for flowering intensity, expressed as the average proportion of the crown flowering, and one for the proportion of flowering trees in the stand.

\begin{tabular}{llr} 
Code Flowering intensity at the stand level & Average proportion of the crown flowering (\%) \\
\hline 1 & No flowering: No or only occasional flowers appearing on trees & $0-10$ \\
\hline 2 & Weak flowering: Some flowers appearing on trees. & $>10-30$ \\
\hline 3 & Moderate flowering: Moderate number of flowers appearing on trees. & $>30-60$ \\
\hline 4 & Strong flowering: Abundant number of flowers on trees. & $>60-90$ \\
\hline 5 & Massive: Huge number of flowers on trees. & $>90$ \\
\hline
\end{tabular}

\begin{tabular}{lr} 
Code & Proportion of trees in the stand with the given flowering intensity stage (\%) \\
\hline 1 & $0-10$ \\
\hline 2 & $>10-30$ \\
\hline 3 & $>30-60$ \\
\hline 4 & $>60-90$ \\
\hline 5 & $>90$ \\
\hline
\end{tabular}




\subsubsection{Standard level}

This verifier is recorded during two major flowering events per decade, ideally equally spaced in time from one another. It is recorded at an individual tree level on all 50 monitored trees. A major flowering event is when at the basic level flowering intensity is strong or massive (code 4 or 5 ) and the proportion of trees with the given flowering intensity is above $60 \%$ (code 4 or 5). Recording is carried out when flowering is in full progress. One score is provided for each tree.

\begin{tabular}{|c|c|c|}
\hline Code & Description & Proportion of the crown flowering (\%) \\
\hline 1 & No flowering: No or only occasional flowering appearing on a tree. & $0-10$ \\
\hline 2 & Weak flowering: Some flowers appearing on a tree. & $>10-30$ \\
\hline 3 & Moderate flowering: Moderate number of flowers on a tree. & $>30-60$ \\
\hline 4 & Strong flowering: Abundant number of flowers on a tree. & $>60-90$ \\
\hline 5 & Massive: Huge number of flowers on a tree. & $>90$ \\
\hline
\end{tabular}

\subsubsection{Advanced level}

This verifier is recorded during two major flowering events per decade, ideally equally spaced in time from one another. It is recorded at an individual Abies spp. tree level on all 50 monitored trees. A major flowering event is when at the basic level flowering intensity is strong or massive (code 4 or 5) and the proportion of trees with the given flowering intensity is above $60 \%$ (code 4 or 5). On average, two visits to the plot are needed; the first one early enough to observe the early stages of flowering and the second one when flowering is in full progress.

Three scores are provided for each tree: female and male flowering stages [5], and the proportion of the crown flowering. Proportion of the crown flowering refers to the total amount of flowers (male + female) on the tree. For a graphical representation of flowering stages see Figure 4.

A major flowering event does not necessarily lead to a major fructification event. If no major fructification event follows the assessed flowering event, assessment of both flowering and fructification needs to be repeated the next major flowering event. Basic level observations are used to identify major flowering and fructification events.

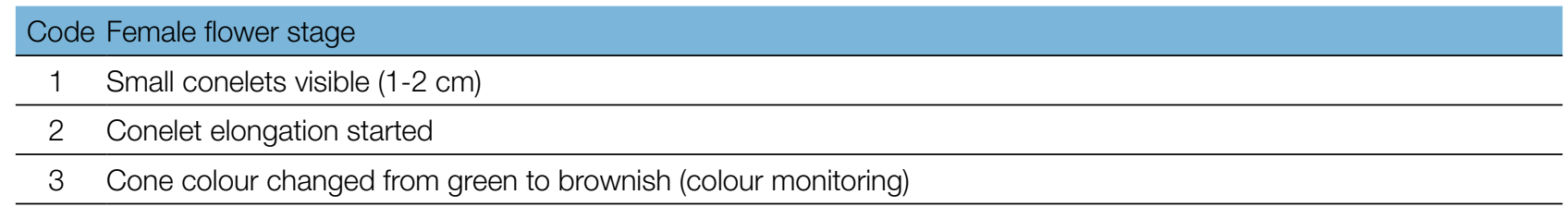

\begin{tabular}{ll}
\multicolumn{2}{l}{ Code Male conelet phenology } \\
\hline 1 & $\begin{array}{l}\text { Micro-sporophylles are starting to extend their size but are still closed and situated very close to the branch (colour - } \\
\text { green/brown/dark red/reddish brown) }\end{array}$ \\
\hline 2 & Pollen bags are extended/swollen, ripened - release of pollen (colour - yellow/dark red/brown/reddish brown) \\
\hline 3 & Release of pollen concluded, bags still hanging on the branch but empty (colour - brown/dark red/reddish brown) \\
\hline
\end{tabular}

\begin{tabular}{lr} 
Code & Proportion of the crown flowering (\%; male and female flowering together) \\
\hline 1 & $0-10$ \\
\hline 2 & $>10-30$ \\
\hline 3 & $>30-60$ \\
\hline 4 & $>60-90$ \\
\hline 5 & $>90$ \\
\hline
\end{tabular}

Background information on flowering synchronisation can be estimated from the scores for female and male flowering recorded by this verifier. 

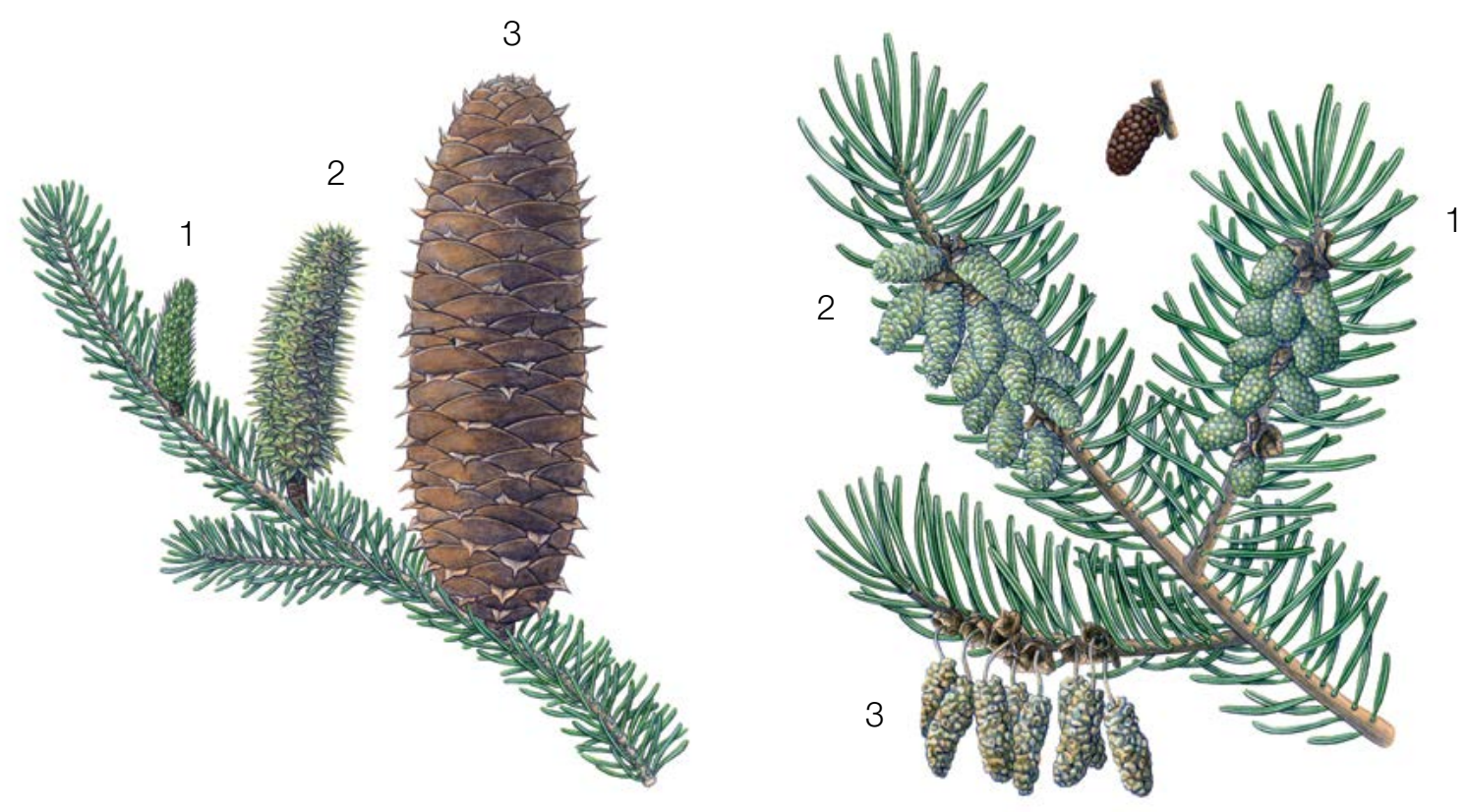

Figure 4: Picture guide for description of female (left) and male flowering (right) stages for the advanced level verifier Flowering.

\subsubsection{Fructification}

This verifier describes the presence of fructification and its abundance for Abies spp. Data for this verifier should be collected during fructification of Abies spp., which usually occurs in August/September in central Europe.

\subsubsection{Basic level}

This verifier is recorded every year at the stand level. The estimate of average condition is provided after a walk throughout the monitoring plot. Two scores are given, one for fructification intensity and one for the proportion of fructifying trees in the stand.

\begin{tabular}{llr}
\hline \multicolumn{2}{l}{ Code Fructification intensity at the stand level } & Average proportion of the crown bearing fruit (\%) \\
\hline 1 & No fructification: No or only occasional fruits appearing on trees & $0-10$ \\
\hline 2 & Weak fructification: Some fruits appearing on trees & $>10-30$ \\
\hline 3 & Moderate fructification: Moderate number of fruits appearing on trees & $>30-60$ \\
\hline 4 & Strong fructification: Abundant number of fruits appearing on trees & $>60-90$ \\
\hline 5 & Massive: Huge number of fruits appearing on trees & $>90$ \\
\hline & Proportion of trees in the stand with the given stage of Fructification intensity (\%) \\
\hline Code & $0-10$ \\
\hline 1 & & $>10-30$ \\
\hline 2 & & $>30-60$ \\
\hline 3 & & $>60-90$ \\
\hline 4 & & $>90$ \\
\hline 5 & & 0 \\
\hline
\end{tabular}




\subsubsection{Standard level}

This verifier is recorded during the same years as the assessment of the flowering at the standard level (regardless of the fructification intensity). It is recorded at an individual tree level on all 50 monitored trees. Recording is carried out before fruits start falling. One score is provided for each tree.

Ideally, one major fructification event should be captured following observations of major flowering events each decade. However, a major flowering event does not necessarily lead to a major fructification event. If no major fructification event follows the assessed flowering event, assessment of both flowering and fructification needs to be repeated during the next major flowering event, regardless of the time passed between successive major flowering events. Basic level observations are used to identify major fructification events. A major fructification event is when at the basic level fructification intensity is strong or massive (code 4 or 5 ) and the proportion of trees with the given fructification intensity is above $60 \%$ (code 4 or 5 ).

\begin{tabular}{|c|c|c|}
\hline Cod & Fructification intensity & Proportion of the crown fructifying (\%) \\
\hline 1 & No fructification: No or only occasional fruits appearing on a tree. & $0-10$ \\
\hline 2 & Weak fructification: Some fruits appearing on a tree. & $>10-30$ \\
\hline 3 & Moderate fructification: Moderate number of fruits appearing on a tree. & $>30-60$ \\
\hline 4 & Strong fructification: Abundant number of fruits appearing on a tree. & $>60-90$ \\
\hline 5 & Massive: Huge number of fruits appearing on a tree. & $>90$ \\
\hline
\end{tabular}

\subsubsection{Advanced level}

This verifier is recorded at an individual tree level on all 50 monitored trees during the same years as the assessment of flowering at the advanced level, regardless of the fructification intensity. Recording is carried out before fruits start falling. One score is provided for each tree. Simultaneously, seed is collected for seed and genetic analysis for the advanced level verifiers and background information.

Ideally, one major fructification event should be captured following observations of major flowering events each decade. However, a major flowering event does not necessarily lead to a major fructification event. If no major fructification event follows the assessed flowering event, assessment of both flowering and fructification needs to be repeated during the next major flowering event, regardless of the time passed between successive major flowering events. Basic level observations are used to identify major fructification events. A major fructification event is when at the basic level fructification intensity is strong or massive (code 4 or 5) and the proportion of trees with the given fructification intensity is above $60 \%$ (code 4 or 5 ).

The verifier is recorded by counting cones using binoculars. The average of three rounds of counting is reported. Each round of counting consists of the number of cones that the observer is able to count in 30 seconds. For all trees, the same part of the crown should be investigated. Once the observation part of the crown part is selected, the same one should be selected for every subsequent monitoring of this verifier. The upper third of the crown is preferred to the bottom and middle parts for counting.

Two values are recorded; the number of fruits and the part of the crown monitored.

$\underline{\text { Number of fruits counted in } 30 \text { seconds (average of } 3 \text { rounds) }}$

$$
\mathrm{x}
$$

\begin{tabular}{cr} 
Code & Part of the crown monitored \\
\hline 1 & Bottom \\
\hline 2 & Middle \\
\hline 3 & Top \\
\hline
\end{tabular}




\subsubsection{Natural regeneration abundance}

This verifier describes the presence and abundance of natural regeneration (NR) at the monitoring plot.

\subsubsection{Basic level}

This verifier is recorded at the stand level every year in the autumn. Expert opinion is used for estimation considering the situation over the whole monitoring plot. Two values should be recorded, one for new natural regeneration (current-year seedlings) and one for established regeneration (saplings that are older than one year). Since Abies spp. fructifies every three to five years, the establishment of new NR should be estimated next summer/autumn after mast year.

\begin{tabular}{l} 
Code Description: new regeneration (current-year seedlings) \\
\begin{tabular}{cc} 
1a & There is no or very little new natural regeneration on the monitoring plot \\
\hline $2 \mathrm{a}$ & New regeneration is present in sufficient quantity on the monitoring plot
\end{tabular} \\
\hline
\end{tabular}

Code Description: established natural regeneration (saplings)
\begin{tabular}{cc}
$\mathrm{1b}$ & There is no or very little established natural regeneration on the monitoring plot \\
\hline $\mathrm{2b}$ & Established regeneration is present in sufficient quantity on the monitoring plot
\end{tabular}

\subsubsection{Standard level}

Abies spp. seed dormancy lasts one winter, therefore, this verifier is recorded by counting of plants/seedlings starts in the $1^{\text {st }}$ autumn after the fructification event (the year of the fructification event is regarded as year 0 ) and $6^{\text {th }}$ autumn after the fructification event.

Counting of seedlings:

After the establishment of NR subplots all Abies seedlings present at each of the $20 \mathrm{NR}$ subplots must be counted. Any older Silver fir/King Boris fir saplings that are present on the NR subplot must not be included. During the next counting round, only saplings of the appropriate age must be counted - in the $6^{\text {th }}$ year, five-year old saplings.

\section{Number of seedlings counted on a subplot}

$\mathrm{X}$

Mortality/survival of natural regeneration is calculated from the values recorded for this verifier.

For subplot establishment see 6.2 Establishment of natural regeneration subplots.

\subsubsection{Advanced level}

Abies spp. seed dormancy lasts one winter, therefore this verifier is recorded by counting seedlings at each of the $20 \mathrm{NR}$ subplots in the $1^{\text {st }}$ autumn after the major fructification event (the year of the fructification event is regarded as year 0 ) and in $6^{\text {th }}, 11^{\text {th }}$, and $16^{\text {th }}$ autumns after the fructification event. The next round of monitoring of natural regeneration abundance (establishment of new 20 NR subplots and assessment of NR abundance) is carried out after the first fructification event at least five years after the previous major fructification event (see Table 3 for representation of the NR abundance assessment timeline). Assessment of NR abundance from one or two major fructification events is expected each monitoring interval. 
Table 3: Timeline of natural regeneration abundance (NR) assessment. In this example, the first major fructification event takes place in the second year of the monitoring decade, and the second assessed fructification event five years later, i.e. in the seventh year of the monitoring. Because major fructification events occur every three to five years for Abies spp., the interval between any two consecutive major fructification events can vary accordingly. Twenty new NR subplots are established after each assessed fructification event. Monitoring of NR abundance on each set of 20 NR subplots is carried out every five years. The fructification events corresponding to the assessed NR and timelines of the assessment activities are shaded in the same colour. After the final round of counting of seedlings, monitoring of NR abundance on the respective set of NR subplots is stopped and the respective NR subplots disestablished. S standard level; A - advanced level.

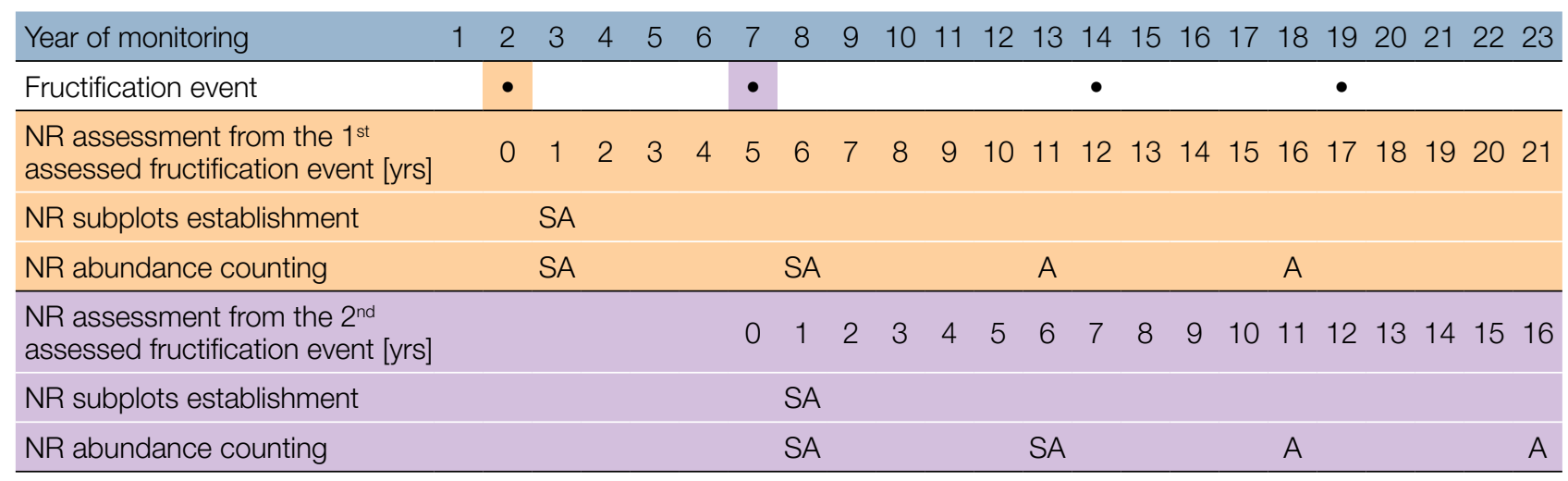

Mortality/survival of natural regeneration is calculated from the values recorded for this verifier.

For subplot establishment see 6.2 Establishment of natural regeneration subplots and for counting 7.1.4.2 Standard level.

\subsection{Protocols for recording of background information}

\subsubsection{DBH class distribution}

\subsubsection{Standard and advanced levels}

$\mathrm{DBH}$ is recorded on an individual tree level for all 50 monitored trees every 10 years. DBH is the trunk diameter at $1.30 \mathrm{~m}$, i.e. approximately at an adult's breast height. If a tree has more than one trunk, measure all of them and record the average (but try to avoid trees with many small trunks). Note that the tree is a multi-trunk one in the notes. If the tree is leaning, measure DBH perpendicular to the tree trunk. DBH can be measured in two ways:

1) using a calliper, in which cases you would need to measure two perpendicular diameters and take the average,

2) measure the circumference of the tree and compute the diameter from that value (i.e. divide by $\pi, \sim 3.14$ or use a pi-meter).

The DBH is recorded in cm. The same method must be applied for every subsequent measurement.

\subsubsection{Height class distribution}

\subsubsection{Standard and advanced levels}

Height is recorded on an individual tree level on all 50 monitored trees every 10 years. Height is measured from the ground to the tallest part of the crown, ideally using a clinometer or hypsometer (e.g. vertex). Height is recorded in meters, rounded to the closest full meter. If the crown is damaged, this must be recorded as well as the stipulated reason in the notes. 


\subsubsection{Budburst}

Budburst describes the process of budbursting (flushing). In silver fir, budbursting starts a bit later than flowering. Recording of this parameter is only carried out at the standard and advanced levels. Data of this background information should be collected in April - May in central Europe, until all monitored trees have reached fully developed needles.

\subsubsection{Standard level}

At standard level, budburst is recorded on an individual tree level on all 50 monitored trees every five years. We are looking for the initiation of budbursting (stage 2) and the end of budbursting (stage 4). The observations cease when all the trees have reached stage 4. Usually, six visits will be needed. For each tree, two estimates are given: budbursting stage and proportion of the crown budbursting. For a graphical representation of budbursting stages, see Figure 5.

\begin{tabular}{|c|c|}
\hline \multicolumn{2}{|c|}{ Code Stage of budbursting (Simplified stages [5]) } \\
\hline 1 & Buds enclosed by needles and not visible unless the needles are parted \\
\hline 2 & Buds elongation, bud scales and membrane visibly abscised \\
\hline 3 & Elongating brush of soft needles has emerged \\
\hline 4 & Soft shoots with developed needles \\
\hline
\end{tabular}

\begin{tabular}{lr} 
Code & Proportion of the crown with a given stage of budbursting (\%) \\
\hline 1 & $>0-33$ \\
\hline 2 & $>33-66$ \\
\hline 3 & $>66-99$ \\
\hline 4 & 100 \\
\hline
\end{tabular}

\subsubsection{Advanced level}

At advanced level, budburst is recorded on an individual tree level on all 50 monitored trees every year. For the values (stage of budbursting and the proportion of crown affected) see 7.2.3.1 Standard level.

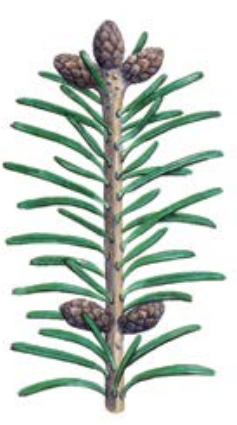

1

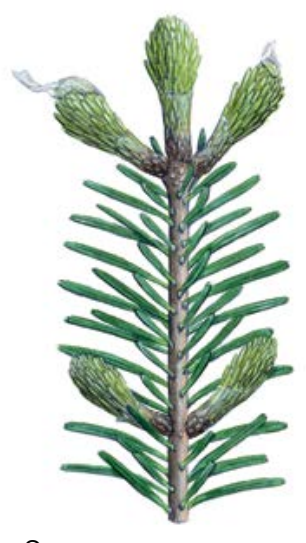

2

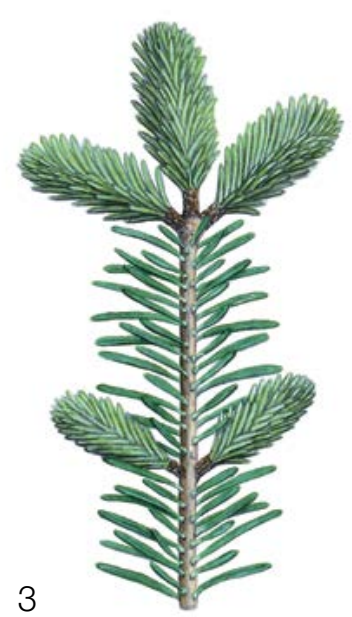

4

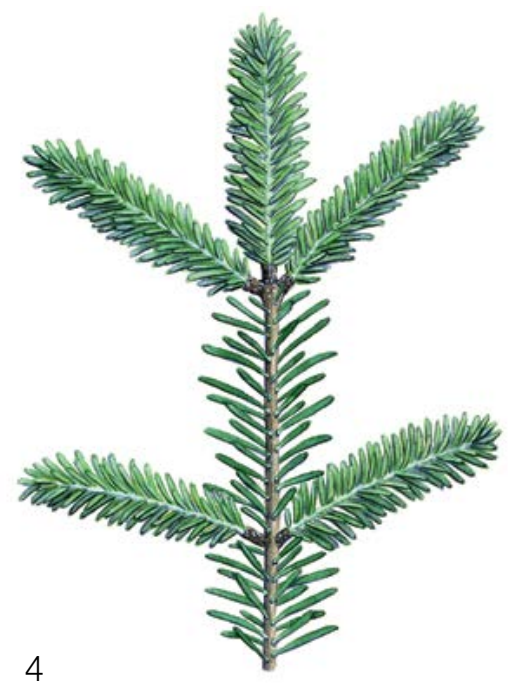

Figure 5: Picture guide for description of budburst (flushing) for the basic, standard and advanced levels, background information Budburst. 


\subsubsection{Flowering synchronisation}

Flowering synchronisation is monitored only at the advanced level, and is based on the data collected for the flowering verifier. It is used to determine whether male and female flowering time occur simultaneously within the monitored stand.

\subsubsection{Advanced level}

Flowering synchronisation is recorded on an individual tree level on all 50 monitored trees, during each assessed major flowering event, in the same years as when seed is collected (the same as Flowering at the advanced level).

\section{For plot establishment use form 'FGM Plot description' \\ For verifiers recording use 'Form for recording field level verifiers within FGM' \\ For background information recording use 'Form for recording field level background information within FGM'}

\section{References}

1. Alizoti PG, Fady B, Prada MA, Vendramin GG (2011) EUFORGEN Technical guidelines for genetic conservation and use of Mediterranean firs (Abies spp). Bioversity International, Rome

2. Aravanopoulos FA, Tollefsrud MM, Graudal L, Koskela J, Kätzel R, Soto A, Nagy L, Pilipovic A, Zhelev P, Božic G and Bozzano M (2015) Development of genetic monitoring methods for genetic conservation units of forest trees in Europe. European Forest Genetic Resources Programme (EUFORGEN), Bioversity International, Rome

3. Carkin RE, Franklin JF, Booth J, Smith CE (1978) Seeding habits of upper-slope tree species: 4. Seed flight of noble fir and Pacific silver fir. Res. Note PNW-312. Corvallis, OR: USDA Forest Service, Pacific Northwest Forest and Range Experiment Station, pp 1-10

4. Caudullo G, Tinner W (2016) Abies - Circum-Mediterranean firs in Europe: distribution, habitat, usage and threats. In: San-Miguel-Ayan J, de Rigo D, Caudullo G, Houston Durran T, Mauri A (ed) European Atlas of Forest Tree Species. Publ. Off. EU, Luxembourg, pp e015be7+

5. Ducci F, De Cuyper B, Paques LE, Proietti R, Wolf H (2012) Reference protocols for assessment of trait and reference genotypes to be used as standards in international research projects. CRA SEL - Arezzo, Italy

6. Eis S (1970) Reproduction and reproductive irregularities of Abies lasiocarpa and A. grandis. Can J Botany 48:141-143. https://doi.org/10.1139/b70-018

7. Farjon A (2010) A Handbook of the World's Conifers. Brill Academic Publishers, Leiden, pp 1-1111. https://doi. org/10.1163/9789047430629

8. Fowells HA, Schubert GH (1956) Seed crops of forest trees in the pine region of California. Tech. Bull. 1150. USDA Forest Service, Washington, DC, pp 1-48

9. Franklin JF (1982) Ecology of noble fir. In: Oliver CD, Kenady RM, eds. Proceedings, Symposium on Biology and Management of True Fir in the Pacific Northwest; 1981; Seattle/Tacoma, WA. Contrib. 45. University of Washington Institute of Natural Resources, Seattle, pp 59-69

10. Franklin JF, Ritchie GA (1970) Phenology of cone and shoot development of noble fir and some associated true firs. Forest Sci 16:356-364

11. FUTMON project (2009 FUT-MON FIELD PROTOCOL PHENOLOGY (D1). http://www.futmon.org/futmon-fieldprotocols.html. Accessed 12 September 2016

12. Houle G (1992) The reproductive ecology of Abies balsamea, Acer saccharum and Betula alleghaniensis in the Tantare Ecological Reserve, Quebec. J Ecol 80:611-623

13. Houle G (1995) Seed dispersal and seedling recruitment: the missing link(s). Ecoscience 2:238-244. https://doi.org/10. 1080/11956860.1995.11682289

14. Jacobs BF, Werth CR, Guttman, SI (1984) Genetic relationships in Abies (fir) of eastern United States: an electrophoretic study. Can J Bot 62(4):609-616 
15. Löffler J (1988) Do air pollutants threaten the regeneration potential of West German forests? Allg Forstzts 33:916-918

16. Mauri A, de Rigo D, Caudullo G (2016) Abies alba in Europe: distribution, habitat, usage and threats. In: San-MiguelAyan J, de Rigo D, Caudullo G, Houston Durrant T, Mauri A (ed), European Atlas of Forest Tree Species. Publ. Off. EU, Luxembourg, pp e01493b+. https://doi.org/10.2788/4251

17. Nekrasova P (1974) Losses of cone and seed crops in coniferous species. Lesovedenie 4:3-8

18. Owens JN, Molder M (1974) Bud development in western hemlock: 2. Initiation and early development of pollen cones and seed cones. Can J Bot 52:283-294. https://doi.org/10.1139/b74-037

19. Owens JN, Molder M (1977) Vegetative bud development and cone differentiation in Abies amabilis. Can J Bot 55:992-1008. https://doi.org/10.1139/b77-117

20. Owens JN, Morris SJ (1998) Factors affecting seed production in amabilis fir (Abies amabilis (L.) Mill.). Can J For Res 28:1146-1163. https://doi.org/10.1139/x98-089

21. Pintarić K (1991) Uzgajanje šuma II dio, Tehnika obnove i njege sastojina. Šumarski fakultet u Sarajevu, Sarajevo, pp $1-246$

22. Prpić B, Seletković Z (2001) Ekološka konstitucija obične jele. In: Obična jela u Hrvatskoj, Zagreb, pp 255-269

23. Shea PJ (1989a) Interactions among phytophagous insect species colonizing cones of white fir (Abies concolor). Oecologia 81:104-110. https://doi.org/10.1007/BF00377018

24. Shea PJ (1989b) Phytophagous insect complex associated with cones of white fir, Abies concolor (Gord. and Glend.) Lindl., and its impact on seed production. Can Entomol 121:699-708. doi:10.4039/Ent121699-8

25. Sidhu SS, Staniforth RJ (1986) Effects of atmospheric fluorides on foliage, and cone and seed production in balsam fir, black spruce, and larch. Can J Bot 64:923-931. https://doi.org/10.1139/b86-124

26. Vidaković M (1982) Četinjače - morfologija i varijabilnost, JAZU i Sveuč. nakl. Liber, Zagreb, pp 1-710

27. Vidaković M (1993) Četinjače - morfologija i varijabilnost. Grafički zavod Hrvatska i Hrvatske šume, p.o. Zagreb, Zagreb, pp 1-741

28. Wolf H (2003) EUFORGEN Technical Guidelines for genetic conservation and use for silver fir (Abies alba Mill.). International Plant Genetic Resources Institute, Rome

29. Wolfenbarger DO (1946) Dispersion of small organisms: Distance dispersion rates of bacteria, spores, seeds, pollen and insects: incidence rates of diseases and injuries. Am Midl Nat 35:1-152

The following resources were consulted for the currently accepted (December 2020) scientific names of the species covered or mentioned in this document:

a. CABI (2020) Invasive Species Compendium. CAB International, Wallingford, UK. www.cabi.org/isc. Accessed 15 December 2020

b. EPPO (2020) EPPO Global Database (available online). https://gd.eppo.int. Accessed 15 December 2020

c. GBIF (2020) Global Biodiversity Information Facility. https://www.gbif.org Accessed 15 December 2020

d. IPNI (2020) International Plant Names Index. The Royal Botanic Gardens, Kew, Harvard University Herbaria \& Libraries \& Australian National Botanic Gardens. http://www.ipni.org, Accessed 10 December 2020

e. National Center for Biotechnology Information (NCBI) (1998) National Library of Medicine (US), National Center for Biotechnology Information, Bethesda (MD). https://www.ncbi.nlm.nih.gov/. Accessed 15 December 2020

f. The Plant List (2013) Version 1.1. http://www.theplantlist.org/. Accessed 12 December 2020

g. Tropicos.org (2020) Missouri Botanical Garden. http://www.tropicos.org. Accessed 15 December 2020

h. WFO (2020) World Flora Online. http://www.worldfloraonline.org. Accessed 15 December 2020 


\section{Guidelines for genetic monitoring of}

\subsubsection{European beech (Fagus sylvatica L.)}

Marjana WESTERGREN ${ }^{1}$, Darius KAVALIAUSKAS², Paraskevi ALIZOTI', Marko BAJC 1 , Filippos A. ARAVANOPOULOS ${ }^{3}$, Gregor BOŽIČ ${ }^{1}$, Rok DAMJANIĆ ${ }^{1}$, Natalija DOVČ', Domen FINŽGAR ${ }^{1,4}$, Barbara FUSSI², Fotios KIOURTSIS ${ }^{5}$, Hojka KRAIGHER ${ }^{1}$

Botanical illustrations by Marija PRELOG

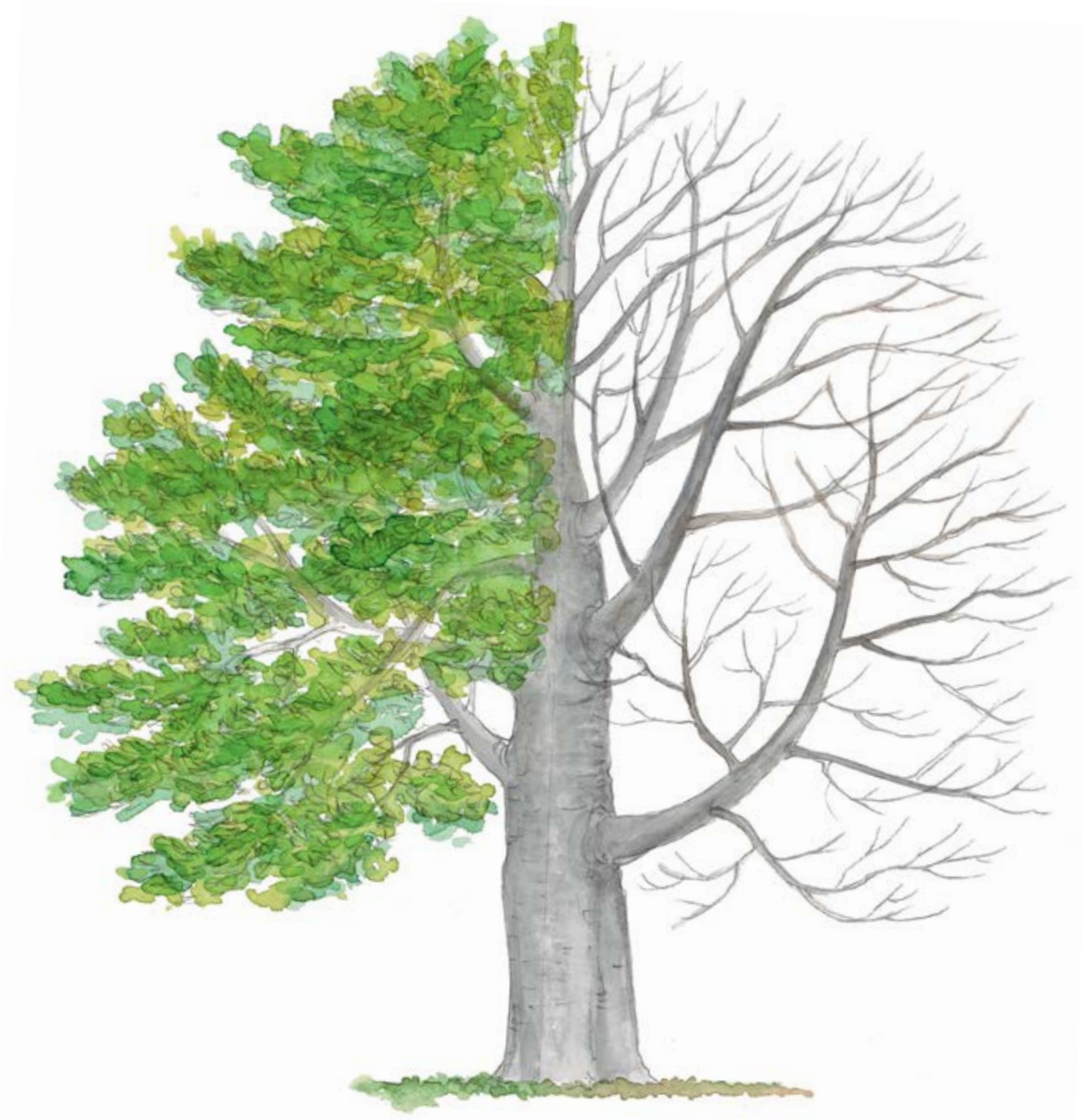

Citation: Westergren et al. (2020) Guidelines for genetic monitoring of European beech (Fagus sylvatica L.). In: Bajc et al. (eds) Manual for Forest Genetic Monitoring. Slovenian Forestry Institute: Silva Slovenica Publishing Centre, Ljubljana, pp 179-194. http://dx.doi.org/10.20315/SFS.167

Affiliations:

1. Slovenian Forestry Institute (GIS), Slovenia

2. Bavarian Office for Forest Genetics (AWG), Germany

3. Aristotle University of Thessaloniki (AUTh), Greece

4. Institute of Evolutionary Biology, University of Edinburgh, UK

5. Decentralized Administration of Macedonia \& Thrace,

General Directorate of Forests \& Rural Affairs, Greece 


\section{Executive summary}

European beech (Fagus sylvatica L.) is a monoecious, stand forming deciduous tree species present throughout most of Europe. This very competitive and shade tolerant species can naturally regenerate in continuous cover silvicultural systems, and is able to conserve the productive capacity of the soil better than many other species. With its high ecological importance and strong wood, this species is a good candidate for genetic monitoring.

These guidelines briefly describe the European beech, its reproduction, environment and threats. They provide guidance on establishing a genetic monitoring plot and recording all field level verifiers.
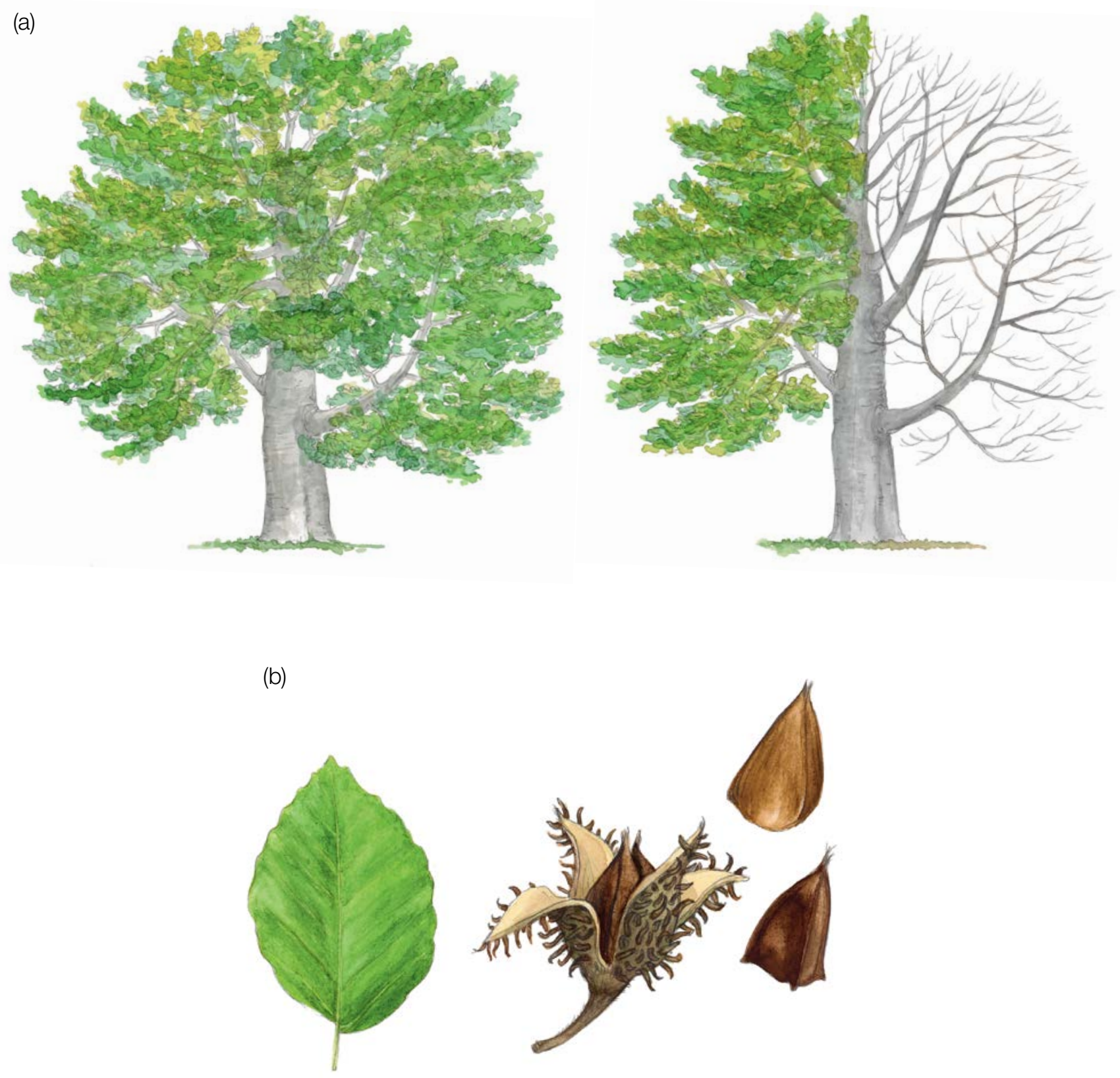

Figure 1: (a) European beech (Fagus sylvatica L.) habitus; (b) a leaf and fruit of the European beech. 


\section{Species description}

The European beech (Figure 1a) is a shade tolerant, large deciduous tree reaching $30-40 \mathrm{~m}$, in some locations up to $50 \mathrm{~m}$ [1]. It has a long-life span, up to 250 to 300 years, although it is typically harvested at 80 to 120 years $[1,2]$. In contrast to many other tree species, it maintains a high growth rate into maturity [2]. The bark is thin, smooth, silver-grey and very characteristic of beech [1, 2]. Light green ovoid leaves (Figure 1b) with silky hairs turn to shiny dark green in the late spring [2]. They have six or seven parallel veins on each side of the main one. They have no lobes or peaks and have a short stalk. In the winter, beech is easily identifiable by sharply pointed long and slender buds not pressed against the twigs [4].

Where sympatric with Fagus orientalis Lipsky, hybridisation may occur between the two species [1].

\section{Reproduction}

Wind pollinated beech is monoecious [1, 2]; separate male and female flowers are borne on the same branches emerging from the same bud. The male flowers are borne in small catkins. It starts reproducing very late, in forest stands when it is $40-50$ years old. A full mast year normally occurs every 5 to 8 years, sometimes in larger intervals, usually following hot summers of the previous year [1, 3].

Start of budbursting (flushing) varies from population to population and from year to year; budbursting that occurs from the end of March to May in central Europe is closely followed by flowering from April to May. Once the female flowers have been pollinated by wind, they develop into clearly visible fruits; nuts are sharply tri-angled (Figure 1b) and are borne singly or in pairs in soft-spined cupules $[1,2,3]$. They ripen and fall off the tree in September to November [3]. Beech seed has strong dormancy [3].

European beech exhibits properties of a climax species. Dispersal and natural regeneration are efficient, and beech is very competitive, especially in shady conditions [1].

\section{Environment}

European beech grows throughout central and western Europe, reaching southern Scandinavia in the north and Sicily in the south [1, 2]. Because it requires a humid atmosphere with precipitation well distributed throughout the year, its distribution is limited by high summer temperatures, drought and low moisture availability, as well as continentality in north-western Europe [1]. It tolerates winter cold but is sensitive to late spring frosts, which limits its distribution in the northern boreal regions [1]. It thrives in moderately fertile soils, calcified or lightly acidic, but does not like waterlogged or compacted soils [1]. It is a stand forming tree species [2].

\section{Threats}

European beech is a hardy species. Still, spring frosts often damage young trees or flowers appearing at the same time as leaves. Old trees may get a 'red heart' which reduces stability and timber value. Mikiola fagi Hartig, gall midge can kill young beech trees and reduce increment in heavily attacked trees. Beech is also among the susceptible hosts of Phytophthora ramorum Werres, De Cock \& Man, a quarantine fungus. Anoplophora chinensis Forster, the citrus long-horned beetle and Anoplophora glabripennis Motschulsky, the Asian long-horned beetle, both originating from Asia, are an emerging threat for beech [5].

\section{Plot establishment and maintenance}

European beech is a stand forming tree species which can form pure or mixed forest stands with silver fir, Norway spruce and other tree species [1]. 
A forest genetic monitoring plot consists of 50 reproducing trees with a Diameter at breast height (DBH) of over $15 \mathrm{~cm}$ and the minimum distance of $30 \mathrm{~m}$ between any two trees. If a tree is flowering, it is regarded as a reproducing tree. $\mathrm{DBH}$ and social class can be used as a proxy to identify a reproducing tree if the plot is being established outside of the flowering season, relying on the expertise of the local forester. During plot installation, trees should be labelled and coordinates of all trees taken. At the same time $\mathrm{DBH}$ can be measured and samples for DNA extraction taken.

Equipment needed:

- a device for distance measurement (a pair of range-finding binoculars is recommended),

- a compass,

- a paint and a brush or spray for marking trees,

- a tree calliper for DBH measurements, and

- a GPS device that is precise enough and allows saving trees' coordinates.

\subsubsection{Plot establishment}

\subsubsection{Selection of the centre of the plot}

The general procedure for random plot site selection consists of the following steps (Figure 2a):

- Random selection of a point (green dot) on a map along the forest road or path, which runs along the stand,

- Drawing a line that is approximately perpendicular to the road from the randomly selected point on a road,

- Random selection of one point on the line (red dot) - this point represents the centre of the forest genetic monitoring plot.

The minimum distance between the selected central point and stand border is approximately $150 \mathrm{~m}$. If the selected central point doesn't meet this demand, a new point must be selected following the protocol described above.

(a)

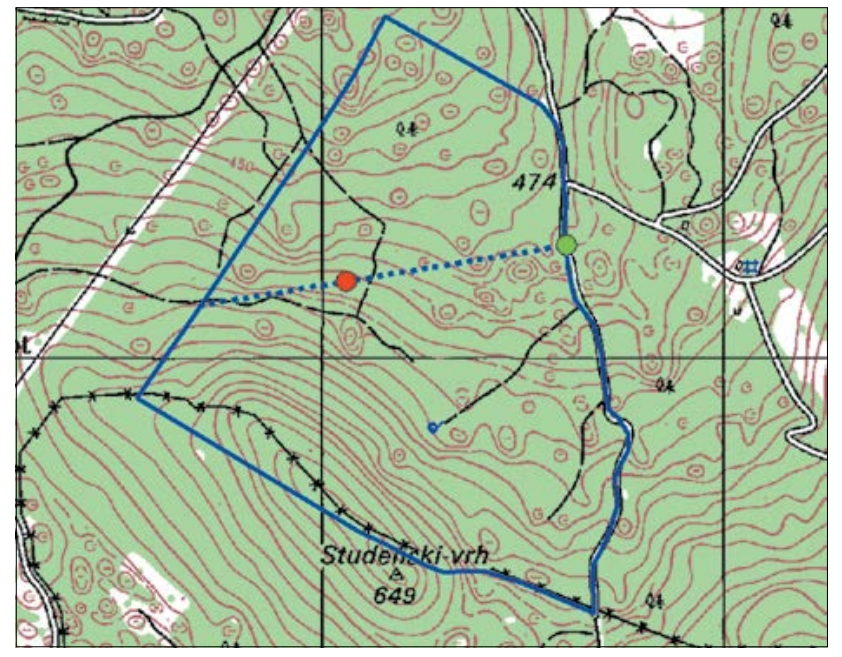

(b)

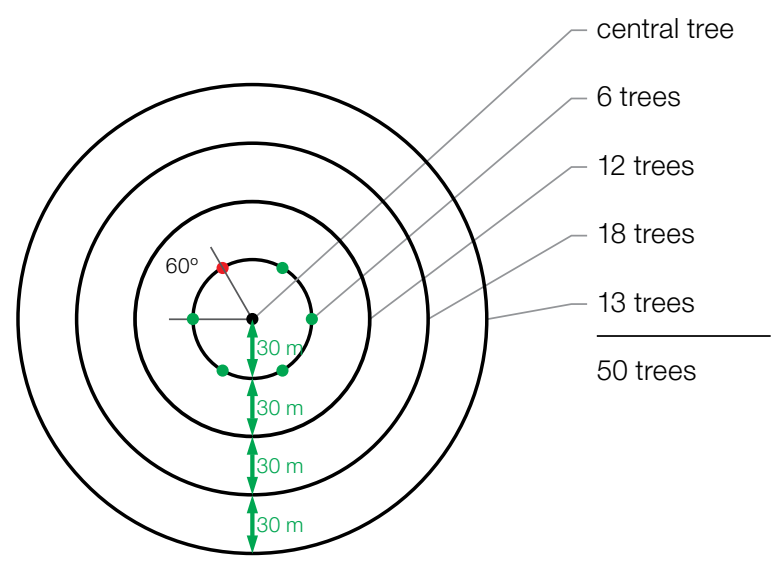

Figure 2: Random selection of the centre of the forest genetic monitoring plot (a); Selection of trees in concentric circles around previously selected central tree with an increasing radius of $30 \mathrm{~m}$ (b).

Instead of the procedure described above, tools for creating random points in GIS software can also be used.

The selected point's coordinate should be saved into a GPS device that will be used in the field. 


\subsubsection{Plot installation in the field}

In the field, the closest reproducing tree to the saved GPS coordinate becomes the centre of the monitoring plot and is marked with number 1 .

Other trees are selected in concentric circles around the central tree with an increasing radius of $30 \mathrm{~m}$ (Figure 2b). The first tree in each circle should be selected randomly, which can be done in different ways: by using a random azimuth (Table 1) observed from the central tree, by following the direction of the second hand on an analogue watch or any other approach that allows for objective selection. The remaining trees in each circle are selected by an appropriately enlarged azimuth to assure a minimum distance of $30 \mathrm{~m}$ between any two trees:

- $+60^{\circ}$ for the first circle,

- $+30^{\circ}$ for the second circle,

$+20^{\circ}$ for the third circle,

- $+15^{\circ}$ for the fourth circle.

If it is not possible to find six, 12 and 18 trees in the inner three circles (Figure 2b), additional trees are selected in the outermost circle.

Table 1: Randomly generated azimuths that can be used for selection of the first tree in each circle.

\begin{tabular}{rrrrrrrrrr}
108 & 15 & 186 & 35 & 178 & 29 & 305 & 351 & 44 & 150 \\
\hline 232 & 23 & 160 & 141 & 112 & 292 & 216 & 83 & 245 & 214 \\
\hline 63 & 65 & 345 & 234 & 95 & 78 & 279 & 323 & 40 & 236 \\
\hline 201 & 313 & 275 & 144 & 182 & 68 & 268 & 289 & 185 & 92 \\
\hline 356 & 177 & 93 & 1 & 145 & 198 & 287 & 251 & 224 & 142 \\
\hline
\end{tabular}

\subsubsection{Labelling of trees}

Each selected tree must be marked with a corresponding number and preferably a band painted around the trunk to aid the visibility of the trees from all directions. Mark the central tree (number 1) with two or more bands to differentiate it from other trees (Figure 3a). It is recommended to paint the number on the side of the tree that is pointing away from the central tree, as this helps in locating the central tree, particularly from the outer rings of the plot (Figure 3b).
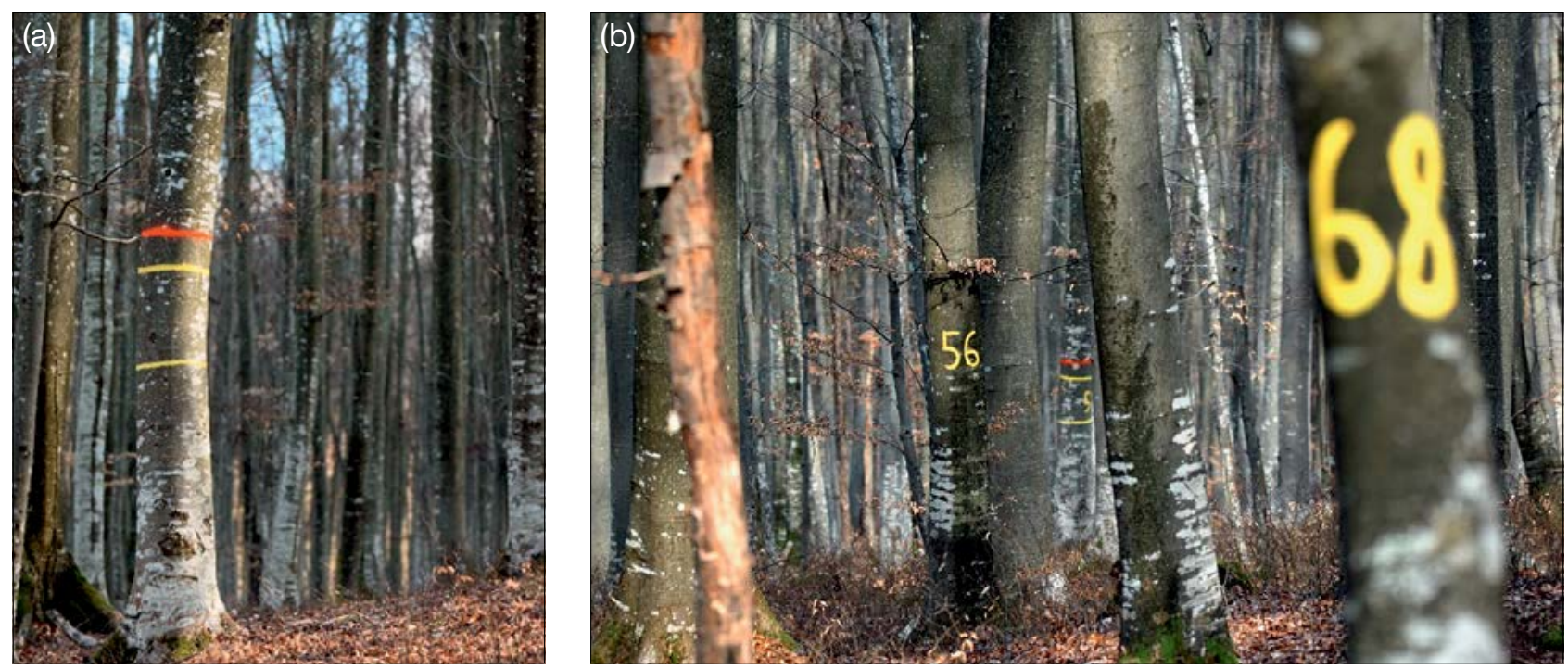

Figure 3: a) The central tree on the genetic monitoring plot is marked with multiple bands to differentiate it from other trees; b) numbers are painted on selected trees so that they point away from the central tree. 


\subsection{Establishment of natural regeneration subplots}

The establishment of natural regeneration (NR) subplots should be carried out during germination after a strong or massive fructification event.

Natural regeneration centres from the last mast year should be surveyed in the field and their locations logged (GPS coordinates, number of the tree which is next to an NR centre). From all logged regeneration centres, 20 should be chosen randomly for plot installation. If 20 or fewer natural regeneration centres are present, all should be used.

Inside each selected natural regeneration centre a $1 \mathrm{~m}^{2}$ plot is to be installed and marked with metal rods. Metal rods should be driven into the ground at each corner of the subplot as deep as possible to prevent them from being removed by animals. Tips of the metal rods should be painted to aid their visibility.

\subsection{Plot maintenance}

\subsubsection{General maintenance}

Tree markings and subplot markings must be checked periodically (every two years) and repaired if needed.

\subsubsection{Replacement of trees}

If a monitored tree dies or is cut due to management, it must be replaced. The nearest suitable tree to the dead one should be chosen considering that the distance requirement of $30 \mathrm{~m}$ to the nearest monitored tree is fulfilled. Otherwise a tree from the periphery (preferably in the outer circle) of the FGM plot is to be selected. The replacement tree is marked with the next available number higher than 50, i.e. 51, 52, 53, etc. to positively differentiate it from the original 50 selected trees.

If the crown is damaged due to, for example, wing break, ice or snow break but continues to fructify, the tree is kept for monitoring. If the damage is too severe and fructification is not expected anymore, the monitored tree must be replaced. The cause of damage needs to be recorded, as the damage can affect the values recorded for field verifiers and background information.

\section{Recording of verifiers and background information}

Verifiers and background information are periodically recorded on the monitoring plot. Verifiers are used to monitor the population's genetic properties and its adaptation to environmental changes and/or management, while background information is recorded to assist interpretation of the verifiers.

Higher levels of verifiers (standard, advanced) must also include recording on all the preceding levels (basic, standard). This is not necessary for recording of background information. 
Table 2: List of verifiers and background information with a short description and observation frequency to be recorded during fieldwork at the beech monitoring plots.

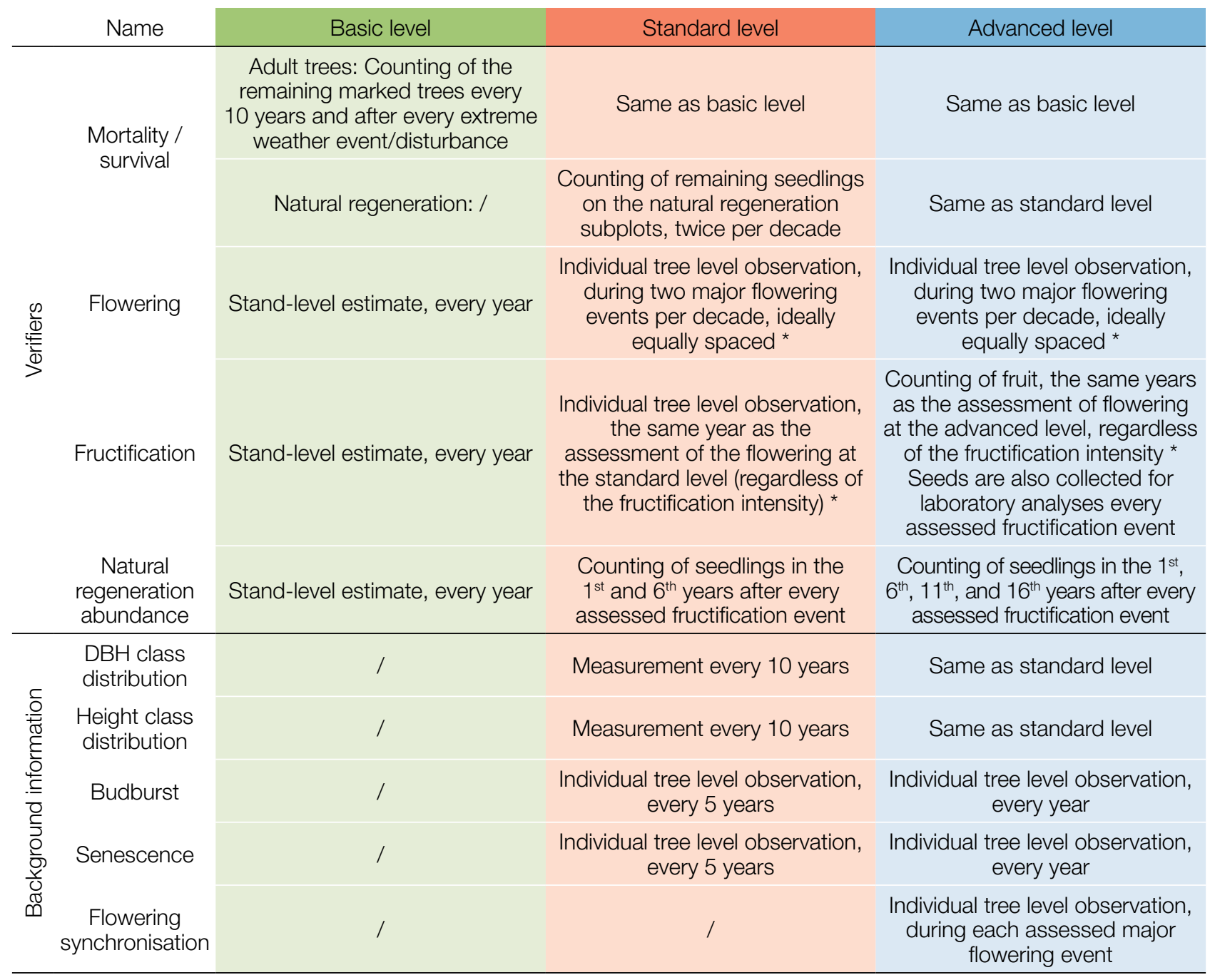

* Ideally at least one major fructification event should be assessed per decade. However, a major flowering event does not necessarily lead to a major fructification event. If no major fructification event follows the assessed flowering event, assessment of both flowering and fructification needs to be repeated during the next major flowering event, regardless of the time passed between successive major flowering events. Basic level observations are used to identify major flowering and fructification events.

\subsection{Protocols for recording of verifiers}

\subsubsection{Mortality / survival}

Mortality describes the mortality of adult trees and natural regeneration. Its counterpart survival stands for trees that are still alive since the previous assessment. Survival is calculated as 1 - Mortality.

\subsubsection{Adult trees: Basic, standard and advanced level}

Verifier for mortality of adult trees. It is estimated by counting the remaining alive marked trees every 10 years and after every extreme weather event/disturbance. Mortality is the difference between the initial number of marked trees and the trees remaining alive of the original 50.

\subsubsection{Natural regeneration: Standard and advanced level}

Mortality of natural regeneration is calculated from the verifier Natural regeneration abundance. Mortality is the difference between the initial number of NR plants and the plants remaining alive at the time of the next counting. 
For each round of assessment, the NR is counted first in the year of germination and then again after 5 years at the standard level, while at the advanced level the counting is also performed after 10 and 15 years. Assessment of NR abundance is carried out twice per decade, ideally approximately every five years.

\subsubsection{Flowering}

This verifier describes the flowering intensity and the proportion of trees thus affected. It can be recorded in April to May in central Europe.

\subsubsection{Basic level}

This verifier is recorded every year at the stand level. Recording is carried out when flowering is in full progress. The estimate of average condition is provided after a walk throughout the monitoring plot. Two scores are given, one for flowering intensity, expressed as the average proportion of the crown flowering, and one for the proportion of flowering trees in the stand.

\begin{tabular}{|c|c|c|}
\hline Cod & Flowering intensity at the stand level & Average proportion of crown flowering (\%) \\
\hline 1 & No flowering: No or only occasional flowers appearing on trees & $0-10$ \\
\hline 2 & Weak flowering: Some flowers appearing on trees. & $>10-30$ \\
\hline 3 & Moderate flowering: Moderate number of flowers appearing on trees. & $>30-60$ \\
\hline 4 & Strong flowering: Abundant number of flowers on trees. & $>60-90$ \\
\hline 5 & Massive: Huge number of flowers on trees. & $>90$ \\
\hline
\end{tabular}

\begin{tabular}{lr} 
Code & Proportion of trees in the stand with the given flowering intensity stage (\%) \\
\hline 1 & $0-10$ \\
\hline 2 & $>10-30$ \\
\hline 3 & $>30-60$ \\
\hline 4 & $>60-90$ \\
\hline 5 & $>90$ \\
\hline
\end{tabular}

\subsubsection{Standard level}

This verifier is recorded during two major flowering events per decade, ideally equally spaced in time from one another. It is recorded at an individual tree level on all 50 monitored trees. A major flowering event is when at the basic level flowering intensity is strong or massive (code 4 or 5 ) and the proportion of trees with the given flowering intensity is above $60 \%$ (code 4 or 5 ). Recording is carried out when flowering is in full progress. One score is provided for each tree.

\begin{tabular}{clc} 
Code & Description & Proportion of the crown flowering (\%) \\
\hline 1 & No flowering: No or only occasional flowering appearing on a tree. & $0-10$ \\
\hline 2 & Weak flowering: Some flowers appearing on a tree. & $>10-30$ \\
\hline 3 & Moderate flowering: Moderate number of flowers on a tree. & $>30-60$ \\
\hline 4 & Strong flowering: Abundant number of flowers on a tree. & $>60-90$ \\
\hline 5 & Massive: Huge number of flowers on a tree. & $>90$ \\
\hline
\end{tabular}

\subsubsection{Advanced level}

This verifier is recorded during two major flowering events per decade, ideally equally spaced in time from one another. It is recorded at an individual tree level on all 50 monitored trees. A major flowering event is when at 
the basic level flowering intensity is strong or massive (code 4 or 5 ) and the proportion of trees with the given flowering intensity is above $60 \%$ (code 4 or 5). On average, two visits to the plot are needed; the first one early enough to observe the early stages of flowering and the second one when flowering is in full progress.

Three scores are provided for each tree: female flowering stage, male flowering stage and the proportion of the crown flowering. The proportion of the crown flowering refers to the total number of flowers (male + female) on the tree. For a graphical representation of flowering stages, see Figure 4.

\begin{tabular}{ll} 
Code & Female flowering stage \\
\hline 1 & Female flower fully developed \\
\hline 2 & Formation of fruit or nuts fully formed but nuts shells not yet open \\
\hline
\end{tabular}

\begin{tabular}{ll}
\multicolumn{2}{l}{ Code } \\
\hline 1 & Elongated flowering stage \\
\hline 2 & Anthers releasing pollen (yellow) \\
\hline 3 & Empty anthers (pollen released) (brown) \\
\hline
\end{tabular}

\begin{tabular}{lr} 
Code & Proportion of the crown flowering (\%; male and female flowering together) \\
\hline 1 & $0-10$ \\
\hline 2 & $>10-30$ \\
\hline 3 & $>30-60$ \\
\hline 4 & $>60-90$ \\
\hline 5 & $>90$ \\
\hline
\end{tabular}

The background information Flowering Synchronisation can be estimated from the scores for female and male flowering recorded by this verifier.

(a)

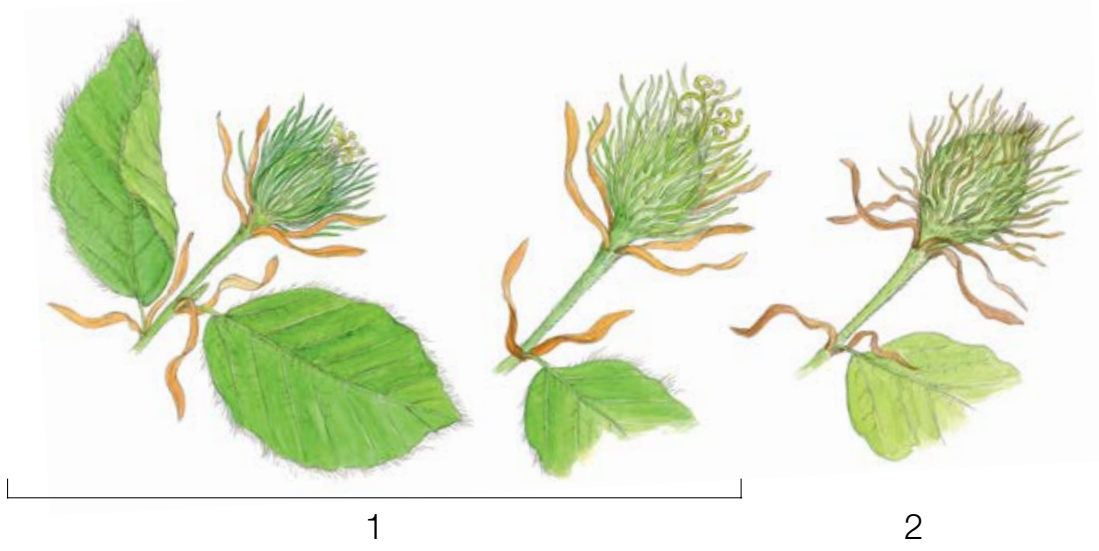

(b)
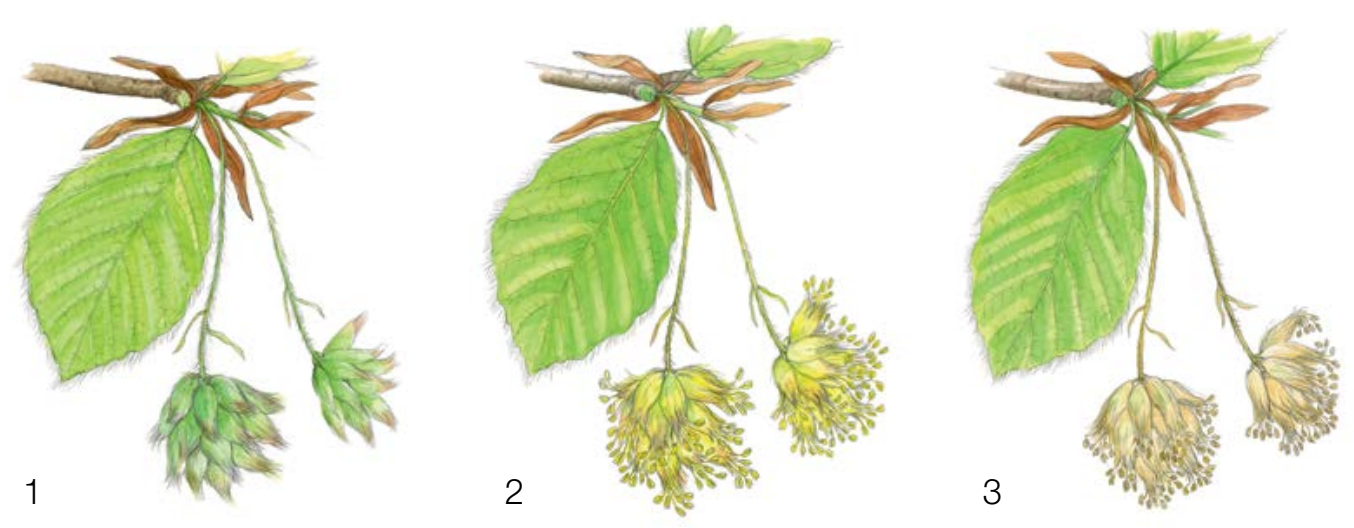

Figure 4: Picture guide for description of female (a) and male flowering (b) stages for the advanced level verifier Flowering. 


\subsubsection{Fructification}

This verifier describes the presence of fructification and its abundance. Data for this verifier should be collected during fructification, in August to October in central Europe.

\subsubsection{Basic level}

This verifier is recorded every year at the stand level. The estimate of average condition is provided after a walk throughout the monitoring plot. Two scores are given, one for fructification intensity and one for the proportion of fructifying trees in the stand.

\begin{tabular}{|c|c|c|}
\hline Code & Fructification intensity at the stand level & Average proportion of the crown bearing fruit (\%) \\
\hline 1 & No fructification: No or only occasional fruit appearing on trees & $0-10$ \\
\hline 2 & Weak fructification: Some fruit appearing on trees & $>10-30$ \\
\hline 3 & Moderate fructification: Moderate amount of fruit appearing on trees & $>30-60$ \\
\hline 4 & Strong fructification: Abundant amount of fruit appearing on trees & $>60-90$ \\
\hline 5 & Massive: Huge amount of fruit appearing on trees & $>90$ \\
\hline
\end{tabular}

\begin{tabular}{lr} 
Code & Proportion of trees in the stand with the given stage of fructification intensity (\%) \\
\hline 1 & $0-10$ \\
\hline 2 & $>10-30$ \\
\hline 3 & $>30-60$ \\
\hline 4 & $>60-90$ \\
\hline 5 & $>90$ \\
\hline
\end{tabular}

\subsubsection{Standard level}

This verifier is recorded during the same years as the assessment of the flowering at the standard level (regardless of the fructification intensity). It is recorded at an individual tree level on all 50 monitored trees. Recording is carried out before fruits start falling. One score is provided for each tree.

Ideally, one major fructification event should be captured following observations of major flowering events per decade. However, a major flowering event does not necessarily lead to a major fructification event. If no major fructification event follows the assessed flowering event, then the assessment of both flowering and fructification needs to be repeated during the next major flowering event, regardless of the time passed between successive major flowering events. Basic level observations are used to identify major fructification events. A major fructification event is when at the basic level fructification intensity is strong or massive (code 4 or 5 ) and the proportion of trees with the given fructification intensity is above $60 \%$ (code 4 or 5 ).

\begin{tabular}{llr}
\hline 1 & No fructification: No or only occasional fruit appearing on a tree. & $0-10$ \\
\hline 2 & Weak fructification: Some fruit appearing on a tree. & $>10-30$ \\
\hline 3 & Moderate fructification: Moderate amount of fruit appearing on a tree. & $>30-60$ \\
\hline 4 & Strong fructification: Abundant amount of fruit appearing on a tree. & $>60-90$ \\
\hline 5 & Massive: Huge amount of fruit appearing on a tree. & $>90$ \\
\hline
\end{tabular}




\subsubsection{Advanced level}

This verifier is recorded at an individual tree level on all 50 monitored trees during the same years as the assessment of flowering at the advanced level, regardless of the fructification intensity. Recording is carried out before fruits start falling. One score is provided for each tree. Simultaneously, seed is collected for seed and genetic analysis for the advanced level verifiers and background information.

Ideally, one major fructification event should be captured following observations of major flowering events per decade. However, a major flowering event does not necessarily lead to a major fructification event. If no major fructification event follows the assessed flowering event, assessment of both flowering and fructification needs to be repeated during the next major flowering event, regardless of the time passed between successive major flowering events. Basic level observations are used to identify major fructification events. A major fructification event is when at the basic level fructification intensity is strong or massive (code 4 or 5) and the proportion of trees with the given fructification intensity is above $60 \%$ (code 4 or 5 ).

The verifier is recorded by counting fruits using binoculars. The average of three rounds of counting is reported. Each round of counting consists of the number of fruits that the observer counts in 30 seconds. For all trees, the same part of the crown should be investigated. Once the observation part of the crown part is selected, the same one should be selected for every subsequent monitoring of this verifier. The upper third of the crown is preferred to the bottom and middle part for counting.

Two values are recorded; the number of fruits and the part of the crown monitored.

\section{Number of fruits counted in 30 seconds (average of 3 rounds)}

$$
\mathrm{x}
$$

\section{Code Part of the crown monitored}

\begin{tabular}{ll}
\hline 1 & Bottom \\
\hline 2 & Middle \\
\hline 3 & Top \\
\hline
\end{tabular}

\subsubsection{Natural regeneration abundance}

This verifier describes the presence and abundance of natural regeneration (NR) at the monitoring plot.

\subsubsection{Basic level}

The verifier is recorded at the stand level every year in the autumn. Expert opinion is used for estimation considering the situation over the whole monitoring plot. Two values should be recorded, one for 'new NR' (seedlings that germinated the same year as the assessment is carried out) and one for 'established NR' (NR older than 'new NR').

\begin{tabular}{cc} 
Code & Description: new natural regeneration (current-year seedlings) \\
\hline 1a & There is no or very little new natural regeneration on the monitoring plot \\
\hline $2 a$ & New regeneration is present in sufficient quantity on the monitoring plot \\
\hline
\end{tabular}

\section{Code Description: established natural regeneration (saplings older than 1 year)}

1b There is no or very little established natural regeneration on the monitoring plot

$2 \mathrm{~b}$ Established regeneration is present in sufficient quantity on the monitoring plot 


\subsubsection{Standard level}

This verifier is recorded by counting seedlings in the $1^{\text {st }}$ autumn after every assessed fructification event (the year of the fructification event is regarded as year 0 ) and $6^{\text {th }}$ autumn after the fructification event.

Counting of seedlings:

After the establishment of NR sublots all beech seedlings present at each of the 20 NR sublots must be counted. Any older beech saplings that are present on the NR subplot must not be included. During the next counting round, only saplings of the appropriate age must be counted - i.e., in the $6^{\text {th }}$ year, five-year old saplings.

\section{Number of seedlings counted on a subplot}

$\mathrm{x}$

Mortality/survival of natural regeneration is calculated from the values recorded for this verifier.

For subplot establishment see 6.2 Establishment of natural regeneration subplots.

\subsubsection{Advanced level}

This verifier is recorded by counting seedlings at each of the $20 \mathrm{NR}$ subplots in the $1^{\text {st }}$ autumn after every assessed fructification event (the year of the fructification event is regarded as year 0 ) and $6^{\text {th }}$, $11^{\text {th }}$, and $16^{\text {th }}$ autumn after this fructification event.

Table 3: Timeline of natural regeneration abundance (NR) assessment. In this example, the first fructification event takes place in the second year of the monitoring decade, and the second assessed fructification event five years later, i.e. in the $7^{\text {th }}$ year of the monitoring. Twenty new NR subplots are established after each assessed fructification event. Monitoring of NR abundance on each set of 20 NR subplots is carried out every five years. The fructification events corresponding to the assessed NR and timelines of the assessment activities are shaded in the same colour. After the final round of counting of seedlings, monitoring of NR abundance on the respective set of NR subplots is stopped and the respective NR subplots disestablished. S - standard level; A - advanced level.

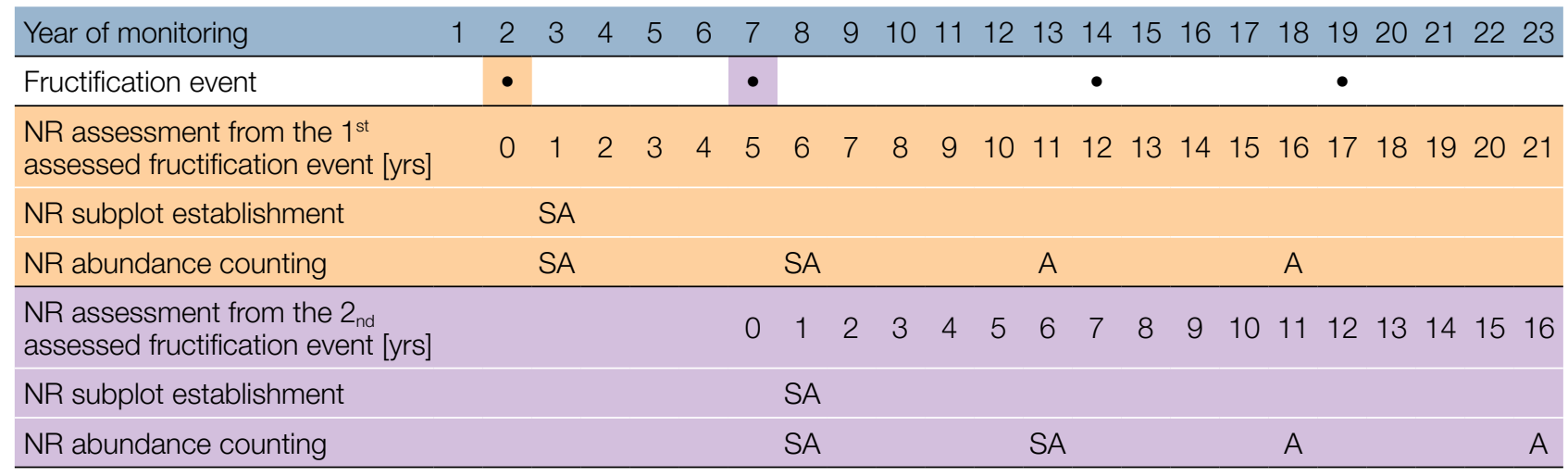

Mortality/survival of natural regeneration is calculated from the values recorded for this verifier.

For subplot establishment see 6.2 Establishment of natural regeneration subplots and for counting 7.1.4.2 Standard level. 


\subsection{Protocols for recording of background information}

\subsection{1 $\mathrm{DBH}$ class distribution}

\subsubsection{Standard and advanced level}

$\mathrm{DBH}$ is recorded on an individual tree level on all 50 monitored trees every 10 years. DBH is the trunk diameter at $1.30 \mathrm{~m}$, i.e. approximately at an adult's breast height. If a tree has more than one trunk, measure all of them and record the average (but try to avoid trees with many small trunks). Note that the tree is a multi-trunk one in the notes and include the number of trunks measured. If the tree is leaning, measure DBH perpendicular to the tree trunk. DBH can be measured in two ways:

1) using a calliper, in which case you need to measure two perpendicular diameters and take the average

2) measure the circumference of the tree and compute the diameter from that value (i.e. divide by $\pi, \sim 3.14$ or use a pi-meter)

The $\mathrm{DBH}$ is recorded in $\mathrm{cm}$. The same method must be applied for every subsequent measurement.

\subsubsection{Height class distribution}

\subsubsection{Standard and advanced level}

Height is recorded on an individual tree level on all 50 monitored trees every 10 years. Height is measured from the ground to the tallest part of the crown, ideally using a clinometer or hypsometer (e.g. vertex). Height is recorded in meters to one decimal place. If the crown is damaged, this must be recorded as well as the reason for this in the notes.

\subsubsection{Budburst}

Budburst describes the process of budbursting (flushing). Recording of this background information is only carried out at the standard and advanced levels. Data for this background information should be collected from the end of March (in central Europe) until all monitored trees have reached fully developed leaves.

\subsubsection{Standard level}

At standard level, budburst is recorded on an individual tree level on all 50 monitored trees every five years. We are looking for the initiation of budbursting (stage 3) and the end of budbursting (stage 5). The observations cease when all the trees have reached stage 5. Usually, six visits will be needed. For each tree, two estimates are given: budbursting stage and proportion of the crown budbursting. For a graphical representation of budbursting stages see Figure 5.

\begin{tabular}{|c|c|}
\hline \multicolumn{2}{|c|}{ Code Stage of budbursting } \\
\hline 1 & Dormant winter bud \\
\hline 2 & Buds swollen and elongated \\
\hline 3 & Buds begin to burst (first green is visible) \\
\hline 4 & Folded and hairy leaves begin to appear; individually visible folded and hairy leaves \\
\hline 5 & Leaves fully unfolded, smooth and bright \\
\hline
\end{tabular}

\begin{tabular}{lr} 
Code & Proportion of the crown with a given stage of budbursting (\%) \\
\hline 1 & $>0-33$ \\
\hline 2 & $>33-66$ \\
\hline 3 & $>66-99$ \\
\hline 4 & 100 \\
\hline
\end{tabular}


1

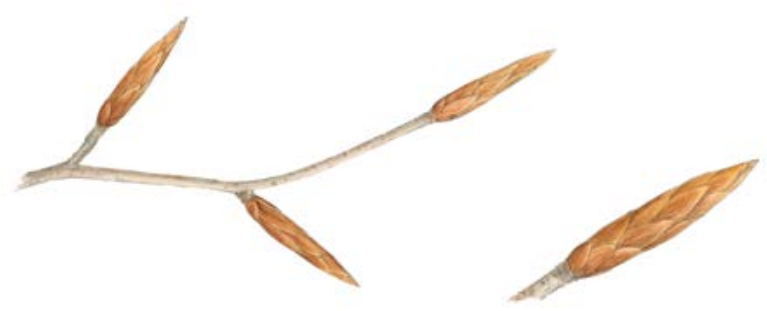

3

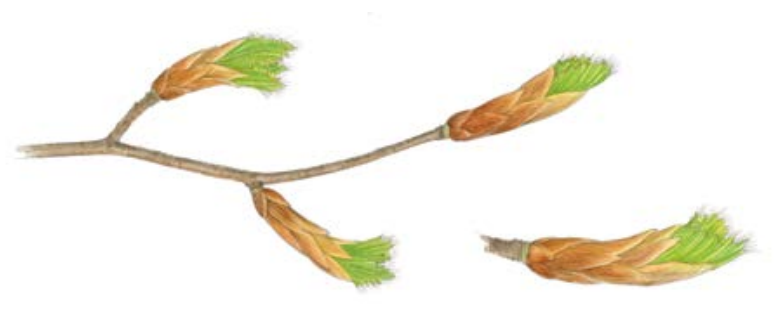

2

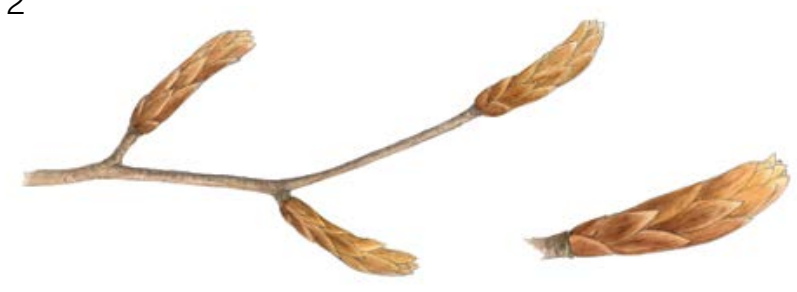

4

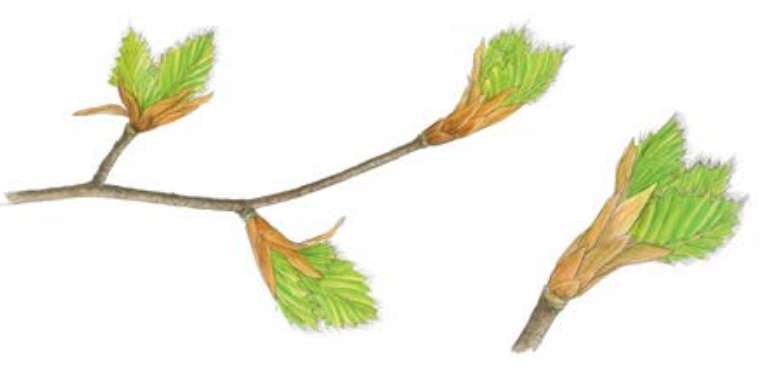

5

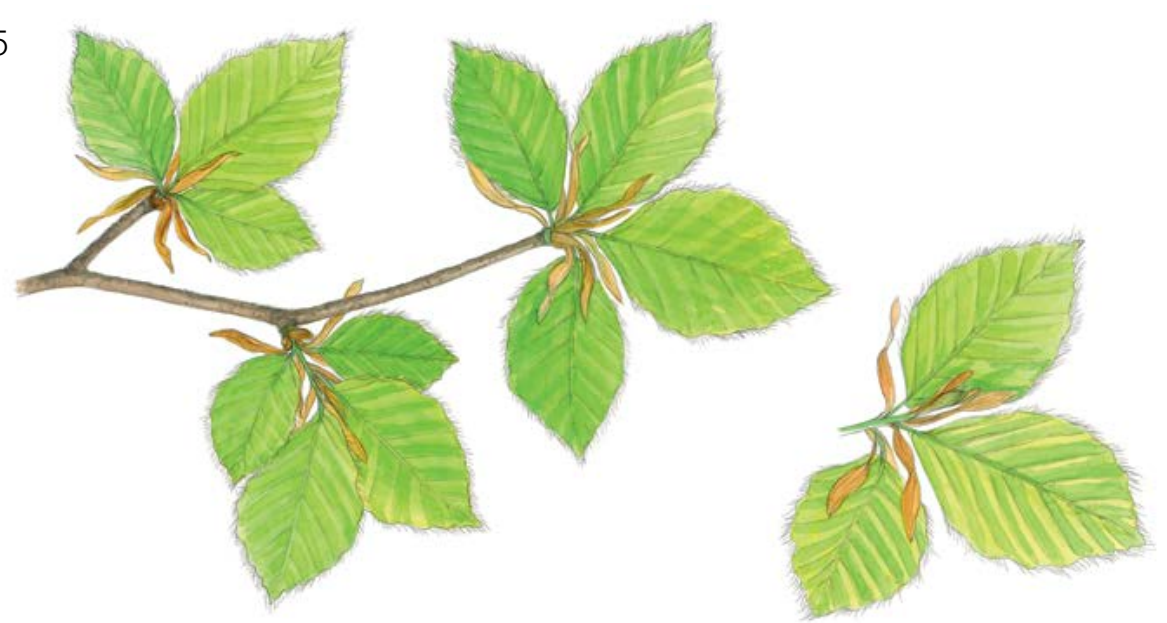

Figure 5: Picture guide for description of budburst (flushing) for the standard, and advanced level background information Budburst.

\subsubsection{Advanced level}

At advanced level, budburst is recorded on an individual tree level on all 50 monitored trees every year. in the same way as at the standard level. For details see 7.2.3.1 Standard level.

\subsubsection{Senescence}

Senescence describes the process of senescence. Recording of this background information is only carried out at the standard and advanced levels.

\subsubsection{Standard level}

At standard level, senescence is recorded on an individual tree level on all 50 monitored trees every five years. We are looking for stage 3, when leaves are yellow and do not photosynthesise anymore. Observations stop when all the trees have reached stage 3. Usually, two (2) visits to the plot will be needed. For each tree, two estimates 
1

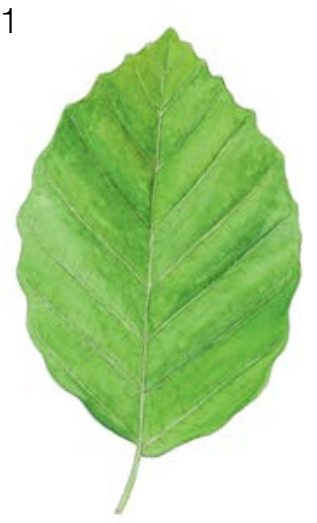

2

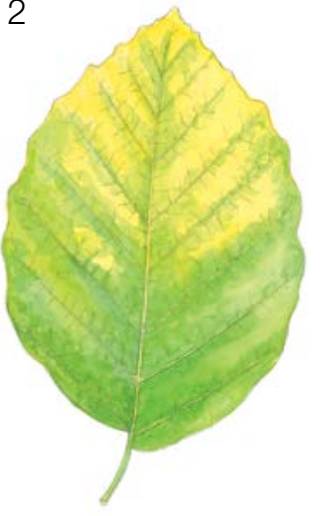

3

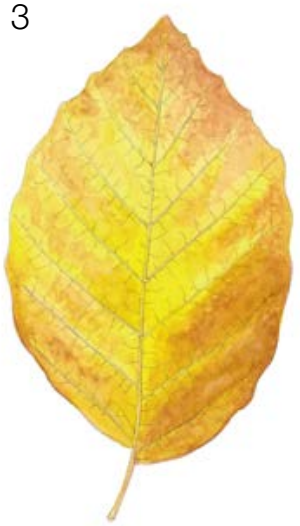

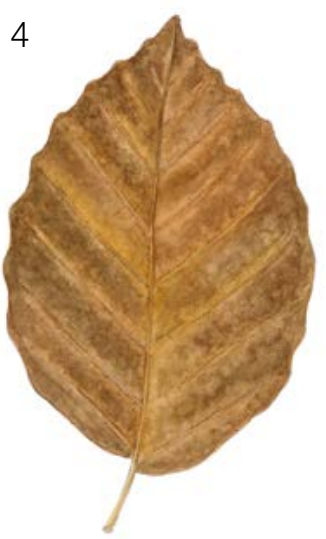

Figure 6: Picture guide for description of senescence for the standard and advanced level background information Senescence.

are given: stage of senescence and proportion of the crown senescing. For a graphical representation of stages of senescence, see Figure 6.

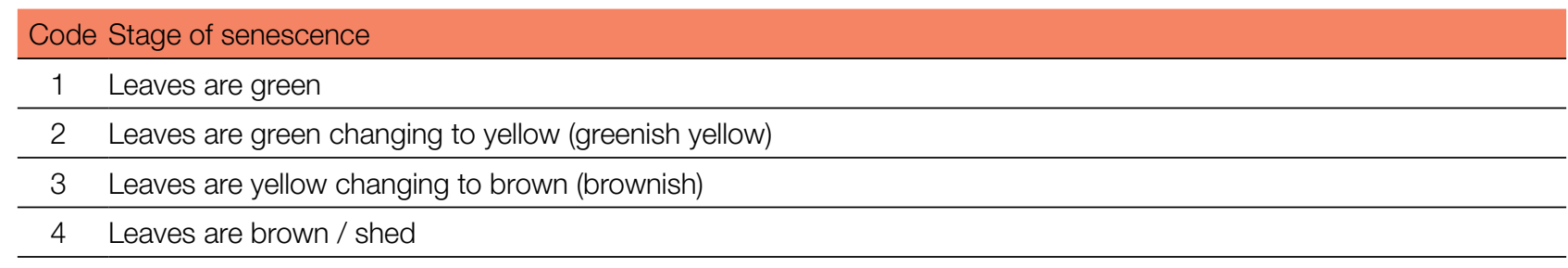

\begin{tabular}{lr} 
Code & Proportion of the crown with a given stage of senescence (\%) \\
\hline 1 & $>0-33$ \\
\hline 2 & $>33-66$ \\
\hline 3 & $>66-99$ \\
\hline 4 & 100 \\
\hline
\end{tabular}

\subsubsection{Advanced level}

Senescence is recorded on an individual tree level on all 50 monitored trees every year in the same way as at the standard level. For details, see 7.2.4.1 Standard level.

\subsubsection{Flowering synchronisation}

\subsubsection{Advanced level}

Flowering synchronisation is monitored only at the advanced level, and is based on the data collected for the verifier Flowering. It is used to determine whether male and female flowering times occur simultaneously within the monitored stand.

\section{For plot establishment use form 'FGM Plot description'}

For verifiers recording use 'Form for recording field level verifiers within FGM'

For background information recording use 'Form for recording field level background information within FGM' 


\section{References}

1. Houston Durrant T, de Rigo D, Caudullo G (2016) Fagus sylvatica and other beeches in Europe: distribution, habitat, usage and threats. In: San-Miguel-Ayanz J, de Rigo D, Caudullo G, Houston Durrant T, Mauri A (Eds.) European Atlas of Forest Tree Species. Publ. Off. EU, Luxembourg, pp 94-97. DOI: 10.2788/4251

2. von Wuehlisch G (2008) EUFORGEN Technical Guidelines for genetic conservation and use for European beech (Fagus sy/vatica). Bioversity International, Rome

3. Kraigher H, Westergren M (2011) Gozdno semenarstvo in drevesničarstvo. In: Gospodarjenje z gozdom za lastnike gozdov. Kmečki glas, Ljubljana

4. Johnson O \& More D (2010) Collins Tree guide. Slovenian edition, Narava d.o.o., Kranj

5. Ogris N (2020) Varstvo gozdov Slovenije - portal. https://www.zdravgozd.si/meni_index.aspx. Accessed 15 September 2020

The following resources were consulted for the currently accepted (December 2020) scientific names of the species covered or mentioned in this document:

a. CABI (2020) Invasive Species Compendium. CAB International, Wallingford, UK. www.cabi.org/isc. Accessed 15 December 2020

b. EPPO (2020) EPPO Global Database (available online). https://gd.eppo.int. Accessed 15 December 2020

c. GBIF (2020) Global Biodiversity Information Facility. https://www.gbif.org Accessed 15 December 2020

d. IPNI (2020) International Plant Names Index. The Royal Botanic Gardens, Kew, Harvard University Herbaria \& Libraries \& Australian National Botanic Gardens. http://www.ipni.org, Accessed 10 December 2020

e. National Center for Biotechnology Information (NCBI) (1998) National Library of Medicine (US), National Center for Biotechnology Information, Bethesda (MD). https://www.ncbi.nlm.nih.gov/. Accessed 15 December 2020

f. Stevens PF (2001) Angiosperm Phylogeny Website, Version 14. http://www.mobot.org/MOBOT/research/APweb/. Accessed 15 December 2020

g. The Plant List (2013) Version 1.1. http://www.theplantlist.org/. Accessed 12 December 2020

h. Tropicos.org (2020) Missouri Botanical Garden. http://www.tropicos.org. Accessed 15 December 2020

i. WFO (2020) World Flora Online. http://www.worldfloraonline.org. Accessed 15 December 2020 


\section{Guidelines for genetic monitoring of}

\subsubsection{Common ash (Fraxinus excelsior L.)}

Marjana WESTERGREN¹, Marko BAJC'1, Rok DAMJANIĆ ${ }^{1}$, Barbara FUSSI ${ }^{2}$, Dalibor BALLIAN ${ }^{1,3}$, Andrej BREZNIKAR ${ }^{4}$, Darius KAVALIAUSKAS²,

Peter ŽELEZNII'1', Hojka KRAIGHER'

Botanical illustrations by Metka KLADNIK

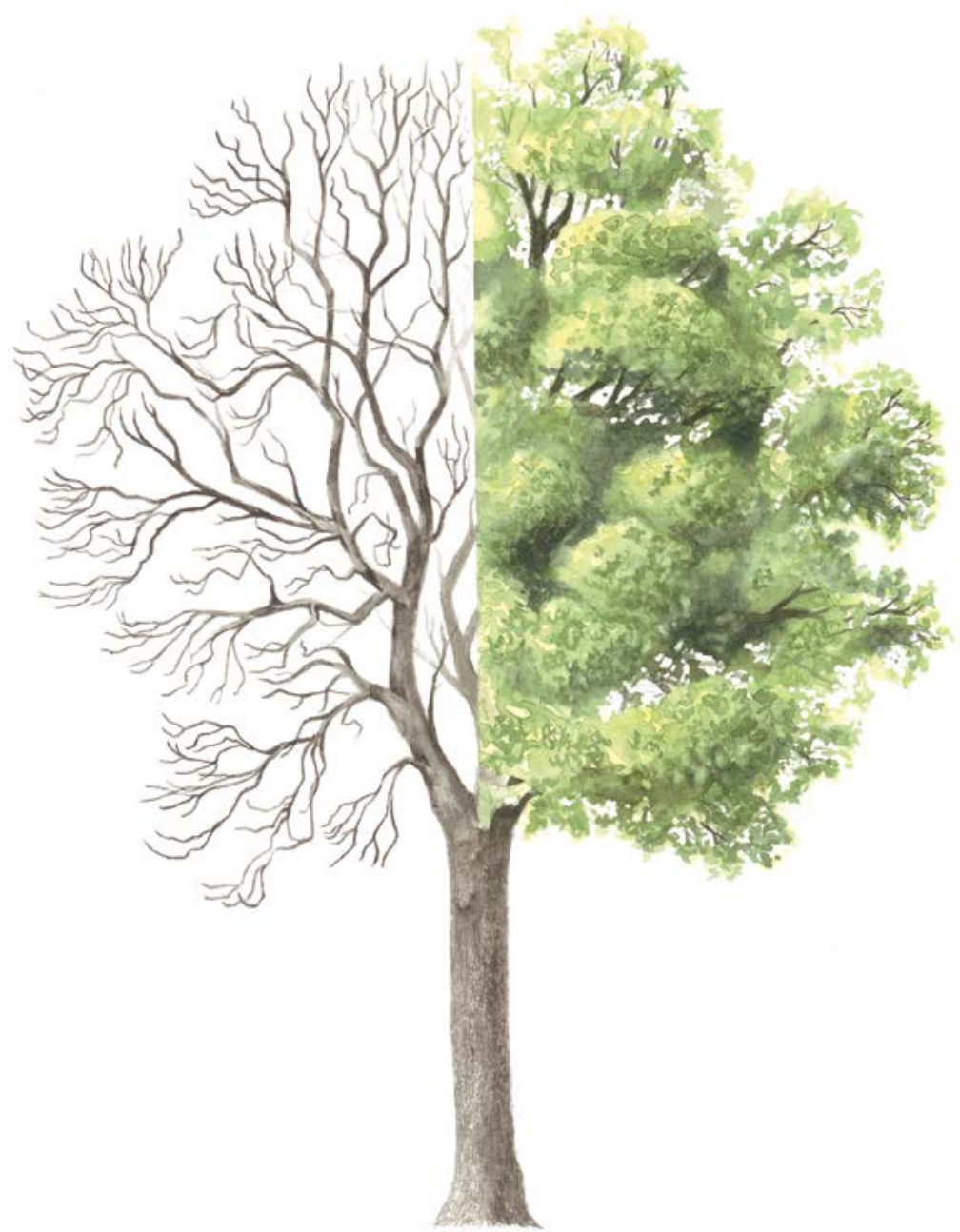

Citation: Westergren et al. (2020) Guidelines for genetic monitoring of Common ash (Fraxinus excelsior L.). In: Bajc et al. (eds) Manual for Forest Genetic Monitoring. Slovenian Forestry Institute: Silva Slovenica Publishing Centre, Ljubljana, pp 195-213. http://dx.doi.org/10.20315/SFS.167

1. Slovenian Forestry Institute (GIS), Slovenia

2. Bavarian Office for Forest Genetics (AWG), Germany

3. University of Sarajevo, Forestry Faculty, Bosnia and Herzegovina

4. Slovenia Forest Service (ZGS), Slovenia 


\section{Executive summary}

Common ash (Fraxinus excelsior L.) is a polygamous, deciduous tree species present throughout Europe except in the driest Mediterranean areas. Common ash can form pure stands but is more commonly found growing in smaller groups of trees in mixed stands akin to species with scattered distribution. It is closely related to narrow leaved ash (F. angustifolia Vahl.) with which it hybridises. With its high ecological importance and utility in the timber industry, this species that is strongly threatened by the ash dieback is a prime candidate for genetic monitoring.

These guidelines briefly describe the common ash, its reproduction, environment and threats. They provide guidance on establishing a genetic monitoring plot and on recording all field level verifiers and background information.

\section{Species description}

Common ash (Figure 1) is a deciduous tree reaching heights up to $40 \mathrm{~m}$ when 90-120 years old [1]. The crown is irregular with massive branches, elongated in forest stands [1]. The bark is pale brown to grey, which fissures as the tree ages [2]. In the winter, it is easily identified by smooth twigs that have distinctively black, velvety leaf buds arranged opposite each other. Leaves are pinnately compound, typically comprising 7-13 oval leaflets with long tips including an additional singular 'terminal' leaflet at the end [2, 3] (Figure 2a). These leaves are up to $35 \mathrm{~cm}$ long [2], light green on the bottom side and green-grey on the upper one.

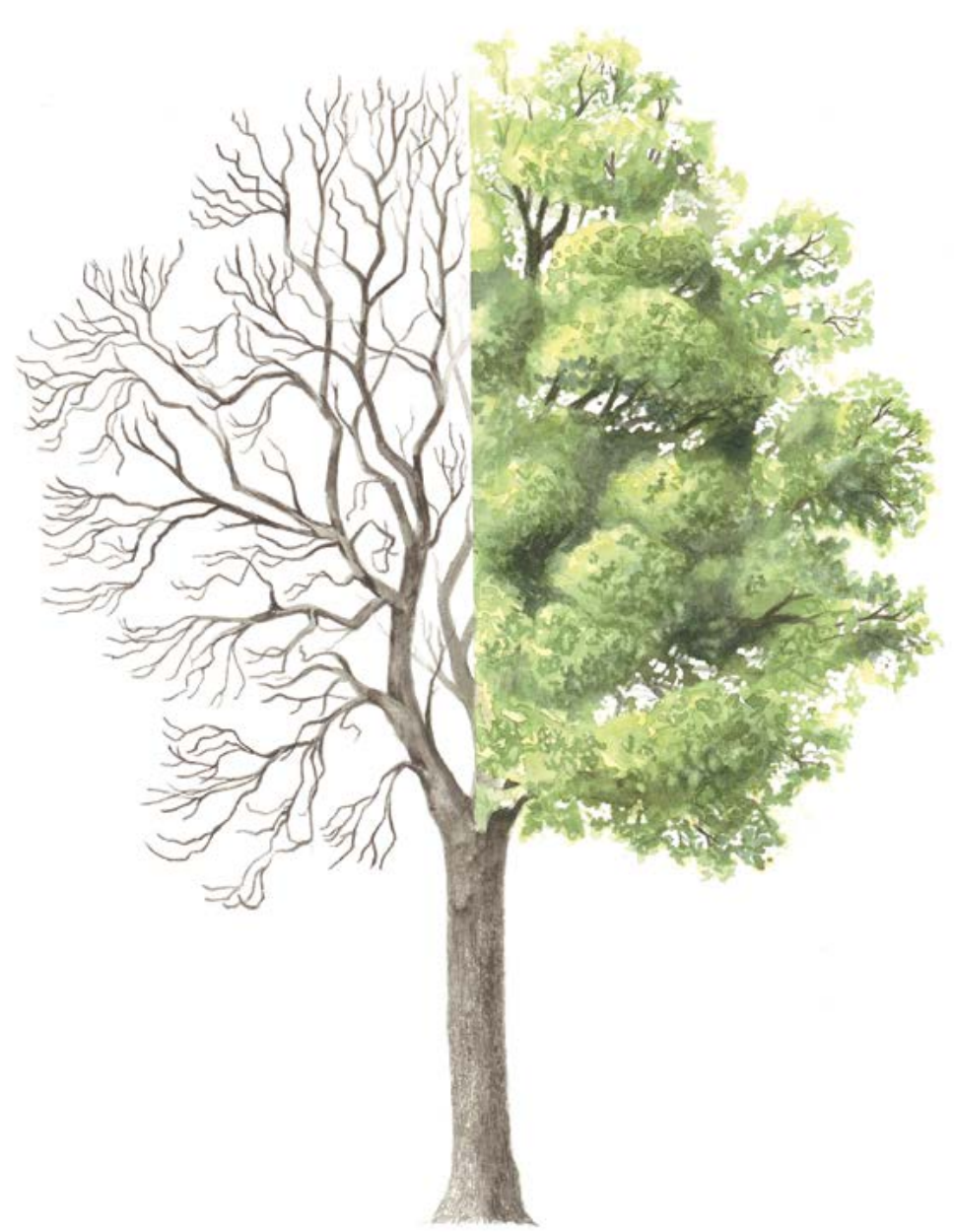

Figure 1: Common ash (F. excelsior) habitus.

Common ash is closely related to $F$. angustifolia Inflorescence or fructification type is the most reliable characteristic to distinguish them (Figure 2); common ash has a branched inflorescence while $F$. angustifolia has an unbranched simple raceme [3]. However, some F. excelsior trees have mixed inflorescences with hermaphrodite flowers only 
on the main axis of inflorescences and male flowers only on the secondary branches of inflorescences, and these can be misidentified as after the fall of male flowers their raceme may appear as an unbranched raceme of $F$. angustifolia [3]. Hybrids have been reported in areas where the two species grow together [2, 3].

(a)

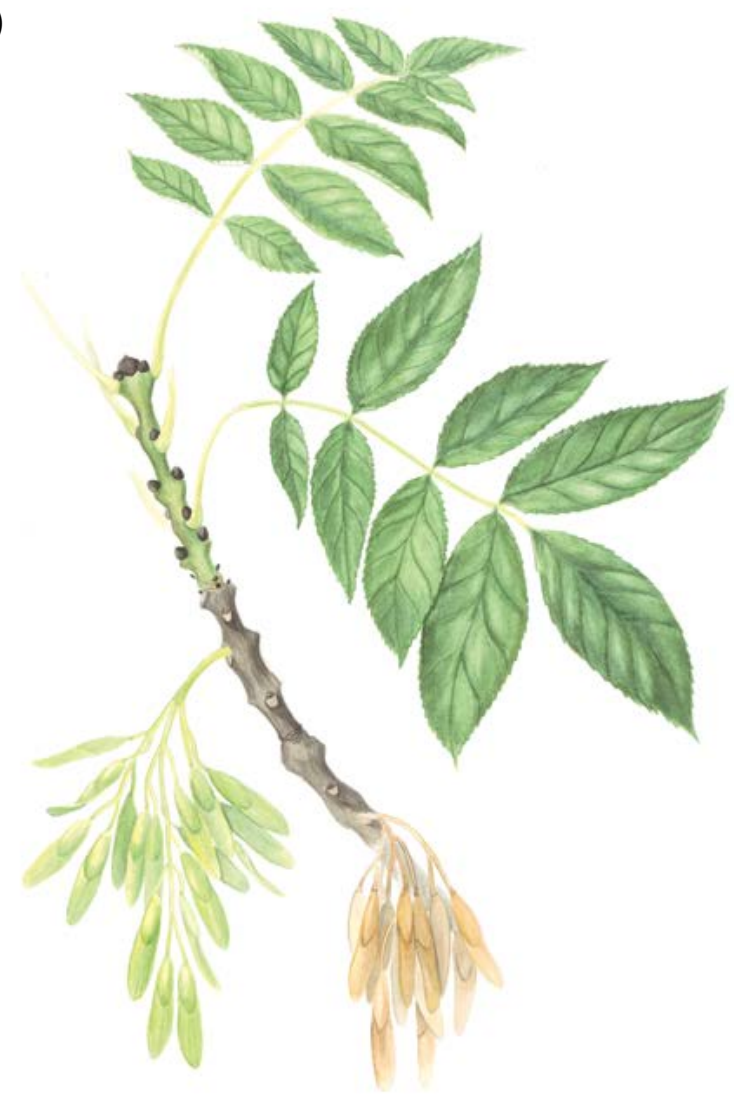

(b)

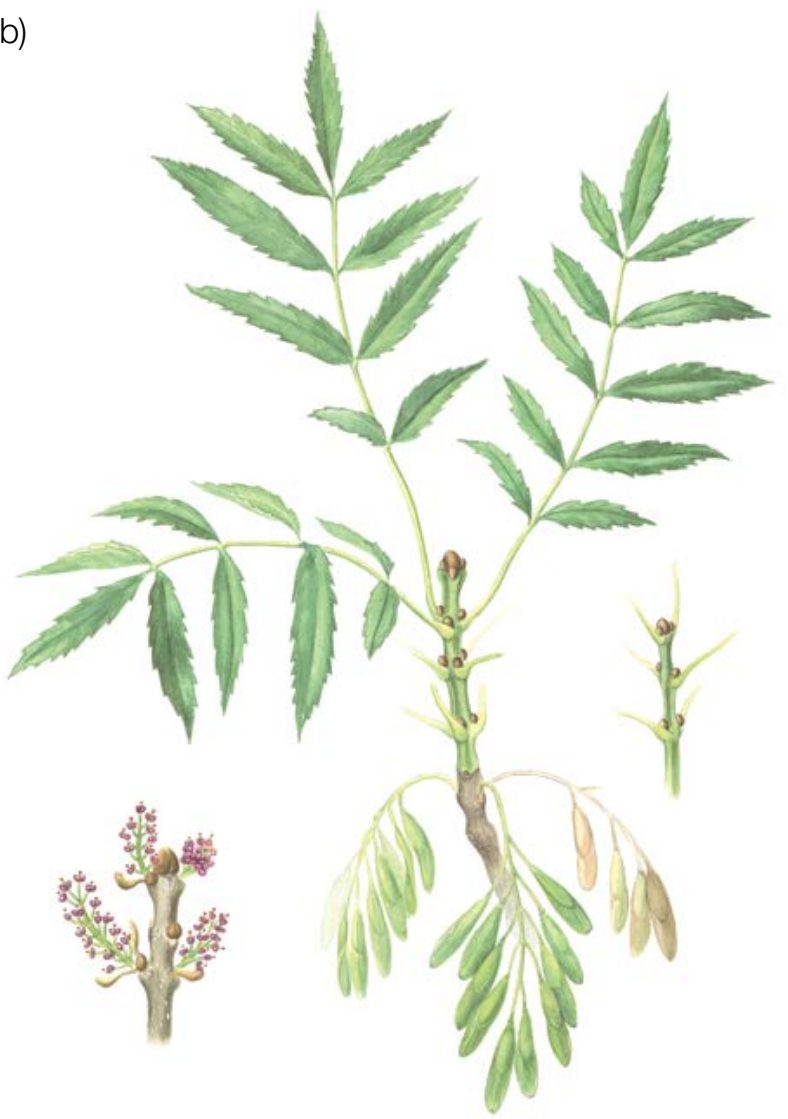

Figure 2: Morphological signs for differentiating F. excelsior (a) from F. angustifolia (b).

\section{Reproduction}

Common ash is polygamous; it can develop only male or female inflorescences on a single tree, or unisexual inflorescences with only male and female inflorescences carried separately on the same tree, or even hermaphrodite inflorescences [1, 2, 3]. It is self-fertile [3]. However, selfed seeds may not survive because of inbreeding depression, making the species possibly functionally dioecious [3]. Both male and female inflorescences are purple and appear in March to April in central Europe, before the leaves in the spring, growing in spiked clusters at the tips of twigs. Leaves flush after flowering has finished, on the shoots that emerge from the terminal buds. The start of budbursting (flushing) varies from population to population and year to year; flowering and budbursting are earlier when preceded by a warm winter [3].

Once the female inflorescences have been pollinated by wind, they develop into clearly visible winged fruits samaras - in late summer and autumn. They fall from the trees in winter and early spring, and are mainly dispersed by wind $[1,2,3]$. Flowering starts at 15-20 years on single trees and at around 30 years within stands at irregular intervals [1]. Seeds are usually dormant for two winters before germinating, but also longer, for up to six years on dry or high locations [2, 3].

Common ash exhibits intermediate properties between a pioneer and climax species. Dispersal and natural regeneration are efficient; however, its competition ability is only strong when the ecological requirements are met $[2,3]$. Vegetative regeneration is strong after coppicing [3]. 


\subsection{Identification of tree's sex}

Male trees are trees on which most inflorescences are male. This category can be subdivided into purely male trees (with only male inflorescences) and those with a mix of male and hermaphrodite inflorescences. These male-hermaphrodite mix trees can produce a few seeds [3].

Female trees are trees with mainly female inflorescences and produce seed [3].

Hermaphrodite trees are trees with mainly hermaphrodite inflorescences. They mainly produce seed but can also father some seeds as they produce pollen. Hermaphrodite trees may vary in their sex, becoming more female or male in the mast year [3].

\section{Environment}

Common ash grows throughout Europe but is absent from the driest Mediterranean areas as it does not tolerate extended summer drought, and from the northern boreal regions, because its seedlings are vulnerable to late spring frost [1, 2, 3]. It grows best on rich soils where soil pH exceeds 5.5, and soil controls its local distribution. Ash tolerates seasonal waterlogging, but not prolonged flooding [2]. It is a scattered tree species and rarely forms pure stands; it is more often found in small groups within mixed stands [2].

\section{Threats}

The biggest threat to common ash is currently a fungus called Hymenoscyphus fraxineus (T. Kowalski) Baral, Queloz \& Hosoya (previously Chalara fraxinea). The disease was first discovered in Poland in 1992, and is now widespread throughout Europe with up to $80-90 \%$ of trees affected in many countries. The symptoms include

(a)

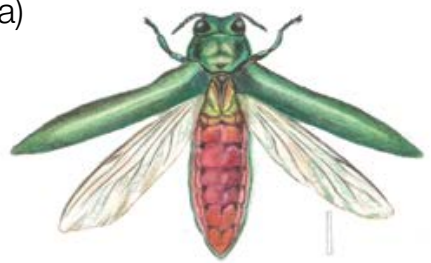

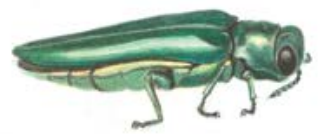
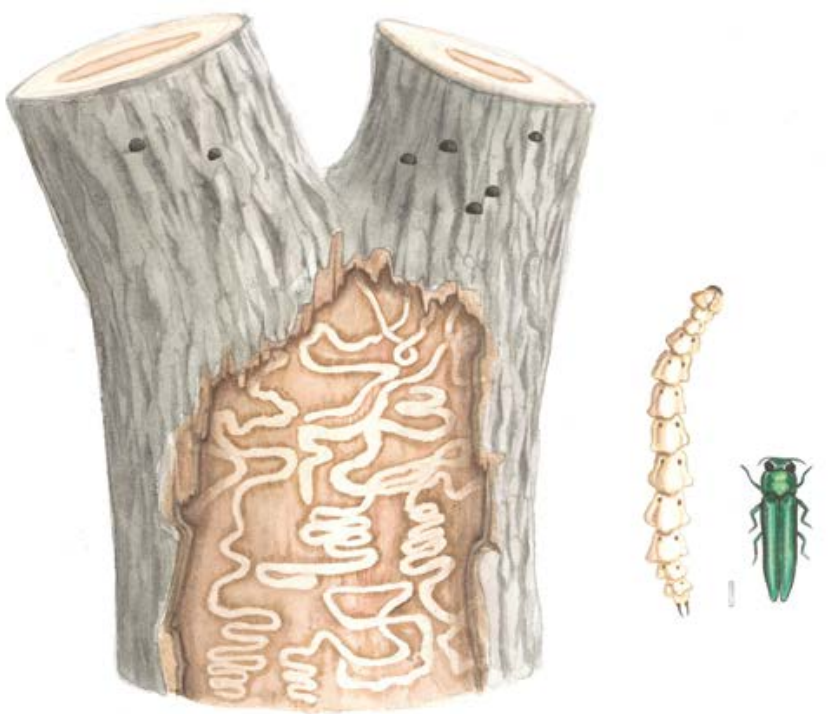

(b)

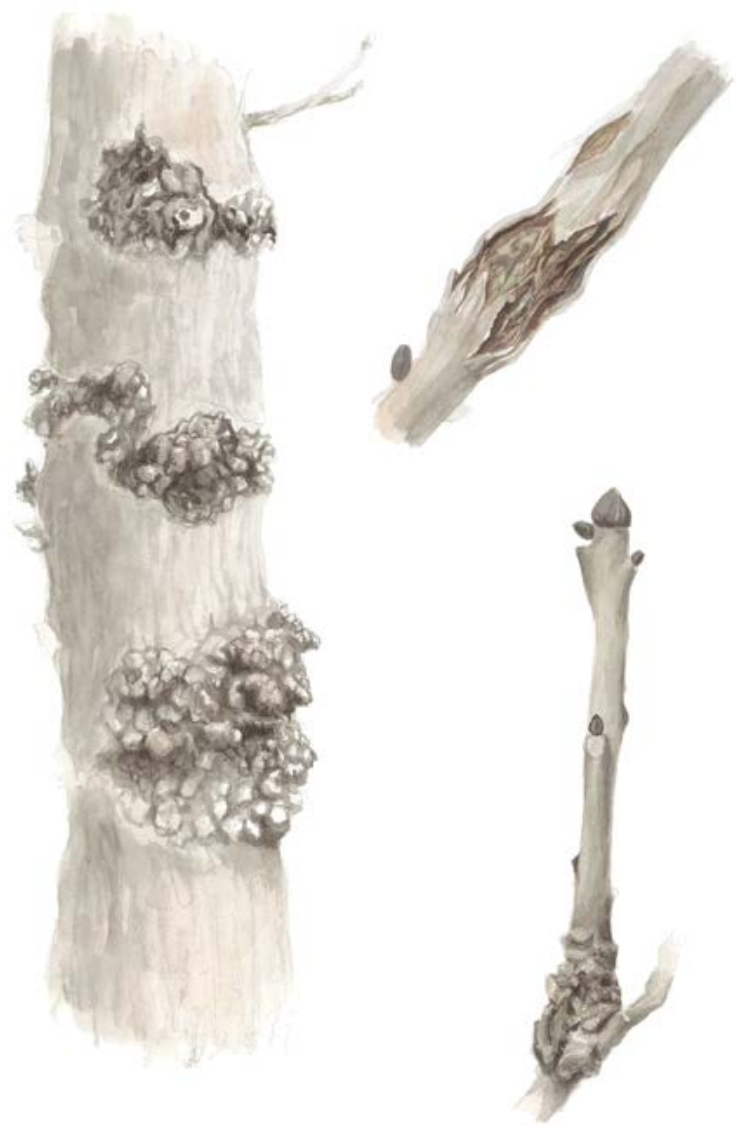

Figure 3: Emerald ash borer, an emerging threat to common ash (a) and ash canker (b). 
severe defoliation, wilting, bark necrosis on stems and discolouration of the wood. Ash trees of all sizes (adult trees, saplings and seedlings) are affected. The disease has been observed to spread up to $20-30 \mathrm{~km} /$ year. In addition to spores, the disease can also spread via plant material. Other threats to ash health are ash cankers Neonectria ditissima (Tul. \& C. Tul.) Samuels \& Rossman and Pseudomonas savastanoi (Janse) Gardan, et al., Phyllactinia fraxini (DC.) Fuss, Armillaria gallica Marxm. \& Romagn. and others [2, 4] (Figure 3b).

A potentially devastating threat is the emerald ash borer (Agrilus planipennis Fairmaire), a beetle native to Asia and eastern Russia (Figure 3a). While its adults graze on ash leaves, the larvae feed on the phloem, killing the tree. The borer was observed in western Russia and Sweden in 2007, and there is a strong concern that it might spread to all of Europe, devastating ash as it did in the US [2, 4].

\section{Plot establishment and maintenance}

A forest genetic monitoring plot consists of 50 reproducing trees, with the minimum distance of $30 \mathrm{~m}$ between any two trees. If a tree is flowering, it is regarded as a reproducing tree. Diameter at breast height $(\mathrm{DBH})$ and social class can be used as a proxy to identify a reproducing tree if the plot is being established outside of the flowering season, relying on the expertise of the local forester. During plot installation, trees should be labelled and the coordinates of all trees taken. At the same time DBH can be measured and samples for DNA extraction taken.

Because common ash is most commonly a scattered tree species ${ }^{1}$, a preliminary field study is needed; the size and shape of the genetic monitoring plot will need to be adapted to include 50 reproducing trees. Twenty-five of these should be functionally female and 25 functionally male. Hermaphrodite trees are often functionally female as they produce a fair amount of seed. As these hermaphrodite trees may vary in their sex, becoming more female or male in the mast year, the actual share of functionally female and male trees may change over the years.

Equipment needed:

- a device for distance measurement (a pair of range-finding binoculars is recommended)

- a compass

- paint and a brush or spray for marking trees

- a tree calliper for DBH measurements and

- a GPS device that is precise enough and allows saving trees' coordinates

\subsection{Plot establishment}

\subsubsection{Plot selection}

To establish a monitoring plot for $F$. excelsior, ideally the initial work should be carried out in spring, when the trees are flowering. At this time, all ash trees in the stand should be mapped using a GPS device, and their sex recorded. In the summer, when trees are bearing fruit, the functional sex should be recorded for the hermaphrodite trees.

After the sex (and functional sex in the case of hermaphrodites) has been recorded, the GPS locations of all trees should be plotted as a point feature layer in GIS software. Fifty points representing trees, with a minimum distance of $30 \mathrm{~m}$ from each other, should be randomly selected keeping the ratio of $50 \%$ functionally male and $50 \%$ functionally female trees, including male, female and hermaphrodite trees. To account for GPS measuring errors we recommend looking for trees separated by more than $35 \mathrm{~m}$ (adjusting the minimum distance to $35 \mathrm{~m}$ ). During plot installation, these pre-selected trees must be identified in the field and marked (Figure 4a).

\footnotetext{
1 Common ash has a scattered distribution in the majority of its natural distribution range. In locations where it forms stands, the FGM plot must be established according to the guidelines for stand forming species, such as the European beech (Fagus sylvatica L.).
} 
If two visits for recording tree sex are not possible, plot establishment should be carried out in the summer, recording and later randomly selecting 25 functionally male (trees not bearing fruit) and 25 functionally female (fruit-bearing) trees.

\subsubsection{Plot installation in the field}

Using the GPS, trees that were randomly selected in the office are located in the forest stand and marked. The minimum distance of $30 \mathrm{~m}$ between trees needs to be checked again.
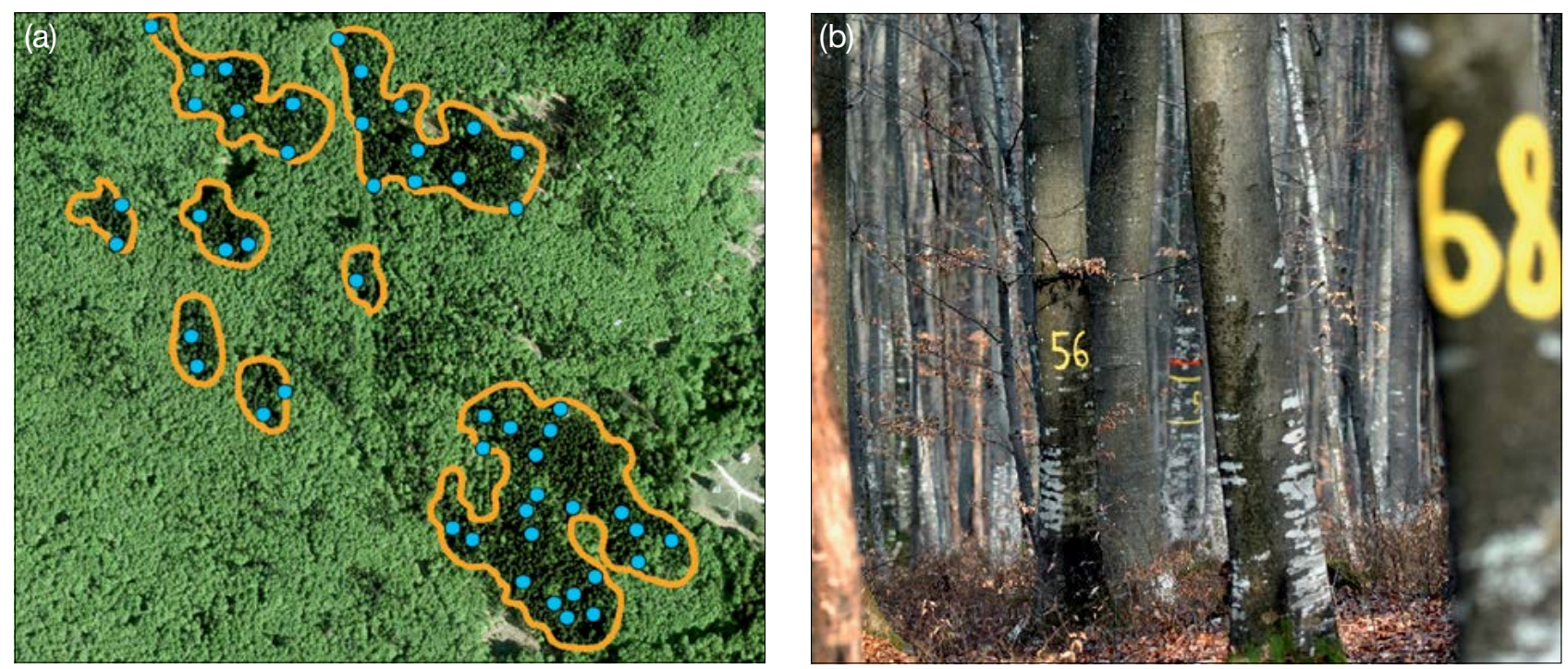

Figure 4: Plotted locations of randomly selected trees growing in multiple clusters (a); Each tree selected for genetic monitoring must be labelled with a corresponding number (image depicts the Fagus sylvatica FGM plot in Slovenia). To improve the visibility of selected trees from all directions, a band can also be painted around their trunks.

\subsubsection{Labelling of trees}

Each selected tree must be marked with a corresponding number (1 to 50) (Figure 4b), and preferably a band painted around the trunk to aid the visibility of the tree from all directions.

\subsection{Establishment of natural regeneration subplots}

The establishment of natural regeneration (NR) subplots should be carried out during germination two or more years after a strong or massive fructification event; the interval depends on the length of seed dormancy in a particular population.

Natural regeneration centres from the last mast year should be surveyed in the field and their locations logged (GPS coordinates, number of the tree which is next to an NR centre). From all logged regeneration centres, 20 should be chosen randomly for plot installation. If 20 or fewer natural regeneration centres are present, all should be used.

Inside each selected natural regeneration centre a $1 \mathrm{~m}^{2}$ plot is to be installed and marked with metal rods. Metal rods should be driven into the ground at each corner of the subplot as deep as possible to prevent them from being removed by animals. The tips of the metal rods should be painted to aid their visibility. 


\subsection{Plot maintenance}

\subsubsection{General maintenance}

Tree markings and subplot markings must be checked periodically (every two years) and repaired if needed.

\subsubsection{Replacement of trees}

If a monitored tree dies or is cut due to management, it must be replaced. The nearest suitable tree to the dead one should be chosen considering that the distance requirement of $30 \mathrm{~m}$ to the nearest monitored tree is fulfilled. The replacement tree is marked with the next available number higher than 50 , i.e. 51,52 , 53, etc. to positively differentiate it from the original 50 selected trees.

If the crown is damaged due to, for example windbreak, ice or snow-break, but continues to fructify, the tree is kept for the monitoring. If the damage is too severe and fructification is not expected anymore, the monitored tree must be replaced. The cause of damage needs to be recorded, as the damage can affect the values recorded for field verifiers and background information. If ash dieback is present in the stand, trees are monitored until they have reached stage 6, as set out in the background information Crown Dieback. Afterwards, they are replaced. 


\section{Recording of verifiers and background information}

Verifiers and background information are periodically recorded on the monitoring plot. Verifiers are used to monitor the population's genetic properties and its adaptation to environmental changes and/or management, while background information needs to be recorded to assist interpretation of the verifiers.

Higher levels of verifiers (standard, advanced) must also include recording on all the preceding levels (basic, standard). This is not necessary for recording of background information.

Table 1: List of verifiers and background information with short descriptions and observation frequency to be recorded during fieldwork at the ash monitoring plots.

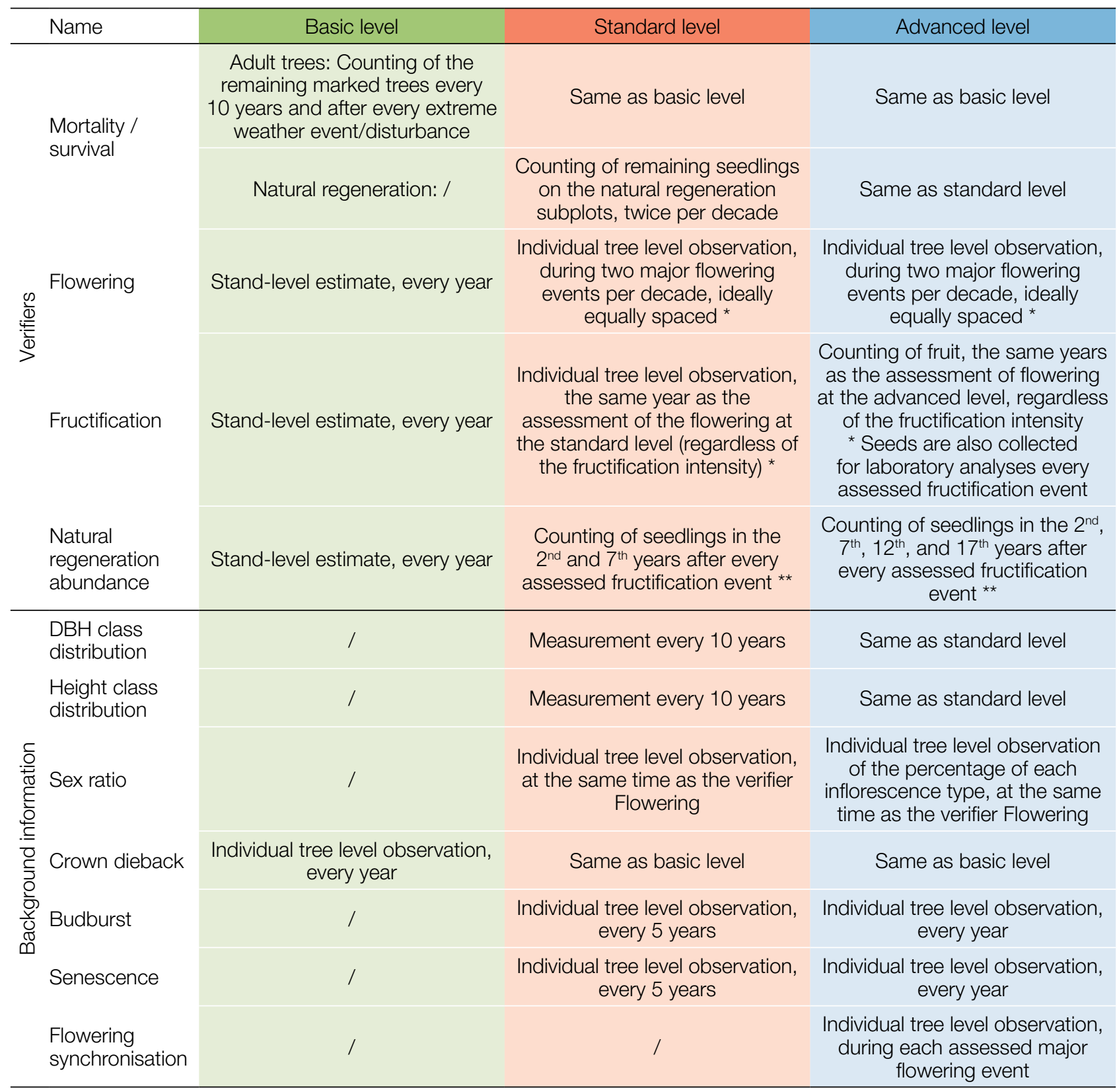

* Ideally at least one major fructification event should be assessed per decade. However, a major flowering event does not necessarily lead to a major fructification event. If no major fructification event follows the assessed flowering event, assessment of both flowering and fructification needs to be repeated during the next major flowering event, regardless of the time passed between successive major flowering events. Basic level observations are used to identify major flowering and fructification events.

${ }^{*}$ Ash has dormant seed; usually dormancy lasts for two winters. Therefore, natural regeneration abundance is first recorded two years after the major fructification event. If seeds are dormant for longer or shorter in the monitored ash stand, the observation years must adapt to the duration of the dormancy. 


\subsection{Protocols for recording of verifiers}

\subsubsection{Mortality / survival}

Mortality describes the mortality of adult trees and natural regeneration. Its counterpart, survival, stands for trees that are still alive since the previous assessment. Survival is calculated as 1 - Mortality.

\subsubsection{Adult trees: Basic, standard and advanced level}

Verifier for mortality of adult trees. It is estimated by counting the remaining alive marked trees every 10 years and after every extreme weather event/disturbance. Mortality is the difference between the initial number of marked trees and the trees remaining alive of the original 50.

\subsubsection{Natural regeneration: Standard and advanced level}

Mortality of natural regeneration is calculated from the verifier Natural regeneration abundance. Mortality is the difference between the initial number of NR plants and the plants remaining alive at the time of the next counting. For each round of assessment, the NR is counted first in the year of germination and then again after 5 years at the standard level, while at the advanced level the counting is also performed after 10 and 15 years. Assessment of NR abundance is carried out twice per decade, ideally approximately every five years.

\subsubsection{Flowering}

This verifier describes the flowering intensity and the proportion of trees thus affected. It can be recorded simultaneously with the background information 7.2.3 Sex ratio during flowering in March to April in central Europe. Flowering is earlier when preceded by a warm winter.

\subsubsection{Basic level}

This verifier is recorded every year at the stand level. Recording is carried out when flowering is in full progress. The estimate of average condition is provided after a walk throughout the monitoring plot. Two scores are given, one for flowering intensity and one for proportion of flowering trees in the stand.

\begin{tabular}{clc}
\hline Code & Flowering intensity at the stand level & Average proportion of crown flowering (\%) \\
\hline 1 & No flowering: No or only occasional flowers appearing on trees & $0-10$ \\
\hline 2 & Weak flowering: Some flowers appearing on trees. & $>10-30$ \\
\hline 3 & Moderate flowering: Moderate number of flowers appearing on trees. & $>30-60$ \\
\hline 4 & Strong flowering: Abundant number of flowers on trees. & $>60-90$ \\
\hline 5 & Massive: Huge number of flowers on trees. & $>90$ \\
\hline
\end{tabular}

\begin{tabular}{lr} 
Code & Proportion of trees in the stand with the given flowering intensity stage (\%) \\
\hline 1 & $0-10$ \\
\hline 2 & $>10-30$ \\
\hline 3 & $>30-60$ \\
\hline 4 & $>60-90$ \\
\hline 5 & $>90$ \\
\hline
\end{tabular}




\subsubsection{Standard level}

This verifier is recorded during two major flowering events per decade, ideally equally spaced in time from one another. It is recorded at an individual tree level on all 50 monitored trees. A major flowering event is when at the basic level flowering intensity is strong or massive (code 4 or 5 ) and the proportion of trees with the given flowering intensity is above $60 \%$ (code 4 or 5 ). Recording is carried out when flowering is in full progress. One score is provided for each tree.

\begin{tabular}{|c|c|c|}
\hline Code & Description & Proportion of the crown flowering (\%) \\
\hline 1 & No flowering: No or only occasional flowering appearing on a tree. & $0-10$ \\
\hline 2 & Weak flowering: Some flowers appearing on a tree. & $>10-30$ \\
\hline 3 & Moderate flowering: Moderate number of flowers on a tree. & $>30-60$ \\
\hline 4 & Strong flowering: Abundant number of flowers on a tree. & $>60-90$ \\
\hline 5 & Massive: Huge number of flowers on a tree. & $>90$ \\
\hline
\end{tabular}

\subsubsection{Advanced level}

This verifier is recorded during two major flowering events per decade, ideally equally spaced in time from one another. It is recorded at an individual tree level on all 50 monitored trees. A major flowering event is when at the basic level flowering intensity is strong or massive (code 4 or 5 ) and the proportion of trees with the given flowering intensity is above $60 \%$ (code 4 or 5). On average, two visits to the plot are needed; the first one early enough to observe the early stages of flowering, and the second when flowering is in full progress.

Three scores are provided for each tree: female flowering stage, male flowering stage and the proportion of the crown flowering. The proportion of the crown flowering refers to the total number of inflorescences (male + female + hermaphrodite) on the tree. For graphical representation of flowering stages see Figure 5.

Background information on flowering synchronisation can be estimated from the scores for flowering stage and the background information 7.2.3 Sex ratio.

\begin{tabular}{|c|c|}
\hline \multicolumn{2}{|c|}{ Code Flowering stage } \\
\hline 1 & Buds are closed, swelling of buds can be observed but stamens/pistils are not yet visible \\
\hline 2 & Buds are open, stamens/pistils are visible but not yet shedding pollen/receptive \\
\hline 3 & Inflorescences are fully open, stamens releasing pollen, pistils receptive \\
\hline
\end{tabular}

\begin{tabular}{lr} 
Code & Proportion of the crown flowering (\%) \\
\hline 1 & $0-10$ \\
\hline 2 & $>10-30$ \\
\hline 3 & $>30-60$ \\
\hline 4 & $>60-90$ \\
\hline 5 & $>90$ \\
\hline
\end{tabular}



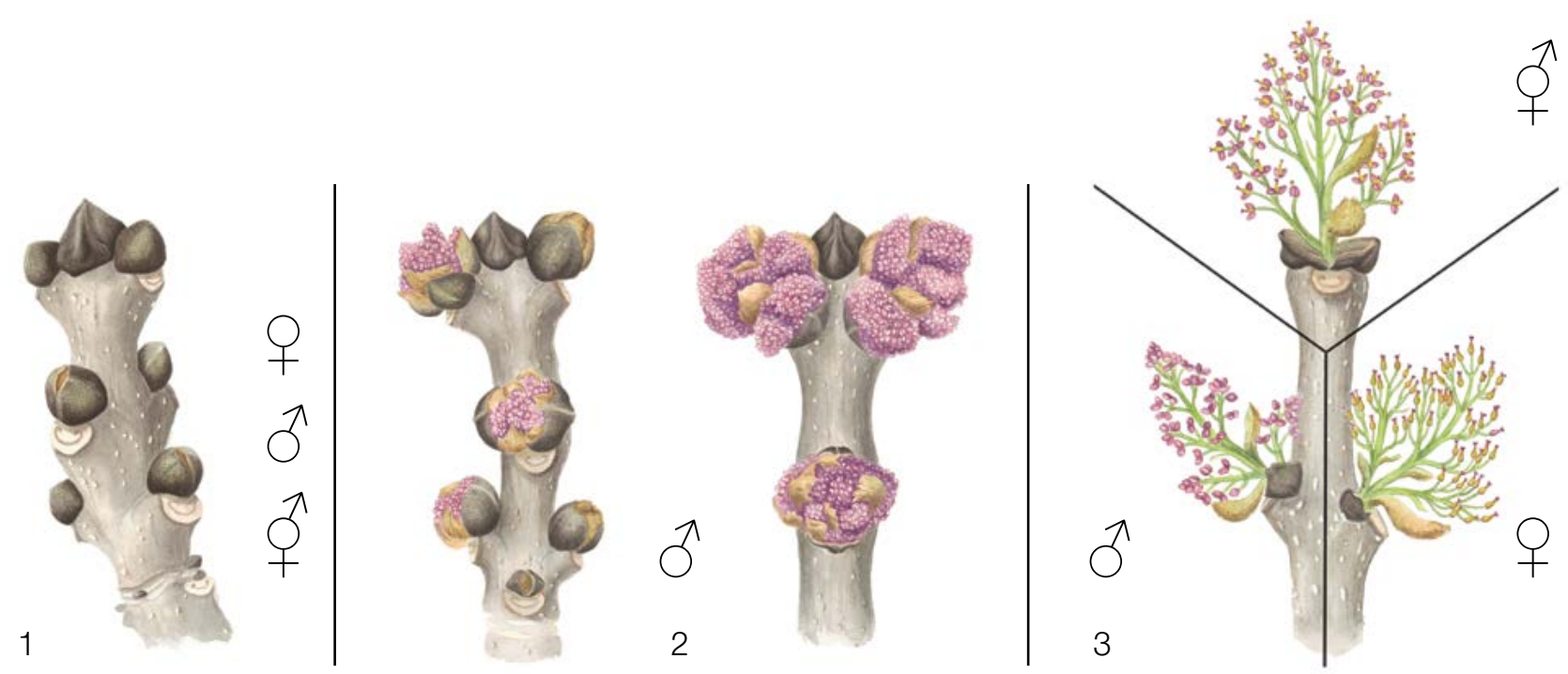

Figure 5: Picture guide for description of flowering stages for the advanced level verifier Flowering. For stage 3, the inflorescence growing from the terminal bud is only for illustrative purposes; in reality leaves develop from the terminal bud.

\subsubsection{Fructification}

This verifier describes the presence of fructification and its abundance. Data for this verifier should be collected during fructification, in August to October in central Europe.

\subsubsection{Basic level}

This verifier is recorded every year at the stand level. The estimate of average condition is provided after a walk throughout the monitoring plot. Two scores are given, one for fructification intensity and one for the proportion of fructifying trees in the stand.

\section{Code Fructification intensity at the stand level}

Average proportion of the crown bearing fruit (\%)

\begin{tabular}{llr}
\hline 1 & No fructification: No or only occasional fruit appearing on trees & $0-10$ \\
\hline 2 & Weak fructification: Some fruit appearing on trees & $>10-30$ \\
\hline 3 & Moderate fructification: Moderate amount of fruit appearing on trees & $>30-60$ \\
\hline 4 & Strong fructification: Abundant amount of fruit appearing on trees & $>60-90$ \\
\hline 5 & Massive: Huge amount of fruit appearing on trees & $>90$ \\
\hline
\end{tabular}

\begin{tabular}{lr} 
Code & Proportion of trees in the stand with the given stage of fructification intensity (\%) \\
\hline 1 & $0-10$ \\
\hline 2 & $>10-30$ \\
\hline 3 & $>30-60$ \\
\hline 4 & $>60-90$ \\
\hline 5 & $>90$ \\
\hline
\end{tabular}

\subsubsection{Standard level}

This verifier is recorded during the same years as the assessment of the flowering at the standard level (regardless of the fructification intensity). It is recorded at an individual tree level on all 50 monitored trees. Recording is carried out before fruits start falling. One score is provided for each tree. 
Ideally, one major fructification event should be captured following observations of major flowering events per decade. However, a major flowering event does not necessarily lead to a major fructification event. If no major fructification event follows the assessed flowering event, then the assessment of both flowering and fructification needs to be repeated during the next major flowering event, regardless of the time passed between successive major flowering events. Basic level observations are used to identify major fructification events. A major fructification event is when at the basic level fructification intensity is strong or massive (code 4 or 5) and the proportion of trees with the given fructification intensity is above $60 \%$ (code 4 or 5 ).

\begin{tabular}{|c|c|c|}
\hline \multicolumn{2}{|c|}{ Code Fructification intensity } & \multirow{2}{*}{$\begin{array}{l}\text { Proportion of the crown fructifying }(\%) \\
\qquad 0-10\end{array}$} \\
\hline 1 & No fructification: No or only occasional fruit appearing on a tree. & \\
\hline 2 & Weak fructification: Some fruit appearing on a tree. & $>10-30$ \\
\hline 3 & Moderate fructification: Moderate amount of fruit appearing on a tree. & $>30-60$ \\
\hline 4 & Strong fructification: Abundant amount of fruit appearing on a tree. & $>60-90$ \\
\hline 5 & Massive: Huge amount of fruit appearing on a tree. & $>90$ \\
\hline
\end{tabular}

Indirectly, recording of this verifier provides information as to whether a tree is functionally female or male, and allows for observation of fluctuation of the functional sex through time.

\subsubsection{Advanced level}

This verifier is recorded at an individual tree level on all 50 monitored trees during the same years as the assessment of flowering at the advanced level, regardless of the fructification intensity. Recording is carried out before fruits start falling. One score is provided for each tree. Simultaneously, seed is collected for seed and genetic analysis for the advanced level verifiers and background information.

Ideally, one major fructification event should be captured following observations of major flowering events per decade. However, a major flowering event does not necessarily lead to a major fructification event. If no major fructification event follows the assessed flowering event, assessment of both flowering and fructification needs to be repeated during the next major flowering event, regardless of the time passed between successive major flowering events. Basic level observations are used to identify major fructification events. A major fructification event is when at the basic level fructification intensity is strong or massive (code 4 or 5) and the proportion of trees with the given fructification intensity is above $60 \%$ (code 4 or 5 ).

The verifier is recorded by counting fruits using binoculars. The average of three rounds of counting is reported. Each round of counting consists of the number of fruits that the observer counts in 30 seconds. For all trees, the same part of the crown should be investigated. Once the observation part of the crown part is selected, the same one should be selected for every subsequent monitoring of this verifier. The upper third of the crown is preferred to the bottom and middle part for counting.

Two values are recorded; the number of fruits and the part of the crown monitored.

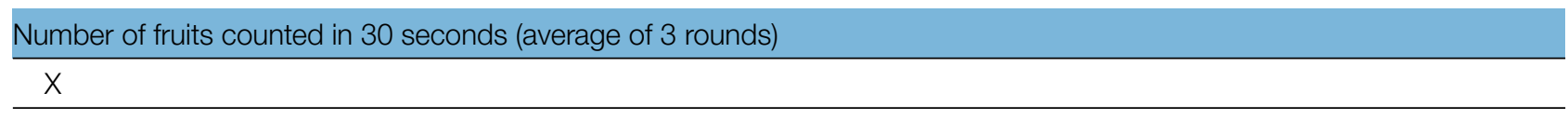

\begin{tabular}{ll} 
Code & Part of the crown monitored \\
\hline 1 & Bottom \\
\hline 2 & Middle \\
\hline 3 & Top \\
\hline
\end{tabular}




\subsubsection{Natural regeneration abundance}

This verifier describes the presence and abundance of natural regeneration at the monitoring plot.

\subsubsection{Basic level}

This verifier is recorded at the stand level every year in the autumn. Expert opinion is used for estimation considering the situation over the whole monitoring plot. Two values should be recorded, one for new natural regeneration (current-year seedlings) and one for established regeneration (saplings that are older than one year).

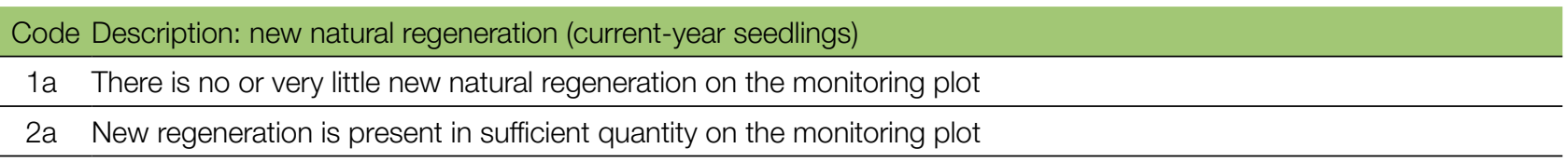

\begin{tabular}{|c|c|}
\hline $1 b$ & There is no or very little established natural regeneration on the monitoring plot \\
\hline $2 b$ & Established regeneration is present in sufficient quantity on the monitoring plot \\
\hline
\end{tabular}

\subsubsection{Standard level}

This verifier is recorded by counting seedlings in the $2^{\text {nd }}$ (in the autumn two years after the major fructification event; the year of the fructification event is regarded as year 0 ) and $7^{\text {th }}$ years after the fructification event, as ash seeds usually remain dormant for two winters in the soil.

Counting of seedlings:

After the establishment of NR sublots, all ash seedlings present at each of the 20 NR sublots must be counted. Any older ash saplings that are present on the NR subplot must not be included. During the next counting round, only saplings of the appropriate age must be counted - i.e., in the $8^{\text {th }}$ year, five-year old saplings.

\section{Number of seedlings counted on a subplot}

$$
\mathrm{x}
$$

Mortality/survival of natural regeneration is calculated from the numbers recorded for this verifier.

The establishment of NR subplots and the beginning of observations must adapt to the actual duration of the seed dormancy in the monitored location.

For subplot establishment see 6.2 Establishment of natural regeneration subplots.

\subsubsection{Advanced level}

This verifier is recorded by counting seedlings at each of the $20 \mathrm{NR}$ subplots in the $2^{\text {nd }}$ autumn after every assessed fructification event (the year of the fructification event is regarded as year 0 ) and $7^{\text {th }}, 12^{\text {th }}$, and $17^{\text {th }}$ years after this fructification event, as ash seeds usually remain dormant for two winters in the soil.

If seeds are dormant for longer in the monitored ash stand, the observation years must adapt to the duration of the dormancy. 
Table 2: Timeline of natural regeneration abundance (NR) assessment. In this example, the first assessed fructification event takes place in the $2^{\text {nd }}$ year of the monitoring decade, and - considering ash seed dormancy of two winters - 20 NR subplots are established in the $4^{\text {th }}$ year of the monitoring decade. The next assessment of fructification is carried out in the $8^{\text {th }}$ year of the monitoring decade. Considering ash seed dormancy, 20 new NR subplots are established in the $10^{\text {th }}$ year of the decade. Twenty new NR subplots are established after each assessed fructification event. Monitoring of NR abundance on each set of 20 NR subplots is carried out every five years. The fructification events corresponding to the assessed NR and timelines of the assessment activities are shaded in the same colour. After the final round of counting of seedlings, monitoring of NR abundance on the respective set of NR subplots is stopped and the respective NR subplots disestablished. S - standard level; A - advanced level.

\begin{tabular}{|c|c|c|c|c|c|c|c|c|c|c|c|c|c|c|c|c|c|}
\hline Year of monitoring & 1 & 2 & 3 & 4 & 5 & 6 & 7 & 8 & 9 & 10 & 11 & 1213 & 141516 & 171819 & 2021 & 2223 & 2425 \\
\hline Fructification event & & $\bullet$ & & & $\bullet$ & $\bullet$ & & $\bullet$ & & $\bullet$ & & $\bullet$ & $\bullet$ & $\bullet$ & $\bullet$ & $\bullet$ & $\bullet$ \\
\hline $\begin{array}{l}\text { NR assessment from the } 1^{\text {st }} \\
\text { assessed fructification event }\end{array}$ & & 0 & 1 & 2 & 3 & 4 & 5 & 6 & 7 & 8 & 9 & 1011 & 121314 & 151617 & 1819 & 2021 & 2223 \\
\hline NR subplots establishment & & & & SA & & & & & & & & & & & & & \\
\hline NR abundance counting & & & & SA & & & & & SA & & & & $A$ & A & & & \\
\hline $\begin{array}{l}\text { NR assessment from the } 2^{\text {nd }} \\
\text { assessed fructification event }\end{array}$ & & & & & & & & 0 & 1 & 2 & 3 & 45 & 678 & 91011 & 1213 & 1415 & 1617 \\
\hline NR subplots establishment & & & & & & & & & & SA & & & & & & & \\
\hline NR abundance counting & & & & & & & & & & SA & & & SA & & $A$ & & $A$ \\
\hline
\end{tabular}

Mortality/survival of natural regeneration is calculated from the numbers recorded for this verifier.

For subplot establishment see 6.2 Establishment of natural regeneration subplots and for counting 7.1.4.2 Standard level.

\subsection{Protocols for recording of background information}

\subsubsection{DBH class distribution}

\subsubsection{Standard and advanced level}

$\mathrm{DBH}$ is recorded on an individual tree level on all 50 monitored trees every 10 years. $\mathrm{DBH}$ is the trunk diameter at $1.30 \mathrm{~m}$, i.e. approximately at an adult's breast height. If a tree has more than one trunk, please measure all of them and record the average (but try to avoid trees with many small trunks). Note that the tree is a multi-trunk one in the notes, and include the number of trunks measured. If the tree is leaning, measure DBH perpendicular to the tree trunk. DBH can be measured in two ways:

1) using a calliper, in which cases you would need to measure two perpendicular diameters and take the average

2) measuring the circumference of the tree and computing the diameter from that value (i.e. dividing by $\pi, \sim 3.14$ ) or using a pi-meter

The DBH is recorded in $\mathrm{cm}$. The same method must be applied for every subsequent measurement.

\subsubsection{Height class distribution}

\subsubsection{Standard and advanced level}

Height is recorded on an individual tree level on all 50 monitored trees every 10 years. Height is measured from the ground to the tallest part of the crown, ideally using a clinometer or hypsometer (e.g. vertex). Height is recorded in meters to one decimal place. If the crown is damaged, this must be recorded as well as the reason for this in the notes. 


\subsubsection{Sex ratio}

This background information describes the sex of individual ash trees. It can be recorded simultaneously with the verifier 7.1.3 Flowering during flowering in March to April in central Europe.

\subsubsection{Standard level}

At the standard level, this background information is recorded on the individual tree level on all 50 monitored trees at the same time as the verifier Flowering. For a graphical representation of male, female and hermaphrodite inflorescences, see Figure 6.

\begin{tabular}{lll} 
Code & Sex & Description \\
\hline 1 & Male & More than half of inflorescences on the tree are male. \\
\hline 2 & Female & More than half of inflorescences on the tree are female. \\
\hline 3 & Hermaphrodite & More than half of inflorescences on the tree are hermaphrodite \\
\hline
\end{tabular}

\subsubsection{Advanced level}

At the advanced level, this background information is recorded on the individual tree level on all 50 monitored trees at the same time as the verifier Flowering. The percentage of male, female and hermaphrodite inflorescences is reported for each monitored tree with $10 \%$ accuracy. For a graphical representation of male, female and hermaphrodite inflorescences, see Figure 6.

\begin{tabular}{ll} 
Code & Sex \\
\hline 1 & $\%$ male inflorescences \\
\hline 2 & $\%$ female inflorescences \\
\hline 3 & $\%$ hermaphrodite inflorescences \\
\hline
\end{tabular}

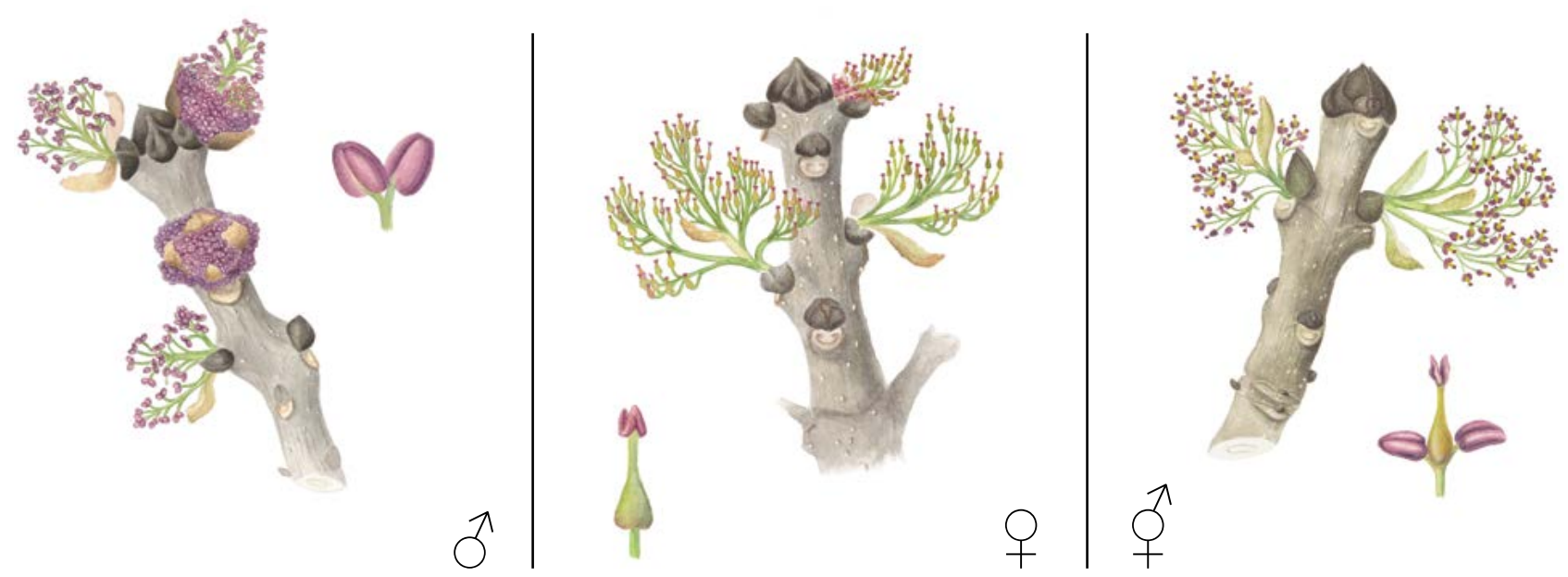

Figure 6: Picture guide for $F$. excelsior inflorescences for sex ratio determination.

Trees with inflorescences that are intermediate between female and hermaphrodite, with small anthers and which may or may not shed pollen are difficult to characterise. If more inflorescences are female, the tree may be characterised as female, if more are hermaphrodite, the tree may be characterised as hermaphrodite.

\subsubsection{Crown dieback}

This background information describes the crown condition due to ash dieback. The verifier is recorded every year by expert observation on all 50 monitored trees. Data for this verifier should be ideally collected during the 
period when the leaves are fully developed, e.g. in July in central Europe. For a graphical representation of stages of crown dieback, see Figure 7.

\subsubsection{Basic, standard and advanced levels}

Code Description

\begin{tabular}{ll}
\hline 1 & healthy crown (0-10\% defoliation) \\
\hline 2 & dead branch tips visible on the crown's edge, crown otherwise in good condition (11-30\% defoliation) \\
\hline 3 & dead branches visible on the crown's edge, crown is thin enough that one can see through it (31-50\% defoliation) \\
\hline 5 & secondary crown is building at the trunk, thick branches without leaves visible, crown is very thin (51-80\% defoliation) \\
\hline 6 & tree is dead (100\% defoliation) \\
\hline
\end{tabular}

1

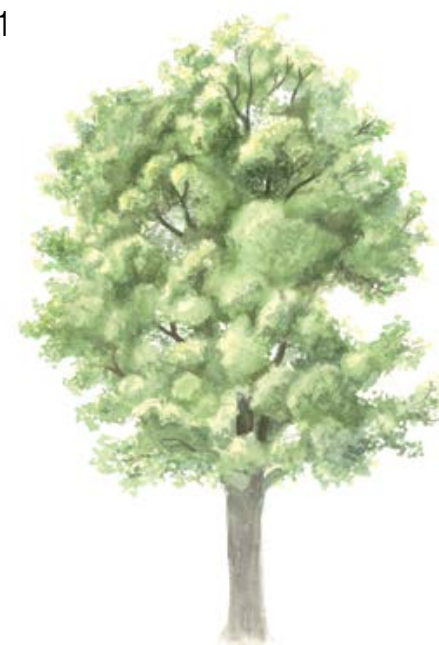

4

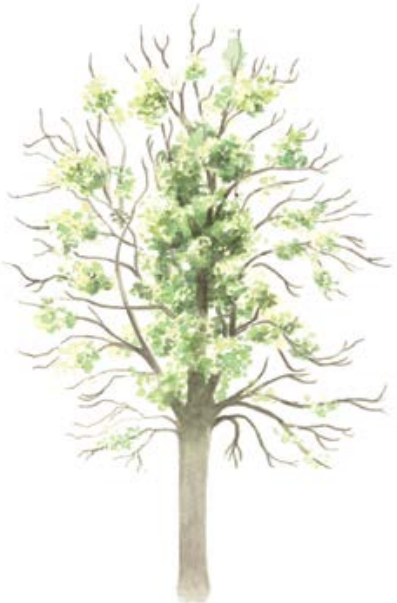

2

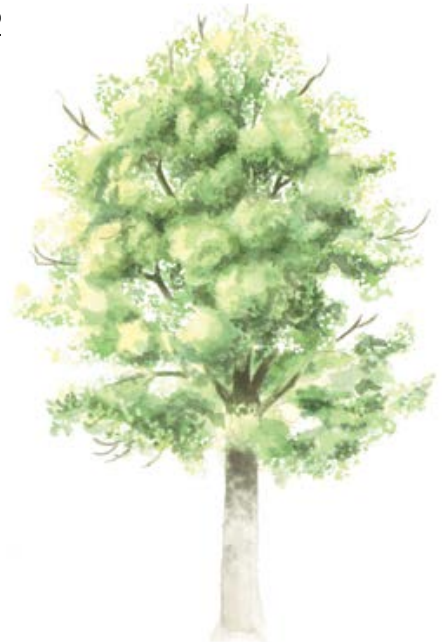

5

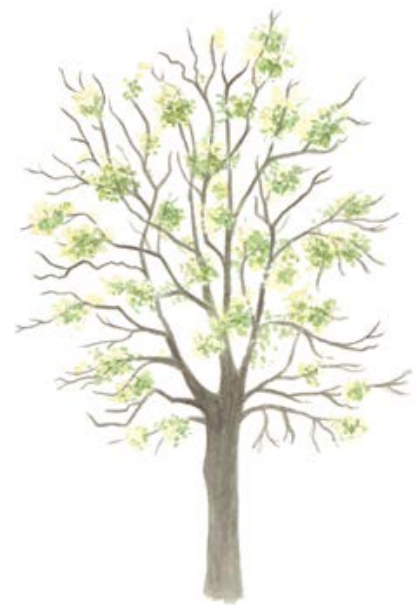

3

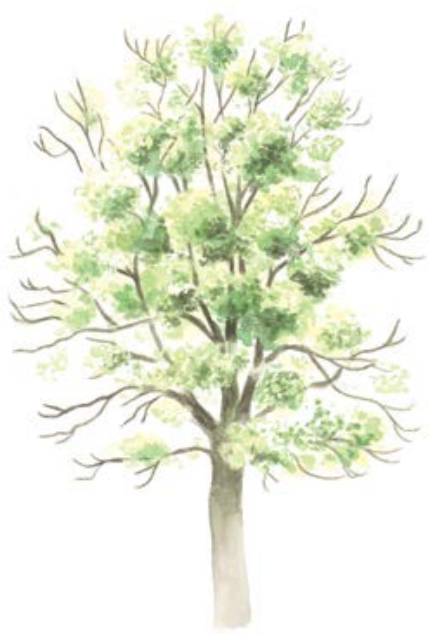

6

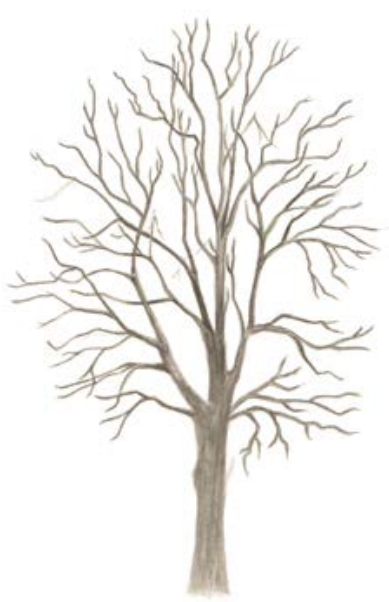

Figure 7: Picture guide for ash dieback estimation 


\subsubsection{Budburst}

Budburst describes the process of budbursting (flushing). In ash, budbursting starts after flowering. Recording is only carried out at the standard and advanced levels. Data for this background information should be collected in April in central Europe; several visits are needed and recording stops when all monitored trees have reached fully developed leaves. Budbursting is earlier when preceded by a warm winter.

\subsubsection{Standard level}

At standard level, budburst is recorded on an individual tree level on all 50 monitored trees every five years. We are looking for the initiation of budbursting (stage 3) and the end of budbursting (stage 5). The observations cease when all the trees have reached stage 5. Usually, six visits will be needed. For each tree, two estimates are given: stage of budbursting and proportion of the crown budbursting. For a graphical representation of budbursting stages, see Figure 8.

\begin{tabular}{ll}
\hline Code & Stage of budbursting \\
\hline 1 & Dormant buds \\
\hline 2 & Buds are swelling but are still closed \\
\hline 3 & Buds are bursting \\
\hline 4 & Buds are elongating \\
\hline 5 & Leaves are separated and start growing vertically \\
\hline
\end{tabular}

\begin{tabular}{lr} 
Code & Proportion of the crown with a given Stage of budbursting (\%) \\
\hline 1 & $>0-33$ \\
\hline 2 & $>33-66$ \\
\hline 3 & $>66-99$ \\
\hline 4 & 100 \\
\hline
\end{tabular}

\subsubsection{Advanced level}

At advanced level, budburst is recorded on an individual tree level on all 50 monitored trees every year in the same way as at the standard level. For details see 7.2.5.1 Standard level.

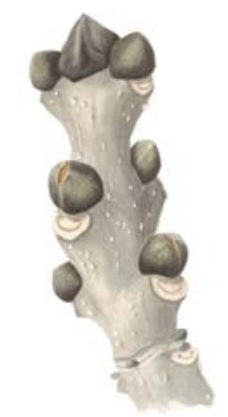

1

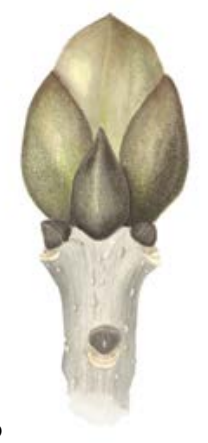

2

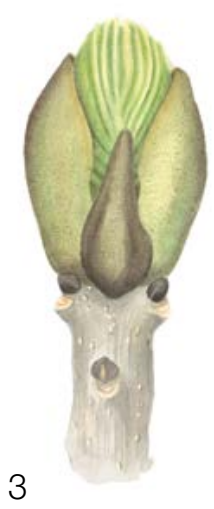

3

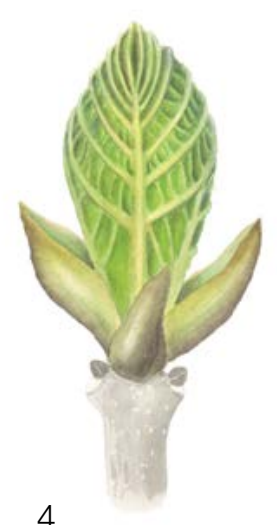

4

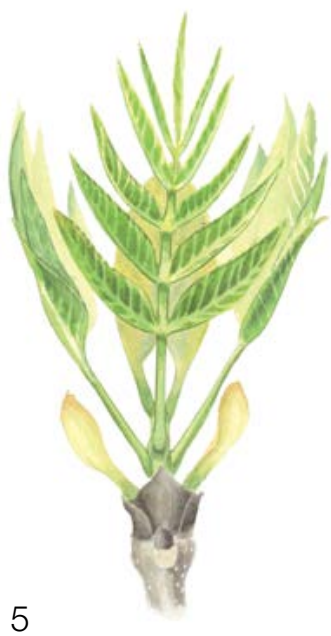

Figure 8: Picture guide for description of budburst (flushing) for the standard and advanced level background information Budburst. 


\subsubsection{Senescence}

Senescence describes the process of leaf senescence. Recording of this background information is only carried out at the standard and advanced levels.

\subsubsection{Standard level}

At the standard level, senescence is recorded on an individual tree level on all 50 monitored trees every five years. We are looking for stage 3, when leaves are yellow and do not photosynthesise anymore. Observations stop when all the trees have reached stage 3. Usually, two (2) visits to the plot will be needed. For each tree, three estimates are given: stage of leaf colouring, proportion of the crown senescing and proportion of the leaves being shed.

\begin{tabular}{ll} 
Code & Stage of leaf colouring \\
\hline 1 & Leaves are fully green \\
\hline 2 & Leaves are green with yellow spots \\
\hline 3 & Leaves are fully yellow \\
\hline 4 & Leaves are brown \\
\hline
\end{tabular}

\begin{tabular}{lr} 
Code & Proportion of the crown with a given score for the stage of leaf colouring (\%) \\
\hline 1 & $0-33$ \\
\hline 2 & $>33-66$ \\
\hline 3 & $>66-99$ \\
\hline 4 & 100 \\
\hline
\end{tabular}

\begin{tabular}{lr} 
Code & Proportion of leaves that have been shed due to senescence (\%) \\
\hline 1 & $>0-33$ \\
\hline 2 & $>33-66$ \\
\hline 3 & $>66-99$ \\
\hline 4 & 100 \\
\hline
\end{tabular}

\subsubsection{Advanced level}

At the advanced level, senescence is recorded on an individual tree level on all 50 monitored trees every year in the same way as at the standard level. For details see 7.2.6.1 Standard level.

\subsubsection{Flowering synchronisation}

\subsubsection{Advanced level}

Flowering synchronisation is monitored only at the advanced level, and is based on the data collected for the verifier Flowering. It is used to determine whether male and female flowering times occur simultaneously within the monitored stand.

\section{For plot establishment use form 'FGM Plot description'}

\section{For verifiers recording use 'Form for recording field level verifiers within FGM'}

For background information recording use 'Form for recording field level background information within FGM' 


\section{References}

1. Pliûra A, Heuertz M (2003) EUFORGEN Technical Guidelines for genetic conservation and use for common ash (Fraxinus excelsior). International Plant Genetic Resources Institute, Rome

2. Beck P, Caudullo G, Tinner W, de Rigo D (2016) Fraxinus excelsior in Europe: distribution, habitat, usage and threats. In: San-Miguel-Ayanz J, de Rigo D, Caudullo G, Houston Durrant T, Mauri A (ed) European Atlas of Forest Tree Species. Publ. Off. EU, Luxembourg, pp 98-99. DOI: 10.2788/4251

3. FRAXIGEN (2005) Ash species in Europe: biological characteristics and practical guidelines for sustainable use. Oxford Forestry Institute, University of Oxford, UK

4. Ogris N (2020) Varstvo gozdov Slovenije - portal. https://www.zdravgozd.si/meni_index.aspx. Accessed 16 September 2020

The following resources were consulted for the currently accepted (December 2020) scientific names of the species covered or mentioned in this document:

a. $\quad$ CABI (2020) Invasive Species Compendium. CAB International, Wallingford, UK. www.cabi.org/isc. Accessed 15 December 2020

b. EPPO (2020) EPPO Global Database (available online). https://gd.eppo.int. Accessed 15 December 2020

c. GBIF (2020) Global Biodiversity Information Facility. https://www.gbif.org Accessed 15 December 2020

d. IPNI (2020) International Plant Names Index. The Royal Botanic Gardens, Kew, Harvard University Herbaria \& Libraries \& Australian National Botanic Gardens. http://www.ipni.org, Accessed 10 December 2020

e. National Center for Biotechnology Information (NCBI) (1998) National Library of Medicine (US), National Center for Biotechnology Information, Bethesda (MD). https://www.ncbi.nlm.nih.gov/. Accessed 15 December 2020

f. Stevens PF (2001) Angiosperm Phylogeny Website, Version 14. http://www.mobot.org/MOBOT/research/APweb/. Accessed 15 December 2020

g. The Plant List (2013) Version 1.1. http://www.theplantlist.org/. Accessed 12 December 2020

h. Tropicos.org (2020) Missouri Botanical Garden. http://www.tropicos.org. Accessed 15 December 2020

i. WFO (2020) World Flora Online. http://www.worldfloraonline.org. Accessed 15 December 2020 



\section{Guidelines for genetic monitoring of}

\subsubsection{European black pine (Pinus nigra J. F. Arnold)}

Paraskevi ALIZOTI', Darius KAVALIAUSKAS², Barbara FUSSI²,

Marjana WESTERGREN ${ }^{3}$, Marko BAJC ${ }^{3}$, Phil ARAVANOPOULOS ${ }^{1}$,

Rok DAMJANIĆ ${ }^{3}$, Hojka KRAIGHER ${ }^{3}$

Botanical illustrations by Klara JAGER

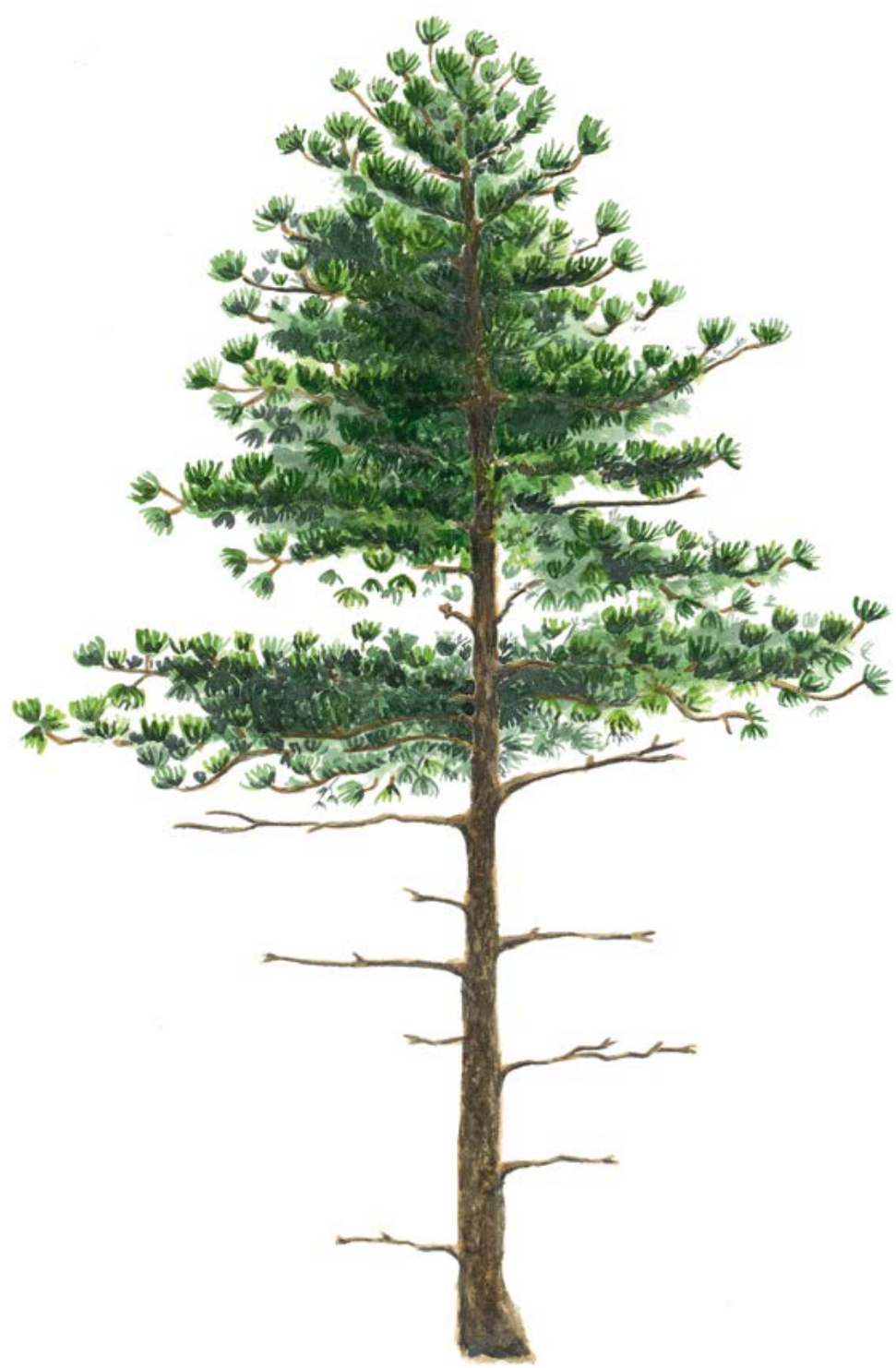

Citation: Alizoti et al. (2020) Guidelines for genetic monitoring of European black pine (Pinus nigra J. F. Arnold). In: Bajc et al. (eds) Manual for Forest Genetic Monitoring. Slovenian Forestry Institute: Silva Slovenica Publishing Centre, Ljubljana, pp 215-233. http://dx.doi.org/10.20315/SFS.167

\footnotetext{
Affiliations:

1. Aristotle University of Thessaloniki (AUTh), Greece

2. Bavarian Office for Forest Genetics (AWG), Germany

3. Slovenian Forestry Institute (GIS), Slovenia
} 


\section{Executive summary}

European black pine (Pinus nigra J. F. Arnold) is a wind-pollinated, monoecious, mainly outcrossing, high elevation, circum-Mediterranean conifer, that also grows in Austria, Crimea, and the Black Sea. Due to the species' extensive distribution in a broad spectrum of environments, that led to its morphological and genetic differentiation, five interfertile sub-species can be recognised across its natural distribution. Black pine is a valuable key-stone species of high economic and ecological importance, producing wood of high quality and natural durability. It is characterised by its tolerance to abiotic stresses, such as poor and salty soils, frosts, ice weight, strong winds, and drought. The species regenerates naturally in forest ecosystems, but has no mechanisms of regeneration after fire, a fact that renders it vulnerable to the extensive wildfires usually occurring across the Mediterranean basin. Given the high economic and ecological significance of the species, its extensive natural distribution to a variety of habitats and the existence of isolated and marginal populations that could be at risk in the face of climate change, it can be considered as a good candidate species for genetic monitoring.

The present guidelines provide a short description of the European black pine; its distribution, ecology, reproduction and threats posing risks for the species, together with guidance on the establishment of a monitoring plot and the recording of all field verifiers needed to fulfil the genetic monitoring goals.

\section{Species description}

European black pine is a circum-Mediterranean conifer, growing also in Austria, Crimea, and the Black Sea. The following [1] five subspecies can be recognised based mainly on morphological/anatomical traits: a) P. nigra J. F. Arnold subsp. nigra, distributed in southeastern Austria, northern Italy, the Balkan Peninsula, Bulgaria, Romania, Turkey-in Europe; b) P. nigra subsp. dalmatica (Vis.) Franco, distributed in Croatia; c) P. nigra subsp. laricio (Poir.) Palib. ex Maire, distributed in France (Corsica) and Italy (Apennines, Sicily); d) P. nigra subsp. pallasiana (Lamb.) Holmboe distributed to Greece, Cyprus, southwest Bulgaria, southeast North Macedonia, south Albania, and from Crimea along the Black Sea coast to Turkey; and e) P. nigra subsp. salzmannii (Dunal) Franco, distributed in southwest Europe, France (Hérault, Pyrenees), Spain, Algeria and Morocco. The species grows in association with Pinus sylvestris L., Pinus mugo Turrra, Pinus halepensis Mill., Pinus pinea L. and Pinus heldreichii Christ [2]. In most of the cases the species forms pure stands, while it can be found in mixed stands together with other pines and especially Pinus sylvestris [12].

(a)

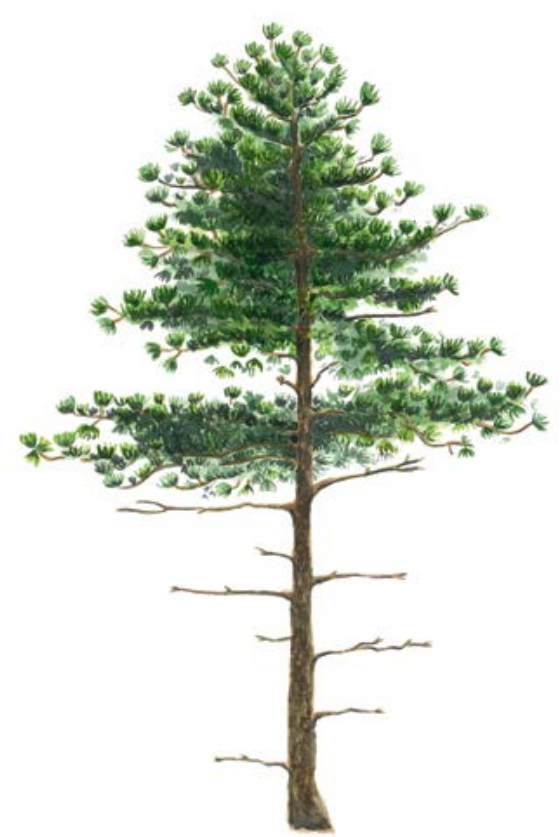

(b)

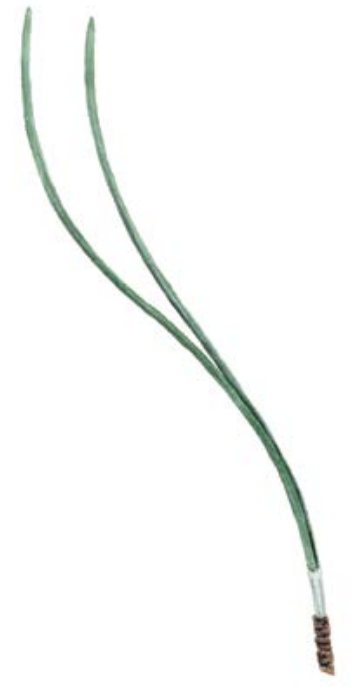

Figure 1: Pinus nigra habitus (a) and needles (b). 
Natural interspecific hybridisation among Pinus nigra and other pine species has been reported, as for example with $P$. sylvestris, P. heldreichii, P. densiflora Siebold \& Zucc., P. resinosa Aiton, P. tabulaeformis Carrière, P. taiwanensis Hayata, $P$. mugo, $P$. thunbergii Parl. $[3,4,5,6,7]$, when the species naturally co-exist with black pine or when artificially introduced. Intraspecific hybridisation among subspecies is possible, as the reproductive barriers to gene exchange among them are weak, leading to transitional forms that result from the extensive gene flow due to the long-distance pollen dispersal [8].

The species is a medium-sized two needle pine (Figure 1), reaching at the maturation age (80 years of age) a height of $30-50 \mathrm{~m}$, being characterised by a straight stem form. The bark colour ranges from light grey to dark grey-brown and is widely split by flaking fissures into scaly plates in old trees [9]. The bark becomes increasingly creviced with age [10]. The crown has pyramidal form in the young age but rounds with age forming a spreading flat top or dome. The needles are stiff, 8 to $16 \mathrm{~cm}$ long and 1-2 $\mathrm{mm}$ wide, straight or curved and finely serrated, while the needle sheath is $10-12 \mathrm{~mm}$ long [11,12].

\section{Reproduction}

European black pine is a monoecious anemophilous conifer with winged seeds, dispersed by the wind. Reproductive maturity is reached at the 15-20 years of age. The male strobili and the female strobili (conelets) (Figure 2a) appear every year during May. The female strobili (conelets) are red to purple and the male strobili when immature are green turning gradually to yellow when they reach maturity and shed their pollen. The pollen dispersal and female conelet receptivity occur from May to early June, while the duration of conelet receptivity usually lasts for three days [8]. Fertilisation occurs 13 months after pollination. The mature cones (Figure 2b) are sessile and horizontally spreading, 4-8 cm long and 2-4 cm wide, with a colour ranging from brown to yellow brown or even light yellow. The cones ripen from September to November of the second year and open the third year after pollination [12]. Usually each fertile cone scale produces two winged seeds (Figure 2c) and the cones usually bear 30-40 seeds out of which almost half germinate. The seed dispersal occurs from October till November of the second growing season. The seed colour may range from grey to light yellow and seed length from 5-7mm, while the wing length from $19-26 \mathrm{~mm}$. Mast seeding occurs every two to five years [13].

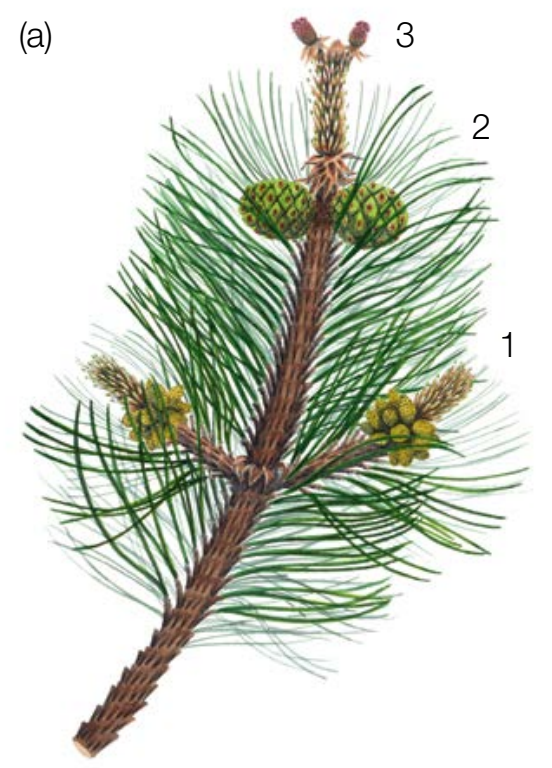

(b)

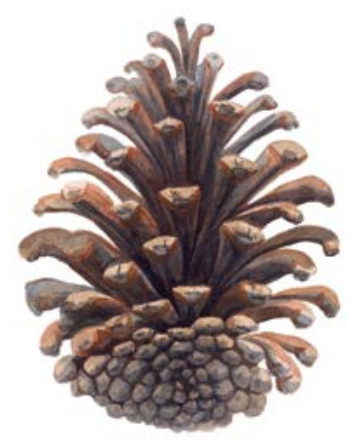

(c)

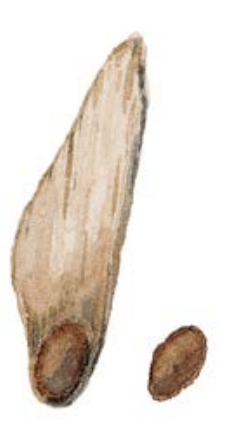

Figure 2: Pinus nigra branch with male strobili (a-1), female immature first year cones (a-2) and current year conelets (a-3), mature open cone (b) and seed with and without wing (c). 


\section{Environment}

Pinus nigra is characterised by an extensive natural distribution (i.e. circum-Mediterranean distribution with occurrences in Austria, Crimea and Black Sea) that includes a broad array of environments. It grows at altitudes ranging between $350 \mathrm{~m}$ to $2200 \mathrm{~m}$ (Taurus Mts), but its optimum altitude is between $800 \mathrm{~m}$ to $1500 \mathrm{~m}$. The species can grow in dry environments with poor soils and on a variety of substrates, ranging from limestone, to dolomites, acidic or volcanic soils [8]. Most of the species distribution falls within the Mediterranean-type climate, while the bioclimatic conditions may range from humid, to sub-humid and semi-arid. In parts of its native range it grows in cool to cold temperate climates, while the northern populations are frost-hardy, withstanding temperatures of $-30^{\circ} \mathrm{C}$, in contrast to the southern ones that may tolerate up to $-7^{\circ} \mathrm{C}$ [2]. Photosynthesis has been recorded even at the $-5^{\circ} \mathrm{C}$, and respiration could still be detected at $-19^{\circ} \mathrm{C}[2,14]$. The species can also withstand well the weight of ice and it is generally considered as a hardy one. The species is photophilous, shade intolerant, and can tolerate well winds, drought and salty soils.

\section{Threats}

The species may face risks, especially when growing in isolated populations, due to several factors that may cause extinction, such as wildfires, insects and diseases, illegal cutting and the overarching threat of climate change. Insects like Rhyacionia buoliana Denis \& Schiffermüller, Thaumetopoea pityocampa Denis \& Schiffermüller, Acantholyda hieroglyphica Christ, Diprion pini L., Pissodes validirostis L., Marchalina hellenica (Monophlebus hellenicus) Gen., and Ips pini Say, Bursaphelenchus xylophilus may infest the species [8,15]. Fungi like Mycosphaerella pini Rostr. (Dothistroma pini Hulbary), Lophodermella spp., Sphaeropsis sapinea (Fr.) Dyko \& B. Sutton (Diplodia pinea (Desm.) J. Kickx f.) may also infect the black pine needles $[16,17,18]$.

Additionally, mixing of gene pools across the whole of Europe, due to the extensive plantations established in the last two centuries with genetic material of unknown origin that can be maladapted to local conditions, constitutes a threat to the gene pools of autochthonous populations [8], as well as to their adaptive and evolutionary potential.

\section{Plot establishment and maintenance}

European black pine is a stand-forming tree species that in most of the cases forms pure stands, but it can also grow in mixture with $P$. sylvestris and other coniferous or broadleaved tree species [2]. Therefore, the regular Forest Genetic Monitoring (FGM) scheme followed for stand-forming tree species can be followed for black pine too.

An FGM plot should consist of 50 reproductively mature (i.e. flowering) trees, selected to fulfil the requirement of the $30 \mathrm{~m}$ distance among any two of them. The trees reach sexual maturity at the age of 15-20 years in their natural habitat [8]. The social class and $\mathrm{DBH}(\geq 15 \mathrm{~cm})$ could be used as proxy variables to locate potentially reproducing trees, in case the establishment of the plot does not take place during the flowering period, relying on the expertise of the local foresters. Furthermore, the presence of sufficiently dense natural regeneration (NR) must be considered, prior to designating an FGM area, in case NR subplots will need to be established to study the mating system patterns, gene flow and level of potential genetic variation changes among different generations. The selected reproductively mature trees within the plot need to be labelled and their coordinates should be recorded. Additionally, up to 20 NR subplots have to be selected and marked for NR abundance assessment and sampling.

DBH measurement and sampling for DNA extraction can also be performed during the time of plot establishment, as well as the assessment of flowering in case the plot is being established within the flowering period. 
Equipment needed:

- a device for distance measurement (a pair of range-finding binoculars is recommended)

- a compass

- paint and a paintbrush or paint sprayer for tree labelling

- a mask, safety glasses and gloves for spraying/labelling the trees

- a tree calliper for DBH measurements

- a GPS device that is precise enough and allows saving trees' coordinates

- a photo-camera to obtain pictures, in case the establishment of the plot is taking place during the flowering period.

Genetic monitoring plots in cases of isolated, marginal or threatened populations of this species can be larger than the regular ones. In those cases, the size and shape of the FGM plot should be flexible, but for practical reasons it should preferably not exceed 10 ha.

\subsection{Plot establishment}

\subsubsection{Selection of the centre of the plot}

The general procedure for random plot site selection consists of the following steps (Figure 3):

- Random selection of a point (green dot) on a map along the forest road or path, which runs along the stand,

- Drawing a perpendicular line from the randomly selected point on a road,

- Random selection of one point per line (red dot) - this point represents the centre of the FGM plot.

The minimum distance between the selected central point and stand border is approximately $150 \mathrm{~m}$. If the selected central point doesn't meet this demand, a new point must be selected following the protocol described above.

(a)

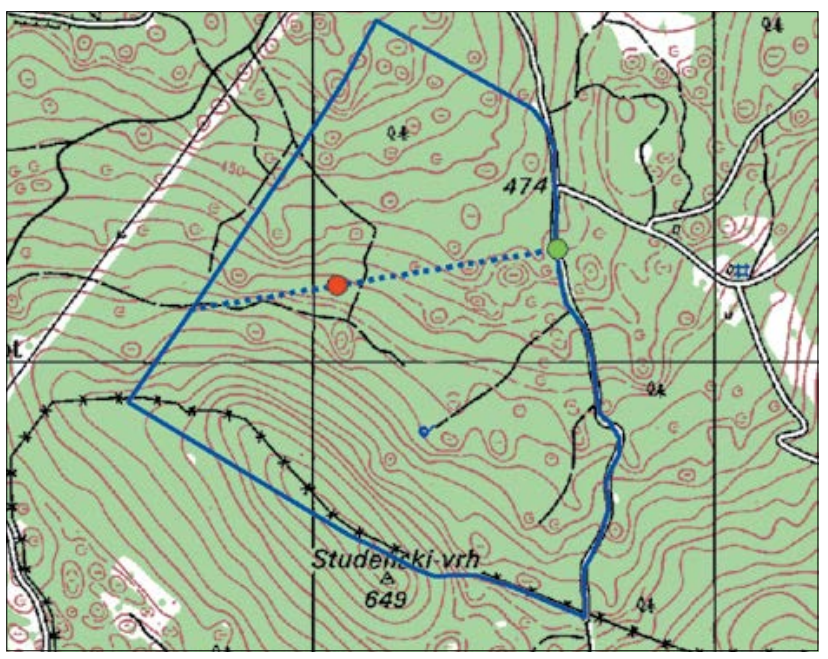

(b)

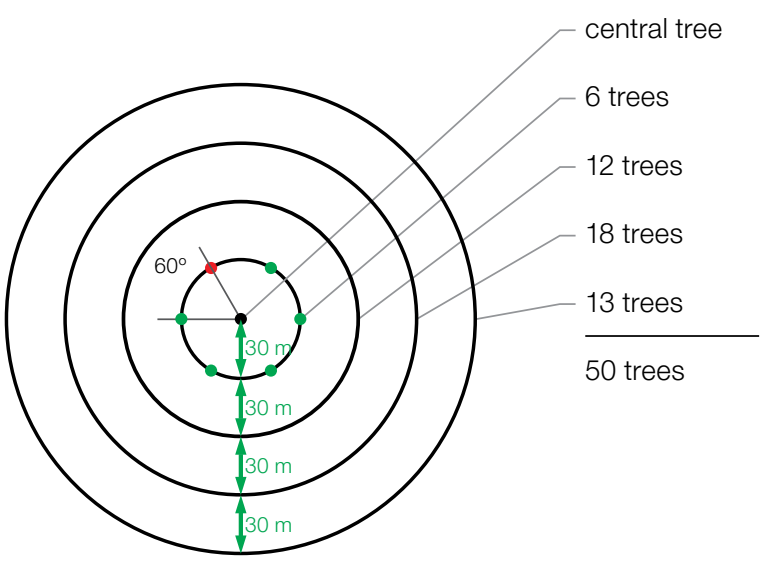

Figure 3: Random selection of the centre of the forest genetic monitoring plot (a); selection of trees in concentric circles around previously selected central tree with an increasing radius of $30 \mathrm{~m}$ (b).

Instead of the procedure described above, tools for creating random points in GIS software can also be used.

The selected point's coordinate should be saved in a GPS device that will be used in the field. 


\subsubsection{Plot installation in the field}

In the field, the closest reproducing tree to the saved GPS coordinate becomes the centre of the monitoring plot and is marked with number 1 .

Other trees are selected in concentric circles around the central tree with an increasing radius of $30 \mathrm{~m}$ (Figure 3b). The first tree in each circle should be selected randomly, which can be done in different ways: by using a random azimuth (Table 1) observed from the central tree, by following the direction of the second hand on an analogue watch or any other approach that allows for objective selection. The remaining trees in each circle are selected by an appropriately enlarged azimuth to assure a minimum distance of $30 \mathrm{~m}$ between any two trees:

- $+60^{\circ}$ for the first circle

- $+30^{\circ}$ for the second circle

- $+20^{\circ}$ for the third circle

$\cdot+15^{\circ}$ for the fourth circle

If it is not possible to find 6, 12 and 18 trees in the inner 3 circles (Figure 3b), additional trees are selected in the outermost circle.

Table 1: Randomly generated azimuths that can be used for selection of the first tree in each circle.

\begin{tabular}{rrrrrrrrrrr}
\hline 108 & 15 & 186 & 35 & 178 & 29 & 305 & 351 & 44 & 150 \\
\hline 232 & 23 & 160 & 141 & 112 & 292 & 216 & 83 & 245 & 214 \\
\hline 63 & 65 & 345 & 234 & 95 & 78 & 279 & 323 & 40 & 236 \\
\hline 201 & 313 & 275 & 144 & 182 & 68 & 268 & 289 & 185 & 92 \\
\hline 356 & 177 & 93 & 1 & 145 & 198 & 287 & 251 & 224 & 142 \\
\hline
\end{tabular}

In the case that the central tree is not visible due to existing obstacles (i.e. other trees covering the central tree) or topography, then the selection of trees can be based mainly on its minimum distance from the other selected trees $(\geq 30 \mathrm{~m}$ ), while the approximate location of the central tree could only be assumed if considering the position of the selected trees from the previous circles or by plotting the coordinates on open Earth plotting platforms (i.e. google maps/earth).

\subsubsection{Labelling of trees}

Each selected tree must be marked with a corresponding number and a band painted around the trunk to aid the visibility of the trees from all directions. Mark the central tree (number 1) with two or more bands to differentiate it from other trees (Figure 4a). It is recommended to paint the number on the side of the tree that is pointing away from the central tree, as this helps in locating the central tree, particularly from the outer rings of the plot (Figure 4b). 

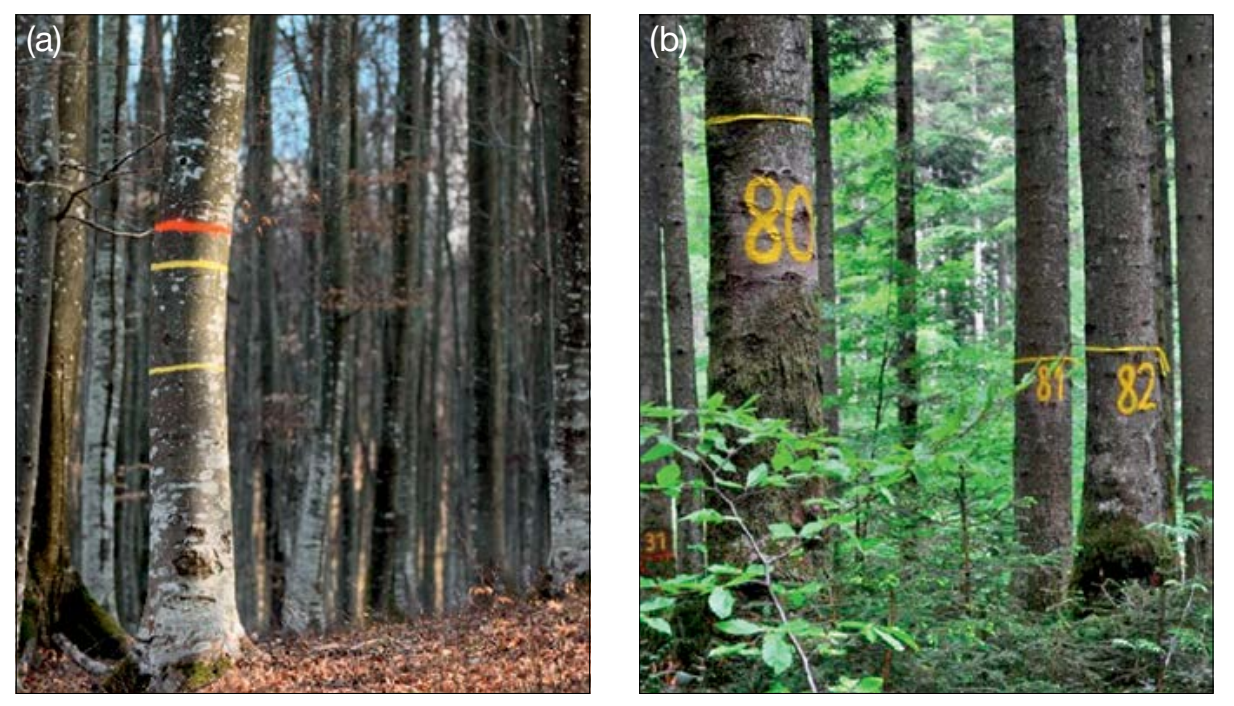

Figure 4: a) The central tree on the genetic monitoring plot is marked with multiple bands to differentiate it from other trees (an example of a European beech FGM plot); b) numbers are painted on selected trees so that they point away from the central tree. Image depicts a Silver fir (Abies alba Mill.) forest genetic monitoring plot in Bavaria.

\subsection{Establishment of natural regeneration subplots}

The establishment of natural regeneration (NR) subplots should be carried out during germination after a strong or massive fructification event.

Natural regeneration centres from the last mast year should be surveyed in the field and their locations logged (GPS coordinates, number of the tree which is next to an NR centre). From all logged regeneration centres, 20 should be chosen randomly for plot installation. If 20 or fewer natural regeneration centres are present, all should be used.

Inside each selected natural regeneration centre a $1 \mathrm{~m}^{2}$ plot is to be installed and marked with metal rods. The metal rods should be driven into the ground at each corner of the subplot as deep as possible to prevent them from being removed by animals. The tips of the metal rods should be painted to aid their visibility.

\subsection{Plot maintenance}

\subsubsection{General maintenance}

Tree markings and subplot markings must be checked periodically (every two years) and repaired if needed.

\subsubsection{Replacement of trees}

If a monitored tree dies or is cut due to management, it must be replaced. The nearest suitable tree to the dead one should be chosen considering that the distance requirement of $30 \mathrm{~m}$ to the nearest monitored tree is fulfilled. Otherwise a tree from the periphery (preferably in the outer circle) of the FGM plot is to be selected. The replacement tree is marked with the next available number higher than 50, i.e. 51, 52, 53, etc. to positively differentiate it from the original 50 selected trees.

If the crown is damaged due to, for example, wind break, ice or snow break but continues to fructify, the tree is kept for monitoring. If the damage is too severe and fructification is not expected anymore, the monitored tree must be replaced. The cause of damage needs to be recorded, as the damage can affect the values recorded for field verifiers and background information. 


\section{Recording of verifiers and background information}

Verifiers and background information are periodically recorded on the monitoring plot. Verifiers are used to monitor the population's genetic properties and its adaptation to environmental changes and/or management, while background information is recorded to assist interpretation of the verifiers.

Higher levels of verifiers (standard, advanced) must also include recording on all the preceding levels (basic, standard). This is not necessary for recording of background information.

Table 2: List of verifiers and background information with short description and observation frequency to be recorded during field work at the black pine monitoring plots.

\begin{tabular}{|c|c|c|c|c|}
\hline & Name & Basic level & Standard level & Advanced level \\
\hline \multirow{5}{*}{ 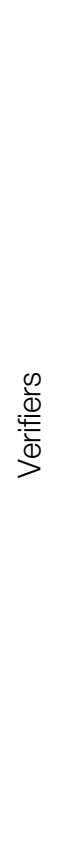 } & \multirow{2}{*}{$\begin{array}{l}\text { Mortality / } \\
\text { survival }\end{array}$} & $\begin{array}{l}\text { Adult trees: Counting of the } \\
\text { remaining marked trees every } \\
10 \text { years and after every extreme } \\
\text { weather event/disturbance }\end{array}$ & Same as basic level & Same as basic level \\
\hline & & Natural regeneration: / & $\begin{array}{l}\text { Counting of remaining seedlings } \\
\text { on the natural regeneration } \\
\text { subplots, twice per decade }\end{array}$ & Same as standard level \\
\hline & Flowering & Stand-level estimate, every year & $\begin{array}{c}\text { Individual tree level observation, } \\
\text { during two major flowering } \\
\text { events per decade, ideally } \\
\text { equally spaced * }\end{array}$ & $\begin{array}{c}\text { Individual tree level observation, } \\
\text { during two major flowering } \\
\text { events per decade, ideally } \\
\text { equally spaced * }\end{array}$ \\
\hline & Fructification & Stand-level estimate, every year & $\begin{array}{l}\text { Individual tree level observation, } \\
\text { the same year as the } \\
\text { assessment of the flowering at } \\
\text { the standard level (regardless of } \\
\text { the fructification intensity) }{ }^{*}\end{array}$ & $\begin{array}{l}\text { Counting of fruit, the same years } \\
\text { as the assessment of flowering } \\
\text { at the advanced level, regardless } \\
\text { of the fructification intensity } \\
{ }^{\star} \text { Seeds are also collected } \\
\text { for laboratory analyses every } \\
\text { assessed fructification event }\end{array}$ \\
\hline & $\begin{array}{l}\text { Natural } \\
\text { regeneration } \\
\text { abundance }\end{array}$ & Stand-level estimate, every year & $\begin{array}{l}\text { Counting of seedlings in the } \\
1 \text { st and 6th years after every } \\
\text { assessed fructification event }\end{array}$ & $\begin{array}{c}\text { Counting of seedlings in the } 1^{\text {st }} \text {, } \\
6^{\text {th }}, 11^{\text {th }} \text {, and } 16^{\text {th }} \text { years after } \\
\text { every assessed fructification } \\
\text { event }\end{array}$ \\
\hline \multirow{4}{*}{ 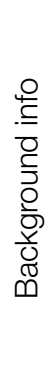 } & $\begin{array}{l}\text { DBH class } \\
\text { distribution }\end{array}$ & / & Measurement every 10 years & Same as standard level \\
\hline & $\begin{array}{l}\text { Height class } \\
\text { distribution }\end{array}$ & / & Measurement every 10 years & Same as standard level \\
\hline & 3udburst & / & $\begin{array}{c}\text { Individual tree level observation, } \\
\text { every } 5 \text { years }\end{array}$ & $\begin{array}{c}\text { Individual tree level observation, } \\
\text { every year }\end{array}$ \\
\hline & $\begin{array}{l}\text { Flowering } \\
\text { synchronisation }\end{array}$ & / & / & $\begin{array}{l}\text { Individual tree level observation, } \\
\text { during each assessed major } \\
\text { flowering event }\end{array}$ \\
\hline
\end{tabular}

* Ideally at least one major fructification event should be assessed per decade. However, a major flowering event does not necessarily lead to a major fructification event. If no major fructification event follows the assessed flowering event, assessment of both flowering and fructification needs to be repeated during the next major flowering event, regardless of the time passed between successive major flowering events. Basic level observations are used to identify major flowering and fructification events. 


\subsection{Protocols for recording of verifiers}

\subsubsection{Mortality / survival}

Mortality describes the mortality of adult trees and natural regeneration. Its counterpart survival stands for trees that are still alive since the previous assessment. Survival is calculated as 1 - Mortality.

\subsubsection{Adult trees: Basic, standard and advanced levels}

The verifier for mortality of adult trees is estimated by counting the remaining alive marked trees every 10 years and after every extreme weather event/disturbance. Mortality is the difference between the initial number of marked trees and the trees remaining alive of the original 50 trees.

\subsubsection{Natural regeneration: Standard and advanced levels}

Mortality of natural regeneration is calculated from the verifier Natural regeneration abundance. Mortality is the difference between the initial number of NR plants and the plants remaining alive at the time of the next counting. For each round of assessment, the NR is counted first in the year of germination and then again after 5 years at the standard level, while at the advanced level the counting is also performed after 10 and 15 years. Assessment of NR abundance is carried out twice per decade, ideally approximately every five years.

\subsubsection{Flowering}

This verifier describes the flowering intensity and the proportion of trees thus affected. It can usually be recorded from late April till early June.

\subsubsection{Basic level}

This verifier is recorded every year at the stand level. Recording is carried out when flowering is in full progress. The estimate of average condition is provided after a walk throughout the monitoring plot. Two scores are given, one for flowering intensity, expressed as the average proportion of the crown flowering, and one for the proportion of flowering trees in the stand.

\begin{tabular}{llr} 
Code & Flowering intensity at the stand level & Average proportion of crown flowering (\%) \\
\hline 1 & No flowering: No or only occasional flowers appearing on trees & $0-10$ \\
\hline 2 & Weak flowering: Some flowers appearing on trees. & $>10-30$ \\
\hline 3 & Moderate flowering: Moderate number of flowers appearing on trees. & $>30-60$ \\
\hline 4 & Strong flowering: Abundant number of flowers on trees. & $>60-90$ \\
\hline 5 & Massive: Huge number of flowers on trees. & $>90$ \\
\hline
\end{tabular}

\begin{tabular}{lr}
\hline Code Proportion of trees in the stand with the given flowering intensity stage (\%) & $0-10$ \\
\hline 1 & $>10-30$ \\
\hline 2 & $>30-60$ \\
\hline 3 & $>60-90$ \\
\hline 4 & $>90$ \\
\hline 5
\end{tabular}




\subsubsection{Standard level}

This verifier is recorded during two major flowering events per decade, ideally equally spaced in time from one another. It is recorded at an individual tree level on all 50 monitored trees. A major flowering event is when at the basic level flowering intensity is strong or massive (code 4 or 5 ) and the proportion of trees with the given flowering intensity is above $60 \%$ (code 4 or 5). Recording is carried out when flowering is in full progress. One score is provided for each tree.

\begin{tabular}{|c|c|c|}
\hline Code & Description & Proportion of the crown flowering (\%) \\
\hline 1 & No flowering: No or only occasional flowering appearing on a tree. & $0-10$ \\
\hline 2 & Weak flowering: Some flowers appearing on a tree. & $>10-30$ \\
\hline 3 & Moderate flowering: Moderate number of flowers on a tree. & $>30-60$ \\
\hline 4 & Strong flowering: Abundant number of flowers on a tree. & $>60-90$ \\
\hline 5 & Massive: Huge number of flowers on a tree. & $>90$ \\
\hline
\end{tabular}

\subsubsection{Advanced level}

This verifier is recorded during two major flowering events per decade, ideally equally spaced in time from one another. It is recorded at an individual tree level on all 50 monitored trees. A major flowering event is when at the basic level flowering intensity is strong or massive (code 4 or 5 ) and the proportion of trees with the given flowering intensity is above $60 \%$ (code 4 or 5). On average, two visits to the plot are needed; the first one early enough to observe the early stages of flowering and the second one when flowering is in full progress.

Three scores are provided for each tree: female and male flowering stages [5], and the proportion of the crown flowering. The proportion of the crown flowering refers to the total number of flowers (male + female) on the tree. For graphical representation of the flowering stages, see Figure 5.

A major flowering event does not necessarily lead to a major fructification event. If no major fructification event follows the assessed flowering event, assessment of both flowering and fructification needs to be repeated the next major flowering event. Basic level observations are used to identify major flowering and fructification events.

\section{Code Female conelets phenological stages}

1 Female flowering buds clearly visible on the top of the shoot but scales are completely covering the female conelet.

2 The apex of the cylindrical conelet is opened and the first ovuliferous scales appear.

3 The scales of the female conelet are separated and almost form right angles with the conelet axis (receptivity 100\%).

4 The scales of the conelet are closed.

\section{Code Male strobili phenological stages}

1 Male strobili are developing, but still closed in integuments.

2 Microsporangia are not tightly packed, and green to yellow liquid emerges from the strobili when pressed.

3 Yellow strobili shedding their pollen.

\begin{tabular}{lr}
\hline Code Proportion of the crown flowering (\%; male and female flowering together) \\
\hline 1 & $0-10$ \\
\hline 2 & $>10-30$ \\
\hline 3 & $>30-60$ \\
\hline 4 & $>60-90$ \\
\hline 5 & $>90$ \\
\hline
\end{tabular}


The background information Flowering Synchronisation can be estimated from the scores for female and male flowering recorded by this verifier.

(a)

1

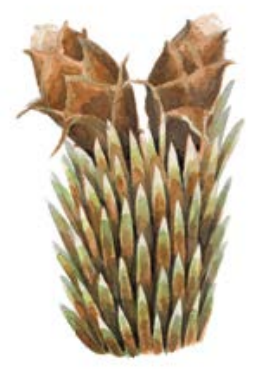

2

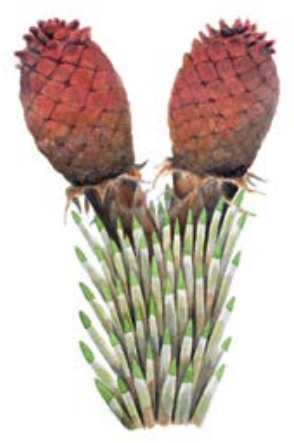

3

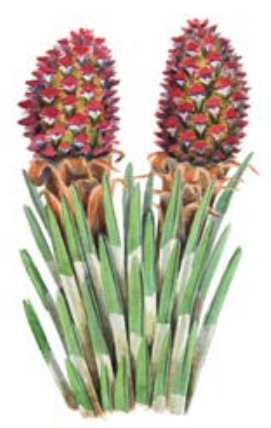

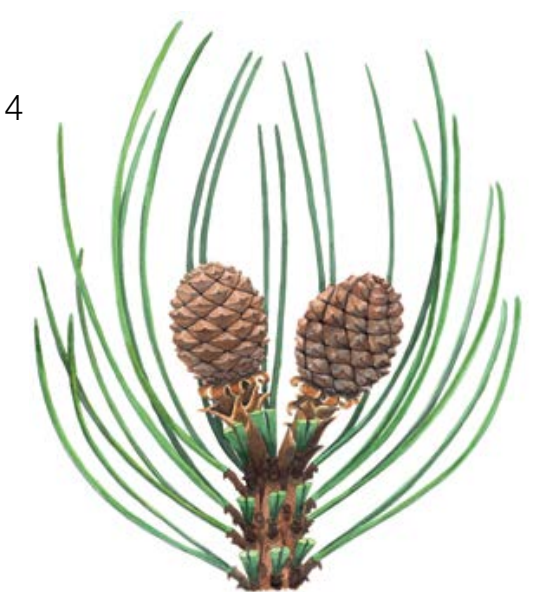

4

(b)

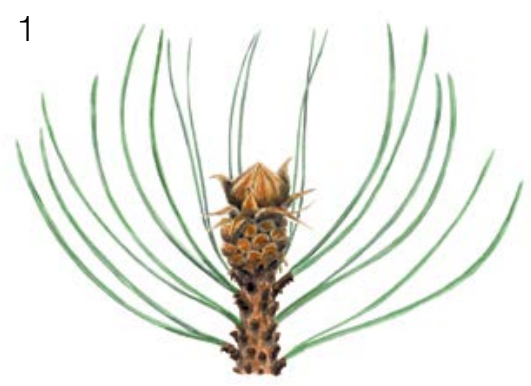

2

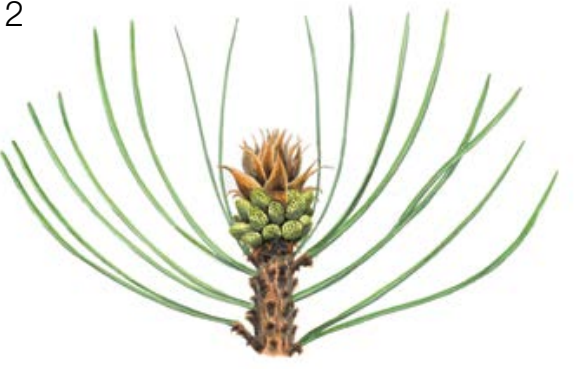

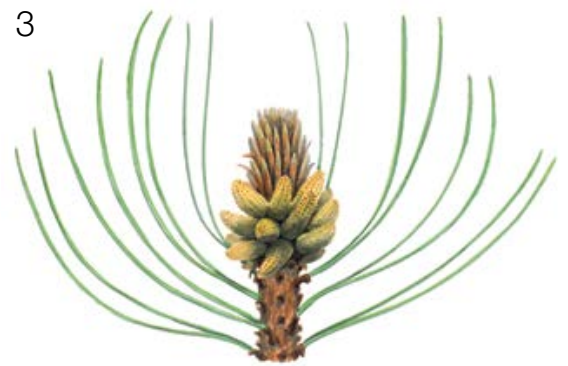

Figure 5: Picture guide for description of Pinus nigra female conelets (a) and male strobili (b) stages for the advanced level verifier Flowering.

\subsubsection{Fructification}

The verifier indicates the presence of fructification and its abundance for Pinus nigra. Data for this verifier should be collected during the fructification period of Pinus nigra, and when cones are mature, i.e. from September to November. It should be mentioned here that the cones of the species mature the second autumn after the flowering. 


\subsubsection{Basic level}

This verifier is recorded every year at the stand level. The estimate of average condition is provided after a walk throughout the monitoring plot. Two scores are given, one for fructification intensity and one for the proportion of fructifying trees in the stand.

\begin{tabular}{clr}
\multicolumn{2}{l}{ Code Fructification intensity at the stand level } & Average proportion of the crown bearing fruit (\%) \\
\hline 1 & No fructification: No or only occasional cones appearing on trees. & $0-10$ \\
\hline 2 & Weak fructification: Some cones appearing on trees. & $>10-30$ \\
\hline 3 & Moderate fructification: Moderate number of cones appearing on trees. & $>30-60$ \\
\hline 4 & Strong fructification: Abundant number of cones appearing on trees. & $>60-90$ \\
\hline 5 & Massive: Huge number of cones appearing on trees. & $>90$ \\
\hline
\end{tabular}

\begin{tabular}{lr} 
Code & Proportion of trees in the stand with the given stage of fructification intensity (\%) \\
\hline 1 & $0-10$ \\
\hline 2 & $>10-30$ \\
\hline 3 & $>30-60$ \\
\hline 4 & $>60-90$ \\
\hline 5 & $>90$ \\
\hline
\end{tabular}

\subsubsection{Standard level}

This verifier should be recorded the second autumn (September/November) after the assessment of the flowering at the standard level (regardless of the fructification intensity). It is recorded at an individual tree level on all 50 monitored trees. Recording is carried out before the mature cones shed their seeds and start falling. One score is provided for each tree.

Ideally, one major fructification event should be captured following observations of major flowering events per decade. However, a major flowering event does not necessarily lead to a major fructification event. If no major fructification event follows the assessed flowering event, then the assessment of both flowering and fructification needs to be repeated when the next major flowering event and the subsequent fructification occurs, regardless of the time passed between successive major flowering events. Basic level observations are used to identify major fructification events. A major fructification event is occurring at the basic level when fructification intensity is strong or massive (code 4 or 5), and the proportion of trees with the given fructification intensity is above $60 \%$ (code 4 or 5 ).

\begin{tabular}{clc} 
Code & Fructification intensity & Proportion of the crown fructifying (\%) \\
\hline 1 & No fructification: No or only occasional fruits appearing on a tree. & $0-10$ \\
\hline 2 & Weak fructification: Some fruits appearing on a tree. & $>10-30$ \\
\hline 3 & Moderate fructification: Moderate amount of fruit appearing on a tree. & $>30-60$ \\
\hline 4 & Strong fructification: Abundant amount of fruit appearing on a tree. & $>60-90$ \\
\hline 5 & Massive: Huge amount of fruit appearing on a tree. & $>90$ \\
\hline
\end{tabular}

\subsubsection{Advanced level}

This verifier is recorded at an individual tree level on all 50 monitored trees two years (the second autumn) after the assessment of flowering at the advanced level, regardless of the fructification intensity. Recording is carried out before cones are open and seed is dispersed. One score is provided for each tree. Simultaneously, seed is collected for seed and genetic analysis for the advanced level verifiers and background information. 
Ideally, one major fructification event should be captured following observations of major flowering events per decade. However, a major flowering event does not necessarily lead to a major fructification event. If no major fructification event follows two years after the assessed flowering event, assessment of both flowering and fructification needs to be repeated during the next major flowering event, regardless of the time passed between successive major flowering events. Basic level observations are used to identify major fructification events. A major fructification event is when at the basic level fructification intensity is strong or massive (code 4 or 5) and the proportion of trees with the given fructification intensity is above $60 \%$ (code 4 or 5 ).

The verifier is recorded by counting cones using binoculars. The average of three rounds of counting is reported. Each round of counting consists of the number of cones that the observer counts in 30 seconds. For all trees, the same part of the crown should be observed for cone counting. Once the observation part of the crown part is selected, the same one should be selected for every subsequent monitoring of this verifier. The upper third of the crown is preferred to the bottom and middle parts for cone counting.

Two values are recorded; the number of fruits and the part of the crown monitored.

\begin{tabular}{|c|c|}
\hline Numb & er of cones counted in 30 seconds (average of 3 rounds) \\
\hline$x$ & \\
\hline Cod & Part of the crown monitored \\
\hline 1 & Bottom \\
\hline 2 & Middle \\
\hline 3 & Top \\
\hline
\end{tabular}

\subsubsection{Natural regeneration abundance}

This verifier describes the presence and abundance of natural regeneration (NR) at the monitoring plot.

\subsubsection{Basic level}

This verifier is recorded at the stand level every year in the autumn. Expert opinion is used for estimation considering the situation over the whole monitoring plot. Two values should be recorded, one for new natural regeneration (current-year seedlings) and one for established regeneration (saplings that are older than one year). Since full seed crops (mast years) for Pinus nigra usually occur every 3 to 5 years, the establishment of new NR should be estimated the summer/autumn following the mast year.

\section{Code Description: new regeneration (current-year seedlings)}

1a There is no or very little new natural regeneration on the monitoring plot.

2a New regeneration is present in sufficient numbers on the monitoring plot.

\section{Code Description: established natural regeneration (saplings)}

$1 \mathrm{~b}$ There is no or very little established natural regeneration on the monitoring plot.

$2 \mathrm{~b}$ Established regeneration is present in sufficient quantity on the monitoring plot. 


\subsubsection{Standard level}

This verifier is recorded by counting of plants/seedlings the $1^{\text {st }}$ autumn after every assessed fructification event (the year of the fructification event is regarded as year 0 ) and $6^{\text {th }}$ autumn after the fructification event.

Counting of seedlings:

After the establishment of NR subplots all Pinus nigra seedlings present at each of the 20 NR subplots must be counted. Any older black pine saplings that are growing on the NR subplot should not be included. During the next counting round, only saplings of the appropriate age must be counted - i.e. in the $6^{\text {th }}$ year, 5 -year old saplings.

\section{Number of seedlings counted on a subplot}

$\mathrm{x}$

Mortality/survival of natural regeneration is calculated from the values recorded for this verifier.

For subplot establishment see 6.2 Establishment of natural regeneration subplots.

\subsubsection{Advanced level}

This verifier is recorded by counting seedlings at each one of the $20 \mathrm{NR}$ subplots in the $1^{\text {st }}$ autumn after the major fructification event (the year of the fructification event is regarded as year 0 ) and the $6^{\text {th }}, 11^{\text {th }}$, and $16^{\text {th }}$ autumns after the fructification event. The next round of monitoring of natural regeneration abundance (establishment of new $20 \mathrm{NR}$ subplots and assessment of NR abundance) is carried out after the first fructification event at least 5 years after the previous major fructification event (see Table 3 for a representation of the NR abundance assessment timeline). Assessment of NR abundance from one or two major fructification events per monitoring interval is expected.

Table 3: Timeline of natural regeneration abundance (NR) assessment. In this example, the first major fructification event takes place in the second year of the monitoring decade, and the second assessed fructification event five years later, i.e. in the $7^{\text {th }}$ year of the monitoring. Because major fructification events occur every $3-5$ years for Pinus nigra, the interval between any two consecutive major fructification events can vary accordingly. Twenty new NR subplots are established after each assessed fructification event. Monitoring of NR abundance on each set of 20 NR subplots is carried out every five years. The fructification events corresponding to the assessed NR and timelines of the assessment activities are shaded in the same colour. After the final round of counting of seedlings, monitoring of NR abundance on the respective set of NR subplots is stopped and the respective NR subplots disestablished. S - standard level; A - advanced level.

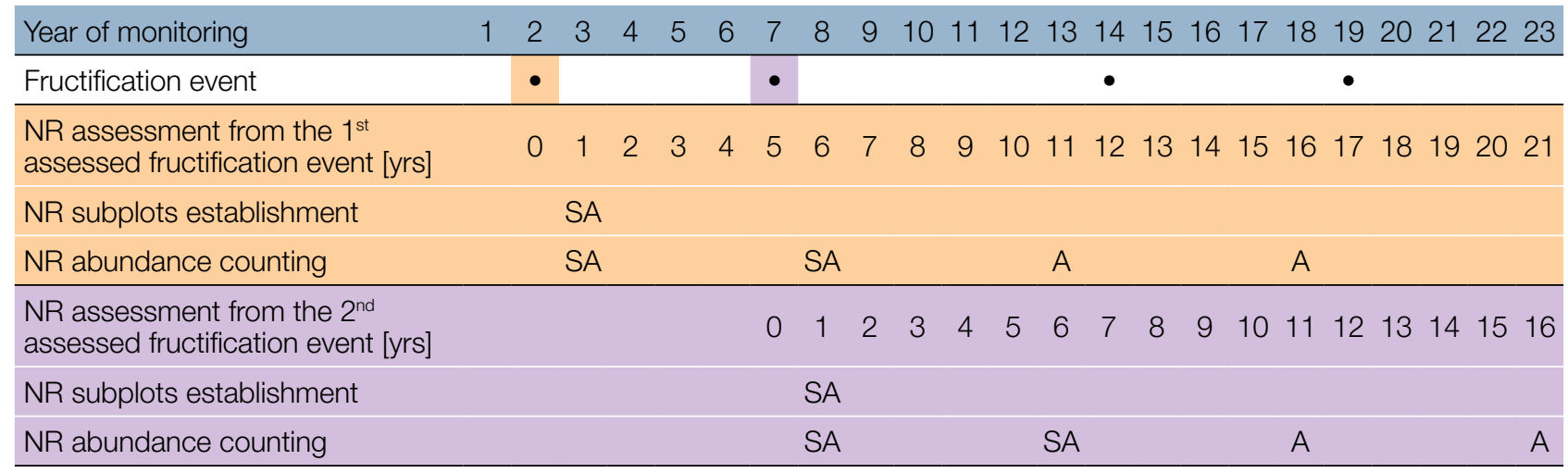

Mortality/survival of natural regeneration is calculated from the values recorded for this verifier. For subplot establishment see 6.2 Establishment of natural regeneration subplots and for counting 7.1.4.2 Standard level. 


\subsection{Protocols for recording of background information}

\subsubsection{DBH class distribution}

\subsubsection{Standard and advanced levels}

$\mathrm{DBH}$ is recorded at an individual tree level on all the 50 monitored trees every 10 years. $\mathrm{DBH}$ is the trunk diameter at $1.30 \mathrm{~m}$, i.e. approximately at an adult's breast height. If a tree has more than one trunk, all of them should be measured and their average value should be estimated (try to avoid individuals with many thin trunks). Keep a note indicating that the tree is a multi-trunk one in the notes section. If the tree is leaning, the $\mathrm{DBH}$ should be measured perpendicular to the trunk. DBH can be measured in two ways:

1) By using a calliper, in which case you need to measure two perpendicular diameters and take the average.

2) By measuring the circumference of the tree and computing the diameter from that value (i.e. divide by $\pi, \sim 3.14$ or use a pi-meter)

The $\mathrm{DBH}$ is recorded in $\mathrm{cm}$. The same method must be applied for every subsequent measurement.

\subsubsection{Height class distribution}

\subsubsection{Standard and advanced levels}

Height is recorded at an individual tree level on all the 50 monitored trees, every 10 years. Height is measured from the ground to the tallest part of the crown, ideally by using a clinometer or a hypsometer (e.g. vertex). Height is recorded in metres, to one decimal place. If the crown is damaged, this must be recorded as well as the reason for this in the notes.

\subsubsection{Budburst}

Budburst describes the process of budbursting (flushing). In Pinus nigra, budbursting starts a bit later than flowering. Recording of this parameter is only carried out at the standard and advanced levels. Data of this background information should be collected in April - May, until all monitored trees have reached the stage of fully developed needles. 


\subsubsection{Standard level}

At standard level, budburst is recorded at an individual tree level on all the 50 monitored trees, every 5 years. We are looking for the initiation of budbursting (stage 2) and the end of budbursting (stage 5). The observations are terminated when all the trees have reached stage 5. Usually, six visits will be needed. For each tree, two estimates are given: stage of budbursting and the proportion of the crown budbursting. For a graphical representation of budbursting stages please see Figure 6.

\begin{tabular}{|c|c|}
\hline Cod & Stage of budbursting (Simplified stages [5]) \\
\hline 1 & Dormant buds \\
\hline 2 & Start of elongation \\
\hline 3 & Significant elongation of terminal bud \\
\hline 4 & Needles emerge from transparent envelopes \\
\hline 5 & The two needles of the same brachyblast are clearly distinct \\
\hline
\end{tabular}

\begin{tabular}{lr}
\hline Code Proportion of the crown with a given Stage of budbursting (\%) & $>0-33$ \\
\hline 1 & $>33-66$ \\
\hline 2 & $>66-99$ \\
\hline 3 & 100 \\
\hline 4 & \\
\hline
\end{tabular}

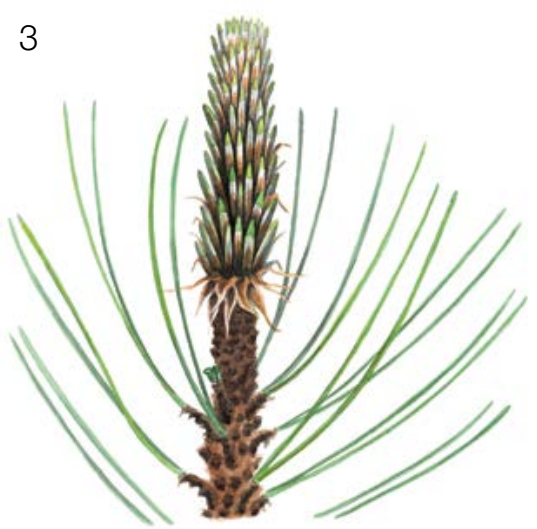

$$
4
$$

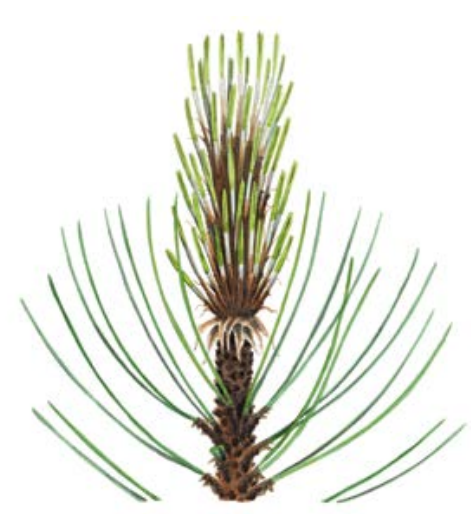

2
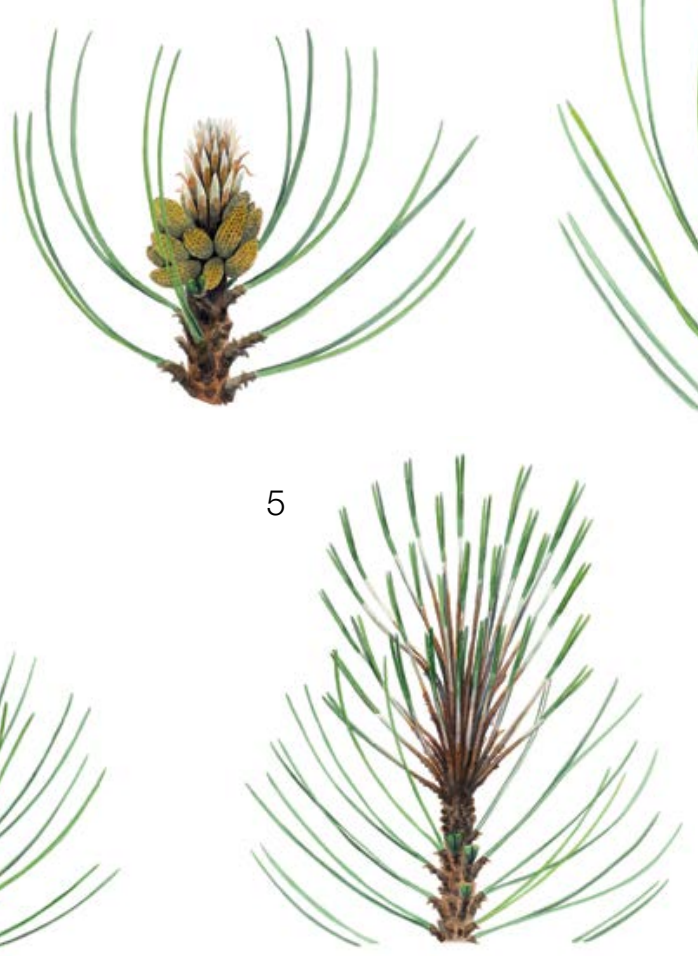

Figure 6: Picture guide for description of budburst (flushing) for the basic, standard and advanced level background information Budburst. 


\subsubsection{Advanced level}

At the advanced level, budburst is recorded at an individual tree level on all the 50 monitored trees, every year in the same way as at the standard level. For details see 7.2.3.1 Standard level.

\subsubsection{Flowering synchronisation}

Flowering synchronisation is monitored only at the advanced level, and is based on the data collected for the verifier Flowering. It is used to determine whether the male and female flowering periods overlap for the trees on the monitoring plot [19].

\subsubsection{Advanced level}

Flowering synchronisation is recorded at an individual tree level, and for all the 50 monitored trees, during each assessed major flowering event. From that flowering event the seed that will be collected the second autumn after flowering will be produced.

\section{For plot establishment use form 'FGM Plot description'}

\section{For verifiers recording use 'Form for recording field level verifiers within FGM'}

For background information recording use 'Form for recording field level background information within FGM' 


\section{References}

1. Farjon A (2017) A Handbook of the World's Conifers. 2nd revised Edition, Volume 1. Brill Leiden - Boston. Brill Acad. Publ. https://doi.org/10.1163/9789047430629

2. Burns RM, Honkala BH (1990) Silvics of North America. Volume 1. Conifers. Agriculture Handbook 654, USDA Forest service, Washington

3. Vidaković M (1958) Investigation on the intermediate type between the Austrian and Scots pine. Silv Gen 7:12-19.

4. Fukarek P (1958) Die Standortstrassen per Shwarzföhre (Pinus nigra Arn.). Centralblatt fuer das gesamte Forstwesen 75:203-207

5. McWilliam JR (1959) Interspecific incompatibility in Pinus. Am J Bot 46:425-433. https://doi. org/10.1002/j.1537-2197.1959.tb07033.x

6. Righter Fl, Duffield JW (1951) Interspecific hybrids in pines. J Hered 42:75-80. https://doi.org/10.1093/oxfordjournals. jhered.a106169

7. Juranović-Cindrić I, Zeiner M, Starčević A, Liber Z, Rusak G, Idžojtić M, Stingeder G (2018) Influence of F1 hybridization on the metal uptake behaviour of pine trees (Pinus nigra $x$ Pinus thunbergiana; Pinus thunbergiana $x$ Pinus nigra). J. Trace Elem Med Biol 48:190-195. https://doi.org/10.1016/j.jtemb.2018.04.009

8. Vidaković M (1974) Genetics of European black pine (Pinus nigra Arn.). Annales Forestales (6/3):57-86.

9. Mitchell AF (1972) Conifers in the British Isles: A descriptive handbook. Forestry Commission Booklet No. 33. London: Her Majesty's Stationery Office

10. Rose Cl (1979) Observations on the ecology and conservation value of native and introduced tree species. Q J Forest 73(4):219-229

11. Athanasiadis NH (1986) Forest Botany (Trees and Shrubs of the Hellenic Forests). Part II. Publ. Giahoudi Thessaloniki

12. Isajev V, Fady B, Semerci H, Andonovski V (2004) EUFORGEN technical guidelines for genetic conservation and use of European black pine (Pinus nigra). International Plant Genetic Resources Institute, Rome

13. Van Haverbeke DF (1990) Pinus nigra Arnold - European black pine. In: Burns RM; Honkala BH (eds). Silvics of North America. Volume 1. Conifers. Agric. Handb. U.S. Department of Agriculture, Forest Service, Washington, DC

14. Freeland RO (1944) Apparent photosynthesis in some conifers during the winter. PI Physiol 19:179-185

15. Boutheina A, El Aouni MH, Balandier P (2013) Influence of stand and tree attributes and silviculture on cone and seed productions in forests of Pinus pinea L. in northern Tunisia. Options Méditerranéennes Series A: Mediterranean Seminars, No. 105. CIHEAM, FAO, INIA, IRTA, CESEFOR, CTFC, Zaragoza

16. Nicholls TH, Hudler GW (1971) Dothistroma pini on Pinus nigra in Minnesota. Plant Disease Reporter 55: 1040.

17. Millar CS (1970) Role of Lophodermella species in premature death of Pine needles in Scotland. Report on Forest Research, London, pp 176-178

18. Blodgett JT, Eyles A, Bonello P (2007) Organ-dependent induction of systemic resistance and systemic susceptibility in Pinus nigra inoculated with Sphaeropsis sapinea and Diplodia scrobiculata. Tree Physiol 27: 511-517. https://doi. org/10.1093/treephys/27.4.511

19. Alizoti PG, Kilimis K, Gallios P (2010). Temporal and spatial variation of flowering among Pinus nigra Arn. clones under changing climatic conditions. For Ecol Manag 259:768-797. http://dx.doi.org/10.1016/j.foreco.2009.06.029 
The following resources were consulted for the currently accepted (December 2020) scientific names of the species covered or mentioned in this document:

a. Avtzis N (1985) Marchalina hellenica (Monophlebus hellenicus) Gen. An important honey producing insect of Greece. Dasiki Erevna VI(1):51-63

b. Bußkamp J, Langer GJ \& Langer EJ (2020) Sphaeropsis sapinea and fungal endophyte diversity in twigs of Scots pine (Pinus sy/vestris) in Germany. Mycol Progress 19:985-999. https://doi.org/10.1007/s11557-020-01617-0

c. CABI (2020) Invasive Species Compendium. CAB International, Wallingford, UK. www.cabi.org/isc. Accessed 15 December 2020

d. EPPO (2020) EPPO Global Database (available online). https://gd.eppo.int. Accessed 15 December 2020

e. GBIF (2020) Global Biodiversity Information Facility. https://www.gbif.org Accessed 15 December 2020

f. IPNI (2020) International Plant Names Index. The Royal Botanic Gardens, Kew, Harvard University Herbaria \& Libraries \& Australian National Botanic Gardens. http://www.ipni.org, Accessed 10 December 2020

g. National Center for Biotechnology Information (NCBI) (1998) National Library of Medicine (US), National Center for Biotechnology Information, Bethesda (MD). https://www.ncbi.nlm.nih.gov/. Accessed 15 December 2020

h. The Plant List (2013) Version 1.1. http://www.theplantlist.org/. Accessed 12 December 2020

i. Tropicos.org (2020) Missouri Botanical Garden. http://www.tropicos.org. Accessed 15 December 2020

j. $\quad$ WFO (2020) World Flora Online. http://www.worldfloraonline.org. Accessed 15 December 2020 



\section{Guidelines for genetic monitoring of}

\subsubsection{European black poplar (Populus nigra L.)}

Gregor BOŽIČ' ${ }^{1}$, Sándor BORDÁCS², Berthold HEINZE³, Marko BAJC'1, Filippos A. ARAVANOPOULOS ${ }^{4}$, Dalibor BALLIAN ${ }^{1,5}$, Rok DAMJANIĆ ${ }^{1}$, Barbara FUSSI ${ }^{6}$, Darius KAVALIAUSKAS ${ }^{6}$, Zvonimir VUJNOVIĆ7, Marjana WESTERGREN', Hojka KRAIGHER ${ }^{1}$

Botanical illustrations by Marina Gabor

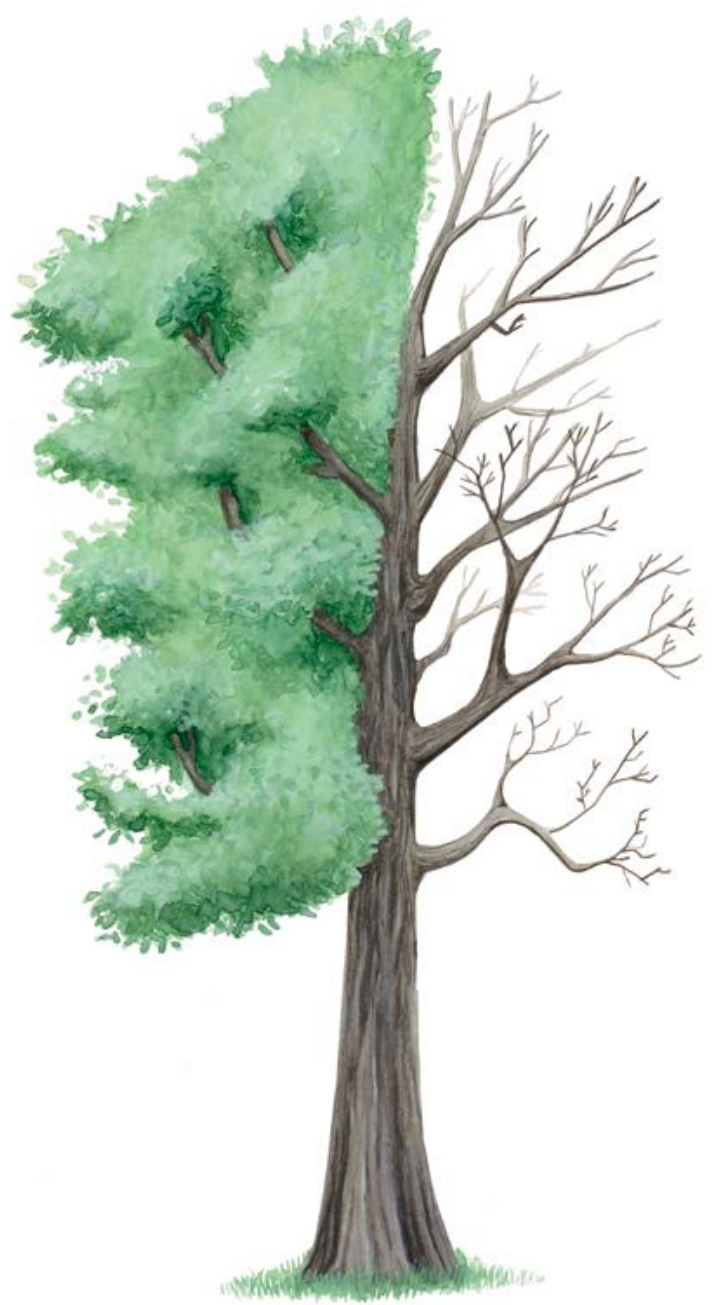

Citation: Božič et al. (2020) Guidelines for genetic monitoring of European black poplar (Populus nigra L.). In: Bajc et al. (eds) Manual for Forest Genetic Monitoring. Slovenian Forestry Institute: Silva Slovenica Publishing Centre, Ljubljana, pp 235-254. http://dx.doi.org/10.20315/SFS.167

\footnotetext{
Affiliations:

1. Slovenian Forestry Institute (GIS), Slovenia

2. Szent István University (SZIE), Hungary

3. Federal Research and Training Centre for Forests, Natural Hazards and Landscape (BFW), Austria

4. Aristotle University of Thessaloniki (AUTh), Greece

5. University of Sarajevo, Forestry Faculty, Bosnia and Herzegovina

6. Bavarian Office for Forest Genetics (AWG), Germany

7. Croatian Forest Research Institute (CFRI), Croatia
} 


\section{Executive summary}

European black poplar (Populus nigra L.) is an ecologically important fast growing and short-lived deciduous forest tree species of mixed riparian forests with the physiological adaptation to colonise open areas after disturbances and survive changes associated with dynamic river systems. It enables natural control of flooding, is a keystone species for dynamic conservation and habitat restoration of floodplain forests, and is considered as an indicator species for the health and biodiversity of riparian ecosystems [1]. European black poplar is also known for its inherent ability to grow rapidly and taking up large volumes of water and nutrients from soil. This capability makes it important for phytoremediation, restoration, and environmental applications in polluted industrial zones, for microclimate regulation and for the improvement of biological diversity in open agricultural landscapes [2]. It is used as a parent pool for several poplar breeding programs around the world. It can be managed easily by coppicing, which makes it suitable for long-term conservation of the best genotypes of pure European black poplar plant material in ex situ collections. A wide range of recommendations for in situ conservation units and ex situ conservation methods were proposed within the framework of EUFORGEN [3] and later approved by several regional projects [4].

European black poplar naturally forms metapopulations of inter-linked local populations rather than small, isolated populations [6]. To ensure representative sampling across the metapopulation it is important to design a genetic monitoring system with randomly selected monitoring plots of adult trees in local populations, and monitoring plots in their natural regeneration centres along a river system as part of a complete network of interlinked local populations. Genetic identification of European black poplar trees must be performed by the use of species diagnostic DNA markers. The main obstacle to forest genetic monitoring (FGM) of European black poplar is finding habitats where the species reproduces effectively, and where conditions support long-term survival of the offspring.

These guidelines briefly describe European black poplar, its reproduction, environment, and threats, and provide guidance on establishing genetic monitoring plots in situ and recording all field level verifiers and background information.

\section{Species description}

The European black poplar (Figure 1) is a native, heliophilous and nutrient demanding deciduous forest tree species of temperate regions of Eurasia. It belongs to section Aigeros of the genus Populus, family Salicaceae [5]. It colonises open areas after disturbances, particularly due to dynamic river systems, and is found in the early successional stages of riparian mixed forest ecosystems. It forms different types of populations, that range from isolated trees to large pure or mixed stands. European black poplar naturally forms metapopulations comprised of smaller local populations [6, 7].

European black poplar is a medium to large-sized tree, generally reaching up to $40 \mathrm{~m}$ in height and up to $300 \mathrm{~cm}$ in diameter and living 100-200 years. In rare cases, individuals can reach 400 years of age [8, 9]. It often produces an irregular, branchy crown. The often crooked or swept, buttressed bole can be massive, frequently producing large burls or epicormic branches, but some trees in stands can also be straight and well formed [10]. The bark on mature trees is dark brown or black (Figure 2a) with numerous deep fissures [11]. Leaves are diamond-shaped to triangular, 5-12 cm long and 4-10 cm broad with the petiole of 2-6 cm in length $[12,13]$ with serrated margins and green on both surfaces (Figure 2b). Trees reach reproductive maturity within 10 to 15 years [14].

The morphological and phenological traits of Populus nigra can be used as a first level approach for characterisation of pure (not hybridised) European black poplar trees, at least in the case of adult and middle-aged individuals. The most stable species-specific traits and characters are detailed in the EUFORGEN identification sheet of Populus nigra [24]:

- shape of trees,

- epicormic shoots and dormant buds along the trunk

- intercrossing bark fissures along lower part of the trunk, 
- leaf shapes (diamond, rhomboid or triangular),

- absence of European mistletoe (Viscum album L.) within the crown,

- presence of gall-making aphid species of the genus Pemphigus on leaves' petiole.

Based on experiences of European projects (EUROPOP, DANUBEPARKS, etc.) the trees, which were characterised by the above listed morphological traits and selected for gene conservation purposes, were in most cases also confirmed as 'pure' Populus nigra by diagnostic molecular markers.
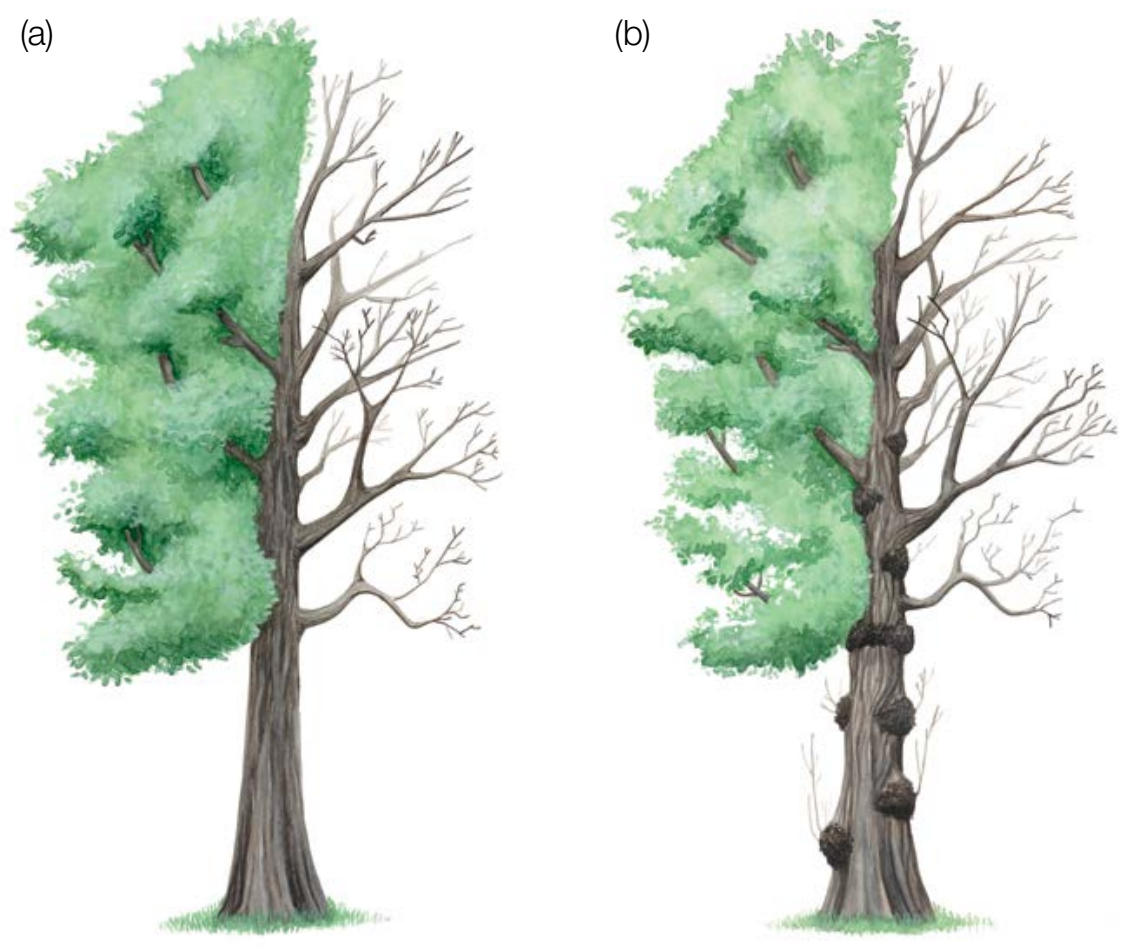

Figure 1: European black poplar (Populus nigra) habitus without epicormic shoots (a) and with epicormic shoots, which are a common feature (b).

(a)

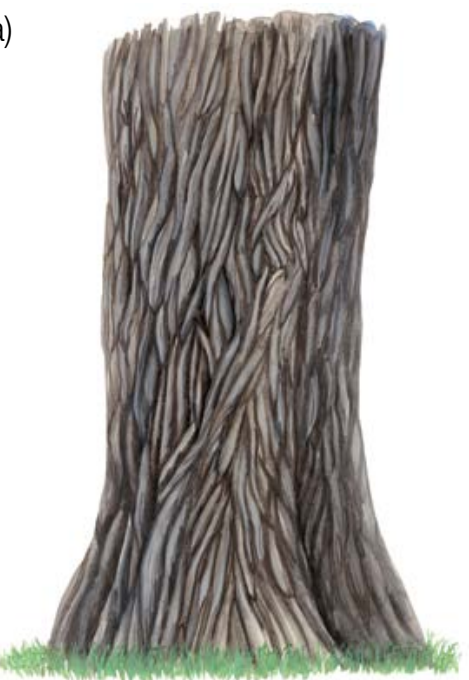

(b)

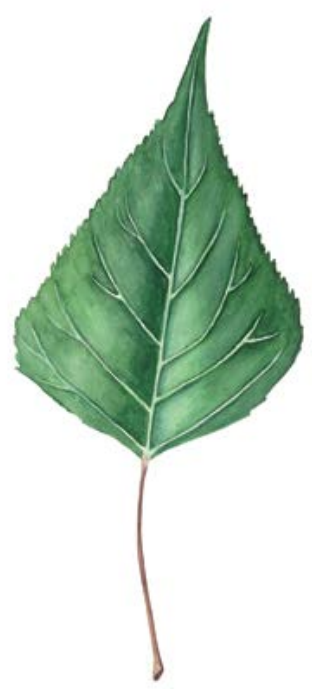

Figure 2: The bark on mature trees is dark greyish-brown or black with numerous deep intercrossing fissures (a). Characteristic diamond (rhomboid) to triangular shaped European black poplar leaf (b). 
European black poplar is a dioecious species. Unisexual male or female flowers (Figure 3 ) develop from specialised buds containing preformed inflorescences [11]. Flowers are clustered in pendulous catkins on separate trees, which allows for strict outcrossing. Male catkins have reddish-purple anthers, while female catkins have yellowgreen stigmas.

(a)

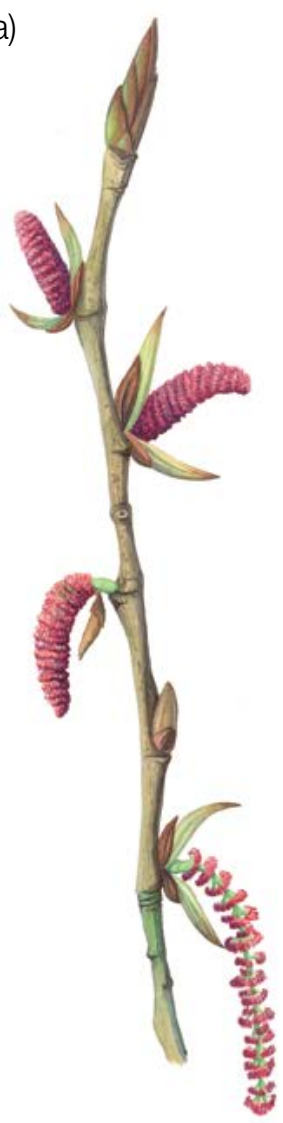

(b)

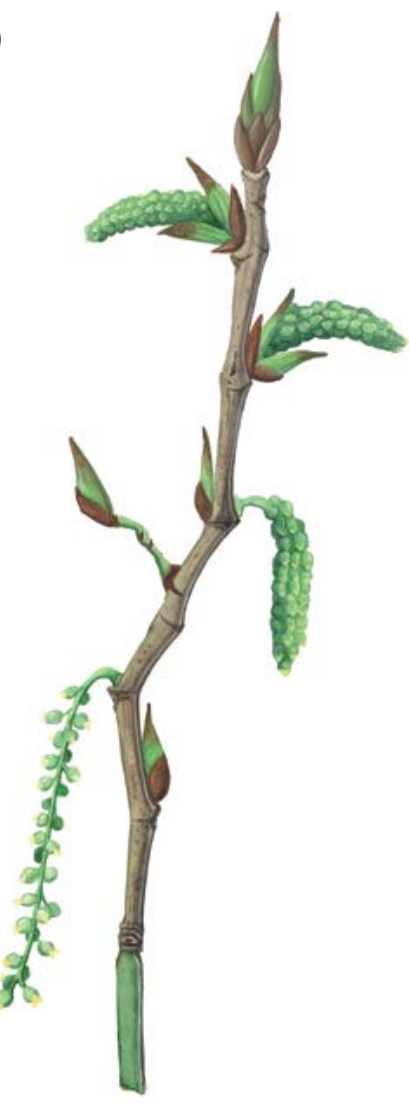

Figure 3: Identification of tree's sex: male flowers (a), female flowers (b) schematically presented in different development phases.

\section{Reproduction}

Male trees are trees with only male flowers, and they produce pollen, female trees are trees with only female flowers, and they produce seeds. The flowers appear from specialised buds approximately 1-2 weeks prior to leaf initiation in the early spring (March-April) in lower elevations and latitudes, while at higher latitudes and elevations flowering is delayed until May [15]. The timing and duration of flowering and length of the seed maturation process are related to both the photoperiod and local temperatures and, therefore, will vary from one locality to the next with implications for the timing of seed release [16]. There may also be a genetic component resulting in early and late timing phenotypes. Pollen is dispersed by the wind. Once female flowers are fertilised, approximately 20-50 bare and round green-brown fruit capsules will ripen on each catkin in 4-6 weeks (Figure 4a), producing up to 250 small light-brown seeds per catkin [17]. Female catkins develop into fluffy cotton-like airborne seeds with long, white, silky hairs attached to the seed (Figure 4b), which fall in the early summer [17].

European black poplar produces seed almost every year. Seeds have a short (1-3 days) viability period and need specific water and soil conditions with continuously wet substrate for a 4-week period to allow germination [18].

European black poplar can reproduce generatively as described above or vegetatively (clonally). Natural clonal reproduction is possible by suckering from root sprouts, from stumps, fallen trees and broken branches at the 
(a)

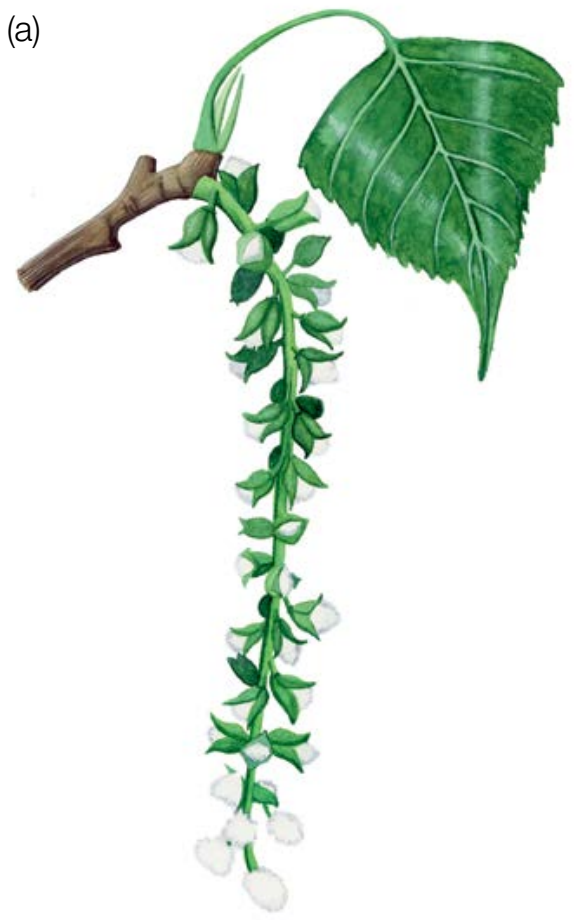

(b)

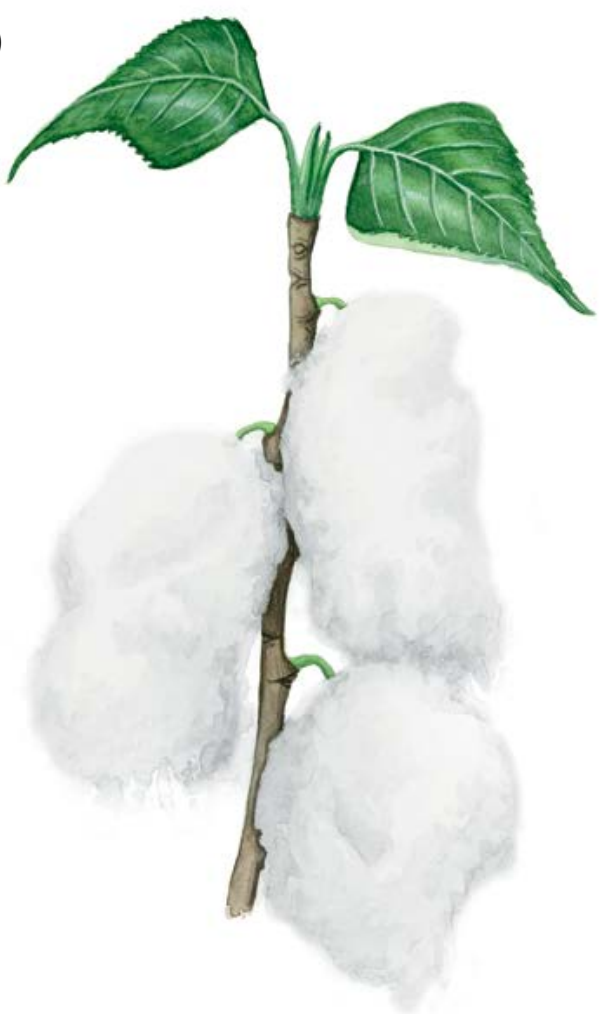

Figure 4: Female catkin with ripening seed capsules (a); mature seeds of Populus nigra have long, white silky hairs attached to them, giving a fluffy, cotton-like appearance (b).

juvenile stage [17]. Natural vegetative reproduction is possible even when seedling establishment is absent. and therefore can contribute to overall recruitment. Populus nigra often exhibits a polycorm of clonal plants [2].

\section{Identification of regeneration sites}

European black poplar naturally regenerates only on riverbanks on patches of ruderal, moist sandy and loamy soils exposed after seasonal river flooding [14], but not under trees of reproductive age in older floodplain forest stands. Seedling recruitment occurs along meandering rivers in arcuate bands of successive ages, while in braided river systems in association with specific microsites (e.g. in patches of sand which have accumulated behind clumps of vegetation, or woody debris, in silt-filled depressions on the floodplain) [17]. Successful natural regeneration is usually patchy and sporadic. Due to changes in site conditions the species' population size may fluctuate (expand or contract) over time [7].

\section{Environment}

European black poplar has a wide natural distribution range throughout Europe, except for the Nordic countries and from North Africa to Central Asia, including the Caucasus and the large part of the Middle East. Its range extends as far as Kazakhstan and China [11], and from sea level to $4000 \mathrm{~m}$ in elevation [19]. Throughout its natural range, cultivated forms or hybrids often replace the natural Populus nigra stands [20]. European black poplar is primarily preserved along the main rivers and their tributaries on alluvial sites. European black poplar naturally forms metapopulations rather than small, isolated populations (Figure 5) [6, 7]. In stands, it is present as many individual trees (solitaires) or smaller groups of over-mature trees. It grows together with white poplar (Populus alba L.), willows (Salix spp.), alder (Alnus spp.), maple (Acer spp.), elm (Ulmus spp.), and sometimes oak (Quercus spp.) [21]. The best growth is observed on deep medium texture soils with $\mathrm{pH}$ between 5.5 and 7.5 and high nutrient content. Because of its sporadic occurrence in mixed riparian stands it is generally not included in the regular forest inventories. 


\section{Threats}

Despite its wide distribution range, European black poplar is a vulnerable and rare tree species currently close to extinction in several parts of its range due to human influences such as: i) over-exploitation of its natural sites; ii) alteration of riparian ecosystems by human activities; iii) cultivation of superior hybrids of $P . \times$ canadensis Moench (hybrids between Populus deltoides W. Bartram ex Marshall and Populus nigra), Eastern Cottonwood (Populus deltoides) and Balsam poplars (Populus trichocarpa Torr. \& A. Gray ex. Hook, Populus maximowiczii Henry) within its natural range; and iv) gene introgression from the introduced female hybrid clones when their flowering is synchronised with the male European black poplar [22, 14, 11].

A frequently observed pest on European black poplar is Chrysomela populi L., while the most frequent diseases are poplar leaf rust (Melampsora larici-populina Kleb.) and Marssonina leafspot of poplar (Drepanopeziza punctiformis Gremmen, also known as Marssonina brunnea (Ellis \& Everh.) Magnus. Dieback of old European black poplar trees is also frequently observed in its native sites due to changes in site conditions and drought (rapid decline of groundwater levels). Old trees are finally destroyed by the dothichiza bark necrosis of poplar caused by Plagiostoma populinum (Fuckel) L. C. Mejía (formerly Cryptodiaporthe populea (Saccardo) Butin, also known as Dothichiza populea Saccardo) as well as windbreaks, and consequently the natural succession of mixed riparian forest is towards hardwood formations.

\section{Plot establishment and maintenance}

European black poplar is a pioneer species, which is present in riparian mixed forests. It is characterised by a metapopulation structure across the wide floodplain system. FGM of European black poplar should be implemented on the scale of a metapopulation representing a whole network of inter-linked local subpopulations, among which exchange of pollen and seed is putatively present, and must not be applied to a single locally isolated site.

(a)

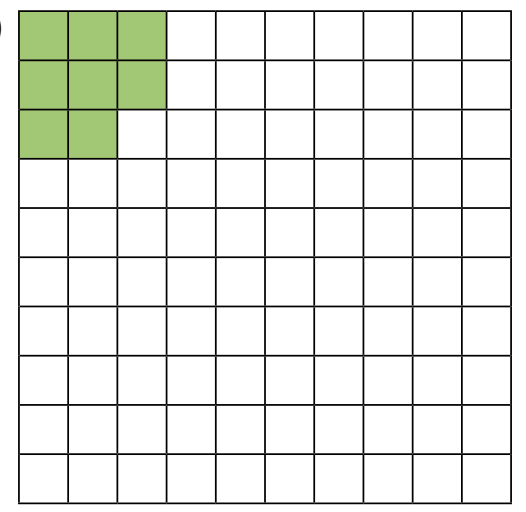

(b)

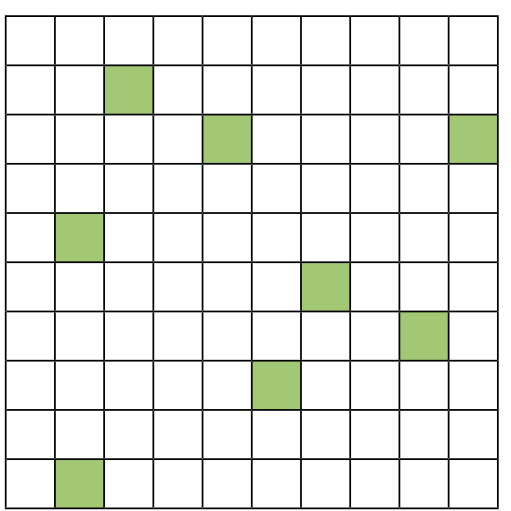

Figure 5: Schematic presentation of inter-linked black poplar local populations along a river system (a) vs. the local black poplar population in isolation (b).

To ensure representative sampling across the metapopulation it is important to design a genetic monitoring system with randomly selected monitoring plots of mature trees in local populations and their natural regeneration centres along the river system. An FGM plot for European black poplar consists of as many plots as there are local populations that form the metapopulation of interest. The number of trees in each plot should be proportional to the local population size, with the total sum of 50 mature (reproducing) genetically different pure Populus nigra trees with preferably equal representation of male and female individuals (sex ratio 1:1). The monitoring plot in each local population should include at least 20 trees distributed across a maximum distance of $5 \mathrm{~km}$. 
The trees are proposed to be pre-selected on site by assessment of morphological traits, detailed in the species description. Based on the results of long-term gene conservation projects in Hungary [23], for which a complex of stable morphological traits were used and the pre-selected trees were additionally tested by diagnostic DNA markers, the pre-selection could in most cases exclude hybrid and introgressed genotypes. However, diagnostic molecular genetic markers for characterisation of taxonomic status should be used in all cases to confirm the taxonomic identity and non-hybrid nature of the tested trees as pure Populus nigra individuals [7, 23]. Therefore, use of genetic tests by molecular diagnostic markers must be an essential element of genetic monitoring of Populus nigra on all monitoring levels. Additionally, the trees must also be tested for clonality by genotyping (only one individual of the same genotype can be included in the monitoring). If a tree is flowering it is regarded as a reproducing tree. In order to distinguish between the sexes, the plot installation in the field should ideally be carried out in the flowering season. During plot installation, trees should be labelled and georeferenced. At the same time height and DBH can be measured and samples for DNA extraction taken.

\subsection{Plot establishment}

\subsubsection{Definition of the sampling frame}

Before an FGM plot is installed in the field, a map of the European black poplar metapopulation should be prepared in GIS software. For this reason, the local population locations, where the species appears in sufficient density to set up a monitoring plot, should be surveyed in more detail in the field. It is recommended to record a walking track using a mobile phone app (e.g. Locus map) or a GPS device during this initial surveying, which greatly facilitates further planning.

The locations of local populations are plotted on the map in the form of polygons, which all together represent a sampling frame. Trees within each local population should be selected randomly. The approach that enables random selection is creating an appropriate number (proportional to the local population size) of random GPS coordinates in GIS software with a minimum distance of $35 \mathrm{~m}$ between them. The rationale behind using a longer distance between random points is to provide a safety margin for the reduced accuracy of GPS devices in forests and the distance of the nearest tree from the random GPS point. Random points' coordinates are saved into a GPS device, which is to be used in the field. If the instructions described are not feasible due to the complexity of the river channels in alluvial forests, a simplified "seek and find approach" within all local populations may be used: preferably with the help of a local forester, the area, where local populations occur, is combed in a systematic pattern using a GPS device or mobile phone app with track recording, which ensures that the same area is not inspected repeatedly, or any part of the area is not overlooked. Coordinates of all reproducing trees are logged, and their sex determined. An appropriate number of trees is selected randomly from the pool of suitable ones for each local population.

All adult trees must be genotyped to exclude hybrids and clones on all monitoring levels.

\subsubsection{Plot installation in the field}

Since the coordinates of approximate tree locations are known, the procedure for plot installation in selected local population is:

- finding saved GPS coordinates in the forest stands,

- selecting and marking the closest reproducing tree to the saved GPS coordinate.

\subsubsection{Labelling of trees}

Each selected tree must be marked with a corresponding number and a band painted around the trunk to aid the visibility of the trees from all directions. 


\subsubsection{Sampling for genetic analyses}

Samples for DNA extraction for all selected trees must be collected for assessment of hybridisation and presence of clones. Hybrids and clones must be excluded and replaced by non-hybrid individuals with unique genotypes (not clones). Consequently, it may be necessary to select and sample a larger number of trees to find the 50 European black poplar trees that are not hybridogenous or clones.

\subsection{Natural regeneration centres}

Sampling design of natural regeneration (NR) follows the metapopulation concept of multiple regeneration centres (subplots) to capture the whole genetic diversity of European black poplar and assess the risk of gene introgression and hybridisation from exotic poplar species, and Lombardy poplar sources in the given area. For NR sites, we must take into account flood disturbances and therefore the constantly changing shapes of the microsites' locations, environmental conditions or potentially even their disappearance.

The microsites of possible NR should be frequently monitored (at least once per week) at the end of the fructification phase in early summer (mainly from April to June), and where newly germinated NR centres are discovered the European black poplar offspring with the cotyledons or initial leaves should be sampled immediately. NR centres sampled should be mapped by recording their GPS coordinates. Ideally, 20 NR subplots with a size of $1 \mathrm{~m}^{2}$ each should be located across the FGM area, with an additional $0.5 \mathrm{~km}$ in both directions of the river system.

European black poplar should be sampled in NR subplots due to very diverse covering of offspring on each site. Ideally, 5 plants randomly selected from each subplot of $1 \mathrm{~m}^{2}$ should be collected for a total of 100 samples. If fewer than 20 NR locations are discovered, a proportionately higher number of samples per each NR subplot should be sampled. All samples are tested for hybridisation, and among them 50 pure European black poplar are randomly selected for further FGM analyses; if it is not possible to get 50 pure species plants from those 100 , sampling and testing of an additional batch of 100 samples must be performed until the minimum required number of 50 genotypes of pure Populus nigra individuals from NR centres needed for the FGM analysis is reached.

\subsection{Plot maintenance}

\subsubsection{General maintenance}

Tree markings markings must be checked periodically (every 2 years) and renewed if needed.

\subsubsection{Replacement of trees}

If a monitored tree dies or is cut due to management, it must be replaced. The nearest suitable tree to the dead one should be chosen considering that the distance requirement of $30 \mathrm{~m}$ to the nearest monitored tree is fulfilled. Otherwise a tree from the periphery of the FGM plot is to be selected.

If the crown is damaged due to, for example, windbreak, ice or snow break, but continues to fructify, the tree is kept for the monitoring. If the damage is too severe and fructification is not expected anymore, the monitored tree must be replaced. The cause of damage needs to be recorded, as the damage can affect the values recorded for field verifiers and background information. 


\section{Recording of verifiers and background information}

Molecular genetic identification of European black poplar trees should be performed with the use of species diagnostic genetic markers. Clonality detection in both the adult tree metapopulation and juvenile regeneration centres should be evaluated by genetic markers as a part of molecular genetic analyses. A set of verified reference samples of both (or even more) hybridising species is needed to discriminate between pure species and interspecific hybrids.

- In general, the following should be kept in mind that:

- The European black poplar population has a metapopulation structure.

- FGM plots are "local population plots" in the metapopulation.

- FGM plot chosen in a metapopulation along the river system form a FGM plot with 50 mature trees of European black poplar in total.

- All mature FGM European black poplar trees are considered for observations and measurements.

- Molecular genetic analyses are required to be performed on all monitoring levels in order to include "pure species" individuals in the monitoring. Therefore, FGM for this species becomes significantly more expensive to start with in comparison with that for non-hybridising tree species.

Verifiers and background information are periodically recorded on the monitoring plot. Verifiers are used to monitor the population's genetic properties and its adaptation to environmental changes and/or management, while background information needs to be recorded to assist interpretation of the verifiers.

Higher levels of verifiers (standard, advanced) must also include recording on all the preceding levels (basic, standard). This is not necessary for the recording of background information. 
Table 1: List of verifiers and background information with short description and observation frequency to be recorded during field work at the FGM plots

\begin{tabular}{|c|c|c|c|c|}
\hline & Name & Basic level & Standard level & Advanced level \\
\hline \multirow{5}{*}{ 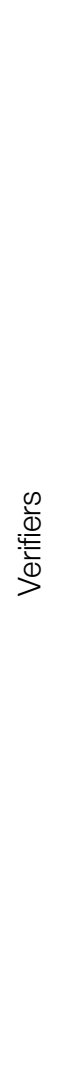 } & $\begin{array}{l}\text { Mortality / } \\
\text { survival }\end{array}$ & $\begin{array}{l}\text { Adult trees: Counting of } \\
\text { remaining marked mature } \\
\text { trees every } 10 \text { years and after } \\
\text { every extreme weather event/ } \\
\text { disturbance }\end{array}$ & Same as basic level & Same as basic level \\
\hline & & $\begin{array}{c}\text { Natural regeneration: mortality / } \\
\text { survival is not estimated for this } \\
\text { species }\end{array}$ & / & / \\
\hline & Flowering & $\begin{array}{c}\text { FGM plot level expert opinion, } \\
\text { every year. }\end{array}$ & $\begin{array}{c}\text { Individual tree level observation, } \\
\text { during two major flowering } \\
\text { events per decade, ideally } \\
\text { equally spaced. * }\end{array}$ & $\begin{array}{l}\text { Same as standard level, but } \\
\text { flowering stage also recorded. * }\end{array}$ \\
\hline & Fructification & $\begin{array}{l}\text { Individual tree level observation } \\
\text { twice per decade, the same } \\
\text { year as major flowering was } \\
\text { observed. (regardless of the } \\
\text { fructification intensity).* }\end{array}$ & $\begin{array}{l}\text { Individual tree level observation, } \\
\text { the same year as the } \\
\text { assessment of the flowering at } \\
\text { the standard level (regardless of } \\
\text { the fructification intensity). }{ }^{*}\end{array}$ & $\begin{array}{l}\text { Counting of fruit (cotton-like } \\
\text { catkins with mature seed } \\
\text { capsules), during the same years } \\
\text { as the assessment of flowering } \\
\text { at the advanced level, regardless } \\
\text { of the fructification intensity. } \\
\text { * Seeds are collected for } \\
\text { laboratory analyses for every } \\
\text { assessed fructification event at } \\
\text { the advanced level }\end{array}$ \\
\hline & $\begin{array}{l}\text { Natural } \\
\text { regeneration } \\
\text { abundance }\end{array}$ & $\begin{array}{l}\text { Expert opinion on the FGM plot } \\
\text { level. }{ }^{* \star}\end{array}$ & $\begin{array}{c}\text { Counting of seedlings on up } \\
\text { to } 20 \text { NR centres of only the } \\
\text { newly germinated NR after every } \\
\text { assessed major fructification } \\
\text { event. Samples for genetic } \\
\text { analyses are also collected at } \\
\text { the same time. }{ }^{\star *}\end{array}$ & The same as standard level. ** \\
\hline \multirow{5}{*}{ 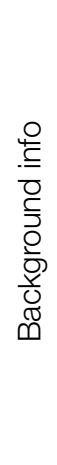 } & $\begin{array}{l}\text { DBH class } \\
\text { distribution }\end{array}$ & / & Measurement every 10 years & Same as standard level \\
\hline & $\begin{array}{l}\text { Height class } \\
\text { distribution }\end{array}$ & / & Measurement every 10 years & Same as standard level \\
\hline & Budburst & / & $\begin{array}{l}\text { Individual tree level observation } \\
\text { according, every } 5 \text { years }\end{array}$ & $\begin{array}{c}\text { Individual tree level observation, } \\
\text { every year }\end{array}$ \\
\hline & Senescence & / & $\begin{array}{c}\text { Individual tree level observation, } \\
\text { every } 5 \text { years }\end{array}$ & $\begin{array}{c}\text { Individual tree level observation, } \\
\text { every year }\end{array}$ \\
\hline & $\begin{array}{l}\text { Flowering } \\
\text { synchronisation }\end{array}$ & / & / & $\begin{array}{l}\text { Individual tree level observation, } \\
\text { during each assessed major } \\
\text { flowering event }\end{array}$ \\
\hline
\end{tabular}

* Ideally at least one major fructification event should be assessed per decade. However, a major flowering event does not necessarily lead to a major fructification event. If no major fructification event follows the assessed flowering event, assessment of both flowering and fructification needs to be repeated during the next major flowering event, regardless of the time passed between successive major flowering events. Basic level observations are used to identify major flowering and fructification events.

** If no new NR centres are present after an assessed major flowering and fructification event (in an event such as floodwater washing the seedlings away), then the assessment of all three verifiers (flowering, fructification and NR abundance) must be repeated the next major flowering event, regardless of the time passed between successive major flowering events. Basic level observations are used to identify major flowering and fructification events. 


\subsection{Protocols for recording of verifiers}

\subsubsection{Mortality / survival}

Mortality describes the mortality of adult trees. Its counterpart survival stands for trees that are still alive since the previous assessment. Survival is calculated as $1-$ Mortality.

\subsubsection{Adult trees: Basic, standard, and advanced levels}

The verifier for mortality of adult trees. It is estimated by counting the marked trees remaining alive every 10 years and after every extreme weather event/disturbance. Mortality is the difference between the initial number of marked trees and the trees remaining alive of the original 50 trees.

\subsubsection{Flowering}

This verifier describes the flowering intensity and proportion of trees thus affected. It can be recorded in April in Central Europe. Flowering is earlier when preceded by a warm winter.

\subsubsection{Basic level}

This verifier is recorded every year at the stand level. Recording is carried out when flowering is in full progress. The estimate of average condition is provided after a walk throughout the monitoring plot. Two scores are given, one for flowering intensity and one for the proportion of flowering trees in the stand.

\begin{tabular}{clc} 
Code & Flowering intensity at the stand level & Average proportion of crown flowering (\%) \\
\hline 1 & No flowering: No or only occasional flowers appearing on trees & $0-10$ \\
\hline 2 & Weak flowering: Some flowers appearing on trees. & $>10-30$ \\
\hline 3 & Moderate flowering: Moderate number of flowers appearing on trees. & $>30-60$ \\
\hline 4 & Strong flowering: Abundant number of flowers on trees. & $>60-90$ \\
\hline 5 & Massive: Huge number of flowers on trees. & $>90$ \\
\hline
\end{tabular}

\begin{tabular}{lr} 
Code Proportion of trees in the stand with the given flowering intensity stage (\%) & $0-10$ \\
\hline 1 & $>10-30$ \\
\hline 2 & $>30-60$ \\
\hline 3 & $>60-90$ \\
\hline 4 & $>90$ \\
\hline 5 & \\
\hline
\end{tabular}




\subsubsection{Standard level}

This verifier is recorded during two major flowering events per decade, ideally equally spaced in time from one another. It is recorded at an individual tree level on all 50 monitored trees. A major flowering event is when at the basic level flowering intensity is strong or massive (code 4 or 5 ) and the proportion of trees with the given flowering intensity is above $60 \%$ (code 4 or 5). Recording is carried out when flowering is in full progress. One score is provided for each tree.

\begin{tabular}{|c|c|c|}
\hline Code & Description of flowering intensity & Proportion of the crown flowering (\%) \\
\hline 1 & No flowering: No or only occasional flowering appearing on a tree. & $0-10$ \\
\hline 2 & Weak flowering: Some flowers appearing on a tree. & $>10-30$ \\
\hline 3 & Moderate flowering: Moderate number of flowers on a tree. & $>30-60$ \\
\hline 4 & Strong flowering: Abundant number of flowers on a tree. & $>60-90$ \\
\hline 5 & Massive: Huge number of flowers on a tree. & $>90$ \\
\hline
\end{tabular}

\subsubsection{Advanced level}

This verifier is recorded during two major flowering events per decade, ideally equally spaced in time from one another. It is recorded at an individual tree level on all 50 monitored trees. A major flowering event is when at the basic level flowering intensity is strong or massive (code 4 or 5) and the proportion of trees with the given flowering intensity is above $60 \%$ (code 4 or 5 ).

Two scores are provided for each tree: flowering stage to describe the stage of flower bud development for male and female trees with flowering intensity and the proportion of the crown flowering. On average, two visits to the plot are needed; the first one early enough to observe the early stages of flowering, and the second when flowering is in full progress. Background information on flowering synchronisation can be estimated from the scores for male and female flowering recorded by this verifier. For a graphical representation of male and female trees flowering stages, see Figures 6 and 7 .

\begin{tabular}{|c|c|}
\hline Cod & Female flowering stage \\
\hline 1 & Female flowering buds not active (brown coloured buds) \\
\hline 2 & Female flowering buds increase in size and start to break (light-green coloured buds) \\
\hline 3 & Flower elongation (short light-green coloured flowers) \\
\hline 4 & Flowers open (greenish coloured catkins) \\
\hline 5 & Flowers open (fully developed yellow-green coloured flowers in catkins) \\
\hline
\end{tabular}

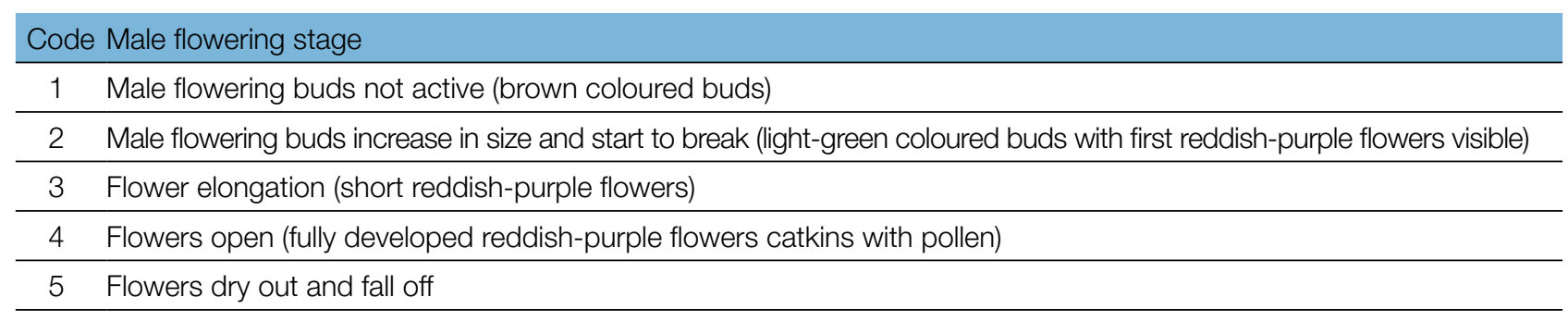

\begin{tabular}{clr}
\hline Code & Flowering intensity for each tree, valid for both sexes & Proportion of the crown flowering (\%) \\
\hline 1 & No flowering: No or only occasional flowering appearing on a tree. & $0-10$ \\
\hline 2 & Weak flowering: Some flowers appearing on a tree. & $>10-30$ \\
\hline 3 & Moderate flowering: Moderate number of flowers on a tree. & $>30-60$ \\
\hline 4 & Strong flowering: Abundant number of flowers on a tree. & $>60-90$ \\
\hline 5 & Massive: Huge number of flowers on a tree. & $>90$ \\
\hline
\end{tabular}


1

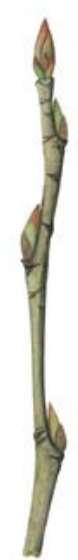

2

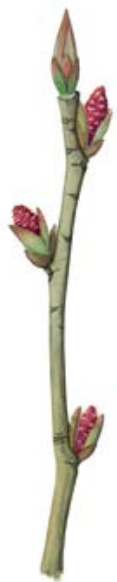

3

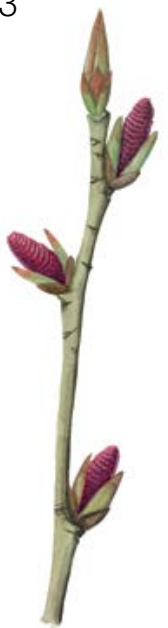

4

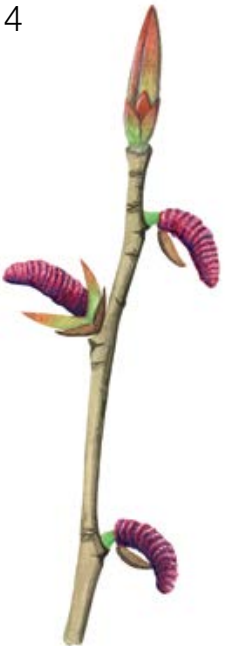

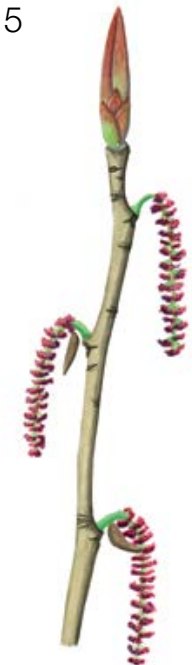

Figure 6: Picture guide for male reddish-purple coloured catkin flowering development stages for the advanced level verifier Flowering.

1

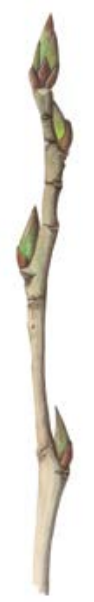

2

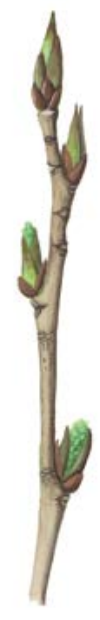

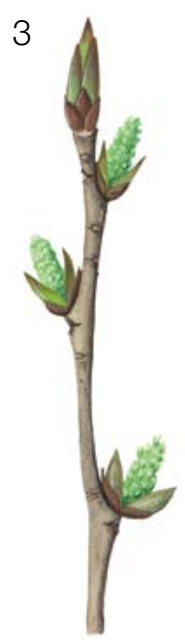

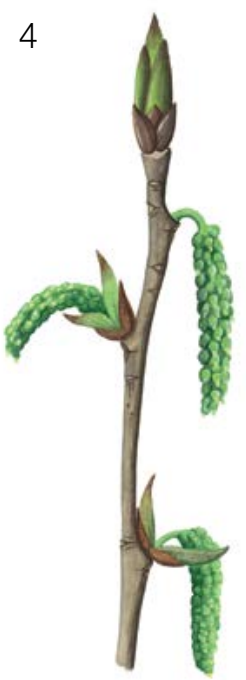

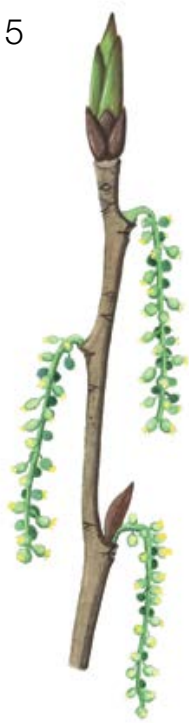

Figure 7: Picture guide for female yellow-green coloured catkin flowering development stages for the advanced level verifier Flowering

\subsubsection{Fructification}

This verifier describes the presence of fructification and its abundance. Data for this verifier should be collected during fructification, mainly from late April to June in Central Europe.

\subsubsection{Basic and standard levels}

This verifier is recorded twice per decade during the years of major flowering. Ideally, assessments of fructification should be equally spaced in time from one another. It is recorded at an individual tree level on all monitored female trees (ideally 25). Recording is carried out before seeds start falling. One score is provided for each tree.

Ideally, one major fructification event should be captured following observations of major flowering events per decade. However, a major flowering event does not necessarily lead to a major fructification event. If no major fructification event follows the assessed flowering event, then the assessment of both flowering and fructification needs to be repeated during the next major flowering event, regardless of the time passed between successive 
major flowering events. A major fructification event is when fructification intensity is strong or massive (code 4 or 5) for at least $60 \%$ of the monitored female trees.

\begin{tabular}{|c|c|c|}
\hline Code & Fructification intensity & Proportion of the crown fructifying (\%) \\
\hline 1 & No fructification: No or only occasional fruit appearing on a tree. & $0-10$ \\
\hline 2 & Weak fructification: Some fruit appearing on a tree. & $>10-30$ \\
\hline 3 & Moderate fructification: Moderate amount of fruit appearing on a tree. & $>30-60$ \\
\hline 4 & Strong fructification: Abundant amount of fruit appearing on a tree. & $>60-90$ \\
\hline 5 & Massive: Huge amount of fruit appearing on a tree. & $>90$ \\
\hline
\end{tabular}

\subsubsection{Advanced level}

This verifier is recorded during the same years as the assessment of the flowering at standard and advanced levels (regardless of the fructification intensity). It is recorded at an individual tree level on all monitored female trees (ideally 25). Recording is carried out before seeds start falling. One score is provided for each tree. Simultaneously, seed is collected from 20 female trees for seed and genetic analysis for the advanced level verifiers and background information.

Ideally, one major fructification event should be captured following observations of major flowering events per decade. However, a major flowering event does not necessarily lead to a major fructification event. If no major fructification event follows the assessed flowering event, assessment of both flowering and fructification needs to be repeated during the next major flowering event, regardless of the time passed between successive major flowering events. Basic level observations are used to identify major fructification events. A major fructification event is when at the basic or standard level fructification intensity is strong or massive (code 4 or 5) for at least $60 \%$ of the monitored female trees.

The verifier is recorded by counting fruits (cotton-like catkins with mature seed capsules) using binoculars. The average of three rounds of counting is reported. Each round of counting consists of the number of fruits that the observer counts in 30 seconds. For all trees, the same part of the crown should be investigated. Once the observation part of the crown part is selected, the same one should be selected for every subsequent monitoring of this verifier. The upper third of the crown is preferred to the bottom and middle part for counting.

Two values are recorded; the number of fruits and the part of the crown monitored.

\section{Number of fruits counted in 30 seconds (average of 3 rounds)}

$$
\mathrm{X}
$$

\begin{tabular}{ll} 
Code & Part of the crown monitored \\
\hline 1 & Bottom \\
\hline 2 & Middle \\
\hline 3 & Top \\
\hline
\end{tabular}




\subsubsection{Natural regeneration presence and abundance}

This verifier describes the presence and abundance of natural regeneration at the monitoring plot.

\subsubsection{Basic level}

This verifier is recorded at the FGM plot level every year, in late spring to early summer. Expert opinion is used for estimation considering the situation on the FGM monitoring area as a whole.

\begin{tabular}{ll} 
Code Description: new regeneration (newly germinated seedlings) \\
\hline $1 \mathrm{a}$ & There is no or very little new natural regeneration on the monitoring plot \\
\hline $2 \mathrm{a}$ & New regeneration is present in sufficient quantity on the monitoring plot \\
\hline
\end{tabular}

Code Description: established natural regeneration (saplings)

1b There is no or very little established natural regeneration on the monitoring plot

$2 \mathrm{~b}$ Established regeneration is present in sufficient quantity on the monitoring plot

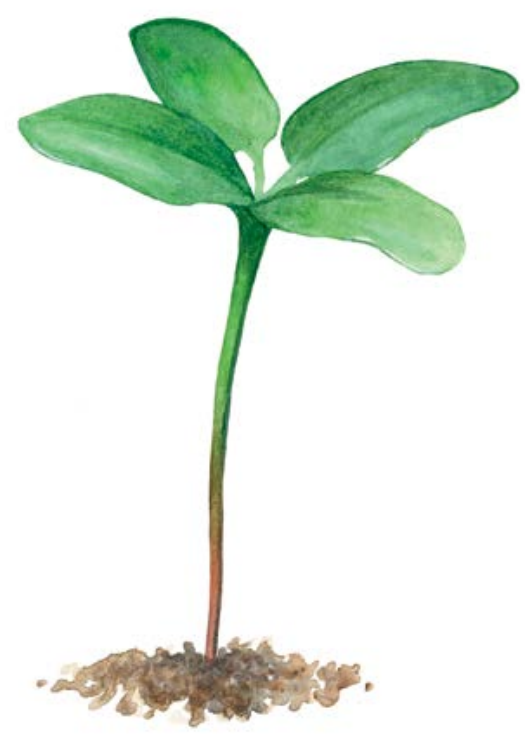

Figure 8: Newly germinated seedling of European black poplar with characteristic cotyledons or initial developed leaves.

\subsubsection{Standard level and Advanced level}

This verifier is recorded by counting newly germinated seedlings (Figure 8) after every assessed major fructification event on up to $20 \mathrm{NR}$ centres. NR subplots are not established for European black poplar due to high expected loss of NR because of regular river flooding. Consequently, counting is performed only once, immediately after germination, and survival/mortality of NR is not assessed for this species. At the same time, NR regeneration samples are collected for genetic analyses.

Counting of seedlings:

All European black poplar seedlings present at each of the $20 \mathrm{NR}$ centres must be counted. Any older European black poplar saplings that are present on the NR subplot must not be included.

If no new NR centres are present after an assessed major flowering and fructification event (in an event such as floodwater washing the seedlings away), then the assessment of all three verifiers (flowering, fructification and NR abundance) must be repeated the next major flowering event, regardless of the time passed between successive major flowering events. Basic level observations are used to identify major flowering and fructification events. 
If no new NR centres are formed in 5 consecutive monitoring years (after two major fructification events in a decade) then NR should be estimated and samples collected for genetic analyses once per decade in already successfully established NR sites. In such cases, the approximate age of NR must be assessed and recorded.

Number of seedlings counted on a subplot

$\mathrm{X}$

\subsection{Protocols for recording of background information}

\subsubsection{DBH class distribution}

\subsubsection{Standard and advanced levels}

$\mathrm{DBH}$ is recorded on an individual tree level on all 50 monitored trees every 10 years. DBH is the trunk diameter at $1.30 \mathrm{~m}$, i.e. approximately at an adult's breast height. If a tree has more than one trunk, please measure all of them and record the average (but try to avoid trees with many small trunks). Note that the tree is multi-trunk in the notes and include the number of trunks measured. If the tree is leaning, measure DBH perpendicular to the tree trunk. DBH can be measured in two ways:

1) using a calliper, in which case you need to measure two perpendicular diameters and take the average

2) measure the circumference of the tree and compute the diameter from that value (i.e. divide by $\pi, \sim 3.14$ or use a pi-meter)

The DBH is recorded in $\mathrm{cm}$. The same method must be applied for every subsequent measurement.

\subsubsection{Height class distribution}

\subsubsection{Standard and advanced levels}

Height is recorded on an individual tree level on all 50 monitored trees every 10 years. Height is measured from the ground to the tallest part of the crown, ideally using a clinometer or hypsometer (e.g. vertex). Height is recorded in metres to one decimal place. If the crown is damaged, this must be recorded as well as the stipulated reason in the notes.

\subsubsection{Budburst}

Budburst describes the process of budbursting (flushing). Recording of this parameter is only carried out at the standard and advanced levels. In European black poplar, budbursting starts later than flowering. Data for this verifier should be collected in March - May in Central Europe. Budbursting is earlier when preceded by a warm winter. Recording of this parameter is only carried out at the standard and advanced levels. 


\subsubsection{Standard level}

At standard level, budburst is recorded on an individual tree level on all 50 monitored trees every 5 years. For each tree, two estimates are given: budbursting stage and proportion of the crown budbursting. For a graphical representation of budbursting stages, see Figure 9 .

\begin{tabular}{lll}
\multicolumn{2}{l}{ Code Stage } & Stage of budbursting \\
\hline 1 & Dormant bud & buds from completely enveloped by the scale to the first sign of swelling \\
\hline 2 & Swelling & buds swelling with scale slightly diverging \\
\hline 3 & Bursting & buds sprouting \\
\hline 4 & Separation of leaves & buds are completely opened with leaves still clustered \\
\hline 5 & Leaves elongate & leaves diverging with their blade \\
\hline 6 & Vertical growth & leaves completely unfolded and fully developed \\
\hline
\end{tabular}

\begin{tabular}{lr} 
Code Proportion of the crown with a given stage of budbursting (\%) & $>0-33 \%$ \\
\hline 1 & $>33-66 \%$ \\
\hline 2 & $>66-99 \%$ \\
\hline 3 & $100 \%$ \\
\hline 4 & \\
\hline
\end{tabular}

1

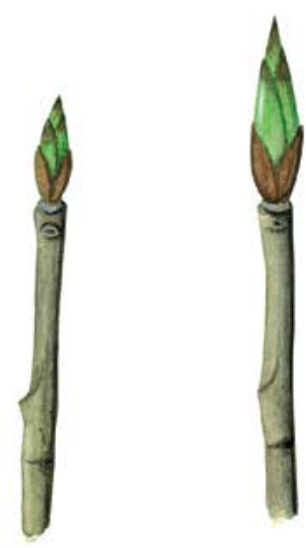

3

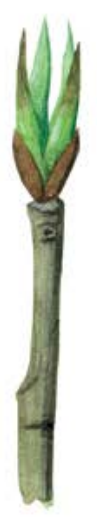

4

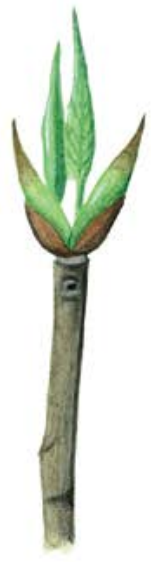

6

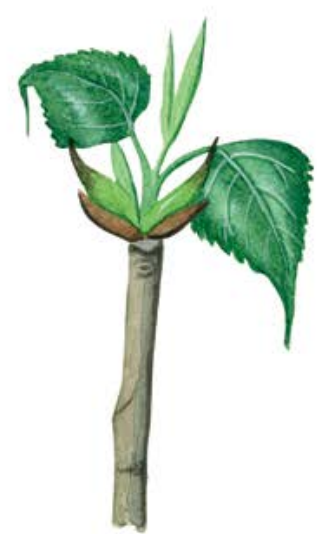

Figure 9: Picture guide for description of budburst (flushing) for the standard, and advanced levels background information Budburst

\subsubsection{Advanced level}

At advanced level, budburst is recorded on an individual tree level on all 50 monitored trees every year. We are looking for the initiation of budbursting (stage 3) and the end of budbursting (stage 6). The observations stop when all trees have reached stage 6. Usually 2 visits will be needed. For the values (stage of budbursting and the proportion of crown affected) see 7.2.3.1 Standard level.

\subsubsection{Senescence}

Senescence describes the process of senescence. Recording of this parameter is only carried out at the standard and advanced levels. 


\subsubsection{Standard level}

At standard level, senescence is recorded on an individual tree level on all 50 monitored trees every 5 years. For each tree, two estimates are given: stage of senescence and proportion of the crown senescing. For graphical representation of stages of senescence see Figure 10.

Code Stage of senescence
\begin{tabular}{lll}
\hline 1 & Leaves are green \\
\hline 2 & Leaves are green changing to yellow (greenish yellow) \\
\hline 3 & Leaves are yellow changing to brown (brownish) \\
\hline 4 & Leaves are brown / shed & $>0-33 \%$ \\
\hline & & $>33-66 \%$ \\
\hline Code Proportion of the crown with a given score for stage of senescence (\%) & $>66-99 \%$ \\
\hline 1 & & $100 \%$ \\
\hline 3 &
\end{tabular}

\subsubsection{Advanced level}

Senescence is recorded on an individual tree level on all 50 monitored trees every year. We are looking for stage 3 , when leaves are yellow and do not photosynthesise anymore. Observations stop when all trees have reached stage 3. Usually 2 visits to the plot will be needed. For the values (stage of senescence and the proportion of crown affected) see 7.2.4.1 Standard level.
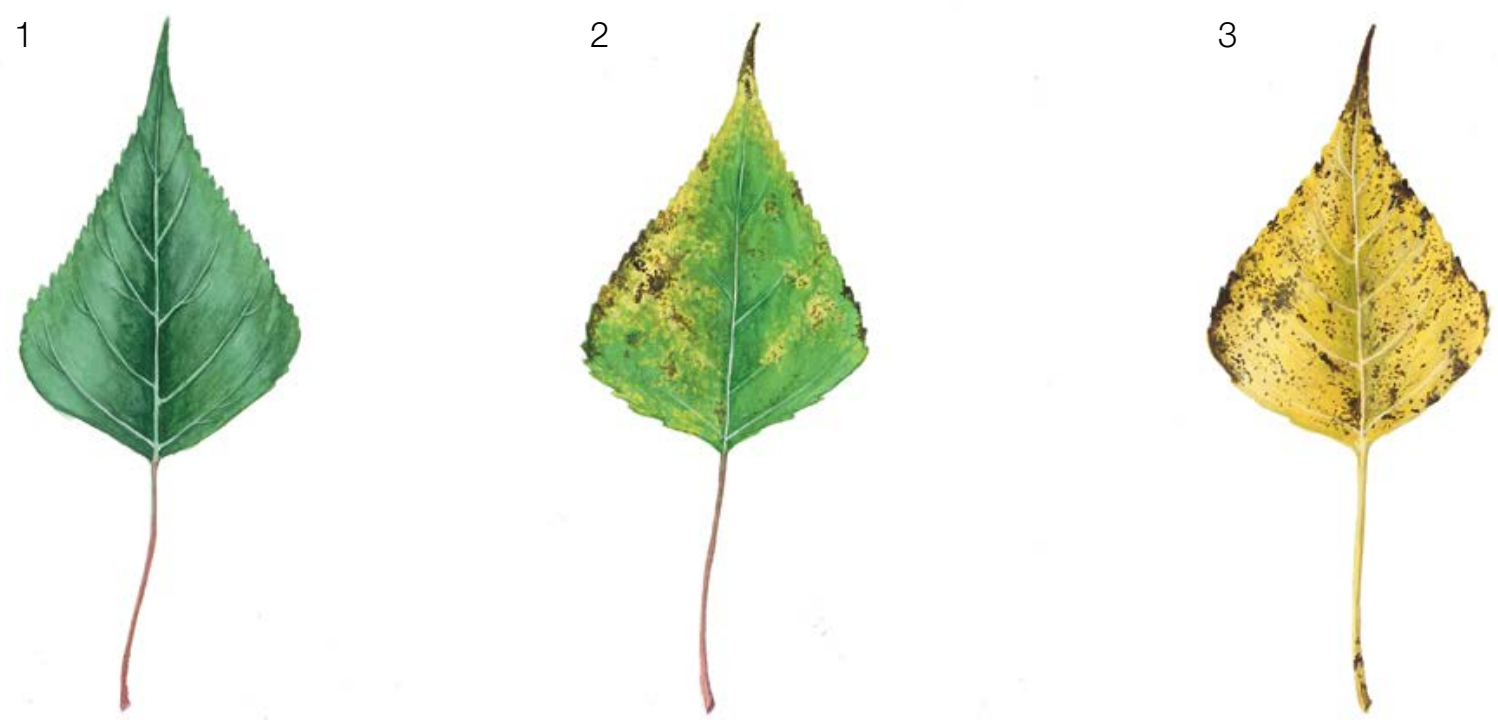

Figure 10: Picture guide for description of senescence (phase 4 is not shown) for the standard and advanced level background information Senescence

\subsubsection{Flowering synchronisation}

\subsubsection{Advanced level}

Flowering synchronisation is monitored only at the advanced level, and is based on the data collected for the verifier Flowering (see 7.1.2.3). It is used to determine whether male and female flowering times occur simultaneously within the monitored stand. 


\section{For plot establishment use form 'FGM Plot description'}

\section{For verifiers recording use 'Form for recording field level verifiers within FGM'}

\section{For background information recording use 'Form for recording field level background information within FGM'}

\section{References}

1. Smulders MJM, Cottrell JE, Lefèvre F, van der Schoot J, Arens P, Vosman B, Tabbener HE, Grassi F, Fossati T, Castiglione S, Krystufek V, Fluch S, Burg K, Vornam B, Pohl A, Gebhardt K, Alba N, Agúndez D, Maestro C, Notivol E, Volosyanchuk R, Pospiśšvá M, Bordács S, Bovenschen J, van Dam BC, Koelewijn HP, Halfmaerten D, Ivens B, van Slycken J, Vanden Broeck A, Storme V, Boerjan W (2008) Structure of the genetic diversity in black poplar (Populus nigra L.) populations across European river systems: Consequences for conservation and restoration. Forest Ecol Manag 255(5-6):1388-1399. DOl:10.1016/j.foreco.2007.10.063

2. Lefèvre F, Barsoum N, Heinze B, Kajba D, Rotach P, de Vries S, Turok J (2001). EUFORGEN Technical Bulletin: In situ conservation of Populus nigra. International Plant Genetic Resources Institute, Rome

3. Lefèvre F, Bordács S, Cottrell JE, Gebhardt K, Smulders MJM, Vanden Broeck A, Vornam B, van Dam BC (2002) Recommendation for riparian ecosystem management based on the general frame defined in EUFORGEN and results from EUROPOP. In: van Dam BC, Bordács S (eds) Genetic diversity in river populations of European Black Poplar. (Implications for riparian eco-system management), Csiszár Nyomda, Budapest, pp 157-161

4. Jelić M, Patenković A, Skorić M, Mišić D, Kurbalija Novičić Z, Bordács S, Varhidi F, Vasić I, Benke A, Frank G, Šiler B (2015) Indigenous forests of European black poplar along the Danube River: genetic structure and reliable detection of introgression. Tree Genet Genomes 11:89 https://doi.org/10.1007/s11295-015-0915-5

5. Eckenwalder JE (1996) Systematics and evolution of Populus. In: Stettler RF, Bradshaw HD. Jr, Heilman PE, Hinckley TM (eds) Biology of Populus and Its Implications for Management and Conservation. NRC Research Press, Ottawa, pp. 7-32. https://doi.org/10.1139/9780660165066

6. Rotach P (2001) General consideration and basic strategies. In: Lefevre F, Barsoum N, Heinze B, Kajba D, Rotach P, de Vries SMG, Turok J (eds) EUFORGEN technical bulletin: in situ conservation of Populus nigra. International Plant Genetic Resources Institute, Rome, pp 8-15

7. Heinze B, Lefevre F (2001) Genetic considerations for the restoration of riparian populations. In: Lefevre F, Barsoum N, Heinze B, Kajba D, Rotach P, de Vries SMG, Turok J (eds) EUFORGEN technical bulletin: in situ conservation of Populus nigra. International Plant Genetic Resources Institute, Rome, pp 25-35

8. Allegri E (1971) Identification of species and varieties of poplar indigenous in Italy. Annali dell Istituto Sperimentale per la Selvicoltura 2:1-62

9. Popivshchy II; Prokazin AE; Routkovsky LV (1997) Black poplar in the Russian Federation. In: Turok J, Lefévre F, de Vries S, Toth B (eds) Populus nigra Network. Report of the third meeting, Sarvar, Hungary, 5-7 October 1996, IPGRI, Rome, pp 46-52.

10. Dickmann D, Kuzovkina J (2014) Poplars and Willows in the World, With Emphasis on Silviculturally Important Species. In: Isebrands JG, Richardson J (eds) Poplars and Willows: Trees for Society and the Environment. FAO UN, CABI, Rome, pp 8-91. http://dx.doi.org/10.1079/9781780641089.0008

11. de Rigo D, Enescu CM, Houston Durrant T, Caudullo G (2016) Populus nigra in Europe: distribution, habitat, usage and threats. In: San-Miguel-Ayanz J, de Rigo D, Caudullo G, Houston Durrant T, Mauri A (eds) European Atlas of Forest Tree Species. Publ. Off. EU, Luxembourg, pp 136-137. DOI: 10.2788/4251

12. Fitschen JB (2002) Gehölzflora. Quelle \& Meyer Verlag, Wiebelsheim, pp 45-1; 45-7

13. Roloff A, Bärtels A (2006) Flora der Gehölze. Eugen UlmerKG, Stuttgart, pp 457-464

14. Vanden Broeck A (2003) Technical guidelines for genetic conservation and use of European Black Poplar (Populus nigra L.). International Plant Genetic Resources Institute,Rome

15. Braatne JH, Rood SB, Heilman PE (1996) Life history, ecology, and conservation of riparian cottonwoods in North America. In: Stettler RF, Bradshaw HD, Heiman PE, Hinckley TM (eds.) Biology of Populus and its Implications for Management and Conservation. NRC Research Press, Ottawa, pp 57-80. https://doi.org/10.1139/9780660165066

16. Mahoney JM, Rood SB (1998) Streamflow requirements for cottonwood seedling recruitment-an integrative model. Wetlands 18:634-645. https://doi.org/10.1007/BF03161678 
17. Barsoum N (2001) Regeneration requirements and promotion measures. In: Lefevre F, Barsoum N, Heinze B, Kajba D, Rotach P, de Vries SMG, Turok J (eds) EUFORGEN technical bulletin: insitu conservation of Populus nigra. International Plant GeneticResources Institute, Rome, pp 16-24

18. Guilloy-Froget H, Muller E, Barsoum N, Hughes FMR (2002) Dispersal, germination, and survival of Populus nigra L. (Salicaceae) in changing hydrologic conditions. Wetlands 22:478-488. https://doi. org/10.1672/0277-5212(2002)022[0478:DGASOP]2.0.CO;2

19. Rihardson J, Isebrands JG, Ball JB (2014) Ecology and Physiology of Populus and Willows. In: Isebrands JG, Richardson J (eds) Poplars and Willows: Trees for Society and the Environment. CAB International, Food and Agriculture Organization of the United Nations (FAO), pp 92-123. http://dx.doi.org/10.1079/9781780641089.0008

20. Zsuffa L (1974) The genetics of Populus nigra L. Annales Forestales 6:29-53

21. Ballian D (2017) Varijabilnost crne topole (Populus nigra L.) i njeno očuvanje u Bosni i Hercegovini. (Variability of Black poplar (Populus nigra L.) and its preservation in Bosnia and Herzegovina). Forestry Faculty of the University of Sarajevo/Silva Slovenica - Slovenian Forestry Institute Publishing Centre, Sarajevo/Ljubljana.

22. Lefèvre F, Légionnet A, de Vries S, Turok J (1998) Strategies for the conservation of a pioneer tree species, Populus nigra L., in Europe. Genet Sel Evol 30:S181 https://doi.org/10.1186/1297-9686-30-S1-S181

23. Bordács S, Bach I (2014) Restoration and afforestation with Populus nigra in Hungary. In: Bozzano M, Jalonen R, Thomas E, Boshier D, Gallo L, Cavers S, Bordács S, Smith P, Loo J (eds) Genetic considerations in ecosystem restoration using native tree species: State of the World's Forest Genetic Resources. Thematic study, Rome: Food and Agriculture Organization of the United Nations (FAO), pp 233-235. http://www.fao.org/3/a-i3938e.pdf. Accessed 10 August 2020

24. EUFORGEN Identification Sheet of Populus nigra L. http://www.euforgen.org/fileadmin/templates/euforgen.org/ upload/Publications/Other_PDFs/Pop_nigra_IdSheets/English.pdf. Accessed 10 August 2020

The following resources were consulted for the currently accepted (December 2020) scientific names of the species covered or mentioned in this document:

a. CABI (2020) Invasive Species Compendium. CAB International, Wallingford, UK. www.cabi.org/isc. Accessed 15 December 2020

b. EPPO (2020) EPPO Global Database (available online). https://gd.eppo.int. Accessed 15 December 2020

c. GBIF (2020) Global Biodiversity Information Facility. https://www.gbif.org Accessed 15 December 2020

d. IPNI (2020) International Plant Names Index. The Royal Botanic Gardens, Kew, Harvard University Herbaria \& Libraries \& Australian National Botanic Gardens. http://www.ipni.org, Accessed 10 December 2020

e. National Center for Biotechnology Information (NCBI) (1998) National Library of Medicine (US), National Center for Biotechnology Information, Bethesda (MD). https://www.ncbi.nlm.nih.gov/. Accessed 15 December 2020

f. Stevens PF (2001) Angiosperm Phylogeny Website, Version 14. http://www.mobot.org/MOBOT/research/APweb/. Accessed 15 December 2020

g. The Plant List (2013) Version 1.1. http://www.theplantlist.org/. Accessed 12 December 2020

h. Tropicos.org (2020) Missouri Botanical Garden. http://www.tropicos.org. Accessed 15 December 2020

i. WFO (2020) World Flora Online. http://www.worldfloraonline.org. Accessed 15 December 2020 


\section{Guidelines for genetic monitoring of}

\subsubsection{Wild cherry (Prunus avium (L.) L.)}

Darius KAVALIAUSKAS ${ }^{1}$, Barbara FUSSI', Filippos ARAVANOPOULOS², Paraskevi ALIZOTI², Dalibor BALLIAN³,4, Nikos TOURVAS², Gregor BOŽIČ³, Evangelos BARBAS ${ }^{2}$, Marjana WESTERGREN ${ }^{3}$, Marko BAJC ${ }^{3}$, Rok DAMJANIĆ ${ }^{3}$, Hojka KRAIGHER ${ }^{3}$

Botanical illustrations by Teja MILAVEC

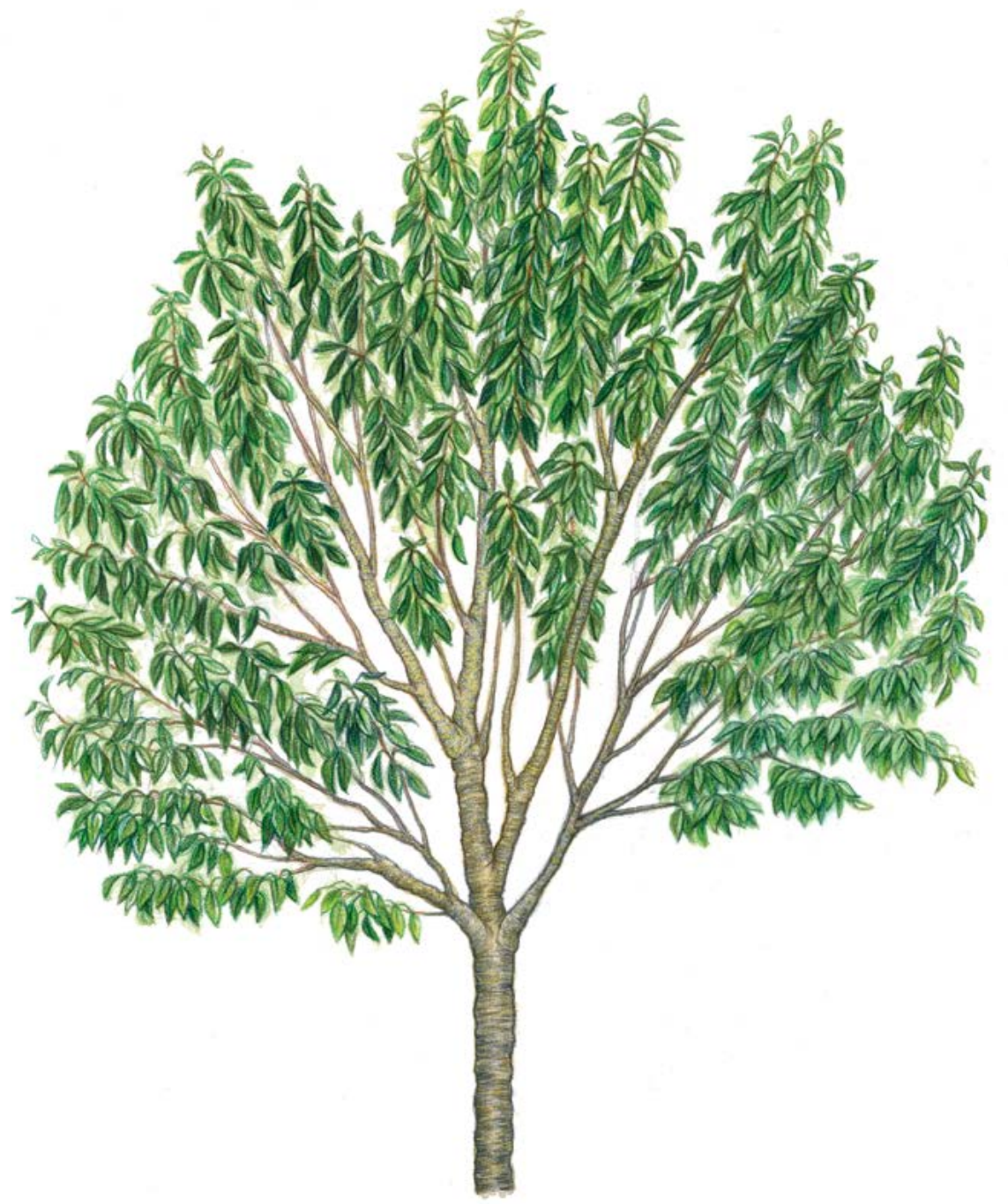

Citation: Kavaliauskas et al. (2020) Guidelines for genetic monitoring of Wild cherry (Prunus avium (L.) L.). In: Bajc et al. (eds) Manual for Forest Genetic Monitoring. Slovenian Forestry Institute: Silva Slovenica Publishing Centre, Ljubljana, pp 255-270. http://dx.doi.org/10.20315/SFS.167

2. Aristotle University of Thessaloniki (AUTh), Greece

3. Slovenian Forestry Institute (GIS), Slovenia

4. University of Sarajevo, Forestry Faculty, Bosnia and Herzegovina 


\section{Executive summary}

Wild cherry (Prunus avium (L.) L.), is a medium sized, fast growing and rather short-lived deciduous tree, with wide natural distribution range, which includes western Eurasia and the northern part of Africa [1]. The species is a pioneer one that grows in a wide range of habitats; however, the species is extremely scattered throughout its distribution as it is highly light demanding and a weak competitor. The species natural populations are characterised by their small size and occur in small groups or are composed of single trees growing at the edges and in the gaps of forest stands. Wild cherry is an important forest tree species from an ecological (it is vital as a food source for many bird and insect species) and economic point of view (wood of wild cherry is as valuable as it is of high-quality and easy to work, therefore is often used for veneer and furniture production, cabinetry, etc.).

These guidelines briefly describe the wild cherry, its reproduction, niche requirements and threats. They provide guidance on establishing a genetic monitoring plot and on recording all field level verifiers.

\section{Species description}

Wild cherry (Figure 1) is a medium sized, fast growing and rather short-lived deciduous tree reaching the height of 15-30 m. (up to $35 \mathrm{~m}$.) and with a stem diameter (DBH) of up to 90-120 cm [3, 4, 5, 16, 19 and references therein]. Wild cherry has strong apical growth and most of its lateral branches are arranged in annual whorls. The crown is broadly conical and the trunk usually straight. The bark is shiny with large lenticels and peels horizontally [16, 19]. Leaves are light green in spring, dark green in summer and yellow, orange or reddish brown in autumn. They are alternate, pendulous, simple and elliptic-ovate to obovate acute in shape, and their margins are characterised by slightly rounded teeth. There are conspicuous pairs of dark-red glands at the $2-3.5 \mathrm{~cm}$ long petiole below the lamina [19].

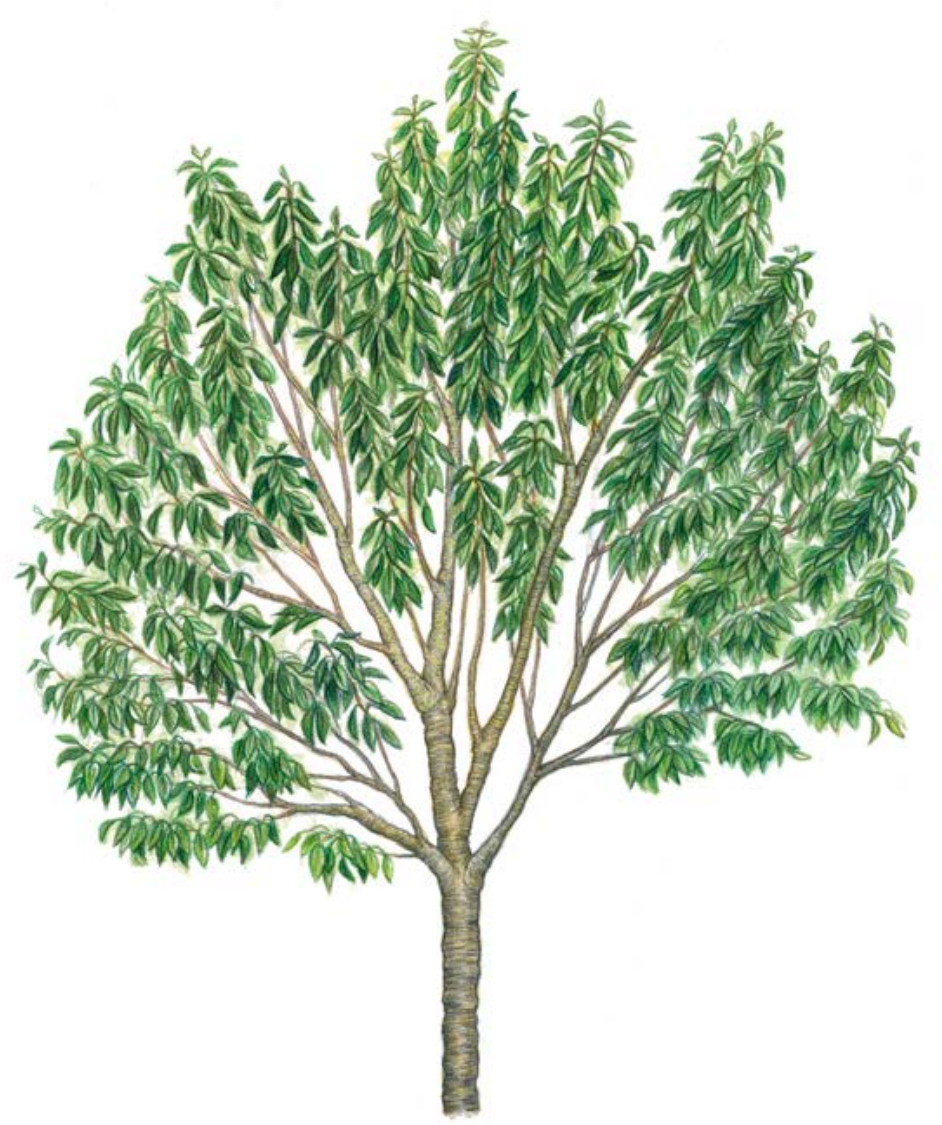

Figure 1. Wild cherry tree (Prunus avium) habitus. 


\section{Reproduction}

Wild cherry is a species with a mixed reproduction system involving asexual reproduction via root suckers and sexual reproduction. The species is a monoecious, hermaphrodite tree, with flowers typically pentameric, with white petals, pedunculate and assembled on brachyblasts in groups of three to ten or more [3, 9]. Flowers are insect pollinated, mainly by honeybees, wild bees and bumblebees [2, 3, 5, 16, 19]. Flowering and seed production of wild cherries start at the 4-6 years of age under optimal conditions. It is one of the first trees to flower in the spring and produces masses of white blossoms. The small red or black fruits are edible (Figure 2) $[2,6]$. The seeds are spread by birds, and small mammals $[5,16,19]$. Seed dormancy lasts one to two winters. A combination of warm and cold stratification is applied for germination of stored seed [16].
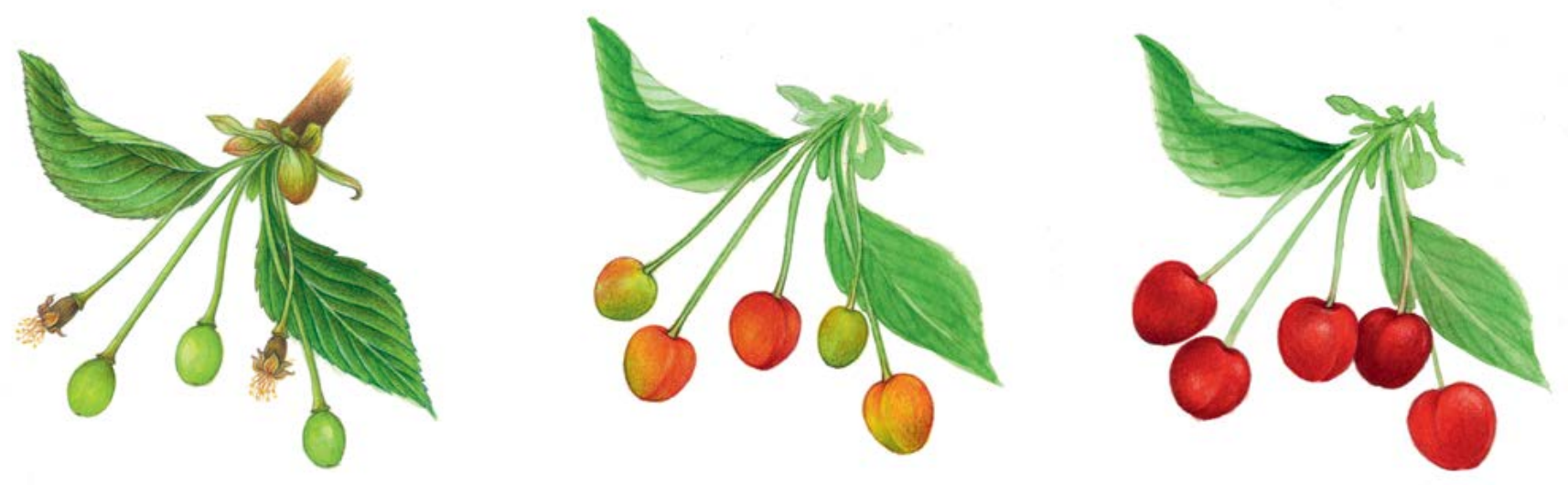

Figure 2. Development of wild cherry (Prunus avium) fruits.

The species sexual reproduction is characterised by a gametophytic self-incompatibility system (which is regulated by "S" allele) which favours outcrossing and prevents self-fertilisation [7, 11, 12, 15, 16, 17, 9 and references therein]. It can hybridise with other cherry species, particularly when their natural distribution ranges overlap, e.g. with sweet cherry, sour cherry (Prunus cerasus L.), European dwarf cherry (Prunus fruticosa Pall.) [7, $14,16,18]$, or when the species grows close to areas of cherry cultivation.

Regarding local establishment strategies of the species related to its mixed reproductive system, it is considered that the establishment of a new niche is achieved via seedling recruitment, if it is followed by asexual reproduction via root suckers [13].

\section{Environment}

The species is a pioneer and grows in a wide range of habitats; however, it falls in the category of species with scattered distribution range, due to its low competitive ability and high demand for light. Wild cherry natural populations are mainly of limited size forming small groups or consisting of single trees growing at the edges and in the gaps of forest stands, due to forest disturbances [16]. The species can quickly colonise open areas (gaps) by seeds or root suckers during the early forest successional stages, but it is often replaced by other hardwood species (climax tree species) during ongoing forest succession [16, 19]. Typically wild cherry prefers deep, light, silty soils ( $\mathrm{pH}$ 5.5-8.5) that are fertile with a good water supply (precipitation 580-1800 mm per year). It is a cold winter resistant tree species, but flowers can be damaged by late spring frosts. In the core of its distribution the species can be found in deciduous mixed forest type communities of the class Querco-Fagetea, such as ravine forests (Tilio-Acerion), oak-Hornbeam forests (Carpinion betuli), lowland beech forests (Fagion), and riverine floodplain forests (Alno-UImion) [19 and references therein]. 


\section{Threats}

As the high forest management system and longer rotation periods have been prevailing in forestry over the last few decades, the conditions for wild cherry have not been the best. Currently, the role of wild cherry in improving the biodiversity of forest ecosystems is recognised, and forest owners promote wild cherry in their forests [9]. The species is relatively sensitive to environmental stresses (e.g. droughts) and can be easily affected by diseases and pests in unfavourable conditions. In addition, its root system is characterised by far-reaching lateral roots in topsoil horizons, and it is vulnerable to strong winds [9, 19 and references therein]. Roots may be attacked by mice and voles, while the natural regeneration of wild cherry trees is especially susceptible to browsing. Leaves can be damaged by caterpillars such as those of the winter moth (Operophtera brumata L.), gypsy moth (Lymantria dispar L.); fruits can be attacked by European cherry fruit fly (Rhagoletis cerasi L.) and the bird-cherry weevil (Anthonomus rectirostris L.). Wild cherry can be damaged by bacterial cankers, such as Pseudomonas syringae Van Hall or fireblight (Erwinia amylovora Burrill), cherry leaf roll virus (CLRV) and fungal pathogens (Apiognomonia erythrostoma Höhnel, Blumeriella jaapi (Rehm) Arx) [19 and references therein].

\section{Plot establishment and maintenance}

A forest genetic monitoring plot consists of 50 reproducing trees and the minimum distance of $30 \mathrm{~m}$ between any two trees. If a tree is flowering, it is regarded as a reproducing tree. Diameter at breast height ( $\mathrm{DBH}$ ) and social class can be used as a proxy to identify a reproducing tree if the plot is being established outside of the flowering season, relying on the expertise of the local forester. During plot installation, trees should be labelled and the coordinates of all trees taken. At the same time DBH can be measured and samples for DNA extraction taken.

Because of the Prunus avium hybridisation with cultivated cherry varieties, it is recommended that FGM plots are selected and established at a secure distance $(8-10 \mathrm{~km})$ from the cultivation of domesticated cherry.

Due to wild cherry's scattered distribution and low density in natural forest stands, a preliminary field study is needed; the size and shape of the genetic monitoring plot will need to be adapted to include 50 reproducing trees. In addition, natural regeneration (as cohorts or single saplings) has to be present in the plot. However, it is recommended that the size of the plot is limited to 10 ha; otherwise FGM procedures (sampling, phenology observations, etc.) become too complicated. During wild cherry tree selection it is important to avoid possible clones, therefore if groups of wild cherry are formed by only one genotype per group then only one tree out of them should be selected for FGM.

Equipment needed:

- a device for distance measurement (a pair of range-finding binoculars is recommended)

- a compass,

- a paint with a brush or spray for marking trees

- a tree calliper for DBH measurements and

- a GPS device that is precise enough and allows saving trees' coordinates.

\subsection{Plot establishment}

\subsubsection{Plot selection}

To establish a monitoring plot for Prunus avium, ideally the initial work should be carried out in spring, when the trees are flowering. Wild cherry can be clearly visible and distinguished from other species in the area in springtime by white coloured blossoms. Visual inspection of the area photos may be used instead of, or additional to, an initial field survey to assess the approximate number, density and distribution of reproducing wild cherry trees in 
the selected area. In cases when other trees with white coloured blossom may co-exist in the area at the same time, then priority should be given to a field survey.

At this time, all wild cherry trees in the stand should be mapped using a GPS device. Fifty (50) trees, with the minimum distance of $30 \mathrm{~m}$ from each other, should then be randomly selected (Figure 3a). During plot installation these pre-selected trees must be identified in the field and marked.

\subsubsection{Plot installation in the field}

Using the GPS, all trees selected in the office are located in the forest stand and marked. The minimum distance of $30 \mathrm{~m}$ between trees needs to be checked again.

\subsubsection{Labelling of trees}

Each selected tree must be marked with a corresponding number (1 to 50) and preferably a band painted around the trunk to aid the visibility of the trees from all directions (Figure 3b).
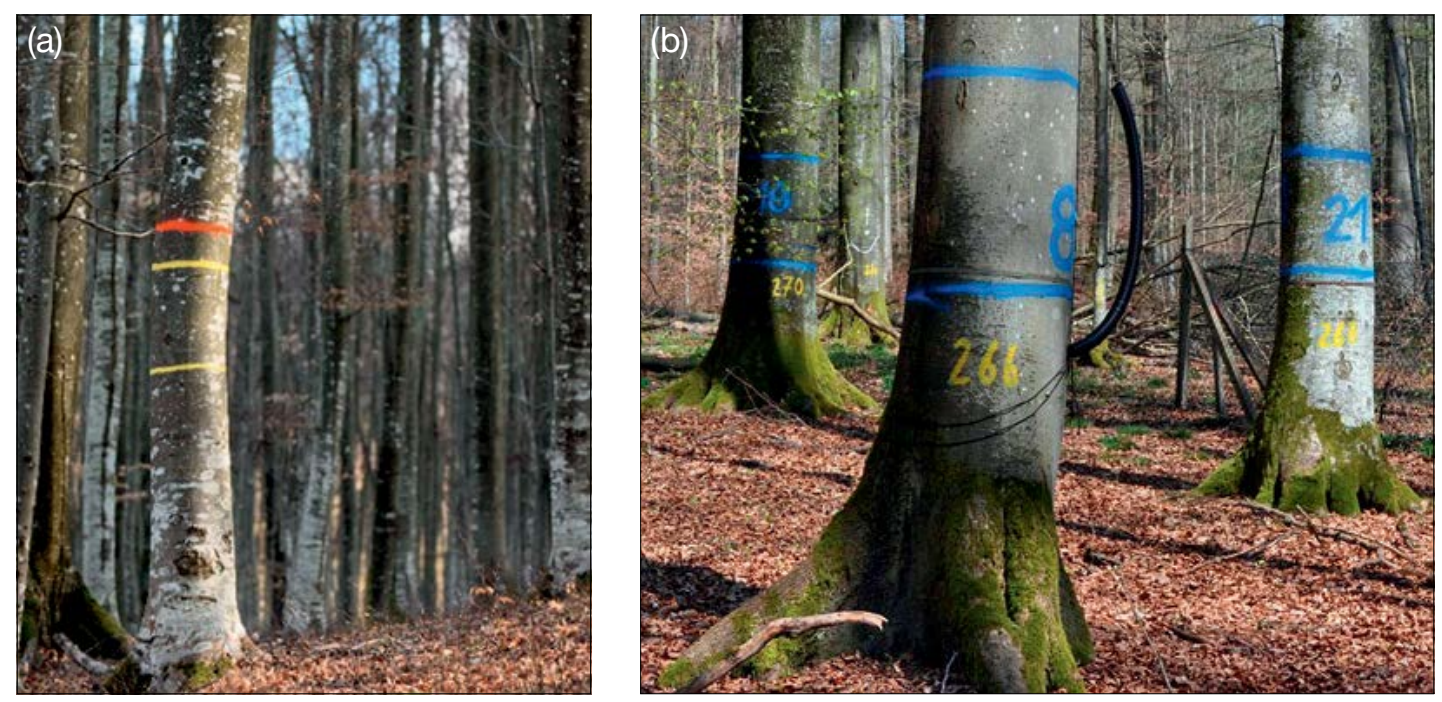

Figure 3: a) All reproducing wild cherry trees in the selected stand are first mapped using a GPS device. Fifty trees, with the minimum distance of $30 \mathrm{~m}$ from each other, are then randomly selected for FGM ; b) trees selected for FGM are labelled with corresponding numbers and bands around their trunks to aid the visibility of the trees from all directions (photos are as an example for marking from a European beech FGM plot).

\subsection{Establishment of natural regeneration subplots}

Natural regeneration centres from the last mast year should be surveyed in the field and their locations logged (GPS coordinates, number of the tree which is next to a NR centre). Because of seed dormancy in wild cherry, natural regeneration of a mast year (year of massive fruit/seed production) can occur one or two years later and seedlings from several years may have originated from the same mast year. From all logged regeneration centres, 20 should be chosen randomly for plot installation. If 20 or fewer natural regeneration centres are present, all should be used.

Inside each selected natural regeneration centre a $1 \mathrm{~m}^{2}$ plot is to be installed and marked with metal rods. Metal rods should be driven into the ground at each corner of the subplot as deep as possible to prevent them from being removed by animals. The tips of the metal rods should be painted to aid their visibility. 


\subsection{Plot maintenance}

\subsubsection{General maintenance}

Tree markings and subplot markings must be checked periodically (every two years) and renewed if needed.

\subsubsection{Replacement of trees}

If a monitored tree dies or is cut due to management, it must be replaced. The nearest suitable tree to the dead one should be chosen considering that the distance requirement of $30 \mathrm{~m}$ to the nearest monitored tree is fulfilled. The replacement tree is marked with the next available number higher than 50 , i.e. 51,52 , 53, etc. to positively differentiate it from the original 50 selected trees.

If the crown is damaged due to, for example, windbreak, ice or snow-break, but continues to fructify, the tree is kept for monitoring. If the damage is too severe and fructification is not expected anymore, the monitored tree must be replaced. The cause of damage needs to be recorded, as the damage can affect the values recorded for field verifiers and background information.

\section{Recording of verifiers and background information}

On the monitoring plot, verifiers and background information are periodically recorded. Verifiers are used to monitor the population's genetic properties and its adaptation to environmental changes and/or management, while background information needs to be recorded to assist interpretation of the verifiers. Verifiers can be observed at three different intensity levels: basic, standard and advanced.

Higher levels of observation (standard, advanced) must also include recording for all the preceding levels (basic, standard). This is not necessary for recording of background information. 
Table 1. List of verifiers and background information with short description and observation frequency to be recorded during field work at the wild cherry genetic monitoring plots.

\begin{tabular}{|c|c|c|c|c|}
\hline & Name & Basic level & Standard level & Advanced level \\
\hline \multirow{5}{*}{$\stackrel{\frac{\infty}{\infty}}{\stackrel{\infty}{\frac{D}{\infty}}}$} & Mortality / & $\begin{array}{l}\text { Adult trees: Counting of the } \\
\text { remaining marked trees every } \\
\text { year or after every extreme } \\
\text { weather event/disturbance }\end{array}$ & Same as basic level & Same as basic level \\
\hline & & Natural regeneration: / & $\begin{array}{l}\text { Counting of remaining seedlings } \\
\text { on the natural regeneration } \\
\text { subplots, twice per decade }\end{array}$ & Same as standard level \\
\hline & Flowering & Stand-level estimate, every year & $\begin{array}{c}\text { Individual tree level observation, } \\
\text { during two major flowering } \\
\text { events per decade, ideally } \\
\text { equally spaced* }\end{array}$ & $\begin{array}{c}\text { Individual tree level observation, } \\
\text { during two major flowering } \\
\text { events per decade, ideally } \\
\text { equally spaced* }\end{array}$ \\
\hline & Fructification & Stand-level estimate, every year & $\begin{array}{l}\text { Individual tree level observation, } \\
\text { the same year as the } \\
\text { assessment of the flowering at } \\
\text { the standard level (regardless of } \\
\text { the fructification intensity) }\end{array}$ & $\begin{array}{l}\text { Counting of fruit, during the } \\
\text { same years as the assessment } \\
\text { of flowering at the advanced } \\
\text { level, regardless of the } \\
\text { fructification intensity } \\
\text { * Seeds are collected for } \\
\text { laboratory analyses for every } \\
\text { assessed fructification event at } \\
\text { the advanced level }\end{array}$ \\
\hline & $\begin{array}{l}\text { Natural } \\
\text { regeneration } \\
\text { abundance }\end{array}$ & Stand-level estimate, every year & $\begin{array}{l}\text { Counting of seedlings according } \\
\text { to the protocol in the } 2^{\text {nd }} \text { and } 7^{\text {th }} \\
\text { years after the mast year*^}\end{array}$ & $\begin{array}{c}\text { Counting of seedlings according } \\
\text { to the protocol in the } 2^{\text {nd }}, 7^{\text {th }} \\
12^{\text {th }} \text {, and } 17^{\text {th }} \text { years after the } \\
\text { mast year }\end{array}$ \\
\hline \multirow{7}{*}{ 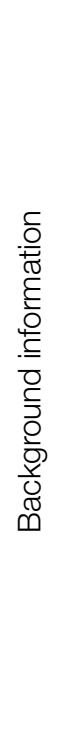 } & $\begin{array}{l}\text { DBH class } \\
\text { distribution }\end{array}$ & / & Measurement every 10 years & Same as standard level \\
\hline & $\begin{array}{l}\text { Height class } \\
\text { distribution }\end{array}$ & / & Measurement every 10 years & Same as standard level \\
\hline & Budburst & / & $\begin{array}{c}\text { Individual tree level observation } \\
\text { according to the protocol, every } \\
5 \text { years }\end{array}$ & $\begin{array}{c}\text { Individual tree level observation } \\
\text { according to the protocol, every } \\
\text { year }\end{array}$ \\
\hline & Senescence & / & $\begin{array}{l}\text { Individual tree level observation } \\
\text { according to the protocol, every } \\
5 \text { years }\end{array}$ & $\begin{array}{c}\text { Individual tree level observation } \\
\text { according to the protocol, every } \\
\text { year }\end{array}$ \\
\hline & $\begin{array}{l}\text { Flowering } \\
\text { synchronisation }\end{array}$ & / & / & $\begin{array}{l}\text { Individual tree level observation, } \\
\text { during each assessed major } \\
\text { flowering event }\end{array}$ \\
\hline & Senescence & / & $\begin{array}{c}\text { Individual tree level observation, } \\
\text { every } 5 \text { years }\end{array}$ & $\begin{array}{c}\text { Individual tree level observation, } \\
\text { every year }\end{array}$ \\
\hline & $\begin{array}{l}\text { Flowering } \\
\text { synchronisation }\end{array}$ & / & / & $\begin{array}{l}\text { Individual tree level observation, } \\
\text { during each assessed major } \\
\text { flowering event }\end{array}$ \\
\hline
\end{tabular}

* Ideally at least one major fructification event should be assessed per decade. However, a major flowering event does not necessarily lead to a major fructification event. If no major fructification event follows the assessed flowering event, assessment of both flowering and fructification needs to be repeated during the next major flowering event, regardless of the time passed between successive major flowering events. Basic level observations are used to identify major flowering and fructification events.

** Because of wild cherry seed dormancy, natural regeneration of a mast year (year of massive fruit/seed production) can occur one or two years later and seedlings from several years may have originated from the same mast year. 


\subsection{Protocols for recording of verifiers}

\subsubsection{Mortality / survival}

Mortality describes mortality of adult trees. Its counterpart survival stands for trees that are still alive since the previous assessment. Survival is calculated as 1 - Mortality.

\subsubsection{Adult trees: Basic, standard and advanced level}

The verifier for mortality of adult trees. It is estimated by counting the remaining alive marked trees every 10 years and after every extreme weather event/disturbance. Mortality is the difference between the initial number of marked trees and the trees remaining alive of the original 50.

\subsubsection{Natural regeneration: Standard and advanced level}

Mortality of natural regeneration is calculated from the verifier Natural regeneration abundance. Mortality is the difference between the initial number of NR plants and the plants remaining alive at the time of the next counting. For each round of assessment, the NR is counted first in the year of germination and then again after 5 years at the standard level, while at the advanced level the counting is also performed after 10 and 15 years. Assessment of NR abundance is carried out twice per decade, ideally approximately every five years.

\subsubsection{Flowering}

This verifier describes the flowering intensity and the proportion of trees thus affected. Usually wild cherry flowers can be recorded from March until May in central Europe. Flowering is earlier when preceded by a warm winter. Usually wild cherry flowers every second year.

\subsubsection{Basic level}

This verifier is recorded every year at the stand level; however, because of the scattered distribution of wild cherry all 50 monitored trees must be visited to get a good estimate of the average condition in the stand. Recording is carried out when flowering is in full progress. The estimate of average condition is provided after a walk throughout the monitoring plot. Two scores are given, one for flowering intensity and one for proportion of flowering trees in the stand.

\begin{tabular}{clr} 
Code & Flowering intensity at the stand level & Average proportion of the crown flowering (\%) \\
\hline 1 & No flowering: No or only occasional flowers appearing on trees & $0-10$ \\
\hline 2 & Weak flowering: Some flowers appearing on trees. & $>10-30$ \\
\hline 3 & Moderate flowering: Moderate number of flowers appearing on trees. & $>30-60$ \\
\hline 4 & Strong flowering: Abundant number of flowers on trees. & $>60-90$ \\
\hline 5 & Massive: Huge number of flowers on trees. & $>90$ \\
\hline
\end{tabular}

\begin{tabular}{lr}
\hline Code Proportion of trees in the stand with the given flowering intensity stage (\%) & $0-10$ \\
\hline 1 & $>10-30$ \\
\hline 2 & $>30-60$ \\
\hline 3 & $>60-90$ \\
\hline 4 & $>90$ \\
\hline 5 &
\end{tabular}




\subsubsection{Standard level}

This verifier is recorded during two major flowering events per decade, ideally equally spaced in time from one another. It is recorded at an individual tree level on all 50 monitored trees. A major flowering event is when at the basic level flowering intensity is strong or massive (code 4 or 5 ) and the proportion of trees with the given flowering intensity is above $60 \%$ (code 4 or 5 ). Recording is carried out when flowering is in full progress. One score is provided for each tree.

\begin{tabular}{clr}
\hline \multicolumn{2}{l}{ Code Description } & Proportion of the crown flowering (\%) \\
\hline 1 & No flowering: No or only occasional flowering appearing on a tree. & $0-10$ \\
\hline 2 & Weak flowering: Some flowers appearing on a tree. & $>10-30$ \\
\hline 3 & Moderate flowering: Moderate number of flowers on a tree. & $>30-60$ \\
\hline 4 & Strong flowering: Abundant number of flowers on a tree. & $>60-90$ \\
\hline 5 & Massive: Huge number of flowers on a tree. & $>90$ \\
\hline
\end{tabular}

\subsubsection{Advanced level}

This verifier is recorded during two major flowering events per decade, ideally equally spaced in time from one another. It is recorded at an individual tree level on all 50 monitored trees. A major flowering event is when at the basic level flowering intensity is strong or massive (code 4 or 5 ) and the proportion of trees with the given flowering intensity is above $60 \%$ (code 4 or 5). On average, two visits to the plot are needed; the first one early enough to observe the early stages of flowering and the second one when flowering is in full progress [8]. For a graphical representation of flowering stages, see Figure 4.

\begin{tabular}{ll} 
Code & Flower phenology stages \\
\hline 1 & Buds not active, scales brown and closed \\
\hline 2 & Buds increase size, scales start to separate so that first leave edges are visible \\
\hline 3 & Flower bud broken, flowers petals still closed, petiole elongating \\
\hline 4 & Flowers petals open completely, the stigma is receptive, and the anthers dehisce their pollen \\
\hline
\end{tabular}

\begin{tabular}{clr}
\multicolumn{2}{l}{ Code Description } & $\%$ crown flowering \\
\hline 1 & No flowers: No or only occasional flowers appearing on a tree. & $0-10$ \\
\hline 2 & Weak flowering: Some flowers appearing on a tree. & $>10-30$ \\
\hline 3 & Moderate flowering: Moderate number of flowers. & $>30-60$ \\
\hline 4 & Strong flowering: Abundant number of flowers. & $>60-90$ \\
\hline 5 & Massive flowering: Huge number of flowers. & $>90$ \\
\hline
\end{tabular}

1

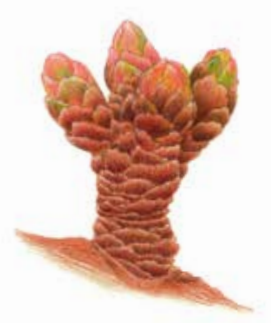

2

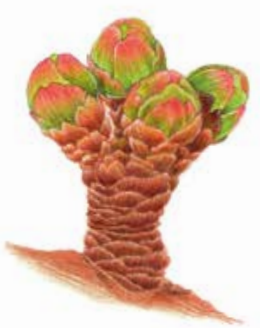

3

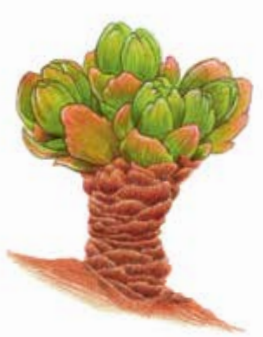

4

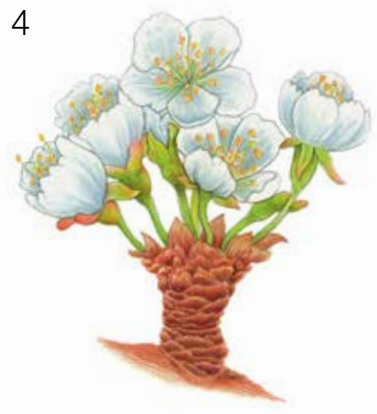

Figure 4: Picture guide for description of flowering for the advanced level verifier Flowering. 


\subsubsection{Fructification}

This verifier describes the presence of fructification and its abundance. Data for this verifier should be collected during fructification, from late spring to mid or late summer in central Europe. Usually wild cherry fructification occurs every second year.

\subsubsection{Basic level}

This verifier is recorded every year at the stand level; however, because of the scattered distribution of wild cherry all 50 monitored trees must be visited to get a good estimate of the average condition in the stand. Two scores are given, one for fructification intensity and one for proportion of fructifying trees in the stand.

\begin{tabular}{llr}
\multicolumn{2}{l}{ Code Fructification intensity at the stand level } & Average proportion of the crown bearing fruit (\%) \\
\hline 1 & No fructification: No or only occasional fruit appearing on trees & $0-10$ \\
\hline 2 & Weak fructification: Some fruit appearing on trees & $>10-30$ \\
\hline 3 & Moderate fructification: Moderate amount of fruit appearing on trees & $>30-60$ \\
\hline 4 & Strong fructification: Abundant amount of fruit appearing on trees & $>60-90$ \\
\hline 5 & Massive: Huge amount of fruit appearing on trees & $>90$ \\
\hline & & $0-10$ \\
\hline Code Proportion of trees in the stand with the given stage of fructification intensity (\%) & $>10-30$ \\
\hline 1 & & $>30-60$ \\
\hline 2 & & $>60-90$ \\
\hline 3 & & $>90$ \\
\hline 4 & & \\
\hline 5 &
\end{tabular}

\subsubsection{Standard level}

This verifier is recorded during the same years as the assessment of the flowering at the standard level (regardless of the fructification intensity). It is recorded at an individual tree level on all 50 monitored trees. Recording is carried out before fruits start falling or are eaten by birds. One score is provided for each tree.

Ideally, one major fructification event should be captured following observations of major flowering events per decade. However, a major flowering event does not necessarily lead to a major fructification event. If no major fructification event follows the assessed flowering event, assessment of both flowering and fructification needs to be repeated during the next major flowering event, regardless of the time passed between successive major flowering events. Basic level observations are used to identify major fructification events. A major fructification event is when at the basic level fructification intensity is strong or massive (code 4 or 5 ) and the proportion of trees with the given fructification intensity is above $60 \%$ (code 4 or 5 ).

\begin{tabular}{|c|c|c|}
\hline Cod & Fructification intensity & Proportion of the crown fructifying (\%) \\
\hline 1 & No fructification: No or only occasional fruits appearing on a tree. & $0-10$ \\
\hline 2 & Weak fructification: Some fruit appearing on a tree. & $>10-30$ \\
\hline 3 & Moderate fructification: Moderate amount of fruit appearing on a tree. & $>30-60$ \\
\hline 4 & Strong fructification: Abundant amount of fruit appearing on a tree. & $>60-90$ \\
\hline 5 & Massive: Huge amount of fruit appearing on a tree. & $>90$ \\
\hline
\end{tabular}




\subsubsection{Advanced level}

This verifier is recorded at an individual wild cherry tree level on all 50 monitored trees during the same years as the assessment of flowering at the advanced level, regardless of the fructification intensity. Recording is carried out before fruits start falling. One score is provided for each tree. Simultaneously, seed is collected for seed and genetic analysis for the advanced level verifiers and background information.

Ideally, one major fructification event should be captured following observations of major flowering events per decade. However, a major flowering event does not necessarily lead to a major fructification event. If no major fructification event follows the assessed flowering event, assessment of both flowering and fructification needs to be repeated during the next major flowering event, regardless of the time passed between successive major flowering events. Basic level observations are used to identify major fructification events. A major fructification event is when at the basic level fructification intensity is strong or massive (code 4 or 5) and the proportion of trees with the given fructification intensity is above $60 \%$ (code 4 or 5 ).

The verifier is recorded by counting fruits using binoculars. The average of three rounds of counting is reported. Each round of counting consists of the number of fruits that the observer is able to count in 30 seconds. For all trees, the same part of the crown should be investigated. Once the observation part of the crown part is selected, the same one should be selected for every subsequent monitoring of this verifier. The upper third of the crown is preferred to the bottom and middle part for counting.

Two values are recorded; the number of fruits and the part of the crown monitored.

\begin{tabular}{ll}
$\begin{array}{l}\text { Number of fruits counted in } 30 \text { seconds (average of } 3 \text { rounds) } \\
X\end{array}$ \\
\hline Code Part of the crown monitored \\
\hline 1 & Bottom \\
\hline 2 & Middle \\
\hline 3 & Top \\
\hline
\end{tabular}

\subsubsection{Natural regeneration abundance}

This verifier describes the presence and abundance of natural regeneration (NR) at the monitoring plot. At the basic level it is recorded every year using expert opinion. Wild cherry seed dormancy can last one or two winters, so first seedlings might occur only $1.5-2.5$ years after fructification.

\subsubsection{Basic level}

This verifier is recorded at the stand level (check the areas with existing and flowering wild cherry trees and open areas suitable for new NR establishment) every year, in the autumn. Expert opinion is used for estimation. Two values should be selected, one for new natural regeneration (one-year seedlings) and one for established regeneration (seedlings that are older than one year). Since light is a crucial factor for new NR establishment of wild cherry, forest gaps and open areas or forest edges should be the focus. Since the abundance of natural regeneration for wild cherry is usually scarce, only two abundance stages are applied.

\section{Code Description: new regeneration (current-year seedlings)}

1a There is no or very little new natural regeneration on the monitoring plot

2a New regeneration is present in sufficient quantity on the monitoring plot

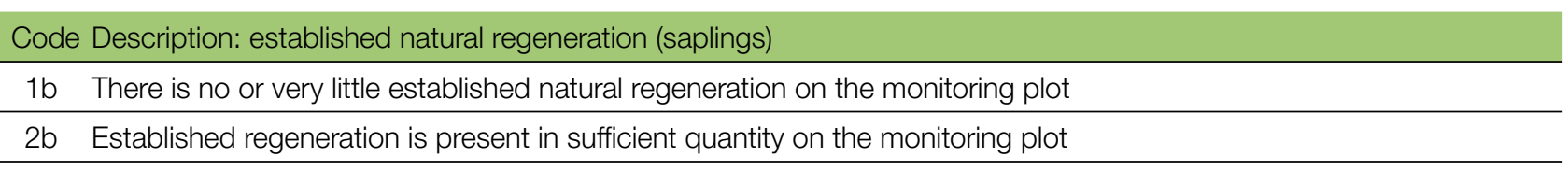




\subsubsection{Standard level}

Wild cherry seed dormancy can last one or two winters, so the first seedlings might occur only $1.5-2.5$ years after fructification. The establishment of NR subplots and the beginning of NR abundance observations must adapt to the duration of the seed dormancy in the monitored location. This verifier is recorded by counting of plants/seedlings $2^{\text {nd }}$ and $7^{\text {th }}$ years after the assessed major fructification event. Ideally, twenty (20) new NR subplots for wild cherry have to be established after the next assessed major fructification event which should be approximately five years after the previous one.

\section{Number of seedlings counted on a subplot}

$\mathrm{X}$

For subplot establishment see 6.2 Establishment of natural regeneration subplots.

\subsubsection{Advanced level}

Wild cherry seed dormancy can last one or two winters, so the first seedlings might occur only $1.5-2.5$ years after fructification. The establishment of NR subplots and the beginning of NR abundance observations must adapt to the duration of the seed dormancy in the monitored location. This verifier is recorded by counting of plants/seedlings $2^{\text {nd }}, 7^{\text {th }}, 12^{\text {th }}$ and $17^{\text {th }}$ years after the assessed major fructification event. Twenty (20) new NR subplots for wild cherry have to be established after the next assessed major fructification event. When a major fructification event is every year or every two years then approximately five years should be between the consecutive assessed major fructification events.

Table 2: Timeline of natural regeneration abundance (NR) assessment. In this example, the first assessed fructification event takes place in the $2^{\text {nd }}$ year of the monitoring decade, and considering wild cherry seed dormancy of one or two winters, $20 \mathrm{NR}$ subplots are established in the $4^{\text {th }}$ year of the monitoring decade. The next assessment of fructification is carried out in the $8^{\text {th }}$ year of the monitoring decade. Considering wild cherry seed dormancy, 20 new NR subplots are established in the $10^{\text {th }}$ year of the decade. Twenty new NR subplots are established after each assessed fructification event. Monitoring of NR abundance on each set of 20 NR subplots is carried out every five years. The fructification events corresponding to the assessed NR and timelines of the assessment activities are shaded in the same colour. After the final round of counting of seedlings, monitoring of NR abundance on the respective set of NR subplots is stopped and the respective NR subplots disestablished. S - standard level; A - advanced level.

\begin{tabular}{|c|c|c|c|c|c|c|c|c|c|c|c|c|c|c|c|c|}
\hline Year of monitoring & 1 & 2 & 3 & 4 & 5 & 6 & 7 & 8 & 9 & 1011 & 1213 & 141516 & 171819 & 2021 & 12223 & 32425 \\
\hline Fructification event & & $\bullet$ & & & - & - & & - & & - & - & - & - & - & - & • \\
\hline $\begin{array}{l}\text { NR assessment from the } 1^{\text {st }} \\
\text { assessed fructification event }\end{array}$ & & 0 & 1 & 2 & 3 & 4 & 5 & 6 & 7 & 89 & 1011 & 121314 & 151617 & 1819 & 92021 & 2223 \\
\hline NR subplots establishment & & & & SA & & & & & & & & & & & & \\
\hline NR abundance counting & & & & SA & & & & & SA & & & A & A & & & \\
\hline $\begin{array}{l}\text { NR assessment from the } 2^{\text {nd }} \\
\text { assessed fructification event }\end{array}$ & & & & & & & & 0 & 1 & 23 & 45 & 78 & 91011 & 1213 & 31415 & 16 \\
\hline NR subplots establishment & & & & & & & & & & SA & & & & & & \\
\hline NR abundance counting & & & & & & & & & & SA & & SA & & A & & A \\
\hline
\end{tabular}

For subplot establishment see 6.2 Establishment of natural regeneration subplots and for counting 


\subsection{Protocols for recording of background information}

\subsection{1 $\mathrm{DBH}$ class distribution}

\subsubsection{Standard and advanced levels}

$\mathrm{DBH}$ is recorded at an individual tree level on all 50 monitored trees every 10 years. DBH is the trunk diameter at $1.30 \mathrm{~m}$ of height, i.e. approximately at an adult's breast height. If a tree has more than one trunk, please measure all of them and estimate the average (but try to avoid trees with many small trunks). Add a note in the case of a multi-trunk tree in the notes section. If the tree is leaning, measure $\mathrm{DBH}$ perpendicular to the tree trunk. $\mathrm{DBH}$ can be measured in two ways:

1) using a calliper, in which cases you would need to measure two perpendicular diameters and estimate the average

2) measure the circumference of the tree and compute the diameter from that value (i.e. divide by $\pi, \sim 3.14$ or use a pi-meter)

The $\mathrm{DBH}$ is recorded in $\mathrm{cm}$. The same method must be applied for every subsequent measurement.

\subsubsection{Height class distribution}

\subsubsection{Standard and advanced levels}

Height is recorded at an individual tree level on all 50 monitored trees every 10 years. Height is measured from the ground to the tallest part of the crown, ideally using a clinometer or hypsometer (vertex). Height is recorded in metres to one decimal place.

\subsubsection{Budburst}

Budburst describes the process of budbursting (flushing). In wild cherry, budbursting starts together with flowering. Recording is only carried out at the standard and advanced levels. Data for this background information should be recorded in March - May in central Europe. Flushing is earlier when preceded by a warm winter.

\subsubsection{Standard level}

At standard level, budburst is recorded on an individual tree level on all 50 monitored trees every five years. We are looking for the initiation of budbursting (stage 2) and the end of budbursting (stage 4) [8]. The observations cease when all the trees have reached stage 4. Usually, six visits will be needed. For each tree, two estimates are given: stage of budbursting and proportion of the crown budbursting. For a graphical representation of budbursting stages, see Figure 5.

\begin{tabular}{|c|c|}
\hline \multicolumn{2}{|c|}{ Code Stage of budbursting } \\
\hline 1 & Buds are swollen, some leave scales separate so that first leave edges are visible \\
\hline 2 & Leaflets reach the same size as the former buds and start to separate \\
\hline 3 & Leaves elongate more but still folded \\
\hline 4 & $\begin{array}{l}\text { Leaves are extremely spread out; leave area clearly increased; peduncles appear so that leaves start to turn round } \\
\text { and hang down. }\end{array}$ \\
\hline \multicolumn{2}{|r|}{ Code Proportion of the crown with a given stage of budbursting (\%) (Modified after [10]) } \\
\hline 1 & $>0-33$ \\
\hline 2 & $>33-66$ \\
\hline 3 & $>66-99$ \\
\hline 4 & 100 \\
\hline
\end{tabular}


1

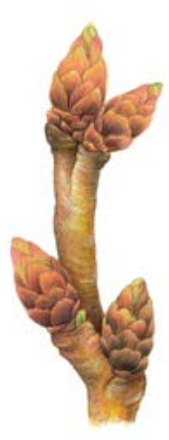

2

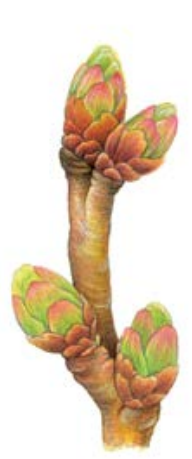

3

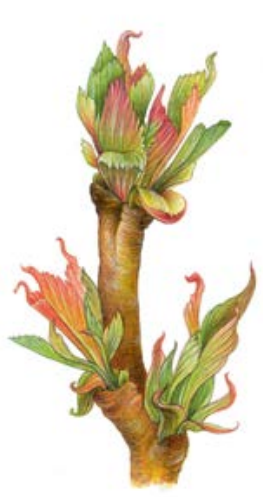

4

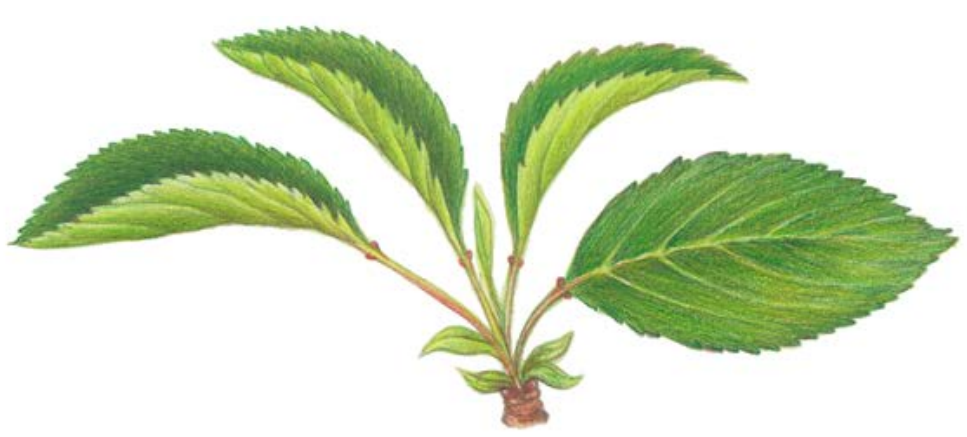

Figure 5: Picture guide for description of budburst (flushing) for the basic, standard and advanced levels background information Budburst.

\subsubsection{Advanced level}

At the advanced level, budburst is recorded at an individual tree level on all 50 monitored trees every year. For the values (stage of budbursting and the proportion of crown affected) see 7.2.3.1 Standard level.

\subsubsection{Senescence}

Senescence describes the process of senescence. Recording of this background information is only carried out at the standard and advanced levels.

\subsubsection{Standard level}

At standard level, senescence is recorded on an individual tree level on all 50 monitored trees every five years. We are looking for stage 3, when leaves are yellow and do not photosynthesise anymore. Observations stop when all the trees have reached stage 3. Usually two (2) visits to the plot will be needed. For each tree, two estimates are given: stage of senescence and proportion of the crown senescing. For a graphical representation of stages of senescence, see Figure 6.

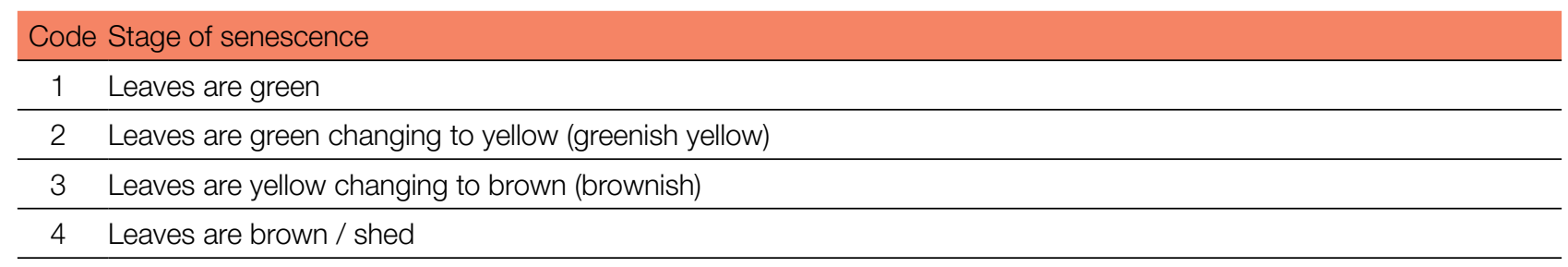

\section{Code Proportion of the crown with a given score for stage of senescence (\%)}

\begin{tabular}{rr}
\hline 1 & $>0-33$ \\
\hline 2 & $>33-66$ \\
\hline 3 & $>66-99$ \\
\hline 4 & 100 \\
\hline
\end{tabular}



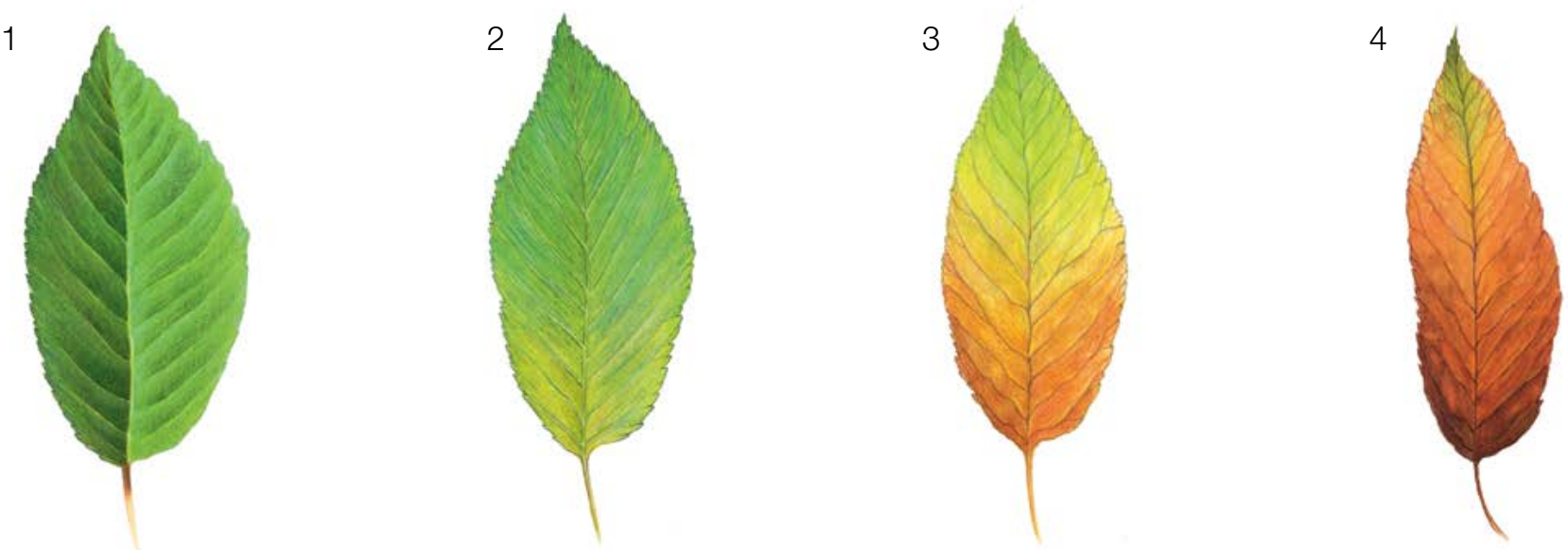

Figure 6: Picture guide for description of leaf colouring for standard and advanced level background information Senescence.

\subsubsection{Advanced level}

At advanced level senescence is recorded on an individual tree level on all 50 monitored trees every year. For the values (stage of senescence and the proportion of crown affected) see 7.2.4.1 Standard level.

\subsubsection{Flowering synchronisation}

Flowering synchronisation is monitored only at the advanced level, and is based on the data collected for the verifier Flowering. It is used to determine whether flowering time occurs simultaneously within the monitored stand.

\subsubsection{Advanced level}

Flowering synchronisation is recorded on an individual tree level on all 50 monitored trees, during each assessed major flowering event, in the same years as when seed is collected (the same as Flowering at advanced level).

\section{For plot establishment use form 'FGM Plot description' \\ For verifiers recording use 'Form for recording field level verifiers within FGM' \\ For background information recording use 'Form for recording field level background information within FGM'}

\section{References}

1. EUFORGEN (2009) Distribution map of Wild cherry (Prunus avium L.). http://www.euforgen.org/species/prunus-avium/. Accessed 25 August 2020

2. Ballian D (2000) Početna istraživanja varijabilnosti morfoloških svojstava sjemena divlje trešnje (Prunus avium L.). Šum list 5-6:271-278

3. Ballian D (2002) Variability of characteristics of the wild cherry blossom (Prunus avium L.) in the region of central Bosnia, Annales forestales 25/2:1-19

4. Ballian D, Bogunić F (2006) Preliminary results of investigation of morphological traits variation of wild cherry (Prunus avium L.) in Bosnia and Herzegovina. International Scientific Conferrence In occasion of 60 year of operation of Institute of Forestry, Belgrade, Serbia, Donji Milanovac 08.-10.11. 2006. PROCEEDINGS pp. 47-51 
5. Ballian D, Bogunić F, Čabaravdić A, Pekeč S, Franjić J (2012) Population differentiation in the wild cherry (Prunus avium L.) in Bosnia and Herzegovina. Period Biol 114(1):43-54

6. Ballian D, Mujagić-Pašić A (2013) Morphological variability of the fruit and seed of wild cherry (Prunus avium L.) in a part of its natural distribution in Bosnia and Herzegovina. Biologica Nyssana 4(1-2):15-17

7. Buiteveld J (2012) Prunus avium L. In: Fussi B, Belle C, Konnert M, Blanc-Jolivet C, Liesebach M, Buiteveld J, Piotti A, Vendramin GG, Wagner S, Petit RJ, Jahn D, Heinze B (ed) Project: Designing Trees for the Future. D7.1 - Report on review of available and tested methods for identification and on new marker development. http://www.trees4future.eu/ publications/deliverables-2.html\#wp2 Accessed 09 September 2020

8. Ducci F, De Cuyper B, Pâques LE, Proietti R, Wolf H (2012) Reference protocols for assessment of trait and reference genotypes to be used as standards in international research projects. Ed. CRA SEL - Arezzo, p 82.

9. Ducci F, De Cuyper B, De Rogatis A, Dufour J, Santi F (2013) Wild cherry breeding (Prunus avium L.). In: Pâques LE (ed) Forest Tree Breeding in Europe. Springer, Dordrecht, pp 463-511. DOI: 10.1007/978-94-007-6146-9

10. FUTMON project. (2009) FUTMON FIELD PROTOCOL PHENOLOGY (D1). http://www.futmon.org/futmon-fieldprotocols.html. Accessed 12 September 2016

11. Ganopoulos I, Aravanopoulos FA, Argiriou A, Kalivas A \& A Tsaftaris (2012) Genome and population dynamics under selection and neutrality: an example of S-allele diversity in wild cherry (Prunus avium L.). Tree Genet. Genomes 8(6):1181-1190. https://doi.org/10.1007/s11295-012-0504-9

12. Hedhly A, Wünsch A, Kartar Ö, Herrero M, Hormaza Jl (2016) Paternal-specific S-allele transmission in sweet cherry (Prunus avium L.): the potential for sexual selection. J Evol Biol 29(3):490-501. https://doi.org/10.1111/jeb.12790

13. Höltken AM, Gregorious HR (2006) Detecting local establishment strategies of wild cherry (Prunus avium L.). BMC Ecol 6(1):13. https://doi.org/10.1186/1472-6785-6-13

14. Olden EJ, Nybom N (1968) On the origin of Prunus cerasus L. Hereditas 59(2-3):327-345. https://doi. org/10.1111/j.1601-5223.1968.tb02181.x

15. Radičević S, Marić S, Cerović R (2015) S-allele Constitution and Flowering Time Synchronization - Preconditions for Effective Fertilization in Sweet Cherry (Prunus avium L.) Orchards. Romanian Biotechnological Letters 20(6):10997-11006

16. Russell K (2003) EUFORGEN Technical Guidelines for genetic conservation and use for wild cherry (Prunus avium). International Plant Genetic Resources Institute, Rome

17. Schuster M, Früh S (2005) Bestimmung der S-Allele in Brennkirschensorten (Prunus avium L.). Erwerbs-Obstbau 47:40-45. DOI: 10.1007/s10341-004-0051-0

18. Tavaud M, Zanetto A, David JL, Laigret F, Dirlewanger E (2004) Genetic relationships between diploid and allotetraploid cherry species (Prunus avium, Prunus × gondouinii and Prunus cerasus). Heredity 93(6):631-638. DOI: 10.1038/ sj.hdy.6800589

19. Welk E, de Rigo D, Caudullo G (2016) Prunus avium in Europe: distribution, habitat, usage and threats. In: San-MiguelAyanz J, de Rigo D, Caudullo G, Houston Durrant T, Mauri A (Eds.) European Atlas of Forest Tree Species. Publ. Off. EU, Luxembourg, pp e01491d+. https://ies-ows.jrc.ec.europa.eu/efdac/download/Atlas/pdf/Prunus_avium.pdf. Accessed 25 August 2020

The following resources were consulted for the currently accepted (December 2020) scientific names of the species covered or mentioned in this document:

a. CABI (2020) Invasive Species Compendium. CAB International, Wallingford, UK. www.cabi.org/isc. Accessed 15 December 2020

b. EPPO (2020) EPPO Global Database (available online). https://gd.eppo.int. Accessed 15 December 2020

c. GBIF (2020) Global Biodiversity Information Facility. https://www.gbif.org Accessed 15 December 2020

d. IPNI (2020) International Plant Names Index. The Royal Botanic Gardens, Kew, Harvard University Herbaria \& Libraries \& Australian National Botanic Gardens. http://www.ipni.org, Accessed 10 December 2020

e. National Center for Biotechnology Information (NCBI) (1998) National Library of Medicine (US), National Center for Biotechnology Information, Bethesda (MD). https://www.ncbi.nlm.nih.gov/. Accessed 15 December 2020

f. Stevens PF (2001) Angiosperm Phylogeny Website, Version 14. http://www.mobot.org/MOBOT/research/APweb/. Accessed 15 December 2020

g. The Plant List (2013) Version 1.1. http://www.theplantlist.org/. Accessed 12 December 2020

h. Tropicos.org (2020) Missouri Botanical Garden. http://www.tropicos.org. Accessed 15 December 2020

i. $\quad$ WFO (2020) World Flora Online. http://www.worldfloraonline.org. Accessed 15 December 2020 


\section{Guidelines for genetic monitoring of}

\subsubsection{Pedunculate oak (Quercus robur L.)}

\section{and}

\section{Sessile oak (Quercus petraea (Matt.) Liebl.)}

Kristina SEVER ${ }^{1}$, Andrej BREZNIKAR¹, Marko BAJC², Phil ARAVANOPOULOS ${ }^{3}$,

Rok DAMJANIĆ ${ }^{2}$, Barbara FUSSI ${ }^{4}$, Darius KAVALIAUSKAS ${ }^{4}$,

Marjana WESTERGREN², Hojka KRAIGHER ${ }^{2}$

Botanical illustrations by Eva MARGON
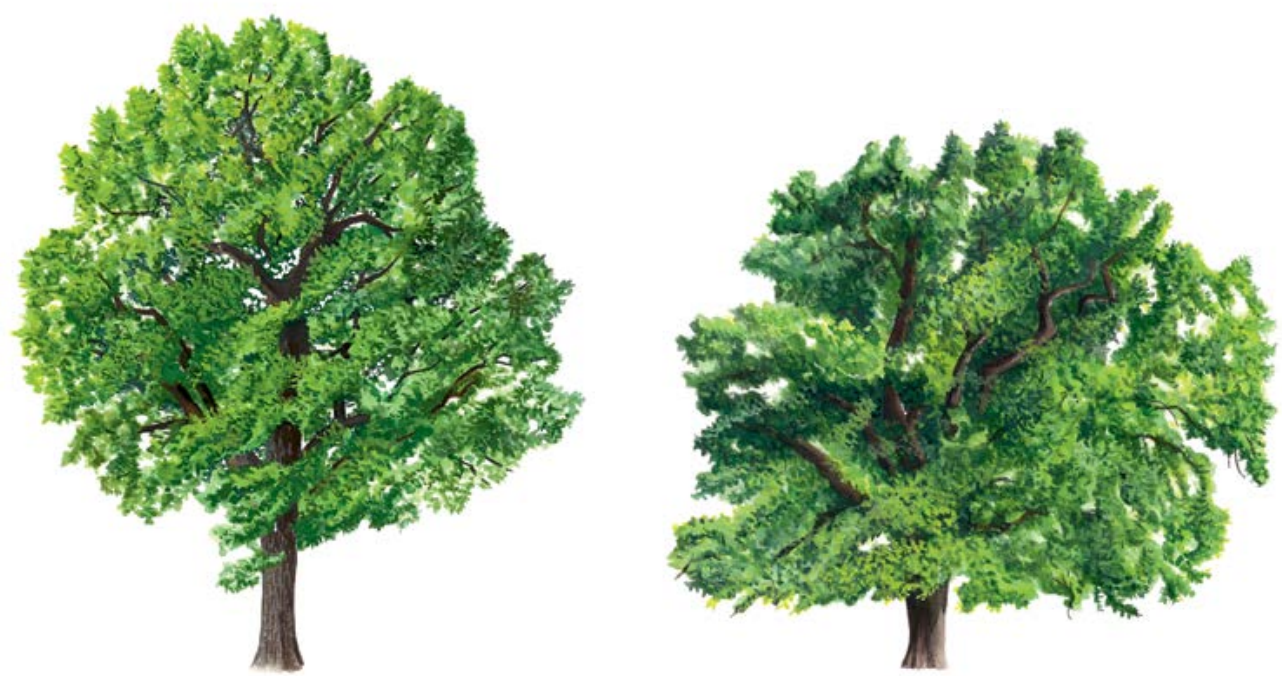

Citation: Sever et al. (2020) Guidelines for genetic monitoring of Pedunculate oak (Quercus robur L.) and Sessile oak (Quercus petraea (Matt.) Liebl.). In: Bajc et al. (eds) Manual for Forest Genetic Monitoring. Slovenian Forestry Institute: Silva Slovenica Publishing Centre, Ljubljana, pp 271-290. http://dx.doi.org/10.20315/SFS.167

4. Bavarian Office for Forest Genetics (AWG), Germany 


\section{Executive summary}

Among the 13 European white oak species, pedunculate (Quercus robur L.) and sessile (Q. petraea (Matt.) Liebl.) oak are the most important deciduous forest tree species in Europe, both economically and ecologically. Both oak species are widely distributed in Europe; from northern Spain to southern Scandinavia and from Ireland to Eastern Europe. Moreover, both are closely related; they can mix, compete and naturally hybridise with one another and with other oak [2, 3, 5, 8].

Oak are among the most diverse species of forest trees. High levels of diversity are most likely due to the maintenance of large population sizes, overlapping of ecological niches, long-distance gene flow and interfertility. The human impact on oak populations is very large, and most oak forests are managed, primeval forests like Bialowieza in Poland and Belarus being very rare. Genetic resources of oak are endangered not only due to the loss of natural ecosystems and limitation of seed sources, but also by the impact of several decades of air pollution and by long-term climate changes [3].

These guidelines briefly describe pedunculate and sessile oak, their reproduction, ecology, importance, distribution and threats. They provide guidance on establishing a genetic monitoring of Quercur robur/petraea complex and on recording all field level verifiers.

\section{Species description}

Pedunculate oak (Quercus robur) and sessile oak (Q. petraea) are large deciduous trees that reach $30-40 \mathrm{~m}$ in height and live up to 800 years or more. These two tree species, as well as other oak, are very variable morphologically, and can naturally hybridise, generating individuals showing intermediate traits or the prevalence of one, so that it can be difficult to characterise them unequivocally by observations alone [1, 2, 3, 5].

Both the pedunculate and sessile oak have an extended and mostly overlapping distribution throughout most of Europe. Their natural range extends from Ireland and northwestern parts of the Pyrenean peninsula in the west, to Eastern Europe in the east, southern parts of Scandinavia in the north, while their southerly range limits are more difficult to define, as these oak can mix, compete and naturally hybridize with other Mediterranean oak, such as Quercus pubescens Willd. and Quercus frainetto Ten., even if at relatively low rates $[3,5]$. In the east the pedunculate oak has a more extended distribution, reaching the Ural Mountains, while the sessile oak's extends to Ukraine.

The main differences between pedunculated and sessile oak are the characteristics of the leaves, fruits and trunks.

The main trunk of $Q$. robur tends to disappear in the crown, developing irregular boughs with twisting branches (Figure 1), while $Q$. petraea usually develops a main stem with boughs gradually decreasing in size (Figure 2) $[1,2,3,5]$. The bark of both species is grey, fissured, forming rectangular elongate blocks, which are thicker in $Q$. robur, while those of $Q$. petraea often tend to exfoliate.

The leaves are simple, obovate-oblong and deeply and irregularly lobed, with a short stalk $(2-7 \mathrm{~mm})$ in $Q$. robur and a long stalk (13-25 mm) in Q. petraea (Figure 3) [1, 2, 3, 5].

The fruits are acorns, which are often in pairs and sit in scaly cups on the ends of long stalks in $Q$. robur and on short or absent stalks in $Q$. petraea. The acorns are very variable in size and shape, but those of $Q$. robur are usually smaller and rounded with olive-green longitudinal stripes visible when fresh [1, 2, 3, 5].

It can be sometimes difficult to characterize them only by visual observations, and molecular methods are the most reliable tool for species differentiation. When in the field, leaves and acorn characteristics are the key features to determine the species and define the level of hybridisation, between sessile and pedunculate oak in mixed populations. The main criterion for the taxonomic determination of sessile and pedunculate oak hybrids is the intermediate value of several morphological signs considering typical values for each species. The best basis 

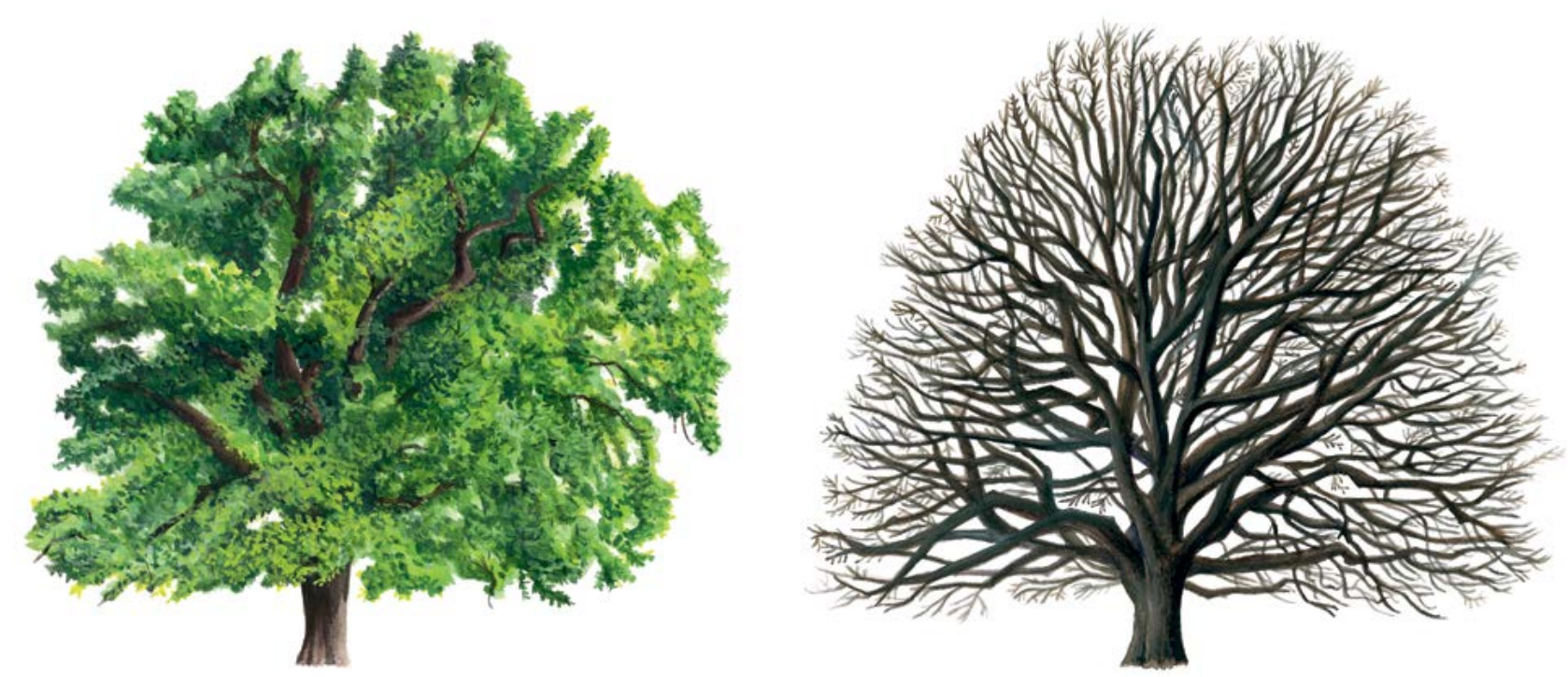

Figure 1: Pedunculate oak (Quercus robur) habitus in summer and winter
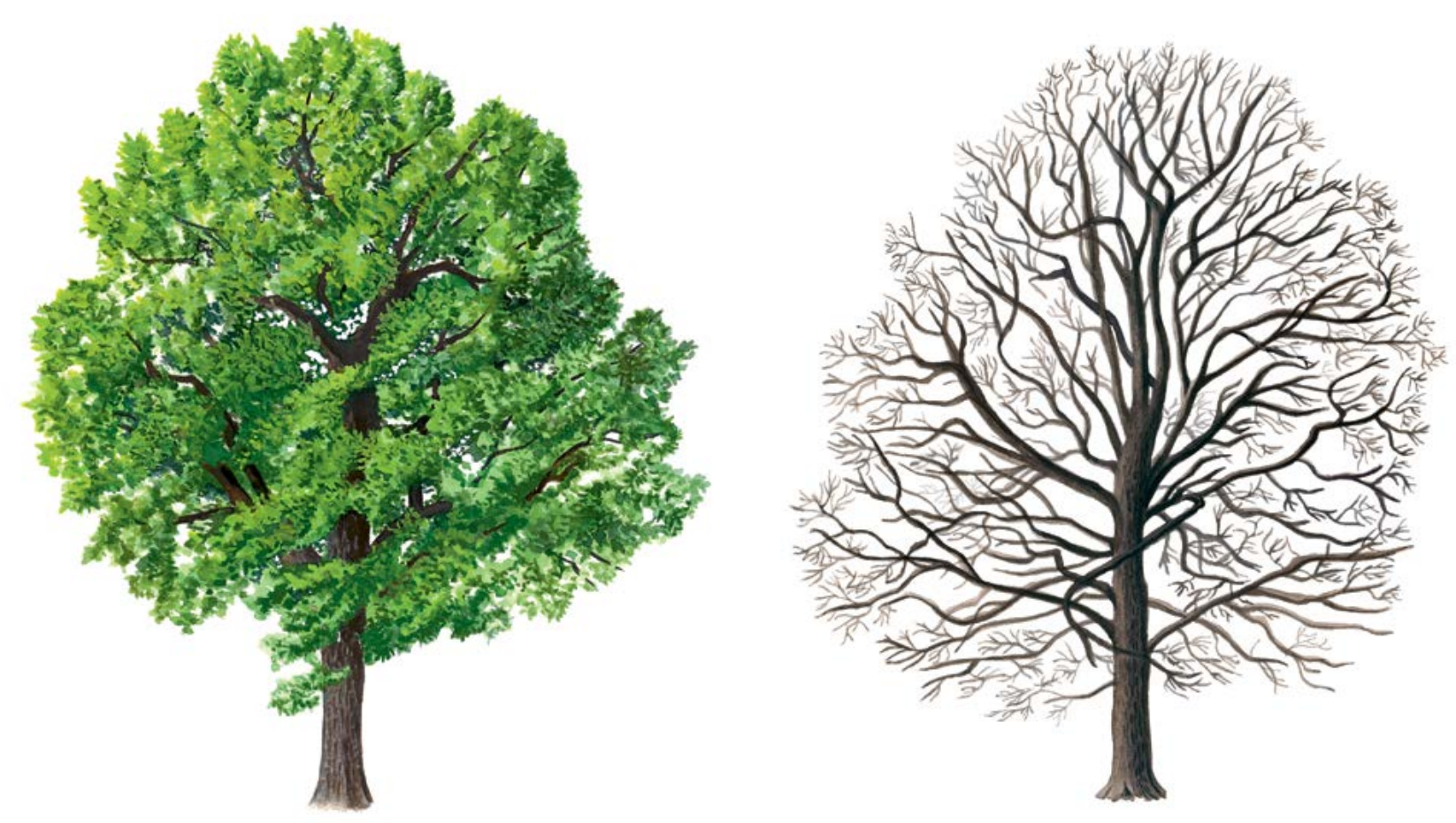

Figure 2: Sessile oak (Quercus petraea) habitus in summer and winter

for differentiation is provided by length of leaf stalk (sessile oak - long, pedunculate oak - short), length of acorn stalk (sessile oak - short, pedunculate oak - long), leaf indentations (sessile oak - not so deep, pedunculate oak - deep), leaf veins in the indentations (sessile oak - not present, pedunculate oak - very common), the shape of leaf base (sessile oak - clinal or unpronounced lobes, pedunculate oak - very pronounced lobes), leaf hairs (sessile oak - flat-lying, stellate hairs over leaf underside, pedunculate oak - no hairs) [1, 2, 3, 5]. 

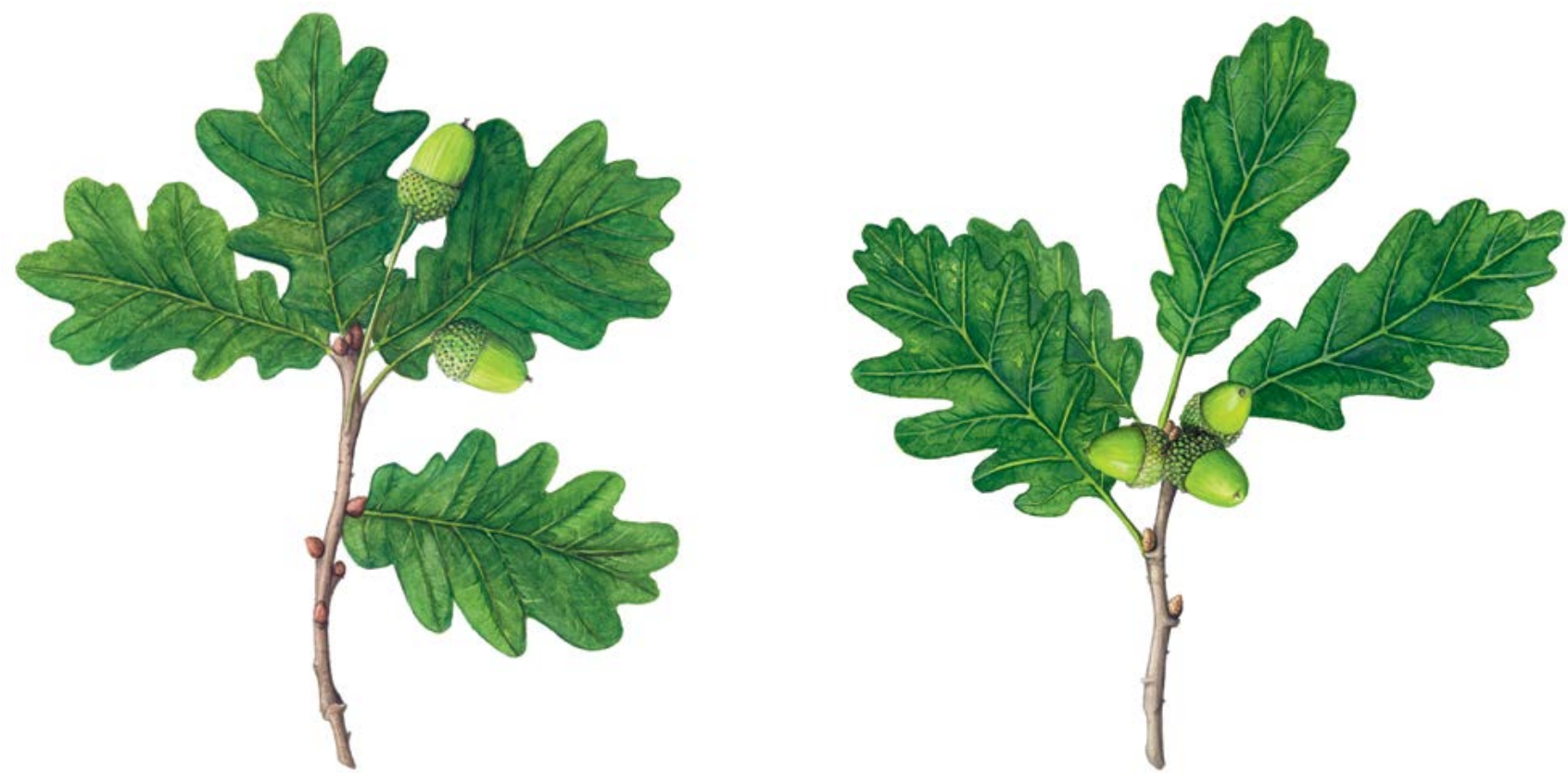

Figure 3: Leaves and fruit of pedunculate oak (Quercus robur) (left) and sessile oak (Q. petraea) (right)

\section{Reproduction}

These oak are monoecious and wind-pollinated, with distinct male and female flowers borne on two types of inflorescences $[1,2,3,5,6]$.

Male flowers are grouped in catkins, about $5 \mathrm{~cm}$ long; they develop in the axils of either the inner bud scales or the first leaves. Both species bloom in late spring (the end of April and in May), together with leaf expansion (Q. robur two weeks before $Q$. petraea). For a given tree, if weather conditions are suitable, catkin growth is achieved in 1-2 weeks after bud opening, and pollination is completed in 2-4 days [1, 2, 3, 5, 6].

Female flowers appear at terminal shoots just after the first leaves (and male catkins) have flushed. They are globular and only $1 \mathrm{~mm}$ in size, thus being very inconspicuous and difficult to observe. When receptive, they become sticky and reddish. On $Q$. robur they appear individually or in small groups on long stems, while on Q. petraea they are sedentary and grow in groups of $2-5[1,2,3,5,6]$.

Allogamy is supported by several mechanisms, like different male and female flowering times on the same tree, physiological advantages of foreign pollen, the same trees in the stand do not flower and fructify every year, etc. $[3,6]$.

After fertilisation, the acorns mature within approximately 3 months, then fall off the tree. Acorns of Q. robur mature at the end of September or beginning of October, earlier than the acorns of $Q$. petraea, which mature in October [1, 2, 3, 5]. Trees usually start fructifying at the age of between 40 and 100 years, in coppice stands at 20. Mast years usually occur every 5 to 7 years and vary according to individual tree, population, region, year and tree density (a low density favours earlier reproductive maturity) [3].

The reproduction of oak is done mainly with seed. Mammals and birds are important for seed dispersal, especially the Eurasian jay (Garrulus glandarius L.), which can be considered the primary propagator, since it can spread seeds up to $5 \mathrm{~km}$ in distance. The capacity for stump sprouting may be present in juveniles and, although decreasing with the age of the trunk, may enable oak to maintain their populations even in the absence of acorn production. In contrast to pollen and acorn dispersal, vegetative propagation is not an important component of gene flow. It can, however, participate in the maintenance of genetic variability within a population $[2,3,4,5,6]$. 


\section{Environment}

Q. robur and Q. petraea co-occur at many sites as a main component of temperate deciduous mixed forests, and they share several common characteristics. These oak are vigorous trees with large ecological amplitude, although they prefer fertile and moist soils, and are able to dominate forests in number and size at low-mid elevations. Both are able to behave as pioneer trees, are rarely affected by late frost due to late budbursting (flushing), and have a good re-sprouting attitude, so they coppice and pollard easily. Their deep and penetrating taproots (more developed in Q. petraea) give them structural stability against windthrow and allow them to withstand moderate droughts by accessing deeper water. However, in conditions far from their optimum, they show ecological differences. The tendency is for $Q$. robur to grow on heavier soils in more continental climates, in wet lowlands and damp areas by streams and rivers, tolerating periodic flooding. Q. petraea is more tolerant of drought and poor soil than pedunculate oak, but more sensitive to heavy soil conditions. It prefers to grow in more Atlantic climates on light and well-drained, often rocky, soils, generally occurring on slopes and hill tops, and preferring a more acidic soil. They are both light-demanding trees (Q. robur more so than $Q$. petraea), and their canopies permit a good deal of light to pass through to the undergrowth, promoting the regeneration of many tree species and enriching forest diversity. These oak rarely form pure forests under natural conditions. On plains, plateaus and hills, pedunculate oak is a pioneer species and sessile oak a late successional species. Sessile oak can reach the climax stage if summers are dry. In valleys and floodplains pedunculate oak is a late successional species which reaches climax with sycamore, plane, maple, ash and elm [2, 3, 5].

\section{Threats}

Oak populations are at risk because of climate change and fragmentation of their habitats (mostly Q. robur in lowland), changes in groundwater regime and over-exploitation of mature trees [2].

The big threat to the genetic diversity of the oak is the introduction of exotic genotypes through plantations. Populations that occupy more extreme habitats are at a particularly high risk of disappearing, because the number of individuals is low, habitats are unstable and human impact is often considerable [3].

Due to the unbalanced ratio of development phases, over-abundance of game or changes in groundwater regime natural regeneration can be limited. Often, seedlings die within a couple of years after germination [1, 2].

Pests and pathogens also represent a serious threat. Oak mildew (Erysiphe alphitoides (Griffon \& Maubl.) U. Braun \& S. Takam) is reported to be the most common oak pathogen. Acute Oak Decline is a new syndrome principally affecting pedunculate and sessile oak, characterised by a decrease in the density of the crown, the appearance of dark oozing wounds ('bleeds') on the trunk, and in most cases the presence of the jewel beetle Agrilus biguttatus Fabricius [3].

Defoliation of the first flush of leaves is common and caused by caterpillars of several butterfly species, e.g. Tortrix viridana L., Lymantria dispar L., Operophtera brumata L. and Thaumetopoea processionea L.. Knopper gall wasps (Andricus quercuscalicis Burgsdorf) can also cause some damage to acorn crops [3].

\section{Plot establishment and maintenance}

Since oak forms almost pure or mixed stands with many lowland forest tree species, establishment of a regular forest genetic monitoring (FGM) plot, as for other stand-forming species, should be followed with 50 reproducing trees. These are dominant or subdominant trees that are phenotypically appropriate and are at least $30 \mathrm{~m}$ apart and will contribute to new generations. If a tree is flowering, it is regarded as a reproducing tree.

The best time for FGM plot establishment and tree selection is in the spring, when reproducing trees are flowering and leaves and acorns for species (hybrid) determination can be collected from the ground. In cases when the plot cannot be established in the flowering season, DBH and social class can be used as a proxy to 
identify a reproducing tree, relying on the expertise of the local forester. During plot installation trees should be labelled and the coordinates of all trees taken. At the same time DBH can be measured and samples for DNA extraction taken.

Due to natural crossbreeding between oak, it is advisable to perform morphometric analyses of fallen leaves and acorns to determine the species and population taxonomy of the forest stand before establishing a genetic monitoring plot. The main criteria for the taxonomic determination of oak hybrids are described in species description.

\section{Equipment needed:}

- a device for distance measurement (a pair of range-finding binoculars is recommended),

- a compass,

- a paint and a brush or spray for marking trees,

- a tree calliper for DBH measurements, and

- a GPS device that is precise enough and allows saving trees' coordinates.

\subsection{Plot establishment}

\subsubsection{Selection of the centre of the plot}

The general procedure for random plot site selection consists of the following steps (Figure 4a):

- Random selection of a point (green dot) on a map along the forest road or path, which runs along the stand,

- Drawing a line that is approximately perpendicular to the road from the randomly selected point on a road,

- Random selection of one point per line (red dot) - this point represents the centre of the FGM plot.

The minimum distance between the selected central point and stand border is approximately $150 \mathrm{~m}$. If the selected central point does not meet this demand, a new point must be selected following the protocol described above.

(a)

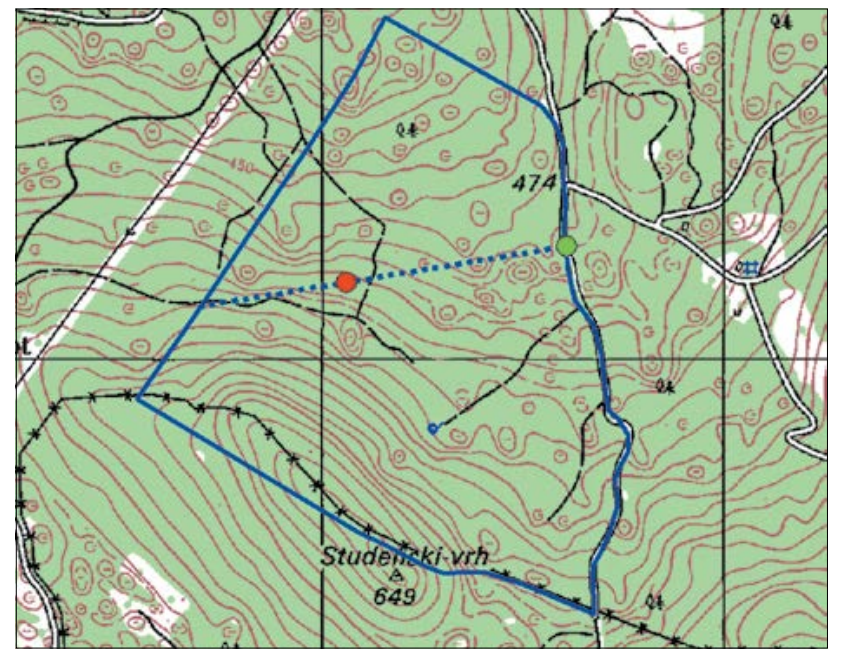

(b)

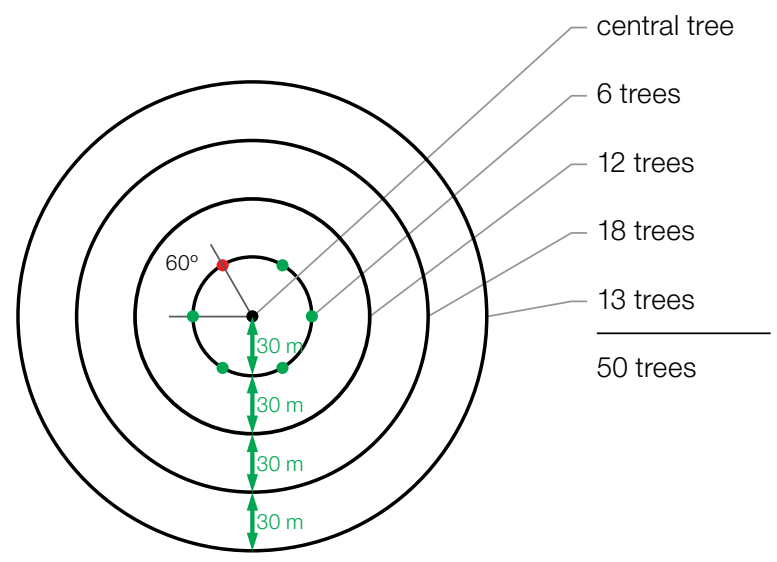

Figure 4: Random selection of the centre of the FGM plot (a); selection of trees in concentric circles around previously selected central tree with an increasing radius of $30 \mathrm{~m}$ (b).

Instead of the above described procedure, tools for creating random points in GIS software can also be used.

The selected point's coordinates are to be saved in a GPS device that will be used in the field. 


\subsubsection{Plot installation in the field}

In the field, the closest reproducing tree to the saved GPS coordinate becomes the centre of the monitoring plot and is marked with number 1 .

Other trees are selected in concentric circles around the central tree with an increasing radius of $30 \mathrm{~m}$ (Figure 4b). The first tree in each circle should be selected randomly, which can be done in different ways: by using a random azimuth (Table 1) observed from the central tree, by following the direction of the second hand on an analogue watch or any other approach that allows for objective selection. The remaining trees in each circle are selected by an appropriately enlarged azimuth to assure a minimum distance of $30 \mathrm{~m}$ between any two trees:

- $+60^{\circ}$ for the first circle

$\cdot+30^{\circ}$ for the second circle

- $+20^{\circ}$ for the third circle

$\cdot+15^{\circ}$ for the fourth circle

If it is not possible to find 6,12 and 18 trees in the inner 3 circles (Figure 4b), additional trees are selected in the outermost circle.

Table 1: Random azimuths to be used for selection of the first tree in each circle

\begin{tabular}{rrrrrrrrrrr}
\hline 108 & 15 & 186 & 35 & 178 & 29 & 305 & 351 & 44 & 150 \\
\hline 232 & 23 & 160 & 141 & 112 & 292 & 216 & 83 & 245 & 214 \\
\hline 63 & 65 & 345 & 234 & 95 & 78 & 279 & 323 & 40 & 236 \\
\hline 201 & 313 & 275 & 144 & 182 & 68 & 268 & 289 & 185 & 92 \\
\hline 356 & 177 & 93 & 1 & 145 & 198 & 287 & 251 & 224 & 142 \\
\hline
\end{tabular}




\subsubsection{Labelling of trees}

Each selected tree must be marked with a corresponding number and preferably a band painted around the trunk to aid the visibility of the trees from all directions. Mark the central tree (number 1) with two or more bands to differentiate it from other trees (Figure 5a). It is recommended to paint the number on the side of the tree that is pointing away from the central tree, as this helps locating the central tree, particularly from the outer rings of the plot (Figure $5 \mathrm{~b}$ ).
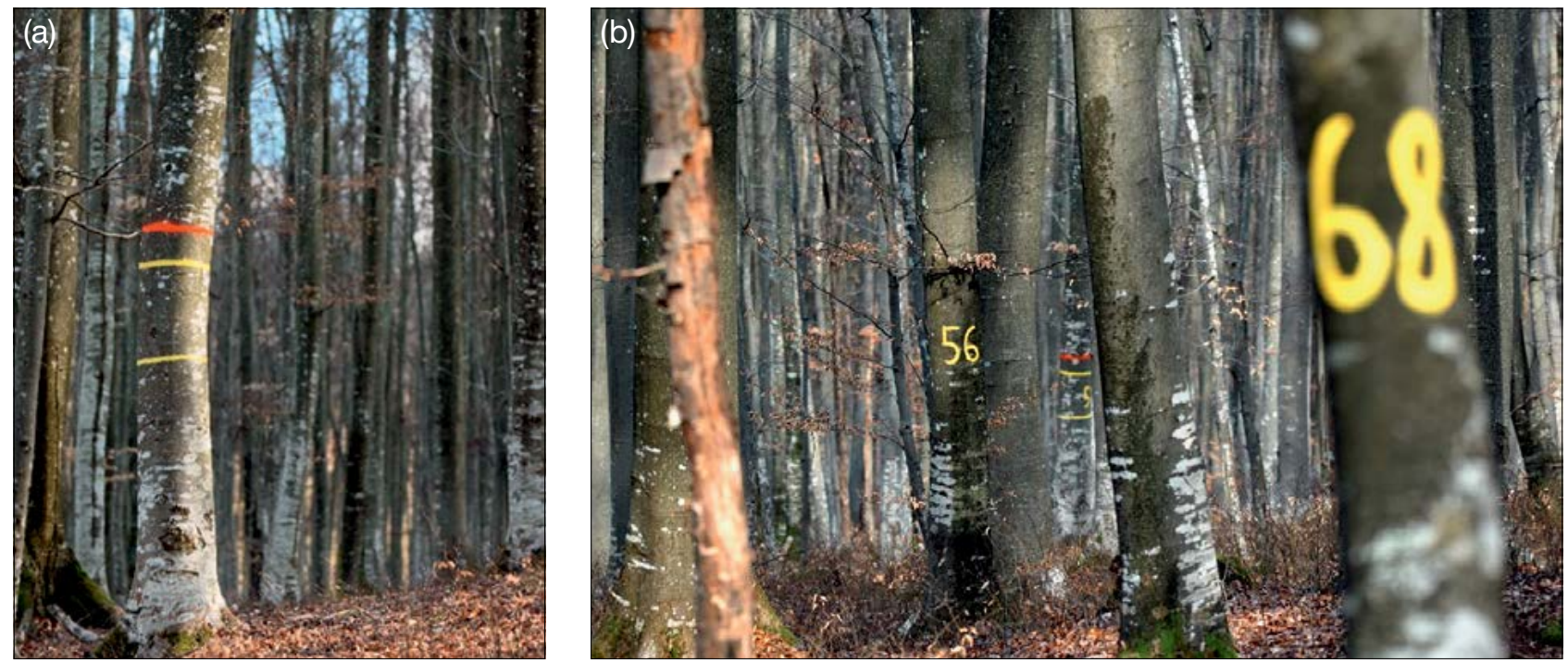

Figure 5: a) The central tree on the genetic monitoring plot is marked with multiple bands to differentiate it from other trees; b) numbers are painted on selected trees so that they point away from the central tree. Both images depict a Fagus sylvatica genetic monitoring plot.

\subsection{Establishment of natural regeneration subplots}

The establishment of natural regeneration (NR) subplots should be carried out during germination after a major fructification event.

Natural regeneration centres from the last major fructification should be surveyed in the field and their locations logged (GPS coordinates, number of the tree which is next to a NR centre). From all the logged NR centres, 20 should be chosen randomly for plot installation. If 20 or fewer NR centres are present, all should be used.

Inside each selected NR centre a $1 \mathrm{~m}^{2}$ plot is to be installed and marked with metal rods. The metal rods should be driven into the ground at each corner of the subplot as deep as possible to prevent them from being removed by animals. The tips of the metal rods should be painted to aid their visibility.

\subsection{Plot maintenance}

\subsubsection{General maintenance}

Tree markings and NR subplot markings must be checked periodically (every 2 years) and renewed if needed.

\subsubsection{Replacement of trees}

If a monitored tree dies or is cut due to management, it must be replaced. The nearest suitable tree to the dead one should be chosen considering that the distance requirement of $30 \mathrm{~m}$ to the nearest monitored tree is fulfilled. Otherwise a tree from the periphery (preferably in the outer circle) of the FGM plot is to be selected. The replacement tree is marked with the next available number higher than 50 , i.e. $51,52,53$, etc. to positively differentiate it from the original 50 selected trees. 
If the crown is damaged due to, for example, wing break, ice or snow break but continues to fructify, the tree is kept for monitoring. If the damage is too severe and fructification is not expected anymore, the monitored tree must be replaced. The cause of damage needs to be recorded, as the damage can affect the values recorded for field verifiers and background information.

\section{Recording of verifiers and background information}

On the monitoring plot, verifiers and background information are periodically recorded. Verifiers are used to monitor the population's genetic properties and its adaptation to environmental changes and/or management while background information needs to be recorded to assist interpretation of the verifiers.

Higher levels of verifiers (standard, advanced) must also include recording on all the preceding levels (basic, standard). This is not necessary for recording of background information.

Table 2: List of verifiers and background information with short description and observation frequency to be recorded during field work at the oak monitoring plots.

\begin{tabular}{|c|c|c|c|c|}
\hline & Name & Basic level & Standard level & Advanced level \\
\hline \multirow{5}{*}{ 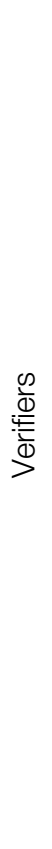 } & \multirow{2}{*}{$\begin{array}{l}\text { Mortality / } \\
\text { survival }\end{array}$} & $\begin{array}{l}\text { Adult trees: Counting of the } \\
\text { remaining marked trees every } \\
10 \text { years and after every extreme } \\
\text { weather event/disturbance }\end{array}$ & Same as basic level & Same as basic level \\
\hline & & Natural regeneration: / & $\begin{array}{l}\text { Counting of the remaining } \\
\text { seedlings on the natural } \\
\text { regeneration subplots, twice per } \\
\text { decade }\end{array}$ & Same as standard level \\
\hline & \multirow[t]{2}{*}{$\frac{0}{2}$ Flowering } & Stand-level estimate, every year & $\begin{array}{c}\text { Individual tree level observation, } \\
\text { during two major flowering } \\
\text { events per decade, ideally } \\
\text { equally spaced * }\end{array}$ & $\begin{array}{c}\text { Individual tree level observation, } \\
\text { during two major flowering } \\
\text { events per decade, ideally } \\
\text { equally spaced * }\end{array}$ \\
\hline & & Stand-level estimate, every year & $\begin{array}{l}\text { Individual tree level observation, } \\
\text { the same year as the } \\
\text { assessment of the flowering at } \\
\text { the standard level (regardless of } \\
\text { the fructification intensity) }{ }^{*}\end{array}$ & $\begin{array}{l}\text { Counting of fruit, the same years } \\
\text { as the assessment of flowering } \\
\text { at the advanced level, regardless } \\
\text { of the fructification intensity } \\
{ }^{*} \text { Seeds are also collected } \\
\text { for laboratory analyses every } \\
\text { assessed fructification event }\end{array}$ \\
\hline & $\begin{array}{l}\text { Natural } \\
\text { regeneration } \\
\text { abundance }\end{array}$ & Stand-level estimate, every year & $\begin{array}{l}\text { Counting of seedlings } 1 \text { st and } \\
6 \text { th years after every assessed } \\
\text { fructification event }\end{array}$ & $\begin{array}{l}\text { Counting of seedlings 1st, 6th, } \\
11 \text { th, 16th years after every } \\
\text { assessed fructification event }\end{array}$ \\
\hline \multirow{4}{*}{ 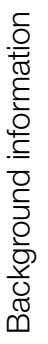 } & $\begin{array}{l}\text { DBH class } \\
\text { distribution }\end{array}$ & / & Measurement every 10 years & Same as standard level \\
\hline & $\begin{array}{l}\text { Height class } \\
\text { distribution }\end{array}$ & / & Measurement every 10 years & Same as standard level \\
\hline & Budburst & / & $\begin{array}{l}\text { Individual tree level observation, } \\
\text { every } 5 \text { years }\end{array}$ & $\begin{array}{c}\text { Individual tree level observation, } \\
\text { every year }\end{array}$ \\
\hline & Senescence & / & $\begin{array}{c}\text { Individual tree level observation, } \\
\text { every } 5 \text { years }\end{array}$ & $\begin{array}{c}\text { Individual tree level observation, } \\
\text { every year }\end{array}$ \\
\hline
\end{tabular}

Ideally at least one major fructification event should be assessed per decade. However, a major flowering event does not necessarily lead to a major fructification event. If no major fructification event follows the assessed flowering event, assessment of both flowering and fructification needs to be repeated during the next major flowering event, regardless of the time passed between successive major flowering events. Basic level observations are used to identify major flowering and fructification events. 


\subsection{Protocols for recording of verifiers}

\subsubsection{Mortality / survival}

Mortality describes the mortality of adult trees and natural regeneration. Its counterpart survival stands for trees that are still alive since the previous assessment. Survival is calculated as 1 - Mortality.

\subsubsection{Adult trees: Basic, standard and advanced levels}

The verifier for mortality of adult trees is estimated by counting the marked trees remaining alive every 10 years and after every extreme weather event/disturbance. Mortality is the difference between the initial number of marked trees and the trees remaining alive of the original 50.

\subsubsection{Natural regeneration: Standard and advanced levels}

Mortality is the difference between the initial number of plants and the plants remaining alive at the time of the next counting. For each assessment of abundance natural regeneration plants are first counted in the year of germination and then 5 years later at the standard level, while at the advanced level counting is also performed 10 and 15 years after germination. NR abundance assessment is carried out twice per decade, ideally approximately every five years.

\subsubsection{Flowering}

This verifier describes the flowering intensity and the proportion of trees thus affected. It can be recorded in April to May in central Europe. Flowering is earlier when preceded by a warm winter.

Male flowers (Figure 7): The criterion for determining the beginning of flowering is defined by the development of catkins. Male flowers (catkins) begin to develop immediately after first leaves appear, the release of pollen begins when catkins lengthen and thicken. The end of flowering of male flowers appears when there are no pollen active male flowers in the crown. The colour of catkins turns dark brown and the consistency is like a cobweb.

Female flowers (Figure 6): Female flowers in oak are very small and hardly visible; therefore all assessments of flowering are focused only on male flowers. Consequently, and in contrast to most other species, the background information Flowering Synchronisation is not monitored for pedunculate and sessile oak.

\subsubsection{Basic level}

This verifier is recorded every year at the stand level. Recording is carried out when flowering is in full progress. The estimate of average condition is provided after a walk throughout the monitoring plot. Two scores are given, one for flowering intensity, expressed as the average proportion of the crown flowering, and one for proportion of flowering trees in the stand.

\begin{tabular}{clc} 
Code & Flowering intensity at the stand level & Average proportion of the crown flowering (\%) \\
\hline 1 & No flowering: No or only occasional flowers appearing on trees & $0-10$ \\
\hline 2 & Weak flowering: Some flowers appearing on trees. & $>10-30$ \\
\hline 3 & Moderate flowering: Moderate number of flowers appearing on trees. & $>30-60$ \\
\hline 4 & Strong flowering: Abundant number of flowers on trees. & $>60-90$ \\
\hline 5 & Massive: Huge number of flowers on trees. & $>90$ \\
\hline
\end{tabular}




\begin{tabular}{lr} 
Code Proportion of trees in the stand with the given flowering intensity stage (\%) & $0-10$ \\
\hline 1 & $>10-30$ \\
\hline 2 & $>30-60$ \\
\hline 3 & $>60-90$ \\
\hline 4 & $>90$ \\
\hline 5 & \\
\hline
\end{tabular}

\subsubsection{Standard level}

This verifier is recorded during two major flowering events per decade, ideally equally spaced in time from one another. It is recorded at an individual tree level on all 50 monitored trees. A major flowering event is when at the basic level flowering intensity is strong or massive (code 4 or 5 ) and the proportion of trees with the given flowering intensity is above $60 \%$ (code 4 or 5 ). Recording is carried out when flowering is in full progress. One score is provided for each tree.

\begin{tabular}{|c|c|c|}
\hline Code & Description of the flowering stage & Proportion of the crown flowering (\%) \\
\hline 1 & No flowering: No or only occasional flowering appearing on a tree. & $0-10$ \\
\hline 2 & Weak flowering: Some flowers appearing on a tree. & $>10-30$ \\
\hline 3 & Moderate flowering: Moderate number of flowers on a tree. & $>30-60$ \\
\hline 4 & Strong flowering: Abundant number of flowers on a tree. & $>60-90$ \\
\hline 5 & Massive: Huge number of flowers on a tree. & $>90$ \\
\hline
\end{tabular}

\subsubsection{Advanced level}

This verifier is recorded during two major flowering events per decade, ideally equally spaced in time from one another. It is recorded at an individual tree level on all 50 monitored trees. A major flowering event is when at the basic level flowering intensity is strong or massive (code 4 or 5 ) and the proportion of trees with the given flowering intensity is above $60 \%$ (code 4 or 5). On average, two visits to the plot are needed; the first one early enough to observe the early stages of flowering, and the second when flowering is in full progress.

Two scores are provided for each tree: male flowering stage and the proportion of the crown flowering. Because female flowers in pedunculate and sessile oak are very small and inconspicuous, the assessment of the female flowering stage cannot be done reliably in practice. The proportion of the crown flowering refers to the total amount of male flowers on the tree. For a graphical representation of female flowers and male flowering stages see Figures 6 and 7.

\begin{tabular}{ll}
\multicolumn{2}{l}{ Code } \\
\hline 1 & Elongated flowering stage \\
\hline 2 & Anthers releasing pollen (yellow) \\
\hline 3 & Empty anthers (pollen released) (brown) \\
\hline
\end{tabular}

\begin{tabular}{lr}
\hline Code Proportion of the crown flowering (\%; male flowers) & $0-10$ \\
\hline 1 & $>10-30$ \\
\hline 2 & $>30-60$ \\
\hline 3 & $>60-90$ \\
\hline 4 & $>90$ \\
\hline 5 & \\
\hline
\end{tabular}


(a)

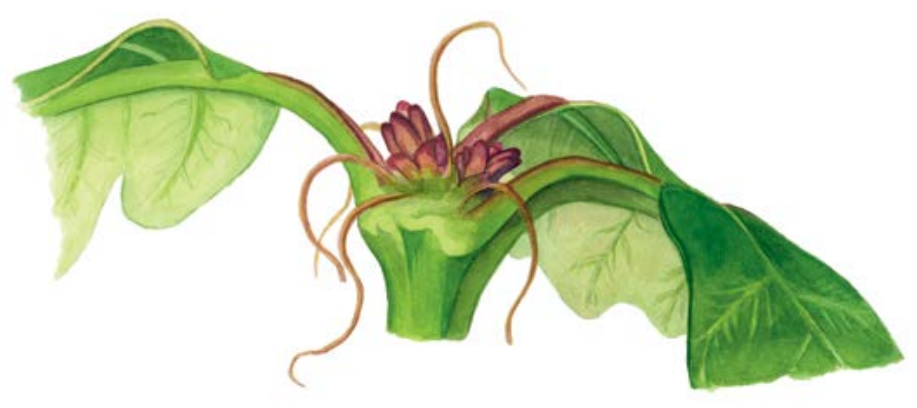

(b)

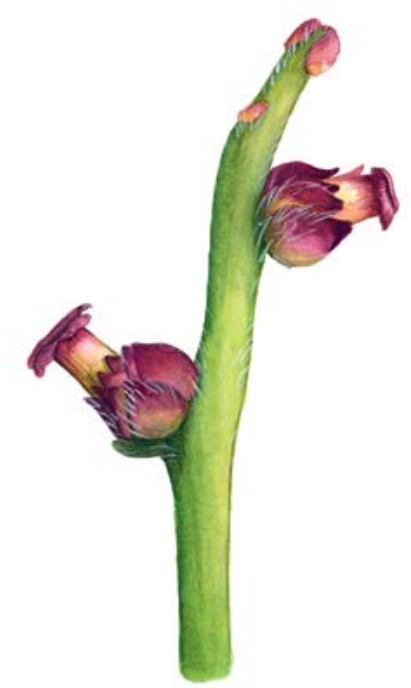

Figure 6: Female flowers of the pedunculate oak (Quercus robur) (a), and sessile oak (Q. petraea) (b). Female flowering is not assessed, as female flowers of both species are too inconspicuous to observe reliably in the field.

1

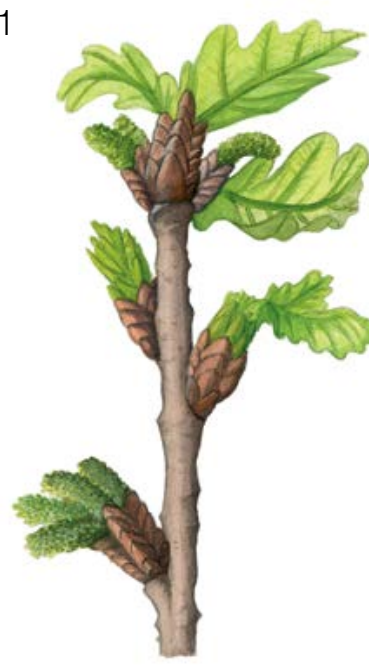

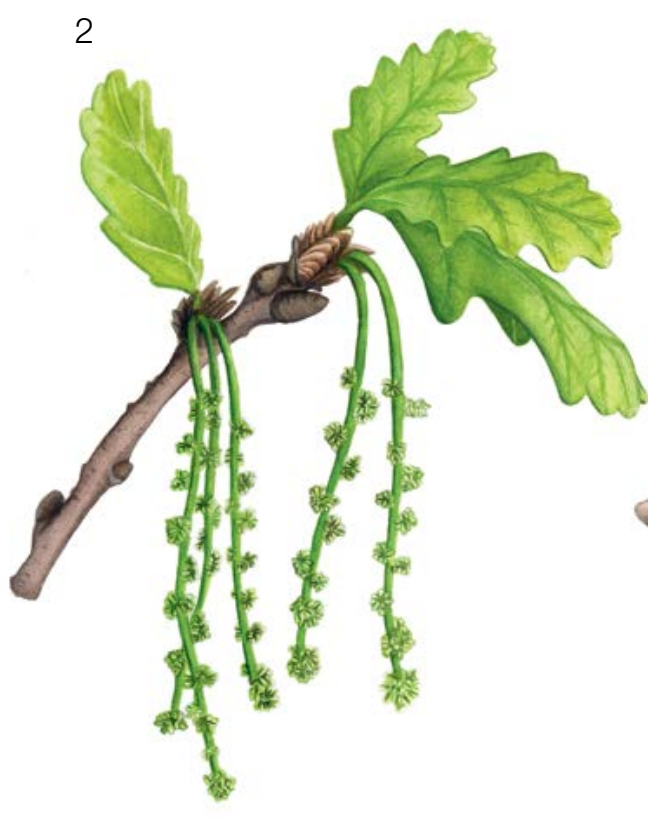

Figure 7: Picture guide for description of male flowering stages for the advanced level verifier Flowering, for pedunculate and sessile oak. 


\subsubsection{Fructification}

This verifier describes the presence of fructification and its abundance. Data for this verifier should be collected during fructification, in September to October in central Europe. Acorns of $Q$. robur mature at the end of September or beginning of October, earlier than the acorns of $Q$. petraea, which mature in October.

\subsubsection{Basic level}

This verifier is recorded every year at the stand level. The estimate of average condition is provided after a walk throughout the monitoring plot. Two scores are given, one for fructification intensity and one for proportion of fructifying trees in the stand.

\begin{tabular}{clc} 
Code & Fructification intensity at the stand level & Average proportion of the crown bearing fruit (\%) \\
\hline 1 & No fructification: No or only occasional fruit appearing on trees & $0-10$ \\
\hline 2 & Weak fructification: Some fruit appearing on trees & $>10-30$ \\
\hline 3 & Moderate fructification: Moderate amount of fruit appearing on trees & $>30-60$ \\
\hline 4 & Strong fructification: Abundant amount of fruit appearing on trees & $>60-90$ \\
\hline 5 & Massive: Huge amount of fruit appearing on trees & $>90$ \\
\hline
\end{tabular}

\begin{tabular}{lr}
\hline Code Proportion of trees in the stand with the given stage of fructification intensity (\%) & $0-10$ \\
\hline 1 & $>10-30$ \\
\hline 2 & $>30-60$ \\
\hline 3 & $>60-90$ \\
\hline 4 & $>90$ \\
\hline
\end{tabular}

\subsubsection{Standard level}

This verifier is recorded during the same years as the assessment of the flowering at the standard level (regardless of the fructification intensity). It is recorded at an individual tree level on all 50 monitored trees. Recording is carried out before the fruit, i.e. acorns, starts falling. One score is provided for each tree.

Ideally, one major fructification event should be captured following observations of major flowering events per decade. However, a major flowering event does not necessarily lead to a major fructification event. If no major fructification event follows the assessed flowering event, assessment of both flowering and fructification needs to be repeated during the next major flowering event, regardless of the time passed between successive major flowering events. Basic level observations are used to identify major fructification events. A major fructification event is when at the basic level fructification intensity is strong or massive (code 4 or 5 ) and the proportion of trees with the given fructification intensity is above $60 \%$ (code 4 or 5 ).

\begin{tabular}{|c|c|c|}
\hline Cod & Fructification intensity & Proportion of the crown fructifying (\%) \\
\hline 1 & No fructification: No or only occasional fruit appearing on a tree. & $0-10$ \\
\hline 2 & Weak fructification: Some fruit appearing on a tree. & $>10-30$ \\
\hline 3 & Moderate fructification: Moderate amount of fruit appearing on a tree. & $>30-60$ \\
\hline 4 & Strong fructification: Abundant amount of fruit appearing on a tree. & $>60-90$ \\
\hline 5 & Massive: Huge amount of fruit appearing on a tree. & $>90$ \\
\hline
\end{tabular}




\subsubsection{Advanced level}

This verifier is recorded at an individual tree level on all 50 monitored trees during the same years as the assessment of flowering at the advanced level, regardless of the fructification intensity. Recording is carried out before fruit, i.e. acorns, starts falling. One score is provided for each tree. Simultaneously, acorns are collected for seed and genetic analysis for the advanced level verifiers and background information.

Ideally, one major fructification event should be captured following observations of major flowering events per decade. However, a major flowering event does not necessarily lead to a major fructification event. If no major fructification event follows the assessed flowering event, assessment of both flowering and fructification needs to be repeated during the next major flowering event, regardless of the time passed between successive major flowering events. Basic level observations are used to identify major fructification events. A major fructification event is when at the basic level fructification intensity is strong or massive (code 4 or 5) and the proportion of trees with the given fructification intensity is above $60 \%$ (code 4 or 5 ).

This verifier is recorded by counting fruit using binoculars. The average of three rounds of counting is reported. Each round of counting consists of the number of fruits that the observer is able to count in 30 seconds. For all trees, the same part of the crown should be investigated. Once the observation part of the crown part is selected, the same one should be selected for every subsequent monitoring of this verifier. The upper third of the crown is preferred to the bottom and middle part for counting.

Two values are recorded; the number of fruits and the part of the crown monitored.

\section{Number of fruits counted in 30 seconds (average of 3 rounds)}

$$
\mathrm{x}
$$

\section{Code Part of the crown monitored}

\begin{tabular}{ll}
\hline 1 & Bottom \\
\hline 2 & Middle \\
\hline 3 & Top \\
\hline
\end{tabular}

\subsubsection{Natural regeneration abundance}

This verifier describes the presence and abundance of natural regeneration (NR) at the monitoring plot.

\subsubsection{Basic level}

This verifier is recorded at the stand level every year in the autumn. Expert opinion is used for estimation considering the situation over the whole monitoring plot. Two values should be recorded, one for 'new NR' (seedlings that germinated the same year as the observation is carried out, Figure 8) and one for the 'established NR' (saplings older than 'new NR').

Code Description: new regeneration (current-year seedlings)

1a There is no or very little new natural regeneration on the monitoring plot

$2 a$ New regeneration is present in sufficient numbers on the monitoring plot

Code Description: established natural regeneration (saplings)

$1 \mathrm{~b}$ There is no or very little established natural regeneration on the monitoring plot

$2 \mathrm{~b}$ Established regeneration is present in sufficient quantity on the monitoring plot 


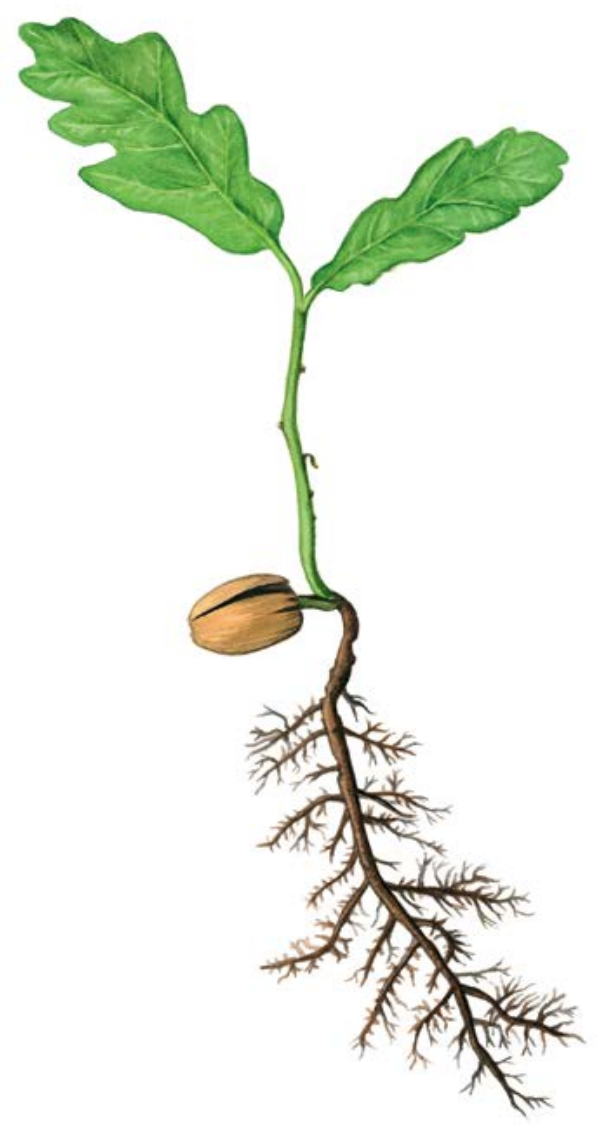

Figure 8: A one-year old seedling.

\subsubsection{Standard level}

This verifier is recorded by counting seedlings in the $1^{\text {st }}$ autumn after every assessed fructification event (the year of the fructification event is regarded as year 0 ) and $6^{\text {th }}$ autumn after the fructification event.

Oak seeds are not dormant and can already sprout in the year following fructification. Because major fructification of pedunculate and sessile oak occurs approximately every 5 to 7 years, the next round of monitoring of natural regeneration abundance follows after the next major fructification event (approximately 5 to 7 years after the establishment of the previous subplots).

Counting of seedlings:

After the establishment of NR subplots all oak seedlings present at each of the 20 NR sublots must be counted. Any older oak saplings that are present on the NR subplot must not be included. During the next round of counting, only saplings of the appropriate age must be counted - in the $6^{\text {th }}$ year, 5 -year old saplings.

\section{Number of seedlings counted on a subplot}

$$
\mathrm{X}
$$

Mortality/survival of natural regeneration is calculated from the values recorded for this verifier.

For subplot establishment see 6.2 Establishment of natural regeneration subplots. 


\subsubsection{Advanced level}

The verifier is recorded by counting seedlings at each of the $20 \mathrm{NR}$ subplots in the $1^{\text {st }}$ autumn after every assessed fructification event (the year of the fructification event is regarded as year 0 ) and $6^{\text {th }}, 11^{\text {th }}, 16^{\text {th }}$ autumns after the fructification event. Only plants of the appropriate age must be counted - in the 6th year, 5 -year old saplings, in the 11th year, 10-year old saplings etc.

Table 3: Timeline of natural regeneration abundance (NR) assessment. In this example, the first fructification event takes place in the second year of the monitoring decade, and the second assessed fructification event five years later, i.e. in the $7^{\text {th }}$ year of the monitoring. Twenty new NR subplots are established after each assessed fructification event. Monitoring of NR abundance on each set of $20 \mathrm{NR}$ subplots is carried out every five years. The fructification events corresponding to the assessed NR and timelines of the assessment activities are shaded in the same colour. After the final round of counting of seedlings, monitoring of NR abundance on the respective set of NR subplots is stopped and the respective NR subplots disestablished. S - standard level; A - advanced level.

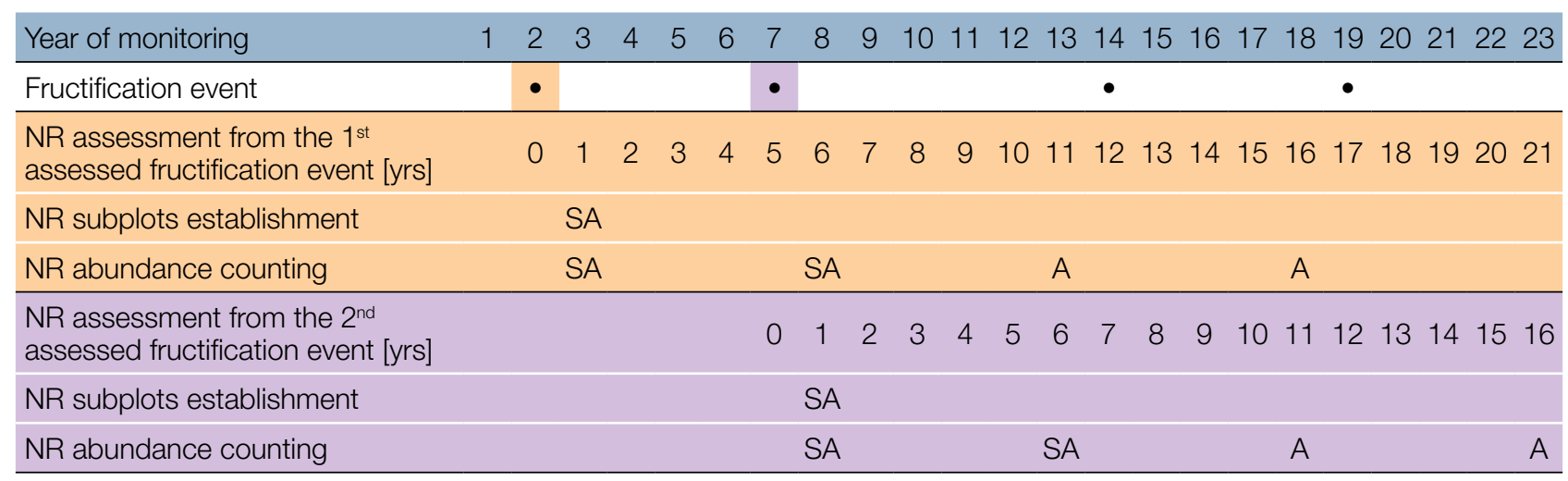

Mortality/survival of natural regeneration is calculated from the values recorded for this verifier.

For subplot establishment see 6.2 Establishment of natural regeneration subplots and for counting 7.1.4.2 Standard level.

\subsection{Protocols for recording of background information}

\subsubsection{DBH class distribution}

\subsubsection{Standard and advanced levels}

$\mathrm{DBH}$ is recorded on an individual tree level on all 50 monitored trees every 10 years. $\mathrm{DBH}$ is the trunk diameter at $1.30 \mathrm{~m}$, i.e. approximately at an adult's breast height. If a tree has more than one trunk, measure all of them and record the average (but try to avoid trees with many small trunks). Note that the tree is multi-trunk in the notes and include the number of trunks measured. If the tree is leaning, measure DBH perpendicular to the tree trunk. $\mathrm{DBH}$ can be measured in two ways:

1) using a calliper, in which case you would need to measure two perpendicular diameters and take the average,

2) measure the circumference of the tree and compute the diameter from that value (i.e. divide by $\pi, \sim 3.14$ or use a pi-meter).

The DBH is recorded in $\mathrm{cm}$. The same method must be applied for every subsequent measurement. 


\subsubsection{Height class distribution}

\subsubsection{Standard and advanced levels}

Height is recorded on an individual tree level on all 50 monitored trees every 10 years. Height is measured from the ground to the tallest part of the crown, ideally using a clinometer or hypsometer (e.g. vertex). Height is recorded in metres to one decimal place. If the crown is damaged, this must be recorded as well as the stipulated reason in notes.

\subsubsection{Budburst}

Budburst describes the process of budbursting (flushing). Recording of this parameter is only carried out at the standard and advanced levels. In pedunculated and sessile oak, budbursting starts together with flowering $(Q$. robur two weeks before Q. petraea). Data for this verifier should be collected in April and May in central Europe until all monitored trees have reached fully developed leaves. Budbursting is earlier when preceded by a warm winter.

\subsubsection{Standard level}

At standard level, budburst is recorded on an individual tree level on all 50 monitored trees every 5 years. We are looking for the initiation of budbursting (stage 2) and the end of budbursting (stage 4). The observations cease when all the trees have reached stage 4. Usually, 6 visits will be needed. For each tree, two estimates are given: budbursting stage and proportion of the crown budbursting. For a graphical representation of budbursting stages see Figure 9.

\begin{tabular}{|c|c|c|}
\hline \multicolumn{3}{|c|}{ Code Stage of budbursting } \\
\hline 1 & Buds completely closed (no green is visible) & \\
\hline 2 & Buds begin to burst (first green is visible) & \\
\hline 3 & Folded and hairy leaves begin to appear; individually visible folded and hairy leaves & \\
\hline 4 & Leaves fully unfolded, smooth and bright & \\
\hline \multicolumn{3}{|c|}{ Code Proportion of the crown with a given stage of budbursting (\%) } \\
\hline 1 & & $>0-33$ \\
\hline 2 & & $>33-66$ \\
\hline 3 & & $>66-99$ \\
\hline 4 & & 100 \\
\hline
\end{tabular}

\subsubsection{Advanced level}

At the advanced level, budburst is recorded on an individual tree level on all 50 monitored trees every year in the same way as at the standard level. For details see 7.2.3.1 Standard level. 
1

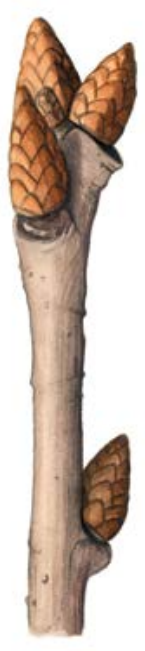

2

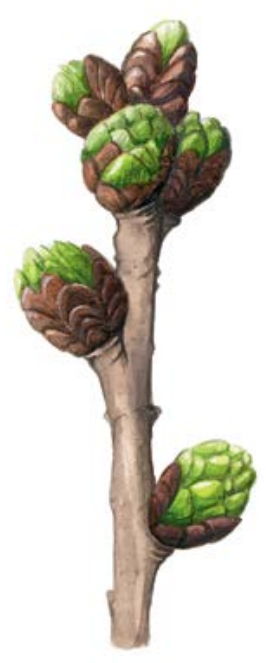

3

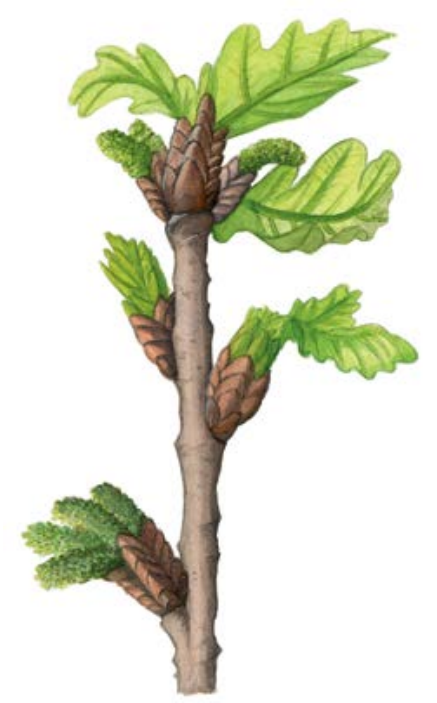

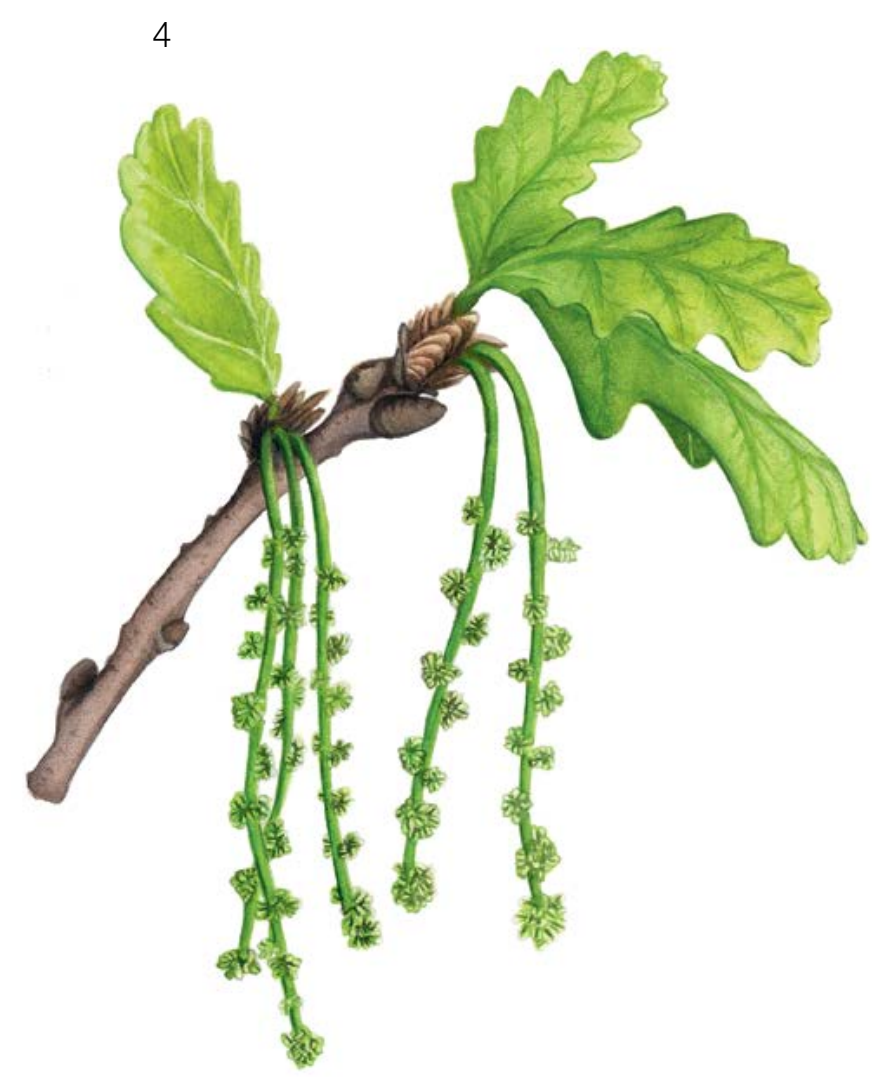

Figure 9: Picture guide for description of budburst (flushing) for the standard and advanced level background information Budburst. 


\subsubsection{Senescence}

Senescence describes the process of senescence. Recording of this background information is only carried out at the standard and advanced levels.

\subsubsection{Standard level}

At standard level, senescence is recorded on an individual tree level on all 50 monitored trees every 5 years. We are looking for stage 3, when leaves are yellow and do not photosynthesise anymore. Observations stop when all the trees have reached stage 3. Usually, two (2) visits to the plot will be needed. For each tree, two estimates are given: stage of senescence and proportion of the crown senescing.

\begin{tabular}{|c|c|}
\hline Cod & Stage of senescence \\
\hline 1 & Leaves are green \\
\hline 2 & Leaves are green changing to yellow (greenish yellow) \\
\hline 3 & Leaves are yellow changing to brown (brownish) \\
\hline 4 & Leaves are brown / shed \\
\hline
\end{tabular}

\begin{tabular}{lr} 
Code Proportion of the crown with a given score for stage of senescence (\%) & $>0-33$ \\
\hline 1 & $>33-66$ \\
\hline 2 & $>66-99$ \\
\hline 3 & 100 \\
\hline 4 &
\end{tabular}

\subsubsection{Advanced level}

Senescence is recorded on an individual tree level on all 50 monitored trees every year in the same way as at the standard level. For details see 7.2.4.1 Standard level.

\section{For plot establishment use form 'FGM Plot description'}

\section{For verifiers recording use 'Form for recording field level verifiers within FGM'}

\section{For background information recording use 'Form for recording field level background information within FGM'}

\section{References}

1. Breznikar A (1997) Morfološka in fenološka variabilnost doba (Quercus robur L.) in gradna (Quercus petraea (Matt.) Liebl.) na robnih območjih njunih naravnih habitatov v severovzhodni Sloveniji/Morphological and phenological variability of pedunculate oak (Quercus robur L.) and sessile oak (Quercus petraea (Matt.) Liebl.) at the edge of their natural habitats in northeastern Slovenia. Master Thesis, Biotechnical Faculty, University of Ljubljana. http://eprints. gozdis.si/800/1/Breznikar,Horvat-Marlot_1998.pdf. Accessed 10 September 2020

2. Brus R. (2005) Dendrologija za gozdarje/Dendrology for foresters. Biotehniška fakulteta, University of Ljubljana, Ljubljana

3. Ballian D, Memišević-Hodžić M (2016) Varijabilnost hrasta lužnjaka (Quercus robur L.) u Bosni i Hercegovini/Variability of the pedunculate oak (Quercus robur L.) in Bosnia and Herzegovina. Silva Slovenica - Slovenian Forestry Institute, Ljubljana 
4. Eriksson G (2015) Quercus petraea and Quercus robur - Recent Genetic Research. Silva Slovenica - Slovenian Forestry Institute, Ljubljana

5. Ducousso A, Bordacs S (2004) EUFORGEN Technical Guidelines for genetic conservation and use for pedunculate and sessile oaks (Quercus robur and Q. petraea). International Plant Genetic Resources Institute, Rome

6. Ducousso A, Michaud H, Lumaret R (1993) Reproduction and gene flow in the genus Quercus L. Ann Sci For 50(1):91 - 106. https://doi.org/10.1051/forest:19930708

7. Eaton E, Caudullo G, Oliveira S, de Rigo D (2016) Quercus robur and Quercus petraea in Europe: distribution, habitat, usage and threats. In: San-Miguel-Ayanz J, de Rigo D, Caudullo G, Houston Durrant T, Mauri A (eds.) European Atlas of Forest Tree Species. Publ. Off. EU, Luxembourg, pp e01c6df+. https://ies-ows.jrc.ec.europa.eu/efdac/download/ Atlas/pdf/Quercus_robur_petraea.pdf. Accessed 15 October 2020

8. Kraigher H (2001) Semenarski praktikum. Skripta za strokovni seminar o gozdnem semenarstvu in predmet podiplomskega študija fiziologija gozdnega drevja/Seed technology practicum. A script for seminar on seed technology in forestry and for the course in postgraduate studies program on physiology of forest tree species. Slovenian Forestry Institute. Ljubljana

9. Kraigher H, Bogovič M, Westergren M (2010) Tehnične smernice za ohranjanje in rabo genskih virov : hrasti = Quercus spp. : Slovenija/Technical guidelines for conservation and use of forest genetic resources: Oak = Quercus spp.: Slovenia. Gozdarski vestnik 68(3):167-174

The following resources were consulted for the currently accepted (December 2020) scientific names of the species covered or mentioned in this document:

a. CABI (2020) Invasive Species Compendium. CAB International, Wallingford, UK. www.cabi.org/isc. Accessed 15 December 2020

b. EPPO (2020) EPPO Global Database (available online). https://gd.eppo.int. Accessed 15 December 2020

c. GBIF (2020) Global Biodiversity Information Facility. https://www.gbif.org Accessed 15 December 2020

d. IPNI (2020) International Plant Names Index. The Royal Botanic Gardens, Kew, Harvard University Herbaria \& Libraries \& Australian National Botanic Gardens. http://www.ipni.org, Accessed 10 December 2020

e. National Center for Biotechnology Information (NCBI) (1998) National Library of Medicine (US), National Center for Biotechnology Information, Bethesda (MD). https://www.ncbi.nlm.nih.gov/. Accessed 15 December 2020

f. Stevens PF (2001) Angiosperm Phylogeny Website, Version 14. http://www.mobot.org/MOBOT/research/APweb/. Accessed 15 December 2020

g. The Plant List (2013) Version 1.1. http://www.theplantlist.org/. Accessed 12 December 2020

h. Tropicos.org (2020) Missouri Botanical Garden. http://www.tropicos.org. Accessed 15 December 2020

i. WFO (2020) World Flora Online. http://www.worldfloraonline.org. Accessed 15 December 2020 




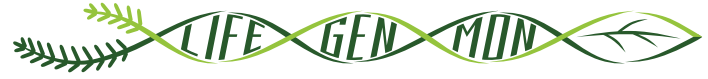

Manual for forest genetic monitoring

\section{chapter $\perp$}

\section{Annex}




\subsection{Description of designation and maps of monitoring regions (supplementary materials for Chapter 2: Plot selection)}

In the cascade of the FGM implementation process, the identification of FGM regions is a priority. Within LIFEGENMON, the delineation of FGM regions has been carried out by a joint data-driven and expert-based approach, in a NW to SE transect spanning from Bavaria to Greece.

This approach is founded upon the representative coverage of environmental zones, the coverage of characterised races or ecotypes, the inclusion of marginal and peripheral populations, the presence of already assigned GCUs, the levels of standing genetic variation (if known), the coverage of standing genetic structure/recolonisation routes, the relevant results of provenance trials (if available), and expert knowledge.

Seven priority species with contrasting biology, ecology and distributional properties were employed: Abies alba/A. borisii-regis complex, Fagus sy/vatica, Fraxinus excelsior, Pinus nigra, Populus nigra, Prunus avium, and Quercus robur/Q. petraea complex. Six to nine monitoring regions per species/species complex were recognised and are presented below.

The monitoring regions as delineated within the LIFEGENMON project are valid for the transect from Bavaria to mainland Greece. If a wider, pan-European, area was assessed, the monitoring regions might be delineated differently. 


\section{Monitoring regions for firs (Abies alba Mill./ Abies borisii-regis Mafft.)}

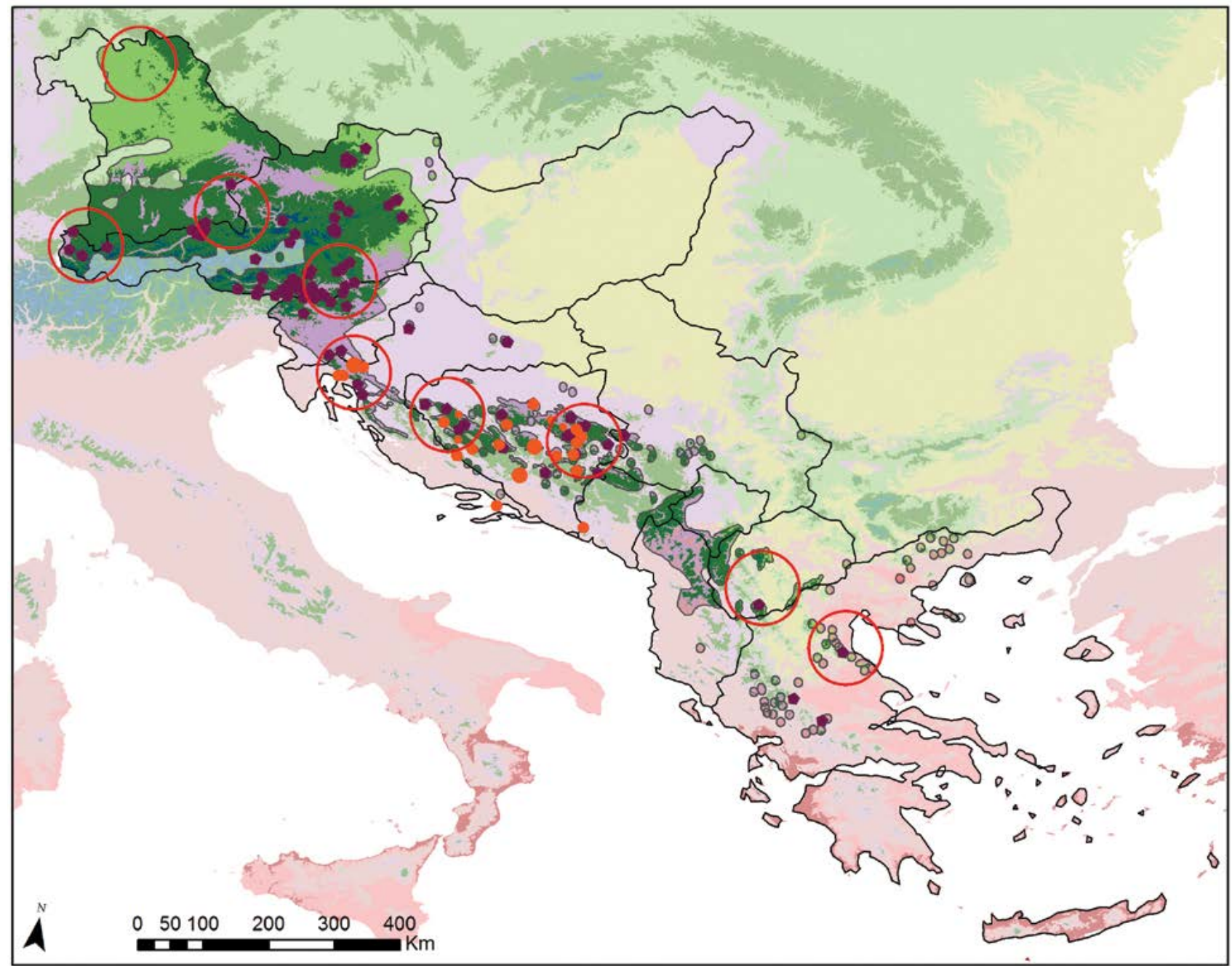

\section{Legend}

\section{Global Environmental Zone}
B. Arctic
C. Extremely cold and wet
D. Extremely cold and wet
E. Cold and wet
F. Extremely cold and mesic
G. Cold and mesic
H. Cool temperate and dry
J. Cool temperate and moist
I. Cool temperate and xeric
K. Warm temperate and mesic
L. Warm temperate and xeric
N. Hot and dry

\section{Monitoring Region}

- EUFGIS GCU

\section{He (isoenzymes)}

- $0.12-0.14$

- $0.14-0.16$

$0.16-0.18$

This map was created within the LIFEGENMON project to show the forest genetic monitoring regions for the transect spanning from Bavaria to Greece. We acknowledge the data sources: Global Environmental Zones (Metzger et al. 2012, Global Ecol. Biogeogr); Species distribution range (www.euforgen.org); EUFGIS Dynamic Gene Conservation Units (EUFORGEN, the EUFGIS project and National Focal Points) and genetic data (published studies available from the LIFEGENMOM project by request). Although a part of the transect, Albania was excluded from monitoring regions delineation as no data was available for this country. 


\section{Monitoring regions for European beech (Fagus sylvatica)}

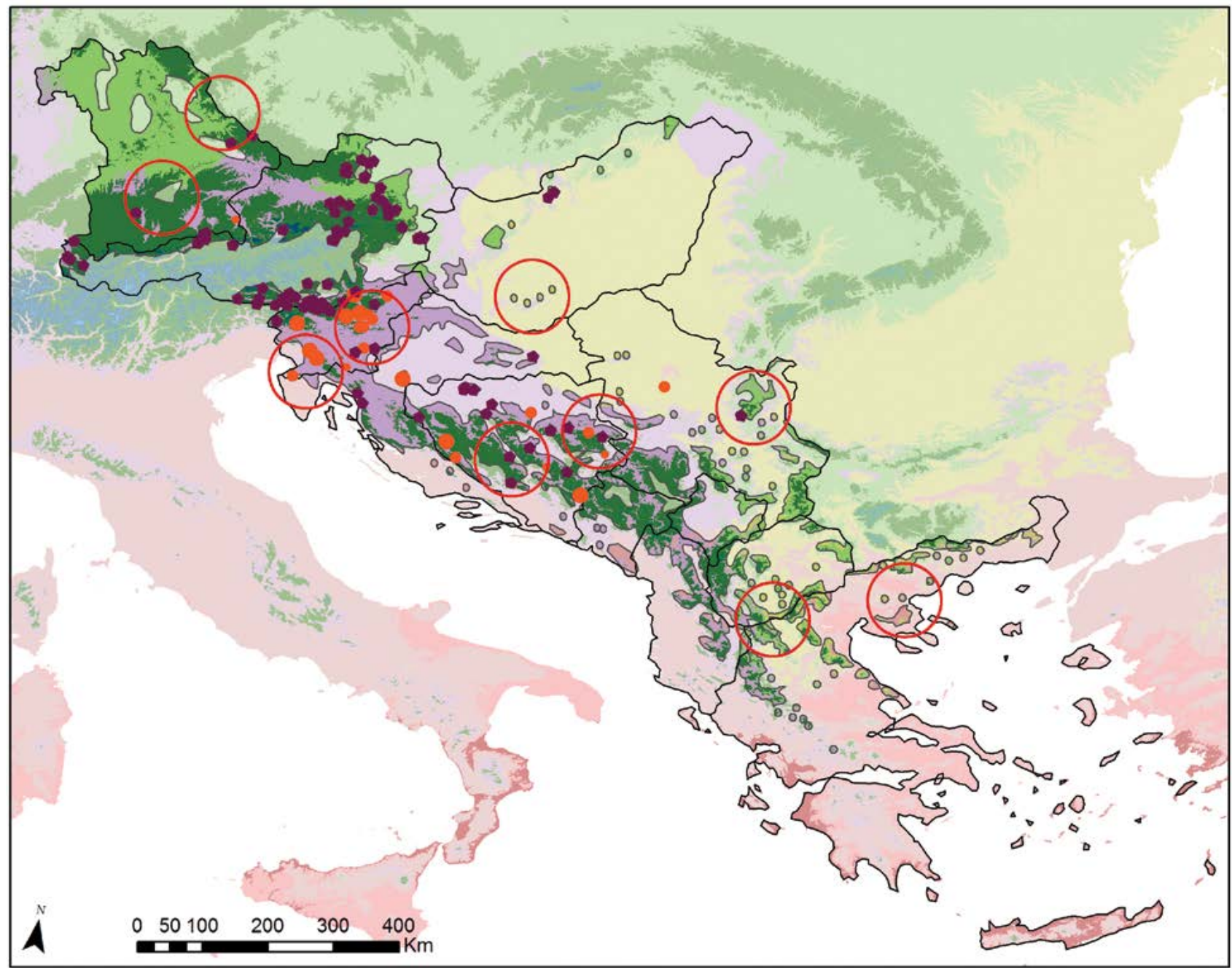

\section{Legend}

\section{Global Environmental Zone}
B. Arctic
C. Extremely cold and wet
D. Extremely cold and wet
E. Cold and wet
F. Extremely cold and mesic
G. Cold and mesic
H. Cool temperate and dry
J. Cool temperate and moist
I. Cool temperate and xeric
K. Warm temperate and mesic
L. Warm temperate and xeric
N. Hot and dry

Monitoring Region

\section{- EUFGIS GCU}

\section{He (isoenzymes)}

- $0.21-0.23$

- $0.23-0.25$

- $0.25-0.28$

This map was created within the LIFEGENMON project to show the forest genetic monitoring regions for the transect spanning from Bavaria to Greece. We acknowledge the data sources: Global Environmental Zones (Metzger et al. 2012, Global Ecol. Biogeogr); Species distribution range (www.euforgen.org); EUFGIS Dynamic Gene Conservation Units (EUFORGEN, the EUFGIS project and National Focal Points) and genetic data (published studies available from the LIFEGENMOM project by request). Although a part of the transect, Albania was excluded from monitoring regions delineation as no data was available for this country. 


\section{Monitoring regions for common ash (Fraxinus excelsior)}

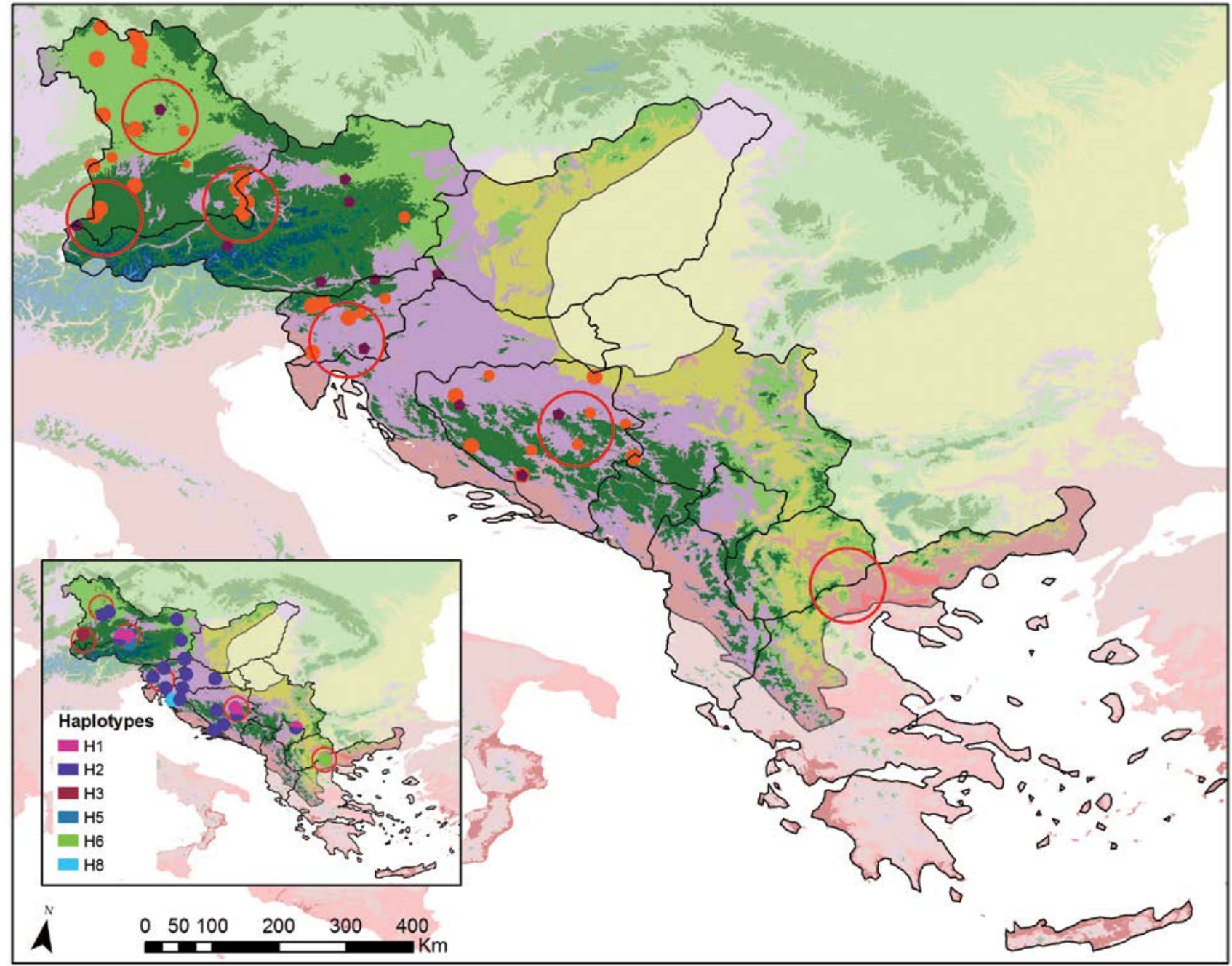

\section{Legend}

\section{Global Environmental Zone}

B. Arctic

C. Extremely cold and wet

D. Extremely cold and wet

E. Cold and wet

F. Extremely cold and mesic

G. Cold and mesic

H. Cool temperate and dry

J. Cool temperate and moist

I. Cool temperate and xeric

K. Warm temperate and mesic

L. Warm temperate and xeric

N. Hot and dry
Monitoring Region

- EUFGIS GCU

\section{He (isoenzymes)}

- $0.85-0.72$

$0.72-0.79$

$0.79-0.88$

This map was created within the LIFEGENMON project to show the forest genetic monitoring regions for the transect spanning from Bavaria to Greece. We acknowledge the data sources: Global Environmental Zones (Metzger et al. 2012, Global Ecol. Biogeogr); Species distribution range (www.euforgen.org); EUFGIS Dynamic Gene Conservation Units (EUFORGEN, the EUFGIS project and National Focal Points) and genetic data (published studies available from the LIFEGENMOM project by request). Although a part of the transect, Albania was excluded from monitoring regions delineation as no data was available for this country. 


\section{Monitoring regions for black pine (Pinus nigra)}

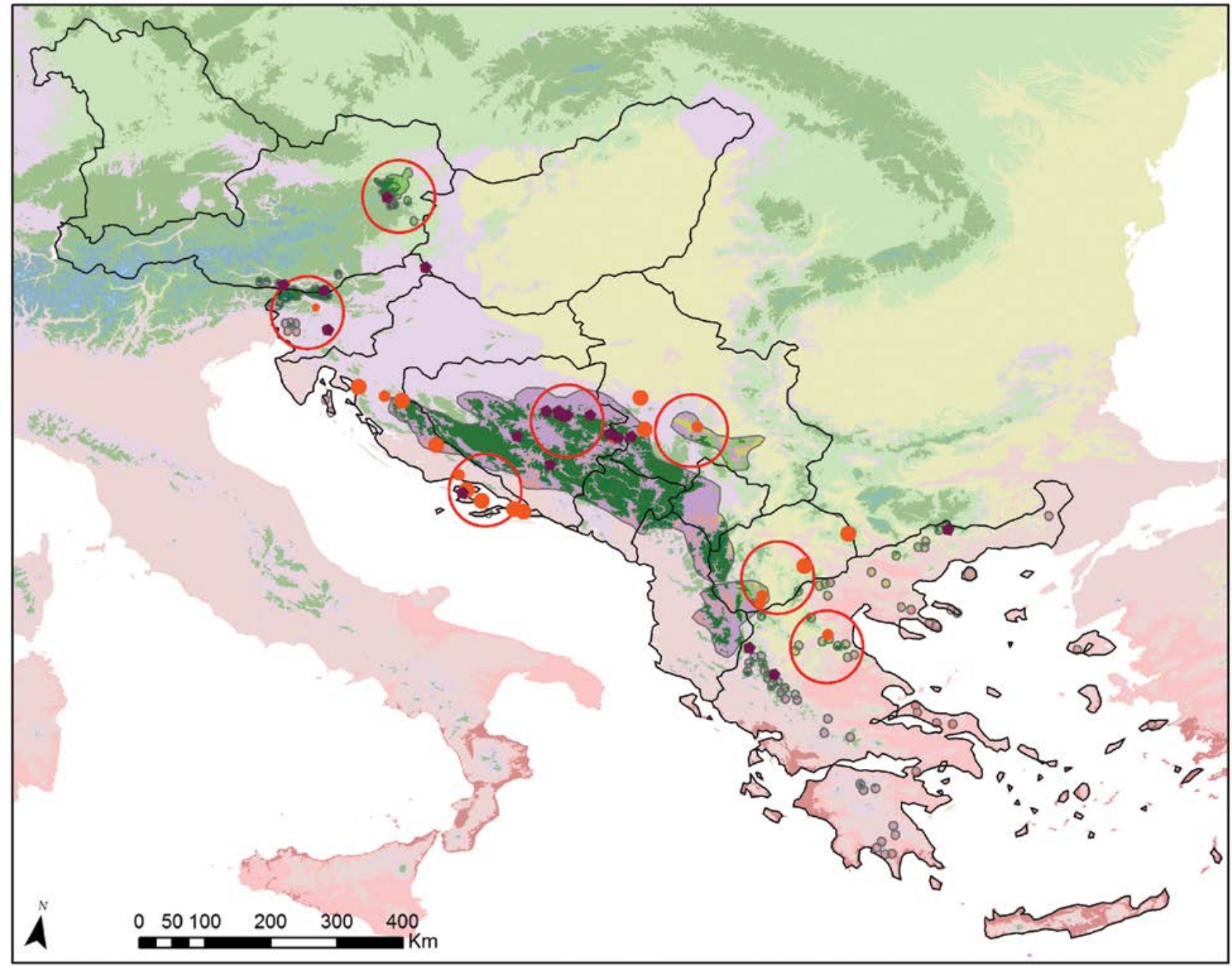

\section{Legend}

\section{Global Environmental Zone}

B. Arctic

C. Extremely cold and wet

D. Extremely cold and wet

E. Cold and wet

F. Extremely cold and mesic

G. Cold and mesic

$\mathrm{H}$. Cool temperate and dry

J. Cool temperate and moist

I. Cool temperate and xeric

K. Warm temperate and mesic

L. Warm temperate and xeric

N. Hot and dry
Monitoring Region

- EUFGIS GCU

\section{He (isoenzymes)}

- $0.00-0.12$

- $0.12-0.24$

$0.24-0.36$

This map was created within the LIFEGENMON project to show the forest genetic monitoring regions for the transect spanning from Bavaria to Greece. We acknowledge the data sources: Global Environmental Zones (Metzger et al. 2012, Global Ecol. Biogeogr); Species distribution range (www.euforgen.org); EUFGIS Dynamic Gene Conservation Units (EUFORGEN, the EUFGIS project and National Focal Points) and genetic data (published studies available from the LIFEGENMOM project by request). Although a part of the transect, Albania was excluded from monitoring regions delineation as no data was available for this country. 


\section{Monitoring regions for black poplar (Populus nigra)}

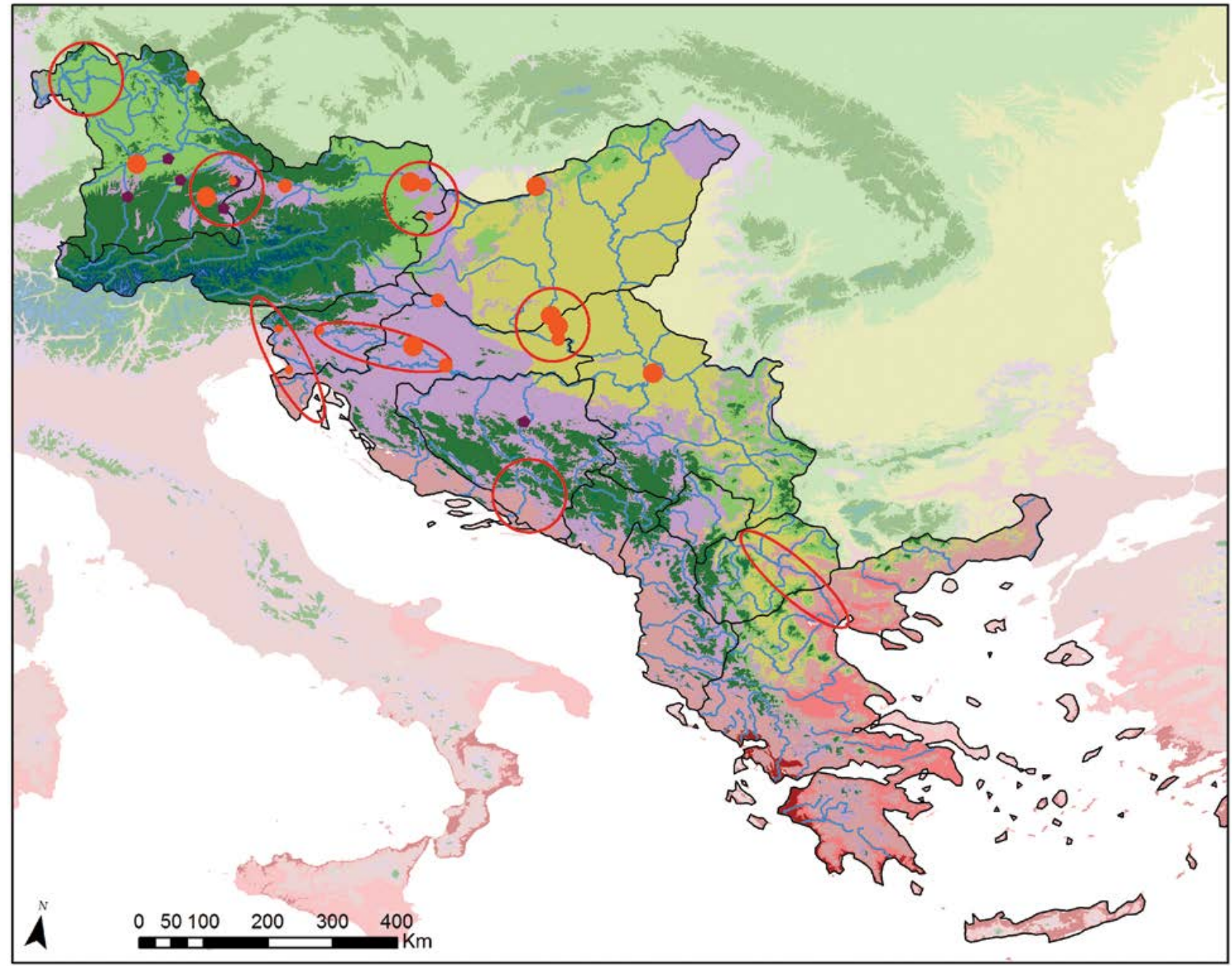

\section{Legend}

\section{Global Environmental Zone}
B. Arctic
C. Extremely cold and wet
D. Extremely cold and wet
E. Cold and wet
F. Extremely cold and mesic
G. Cold and mesic
H. Cool temperate and dry
J. Cool temperate and moist
I. Cool temperate and xeric
K. Warm temperate and mesic
L. Warm temperate and xeric
N. Hot and dry

Monitoring Region

- EUFGIS GCU

\section{He (isoenzymes)}

- $0.74-0.77$

- $0.77-0.80$

- $0.80-0.83$

This map was created within the LIFEGENMON project to show the forest genetic monitoring regions for the transect spanning from Bavaria to Greece. We acknowledge the data sources: Global Environmental Zones (Metzger et al. 2012, Global Ecol. Biogeogr); Species distribution range (www.euforgen.org); EUFGIS Dynamic Gene Conservation Units (EUFORGEN, the EUFGIS project and National Focal Points) and genetic data (published studies available from the LIFEGENMOM project by request). Although a part of the transect, Albania was excluded from monitoring regions delineation as no data was available for this country. 


\section{Monitoring regions for wild cherry (Prunus avium)}

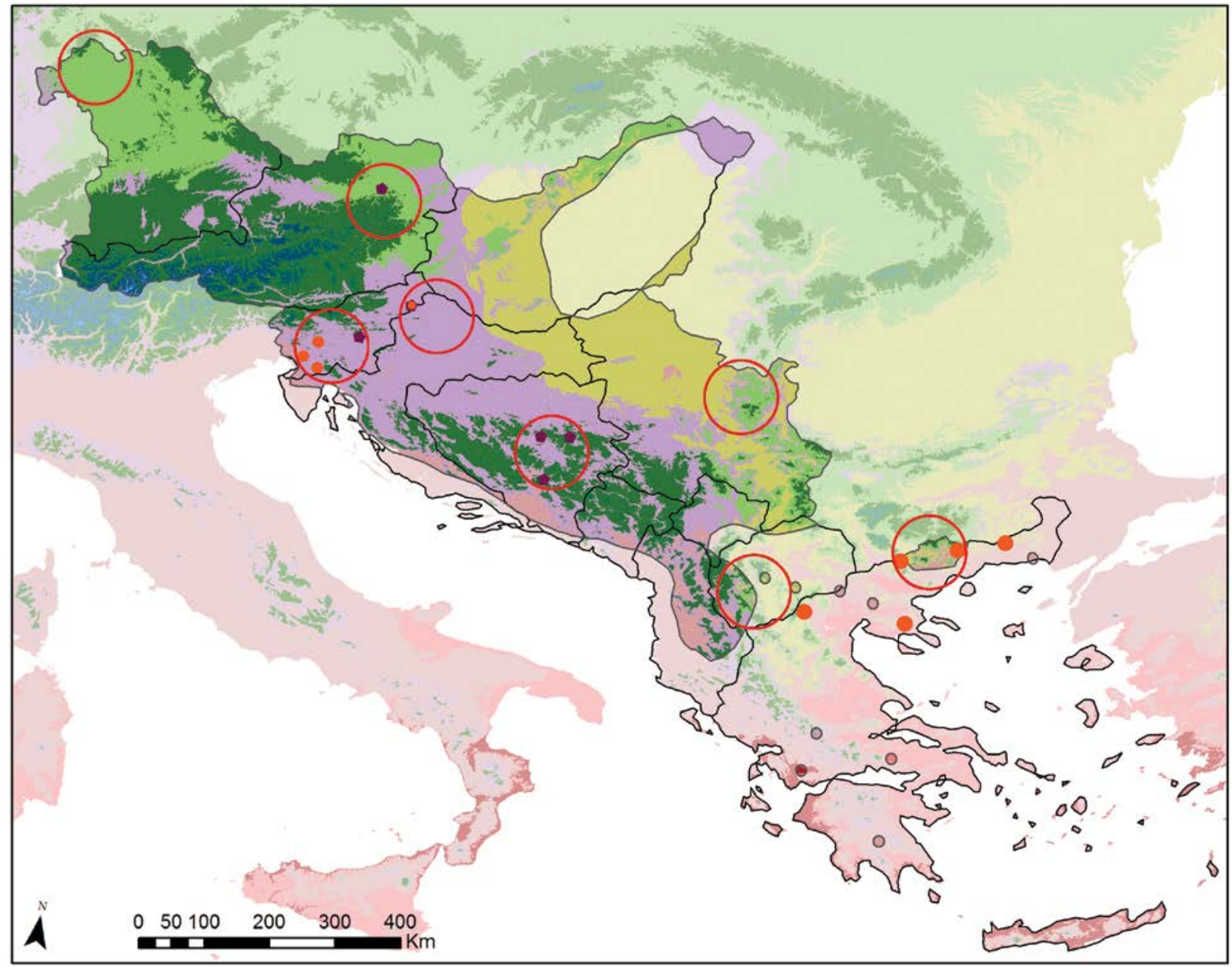

\section{Legend}

\section{Global Environmental Zone}
B. Arctic
C. Extremely cold and wet
D. Extremely cold and wet
E. Cold and wet
F. Extremely cold and mesic
G. Cold and mesic
H. Cool temperate and dry
J. Cool temperate and moist
I. Cool temperate and xeric
K. Warm temperate and mesic
L. Warm temperate and xeric
N. Hot and dry

\section{Monitoring Region}

- EUFGIS GCU

\section{He (isoenzymes)}

- $0.57-0.63$

- $0.63-0.70$

- $0.70-0.77$

This map was created within the LIFEGENMON project to show the forest genetic monitoring regions for the transect spanning from Bavaria to Greece. We acknowledge the data sources: Global Environmental Zones (Metzger et al. 2012, Global Ecol. Biogeogr); Species distribution range (www.euforgen.org); EUFGIS Dynamic Gene Conservation Units (EUFORGEN, the EUFGIS project and National Focal Points) and genetic data (published studies available from the LIFEGENMOM project by request). Although a part of the transect, Albania was excluded from monitoring regions delineation as no data was available for this country. 


\section{Monitoring regions for oaks (Quercus robur, Quercus petraea)}

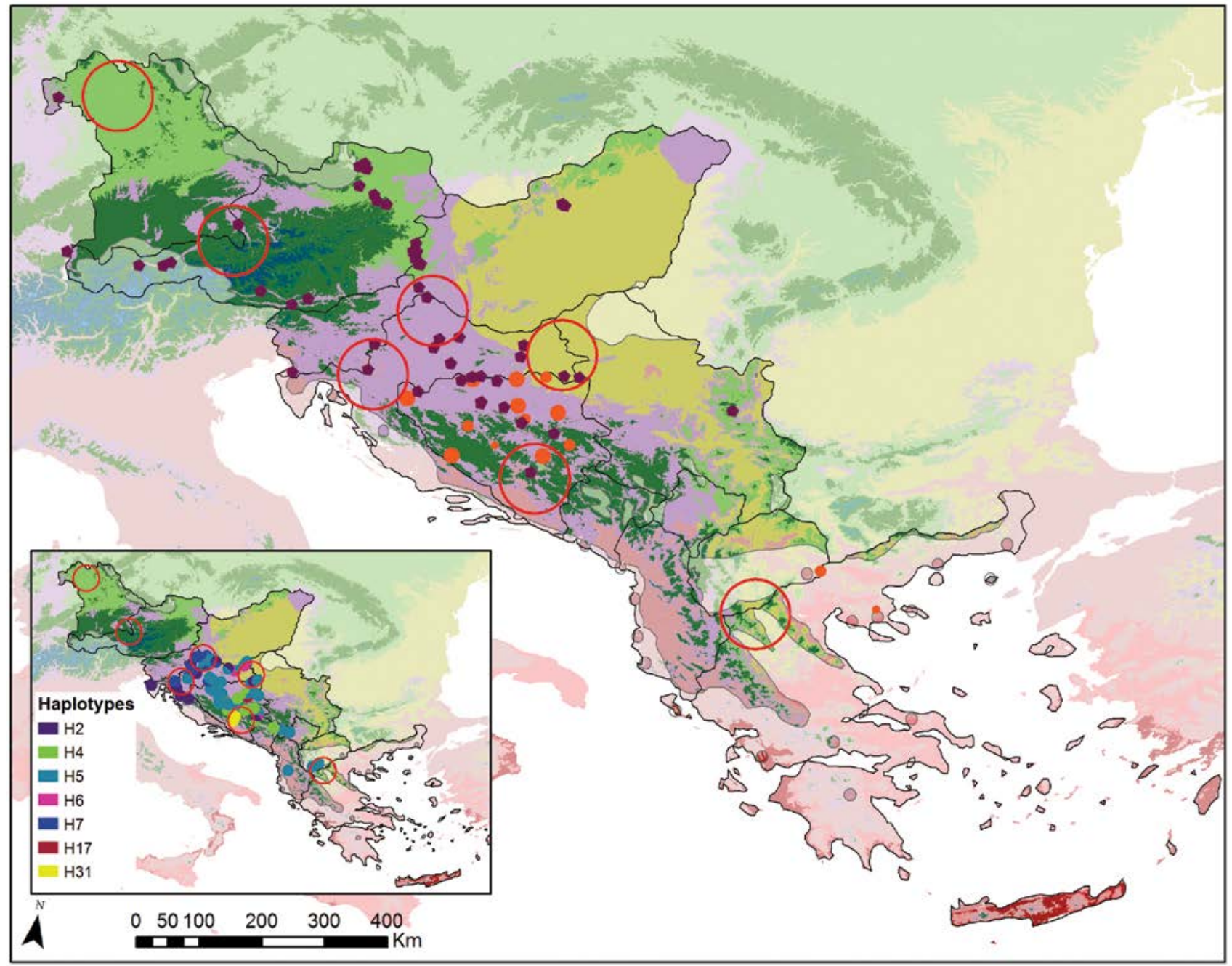

\section{Legend}

\section{Global Environmental Zone}
B. Arctic
C. Extremely cold and wet
D. Extremely cold and wet
E. Cold and wet
F. Extremely cold and mesic
G. Cold and mesic
H. Cool temperate and dry
J. Cool temperate and moist
I. Cool temperate and xeric
K. Warm temperate and mesic
L. Warm temperate and xeric
N. Hot and dry

\section{Monitoring Region}

\section{EUFGIS GCU}

\section{He (isoenzymes)}

- $0.78-0.82$

$0.82-0.85$

$0.85-0.89$

This map was created within the LIFEGENMON project to show the forest genetic monitoring regions for the transect spanning from Bavaria to Greece. We acknowledge the data sources: Global Environmental Zones (Metzger et al. 2012, Global Ecol. Biogeogr); Species distribution range (www.euforgen.org); EUFGIS Dynamic Gene Conservation Units (EUFORGEN, the EUFGIS project and National Focal Points) and genetic data (published studies available from the LIFEGENMOM project by request). Although a part of the transect, Albania was excluded from monitoring regions delineation as no data was available for this country. 


\section{Additional data contributors}

Vlatko ANDONOVSKI ${ }^{1}$, Evangelia V. AVRAMIDOU ${ }^{2,3}$, Roland BAIER ${ }^{4}$, Sandor BORDAC ${ }^{5}$, Andrej BREZNIKAR ${ }^{6}$, loannis V. GANOPOULOS ${ }^{2}$, Mladen IVANKOVIĆ 7 , Davorin KAJBA ${ }^{8}$, Heino KONRAD ${ }^{9}$, Ermioni MALLIAROU², Saša ORLOVIĆ10, Srđan STOJNIĆ10

\footnotetext{
Affiliations:

1. Faculty of Forestry, Ss. Cyril and Methodius University in Skopje, North Macedonia

2. Aristotle University of Thessaloniki (AUTh), Greece

3. Institute of Mediterranean Forest Ecosystems, DEMETER, Greece

4. Bavarian Office for Forest Genetics (AWG), Germany

5. Szent István University, Budapest, Hungary

6. Slovenia Forest Service (ZGS), Slovenia

7. Croatian Forest Research Institute, Jastrebarsko, Croatia

8. Faculty of Forestry, University of Zagreb, Croatia

9. Federal Research and Training Centre for Forests, Natural Hazards and Landscape (BFW), Austria

10. Institute of Lowland Forestry and Environment (ILFE), Novi Sad, Serbia
} 
10.2 Field observation forms

10.2.1 Plot description form

10.2.2 Form for recording field verifiers

10.2.3 Form for recording field background information 


\subsubsection{Plot description form}

\section{FGM PLOT DESCRIPTION FORM}

\section{PLOT DESCRIPTION DATA}

Monitored tree species

Plot size

ha

\section{Exact position *}

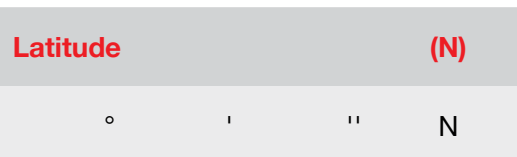

Stand age (range, from - to)

yrs

Altitude

(m, a.s.l.)

\begin{tabular}{l} 
Ownership \\
\hline $\begin{array}{l}\text { Information about owner (restricted information: the parcel } \\
\text { numbers, cadastral number, etc.) }\end{array}$ \\
\hline State Forest Office / District \\
\hline Forest division \\
\hline Forest compartment \\
\hline Forest sub-compartment \\
\hline FGM plot code
\end{tabular}

\begin{tabular}{l} 
Monitored tree species and its \\
proportion in the stand \\
\hline $\begin{array}{l}\text { Non-target species and its proportion } \\
\text { in the stand }\end{array}$ \\
\hline $\begin{array}{l}\text { Non-target species and its proportion } \\
\text { in the stand }\end{array}$ \\
\hline $\begin{array}{l}\text { Non-target species and its proportion } \\
\text { in the stand }\end{array}$
\end{tabular}

Species Latin name

Regional classification into growth areas (growth districts)

\section{Bedrock}

Phytocoenological association (according to Braun-Blanquet)

Soil type (according to FAO, 1971-1981) **

\section{Soil humidity (dry/mesic/wet)}

Proportion, \% 
Nutrient supply (rich/medium/poor)

Regional forest site classification

Climograph

Mean annual temperature $\left(C^{\circ}\right)$

Mean annual temperature during vegetation period $\left(C^{\circ}\right)$

Mean temperature of the warmest month (July) $\left(\mathrm{C}^{\circ}\right)$

Mean precipitation during vegetation period $(\mathrm{mm})$

Ellenberg's climate quotient (EQ)

FOREST MANAGEMENT OBJECTIVES:

1. Wood production

2. Habitat-focused

3. Recreation/aesthetics-focused

4. Multiple use focused

5. Other - specify

SILVICULTURAL SYSTEM:

1. Shelter wood

2. Coppice

3. Continuous cover

4. Selective logging

5. Other - specify

DESIGNATED STATUS:

1. Forest reserve

2. Gene conservation area

3. Protected area

4. Other - specify

If taken out of management, since when

* Exact position is confidential information for LIFEGENMON project use only

** FAO/UNESCO $(1971$ - 1981) the FAO-UNESCO Soil Map of the World. 


\section{Forest health condition}

Describe causes of poor or medium health in remarks

\begin{tabular}{|l|l|l|}
\hline Good & Medium & Poor \\
\hline & & \\
\hline
\end{tabular}

\section{Source}

\begin{tabular}{|c|c|c|}
\hline $\begin{array}{c}\text { Autochth- } \\
\text { onous }\end{array}$ & $\begin{array}{c}\text { Non-Auto- } \\
\text { chthonous }\end{array}$ & Unknown \\
\hline & & \\
\hline
\end{tabular}

\section{Isolation}

Isolated from the nearest stand of the same species by a min. of $400 \mathrm{~m}$

\begin{tabular}{|l|l|l|}
\hline & Yes & No \\
\hline Isolated & & \\
\hline
\end{tabular}

\section{Horizontal structure of stand}

Openness and spacing of canopy

\begin{tabular}{|c|c|c|}
\hline Even & $\begin{array}{c}\text { Even with } \\
\text { openings }\end{array}$ & $\begin{array}{c}\text { Uneven } \\
\text { with } \\
\text { openings }\end{array}$ \\
\hline & & \\
\hline
\end{tabular}

Slope exposition

\begin{tabular}{|c|c|c|c|}
\hline N & NE & E & SE \\
\hline & & & \\
\hline S & SW & W & NW \\
\hline & & & \\
\hline
\end{tabular}

\section{Crown form}

\begin{tabular}{|l|l|l|}
\hline Good & Medium & Poor \\
\hline & & \\
\hline
\end{tabular}

Forest management

\begin{tabular}{|c|c|c|}
\hline & Yes & No \\
\hline Managed & & \\
\hline
\end{tabular}

Natural regeneration

\begin{tabular}{|l|l|l|}
\hline Rare & Modest & Frequent \\
\hline & & \\
\hline
\end{tabular}

\section{Fragmentation}

Species scattered within FGM plot (some grouping is visible)

\begin{tabular}{|c|c|c|}
\hline & Yes & No \\
\hline Fragmented & & \\
\hline
\end{tabular}

\section{Distance between trees /} groups of trees

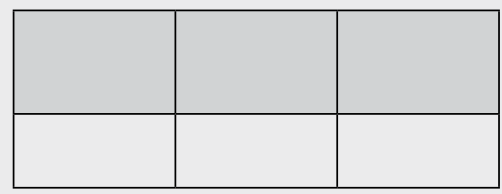

Slope

\begin{tabular}{|l|l|l|}
\hline$<5 \%$ & $5-15 \%$ & $15-40 \%$ \\
\hline & & \\
& & \\
\hline
\end{tabular}

Quality of tree stems in general

Top straightness, forking, etc.

\begin{tabular}{|l|l|l|}
\hline Good & Medium & Poor \\
\hline & & \\
\hline
\end{tabular}

Stand history (origin)

If planted, provide the origin of FRM (if known)

\begin{tabular}{|c|c|}
\hline $\begin{array}{c}\text { Naturally } \\
\text { regenerated }\end{array}$ & Planted \\
\hline & \\
\hline
\end{tabular}

\section{Structure of natural regeneration}

\begin{tabular}{|c|c|}
\hline In Groups & $\begin{array}{c}\text { Evenly } \\
\text { distributed }\end{array}$ \\
\hline & \\
\hline
\end{tabular}

Vertical structure of stands

\begin{tabular}{|c|c|c|}
\hline $\begin{array}{c}\text { Single } \\
\text { Canopy }\end{array}$ & $\begin{array}{c}\text { Two } \\
\text { storied }\end{array}$ & $\begin{array}{c}\text { Multi } \\
\text { layered }\end{array}$ \\
\hline & & \\
& & \\
\hline
\end{tabular}

\section{Genetic data}

\begin{tabular}{|l|l|l|}
\hline & Yes & No \\
\hline Available & & \\
\hline
\end{tabular}

Past records of flowering, fructification (mast years) and seed collection

\begin{tabular}{|l|l|l|}
\hline & Year & $\begin{array}{c}\text { Amount of } \\
\text { seed }\end{array}$ \\
\hline Flowering & & \\
\hline $\begin{array}{l}\text { Fructifica- } \\
\text { tion }\end{array}$ & & \\
\hline $\begin{array}{l}\text { Seed } \\
\text { collection }\end{array}$ & & \\
\hline
\end{tabular}

\section{Accessibility}

Accessibility for seed collection/climbing

\begin{tabular}{|l|l|l|}
\hline Good & Medium & Poor \\
\hline & & \\
\hline
\end{tabular}


Remarks:

Date: Name / Surname / Signature: 
10.2.2 Form for recording field verifiers

\begin{tabular}{|l|l|l|}
\hline Plot: & Signature: \\
\hline Tree species: & \\
\hline Date: & \\
\hline Evaluator: & \\
\hline
\end{tabular}

\section{Verifier: Mortality}

\section{Basic, Standard, Advanced levels}

Please mark with an $x$.

\begin{tabular}{|l|l|l|l|l|l|l|l|l|l|l|l|l|l|}
\hline $\begin{array}{c}\text { Tree } \\
\text { No. }\end{array}$ & Alive & Dead & $\begin{array}{c}\text { Tree } \\
\text { No. }\end{array}$ & Alive & Dead & $\begin{array}{c}\text { Tree } \\
\text { No. }\end{array}$ & Alive & Dead & $\begin{array}{c}\text { Tree } \\
\text { No. }\end{array}$ & Alive & Dead & $\begin{array}{l}\text { Tree } \\
\text { No. }\end{array}$ & Alive \\
\hline 1
\end{tabular}

Notes: 


\begin{tabular}{|l|l|l|}
\hline Plot: & Signature: \\
\hline Tree species: & & \\
\hline Date: & & \\
\hline Evaluator: & & \\
\hline
\end{tabular}

\section{Verifier: Flowering}

\section{Basic level}

Please circle the relevant code.

\begin{tabular}{|c|c|}
\hline \multicolumn{3}{|c|}{ Flowering intensity of the stand } \\
\hline Code & $\begin{array}{c}\text { Percentage of crown } \\
\text { with flowers on an average tree }\end{array}$ \\
\hline 1 & $0-10$ \\
\hline 2 & $>10-30$ \\
\hline 3 & $>30-60$ \\
\hline 4 & $>60-90$ \\
\hline 5 & $>90$ \\
\hline
\end{tabular}

\begin{tabular}{|c|c|}
\hline \multicolumn{2}{|c|}{$\begin{array}{c}\text { Proportion of trees in the stand } \\
\text { with the given flowering intensity stage (\%) }\end{array}$} \\
\hline Code & \% of trees \\
\hline 1 & $0-10$ \\
\hline 2 & $>10-30$ \\
\hline 3 & $>30-60$ \\
\hline 4 & $>60-90$ \\
\hline 5 & $>90$ \\
\hline
\end{tabular}

\section{Standard level}

Please fill in the code. Consult guidelines for the code values.

Proportion of the crown flowering per tree

\begin{tabular}{|c|c|c|c|c|c|c|c|c|c|}
\hline $\begin{array}{l}\text { Tree } \\
\text { No. }\end{array}$ & Code & $\begin{array}{l}\text { Tree } \\
\text { No. }\end{array}$ & Code & $\begin{array}{l}\text { Tree } \\
\text { No. }\end{array}$ & Code & \begin{tabular}{|l} 
Tree \\
No.
\end{tabular} & Code & $\begin{array}{l}\text { Tree } \\
\text { No. }\end{array}$ & Code \\
\hline 1 & & 11 & & 21 & & 31 & & 41 & \\
\hline 2 & & 12 & & 22 & & 32 & & 42 & \\
\hline 3 & & 13 & & 23 & & 33 & & 43 & \\
\hline 4 & & 14 & & 24 & & 34 & & 44 & \\
\hline 5 & & 15 & & 25 & & 35 & & 45 & \\
\hline 6 & & 16 & & 26 & & 36 & & 46 & \\
\hline 7 & & 17 & & 27 & & 37 & & 47 & \\
\hline 8 & & 18 & & 28 & & 38 & & 48 & \\
\hline 9 & & 19 & & 29 & & 39 & & 49 & \\
\hline 10 & & 20 & & 30 & & 40 & & 50 & \\
\hline
\end{tabular}


Plot:

Tree species:

Date:

Evaluator:

\section{Advanced level}

Please fill in the code. Consult guidelines for the code values.

Female and male flowering stage, and proportion of the crown flowering (male and female flowering together) per tree

\begin{tabular}{|c|c|c|c|c|c|c|c|}
\hline $\begin{array}{l}\text { Tree } \\
\text { No. }\end{array}$ & $\begin{array}{c}\text { Female } \\
\text { flowering code }\end{array}$ & $\begin{array}{c}\text { Male } \\
\text { flowering code }\end{array}$ & $\begin{array}{l}\% \text { of crown } \\
\text { flowering code }\end{array}$ & $\begin{array}{l}\text { Tree } \\
\text { No. }\end{array}$ & $\begin{array}{c}\text { Female } \\
\text { flowering code }\end{array}$ & $\begin{array}{c}\text { Male } \\
\text { flowering code }\end{array}$ & $\begin{array}{l}\% \text { of crown } \\
\text { flowering code }\end{array}$ \\
\hline 1 & & & & 26 & & & \\
\hline 2 & & & & 27 & & & \\
\hline 3 & & & & 28 & & & \\
\hline 4 & & & & 29 & & & \\
\hline 5 & & & & 30 & & & \\
\hline 6 & & & & 31 & & & \\
\hline 7 & & & & 32 & & & \\
\hline 8 & & & & 33 & & & \\
\hline 9 & & & & 34 & & & \\
\hline 10 & & & & 35 & & & \\
\hline 11 & & & & 36 & & & \\
\hline 12 & & & & 37 & & & \\
\hline 13 & & & & 38 & & & \\
\hline 14 & & & & 39 & & & \\
\hline 15 & & & & 40 & & & \\
\hline 16 & & & & 41 & & & \\
\hline 17 & & & & 42 & & & \\
\hline 18 & & & & 43 & & & \\
\hline 19 & & & & 44 & & & \\
\hline 20 & & & & 45 & & & \\
\hline 21 & & & & 46 & & & \\
\hline 22 & & & & 47 & & & \\
\hline 23 & & & & 48 & & & \\
\hline 24 & & & & 49 & & & \\
\hline 25 & & & & 50 & & & \\
\hline
\end{tabular}

Signature:

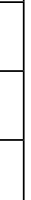




\begin{tabular}{|l|l|l|}
\hline Plot: & Signature: \\
\hline Tree species: & & \\
\hline Date: & & \\
\hline Evaluator: & & \\
\hline
\end{tabular}

\section{Verifier: Fructification}

\section{Basic level}

Please circle the relevant code.

\begin{tabular}{|c|r|}
\hline \multicolumn{2}{|c|}{ Fructification intensity of the stand } \\
\hline Code & Average \% of crowns flowering \\
\hline 1 & $0-10$ \\
\hline 2 & $>10-30$ \\
\hline 3 & $>30-60$ \\
\hline 4 & $>60-90$ \\
\hline 5 & $>90$ \\
\hline
\end{tabular}

\begin{tabular}{|c|c|}
\hline \multicolumn{2}{|c|}{$\begin{array}{c}\text { Proportion of trees in the stand with the given } \\
\text { fructification intensity stage (\%) }\end{array}$} \\
\hline Code & \% of trees \\
\hline 1 & $0-10$ \\
\hline 2 & $>10-30$ \\
\hline 3 & $>30-60$ \\
\hline 4 & $>60-90$ \\
\hline 5 & $>90$ \\
\hline
\end{tabular}

\section{Standard level}

Please fill in the code. Consult guidelines for the code values.

Fructification intensity per tree

\begin{tabular}{|c|c|c|c|c|c|c|c|c|c|}
\hline $\begin{array}{l}\text { Tree } \\
\text { No. }\end{array}$ & Code & $\begin{array}{l}\text { Tree } \\
\text { No. }\end{array}$ & Code & $\begin{array}{l}\text { Tree } \\
\text { No. }\end{array}$ & Code & $\begin{array}{l}\text { Tree } \\
\text { No. }\end{array}$ & Code & $\begin{array}{l}\text { Tree } \\
\text { No. }\end{array}$ & Code \\
\hline 1 & & 11 & & 21 & & 31 & & 41 & \\
\hline 2 & & 12 & & 22 & & 32 & & 42 & \\
\hline 3 & & 13 & & 23 & & 33 & & 43 & \\
\hline 4 & & 14 & & 24 & & 34 & & 44 & \\
\hline 5 & & 15 & & 25 & & 35 & & 45 & \\
\hline 6 & & 16 & & 26 & & 36 & & 46 & \\
\hline 7 & & 17 & & 27 & & 37 & & 47 & \\
\hline 8 & & 18 & & 28 & & 38 & & 48 & \\
\hline 9 & & 19 & & 29 & & 39 & & 49 & \\
\hline 10 & & 20 & & 30 & & 40 & & 50 & \\
\hline
\end{tabular}


Plot:

Tree species:

Date:

Evaluator:

\section{Advanced level}

Please fill in the code. Consult guidelines for the code values.

Fructification abundance at a given part of crown

\begin{tabular}{|c|c|c|c|c|c|c|c|}
\hline $\begin{array}{l}\text { Tree } \\
\text { No. }\end{array}$ & $\begin{array}{c}\text { Female } \\
\text { flowering code }\end{array}$ & $\begin{array}{c}\text { Male } \\
\text { flowering code }\end{array}$ & $\begin{array}{l}\% \text { of crown } \\
\text { flowering code }\end{array}$ & $\begin{array}{l}\text { Tree } \\
\text { No. }\end{array}$ & $\begin{array}{l}\text { Female } \\
\text { flowering code }\end{array}$ & $\begin{array}{c}\text { Male } \\
\text { flowering code }\end{array}$ & $\begin{array}{l}\% \text { of crown } \\
\text { flowering code }\end{array}$ \\
\hline 1 & & & & 26 & & & \\
\hline 2 & & & & 27 & & & \\
\hline 3 & & & & 28 & & & \\
\hline 4 & & & & 29 & & & \\
\hline 5 & & & & 30 & & & \\
\hline 6 & & & & 31 & & & \\
\hline 7 & & & & 32 & & & \\
\hline 8 & & & & 33 & & & \\
\hline 9 & & & & 34 & & & \\
\hline 10 & & & & 35 & & & \\
\hline 11 & & & & 36 & & & \\
\hline 12 & & & & 37 & & & \\
\hline 13 & & & & 38 & & & \\
\hline 14 & & & & 39 & & & \\
\hline 15 & & & & 40 & & & \\
\hline 16 & & & & 41 & & & \\
\hline 17 & & & & 42 & & & \\
\hline 18 & & & & 43 & & & \\
\hline 19 & & & & 44 & & & \\
\hline 20 & & & & 45 & & & \\
\hline 21 & & & & 46 & & & \\
\hline 22 & & & & 47 & & & \\
\hline 23 & & & & 48 & & & \\
\hline 24 & & & & 49 & & & \\
\hline 25 & & & & 50 & & & \\
\hline
\end{tabular}

Signature:

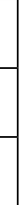




\begin{tabular}{|l|l|l|}
\hline Plot: & Signature: \\
\hline Tree species: & & \\
\hline Date: & & \\
\hline Evaluator: & & \\
\hline
\end{tabular}

\section{Verifier: Natural regeneration abundance}

\section{Basic level}

Please circle the relevant code.

\begin{tabular}{|c|c|}
\hline Code & Description: new regeneration (current-year seedlings) \\
\hline $1 a$ & There is no or very little new natural regeneration on the monitoring plot \\
\hline $2 a$ & New regeneration is present in sufficient numbers on the monitoring plot \\
\hline
\end{tabular}

\begin{tabular}{|c|c|}
\hline Code & Description: established natural regeneration (saplings) \\
\hline $1 \mathrm{~b}$ & There is no or very little established natural regeneration on the monitoring plot \\
\hline $2 \mathrm{~b}$ & Established regeneration is present in sufficient quantity on the monitoring plot \\
\hline
\end{tabular}

\section{Standard level}

Please fill in the number after counting

Age of seedlings:

\begin{tabular}{|c|c|c|c|}
\hline $\begin{array}{c}\text { Subplot } \\
\text { No. }\end{array}$ & No. of seedlings & $\begin{array}{c}\text { Subplot } \\
\text { No. }\end{array}$ & No. of seedlings \\
\hline 1 & & 11 & \\
\hline 2 & & 12 & \\
\hline 3 & & 13 & \\
\hline 4 & & 14 & \\
\hline 5 & & 15 & \\
\hline 6 & & 16 & \\
\hline 7 & & 17 & \\
\hline 8 & & 18 & \\
\hline 9 & & 19 & \\
\hline 10 & & 20 & \\
\hline
\end{tabular}

Age of seedlings:

\begin{tabular}{|c|l|c|l|}
\hline $\begin{array}{c}\text { Subplot } \\
\text { No. }\end{array}$ & No. of seedlings & $\begin{array}{c}\text { Subplot } \\
\text { No. }\end{array}$ & No. of seedlings \\
\hline 1 & & 11 & \\
\hline 2 & & 12 & \\
\hline 3 & & 13 & \\
\hline 4 & & 14 & \\
\hline 5 & & 15 & \\
\hline 6 & & 16 & \\
\hline 7 & & 17 & \\
\hline 8 & & 18 & \\
\hline 9 & & 19 & \\
\hline 10 & & 20 & \\
\hline
\end{tabular}




\begin{tabular}{|l|l|l|}
\hline Plot: & Signature: \\
\hline Tree species: & & \\
\hline Date: & & \\
\hline Evaluator: & & \\
\hline
\end{tabular}

\section{Advanced level}

Please fill in the number after counting.

Age of seedlings:

\begin{tabular}{|c|c|c|c|}
\hline $\begin{array}{c}\text { Subplot } \\
\text { No. }\end{array}$ & No. of seedlings & $\begin{array}{c}\text { Subplot } \\
\text { No. }\end{array}$ & No. of seedlings \\
\hline 1 & & 11 & \\
\hline 2 & & 12 & \\
\hline 3 & & 13 & \\
\hline 4 & & 14 & \\
\hline 5 & & 15 & \\
\hline 6 & & 16 & \\
\hline 7 & & 17 & \\
\hline 8 & & 18 & \\
\hline 9 & & 19 & \\
\hline 10 & & 20 & \\
\hline
\end{tabular}

Age of seedlings:

\begin{tabular}{|c|c|c|c|}
\hline $\begin{array}{c}\text { Subplot } \\
\text { No. }\end{array}$ & No. of seedlings & $\begin{array}{c}\text { Subplot } \\
\text { No. }\end{array}$ & No. of seedlings \\
\hline 1 & & 11 & \\
\hline 2 & & 12 & \\
\hline 3 & & 13 & \\
\hline 4 & & 14 & \\
\hline 5 & & 15 & \\
\hline 6 & & 16 & \\
\hline 7 & & 17 & \\
\hline 8 & & 18 & \\
\hline 9 & & 19 & \\
\hline 10 & & 20 & \\
\hline
\end{tabular}

Age of seedlings:

\begin{tabular}{|c|c|c|c|}
\hline $\begin{array}{c}\text { Subplot } \\
\text { No. }\end{array}$ & No. of seedlings & $\begin{array}{c}\text { Subplot } \\
\text { No. }\end{array}$ & No. of seedlings \\
\hline 1 & & 11 & \\
\hline 2 & & 12 & \\
\hline 3 & & 13 & \\
\hline 4 & & 14 & \\
\hline 5 & & 15 & \\
\hline 6 & & 16 & \\
\hline 7 & & 17 & \\
\hline 8 & & 18 & \\
\hline 9 & & 19 & \\
\hline 10 & & 20 & \\
\hline
\end{tabular}


10.2.3 Form for recording field background information

\begin{tabular}{|l|l|l|}
\hline Plot: & Signature: \\
\hline Tree species: & \\
\hline Date: & & \\
\hline Evaluator: & & \\
\hline
\end{tabular}

Background information: DBH class distribution

Standard, Advanced levels

Please fill in the number after measuring.

\begin{tabular}{|c|c|c|c|c|c|c|c|c|c|}
\hline Tree No. & DBH $[\mathrm{cm}]$ & Tree No. & DBH $[\mathrm{cm}]$ & Tree No. & DBH $[\mathrm{cm}]$ & Tree No. & DBH $[\mathrm{cm}]$ & Tree No. & DBH [cm] \\
\hline 1 & & 11 & & 21 & & 31 & & 41 & \\
\hline 2 & & 12 & & 22 & & 32 & & 42 & \\
\hline 3 & & 13 & & 23 & & 33 & & 43 & \\
\hline 4 & & 14 & & 24 & & 34 & & 44 & \\
\hline 5 & & 15 & & 25 & & 35 & & 45 & \\
\hline 6 & & 16 & & 26 & & 36 & & 46 & \\
\hline 7 & & 17 & & 27 & & 37 & & 47 & \\
\hline 8 & & 18 & & 28 & & 38 & & 48 & \\
\hline 9 & & 19 & & 29 & & 39 & & 49 & \\
\hline 10 & & 20 & & 30 & & 40 & & 50 & \\
\hline
\end{tabular}

Background information: Height class distribution

Standard, Advanced levels

Please fill in the number after measuring.

\begin{tabular}{|c|c|c|c|c|c|c|c|c|c|}
\hline Tree No. & Height $[\mathrm{m}]$ & Tree No. & Height $[\mathrm{m}]$ & Tree No. & Height $[\mathrm{m}]$ & Tree No. & Height $[\mathrm{m}]$ & Tree No. & Height $[\mathrm{m}]$ \\
\hline 1 & & 11 & & 21 & & 31 & & 41 & \\
\hline 2 & & 12 & & 22 & & 32 & & 42 & \\
\hline 3 & & 13 & & 23 & & 33 & & 43 & \\
\hline 4 & & 14 & & 24 & & 34 & & 44 & \\
\hline 5 & & 15 & & 25 & & 35 & & 45 & \\
\hline 6 & & 16 & & 26 & & 36 & & 46 & \\
\hline 7 & & 17 & & 27 & & 37 & & 47 & \\
\hline 8 & & 18 & & 28 & & 38 & & 48 & \\
\hline 9 & & 19 & & 29 & & 39 & & 49 & \\
\hline 10 & & 20 & & 30 & & 40 & & 50 & \\
\hline
\end{tabular}




\begin{tabular}{|l|l|l|}
\hline Plot: & Signature: \\
\hline Tree species: & \\
\hline Date: & & \\
\hline Evaluator: & \\
\hline
\end{tabular}

\section{Background information: Bud break}

\section{Standard, Advanced levels}

Please fill in the code. Consult guidelines for the code values.

\begin{tabular}{|c|c|c|c|c|c|c|c|c|c|c|c|c|c|c|}
\hline $\begin{array}{c}\text { Tree } \\
\text { No. }\end{array}$ & Stage & $\begin{array}{c}\text { \% of } \\
\text { crown }\end{array}$ & $\begin{array}{c}\text { Tree } \\
\text { No. }\end{array}$ & Stage & $\begin{array}{c}\text { \% of } \\
\text { crown }\end{array}$ & $\begin{array}{c}\text { Tree } \\
\text { No. }\end{array}$ & Stage & $\begin{array}{c}\text { \% of } \\
\text { crown }\end{array}$ & $\begin{array}{c}\text { Tree } \\
\text { No. }\end{array}$ & Stage & $\begin{array}{c}\% \text { of } \\
\text { crown }\end{array}$ & $\begin{array}{c}\text { Tree } \\
\text { No. }\end{array}$ & Stage & $\begin{array}{c}\% \text { of } \\
\text { crown }\end{array}$ \\
\hline 1 & & & 11 & & & 21 & & & 31 & & & 41 & & \\
\hline 2 & & & 12 & & & 22 & & & 32 & & & 42 & & \\
\hline 3 & & & 13 & & & 23 & & & 33 & & & 43 & & \\
\hline 4 & & & 14 & & & 24 & & & 34 & & & 44 & & \\
\hline 5 & & & 15 & & & 25 & & & 35 & & & 45 & & \\
\hline 6 & & & 16 & & & 26 & & & 36 & & & 46 & & \\
\hline 7 & & & 17 & & & 27 & & & 37 & & & 47 & & \\
\hline 8 & & & 18 & & & 28 & & & 38 & & & 48 & & \\
\hline 9 & & & 19 & & & 29 & & & 39 & & & 49 & & \\
\hline 10 & & & 20 & & & 30 & & & 40 & & & 50 & & \\
\hline
\end{tabular}

\section{Background information: Senescence}

\section{Standard, Advanced levels}

Please fill in the code. Consult guidelines for the code values. Only relevant for tree species shedding leaves.

\begin{tabular}{|c|c|c|c|c|c|c|c|c|c|c|c|c|c|c|}
\hline $\begin{array}{l}\text { Tree } \\
\text { No. }\end{array}$ & Stage & $\begin{array}{l}\% \text { of } \\
\text { crown }\end{array}$ & $\begin{array}{l}\text { Tree } \\
\text { No. }\end{array}$ & Stage & $\begin{array}{c}\% \text { of } \\
\text { crown }\end{array}$ & $\begin{array}{l}\text { Tree } \\
\text { No. }\end{array}$ & Stage & $\begin{array}{c}\% \text { of } \\
\text { crown }\end{array}$ & $\begin{array}{l}\text { Tree } \\
\text { No. }\end{array}$ & Stage & $\begin{array}{c}\% \text { of } \\
\text { crown }\end{array}$ & $\begin{array}{l}\text { Tree } \\
\text { No. }\end{array}$ & Stage & $\begin{array}{c}\% \text { of } \\
\text { crown }\end{array}$ \\
\hline 1 & & & 11 & & & 21 & & & 31 & & & 41 & & \\
\hline 2 & & & 12 & & & 22 & & & 32 & & & 42 & & \\
\hline 3 & & & 13 & & & 23 & & & 33 & & & 43 & & \\
\hline 4 & & & 14 & & & 24 & & & 34 & & & 44 & & \\
\hline 5 & & & 15 & & & 25 & & & 35 & & & 45 & & \\
\hline 6 & & & 16 & & & 26 & & & 36 & & & 46 & & \\
\hline 7 & & & 17 & & & 27 & & & 37 & & & 47 & & \\
\hline 8 & & & 18 & & & 28 & & & 38 & & & 48 & & \\
\hline 9 & & & 19 & & & 29 & & & 39 & & & 49 & & \\
\hline 10 & & & 20 & & & 30 & & & 40 & & & 50 & & \\
\hline
\end{tabular}




\begin{tabular}{|l|l|l|}
\hline Plot: & Signature: \\
\hline Tree species: & & \\
\hline Date: & & \\
\hline Evaluator: & &
\end{tabular}

\section{Background information: Sex ratio}

\section{Standard level}

Please fill in the code. Consult guidelines for the code values. Only relevant for diecious/polygamous species such as ash, cherry, poplar...

\begin{tabular}{|c|c|c|c|c|c|c|c|c|c|}
\hline Tree No. & Sex & Tree No. & Sex & Tree No. & Sex & Tree No. & Sex & Tree No. & Sex \\
\hline 1 & & 11 & & 21 & & 31 & & 41 & \\
\hline 2 & & 12 & & 22 & & 32 & & 42 & \\
\hline 3 & & 13 & & 23 & & 33 & & 43 & \\
\hline 4 & & 14 & & 24 & & 34 & & 44 & \\
\hline 5 & & 15 & & 25 & & 35 & & 45 & \\
\hline 6 & & 16 & & 26 & & 36 & & 46 & \\
\hline 7 & & 17 & & 27 & & 37 & & 47 & \\
\hline 8 & & 18 & & 28 & & 38 & & 48 & \\
\hline 9 & & 19 & & 29 & & 39 & & 49 & \\
\hline 10 & & 20 & & 30 & & 40 & & 50 & \\
\hline
\end{tabular}




\begin{tabular}{|l|l|l|}
\hline Plot: & Signature: \\
\hline Tree species: & & \\
\hline Date: & & \\
\hline Evaluator: & & \\
\hline
\end{tabular}

\section{Advanced level}

Please fill in the percentage of male/female/hermaphrodite inflorescences. Only relevant for polygamous species such as ash...

\begin{tabular}{|c|c|c|c|c|c|c|c|}
\hline $\begin{array}{l}\text { Tree } \\
\text { No. }\end{array}$ & $\begin{array}{c}\% \text { male } \\
\text { inflorescences }\end{array}$ & $\begin{array}{c}\% \text { female } \\
\text { inflorescences }\end{array}$ & $\begin{array}{c}\% \text { hermaphrodite } \\
\text { inflorescences }\end{array}$ & $\begin{array}{l}\text { Tree } \\
\text { No. }\end{array}$ & $\begin{array}{c}\% \text { male } \\
\text { inflorescences }\end{array}$ & $\begin{array}{c}\% \text { female } \\
\text { inflorescences }\end{array}$ & $\begin{array}{c}\% \text { hermaphrodite } \\
\text { inflorescences }\end{array}$ \\
\hline 1 & & & & 26 & & & \\
\hline 2 & & & & 27 & & & \\
\hline 3 & & & & 28 & & & \\
\hline 4 & & & & 29 & & & \\
\hline 5 & & & & 30 & & & \\
\hline 6 & & & & 31 & & & \\
\hline 7 & & & & 32 & & & \\
\hline 8 & & & & 33 & & & \\
\hline 9 & & & & 34 & & & \\
\hline 10 & & & & 35 & & & \\
\hline 11 & & & & 36 & & & \\
\hline 12 & & & & 37 & & & \\
\hline 13 & & & & 38 & & & \\
\hline 14 & & & & 39 & & & \\
\hline 15 & & & & 40 & & & \\
\hline 16 & & & & 41 & & & \\
\hline 17 & & & & 42 & & & \\
\hline 18 & & & & 43 & & & \\
\hline 19 & & & & 44 & & & \\
\hline 20 & & & & 45 & & & \\
\hline 21 & & & & 46 & & & \\
\hline 22 & & & & 47 & & & \\
\hline 23 & & & & 48 & & & \\
\hline 24 & & & & 49 & & & \\
\hline 25 & & & & 50 & & & \\
\hline
\end{tabular}




\begin{tabular}{|l|l|l|}
\hline Plot: & Signature: \\
\cline { 1 - 2 } Tree species: & \\
\cline { 1 - 2 } Date: & & \\
\cline { 1 - 2 } Evaluator: &
\end{tabular}

\section{Background information: Crown dieback}

\section{Basic, Standard, Advanced levels}

Please fill in the code. Consult guidelines for the code values. Only relevant for species with severe dieback such as ash...

\begin{tabular}{|c|c|c|c|c|c|c|c|c|c|}
\hline Tree No. & Code & Tree No. & Code & Tree No. & Code & Tree No. & Code & Tree No. & Code \\
\hline 1 & & 11 & & 21 & & 31 & & 41 & \\
\hline 2 & & 12 & & 22 & & 32 & & 42 & \\
\hline 3 & & 13 & & 23 & & 33 & & 43 & \\
\hline 4 & & 14 & & 24 & & 34 & & 44 & \\
\hline 5 & & 15 & & 25 & & 35 & & 45 & \\
\hline 6 & & 16 & & 26 & & 36 & & 46 & \\
\hline 7 & & 17 & & 27 & & 37 & & 47 & \\
\hline 8 & & 18 & & 28 & & 38 & & 48 & \\
\hline 9 & & 19 & & 29 & & 39 & & 49 & \\
\hline 10 & & 20 & & 30 & & 40 & & 50 & \\
\hline
\end{tabular}




\subsection{Supplementary tables for Chapter 7: Cost assessment}

Table S7.1: Cost assessment of forest genetic monitoring of European beech (Fagus sylvatica L.) in Germany. The first Forest genetic monitoring interval (Interval $1^{\text {st) }}$ is distinguished from subsequent intervals (Interval $\left.1+\mathrm{N}^{\mathrm{Nh}}\right)$. C - consumables; $\mathrm{O}$ - outsourcing; $\mathrm{F}$ - forester; $\mathrm{T}$ - technician; $\mathrm{R}$ - researcher; $\mathrm{M}-\mathrm{S}$ - mileage and subsistence; $\mathrm{t}$ - time travelling

\begin{tabular}{|c|c|c|c|c|c|c|c|c|c|c|c|c|}
\hline \multirow[b]{3}{*}{ Activity } & \multirow[b]{3}{*}{ Interval } & \multirow[b]{3}{*}{ Level } & \multicolumn{2}{|c|}{ Materials } & \multicolumn{4}{|c|}{ Labour } & \multicolumn{3}{|c|}{ Travelling } & \multirow[b]{2}{*}{ Total } \\
\hline & & & C & 0 & $\mathrm{~F}$ & $T$ & $\mathrm{R}$ & Cost & M-S & t & $\mathrm{t}$ & \\
\hline & & & {$[€]$} & {$[€]$} & [prs h] & [prs h] & [prs h] & {$[€]$} & {$[€]$} & [prs h] & {$[€]$} & {$[€]$} \\
\hline \multirow{6}{*}{ Plot selection } & \multirow{3}{*}{$1^{\text {st }}$} & Basic & 0 & 0 & 40 & 0 & 40 & 2,791 & 395 & 28 & 972 & 4,158 \\
\hline & & Standard & 0 & 0 & 40 & 0 & 40 & 2,791 & 395 & 28 & 972 & 4,158 \\
\hline & & Advanced & 0 & 0 & 40 & 0 & 40 & 2,791 & 395 & 28 & 972 & 4,158 \\
\hline & \multirow{3}{*}{$1+\mathrm{N}^{\text {th }}$} & Basic & 0 & 0 & 0 & 0 & 0 & 0 & 0 & 0 & 0 & 0 \\
\hline & & Standard & 0 & 0 & 0 & 0 & 0 & 0 & 0 & 0 & 0 & 0 \\
\hline & & Advanced & 0 & 0 & 0 & 0 & 0 & 0 & 0 & 0 & 0 & 0 \\
\hline \multirow{6}{*}{$\begin{array}{l}\text { Plot } \\
\text { establishment }\end{array}$} & \multirow{3}{*}{$1^{\text {st }}$} & Basic & 525 & 0 & 0 & 12 & 15 & 854 & 395 & 11 & 357 & 2,130 \\
\hline & & Standard & 845 & 0 & 0 & 23 & 28 & 1,614 & 553 & 22 & 710 & 3,722 \\
\hline & & Advanced & 845 & 0 & 0 & 23 & 28 & 1,614 & 553 & 22 & 710 & 3,722 \\
\hline & \multirow{3}{*}{$1+\mathrm{N}^{\text {th }}$} & Basic & 0 & 0 & 0 & 0 & 0 & 0 & 0 & 0 & 0 & 0 \\
\hline & & Standard & 320 & 0 & 0 & 13 & 15 & 884 & 184 & 13 & 411 & 1,799 \\
\hline & & Advanced & 320 & 0 & 0 & 13 & 15 & 884 & 184 & 13 & 411 & 1,799 \\
\hline \multirow{6}{*}{$\begin{array}{l}\text { Field } \\
\text { observations }\end{array}$} & \multirow{3}{*}{$1^{\text {st }}$} & Basic & 0 & 0 & 0 & 0 & 121 & 4,554 & 1,753 & 74 & 2,809 & 9,116 \\
\hline & & Standard & 0 & 0 & 0 & 46 & 421 & 17,033 & 3,559 & 152 & 5,558 & 26,150 \\
\hline & & Advanced & 0 & 0 & 0 & 43 & 830 & 32,407 & 8,139 & 322 & 11,972 & 52,518 \\
\hline & \multirow{3}{*}{$1+\mathrm{N}^{\text {th }}$} & Basic & 0 & 0 & 0 & 1 & 130 & 4,906 & 1,780 & 76 & 2,875 & 9,561 \\
\hline & & Standard & 0 & 0 & 0 & 47 & 398 & 16,176 & 3,586 & 154 & 5,613 & 25,375 \\
\hline & & Advanced & 0 & 0 & 0 & 87 & 823 & 33,214 & 8,442 & 344 & 12,555 & 54,210 \\
\hline \multirow{6}{*}{ Sampling } & \multirow{3}{*}{$1^{\text {st }}$} & Basic & 0 & 0 & 0 & 0 & 0 & 0 & 0 & 0 & 0 & 0 \\
\hline & & Standard & 10 & 0 & 0 & 7 & 7 & 417 & 158 & 11 & 347 & 932 \\
\hline & & Advanced & 10 & 3,616 & 0 & 7 & 43 & 1,778 & 704 & 22 & 802 & 6,910 \\
\hline & \multirow{3}{*}{$1+\mathrm{N}^{\text {th }}$} & Basic & 0 & 0 & 0 & 0 & 0 & 0 & 0 & 0 & 0 & 0 \\
\hline & & Standard & 7 & 0 & 0 & 1 & 1 & 83 & 79 & 6 & 173 & 342 \\
\hline & & Advanced & 7 & 3,616 & 0 & 1 & 37 & 1,443 & 625 & 17 & 624 & 6,315 \\
\hline \multirow{6}{*}{ Lab. analyses } & \multirow{3}{*}{$1^{\text {st }}$} & Basic & 0 & 0 & 0 & 0 & 0 & 0 & 0 & 0 & 0 & 0 \\
\hline & & Standard & 2,100 & 0 & 0 & 33 & 80 & 3,836 & 0 & 0 & 0 & 5,936 \\
\hline & & Advanced & 13,340 & 0 & 0 & 224 & 80 & 8,485 & 0 & 0 & 0 & 21,825 \\
\hline & \multirow{3}{*}{$1+\mathrm{N}^{\text {th }}$} & Basic & 0 & 0 & 0 & 0 & 0 & 0 & 0 & 0 & 0 & 0 \\
\hline & & Standard & 1,400 & 0 & 0 & 24 & 80 & 3,614 & 0 & 0 & 0 & 5,014 \\
\hline & & Advanced & 12,640 & 0 & 0 & 215 & 80 & 8,263 & 0 & 0 & 0 & 20,903 \\
\hline \multirow{6}{*}{ Total } & & Basic & 525 & 0 & 40 & 12 & 176 & 8,198 & 2,543 & 113 & 4,138 & 15,405 \\
\hline & $1^{\text {st }}$ & Standard & 2,955 & 0 & 40 & 109 & 576 & 25,690 & 4,665 & 214 & 7,587 & 40,898 \\
\hline & & Advanced & 14,195 & 3,616 & 40 & 296 & 1,021 & 47,074 & 9,791 & 395 & 14,456 & 89,132 \\
\hline & & Basic & 0 & 0 & 0 & 1 & 130 & 4,906 & 1,780 & 76 & 2,875 & 9,561 \\
\hline & $1+\mathrm{N}^{\text {th }}$ & Standard & 1,727 & 0 & 0 & 85 & 494 & 20,757 & 3,849 & 173 & 6,197 & 32,530 \\
\hline & & Advanced & 12,967 & 3,616 & 0 & 315 & 955 & 43,805 & 9,251 & 374 & 13,590 & 83,228 \\
\hline
\end{tabular}


Table S7.2: Cost assessment of forest genetic monitoring of Silver fir (Abies alba Mill.) in Germany. The first Forest genetic monitoring interval (Interval $1^{\text {st }}$ ) is distinguished from subsequent intervals (Interval $1+\mathrm{N}^{\text {th }}$ ). $\mathrm{C}-$ consumables; $\mathrm{O}$ - outsourcing; F - forester; $\mathrm{T}$ - technician; $\mathrm{R}$ - researcher; $\mathrm{M}-\mathrm{S}$ - mileage and subsistence; $\mathrm{t}$ - time travelling.

\begin{tabular}{|c|c|c|c|c|c|c|c|c|c|c|c|c|}
\hline \multirow[b]{3}{*}{ Activity } & \multirow[b]{3}{*}{ Interval } & \multirow[b]{3}{*}{ Level } & \multicolumn{2}{|c|}{ Materials } & \multicolumn{4}{|c|}{ Labour } & \multicolumn{3}{|c|}{ Travelling } & \multirow[b]{2}{*}{ Total } \\
\hline & & & C & O & $\mathrm{F}$ & $\mathrm{T}$ & $\mathrm{R}$ & Cost & M-S & $\mathrm{t}$ & $\mathrm{t}$ & \\
\hline & & & {$[€]$} & {$[€]$} & [prs h] & [prs h] & [prs h] & {$[€]$} & {$[€]$} & [prs h] & {$[€]$} & {$[€]$} \\
\hline \multirow{6}{*}{ Plot selection } & \multirow{3}{*}{$1^{s t}$} & Basic & 0 & 0 & 40 & 0 & 40 & 2,791 & 395 & 28 & 972 & 4,158 \\
\hline & & Standard & 0 & 0 & 40 & 0 & 40 & 2,791 & 395 & 28 & 972 & 4,158 \\
\hline & & Advanced & 0 & 0 & 40 & 0 & 40 & 2,791 & 395 & 28 & 972 & 4,158 \\
\hline & \multirow{3}{*}{$1+\mathrm{N}^{\text {th }}$} & Basic & 0 & 0 & 0 & 0 & 0 & 0 & 0 & 0 & 0 & 0 \\
\hline & & Standard & 0 & 0 & 0 & 0 & 0 & 0 & 0 & 0 & 0 & 0 \\
\hline & & Advanced & 0 & 0 & 0 & 0 & 0 & 0 & 0 & 0 & 0 & 0 \\
\hline \multirow{6}{*}{$\begin{array}{l}\text { Plot } \\
\text { establishment }\end{array}$} & \multirow{3}{*}{$1^{\text {st }}$} & Basic & 525 & 0 & 0 & 12 & 15 & 854 & 395 & 11 & 357 & 2,130 \\
\hline & & Standard & 845 & 0 & 0 & 23 & 28 & 1,614 & 553 & 22 & 710 & 3,722 \\
\hline & & Advanced & 845 & 0 & 0 & 23 & 28 & 1,614 & 553 & 22 & 710 & 3,722 \\
\hline & \multirow{3}{*}{$1+\mathrm{N}^{\text {th }}$} & Basic & 0 & 0 & 0 & 0 & 0 & 0 & 0 & 0 & 0 & 0 \\
\hline & & Standard & 320 & 0 & 0 & 13 & 15 & 884 & 184 & 13 & 411 & 1,799 \\
\hline & & Advanced & 320 & 0 & 0 & 13 & 15 & 884 & 184 & 13 & 411 & 1,799 \\
\hline \multirow{6}{*}{$\begin{array}{l}\text { Field } \\
\text { observations }\end{array}$} & \multirow{3}{*}{$1^{\text {st }}$} & Basic & 0 & 0 & 0 & 0 & 121 & 4,554 & 1,753 & 74 & 2,809 & 9,116 \\
\hline & & Standard & 0 & 0 & 0 & 46 & 396 & 16,088 & 3,261 & 141 & 5,141 & 24,490 \\
\hline & & Advanced & 97 & 0 & 0 & 43 & 748 & 29,299 & 6,649 & 267 & 9,884 & 45,928 \\
\hline & \multirow{3}{*}{$1+\mathrm{N}^{\text {th }}$} & Basic & 0 & 0 & 0 & 1 & 130 & 4,906 & 1,780 & 76 & 2,875 & 9,561 \\
\hline & & Standard & 0 & 0 & 0 & 47 & 354 & 14,494 & 3,288 & 143 & 5,185 & 22,967 \\
\hline & & Advanced & 5 & 0 & 0 & 87 & 746 & 30,285 & 6,952 & 288 & 10,485 & 47,727 \\
\hline \multirow{6}{*}{ Sampling } & \multirow{3}{*}{$1^{\text {st }}$} & Basic & 0 & 0 & 0 & 0 & 0 & 0 & 0 & 0 & 0 & 0 \\
\hline & & Standard & 10 & 0 & 0 & 3 & 3 & 192 & 158 & 11 & 347 & 707 \\
\hline & & Advanced & 10 & 3,616 & 0 & 15 & 15 & 938 & 704 & 22 & 694 & 5,962 \\
\hline & \multirow{3}{*}{$1+\mathrm{N}^{\text {th }}$} & Basic & 0 & 0 & 0 & 0 & 0 & 0 & 0 & 0 & 0 & 0 \\
\hline & & Standard & 7 & 0 & 0 & 1 & 1 & 83 & 79 & 6 & 173 & 342 \\
\hline & & Advanced & 7 & 3,616 & 0 & 13 & 13 & 829 & 625 & 17 & 520 & 5,597 \\
\hline \multirow{6}{*}{ Lab. analyses } & \multirow{3}{*}{$1^{\text {st }}$} & Basic & 0 & 0 & 0 & 0 & 0 & 0 & 0 & 0 & 0 & 0 \\
\hline & & Standard & 2,100 & 0 & 0 & 33 & 80 & 3,836 & 0 & 0 & 0 & 5,936 \\
\hline & & Advanced & 13,340 & 0 & 0 & 216 & 80 & 8,290 & 0 & 0 & 0 & 21,630 \\
\hline & \multirow{3}{*}{$1+\mathrm{N}^{\text {th }}$} & Basic & 0 & 0 & 0 & 0 & 0 & 0 & 0 & 0 & 0 & 0 \\
\hline & & Standard & 1,400 & 0 & 0 & 24 & 80 & 3,614 & 0 & 0 & 0 & 5,014 \\
\hline & & Advanced & 12,640 & 0 & 0 & 207 & 80 & 8,068 & 0 & 0 & 0 & 20,708 \\
\hline \multirow{6}{*}{ Total } & & Basic & 525 & 0 & 40 & 12 & 176 & 8,198 & 2,543 & 113 & 4,138 & 15,405 \\
\hline & $1^{\text {st }}$ & Standard & 2,955 & 0 & 40 & 105 & 547 & 24,520 & 4,367 & 203 & 7,170 & 39,012 \\
\hline & & Advanced & 14,292 & 3,616 & 40 & 296 & 911 & 42,931 & 8,301 & 339 & 12,259 & 81,399 \\
\hline & & Basic & 0 & 0 & 0 & 1 & 130 & 4,906 & 1,780 & 76 & 2,875 & 9,561 \\
\hline & $1+\mathrm{N}^{\text {th }}$ & Standard & 1,727 & 0 & 0 & 85 & 450 & 19,075 & 3,551 & 162 & 5,769 & 30,122 \\
\hline & & Advanced & 12,972 & 3,616 & 0 & 319 & 854 & 40,067 & 7,761 & 318 & 11,416 & 75,831 \\
\hline
\end{tabular}


Table S7.3: Cost assessment of forest genetic monitoring of European beech (Fagus sy/vatica L.) in Greece. The first

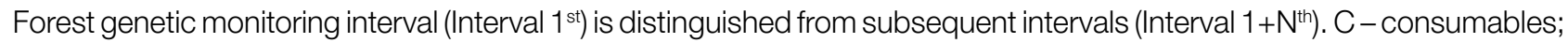
$\mathrm{O}$ - outsourcing; F - forester; $\mathrm{T}$ - technician; $\mathrm{R}$ - researcher; M-S - mileage and subsistence; $\mathrm{t}$ - time travelling.

\begin{tabular}{|c|c|c|c|c|c|c|c|c|c|c|c|c|}
\hline \multirow[b]{3}{*}{ Activity } & \multirow[b]{3}{*}{ Interval } & \multirow[b]{3}{*}{ Level } & \multicolumn{2}{|c|}{ Material } & \multicolumn{4}{|c|}{ Labour } & \multicolumn{3}{|c|}{ Travel } & \multirow[b]{2}{*}{ Total } \\
\hline & & & $\mathrm{C}$ & 0 & $\mathrm{~F}$ & $\mathrm{~T}$ & $\mathrm{R}$ & Cost & M-S & $\mathrm{t}$ & $\mathrm{t}$ & \\
\hline & & & {$[€]$} & {$[€]$} & [prs h] & [prs h] & [prs h] & {$[€]$} & {$[€]$} & [prs h] & {$[€]$} & {$[€]$} \\
\hline \multirow{6}{*}{ Plot selection } & \multirow{3}{*}{$1^{\text {st }}$} & Basic & 0 & 0 & 40 & 0 & 40 & 1,076 & 424 & 33 & 440 & 1,939 \\
\hline & & Standard & 0 & 0 & 40 & 0 & 40 & 1,076 & 424 & 33 & 440 & 1,939 \\
\hline & & Advanced & 0 & 0 & 40 & 0 & 40 & 1,076 & 424 & 33 & 440 & 1,939 \\
\hline & \multirow{3}{*}{$1+\mathrm{N}^{\text {th }}$} & Basic & 0 & 0 & 0 & 0 & 0 & 0 & 0 & 0 & 0 & 0 \\
\hline & & Standard & 0 & 0 & 0 & 0 & 0 & 0 & 0 & 0 & 0 & 0 \\
\hline & & Advanced & 0 & 0 & 0 & 0 & 0 & 0 & 0 & 0 & 0 & 0 \\
\hline \multirow{6}{*}{$\begin{array}{l}\text { Plot } \\
\text { establishment }\end{array}$} & \multirow{3}{*}{$1^{s t}$} & Basic & 434 & 0 & 21 & 0 & 23 & 582 & 254 & 20 & 266 & 1,536 \\
\hline & & Standard & 754 & 0 & 32 & 0 & 36 & 909 & 424 & 33 & 444 & 2,530 \\
\hline & & Advanced & 754 & 0 & 32 & 0 & 36 & 909 & 424 & 33 & 444 & 2,530 \\
\hline & \multirow{3}{*}{$1+\mathrm{N}^{\text {th }}$} & Basic & 0 & 0 & 0 & 0 & 0 & 0 & 0 & 0 & 0 & 0 \\
\hline & & Standard & 320 & 0 & 16 & 0 & 18 & 461 & 198 & 15 & 207 & 1,186 \\
\hline & & Advanced & 320 & 0 & 16 & 0 & 18 & 461 & 198 & 15 & 207 & 1,186 \\
\hline \multirow{6}{*}{$\begin{array}{l}\text { Field } \\
\text { observations }\end{array}$} & \multirow{3}{*}{$1^{s t}$} & Basic & 0 & 0 & 40 & 0 & 81 & 1,700 & 1,282 & 87 & 1,232 & 4,214 \\
\hline & & Standard & 0 & 0 & 1,276 & 40 & 308 & 19,911 & 2,621 & 244 & 2,998 & 25,530 \\
\hline & & Advanced & 0 & 0 & 5,042 & 40 & 458 & 65,428 & 5,679 & 647 & 7,642 & 78,749 \\
\hline & \multirow{3}{*}{$1+\mathrm{N}^{\text {th }}$} & Basic & 0 & 0 & 42 & 0 & 91 & 1,896 & 1,311 & 89 & 1,268 & 4,474 \\
\hline & & Standard & 0 & 0 & 1,278 & 40 & 286 & 19,614 & 2,650 & 247 & 3,014 & 25,277 \\
\hline & & Advanced & 0 & 0 & 5,050 & 80 & 456 & 66,034 & 6,004 & 672 & 7,945 & 79,982 \\
\hline \multirow{6}{*}{ Sampling } & \multirow{3}{*}{$1^{s t}$} & Basic & 0 & 0 & 0 & 0 & 0 & 0 & 0 & 0 & 0 & 0 \\
\hline & & Standard & 16 & 0 & 11 & 0 & 11 & 287 & 169 & 13 & 176 & 648 \\
\hline & & Advanced & 16 & 10,000 & 47 & 0 & 47 & 1,255 & 508 & 39 & 528 & 12,307 \\
\hline & \multirow{3}{*}{$1+\mathrm{N}^{\text {th }}$} & Basic & 0 & 0 & 0 & 0 & 0 & 0 & 0 & 0 & 0 & 0 \\
\hline & & Standard & 11 & 0 & 5 & 0 & 5 & 125 & 85 & 7 & 88 & 309 \\
\hline & & Advanced & 11 & 10,000 & 41 & 0 & 41 & 1,094 & 424 & 33 & 440 & 11,968 \\
\hline \multirow{6}{*}{ Lab. analyses } & \multirow{3}{*}{$1^{s t}$} & Basic & 0 & 0 & 0 & 0 & 0 & 0 & 0 & 0 & 0 & 0 \\
\hline & & Standard & 862 & 1,235 & 0 & 38 & 80 & 1,744 & 0 & 0 & 0 & 3,842 \\
\hline & & Advanced & 6,919 & 7,824 & 0 & 246 & 80 & 4,523 & 0 & 0 & 0 & 19,266 \\
\hline & \multirow{3}{*}{$1+\mathrm{N}^{\text {th }}$} & Basic & 0 & 0 & 0 & 0 & 0 & 0 & 0 & 0 & 0 & 0 \\
\hline & & Standard & 575 & 824 & 0 & 29 & 80 & 1,618 & 0 & 0 & 0 & 3,016 \\
\hline & & Advanced & 6,631 & 7,412 & 0 & 237 & 80 & 4,397 & 0 & 0 & 0 & 18,440 \\
\hline \multirow{6}{*}{ Total } & & Basic & 434 & 0 & 101 & 0 & 143 & 3,358 & 1,960 & 140 & 1,938 & 7,690 \\
\hline & $1^{\text {st }}$ & Standard & 1,632 & 1,235 & 1,358 & 78 & 474 & 23,927 & 3,638 & 323 & 4,058 & 34,490 \\
\hline & & Advanced & 7,689 & 17,824 & 5,160 & 286 & 660 & 73,191 & 7,035 & 752 & 9,054 & 114,791 \\
\hline & & Basic & 0 & 0 & 42 & 0 & 91 & 1,896 & 1,311 & 89 & 1,268 & 4,474 \\
\hline & $1+\mathrm{N}^{\text {th }}$ & Standard & 905 & 824 & 1,299 & 69 & 389 & 21,818 & 2,932 & 268 & 3,309 & 29,788 \\
\hline & & Advanced & 6,962 & 17,412 & 5,107 & 317 & 595 & 71,986 & 6,625 & 720 & 8,592 & 111,576 \\
\hline
\end{tabular}

* phenological observations (Field observations) were performed through digital photography and image analysis. 
Table S7.4: Cost assessment of forest genetic monitoring of King Boris' fir (Abies borisii-regis Mafft.) in Greece. The first Forest genetic monitoring interval (Interval $1^{\text {st }}$ ) is distinguished from subsequent intervals (Interval $1+\mathrm{N}^{\text {th }}$ ). $\mathrm{C}-$ consumables; O - outsourcing; F - forester; T - technician; R - researcher; M-S - mileage and subsistence; $t$ - time travelling.

\begin{tabular}{|c|c|c|c|c|c|c|c|c|c|c|c|c|}
\hline \multirow[b]{3}{*}{ Activity } & \multirow[b]{3}{*}{ Interval } & \multirow[b]{3}{*}{ Level } & \multicolumn{2}{|c|}{ Materials } & \multicolumn{4}{|c|}{ Labour } & \multicolumn{3}{|c|}{ Travel } & \multirow[b]{2}{*}{ Cost } \\
\hline & & & C & $\mathrm{O}$ & $\mathrm{F}$ & $\mathrm{T}$ & $\mathrm{R}$ & Cost & M-S & $\mathrm{t}$ & $\mathrm{t}$ & \\
\hline & & & {$[€]$} & {$[€]$} & [prs h] & [prs h] & [prs h] & {$[€]$} & {$[€]$} & [prs h] & {$[€]$} & {$[€]$} \\
\hline \multirow{6}{*}{ Plot selection } & \multirow{3}{*}{$1^{\text {st }}$} & Basic & 0 & 0 & 40 & 0 & 40 & 1,076 & 424 & 33 & 440 & 1,939 \\
\hline & & Standard & 0 & 0 & 40 & 0 & 40 & 1,076 & 424 & 33 & 440 & 1,939 \\
\hline & & Advanced & 0 & 0 & 40 & 0 & 40 & 1,076 & 424 & 33 & 440 & 1,939 \\
\hline & \multirow{3}{*}{$1+\mathrm{N}^{\text {th }}$} & Basic & 0 & 0 & 0 & 0 & 0 & 0 & 0 & 0 & 0 & 0 \\
\hline & & Standard & 0 & 0 & 0 & 0 & 0 & 0 & 0 & 0 & 0 & 0 \\
\hline & & Advanced & 0 & 0 & 0 & 0 & 0 & 0 & 0 & 0 & 0 & 0 \\
\hline \multirow{6}{*}{$\begin{array}{l}\text { Plot } \\
\text { establishment }\end{array}$} & \multirow{3}{*}{$1^{\text {st }}$} & Basic & 434 & 0 & 21 & 0 & 23 & 582 & 254 & 20 & 266 & 1,536 \\
\hline & & Standard & 754 & 0 & 32 & 0 & 36 & 909 & 424 & 33 & 444 & 2,530 \\
\hline & & Advanced & 754 & 0 & 32 & 0 & 36 & 909 & 424 & 33 & 444 & 2,530 \\
\hline & \multirow{3}{*}{$1+\mathrm{N}^{\text {th }}$} & Basic & 0 & 0 & 0 & 0 & 0 & 0 & 0 & 0 & 0 & 0 \\
\hline & & Standard & 320 & 0 & 16 & 0 & 18 & 461 & 198 & 15 & 207 & 1,186 \\
\hline & & Advanced & 320 & 0 & 16 & 0 & 18 & 461 & 198 & 15 & 207 & 1,186 \\
\hline \multirow{6}{*}{$\begin{array}{l}\text { Field } \\
\text { observations* }\end{array}$} & \multirow{3}{*}{$1^{\text {st }}$} & Basic & 0 & 0 & 40 & 0 & 81 & 1,700 & 1,282 & 87 & 1,232 & 4,214 \\
\hline & & Standard & 0 & 0 & 1,048 & 40 & 304 & 17,235 & 2,421 & 218 & 2,703 & 22,359 \\
\hline & & Advanced & 0 & 0 & 3,902 & 40 & 438 & 52,044 & 4,679 & 516 & 6,133 & 62,855 \\
\hline & \multirow{3}{*}{$1+\mathrm{N}^{\text {th }}$} & Basic & 0 & 0 & 42 & 0 & 91 & 1,896 & 1,311 & 89 & 1,268 & 4,474 \\
\hline & & Standard & 0 & 0 & 1,050 & 40 & 282 & 16,937 & 2,450 & 220 & 2,719 & 22,106 \\
\hline & & Advanced & 0 & 0 & 3,910 & 80 & 436 & 52,650 & 5,004 & 541 & 6,437 & 64,090 \\
\hline \multirow{6}{*}{ Sampling } & \multirow{3}{*}{$1^{\text {st }}$} & Basic & 0 & 0 & 0 & 0 & 0 & 0 & 0 & 0 & 0 & 0 \\
\hline & & Standard & 16 & 0 & 11 & 0 & 11 & 287 & 169 & 13 & 176 & 648 \\
\hline & & Advanced & 16 & 5,008 & 47 & 0 & 47 & 1,255 & 508 & 39 & 528 & 7,315 \\
\hline & \multirow{3}{*}{$1+\mathrm{N}^{\text {th }}$} & Basic & 0 & 0 & 0 & 0 & 0 & 0 & 0 & 0 & 0 & 0 \\
\hline & & Standard & 11 & 0 & 5 & 0 & 5 & 125 & 85 & 7 & 88 & 309 \\
\hline & & Advanced & 11 & 5,008 & 41 & 0 & 41 & 1,094 & 424 & 33 & 440 & 6,976 \\
\hline \multirow{6}{*}{ Lab. analyses } & \multirow{3}{*}{$1^{\text {st }}$} & Basic & 0 & 0 & 0 & 0 & 0 & 0 & 0 & 0 & 0 & 0 \\
\hline & & Standard & 809 & 882 & 0 & 36 & 80 & 1,714 & 0 & 0 & 0 & 3,405 \\
\hline & & Advanced & 6,583 & 5,588 & 0 & 236 & 80 & 4,384 & 0 & 0 & 0 & 16,556 \\
\hline & \multirow{3}{*}{$1+\mathrm{N}^{\text {th }}$} & Basic & 0 & 0 & 0 & 0 & 0 & 0 & 0 & 0 & 0 & 0 \\
\hline & & Standard & 540 & 588 & 0 & 27 & 80 & 1,591 & 0 & 0 & 0 & 2,719 \\
\hline & & Advanced & 6,314 & 5,294 & 0 & 227 & 80 & 4,262 & 0 & 0 & 0 & 15,870 \\
\hline \multirow{6}{*}{ Total } & & Basic & 434 & 0 & 101 & 0 & 143 & 3,358 & 1,960 & 140 & 1,938 & 7,690 \\
\hline & $1^{\text {st }}$ & Standard & 1,579 & 882 & 1,130 & 76 & 470 & 21,219 & 3,438 & 297 & 3,763 & 30,882 \\
\hline & & Advanced & 7,353 & 10,596 & 4,020 & 276 & 640 & 59,668 & 6,035 & 621 & 7,545 & 91,196 \\
\hline & & Basic & 0 & 0 & 42 & 0 & 91 & 1,896 & 1,311 & 89 & 1,268 & 4,474 \\
\hline & $1+\mathrm{N}^{\text {th }}$ & Standard & 870 & 588 & 1,071 & 67 & 385 & 19,115 & 2,732 & 242 & 3,015 & 26,319 \\
\hline & & Advanced & 6,644 & 10,302 & 3,967 & 307 & 575 & 58,466 & 5,625 & 589 & 7,084 & 88,122 \\
\hline
\end{tabular}

phenological observations (Field observations) were performed through digital photography and image analysis. 
Table S7.5: Cost assessment of forest genetic monitoring of European beech (Fagus sylvatica L.) in Slovenia. The first Forest genetic monitoring interval (FGM Interval $1^{\text {st }}$ ) is distinguished from subsequent intervals (FGM Interval $\left.1+\mathrm{N}^{\text {th }}\right)$. $\mathrm{C}$ - consumables; $\mathrm{O}$ - outsourcing; $\mathrm{F}$ - forester; $\mathrm{T}$ - technician; $\mathrm{R}$ - researcher; $\mathrm{M}$-S - mileage and subsistence; $\mathrm{t}$ - time travelling.

\begin{tabular}{|c|c|c|c|c|c|c|c|c|c|c|c|c|}
\hline \multirow[b]{3}{*}{ Activity } & \multirow[b]{3}{*}{ Interval } & \multirow[b]{3}{*}{ Level } & \multicolumn{2}{|c|}{ Materials } & \multicolumn{4}{|c|}{ Labour } & \multicolumn{3}{|c|}{ Travel } & \multirow[b]{2}{*}{ Total } \\
\hline & & & C & $\mathrm{O}$ & $\mathrm{F}$ & $\mathrm{T}$ & $\mathrm{R}$ & Cost & M-S & $\mathrm{t}$ & $\mathrm{t}$ & \\
\hline & & & {$[€]$} & {$[€]$} & [prs h] & [prs h] & [prs h] & {$[€]$} & {$[€]$} & [prs h] & {$[€]$} & {$[€]$} \\
\hline \multirow{6}{*}{ Plot selection } & \multirow{3}{*}{$1^{\text {st }}$} & Basic & 0 & 0 & 40 & 0 & 40 & 1,318 & 240 & 32 & 520 & 2,077 \\
\hline & & Standard & 0 & 0 & 40 & 0 & 40 & 1,318 & 240 & 32 & 520 & 2,077 \\
\hline & & Advanced & 0 & 0 & 40 & 0 & 40 & 1,318 & 240 & 32 & 520 & 2,077 \\
\hline & \multirow{3}{*}{$1+\mathrm{N}^{\text {th }}$} & Basic & 0 & 0 & 0 & 0 & 0 & 0 & 0 & 0 & 0 & 0 \\
\hline & & Standard & 0 & 0 & 0 & 0 & 0 & 0 & 0 & 0 & 0 & 0 \\
\hline & & Advanced & 0 & 0 & 0 & 0 & 0 & 0 & 0 & 0 & 0 & 0 \\
\hline \multirow{6}{*}{$\begin{array}{l}\text { Plot } \\
\text { establishment }\end{array}$} & \multirow{3}{*}{$1^{\text {st }}$} & Basic & 65 & 0 & 0 & 27 & 2 & 434 & 144 & 19 & 288 & 931 \\
\hline & & Standard & 385 & 0 & 0 & 48 & 4 & 798 & 240 & 32 & 481 & 1,904 \\
\hline & & Advanced & 385 & 0 & 0 & 48 & 4 & 798 & 240 & 32 & 481 & 1,904 \\
\hline & \multirow{3}{*}{$1+\mathrm{N}^{\text {th }}$} & Basic & 0 & 0 & 0 & 0 & 0 & 0 & 0 & 0 & 0 & 0 \\
\hline & & Standard & 320 & 0 & 0 & 25 & 2 & 412 & 112 & 15 & 224 & 1,068 \\
\hline & & Advanced & 320 & 0 & 0 & 25 & 2 & 412 & 112 & 15 & 224 & 1,068 \\
\hline \multirow{6}{*}{$\begin{array}{l}\text { Field } \\
\text { observations }\end{array}$} & \multirow{3}{*}{$1^{\text {st }}$} & Basic & 0 & 0 & 20 & 20 & 81 & 2,105 & 1,120 & 84 & 1,469 & 4,694 \\
\hline & & Standard & 0 & 0 & 20 & 157 & 296 & 8,232 & 2,272 & 235 & 4,101 & 14,605 \\
\hline & & Advanced & 0 & 0 & 20 & 428 & 454 & 15,281 & 5,224 & 623 & 10,564 & 31,069 \\
\hline & \multirow{3}{*}{$1+\mathrm{N}^{\text {th }}$} & Basic & 0 & 0 & 20 & 21 & 89 & 2,281 & 1,136 & 86 & 1,513 & 4,930 \\
\hline & & Standard & 0 & 0 & 20 & 158 & 272 & 7,801 & 2,288 & 238 & 4,117 & 14,206 \\
\hline & & Advanced & 0 & 0 & 20 & 474 & 444 & 15,779 & 5,408 & 648 & 10,896 & 32,083 \\
\hline \multirow{6}{*}{ Sampling } & \multirow{3}{*}{$1^{\text {st }}$} & Basic & 0 & 0 & 0 & 0 & 0 & 0 & 0 & 0 & 0 & 0 \\
\hline & & Standard & 4 & 0 & 0 & 18 & 0 & 262 & 96 & 13 & 189 & 551 \\
\hline & & Advanced & 4 & 3,758 & 0 & 90 & 0 & 1,337 & 288 & 38 & 566 & 5,953 \\
\hline & \multirow{3}{*}{$1+\mathrm{N}^{\text {th }}$} & Basic & 0 & 0 & 0 & 0 & 0 & 0 & 0 & 0 & 0 & 0 \\
\hline & & Standard & 3 & 0 & 0 & 10 & 0 & 149 & 48 & 6 & 94 & 295 \\
\hline & & Advanced & 3 & 3,758 & 0 & 82 & 0 & 1,225 & 240 & 32 & 471 & 5,697 \\
\hline \multirow{6}{*}{ Lab. analyses } & \multirow{3}{*}{$1^{\text {st }}$} & Basic & 0 & 0 & 0 & 0 & 0 & 0 & 0 & 0 & 0 & 0 \\
\hline & & Standard & 2,239 & 0 & 0 & 26 & 84 & 1,984 & 0 & 0 & 0 & 4,222 \\
\hline & & Advanced & 14,238 & 0 & 0 & 189 & 107 & 4,857 & 0 & 0 & 0 & 19,094 \\
\hline & \multirow{3}{*}{$1+\mathrm{N}^{\text {th }}$} & Basic & 0 & 0 & 0 & 0 & 0 & 0 & 0 & 0 & 0 & 0 \\
\hline & & Standard & 1,492 & 0 & 0 & 17 & 84 & 1,855 & 0 & 0 & 0 & 3,347 \\
\hline & & Advanced & 13,491 & 0 & 0 & 181 & 107 & 4,728 & 0 & 0 & 0 & 18,219 \\
\hline \multirow{6}{*}{ Total } & & Basic & 65 & 0 & 60 & 47 & 123 & 3,857 & 1,504 & 135 & 2,277 & 7,703 \\
\hline & $1^{\text {st }}$ & Standard & 2,628 & 0 & 60 & 249 & 424 & 12,593 & 2,848 & 311 & 5,290 & 23,359 \\
\hline & & Advanced & 14,627 & 3,758 & 60 & 755 & 605 & 23,591 & 5,992 & 724 & 12,130 & 60,098 \\
\hline & & Basic & 0 & 0 & 20 & 21 & 89 & 2,281 & 1,136 & 86 & 1,513 & 4,930 \\
\hline & $1+\mathrm{N}^{\text {th }}$ & Standard & 1,815 & 0 & 20 & 210 & 358 & 10,217 & 2,448 & 259 & 4,436 & 18,916 \\
\hline & & Advanced & 13,814 & 3,758 & 20 & 762 & 553 & 22,144 & 5,760 & 694 & 11,591 & 57,068 \\
\hline
\end{tabular}


Table S7.6: Cost assessment of forest genetic monitoring of Silver fir (Abies alba Mill.) in Slovenia. The first Forest genetic monitoring interval (FGM Interval $1^{\text {st }}$ ) is distinguished from subsequent intervals (FGM Interval $1+\mathrm{N}^{\text {th }}$ ). $\mathrm{C}-$ consumables; $\mathrm{O}$ - outsourcing; F - forester; $\mathrm{T}$ - technician; $\mathrm{R}$ - researcher; $\mathrm{M}-\mathrm{S}$ - mileage and subsistence; $\mathrm{t}$ - time travelling.

\begin{tabular}{|c|c|c|c|c|c|c|c|c|c|c|c|c|}
\hline \multirow[b]{3}{*}{ Activity } & \multirow[b]{3}{*}{ Interval } & \multirow[b]{3}{*}{ Level } & \multicolumn{2}{|c|}{ Materials } & \multicolumn{4}{|c|}{ Labour } & \multicolumn{3}{|c|}{ Travelling } & \multirow[b]{2}{*}{ Cost } \\
\hline & & & C & $\mathrm{O}$ & $\mathrm{F}$ & $\mathrm{T}$ & $\mathrm{R}$ & Cost & M-S & $\mathrm{t}$ & $\mathrm{t}$ & \\
\hline & & & {$[€]$} & {$[€]$} & [prs h] & [prs h] & [prs h] & {$[€]$} & {$[€]$} & [prs h] & {$[€]$} & {$[€]$} \\
\hline \multirow{6}{*}{ Plot selection } & \multirow{3}{*}{$1^{s t}$} & Basic & 0 & 0 & 40 & 0 & 40 & 1,318 & 240 & 32 & 520 & 2,077 \\
\hline & & Standard & 0 & 0 & 40 & 0 & 40 & 1,318 & 240 & 32 & 520 & 2,077 \\
\hline & & Advanced & 0 & 0 & 40 & 0 & 40 & 1,318 & 240 & 32 & 520 & 2,077 \\
\hline & \multirow{3}{*}{$1+\mathrm{N}^{\text {th }}$} & Basic & 0 & 0 & 0 & 0 & 0 & 0 & 0 & 0 & 0 & 0 \\
\hline & & Standard & 0 & 0 & 0 & 0 & 0 & 0 & 0 & 0 & 0 & 0 \\
\hline & & Advanced & 0 & 0 & 0 & 0 & 0 & 0 & 0 & 0 & 0 & 0 \\
\hline \multirow{6}{*}{$\begin{array}{l}\text { Plot } \\
\text { establishment }\end{array}$} & \multirow{3}{*}{$1^{\text {st }}$} & Basic & 65 & 0 & 0 & 27 & 2 & 434 & 144 & 19 & 288 & 931 \\
\hline & & Standard & 385 & 0 & 0 & 48 & 4 & 798 & 240 & 32 & 481 & 1,904 \\
\hline & & Advanced & 385 & 0 & 0 & 48 & 4 & 798 & 240 & 32 & 481 & 1,904 \\
\hline & \multirow{3}{*}{$1+\mathrm{N}^{\text {th }}$} & Basic & 0 & 0 & 0 & 0 & 0 & 0 & 0 & 0 & 0 & 0 \\
\hline & & Standard & 320 & 0 & 0 & 25 & 2 & 412 & 112 & 15 & 224 & 1,068 \\
\hline & & Advanced & 320 & 0 & 0 & 25 & 2 & 412 & 112 & 15 & 224 & 1,068 \\
\hline \multirow{6}{*}{$\begin{array}{l}\text { Field } \\
\text { observations }\end{array}$} & \multirow{3}{*}{$1^{\text {st }}$} & Basic & 0 & 0 & 20 & 20 & 81 & 2,105 & 1,120 & 84 & 1,469 & 4,694 \\
\hline & & Standard & 0 & 0 & 20 & 146 & 292 & 7,986 & 2,080 & 210 & 3,672 & 13,738 \\
\hline & & Advanced & 97 & 0 & 23 & 397 & 471 & 15,178 & 4,408 & 516 & 8,797 & 28,480 \\
\hline & \multirow{3}{*}{$1+\mathrm{N}^{\text {th }}$} & Basic & 0 & 0 & 20 & 21 & 89 & 2,281 & 1,136 & 86 & 1,513 & 4,930 \\
\hline & & Standard & 0 & 0 & 20 & 147 & 268 & 7,555 & 2,096 & 212 & 3,690 & 13,341 \\
\hline & & Advanced & 5 & 0 & 20 & 421 & 426 & 14,646 & 4,496 & 528 & 8,917 & 28,064 \\
\hline \multirow{6}{*}{ Sampling } & \multirow{3}{*}{$1^{\text {st }}$} & Basic & 0 & 0 & 0 & 0 & 0 & 0 & 0 & 0 & 0 & 0 \\
\hline & & Standard & 4 & 0 & 0 & 18 & 0 & 262 & 96 & 13 & 189 & 551 \\
\hline & & Advanced & 4 & 2,074 & 0 & 98 & 0 & 1,457 & 288 & 38 & 566 & 4,389 \\
\hline & \multirow{3}{*}{$1+\mathrm{N}^{\text {th }}$} & Basic & 0 & 0 & 0 & 0 & 0 & 0 & 0 & 0 & 0 & 0 \\
\hline & & Standard & 3 & 0 & 0 & 10 & 0 & 149 & 48 & 6 & 94 & 295 \\
\hline & & Advanced & 3 & 2,074 & 0 & 90 & 0 & 1,345 & 240 & 32 & 471 & 4,133 \\
\hline \multirow{6}{*}{ Lab. analyses } & \multirow{3}{*}{$1^{\text {st }}$} & Basic & 0 & 0 & 0 & 0 & 0 & 0 & 0 & 0 & 0 & 0 \\
\hline & & Standard & 1,910 & 0 & 0 & 24 & 87 & 2,003 & 0 & 0 & 0 & 3,912 \\
\hline & & Advanced & 12,154 & 0 & 0 & 178 & 125 & 5,026 & 0 & 0 & 0 & 17,180 \\
\hline & \multirow{3}{*}{$1+\mathrm{N}^{\text {th }}$} & Basic & 0 & 0 & 0 & 0 & 0 & 0 & 0 & 0 & 0 & 0 \\
\hline & & Standard & 1,273 & 0 & 0 & 16 & 87 & 1,885 & 0 & 0 & 0 & 3,158 \\
\hline & & Advanced & 11,517 & 0 & 0 & 170 & 125 & 4,909 & 0 & 0 & 0 & 16,426 \\
\hline \multirow{6}{*}{ Total } & & Basic & 65 & 0 & 60 & 47 & 123 & 3,857 & 1,504 & 135 & 2,277 & 7,703 \\
\hline & $1^{\text {st }}$ & Standard & 2,299 & 0 & 60 & 235 & 423 & 12,365 & 2,656 & 286 & 4,861 & 22,181 \\
\hline & & Advanced & 12,640 & 2,074 & 63 & 721 & 639 & 23,777 & 5,176 & 617 & 10,363 & 54,030 \\
\hline & & Basic & 0 & 0 & 20 & 21 & 89 & 2,281 & 1,136 & 86 & 1,513 & 4,930 \\
\hline & $1+\mathrm{N}^{\text {th }}$ & Standard & 1,596 & 0 & 20 & 197 & 357 & 10,002 & 2,256 & 233 & 4,008 & 17,862 \\
\hline & & Advanced & 11,845 & 2,074 & 20 & 706 & 553 & 21,311 & 4,848 & 574 & 9,612 & 49,691 \\
\hline
\end{tabular}







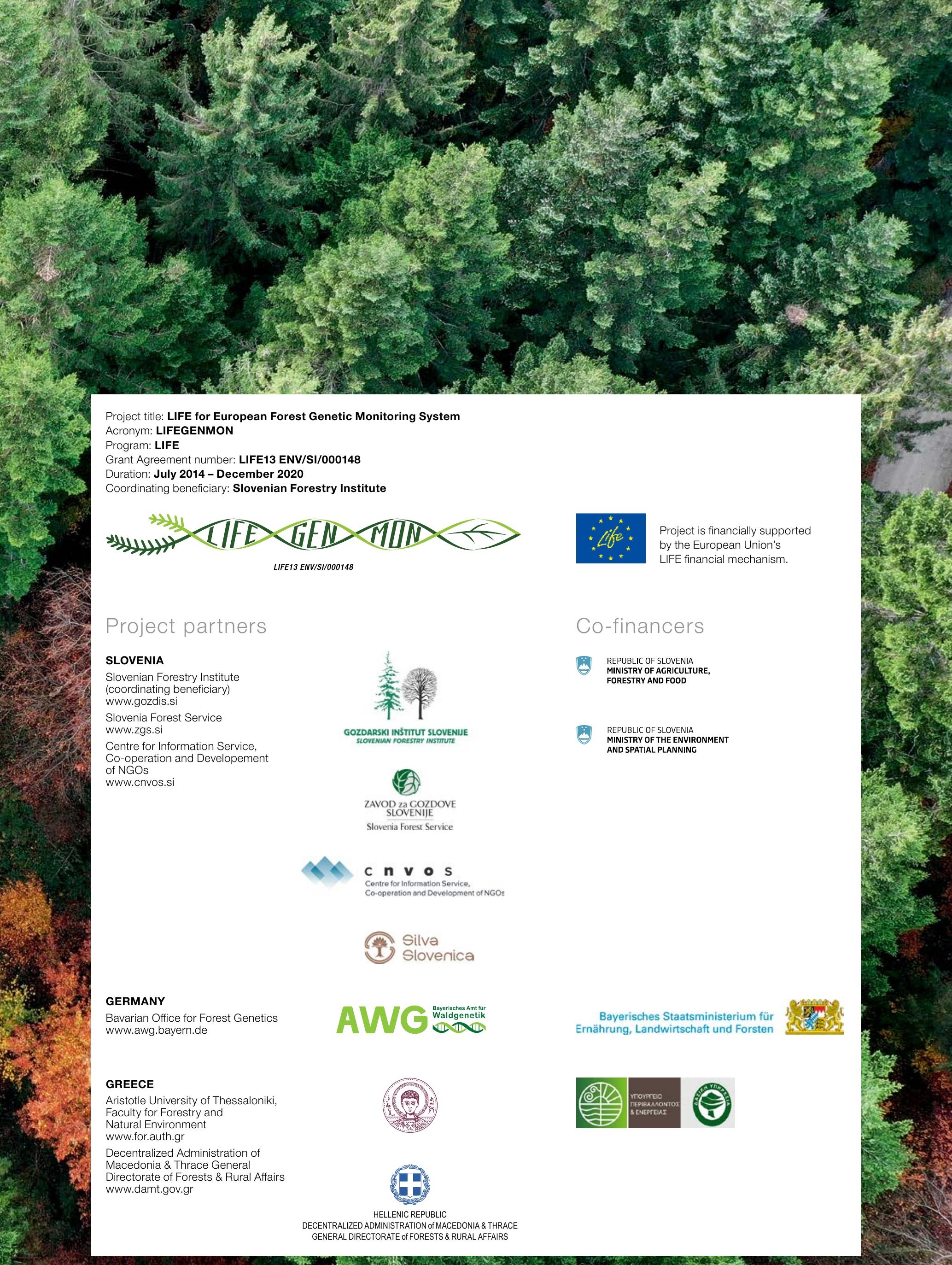

Project title: LIFE for European Forest Genetic Monitoring System

Grant Agreement number: LIFE13 ENV/SI/000148

Duration: July 2014 - December 2020

dinating beneficiary: Slovenian Forestry

Union's

IFE financial mechanism.

\section{Project partners}

\section{o-financers}

SLOVENIA

Slovenian Forestry Institute

www.gozdis si

Service,

AVOD Za GOZDOVE
SLOVENIIE

Slovenia Forest Service

n $\mathbf{Y} \mathbf{s}$

Centre for information Service,

Silva

Slovenica

\section{GERMANY}

Bavarian Office for Forest Genetics

verisches Staatsministerium für

\section{GREECE}

Aristotle University of Thessaloniki,

for Forestry and

Decentralized Administration of

Macedonia \& Thrace General

Directorate of Forests \& Rural Affairs www.damt.gov.gr 